
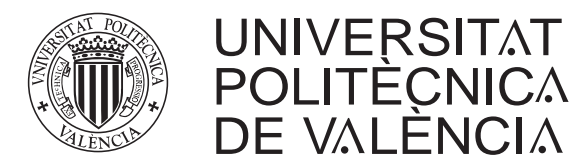

DEPARTAMENTO DE CONSTRUCCIONES ARQUITECTÓNICAS

TESIS DOCTORAL

\title{
FACTORES DETERMINANTES DE LA ARQUITECTURA DE LOS "MILL BUILDINGS" Y SU INFLUENCIA EN LA ARQUITECTURA INDUSTRIAL VALENCIANA
}

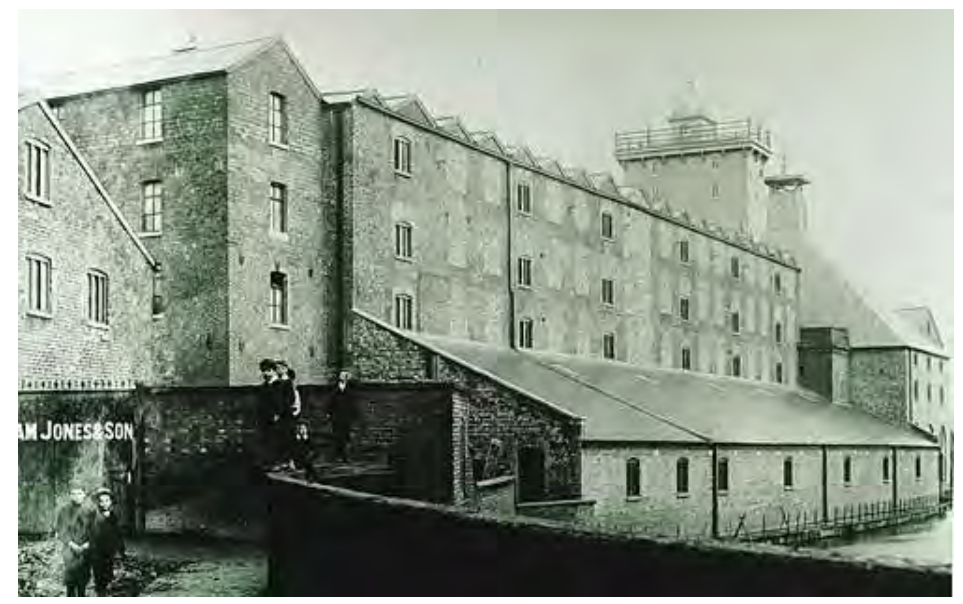

AUTOR:

ALEJANDRO GREGORI FERRER

DIRECTORES:

DR. ANTONIO HOSPITALER PÉREZ DR. MANUEL VALCUENDE PAYÁ 


DEPARTAMENTO DE CONSTRUCCIONES ARQUITECTÓNICAS

\section{FACTORES DETERMINANTES DE LA ARQUITECTURA DE LOS "MILL BUILDINGS" Y SU INFLUENCIA EN LA ARQUITECTURA INDUSTRIAL VALENCIANA}

AUTOR:

ALEJANDRO GREGORI FERRER

DIRECTORES:

DR. ANTONIO HOSPITALER PÉREZ DR. MANUEL VALCUENDE PAYÁ 

FACTORES DETERMINANTES DE LA ARQUITECTURA DE LOS "MILL BUILDINGS" Y SU INFLUENCIA EN LA ARQUITECTURA INDUSTRIAL VALENCIANA 


\section{AGRADECIMIENTOS}

Mis primeras palabras de agradecimiento no pueden ser más que para mis directores de tesis, Manolo y Toni. Y no solo por tanto tiempo invertido en $\mathrm{mi}$, sin miramientos, ni por todo lo que me han enseñado, ni por la paciencia, ni por haber disfrutado tanto aprendiendo, ni por las charlas que nada tenían que ver con la tesis. Por nada de eso -Creedme, nunca os lo podré pagar-. Se merecen ser las primeras porque me han hecho comprender, que yo, he sido capaz de sentarme en una misma mesa con dos profesores de universidad: profesores, profesores. Nada más y nada menos que un director de departamento y un catedrático, lo que para muchos es un sueño inalcanzable. Con esto puedo decir que nada es imposible.

En segundo lugar, aunque al mismo nivel, para mi madre: mi referente. $Y$ no únicamente por ser mi madre, sino porque por pura aleatoriedad de la naturaleza coincidió con la persona de la que copié mis ideales, en los que baso mi proyecto de vida.

En tercer lugar, a todas las personas que me han rodeado en estos años tan duros: mi familia, grande en tamaño y en proximidad, las cuidadoras de mis hijos, mis amigos, y a Manolo, Mayte, Toni, Maria y Remei.

Y en último lugar, pero que son como las primeras palabras, a mi mujer, Berta, por ser parte de mi. Me acuerdo muchas veces de cuando me decías que se podía. Aquí está. No concibo mi vida sin ti. Ni sin ellos. 

La segunda mitad del siglo XVIII se caracteriza, entre otras cosas, porque empiezan a producirse cambios drásticos en los sistemas tradicionales de producción. Esta serie de transformaciones no habían sido las primeras, puesto que al menos dos siglos antes, las monarquías absolutas europeas ya habían implantado las manufacturas reales, que habían servido como ejemplo de renovación al organizar la concentración de artesanos para la fabricación de objetos de lujo para el autoconsumo.

De forma extendida hasta ese momento, la manufactura y los procesos de elaboración de productos en general se realizaban en lugares distribuidos de una forma dispersa, pero se van concentrando en espacios únicos destinados específicamente a una función productiva concreta. Los trabajos en los pequeños 
talleres pasarán a realizarse en espacios de mayor tamaño y con unas características totalmente diferentes.

Así, si se hace una somera comparación entre dos espacios de trabajo, uno de la segunda mitad del siglo XVIII y otro de finales siglo XIX, fácilmente se aprecian varias diferencias: las dimensiones se multiplican, los huecos en fachada aumentan, los recintos interiores se unifican en espacios únicos más diáfanos, la forma de accionamiento y la transmisión de la energía por el interior avanza tecnológicamente, etc.

Desde el interés por este proceso de transformación de los espacios de producción a nuevos edificios fabriles, se establece como punto de partida de este estudio, el hecho de que en Gran Bretaña, principalmente a partir de la aludida segunda mitad del siglo XVIII, aparecen nuevas técnicas constructivas y nuevos materiales que generan unos tipos edificatorios. $Y$ ello también, como respuesta a las exigencias de los empresarios que se concretan en la necesidad de disposición de espacio suficiente para producir, albergando los sistemas necesarios de distribución de energía para el accionamiento de la nueva maquinaria. Todo ello en lugares bien iluminados de forma natural, y sobre todo seguros, evitando el riesgo de incendio al que constantemente estaban sometidos.

Estos nuevos edificios para la producción se conocen en inglés como "mill buildings", terminología que incluye una serie de características concretas. El objetivo fundamental de esta tesis es su estudio y análisis, tomando como base las fábricas inglesas desde el origen de la conocida como revolución industrial hasta principios del siglo XX. Para ello, se evaluarán unos factores concretos que configuraron la forma de los espacios de producción industrial en aquel país, como consecuencia del cambio de modelo productivo, y cómo este patrón se importó al cabo de unos años a la Comunidad Valenciana. 
La segona meitat del segle XVIII es caracteritza, entre altres coses, perquè comencen a produir-se canvis dràstics en els sistemes tradicionals de producció. Esta sèrie de transformacions no havien segut les primeres, ja que al menys dos segles abans, les monarquies absolutes europees ja havien implantat les manufactures reials, que havien servit com a exemple de renovació a l'organitzar la concentració d'artesans per a la fabricació d'objectes de luxe per a l'autoconsum.

De forma estesa fins eixe moment, la manufactura i els processos d'elaboració de productes en general es realitzaven en llocs distribuïts d'una forma dispersa, però es van concentrant en espais únics destinats específicament a una funció 
productiva concreta. Els treballs als xicotets tallers passaran a realitzar-se en espais de major grandària i amb unes característiques diferents.

Així, si es fa una succinta comparació entre dos espais de treball, u de la segona meitat del segle XVIII $i$ altre de finals del segle XIX, fàcilment s'aprecien vàries diferències: les dimensions es multipliquen, els buits de façana augmenten, els recintes interiors s'unifiquen en espais únics més diàfans, la forma d'accionament i la transmissió de l'energia per l'interior avança tecnològicament, etc.

Des de l'interès per este procés de transformació dels espais de producció a nous edificis fabrils, s'estableix com a punt de partida d'este estudi, el fet de què a la Gran Bretanya, principalment a partir de l'al-ludida segona meitat del segle XVIII, apareixen noves tècniques constructives i nous materials que generen uns tipus edificatoris. I açò també, com a resposta a les exigències dels empresaris que es concreten en la necessitat de disposició d'espai suficient per a produir, albergant els sistemes necessaris de distribució d'energia per a l'accionament de la nova maquinària. Tot això en llocs ben il-luminants de forma natural, i sobre tot segurs, evitant el risc d'incendi al que constantment estaven sotmesos.

Estos nous edificis per a la producció es coneixen en anglès com a "mill buildings", terminologia que inclou una sèrie de característiques concretes. L'objectiu fonamental d'esta tesi és el seu estudi $i$ anàlisi prenent com a base les fàbriques angleses des de l'origen de la coneguda com a revolució industrial fins principis del segle XX. Per això, s'avaluaran uns factors concrets que varen configurar la forma dels espais de producció industrial en aquell país, com a conseqüència del canvi de model productiu, i com eixe patró es va importar passats uns anys a la Comunitat Valenciana. 
The second half of the eighteenth century is characterized, among other things, because drastic changes began to occur in traditional production systems. This series of transformations were not the first, since at least two centuries before, European absolute monarchies had already implemented the actual manufacturing, which had been used as an example of renewal of the organization of craftsmen, now gathered, for the manufacture of luxury goods for self consumption.

Broadly speaking, manufacturing and product development processes were generally performed in distributed locations in a dispersed way, but they became gathered in unique spaces, mainly targeted to a specific production. Working in 
small workshops would take place in larger spaces and with completely different characteristics.

Thus, if a brief comparison between two workspaces is made, one of the second half of the eighteenth century and the other of the late nineteenth, several differences can be easily observed: the dimensions are multiplied, increasing gaps in facade, interior rooms unified in more open spaces, the way to drive it and the energy transmission throughout the interior advanced technology, etc.

From the interest in this process of transformation of the production areas into new factory buildings, it is set as the starting point of this study the fact that in Britain, mainly from the aforementioned second half of the eighteenth century, there are new building materials and new building types. And this as well, in response to the demands of entrepreneurs focused on the necessity to produce in enough available spaces, housing the necessary power distribution systems for operating new machinery. All naturally well-lit, and above all, safe, avoiding the risk of fire which they were constantly subjected to.

These new buildings for production are known in English as mill buildings, terminology which includes a number of specific characteristics. The main objective of this thesis is their study and analysis, based on English factories from the beginning of the so-called industrial revolution until the early twentieth century. To this end, some specific factors that shaped the form of industrial production spaces in that country will be assessed, as a result of the changing of the production model, and how this pattern was imported after a few years to the Valencia region. 


\section{ÍNDICE}

1. INTRODUCCIÓN........................................................................ 13

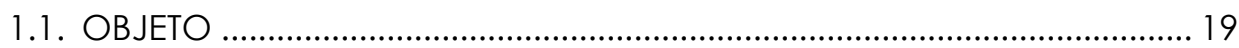

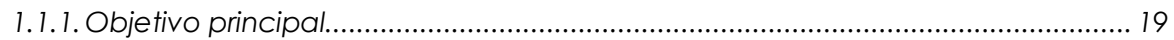

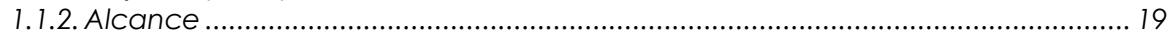

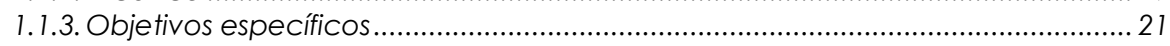

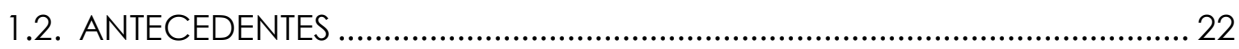

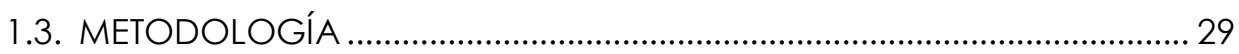

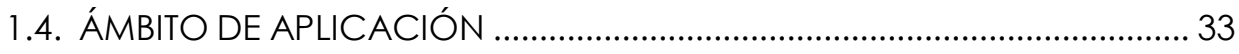

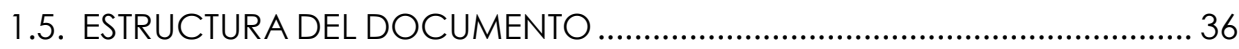

2. LA ARQUITECTURA INDUSTRIAL: DEFINICIONES E HISTORIOGRAFÍA 39

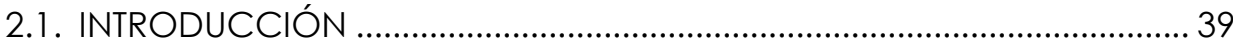

2.2. LA REVOLUCIÓN INDUSTRIAL: UN PUNTO DE INFLEXIÓN EN LA HISTORIA. 41

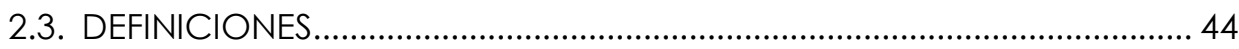

2.4. VISIÓN HISTÓRICA DE LA CONSTRUCCIÓN DE LOS EDIFICIOS INDUSTRIALES. PERIODIZACIONES TIPOLÓGICAS................................... 56

2.4. 1. Los molinos, o protoindustria ....................................................................... 58

2.4.2. Manufacturas y reales fábricas - renovación tipológica ...................................8 81

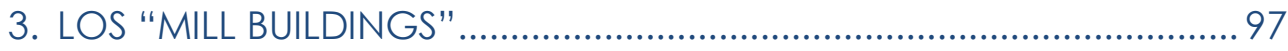

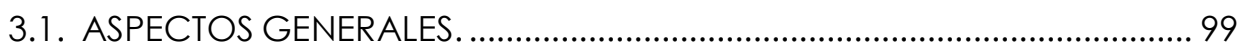

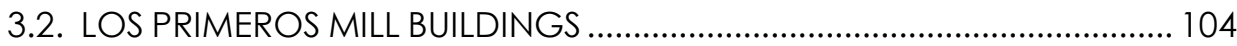

3.2. 1. Lombe's Mill, Derby, 1722, John Lombe .......................................................... 111

3.2.2. Factoría de algodón hidráulica, Cromford, Derbyshire, 1771, Richard Arkwright.. 118

3.2.3. Albion Mill, Londres, 1786, Samuel Wyatt ......................................................... 127

3.2.4. Soho Manufactory, 1766, y Soho Foundry, 1795, Birmingham, Inglaterra......... 136

3.2.5. Ditherington Flax Mill o Marshall, Benyon and Bage, 1796, Charles Bage......... 146

3.2.6. Fábrica de hilos de Salford, o Phillips, Wood \& Lee, 1799; Boulton \& Watt. Salford (Greater Manchester, Inglaterra)......................................................... 164

3.2.7. Strutt's North Mill, 1804, Belper........................................................................... 169

3.2.8. Marshall's Temple Mill o Marshall's One-Storied Mill, Holbeck, West Yorkshire,

1842, I. Bonami................................................................................... 183

3.2.9. The Boat Store, Sheerness, Kent, 1858 $\div$ 1860, Colonel Greene................................. 195

3.2. 10.Fábrica de Chocolates Menier, 1871, Noisel-Sur-Marne, Francia ...................... 209

3.2. 1 1. Packard Motor Car Company, 1905, Detroit, Estados Unidos .............................. 220 


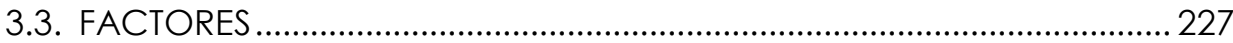

3.4. EL EFECTO DE LA ENERGÍA DE ACCIONAMIENTO EN LOS

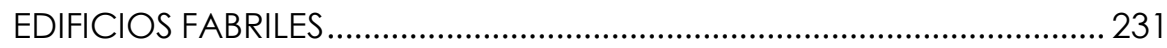

3.5. EL FACTOR DE LOS MATERIALES DE CONSTRUCCIÓN EN LOS

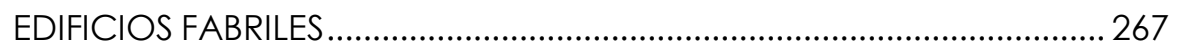

3.6. EL FACTOR ILUMINACIÓN EN LOS EDIFICIOS FABRILES ..........................348

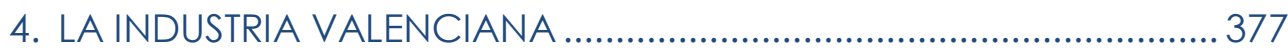

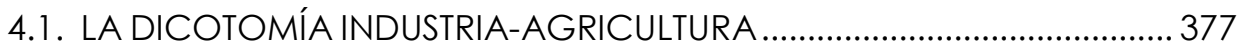

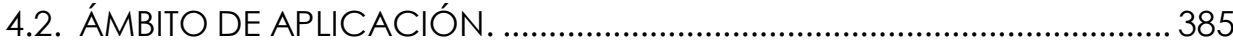

4.2. 1. Los orígenes de la industrialización en Valencia..................................................... 387

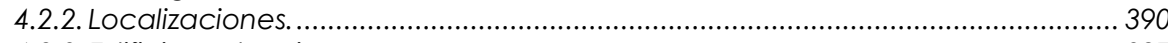

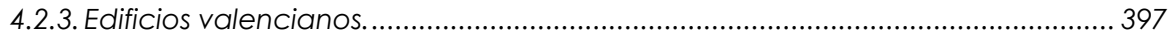

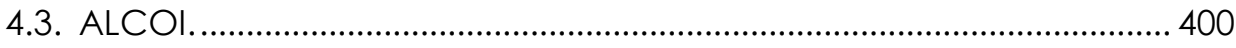

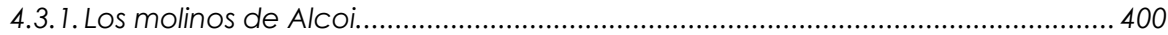

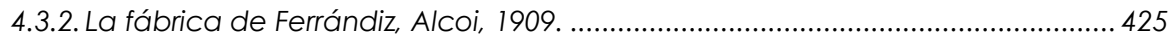

4.3.3. La fábrica de Carbonell, Alcoi, década de 1920................................................. 439

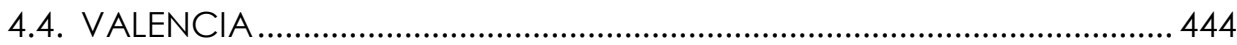

4.4.1. Fábricas en la ciudad de Valencia. Principios del siglo XX..................................444

4.4.1.1.Fábrica de conservas. Camino al Grao (Valencia), 1901 ................................... 448

4.4. 1.2.Fábrica de harinas. C/ de la Industria (Valencia), 1905........................................454

4.4.2. Molino fábrica "Harinas Hijos de Jerónimo Alcañiz". Principios del siglo XX........ 459

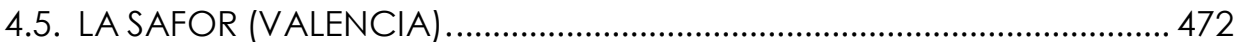

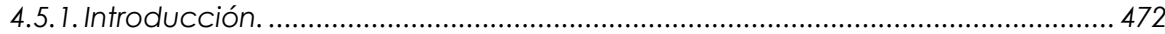

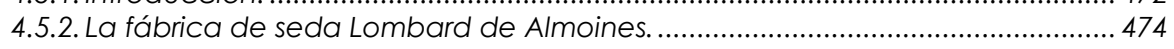

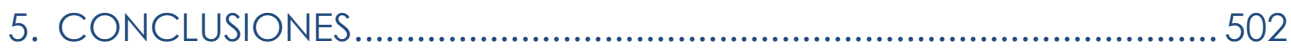

6. FUTURAS LÍNEAS DE INVESTIGACIÓN............................................ 506

7. BIBLIOGRAFÍA ............................................................................. 510 


\section{INTRODUCCIÓN}

La segunda mitad del siglo XVIII se caracteriza, entre otras cosas, porque empiezan a producirse cambios drásticos en los sistemas tradicionales de producción. Esta serie de transformaciones no habían sido las primeras, puesto que estuvo precedida por centros de producción industrial muy relevantes en la historia económica como el Arsenal de Venecia, astilleros en los que de forma coordinada se construían grandes barcos, y del que se tiene constancia de su existencia desde principios del siglo XII. Asimismo también, en la segunda mitad del siglo XVI, las manufacturas reales francesas, que posteriormente se expandieron por todas las monarquías absolutas europeas, habían servido como ejemplo de renovación al implantar la concentración de artesanos para la fabricación de objetos de lujo para el autoconsumo de los propios palacios reales y para el equipamiento de los ejércitos, como resultado de la aplicación de una política mercantilista. 
Pero de forma extendida hasta ese momento, la manufactura y los procesos de elaboración de productos en general se realizaban en lugares distribuidos de una forma dispersa, pero se van concentrando en espacios únicos destinados específicamente a una función productiva concreta. Los trabajos en los pequeños talleres o en las plantas bajas de las viviendas de los artesanos pasarán a realizarse en espacios de mayor tamaño y con unas características totalmente diferentes.

Evidentemente este cambio fue un proceso muy dilatado en el tiempo, y no se produjo de igual modo en todos los lugares de Europa en el mismo momento y de la misma forma. Es por ello que, como cualquier otro periodo de la historia, la llamada genéricamente Revolución Industrial no tiene una fecha concreta de inicio y de final, y ni siquiera ocurrió en un lugar determinado. Lo que sí se puede considerar como punto de partida, al menos en lo que se refiere a la transformación de los espacios de trabajo como nuevos edificios fabriles, fue el hecho de que en Gran Bretaña, principalmente a partir de la aludida segunda mitad del siglo XVIII, aparecen nuevas técnicas constructivas y nuevos materiales que generan modernos tipos edificatorios para los espacios de producción, más económicos que las reales fábricas. Y ello, como respuesta a las exigencias de los empresarios que querían disponer de espacio suficiente para producir, en lugares bien iluminados de forma natural, y sobre todo seguros, evitando el riesgo de incendio al que constantemente estaban sometidos ${ }^{1}$, al mismo tiempo que capaces de soportar los sistemas de distribución de energía para el accionamiento de la nueva maquinaria.

Estos nuevos edificios para la producción se conocen en inglés como "mill buildings", terminología que incluye una serie de características concretas. A saber:

\footnotetext{
${ }^{1}$ Derivado de los sistemas de alumbrado, de las nuevas técnicas de accionamiento mecánico y del tamaño de la actividad.
} 
1. La transmisión mecánica en su interior está toda ella englobada por la propia envolvente del edificio, cuyo origen es inicialmente el accionamiento hidráulico, y posteriormente la máquina de vapor, a modo de punto único.

2. La aplicación de nuevas tecnologías constructivas generalmente están encaminadas a conseguir mayores espacios, más diáfanos y especialmente más resistentes al fuego.

3. Su planta es alargada y estrecha, llevando al máximo las capacidades resistentes de los materiales.

4. En general, son edificios de varias alturas.

Estos puntos mencionados, adquieren una relevancia fundamental en el desarrollo cronológico de los espacios fabriles, y constituyen la parte central de este estudio.

A modo general, esta evolución se puede sintetizar en mayor medida en las fábricas textiles, puesto que este sector era sustancialmente el que más se estaba extendiendo por número de edificios construidos como consecuencia de la pujante demanda de paños y telas, principalmente debido al aumento demográfico beneficiado por los avances en medicina y salubridad. Pero precisamente en esas fábricas el peligro de incendio era considerablemente mayor, debido al polvo en suspensión provocado por el proceso de hilado en sus locales iluminados por las llamas de los candiles.

En España, es la tecnología importada directamente de Inglaterra para la industria textil, como la máquina de vapor, los sistemas de transmisión de la energía y las máquinas de elaboración de los productos (hilo, tejidos, cardas, etc), la que provocará ese cambio, como la máquina de hilar conocida como la selfactina ${ }^{2}$, que data de 1854. La adopción de estas nuevas tecnologías directamente de Inglaterra adaptadas a las tipologías edificatorias propias, comporta un incremento

\footnotetext{
${ }^{2}$ Máquina de hilar muy típica en la revolución industrial textil catalana.
} 
considerable de la capacidad productiva y aumenta la tendencia de todo el proceso hacia un solo espacio de trabajo, basado en la concentración de maquinaria y de mano de obra.

Todo ello induce a un cambio progresivo en la configuración de los edificios y los espacios destinados a la producción y al trabajo, especialmente en el sector textil en Cataluña, aunque también es reseñable lo que ocurrió en el territorio valenciano, y más concretamente en Alcoi.

Así, si se hace una somera comparación entre dos edificaciones destinadas a la confección de telas o cualquier otro tipo de manufactura, una de la segunda mitad del siglo XVIII y otra de la primera mitad del siglo XIX, fácilmente se aprecian varias diferencias: las dimensiones se multiplican, la composición de huecos en fachada y aperturas es diferente, los recintos interiores se unifican en espacios únicos más diáfanos, etc.

En lo que respecta a la industria valenciana, aunque de una forma menos pronunciada debido a la peculiar situación socioeconómica de estos dos siglos, no es tan fácil encontrar ejemplos de edificios fabriles como en otros lugares del estado español. Cataluña tenía una importante burguesía con un alto nivel económico que invertía en promover grandes fábricas de producción textil, y lo mismo ocurrió en el País Vasco, con una situación bastante similar. Por ello, ambas zonas han estado consideradas desde entonces como los dos motores industriales de nuestro país. Pero pese a lo que se podría pensar en un principio, inducido originalmente entre otros motivos por el fracaso de la industria de la seda, en el territorio valenciano se pueden encontrar casos muy interesantes para investigar, aunque en concentraciones localizadas, como Alcoi, Ontinyent, Bocairent, Morella, Valencia, y otros lugares que se verán más adelante.

Es en alguno de estos sitios mencionados donde la industria textil, papelera o relativa al sector agrario, también manifiestan un desarrollo tecnológico, especialmente a lo largo del siglo XIX, sin considerar los altibajos típicos propios 
de las circunstancias del momento. Ese avance también trae consigo un proceso de desarrollo, perfeccionamiento y diversificación de los modelos tipológicos y de los sistemas constructivos de los edificios fabriles.

Más tarde, a principios del siglo XX, ahora ya a la par con el resto de España, los anteriores modelos tipológicos de fábrica comienzan a perder vigencia al desarrollarse los sistemas constructivos hacia el acero en su variante de perfiles laminados estandarizados, y hacia el material estrella, el hormigón ${ }^{3}$. Con el acero, el hormigón y el cristal, la estructura muraria envolvente y la madera del edificio desparece, y la estructura llega a la fachada.

Del mismo modo, en el segundo cuarto también del siglo XX, la estética de los edificios fabriles también cambia desde modelos industriales derivados de los patrones ingleses, o bien de los modernistas, hacia otras expresiones más eclécticas. Este será el momento en que finaliza el ámbito de esta tesis, coincidiendo con la comparación de la idoneidad del edificio en altura como tipología fabril frente al de única planta.

Pero ciñéndose al amplio periodo comprendido entre finales del siglo XVIII, XIX Y principios del $\mathrm{XX}$, la evolución de las edificaciones industriales es muy clara $\mathrm{Y}$ fácilmente reconocible, y obviamente siempre muy paralela a la coyuntura económica del momento, identificando un nacimiento, un desarrollo, y finalmente una pérdida de vigencia de los sistemas constructivos y de la tipología edificatoria propia. Existen numerosos estudios acerca de esta metamorfosis arquitectónica realizados desde una perspectiva historiográfica que han aportado una valiosísima información de cómo la sociedad pasó de ser eminentemente agraria a como se concibe hoy en día. Este trabajo, sin embargo, tiene unas pretensiones diferentes: en primer lugar trata de hacer un análisis más técnico, mediante el estudio de unos factores determinados que condicionaron la forma de los edificios fabriles.

\footnotetext{
${ }^{3}$ Los primeros edificios construidos en hormigón armado en Cataluña son La Farga de Bebié, de 1917, y la Papelera Española, de 1917 también.
} 
Así se pondrá en evidencia cómo por ejemplo la iluminación interior, los sistemas de producción energética, su distribución interior, la maquinaria, el proceso y sus requerimientos espaciales, las condiciones ambientales, los materiales utilizados, y en general los sistemas constructivos, ayudaron a establecer una relación directa entre el edificio y los procesos de producción. Además, tiene como propósito aportar una nueva visión derivada de un análisis profundo de la tipología industrial más característica desde los puntos de vista citados.

En segundo lugar, y basándose en estas variables, se tratará de hacer una comparación entre los primeros edificios que surgieron de la renombrada revolución industrial inglesa de finales del XVIII, con los que se construyeron en Valencia unos años después. 


\subsection{OBJETO}

El objeto de esta tesis es el edificio fabril valenciano.

\subsubsection{Objetivo principal}

El objetivo fundamental de esta tesis es el estudio y el análisis de los "mill buildings", tomando como base las fábricas inglesas desde el origen de la revolución industrial hasta principios del siglo XX. Para ello, se indagará previamente en cómo unos factores concretos forzaron la forma de los espacios de producción industrial en aquel país desde la segunda mitad del siglo XVIII como consecuencia del cambio de modelo productivo, y cómo este patrón se importó al cabo de unos años a la Comunidad Valenciana.

Por tanto, una finalidad será la valoración cualitativa de la influencia de unos factores sobre los espacios de trabajo, desde que se produce el cambio de producción artesanal a una fabricación mediante máquinas, hasta la aparición de la fábrica moderna de comienzos del siglo XX, tal y como se entiende hoy en día, gracias a la aparición de materiales como el hormigón, el acero o el cristal, la renovación de la transmisión de la energía, la racionalidad en la producción, etc.

\subsubsection{Alcance}

La intención de fijar un punto de partida y final en el estudio de la evolución de los edificios se sustenta en dos consideraciones. La primera de ellas, que concretará el momento en el que se inicia la tesis, establece que previo a la aparición de los espacios de trabajo concentrado, la tipología usual era la de molino ubicado en los valles por donde transcurrían los cauces de los ríos o en zonas expuestas al viento por su capacidad motriz. Hasta entonces, el conjunto productivo estaba formado por un sistema motor-máquina-edificio, o sea, todo conformando un mecanismo en el que su envolvente adoptaba la forma de cubrición de la única máquina del proceso, principalmente la de moltura del grano de trigo o la del batán. Esta máquina se confundía con el motor de accionamiento hidráulico o eólico, puesto que no había separación física ni ejes de transmisión entre ambos. 
En segundo lugar, para la consideración del final del ámbito de estudio, se fija la utilización de forma generalizada del hormigón armado y del acero para construir las fábricas a principios del siglo XX. La evolución en este siglo ya girará mayoritariamente en torno a tendencias específicas dependiendo de las corrientes artísticas y técnicas que se generen en los diferentes países industrialmente avanzados.

El trasfondo motivador de este trabajo también subyace de la voluntad de añadir un mayor conocimiento de lo que ha sido el proceso de industrialización y modernización de la Valencia decimonónica y del cambio de siglo, más de 100 años después del comienzo temporal de este estudio, de modo que ello ayude a esclarecer el verdadero papel que ocupó dentro del espacio nacional. Muchos investigadores de la rama histórica y económica han empleado grandes esfuerzos en ello, pero aquí se pretende obtener un complemento técnico a esos estudios. En los recurrentes debates acerca de la naturaleza y desarrollo valenciano, y también sobre el papel histórico de su burguesía, siguen estando presentes en el núcleo central, como ya lo eran en las viejas discusiones sobre naturaleza e historia de la región. Con este estudio se complementan.

Con la valoración de las fábricas, se puede dar un paso a la determinación de cuál fue la importancia de la industria valenciana, porque entre otros es en los edificios fabriles donde se refleja en parte el nivel de industrialización de un país. Se trata de un punto de vista más necesario para entender el proceso de modernización y desarrollo de su economía, al menos en un periodo de tiempo establecido.

Nótese así finalmente que en este trabajo se establecerá mayoritariamente una vinculación entre los análisis históricos y económicos de carácter general (como puede ser la industrialización valenciana del XVIII y XIX) con su vertiente técnica o arquitectónica. 


\subsubsection{Objetivos especificos}

Dentro del objetivo principal del trabajo de investigación, desvelar los factores que determinaron la evolución y expresión arquitectónica de los mill buildings en el siglo XVIII y XIX y su manifestación en la Comunidad Valenciana, se derivan una serie de objetivos específicos o secundarios:

1. Analizar la evolución y la relación entre los tipos y formas edificatorias de las fábricas, los sistemas constructivos, la ordenación de las edificaciones y las necesidades de iluminación, seguridad, ventilación, mecanización, diafanidad ${ }^{4}$, transporte interno de materiales, transmisión y accionamiento de la maquinaria, control de la producción, etc.

2. Evaluar cómo la tecnología aumentó la tendencia hacia la concentración del proceso productivo en un solo espacio de trabajo.

3. Analizar el mill building inglés como pionero de las fábricas modernas.

4. Poner en valor el mill building como punto de inflexión de la vieja tecnología a la de la concentración y producción industrial en masa.

5. Examinar la influencia de las fábricas inglesas del siglo XVIII y XIX en las valencianas postrevolución industrial.

6. Evaluar de qué manera la importancia de las experiencias inglesas (nuevos materiales, nuevas estructuras y sistemas constructivos, nuevos diseños, etc) afectaron a la casuística valenciana.

Para ello, se asumirá la existencia de industria de relevancia en Valencia, cuestionando la concepción agrarista decimonónica, gracias a la puesta en valor de los edificios objeto de análisis, y apreciando así el papel de su industria en el panorama español $\left.\right|^{5}$.

\footnotetext{
${ }_{5}^{4}$ RAE.es: Dicho de un cuerpo: Que deja pasar a su través la luz casi en su totalidad

${ }^{5}$ En lo que se refiere a este último párrafo, es conveniente hacer una reflexión amplia. En general, los investigadores del desarrollo económico e industrial español establecen la Primera Guerra Mundial (1914 - 1919) como el punto de inflexión entre dos etapas: la de industrialización "irregular" del siglo XIX y la del desarrollo contemporáneo. La neutralidad española favoreció
} 


\subsection{ANTECEDENTES}

Para hacer un planteamiento evolutivo a lo largo de la industria desde las primeras civilizaciones, se siguen las pautas que estableció Munford en su libro Técnica y civilización, en 1971 (Mumford, 1971).

\section{LAS ETAPAS DE MUMFORD Y LA CONFIGURACIÓN DE LA FÁBRICA}

El concepto de industria en su sentido más general se remonta a la antigüedad. Desde los orígenes de la humanidad, el hombre ha tratado de transformar todo lo que tenía a su alcance simplemente por mantener la subsistencia. Para ello, siempre ha utilizado los medios de los que disponía, creando las herramientas que iba necesitando con el paso del tiempo. El desarrollo desde los primeros utillajes hasta la maquinaria más avanzada tecnológicamente hablando ha tenido una sucesión paralela al de la transformación y la producción de nuevos productos, o sea, al del progreso de la industria, según Antonio Hospitaler (Hospitaler, 1999): "La máquina, como artificio para aprovechar o dirigir la acción de una fuerza o energía, es el elemento esencial de la industria".

Lewis Mumford ${ }^{6}$ explica perfectamente en su libro Técnica y Civilización cuál ha sido la evolución de la industria desde hace más de mil años. Para representar este largo proceso lo divide en tres etapas fundamentales o "fases sucesivas que se superponen y se interpenetran": eotécnica, paleotécnica y neotécnica. En estos periodos, el desarrollo de la máquina y la civilización están caracterizados

extraordinariamente las exportaciones y el crecimiento de la economía en general. Y esto no sólo para Vizcaya o Cataluña, puesto que Valencia también jugó un papel muy importante. Valga como ejemplo el tren que partía de Sagunt para abastecer de hierro a Gran Bretaña, promovido por el industrial vasco Ramón de la Sota.

${ }^{6}$ Lewis Mumford (1895 - 1990) fue un sociólogo, historiador, filósofo del campo de la tecnociencia, filólogo y urbanista estadounidense. Se ocupó sobre todo, con una visión histórica y regionalista, de la técnica, la ciudad y el territorio. Destacan en particular sus análisis sobre utopía y la Ciudad Jardín, aunque tienen mayor resonancia sus obras interdisciplinares, como El mito de la máquina o el citado Técnica y civilización. 
principalmente por su fuente energética, coincidiendo de algún modo con la subdivisión que hacen otros autores (Hospitaler, 1999) [Tabla 2]:

\begin{tabular}{|c|c|c|c|c|c|}
\hline \multicolumn{5}{|c|}{ FASES DE LA INDUSTRIA } & Autor \\
\hline & $\begin{array}{c}\text { EOTÉCNICO } \\
(1000-1700) \\
\end{array}$ & $\begin{array}{c}\text { PALEOTÉCNICO } \\
(1700-1900)\end{array}$ & $\begin{array}{l}\text { NEOTÉCNICO } \\
(1900-1950) \\
\end{array}$ & $\begin{array}{c}\text { BIOTÉCNICO } \\
(2000-)\end{array}$ & $\begin{array}{c}\text { Lewis } \\
\text { Mumford }\end{array}$ \\
\hline \multirow[t]{2}{*}{$\begin{array}{l}\text { Técnica } \\
\text { del azar }\end{array}$} & $\begin{array}{c}\text { Técnica de la } \\
\text { artesanía }\end{array}$ & \multicolumn{3}{|c|}{$\begin{array}{c}\text { Técnica } \\
\text { del técnico }\end{array}$} & $\begin{array}{c}\text { José } \\
\text { Ortega y } \\
\text { Gaset }\end{array}$ \\
\hline & & $\begin{array}{l}\text { Primera } \\
\text { revolución } \\
\text { tecnológica: } \\
\text { carbón, } \\
\text { hierro, } \\
\text { mecanización } \\
\text { de la industria } \\
\text { textil y vapor } \\
\text { como fuerza } \\
\text { motriz fija }\end{array}$ & $\begin{array}{l}\text { Segunda } \\
\text { revolución } \\
\text { tecnológica: } \\
\text { electricidad, } \\
\text { motor } \\
\text { combustión } \\
\text { interna, } \\
\text { química } \\
\text { moderna, } \\
\text { convertidor } \\
\text { Bessemer, } \\
\text { telecomunicac } \\
\text { iones y la } \\
\text { cadena de } \\
\text { montaje }\end{array}$ & $\begin{array}{l}\text { Tercera } \\
\text { revolución } \\
\text { industrial: } \\
\text { la industria de la } \\
\text { información, la } \\
\text { microelectrónica, } \\
\text { energía nuclear e } \\
\text { industria del ocio }\end{array}$ & $\begin{array}{c}\text { Nadal, } \\
\text { Albert } \\
\text { Carreras } \\
\text { y Martín }\end{array}$ \\
\hline & & $\begin{array}{l}\text { La fábrica, } \\
\text { lugar de } \\
\text { trabajo }\end{array}$ & $\begin{array}{l}\text { La planta } \\
\text { industrial y los } \\
\text { polígonos } \\
\text { industriales }\end{array}$ & $\begin{array}{l}\text { Parques } \\
\text { tecnológicos. La } \\
\text { fábrica inteligente } \\
\text { y el } \\
\text { tecnourbanismo }\end{array}$ & \\
\hline & & $\begin{array}{l}\text { Primera } \\
\text { revolución } \\
\text { tecnológica: } \\
\text { carbón, vapor, } \\
\text { hierro e } \\
\text { industria textil }\end{array}$ & $\begin{array}{l}\text { Segunda } \\
\text { revolución } \\
\text { tecnológica: } \\
\text { hidrocarburos, } \\
\text { electricidad y } \\
\text { química }\end{array}$ & $\begin{array}{l}\text { Tercera } \\
\text { revolución } \\
\text { industrial: } \\
\text { nuclear, } \\
\text { información y } \\
\text { microelectrónica }\end{array}$ & AA.VV \\
\hline
\end{tabular}

Tabla 1. Fases de la industria según diversos autores (Hospitaler, 1999), donde está resaltado en gris el periodo en estudio de esta tesis doctoral. 
En términos generales, Mumford, fundamenta cada una de estas fases en la generación y la utilización de la energía para la producción de algo. Como ejemplo, la invención del telar mecánico en la segunda mitad del XVIII, que provoca la "automatización de los procesos fabriles y con ello, la asunción del trabajo como algo más que la mera subsistencia".

Otras de las referencias destacables es la coincidencia cronológica de la fase paleotécnica con la llamada Revolución Industrial, la cual alcanza su punto álgido en Inglaterra a mitad del siglo XIX, con la Gran Exposición Universal, y el Crystal Palace como referente (1851). Sin embargo, este periodo no ocurre al mismo tiempo en todos los países: en los Estados Unidos, no es hasta 1850 que arranca el régimen paleotécnico, casi un siglo después que en Inglaterra, alcanzando su punto culminante a principios del siglo pasado. En Alemania sin embargo, dominó durante los años entre 1870 y 1914, con la llegada de la fábrica moderna ${ }^{7}$.

\section{LA FASE PALEOTÉCNICA}

Es interesante comentar que ese primer impulso para el futuro industrial británico se localizó en los valles baldíos de Yorkshire, ya que poseían un importante potencial en energía hidráulica, y posteriormente, con la máquina de vapor, en otras zonas deshabitadas del país, que poseían grandes cantidades de carbón. Esta nueva etapa, estará fundamentada precisamente en el carbón a finales del siglo XVIII, que servirá para la calefacción, como recurso energético para las nuevas manufacturas, y para iluminación. Es la iluminación, como se verá a lo largo de toda este trabajo, tanto en su forma natural como en todas sus posibilidades artificiales, uno de los más importantes factores condicionantes en

\footnotetext{
${ }^{7}$ Inglaterra, durante toda la Edad Media, fue uno de los países más atrasados de Europa en términos económicos: se trataba de un país aislado geográficamente y cuyos recursos se basaban exclusivamente en una agricultura poco desarrollada tecnológicamente. La ventaja que de ello sí obtuvo, y que le ayudó a tener un progreso posterior más acelerado, fue que, como el cambio eotécnico apenas se había consolidado en el país, se presentó menos resistencia a la renovación que suponían los nuevos métodos y procedimientos (Mumford, 1971).
} 
la configuración que irán adquiriendo las fábricas a lo largo del proceso de industrialización. Es por eso que con la invención de las primeras máquinas de vapor alimentadas por carbón, con lo que se originará el mayor cambio tecnológico de la era industrial, que incluso modificó la organización de la sociedad hasta nuestros días.

La máquina de vapor pues, provocó por sí sola que la manufactura tendiera hacia el monopolio y la concentración. Pese a la inversión inicial a la que tenían que hacer frente los empresarios, pronto descubrieron su gran potencial, y que junto con las nuevas formas de iluminación alargaron, todavía más si cabe, las jornadas laborales. La producción y el beneficio de los fabricantes textiles estaban alcanzando proporciones no vistas en ningún lugar del mundo hasta el momento: "La máquina de vapor marcaba el paso" (Mumford, 1969):

"Como la máquina de vapor exige una atención constante por parte del que la alimenta y del ingeniero, la energía de vapor era más eficiente en grandes unidades que en pequeñas: en vez de una serie de pequeñas unidades, que trabajaran cuando se les exigiera, se mantenía en continuo movimiento una sola grande. De tal manera, la energía de vapor alentó la tendencia hacia grandes instalaciones industriales ya presentes en la subdivisión del proceso de fabricación. El tamaño grande, exigido por la naturaleza de la máquina de vapor, se convirtió a su vez en símbolo de eficiencia. Los dirigentes industriales no solo aceptaron la concentración y el gigantismo como condición de funcionamiento, exigidos por la máquina de vapor, sino que además llegaron a creer en ellos por sí mismos, como señal de progreso. Con la gran máquina de vapor, la gran fábrica, la gran granja productora, el alto horno, se suponía que la eficiencia existía en razón directa al tamaño. Más grande fue otra forma de decir mejor."

En este párrafo, Mumford demuestra de una forma fácilmente entendible, como el invento de Boulton y Watt agrandó para siempre el tamaño de las fábricas, tanto como lo posibilitaron los nuevos materiales y sistemas constructivos ${ }^{8}$.

\footnotetext{
${ }^{8}$ Hasta este momento predominaban los pequeños molinos, los batanes, los aserraderos, las fundiciones, las herrerías, etc.
} 
Por otro lado, también tomó relevancia el hierro como material, puesto que su producción fue cada vez más barata y más eficiente como resultado directo de la fuerte demanda militar, y que en este periodo no debe dejarse de lado. Así, el carbón y el hierro dominaron el periodo paleotécnico de Mumford ${ }^{9}$. Por su parte, William Fairbairn dedicó gran parte de su vida al estudio del comportamiento del hierro como material de construcción, del que obtuvo interesantes conclusiones con los ensayos empíricos que realizó ${ }^{10}$ (Fairbairn, 1857).

\section{LA FASE NEOTÉCNICA}

Según Mumford, (Mumford, 1971), "la fase neotécnica representa un tercer desarrollo determinado en la máquina durante los últimos mil años". Los comienzos de esta etapa pueden aproximarse de una forma más concreta: con el perfeccionamiento de la turbina hidráulica de Fourneyron ${ }^{11}$, gracias a la mejora en la eficiencia de los generadores de energía, en 1832, y con los inventos de Faraday ${ }^{12}$.

En esta etapa de la técnica, todos los ingenieros, diseñadores, arquitectos e inventores, seguían el método de la práctica empírica, mediante ensayo prueba y error (Mumford, 1971): “De este hábito surgió un nuevo fenómeno: la invención

\footnotetext{
${ }^{9}$ Durante este periodo se alcanzó un gran conocimiento acerca del comportamiento estructural del hierro, con la construcción en 1851 del Crystal Palace, un poco más tarde, los primeros rascacielos en Chicago, y los grandes puentes y viaductos de Eiffel, así como la Torre Eiffel de París, de 1888.

${ }^{10}$ Los principales molinos de finales del siglo XVIII ya empezaron a considerarse resistentes al fuego, fireproof, pero fue el XIX el de la gran evolución de las estructuras, desde los suelos de madera resistentes al fuego de la década de 1790 hasta el de la tipología de construcción con vigas de hierro y suelos de ladrillo del siglo XIX, todo ello pasando por las estructuras y las teorías del industrial e ingeniero Fairbairn.

${ }_{11}$ Benoît Fourneyron (1802 - 1867), fue un ingeniero francés, que destacó, entre otros, por sus significantes contribuciones en el desarrollo de la turbina hidráulica.

${ }^{12}$ Hacia 1850 una buena parte de los descubrimientos científicos fundamentales de esta nueva fase ya se habían realizado: la pila eléctrica, el acumulador eléctrico, la dinamo, el motor, la lámpara eléctrica, el espectroscopio, la teoría de la conservación de la energía, etc. Unos años más tarde, alrededor de 1900, se produjo una gran mejora tecnológica en la central eléctrica generadora de fuerza motriz, lo que provocó una acción directa sobre el funcionamiento y la concepción de la nueva fábrica, con efectos posteriores muy claros sobre las nuevas ciudades y en el medio ambiente.
} 
sistemática y premeditada. He aquí un nuevo material. Problema: buscarle una nueva utilización". Ahora, de este modo, los nuevos ingenieros tenían que dominar todos los problemas que suponía el desarrollo de las nuevas máquinas, y la aplicación de las nuevas formas de energía.

La fase neotécnica fue marcada, desde el principio, por la conquista de una nueva forma de energía: la electricidad ${ }^{13}$ :

"En la aplicación de la energía, la electricidad produjo cambios revolucionarios: estos afectaron a la situación y la concentración de las industrias y la organización detallada de la fábrica, así como una multitud de servicios e instituciones interrelacionadas."

En cuanto a la ubicación de las fábricas, durante la fase anterior, la paleotécnica, la industria dependía absolutamente de la ubicación del carbón como fuente de energía única posible. En cuanto llegó la electricidad, dada la posibilidad de ser generada en diferentes puntos, la ubicación de aquellas ya no dependía tanto de la proximidad de este mineral. El agua, como elemento indispensable para la turbina hidráulica, abrió enormes posibilidades para la implantación de nuevas fábricas, pero ahora en zonas con menores irregularidades topográficas que cuando eran accionadas directamente por los cursos fluviales de los ríos. Y en cuanto a la electricidad, el problema del transporte que tenía el carbón a gran distancia, ya no existía con el transporte y distribución de la energía eléctrica, con menores pérdidas y costes (Mumford, 2010).

"La introducción del motor eléctrico produjo una transformación dentro de la fábrica misma, pues creó flexibilidad en su diseño: no solamente pudieron colocarse la unidades individuales donde se necesitaran, y no solamente pudieron diseñarse para la labor particular requerida, sino que la transmisión directa, que incrementó la eficiencia del motor, también hizo posible modificar la planta misma de la fábrica según las necesidades. La instalación de motores suprimió las correas suspendidas del techo que quitaban luz y disminuían la eficiencia, y abrió el camino para la nueva

\footnotetext{
${ }^{13}$ Central eléctrica y el sistema de distribución de Edison, 1882; Dinamo de Werner Siemens, 1886;
} alternador de Nicola Tesla, 1887. 
disposición de las máquinas en unidades funcionales sin tener en cuenta los árboles de transmisión, y las naves de la fábrica a la antigua. Cada unidad podía trabajar según su propia velocidad, y arrancar y parar según sus propios requerimientos, sin pérdidas de energía para el funcionamiento de la fábrica en conjunto. De acuerdo con los cálculos de un ingeniero alemán, todo esto había incrementado la eficiencia en un 50 por 100."

Hay que fijarse bien en este párrafo, no sólo por su contundencia, sino por la claridad expositiva de la idea: la fábrica ha cambiado su distribución, su funcionalidad y su apariencia, gracias a la colocación de tantos pequeños motores como han sido necesarios. Nada es igual, todo ha cambiado, hasta el tamaño. Reseñar también como se expresa con la palabra "antigua" para resaltar el cambio producido.

Resumiendo, se ha pasado del edificio máquina o edificio motor, a edificio con múltiples máquinas, y posteriormente al de múltiples motores, varios incluso en una máquina ${ }^{14}$. El tamaño de la "unidad productiva" ya no depende de la localización y de sus condicionantes, ni de la máquina de vapor, ni de los sistemas de distribución del accionamiento, ni siquiera de la zona de actuación del operario ${ }^{15}$, sino del proceso de producción en cada momento. Tampoco es necesario que siempre todas las unidades que componen la fábrica hayan de estar en funcionamiento, sino que pueden responder a la demanda puntual de cada instante.

La mayoría de las industrias neotécnicas que fabricaron productos de forma estandarizada automatizaron la producción. Ahora bien, la producción de energía y las máquinas automáticas disminuyeron radicalmente la importancia del obrero en la productividad fabril ${ }^{16}$.

\footnotetext{
${ }^{14}$ Nótese como el ordenador mismo desde el cual se escriben estas palabras está compuesto por innumerables motores insertados. Lo mismo ocurre con el coche, la radio, un proyector, etc.

${ }^{15}$ Idea proveniente del fordismo.

${ }^{16}$ En el segundo puesto en cuanto a importancia que le dio Mumford al descubrimiento de la electricidad, después de la automatización, le siguió el perfeccionamiento de la máquina de vapor y del motor de combustión interna, aunque este último no tuvo incidencia en la conformación del espacio fabril.
} 


\subsection{METODOLOGÍA}

El plan de trabajo que se ha llevado a cabo para la realización de este estudio se concreta en los siguientes puntos:

1. Búsqueda, recopilación, lectura y análisis de bibliografía relacionada con el tema a tratar. Valoración de las fuentes de información.

2. Estudio historiográfico del edificio fabril en sus sucesivas manifestaciones a lo largo del tiempo, desde los primeros aserraderos, herrerías, batanes, etc; hasta el molino, accionado hidráulicamente o por el viento; las reales fábricas, principalmente propiedad de las monarquías borbónicas y de la Europa continental; los mill buildings, con las primeras mecanizaciones de la producción y la concentración de mano de obra, y con sus diferentes formas de accionamiento motriz; las enormes fábricas con una única planta diáfana, principalmente entre ellas las denominadas de diente de sierra o en su término inglés saw teeth roof; hasta finalmente las que tuvieron el hormigón armado y los perfiles de acero laminado como principales elementos de su estructura.

3. Consulta e investigación de archivos, revistas, artículos y libros con documentación sobre los edificios fabriles que se construyeron durante la etapa llamada genéricamente como "revolución industrial" principalmente en Gran Bretaña, pionero en construir mill buildings, con mayor número de edificios y principal país en donde se produjo el cambio de manufactura dispersa a concentración del trabajo, para posteriormente centrarse en una serie de edificios concretos, hitos de la arquitectura industrial por disponer de determinados aspectos relevantes.

4. Creación de una metodología para la determinación del efecto de unos factores concretos sobre las tipologías de los edificios-fábrica, así como la interrelación entre ellos.

5. Trabajo de campo para la localización de edificios industriales valencianos, visitando los ejemplos que se presentan en el trabajo, al resultar 
indispensable la observación "in situ" de dichas instalaciones industriales para su estudio y valoración.

6. Aplicación de la metodología referida en apartados anteriores a los ejemplos concretos valencianos.

Este método de trabajo se ha seguido, principalmente en lo que se refiere a su vertiente histórica, el procedimiento metodológico habitual en historiografía, el cual, según la mayoría de los investigadores se divide en tres partes (Escofet, 2002):

1. Recopilación de información:

- Referente al inicio de la utilización de materiales de construcción, especialmente el hierro fundido y el forjado. La información se ha encontrado en manuales, libros y tesis científicas escritas a finales del siglo XIX, como los de William Fairbairn y el Cast\&Wrought Iron; Joseph Nasmith, de 1894; Tyrrel, de 1901; Ketchum, de 1912 (Ketchum, 1912); Leichenko, de 1917; y de Mitchell, de 1918, así como numerosos artículos científicos.

- En lo que se refiere a la revolución industrial, y a los cambios y movimientos socioeconómicos subsecuentes que se produjeron, en libros especializados de historia, historia en general, biografías y manuales de historia de la arquitectura.

- En cuanto a los espacios industriales, diversas fuentes accesibles por internet, como la página web del English Heritage del Reino Unido: http://www.english-heritage.org.uk/; foros de arquitectura industrial de Andalucía; la Asociación Valenciana de Arquitectura Industrial; del INCUNA - Patrimonio de la Industria, Cultura y Naturaleza; Catálogo Colectivo de la Red de Bibliotecas de los Archivos Estatales Mapas, Planos y Dibujos, sobre todo para la 
información acerca de las reales fábricas; páginas web de las organizaciones que custodian edificios fabriles ingleses, como la del Ditherington Mill o North Mill; Google Maps para la obtención de fotos reales; The International Committee for the Conservation of the Industrial Heritage - TICCIH; Dirección General de Patrimonio Cultural Valenciano; así como diversas revistas como Construction and Building Materials de Elsevier; revistas y boletines de $\mathrm{TICCIH}$; sciencedirect.com, etc.

- Respecto a la casuística valenciana, en artículos escritos por historiadores y economistas valencianos de reconocido prestigio científico, como Inmaculada Aguilar, Azagra, Nadal y Martínez Carrión, entre otros. Asimismo, el arquitecto e historiador Julián Sobrino ha resultado ser de excelente ayuda (Azagra, 1997).

- Tesis y trabajos académicos relacionados con la industrialización valenciana, como Vidal Vidal, Cano Hurtado, Olcina Lloréns, etc.

2. Interpretación de la información:

- Ha sido necesario realizar una labor de interpretación y contrastación de algunos aspectos encontrados en la documentación recopilada, porque algunos de ellos no eran de reconocimiento científico.

Se han realizado también análisis comparativos entre diferentes edificios ubicados en distintas zonas y de épocas diversas, reflejando sus similitudes.

Cabe destacar también, como aspecto relevante de la fase de información, la dificultad que ha representado la obtención de los datos de construcción de algunos edificios valencianos referenciados en el estudio, por no existir documentación sobre ellos y por no encontrarse catalogados en la mayoría de los casos. Mayoritariamente, la dificultad que entraña el patrimonio 
industrial, en cuanto a su conservación y preservación, es el origen de su titularidad, habitualmente de propiedad privada, que no encuentra rendimiento alguno en o para su conservación.

Por otro lado, incidir en que se han desestimado edificaciones cuyo uso no era exclusivamente fabril, o sea, espacios donde solamente se ubicaban máquinas o aquellos destinados exclusivamente al almacenamiento.

3. Síntesis:

Se establecerán las relaciones causales y se contrastarán las hipótesis de partida. De esta forma se pretenderá dar respuesta al objetivo fundamental de la investigación, o sea, la influencia en la forma de las fábricas de los factores descritos.

Esta fase se verá reflejada en el capítulo de conclusiones de la presente tesis.

Para facilitar la lectura del documento, se usará tipografía normal, incluyendo nombres de empresas, apellidos o localidades extranjeras. En cambio, se usará tipografía cursiva en las citas textuales de la bibliografía; y en la terminología extranjera, generalmente inglés, que no se considere de uso habitual o traducción directa, pero que demuestre un interés especial por la concreción del término (Ej. Mill building). 


\section{4. ÁMBITO DE APLICACIÓN}

El ámbito general de estudio del trabajo es el mill building, sobre el que se estudiará la incidencia de unos factores en su manifestación arquitectónica en general, y en particular en la Comunidad Valenciana. Para este último caso, se considerará su evolución tipológica teniendo en cuenta su similitud con modelos surgidos directamente de la llamada revolución industrial, especialmente con aquellos que se construyeron como consecuencia de cambios en los procesos de producción y por la aparición de nuevos materiales estructurales y sistemas constructivos que lo posibilitaron. La investigación de estas fábricas se hará desde el punto de vista de aquellas variables que condicionaron su forma, el aspecto y la distribución de los espacios de trabajo. Todo ello dentro de un marco histórico coincidente con la transformación del sistema manufacturero y del mercado laboral que derivó hacia la organización que se conoce actualmente. Este rango temporal de estudio abarcará desde finales del siglo XVIII hasta principios del XX.

El motivo de la elección del inicio del estudio evolutivo del espacio fabril a finales del siglo XVIII es debido a que, pese a que ya los constructores de las primeras civilizaciones reflexionaron sobre el comportamiento y funcionamiento de sus estructuras constructivas, no es hasta ese momento cuando surgen la mayoría de las teorías modernas sobre el cálculo y el diseño estructural, y su aplicación con nuevos materiales. Además, surge en Inglaterra el edificio para la producción en altura, que será mayoritariamente el prototipo que seguirá toda la industrialización europea.

En cuanto a su final, se opta por el momento en el que se puede considerar la existencia de un cambio drástico en la concepción de los sistemas constructivos y en las tecnologías utilizadas, lo cual coincide con el inicio de la industrialización masiva occidental y además, con la expansión casi generalizada del hormigón armado para la construcción de los edificios industriales. Asimismo, empiezan a utilizarse los perfiles de acero laminado y se inicia una etapa de influencia de 
nuevas tendencias arquitectónicas (periodo ecléctico caracterizado por la imitación de estilos del pasado y por el inicio del racionalismo).

Estudiar la evolución de las tipologías estructurales en su sentido más amplio siempre resulta un ejercicio realmente fascinante. Si además se investiga desde la óptica de la construcción industrial, la cual es muy susceptible al cambio de materiales y en muchas ocasiones pionera en su aplicación, las conclusiones son, si cabe, aún más sugerentes.

La arquitectura industrial, desde siempre, se ha caracterizado por estar continuamente al servicio de las necesidades de los procesos de producción. Al fin y al cabo, siempre ha de cumplir con las exigencias de un contenido para las que se diseña un continente. Si conforme avanza la tecnología de ese contenido tiene que seguir cumpliendo con sus expectativas, necesariamente debe evolucionar de forma paralela. Para ello, tendrá que buscar nuevas soluciones estructurales y nuevos materiales que generen unas tipologías de fábrica concretas. Esto es en esencia, la pretensión última de este trabajo: el análisis de las tipologías a través del tiempo condicionadas por unos factores determinados y cómo estas han llegado posteriormente al territorio valenciano. Ello nos ayudará a comprender el pasado de las construcciones industriales ciñéndose al espectro temporal citado. Por analogía también, valorar el presente gracias a la modernización decimonónica del territorio, y finalmente de algún modo, predecir su futuro.

En cuanto a la delimitación física del edificio a estudiar, dentro de todas las edificaciones que integran los complejos fabriles, se hace referencia a las que contienen la maquinaria que elabora los productos, así como algunos almacenes y talleres que tienen características constructivas similares a los anteriores, excluyendo los destinados a otros usos, como las salas de calderas y máquinas de vapor, contenedores de las turbinas, oficinas y otros. 
Por ello, también con la ayuda de esta rama de la arquitectura, caracterizada por ser extremadamente escueta, explícita y precisa, se podrá reflexionar sobre las soluciones estructurales que se adoptaron en cada caso, tanto en su forma como en la utilización de sus materiales y en los métodos de cálculo utilizados. 


\subsection{ESTRUCTURA DEL DOCUMENTO}

La tesis se organiza en seis capítulos que engloban tres partes perfectamente diferenciadas:

1. En la primera parte, correspondiente a los Capítulos $\mathbf{1}$ y $\mathbf{2}$, se desarrolla un marco teórico y conceptual para encuadrar en el trabajo el significado de fábrica, espacio fabril, industria, maquinaria, etc. Se analizan todos los conceptos básicos necesarios para poder realizar el trabajo, dando así una visión general sobre la arquitectura industrial y todos los conceptos relacionados con ella.

Se definen unos objetivos y unas hipótesis de partida y una metodología de investigación, delimitando espacial y temporalmente el trabajo.

Seguidamente, como apartado central de este trabajo, se realiza una descripción histórica general de los diferentes tipos de edificios fabriles, tomando como referencia el transcurso del tiempo, y cuyos rasgos son claramente diferenciadores: molinos, reales fábricas y mill buildings.

2. En la segunda parte, correspondiente al Capítulo 3, se realiza el estudio de una serie de mill buildings hitos que destacaron en el momento de su construcción por algún aspecto arquitectónico, estructural, funcional (iluminación), de mecanización o de distribución de la energía motriz que accionaba su maquinaria, por el empleo pionero de algún material en su construcción, por el propio sistema constructivo, etc. La gran mayoría de ellos están considerados como el paradigma en varios aspectos: nueva organización del trabajo, instalación de la mecanización y de transmisión de la energía de accionamiento y precursor de la utilización del hierro en sus diferentes variaciones. De hecho, muchos investigadores y expertos en arquitectura industrial sitúan este último en el punto de inflexión entre el antiguo y el nuevo espacio de producción. 
Con estos edificios, lo que se pretende es sintetizar la influencia de unos factores que forzaron a definir la forma de las fábricas: la iluminación, el material, el sistema motriz y de transmisión de la potencia, su comportamiento ante el fuego, su diafanidad y organización interior, etc.

3. En tercer lugar, una vez evaluados estos factores, tratar de considerarlos en unos mill buildings que fueron construidos en la Comunidad Valenciana, y comprobar qué grado de representatividad tuvieron a la hora de construirlos. Todo ello se aborda en el Capítulo 4.

Dado el interés por lo local y por los edificios fabriles, se hace una caracterización económica, social y del espacio industrial valenciano, poniendo en evidencia la existencia de industrialización en los siglos de referencia, el XVIII y el XIX, y motivando así su investigación.

Los Capítulos 5 y 6, al final del estudio, se refieren a las conclusiones finales y a las futuras líneas de investigación, configurando un documento perfectamente estructurado en introducción, investigación, aplicación, conclusiones y posibles vías de análisis abiertas para ampliar el objetivo inicial. 
FACTORES DETERMINANTES DE LA ARQUITECTURA DE LOS "MILL BUILDINGS" Y SU INFLUENCIA EN LA ARQUITECTURA INDUSTRIAL VALENCIANA

$38 / 525$ 


\subsection{INTRODUCCIÓN}

En el presente Capítulo, precedente al cuerpo central del documento en estudio, se realiza una descripción historiográfica de la arquitectura industrial desde el siglo XVIII hasta principios del XX, coincidiendo con el ámbito temporal de esta tesis doctoral. Ello se estructurará en 3 partes claramente diferenciadas:

1. Presentación de la revolución industrial como nuevo sistema productivo y de organización social, cuyo punto de partida se establece con la máquina de hilar de Arkwright accionada por una fuente de energía hidráulica ubicada en el interior de un espacio para el trabajo.

2. Definición de conceptos clave que son necesarios para entender los planteamientos reflejados en apartados posteriores: paisaje industrial, 
industrialización, arquitectura industrial, arqueología industrial y planteamiento de la metodología.

3. Visión histórica de los espacios fabriles, donde se periodizan los 2 primeros grandes grupos de edificios que albergaron la concentración del trabajo: los molinos, en todos sus usos: harinero, textil, batanes, almazaras, etc; y las reales fábricas, como palacios para producir. Las otros 2 tipologías se estudiarán en la introducción del siguiente capítulo: los primeros edificios en altura, que en este estudio se les llama "mill buildings", entendidos como base de las primeras concentraciones industriales inglesas; y finalmente aquellas fábricas de gran tamaño realizadas con acero y hormigón armado que fueron el prototipo de las grandes fábricas automovilísticas de principios del siglo XX. 


\subsection{LA REVOLUCIÓN INDUSTRIAL: UN PUNTO DE INFLEXIÓN EN LA HISTORIA.}

Si se realiza una comparación entre el nivel de vida de un ciudadano de la Europa del siglo XVIII con el de un habitante del Imperio Romano se comprobaría que la diferencia entre ellos no es excesivamente grande. Si a su vez ambos son asimilados al de un ciudadano de la actual Unión Europea, se identificaría inmediatamente que esa diferencia ahora es abismal (Reig, 2007). El XVIII y el siglo siguiente, sin ningún género de dudas, fue un periodo de tiempo en el que se produjo el mayor cambio social, laboral y económico que nunca ha habido en la historia de la humanidad. Motivos hubieron muchísimos, pero fundamentalmente el principal se podría decir que fue la transformación de la forma de trabajar de la mayor parte de la población y de su estilo de vida. Con todo ello, además, por un lado descendió la mortalidad y por otro se duplicó el crecimiento demográfico, por los avances científicos en la medicina.

A partir de la segunda mitad del siglo XVIII, en primer lugar en Gran Bretaña y posteriormente en Francia, Bélgica y Alemania (y fuera de Europa en los Estados Unidos) se produjo un fenómeno completamente extraordinario: el inicio de la llamada Revolución Industrial. El nivel económico de las familias en particular, y de los países en general, se incrementó progresivamente de una forma como no lo había hecho nunca antes (Darley, 1983).

El mercantilismo y las mejoras en las técnicas agrícolas permitieron la existencia de mayores cantidades de alimentos. Comenzó la producción en masa, la industrialización y la utilización de recursos energéticos naturales, como la energía potencial hidráulica, el carbón o el vapor como fuerza motriz de las máquinas, que provocaron originariamente unos profundos cambios en el seno de las manufacturas inglesas (Basalla, 1990). Se inventaron nuevos artefactos mecánicos, principalmente en la industria textil, que permitieron aumentar la producción con un menor gasto en energía humana. Asimismo, surgió una nueva organización de los trabajadores, radicalmente diferente, de modo que se 
implantó el sistema fabril, con un grado de especialización y división de la actividad desconocidos hasta entonces. Aparece la ilustración y la burguesía, con sus correspondientes cambios culturales, también en el ámbito científico, que constantemente inventaba y patentaba nuevos inventos que de alguna manera estimularían cambios en todos los aspectos de la sociedad ${ }^{17}$.

Por su parte, Gran Bretaña ocupaba una posición económica privilegiada y una hegemonía militar y comercial. Sus industrias textiles, y también las metalúrgicas, eran sus protagonistas: la invención del telar mecánico de Edmund Cartwright ${ }^{18} \mathrm{y}$ posteriormente el de Arkwright ${ }^{19}$ en la segunda mitad del siglo XVIII facilitaron la confección de tejidos cada vez más complicados (Falconer, 2006). Paralelamente, la producción de hierro impulsó, no solo la expansión del ferrocarril y el transporte tanto de materias primas como de producto terminado, sino también la construcción de edificios más grandes, más diáfanos y más resistentes.

En el ámbito europeo se fueron incorporando a la industrialización otros países, aunque siempre con un cierto retraso: "España llegó tarde a la primera Revolución Industrial" (Reig, 2007), pero según Nadal, no por falta de iniciativas y proyectos, sino porque estos fracasaron o se consolidaron demasiado tarde (Nadal, 1987). El problema principalmente residió en la inadaptación del sistema político y social a las nuevas realidades económicas europeas, y más aún después de la pérdida de las posesiones americanas.

En España, la industria algodonera más importante se localizó principalmente en Cataluña. Como en principio la metalurgia o la de bienes de equipo requerían mayores inversiones, no se consolidaron originariamente, sino poco después. En

\footnotetext{
${ }^{17}$ Una de las principales consecuencias de la producción en masa de productos manufacturados fue el surgimiento de las clases sociales, en la que los trabajadores asalariados ocupaban mayor espacio económico y una significativa representatividad.

${ }^{18}$ Edward (Edmund) Cartwright (1743 - 1823), clérigo e inventor inglés.

${ }^{19}$ Sir Richard Arkwright (1732 - 1792), industrial inglés que patentó el marco giratorio movido por agua (Water Frame) en 1769, y fundó la primera factoría de algodón hidráulica del mundo en Cromford, Derbyshire en 1771.
} 
Valencia, el éxito industrial llegó más tarde, pero llegó: "El éxito del naranjo, después del fracaso de la morera ${ }^{20}$, no debería ocultar la permanencia y el inmovilismo de un secano bastante más extendido. Sin industria y con una agricultura moderna limitada a los cítricos, la región habría ido consumiendo el siglo XX en condiciones de una inferioridad creciente" (Nadal, 1987).

Así pues, la transformación industrial del conjunto del país tuvo que esperar hasta el siglo XX, sobre todo a partir de la segunda mitad. Ello quedaría fuera del alcance de este estudio, que trata de los orígenes de las tipologías fabriles, por lo que se tendrá que remontar al siglo anterior, antes de este esplendor tan reciente.

No hay que desestimar que durante el siglo XIX habían aparecido diversos núcleos industriales de cierta importancia a nivel europeo, como es el caso de Cataluña y del País Vasco, estando la región valenciana en tercer lugar en términos de industrialización española ${ }^{21}$, por lo que la investigación se centrará en el papel que esta tuvo, y estudiar así con rigor sus mill buildings.

${ }^{20}$ Por la crisis de la "pebrina", o enfermedad de los gusanos de seda.

21 "En termes espanyols, que són els que valen, la regió valenciana és, en finalitzar el segle XIX, segona regió més industrialitzada (la tercera si, tinguéssim en compte Bascònia), darrere Catalunya" (Nadal, 1987). 


\subsection{DEFINICIONES}

\section{EL PAISAJE INDUSTRIAL}

Según Sobrino, a grandes rasgos las actividades económicas han alterado el entorno geográfico. El paisaje aparece como un "nuevo orden social y económico en el cual el azar y la necesidad han marcado de forma determinante el territorio". Precisamente por esta última idea, "la huella sobre el medio ambiente es tan antigua como el de la propia humanidad: deforestación, minas, canteras y construcciones, que en general, han transformado el suelo amoldándolo a la explotación de los recursos" (Sobrino, 1996).

En esta misma obra, y siguiendo esta misma idea sobre la transformación del paisaje, Sobrino comenta: "La primera máquina fue el hogar, natural o construido, entendido éste como fábrica-habitación. [...] En torno a ese hogar-fuego-fábrica se congregaron las gentes, marcando la luz el primer espacio acotado, construido, con su bóveda y paredes producto de la irradiación lumínica". Y con respecto a la idea de la existencia de las primeras fábricas, señala: "El taller primordial va unido al fuego de la misma manera que la primera construcción específicamente industrial, el horno-hogar, es la que origina las tipologías del horno para el pan, el barro y por último los metales. El hogar fue el primer edificio industrial, entendido éste como cobijo de actividades productivas como la talla, el hilado, la cestería, la alfarería, el curtido o la preparación de alimentos. Paralelamente a estos procesos de transformación, el hogar se constituye en almacén y depósito de mercancías y productos, en taller de herramientas. Más tarde, con la aparición de la aldea y la ciudad, se produce un cambio cuantitativo de trascendencia histórica: la ciudad se convierte en un gigantesco taller de chimeneas humeantes" (Sobrino, 1996).

El concepto de paisaje industrial está muy bien tratado por este arquitecto e historiador. Lo introduce como parte de la arquitectura industrial, puesto que no se puede aislar el espacio de producción en sí del entorno que lo acoge. Así, a la 
hora de estudiar un edificio, se deben considerar los elementos adyacentes, puesto que ese proceso es en sí, un conjunto de subprocesos ${ }^{22}$.

De esta manera queda claramente expresada la idea de evolución del espacio fabril desde el hogar-taller como punto de partida ${ }^{23}$ : "El primer prototipo arquitectónico de carácter especificamente industrial lo comparten el molino fluvial y el ya citado horno, ya sea éste panadero, cerámico o metalúrgico", hacia los desarrollados complejos industriales.

Desde el siglo IV d. C. en el Imperio romano se instalaron molinos de notables dimensiones (Ellis, 1833). Un ejemplo de las primeas instalaciones molineras hidráulicas, son los molinos de Barbegal, cerca de la ciudad de Arlés, en Francia, en el 310. Se usaron para moler granos 16 ruedas alimentadas desde arriba que tenían un diámetro de hasta 2,1 m, y una anchura de 0,7 m cada una, y una piedra giratoria de basalto de unos $90 \mathrm{~cm}$ de diámetro, cuyo eje de conexión y ruedas dentadas de transmisión eran de madera. Cada una de ellas accionaba, mediante engranajes de madera, dos máquinas (Masters, 1920). En la fotografía se aprecia el gran impacto que se ejercía sobre el paisaje con estas instalaciones de grandes proporciones con referencia a la época [Figura 1 y Figura 2].

\footnotetext{
22 "El edificio industrial posee tales valores simbólicos que es capaz por sí mismo de crear paisaje, ideal o real, debido a la fuerza y al papel fundacional que el mito de la técnica ha tenido, y tiene, en la generación de actitudes y mentalidades en el subconsciente colectivo de los pueblos.

Las tipologías arquitectónicas industriales son, por tanto, una extensión, una prolongación del hogar como horno, almacén o taller. En un principio, debido al escaso desarrollo económico, estos tipos aparecen incardinados en la propia construcción de las viviendas, para cobrar autonomía, posteriormente, como auténticos espacios industriales exentos, si bien siempre guardaron una estrecha relación tipológico-formal con el prototipo que les dio la vida: la casa" (Sobrino, 1996).

${ }^{23}$ Sobrino considera al molino fluvial como un modelo diseñado por la civilización romana, y así pues, como el realmente primer edificio propio de la revolución industrial. Según él, ha persistido hasta nuestros días con pocas alteraciones, en lo que se refiere al espacio reservado a la producción mediante el uso de medios mecánicos y de energía diferente a la sangre.
} 


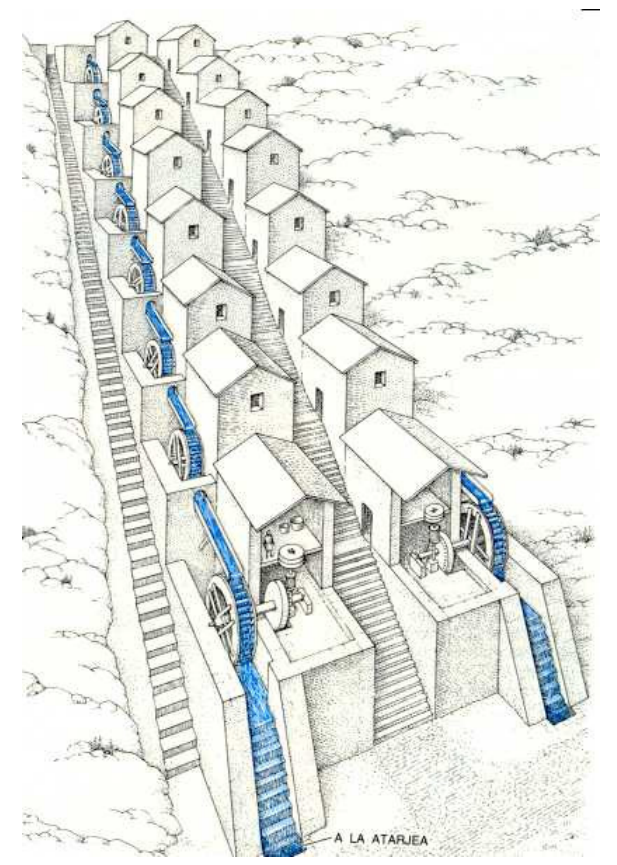

Figura 1. Molinos de Berbegal, hacia el 310 d.C., Francia

(http://cefirevalencia.edu.gva.es/diversificacion/).

La tecnología energética y mecánica del molino harinero será la misma que utilizarán todas las fábricas durante la Edad Media, de tal forma que los batanes, serrerías, casas de moneda, almazaras, herrerías, molinos papeleros, fábricas de armas, molinos de grano y fundiciones comenzarán a poblar los márgenes de los ríos, todos ellos junto con los molinos de viento, también presentes en zonas expuestas. 


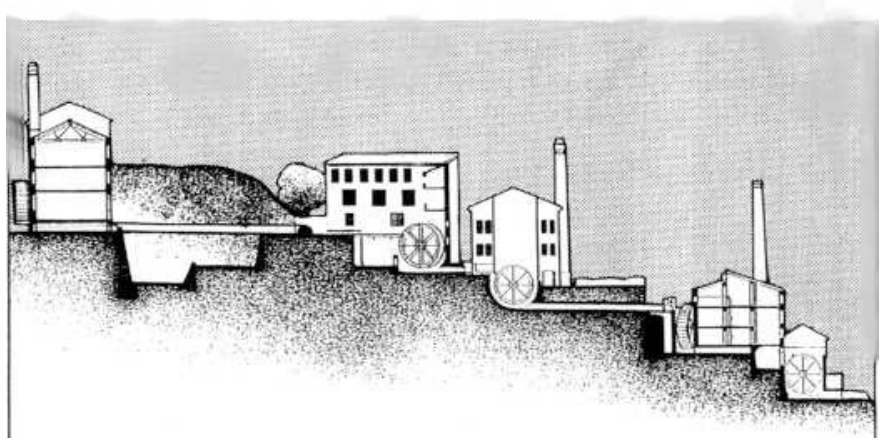

Figura 2. Molinos de Alcoi, en el siglo XIX (Vidal, 1981).

El siguiente paso del proceso de evolución es el de las fábricas reales como primer intento de concentración de oficios (Sebastià, 2007).

\section{REVOLUCIÓN INDUSTRIAL E INDUSTRIALIZACIÓN}

Manuel Cerdá, en su libro Arqueología Industrial, cuando habla de revolución industrial, se refiere a "un conjunto de transformaciones, interconectadas entre sí, que «eliminaron antiguas limitaciones de productividad», «aumentaron bruscamente las ganancias de capital», «modificaron la asignación de los recursos, incluyendo la mano de obra» y «alteraron radicalmente la naturaleza y las condiciones de existencia material, la organización social, la actividad política, el equilibrio internacional de la riqueza y el poder, y la cultura y la civilización»" (Cerdá, 2008).

Según Martínez Gallego la "revolución industrial parte desde el momento mismo en que la revolución burguesa se consuma, que es punto de llegada de la acumulación originaria de capital -en la que el trabajador se ha separado de sus herramientas, en la que el capitalismo ha asentado su base patrimonial [...].

En sentido estricto, entendemos, con Giorgio Mori, que el concepto de revolución industrial cabe reservarlo al caso británico. Fue allí donde, históricamente, primero se produjo el conjunto de cambios -relacionados con la división del trabajo, de la 
centralización de la producción, la aplicación de la máquina [...]. La revolución industrial -británica- será «sinónimo de comienzo del proceso de industrialización», afirma Mori.

A partir de 1843, España se incorpora a tal proceso industrializador, una vez allanado el camino tras la lucha revolucionaria contra la organización feudal de la producción, tanto agraria como manufacturera." (Martínez, 1995).

Según Darley: "De todos los materiales, el hierro fue la clave del siglo de la transformación: de 1750 a 1850. Algunos autores señalan que la revolución industrial se podría llamar la "revolución del hierro". El continuo perfeccionamiento del hierro, en particular de los perfiles laminados, y la siguiente introducción revolucionaria, la del acero barato producido en serie, fueron impulsados por la rápida proliferación y el desarrollo de la red ferroviaria" (Darley, 1983). Justo en los mismos términos se pronuncia Sebastià: "El hierro fundido fue la clave del siglo de la transformación industrial, de 1750 a 1850, momento en el que aparecerá el hierro forjado en vigas" (Sebastià, 2007).

Por su parte, Sobrino (Sobrino, 1996) separa la revolución industrial en tres fases, o "tres revoluciones":

1) La primera revolución industrial (1830-1888), en la que incluye un capítulo para los edificios preindustriales: ferrerías vascas, fargas catalanas, reales fábricas y edificios de la revolución industrial,

2) La gran industria (1888-1936), y por último,

3) La tercera revolución industrial (1939-1990)

Para Aguilar, la revolución industrial es un periodo que lógicamente varía según el país e incluso según la comarca a la que se refiere, y que finaliza observando las implantaciones industriales todavía en funcionamiento (Aguilar, 1998). En su ponencia durante el "1er Congrés de Arqueologia Industrial al País Valencià", celebrado en Alcoi, en 1990, determinó algunas de las características que definían 
la arquitectura en "íntima relación con la industria a partir de mediados del siglo XVIII", dentro de un periodo histórico determinado y particular.

Se reproduce a continuación, por su valor definitorio, la ponencia realizada por la citada autora ${ }^{24}$ :

"Al igual que en otras épocas históricas en las que se manifiesta un cambio en la cultura histórica, debido a los nuevos significados ideológicos del comportamiento humano, la revolución industrial va a crear paulatinamente un ser distinto al de otras épocas. El nuevo alumbrado irrumpe en su horario solar, los nuevos transportes acortan distancias y lugares antes insospechados, las nuevas ciudades masificadas por el incremento de población se cubren de nuevas necesidades públicas, nuevos servicios, nuevas comunicaciones, nuevas nociones de higiene y confort. En esta simple y escueta enumeración menciono algunos de los nuevos conceptos urbanos, a los que a duras penas tuvieron que ir adaptándose los seres humano cuya estructura mental estaba todavía anclada en épocas pasadas. La arquitectura irá también adaptándose a los nuevos conceptos ideológicos que se derivan de los cambios producidos por la revolución industrial.

Todas las historias de la arquitectura contemporánea centran sus orígenes a mediados del siglo XVIII con la revolución industrial. Tanto Pevsner, Benévolo, Giedion, Tafuri, Zevi, Frampton... etc, nos aportan las primeras teorías, que podríamos resumir en tres aspectos:

1) La revolución industrial modifica las técnicas constructivas e introduce nuevos materiales como el hierro y el cristal.

2) La revolución industrial modifica el concepto tradicional de la ciudad: nuevos servicios, nuevas tipologías, nuevos sistemas de comunicación y nuevo concepto del valor del suelo.

3) La revolución industrial estimula el espíritu científico y con él la investigación experimental, comportando como consecuencia inmediata la creación de escuelas especializadas".

24 Una aproximación a la definición de arquitectura industrial, se puede encontrar en "Industrialització i Arquitectura". Actes del primer Congrés del País Valencià. Diputació de València, 1991 pp. 93-119. Y en "Una aproximación a la arquitectura industrial", Gorc, no 8, febrero 1994, pp. 6-7: ponencia en el Congreso celebrado en Ávila el 29, 30 de septiembre y 1 de octubre "Medievalismo y neomedievalismo en la arquitectura española: El siglo XIX", con el título "Arquitectura Industrial". 
A grandes rasgos, se puede afirmar que con los nuevos materiales se construirán espacios fabriles destinados específicamente a un uso productivo, surgidos de las necesidades de la nueva sociedad capitalista e industrial, en los que se requerirán grandes espacios diáfanos, como el invernadero del Crystal Palace de Paxton, mercados, naves, fábricas, puentes, bibliotecas, etc (Benévolo, 2010). Pero sin embargo, muchos arquitectos seguirán utilizando los materiales tradicionales en sus obras, ya que se mostraban reticentes a que los nuevos entraran a formar parte de la arquitectura, como el hierro fundido y el forjado $(\text { Zevi, 1980 })^{25}$.

De nuevo, según Sobrino, la vida en la fábrica ha marcado gran parte del pasado inmediato y desde la llamada revolución industrial, "El espacio del trabajo ha evolucionado a partir de las diferentes elecciones que los gestores de la producción fueron realizando en función de los avances tecnológicos, la demanda de sus productos y los sistemas de organización empresarial. Cada nueva alternativa empresarial iba seguida de un cambio de escala tanto cuantitativo como cualitativo, que se expresaba, entre otros factores, mediante una nueva concepción y configuración del espacio fabril" (Sobrino, 2004).

Y por último, como dice Strike, "El cambio más importante habido en el proceso de edificación durante los setecientos años que precedieron a la Revolución Industrial (cuyos albores datan de 1700) fue el lento pero imparable quebranto de la tradición local. [...]. Dentro del periodo preindutrial, también hay que reconocer un lento pero incesante perfeccionamiento del sistema estructural medieval

\footnotetext{
25 Surge así la polémica y el debate entre arquitectos e ingenieros, los cuales no tenían consideración alguna para la edificación arquitectónica. Asimismo, pese a todas las ventajas de la construcción en acero, que la historia ya se encargó de demostrar, la nueva arquitectura tuvo serios problemas para consolidarse.

Por ello, las primeras edificaciones fabriles serán obras de ingenieros, no de arquitectos. Obras esencialmente prácticas (utilitarias) como estaciones de ferrocarril, puentes, etc, u otras simplemente efímeras (pensadas para ser utilizadas durante un cierto tiempo para luego ser desmontadas). Quizás la obra más emblemática de este nuevo estilo sea el Pabellón que Paxton realizó para la Exposición Universal de Londres.
} 
basado en los muros de carga. [...]. La Revolución Industrial fomentó un tipo de cambio mucho más rápido." (Strike, 2004).

\section{ARQUEOLOGÍA INDUSTRIAL}

Según Cerdá, la arqueología industrial "es la disciplina que se ocupa del pasado de la sociedad industrial a través del estudio de sus restos materiales" (Cerdá, 2008).

Y añade, que es la "metodología que permite profundizar en el conocimiento de la sociedad industrial-capitalista a partir de sus restos materiales, al igual que la arqueología lo hace con otras épocas históricas más remotas".

Inmaculada Aguilar dice: "En lo que refiere a la propia arqueología industrial, por su reciente origen, es confusa en cuanto a su término. Las distintas tendencias nos lo reflejan a la hora de definir su delimitación cronológica. Esta variante abarca desde la prehistoria hasta las últimas naves espaciales. También hemos podido observar esta disparidad de criterios en los inventarios de ámbito español, por lo que esta será una de las primeras dificultades que nos encontramos a la hora de definir este concepto" (Aguilar, 1998). Evidentemente, en la actualidad ya se tiene superado el alcance de este término.

Previamente, en 1964, Kenneth Hudson ya define una nueva arqueología científica, la Arqueología Industrial, cuya finalidad es el "descubrimiento, la catalogación y el estudio de los restos físicos del pasado industrial, para conocer a través de ellos aspectos significativos de las condiciones de trabajo, de los procesos técnicos y de los procesos productivos". Por lo tanto, la disciplina llamada Arqueología Industrial nace en "íntima relación con el movimiento de revalorización del Patrimonio Industrial. Será el interés social o la sensibilización hacia este lo que ha sido determinante para el nacimiento de esta disciplina, su estudio, su intención de preservar y su utilización con fines educativos y culturales" (Aguilar, 1998).

\section{METODOLOGÍA DE LA ARQUITECTURA INDUSTRIAL}


A grandes rasgos, la arqueología industrial ayudará a conocer el espacio fabril, así como sus instalaciones: conducciones de gas, agua, humos y electricidad. Esta ciencia, sirve también para (Aguilar, 1998):

- "Saber diferenciar los espacios destinados a la producción en sus distintas fases.

- Localizar los edificios administrativos, los residenciales, los de almacenamiento de materias primas, los productos acabados y los de combustibles.

- Identificar los diferentes talleres necesarios para los trabajos internos de fábrica.

- Localizar cartográficamente una empresa en suelo urbano o rural junto a las redes de abastecimiento y comunicación."

Estos elementos son tan válidos para analizar una real fábrica del siglo XVIII como una factoría de los años 20 del siglo pasado, de tal manera que se sea capaz de conocer la organización espacial del proceso productivo, identificando las circulaciones de las transmisiones mecánicas, de la energía, de las materias primas, los obreros y los productos acabados.

Igualmente sirve para clasificar y valorar los materiales utilizados en la construcción, los elementos estructurales y de cubierta, los sistemas de iluminación y ventilación, su localización, el entorno, etc (Heredia, 1995). 


\title{
ARQUITECTURA INDUSTRIAL
}

Julián Sobrino, en su libro sobre arquitectura industrial en España (Sobrino, 1996), señala que:

\begin{abstract}
"Hablar hoy de arquitectura industrial supone realizar un esfuerzo de evocación, dar un salto atrás en el tiempo y situarnos en los comienzos de la industrialización alli donde ésta se produjo, en Inglaterra, en un lugar emplazado entre Derby y Cromford, donde todavía resuena el zumbido de los miles de husos que hacia 1780 comenzaron a girar frenéticamente al compás del movimiento por la máquina de vapor".
\end{abstract}

[...]

La arquitectura industrial aparece desde sus inicios no como un modelo tipológico hacia el exterior -esteticismo-, sino como un prototipo funcionalismo- capaz de organizar coherentemente los diversos volúmenes que la constituyen en el espacio y de prever su evolución -flexibilidad-. La belleza no será el primer objetivo y, si hemos de ser sinceros, las industrias y el paisaje industrial de hace escasos años -y aun hoy-, constituyen los mayores ejemplos de fealdad creados por el hombre".

\section{$[\ldots]$}

"La tipología arquitectónica es la concreción de un modelo adaptado a unas necesidades y válido para ser desarrollado en diversos lugares sin sufrir apenas variaciones.

Según Aguilar, "La definición de arquitectura industrial no es una definición que responda exactamente a algo en concreto, sino más bien es un concepto muy amplio. Muchos estudiosos, investigadores e incluso profesionales no coinciden a la hora de determinar qué aspectos de la arquitectura o de la ingeniería responden a la clasificación concreta de industrial. En la bibliografía existen multitud de acepciones utilizadas para referirse a este campo, así como diferentes aspectos que se pueden tratar de forma independiente: arqueología, patrimonio, construcción, materiales, ordenación espacial, etc ${ }^{26}$. Así pues, para poder utilizar el

26 Una aproximación a la definición de arquitectura industrial, se puede encontrar en "Industrialització i Arquitectura". Actes del primer Congrés del País Valencià. Diputació de València, 1991 pp. 93-119. Y en "Una aproximación a la arquitectura industrial" Gorc, no 8, febrero 1994, pp. 
término arquitectura industrial deberemos, cuanto menos, acotarlo en el tiempo e intentar realizar una delimitación temática" (Aguilar, 1998).

Por último, cabe mencionar a Félix Cardellach ${ }^{27}$, ingeniero y arquitecto pionero en tratar sobre la arquitectura industrial en España. Su bibliografía era muy extensa, siendo su mayor referencia el "Tratado de Arquitectura Industrial" y "Filosofía de las estructuras". Pero cabe destacar el hecho de que entre 1907 y 1908, impartió unas famosas conferencias sobre arquitectura industrial, que recogieron distintos aspectos: teóricos, históricos y constructivos ${ }^{28}$. Cardellach ya asistió a principios de siglo a cursos impartidos en las mejores escuelas europeas del momento en arquitectura y construcción, estando en contacto con relevantes obras industriales.

Una de las ideas en las que se basaba Cardellach era que la arquitectura industrial era la arquitectura del ingeniero, o la ingeniería del arquitecto, y así obtener un patrón para la arquitectura fabril:

"Voy pues a hablaros de una arquitectura más nueva, de una arquitectura a la que también concurre como la anterior (la monumental), el sentimiento de nuestro corazón pero con una finalidad explotativa, industrial. Voy, en fin, a hablaros de la Arquitectura del Ingeniero, o en cierto modo, si lo queréis dicho de otra manera, de la Ingeniería del Arquitecto.".

\footnotetext{
6-7: ponencia en el Congreso celebrado en Ávila el 29, 30 de septiembre y 1 de octubre "Medievalismo y neomedievalismo en la arquitectura española: El siglo XIX" con el título "Arquitectura Industrial" (en prensa).

${ }^{27}$ Fèlix Cardellach i Alivés (1875 - 1919) fue un arquitecto e ingeniero industrial catalán del periodo modernista. Fue Catedrático de Arquitectura Industrial en la Escuela de Ingenieros Industriales de Barcelona.

${ }^{28}$ No existe bibliografía española de estas características a principios de siglo, al contrario de lo que sí ocurre en el resto de la Europa industrial, como Inglaterra, Alemania o Francia, donde en la historiografía del siglo XIX quedaba reflejado este ámbito de la arquitectura, debido en gran medida a la existencia de ingenieros y arquitectos del sector, como por ejemplo, la Asociación alemana del Werkbund.
} 
Y según la revista Docomomo ${ }^{29}$, desde el sector de los ingenieros y el de los constructores, llegaron contribuciones y experimentos que se fueron incorporando al mundo arquitectónico: "El programa de la arquitectura de los espacios industriales se ofrecía como un campo abierto a la innovación, por ser más accesible a la experimentación.".

Así pues, tal y como se verá a lo largo de toda este estudio, es importante observar que la arquitectura industrial ha servido en muchas ocasiones para experimentar con las nuevas tecnologías de la construcción, configurando una tipología fabril.

${ }^{29}$ La arquitectura de la industria, 1925-1965: Registro DOCOMOMO Ibérico. Fundación Docomomo Ibérico ed., Barcelona: Fundación DOCOMOMO Ibérico, 2005. 


\subsection{VISIÓN HISTÓRICA DE LA CONSTRUCCIÓN DE LOS EDIFICIOS INDUSTRIALES. PERIODIZACIONES TIPOLÓGICAS.}

Una vez establecidos los objetivos y la motivación de este estudio, y definidos los conceptos y definiciones en los que se basa, resulta muy conveniente la presentación, de una forma somera, de la evolución del edificio entorno a la máquina y a la producción a lo largo de la historia industrial. Para ello, y por facilidad de comprensión, se ha seguido un hilo conductor totalmente cronológico, en el que las diferentes etapas han sido marcadas principalmente por la evolución que las fábricas han tenido según la maquinaria a la que envolvían.

Se partirá del edificio-motor-máquina, todo ello confundido en un único elemento indivisible, como el molino envolvente para la molturación, accionado por un motor hidráulico o eólico, donde no hay más espacio que para la maquinaria y cuya forma responde a un proceso que sigue la ley de la gravedad.

El siguiente paso natural se correspondería con el edificio en altura, donde un único motor hidráulico fuera capaz de accionar diversas máquinas ubicadas en las diferentes plantas, con el propósito de aprovechar al máximo su espacio cerca de la fuente de energía, los ríos. Pero en la Europa continental, principalmente en los países con monarquías con un fuerte poder establecido, se cuelan las reales fábricas. La centralización artesanal en los palaciegos espacios productivos fundamenta las manufacturas dieciochescas, como punto de partida de la producción industrial. Esta novedad tipológica productiva en sí, queda alejada de los mill buildings o molinos en altura ingleses y norteamericanos, pero resulta muy interesante para valorar la transcendencia de la herencia dejada, como por ejemplo las fábricas de tabaco, edificios que todavía persisten en muchas ciudades españolas. Conviene reseñar que la mecanización no será para estas un factor influyente, como sí lo serán, por ejemplo, la iluminación y la estructura, permitiendo una gran diafanidad.

Se acabará la exposición cronológica con el edificio con muchas máquinas, las cuales a su vez estarán compuestas de innumerables motores, y que se 
denominará en este estudio bajo el nombre de "fábrica moderna". Serán el acero laminado y el hormigón los que permitirán cumplir con los requisitos exigibles (Burgos, 2009): solidez, resistencia al fuego, iluminación, ventilación, diafanidad, control y racionalidad. En definitiva, el espacio de producción al servicio de la economía. 


\subsubsection{Los molinos, o protoindustria}

No es excesivamente difícil encontrar documentación en la que se señalen pruebas de la primera existencia de edificaciones relacionadas con procesos productivos. Evidentemente no se les puede llamar fábrica a ninguno de aquellos edificios iniciales hasta el momento en los que en ellos se incluya una máquina. Probablemente de todas estas construcciones originales, el almacén o el cobertizo es el edificio más usual, surgido de la necesidad de abastecimiento de las primeras ciudades con los excedentes de las cosechas. Ya desde la más remota antigüedad los almacenes supusieron el aseguramiento del suministro regular de bienes de consumo, especialmente alimentos ${ }^{30}$.

Todavía se conservan viejos molinos ${ }^{31}$ por toda Europa, en muchas ocasiones reconvertidos en otro uso, como entre otros el de Littlebourne, Kent (Inglaterra) [Figura 4], molino de trigo de varias plantas con una única rueda hidráulica ${ }^{32}$; así como grandes almacenes, como el de la abadía de Ter Duinen en Lissewege, Brujas (Bélgica) [Figura 3]. Bodegas y almazaras se podrían también considerar como arquitectura de almacenamiento y productiva, así como atarazanas (entre otras la de Valencia, que se empezaron a construir en 1338), y arsenales, que aparecen en España ya en el siglo XIII.

\footnotetext{
${ }^{30}$ Otra prueba de su importancia se puede encontrar en las culturas clásicas y preindustriales, de los que todavía quedan ejemplos existentes en adobe, en un buen número de pueblos de la cordillera del Atlas, al noroeste de África.

${ }^{31}$ La RAE, en su 3a acepción, define el molino como la casa o edificio donde hay un molino, el cual, a su vez, es el artefacto con que, por un procedimiento determinado, se quebranta, machaca, lamina o estruja algo. En su 1a entrada, lo define como máquina para moler, compuesta de una muela, una solera y los mecanismos necesarios para transmitir y regularizar el movimiento producido por una fuerza motriz, como el agua, el viento, el vapor u otro agente mecánico.

${ }^{32}$ Ahora destinado a vivienda.
} 


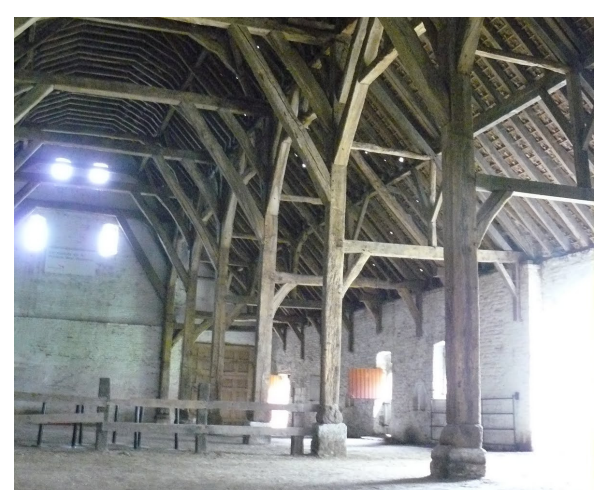

Figura 3. Abadía de Ter Duinen en Lissewege, Brujas (Bélgica), siglo XII, en la actualidad convertida en hotel

(http://www.trekearth.com/gallery/Europe) Belgium.htm).

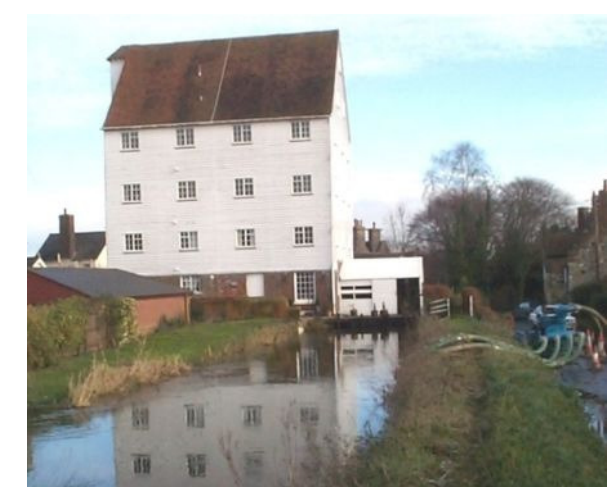

Figura 4. Littlebourne Mill, Kent (Inglaterra), 1803

(http://upload.wikimedia.org/wikipedia/com mons/thumb/e/e5/Wickhambreaux_mill.jpg/ 220px-Wickhambreaux_mill.jpg)

Durante el largo periodo de tiempo de la Edad Media (siglos $\mathrm{V}$ al XV) los principales sectores económicos son el metalúrgico y el textil, en los que se basarán las actividades industriales posteriores, que nacerán principalmente con la utilización de la energía hidráulica, alternativa al accionamiento por sangre. El agua de los ríos será el principal accionamiento de la maquinaria, cada vez más compleja y con mayores rendimientos, hasta la invención de la máquina de vapor. Con esta última, la mayoría de los molinos se transformarán en centros industriales durante los primeros años de la revolución industrial, ya a finales del siglo XVIII. Aquellos primitivos edificios ampliaron sus naves y se convirtieron en fábricas, e incluso alguno de ellos fue origen de pobladas colonias obreras.

Así, a lo largo del tiempo, la rigidez de los edificios tuvo que adaptarse a la flexibilidad con la que la maquinaria cubría las sucesivas necesidades industriales. 


\section{TIPOLOGÍA DE MOLINOS}

La definición de molino según el Diccionario de la Real Academia Española, es el de una máquina para moler, compuesta de una muela, una solera y los mecanismos necesarios para transmitir y regularizar el movimiento producido por una fuerza motriz, como el agua, el viento, el vapor u otro agente mecánico ${ }^{33}$. Por tanto, un molino es una máquina, un "ingenio para moler, trinchar o desmenuzar, triturar o deshacer la estructura de cualquier cosa", aunque por extensión se aplica su mismo nombre a todo el edificio que la contiene (Álvaro, 2001).

Existen varias posibilidades de clasificación de un molino, aunque principalmente se pueden dividir en:

1. Clasificación de los molinos según la energía:
a. Molino de sangre, movido por la energía animal.
b. Molino de viento, si se utiliza la energía eólica.
c. Molino de agua o hidráulico, cuando es el agua la que proporciona la energía.
d. Molino de fuego, si la energía que se aplica es la fuerza del vapor.

2. Clasificación de los molinos según lo que molían:
a. Molino harinero.
b. Molino arrocero.
c. Molino de aceite.
d. Molino de yeso.
e. Molino de sal.
f. Molino de pólvora.
g. Otros.

\footnotetext{
${ }^{33} \mathrm{El}$ agua y el viento han sido, hasta no hace mucho tiempo, las únicas energías que el hombre disponía, y por ello, los molinos fueron la clave de la expansión económica occidental durante más de siete siglos (Álvaro, 2001).
} 
Si bien todos estos molinos utilizaban las muelas, también existían otros artefactos $^{34}$ llamados molinos, que aunque también utilizaban la energía del agua, actuaban mediante mazas, movidas por ruedas de cajones o palas, como por ejemplo:

h. Serrerías, para la madera.

i. Fargas, para forjar el hierro, sobre todo en Cataluña.

j. Molino papelero.

k. Molino para curtir las pieles.

I. Molino textil o batán.

Introducido por iniciativa señorial fue esta institución feudal la que los implantó mayoritariamente a partir de los siglos XI y XII ${ }^{35}$.

Mucho más tarde, alrededor de los molinos, se desarrollaron otros trabajos, aparte de la moltura de cereal, e incluso algunos se convirtieron en fábricas. Este hecho sería suficiente para afirmar que el molino fue el motor que transformó las sociedades agrícolas en sociedades preindustriales o industriales ${ }^{36}$.

\footnotetext{
${ }^{34}$ Máquina, aparato, según la Real Academia de la Lengua, RAE.

${ }^{35}$ En la mayoría de los casos cada señorío, o cada comunidad religiosa, solía disponer de más de un molino. Así, los vasallos tenían que moler en el molino del señor y pagar la moltura en especie.

${ }^{36}$ En el caso valenciano, por las condiciones climatológicas y geográficas del territorio, se disponía de poca agua, la cual se tenía que aprovechar al máximo, sin que se perdiera ni una sola gota para abastecer el riego y la impulsión mecánica. Esta necesidad fue principalmente la que determinó las características de sus molinos. Son remarcables las infraestructuras de acequias entrelazadas, en ocasiones a sendos lados de las riberas de los ríos. De esta manera, en muchas ocasiones, el agua discurría de molino a molino por cotas superiores al lecho del río para evitar pérdidas indeseables en el caso de haberse utilizado directamente el propio cauce.

Un elemento presente en muchos molinos era el azud o presa. No era más que un obstáculo en el cauce del río con la finalidad de desviar la corriente de agua hacia los márgenes y de ahí conducirla hacia las acequias, que bordeando el río y alejándose según los casos, alcanzaban los niveles necesarios para llenar las balsas de almacenamiento. Solían estar construidos con bloques de piedra tallada.
} 
A continuación se estudian los dos tipos de molinos comentados, el hidráulico y el eólico, según la energía motriz utilizada:

\section{EL MOLINO DE AGUA}

Desde los orígenes más remotos, las primitivas actividades productivas requerían fundamentalmente del fuego $\mathrm{y}$ del movimiento como principales agentes intervinientes (Álvaro, 2001). Del fuego provienen los hornos, la cerámica, el vidrio y la metalurgia, y del movimiento, que se conseguía gracias a una fuerza motriz, las actividades de molienda. Su mecanismo o artilugio inicial fue el molino $^{37}$. Asimismo, Vitruvio ${ }^{38}$ ya describe perfectamente el instrumento rueda hidráulica y el engranaje que se emplearía durante más de veinte siglos sin prácticamente ningún cambio.

Como se ha comentado, también existieron previamente los llamados molinos accionados a sangre, por animales de tiro (norias) e incluso los impulsados por el esfuerzo humano, aunque estos siempre estuvieron en clara desventaja respecto a la propulsión hidráulica (Watts, 2006) ${ }^{39}$.

La maquinaria e instalación del molino de agua dominó durante mucho tiempo las ilustraciones de ingenios y máquinas, y desde el Renacimiento (siglo XV) diversos

\footnotetext{
${ }^{37}$ Se puede decir que el origen de las ruedas accionadas por agua se remonta ya hacia el año 2200 a.C. en la antigua China, aunque la rueda hidráulica vertical como tal no se usará hasta alrededor del final del siglo III d.C. Serán comúnmente usadas en Grecia, Roma y Persia.

${ }^{38}$ Vitrubio, De architectura libri decem, siglo I. En la versión española: Los diez libros de arquitectura, traducción de Agustín Blánquez. Barcelona: Iberia, 1986, Libro Décimo, Capítulo X. Pp. 269

${ }^{39}$ Después de la caída del Imperio Romano, que destruyó el tejido industrial y comercial como se ha comentado anteriormente, se produjo un aumento considerable de las ruedas hidráulicas durante la Edad Media. En Inglaterra, en la baja Edad Media, que comienza más o menos en el siglo $\mathrm{XI}$, se contabilizaban en el 'Domesday Book', 5.624 molinos, aunque otras fuentes citaban que había más de 20.000 (Ellis, 1833). El 'Domesday Book' (también conocido como Domesday, Doomsday, o Libro de Winchester) fue el principal registro de Inglaterra, completado en 1086 bajo las órdenes del rey Guillermo I de Inglaterra. Este registro era similar a los censos nacionales que se realizan hoy en día, donde el rey disponía de la información sobre el país que acababa de conquistar, para así poder administrarlo mejor (Masters, 1920).
} 
autores italianos y alemanes dejaron detalles muy explícitos de esas construcciones, aportando sus variantes y mejoras (Fuentes, 2011).

\section{RUEDAS HIDRÁULICAS}

La evolución de la maquinaria y los dispositivos técnicos pertenecientes a los molinos podría ocupar perfectamente todo un capítulo en la historia de la tecnología y de la arqueología industrial. Se abstraerá una parte que pueda resultar relevante, como es la tipología de las ruedas hidráulicas.

Una primera clasificación se podría hacer entre aquellas ruedas con disposición vertical, o de eje horizontal ${ }^{40}$ [Figura 5 y Figura 6], y las horizontales, o de eje vertical $^{41}$.

\footnotetext{
${ }^{40}$ Encyclopédie ou Dictionnaire raisonné des sciences, des arts et des métiers es una enciclopedia francesa editada entre los años 1751 y 1772 bajo la dirección de Denis Diderot y Jean D’Alembert. Es considerada una de las obras más grandes del siglo XVIII, por contener la síntesis de los principales conocimientos de la época. Se convirtió en un símbolo del proyecto de la llustración.

${ }^{41}$ En las de la primera tipología, las más comunes durante mucho tiempo, existían variaciones en función del punto donde accionaba el agua: por debajo (inmersión), desde arriba (por efecto de la caída), o incluso frontalmente a media altura, lo que en Inglaterra se llamaba 'breast whell'. Por el otro lado, entre las de disposición horizontal, son típicos los rodeznos, en los que el agua incidía desde una tobera metálica sobre sus álabes.

Es muy interesante destacar en este punto, que fue en 1824 cuando el ingeniero francés Jean-Victor Poncelet (1788 - 1867) aumentó el rendimiento de las ruedas denominadas de inmersión construyendo una pequeña represa antes de la rueda, aumentando así la energía potencial del agua que tenía que transformarse en energía cinética. Por otro lado, el inglés John Smeaton (1724 - 1792) (Chaloner, 1963), conocido por sus estudios sobre el hormigón, analizó matemáticamente los rendimientos de las ruedas hidráulicas y dedujo que el accionamiento por caída superaba en torno al $50 \%$ al conseguido por inmersión. Otro investigador susceptible de ser nombrado es el francés Benoît Fourneyron (Saint-Étienne, 1802 - París, 1867), que desarrolló la turbina de agua en disposición horizontal, en la que el agua incidía en su centro sobre una parte fija con paletas curvas que tenían por finalidad desviarla hacia otra parte exterior rotatoria (Crump, 2010).
} 


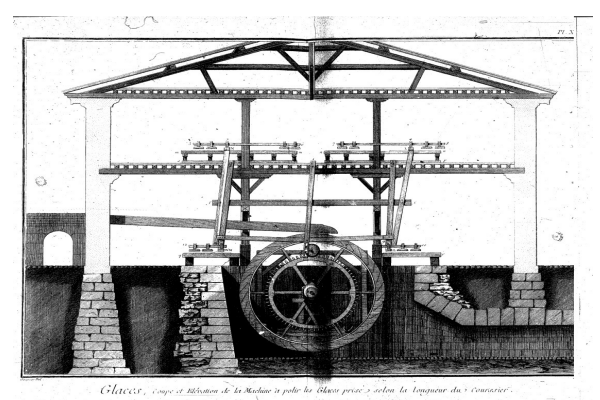

Figura 5. Enciclopedia de Diderot $y$ D’Alambert. Volumen 3. Rueda hidráulica de eje horizontal accionada por la parte superior (siglo XVIII).

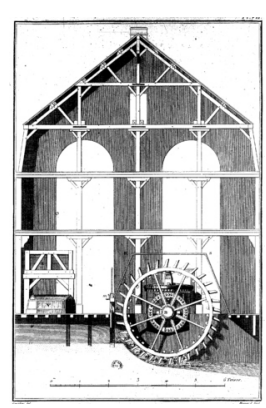

Figura 6. Enciclopedia de Diderot $y$ D’Alambert. Volumen 4. Molino papelero de accionamiento inferior. Ejemplo originario de edificio-motor-máquina.

Como ejemplos de molinos con turbinas hidráulicas utilizadas en edificios de producción cabe citar, por la importancia constructiva, empresarial y simbólica del edificio, hito de la arquitectura industrial y de la arquitectura en hierro y acero, el de la fábrica de chocolates Menier, en Noisel-sur-Marne, Francia, construida por el arquitecto Jules Saulnier ${ }^{42}$ y el ingeniero Armand Moisant ${ }^{43}$, entre 1871 y 1872 , y al que se referirá en varias ocasiones a lo largo de este estudio ${ }^{44}$ \{confrontar el factor iluminación en apartado 3.6 más adelante\} [Figura 7].

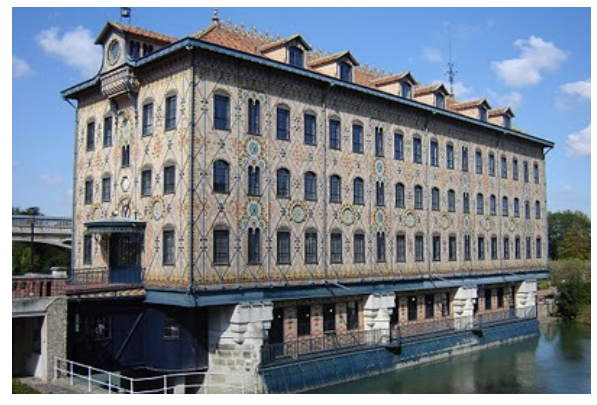

Figura 7. Fábrica de chocolates Menier, en Noiselsur-Marne (Francia). El edificio apoya sobre 4 pilares, entre los que se instalaron 4 turbinas hidráulicas para la producción de de energía mecánica por la fuerza del río.

(http://en.wikipedia.org/wiki/Menier_Chocolate).

42 Jules Saulnier (1817 - 1881).

${ }^{43}$ Armand Moisant (1838 - 1906).

${ }^{44}$ Disponía de turbinas de eje vertical y ha sido referenciada por diversos autores muy relevantes como Giedion, Ragon, Frampton, Lemoine, etc, entre otras cosas por ser uno de los primeros edificios en usar de una forma integral el hierro en su estructura. 


\section{MOLINOS DE VIENTO}

Después de los molinos hidráulicos, los impulsados por la fuerza del viento son el siguiente invento en las manufacturas desde la Edad Media (Hills, 1994). Pese a tener una antigüedad menor que los primeros, sus orígenes se remontan al lejano Oriente. Sus fines utilitarios no se encuentran hasta el siglo VII en Persia, y de los que todavía se pueden localizar algunos ejemplos de este tipo primitivo en la región de Sistán, en Irán, caracterizado por su eje vertical con rústicas aspas de cañas o ramajes entrelazados [Figura 8 y Figura 9].
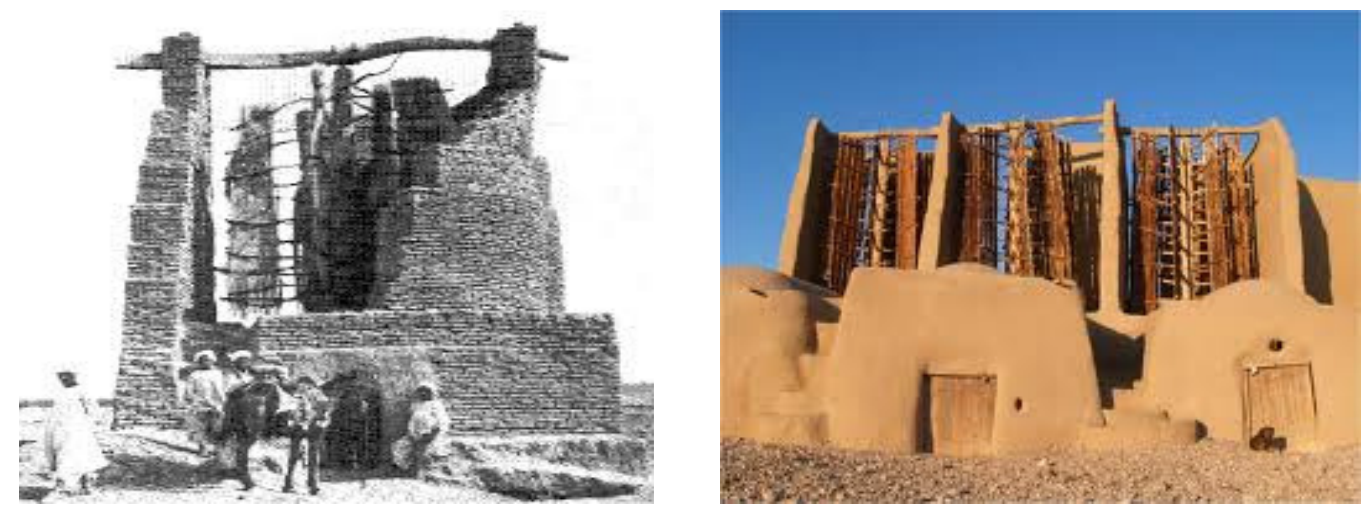

Figura 8. Molino de viento en la región de Sistán, Irán. Eje vertical (Omar, 2000), esta fotografía aparece en "Architecture of the Islamic World, Its History and Social Meaning; Page 188; Edited by George Michell; 1978 Thames \& Hudson Ltd, London". 


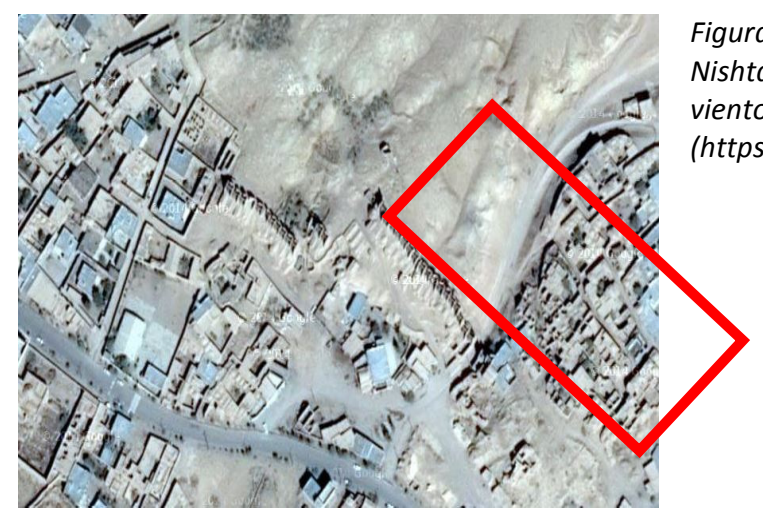

Figura 9. Ubicación de los molinos de viento en Nishtafun, Irán. Se trata de una zona de mucho viento en medio del desierto.

(https://www.google.es/maps).

Las primeras construcciones de esta tipología pero con ejes horizontales se encuentran en Europa, hacia el siglo XII. Se incorporan los engranajes característicos del molino hidráulico con eje horizontal, creando así una combinación de las tecnologías empleadas en el agua y el viento ${ }^{45}$ [Figura 10 y Figura 11].

\footnotetext{
${ }^{45}$ A diferencia de las ruedas accionadas por los cauces de los ríos, cuyo movimiento se produce siempre de la misma manera, se tenía que buscar aquella técnica apropiada que aprovechara la dirección el viento en cada momento para conseguir el mayor rendimiento. En su forma más primitiva, la solución consistiría en orientar las aspas en contra del viento dominante. El primer artilugio orientable fue el denominado 'molino de poste', que se encontraba principalmente en Europa occidental, Francia e Inglaterra. Constaba de un cuerpo pesado o carcasa giratoria que contenía todos los mecanismos, incluidas las muelas, y que se sustentaba en una sólida base en la cual se introducía el eje. Era el molinero el que movía la cabeza girando todo el molino sobre su eje, que formaba una especie de poste vertical robusto de madera. Un ejemplo todavía existente de este tipo de molino se encuentra en Chillenden, cerca de Canterbury, Kent, Inglaterra, del siglo XVIII [Figura 11]. En Holanda todavía quedan ejemplos de este tipo de molinos orientables.
} 


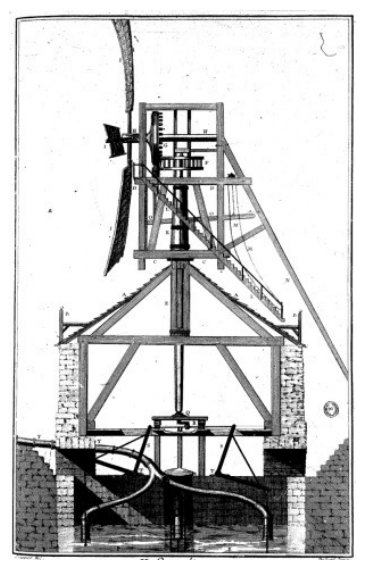

Figura 10. Enciclopedia de Diderot y D'Alambert. Volumen 3. Rueda hidráulica de eje horizontal accionada por la parte superior.

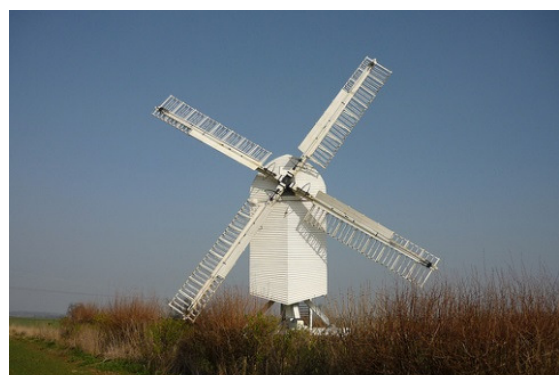

Figura 11. Molino de viento en Chillenden, cerca de Canterbury, Kent (Inglaterra), siglo XVIII.

(https://www.google.es/maps).

Pero ya serán los ingeniosos holandeses los que inventarán los molinos orientables en los que sólo girará la parte de las aspas, permaneciendo inmóvil tanto la maquinaria como las muelas de debajo de la cabeza giratoria. De 1586 es el tratado de Simon Stevin ${ }^{46}$ "Van de Molens" ${ }^{47}$ [Figura 12] ${ }^{48}$.

${ }^{46}$ Simon Stevin (1548-1620).

${ }^{47}$ Es en este país donde tuvo un especial significado el uso de estos molinos para el desecado de lagunas interiores o pólderes, mediante baterías de molinos en serie. Hay que mencionar que existe una amplia gama de denominaciones existentes para estos artilugios.

${ }^{48}$ Recordar los molinos de viento que en 1605 Miguel de Cervantes Saavedra reflejó en su libro EI ingenioso caballero don Quijote de la Mancha, los cuales se encuentran en la localidad de Campo de Criptana, en la provincia de Ciudad Real, contra los que luchó Don Quijote en el capítulo VIII. 


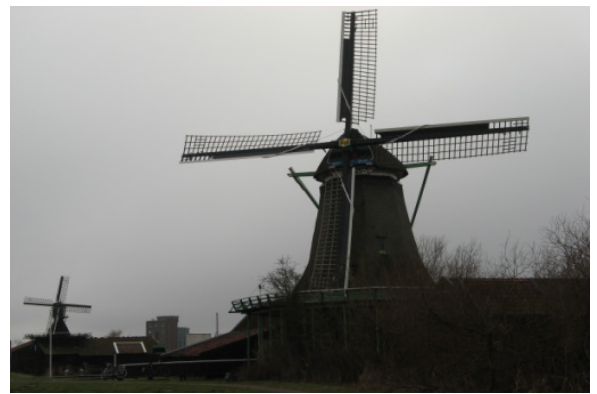

Figura 12. Molino de viento orientable en Holanda, Van de Molens. Principios del siglo XIX.

(http://www.sprekendegevelsalkmaar.nl/

index.php?go=home.showPages\&pagenr=148).

Haciendo ahora una referencia más amplia a su desarrollo tecnológico, el molino fue evolucionando, logrando cada vez un mayor tamaño y altura. En este sentido, fue convirtiéndose en una factoría integrada, en la que se incluía un almacén, un taller e incluso posteriormente una vivienda. El desarrollo en altura, buscando una mayor exposición al viento, se consolidó con el llamado 'molino torre', el cual disponía de una estructura sólida, de fábrica o de madera, de planta circular o poligonal (Sambricio, 2008).

Según referencia geográfica, es imprescindible hablar de la variante popular del molino español, como es el caso del de La Mancha, tipología todavía existente en ciudades como Campo de Criptana, Puerto Lápice y Consuegra, entre otras muchas ${ }^{49}$.

En cuanto a su tecnología, se fue sofisticando con el tiempo, de una manera similar a lo que le ocurrió al molino hidráulico. En este sentido, el ingeniero inglés Edmund Lee, inventó un sistema de poleas capaz de hacer que la cabeza del

Asimismo, en las Relaciones Topográficas de Felipe II, de 1575, ya aparecen la referencia a molinos de viento en la Península, como precisamente los de Campo de Criptana.

${ }^{49}$ Estos molinos son ejemplos ya del sistema giratorio de las cabezas. 
molino se autoorientase en función de la dirección del viento ${ }^{50}$, consiguiendo de forma más autónoma un mayor rendimiento en la molienda ${ }^{51}$.

\section{TRANSMISIÓN DE ENERGÍA}

El molino no es más que el resguardo, como construcción fabril, de un sistema de mecanismos articulados accionados generalmente por corrientes fluviales. De hecho, su dependencia al territorio determinará en gran medida su forma.

Generalmente su inversión inicial solía ser mínima, con la simple adaptación de los procesos de construcción tradicionales a las necesidades de lo que se quería producir, y colocando las máquinas dentro del edificio de la forma más directa, esto es, a lo largo de los árboles de transmisión que reciben la fuerza de la fuente de energía hidráulica [Figura 13].

\footnotetext{
${ }^{50}$ Sistema patentado en 1745 . Ejemplos conservados se pueden encontrar en Sibsey y Boston, ambas en el condado de Lincolnshire, Inglaterra.

${ }^{51}$ En algunas ciudades europeas persistió el sistema de los viejos molinos de viento durante las primeras décadas de implantación de la máquina de vapor. Pero incluso en la actualidad, se pueden presenciar en diversos paisajes repartidos por toda la geografía europea, y especialmente española, numerosos molinos de viento generadores de energía eléctrica que se presentan como alternativa a los combustibles de proveniencia fósil, a modo de energía renovable, si bien, los efectos sobre el medio ambiente no son un tema para tratar en este estudio.
} 


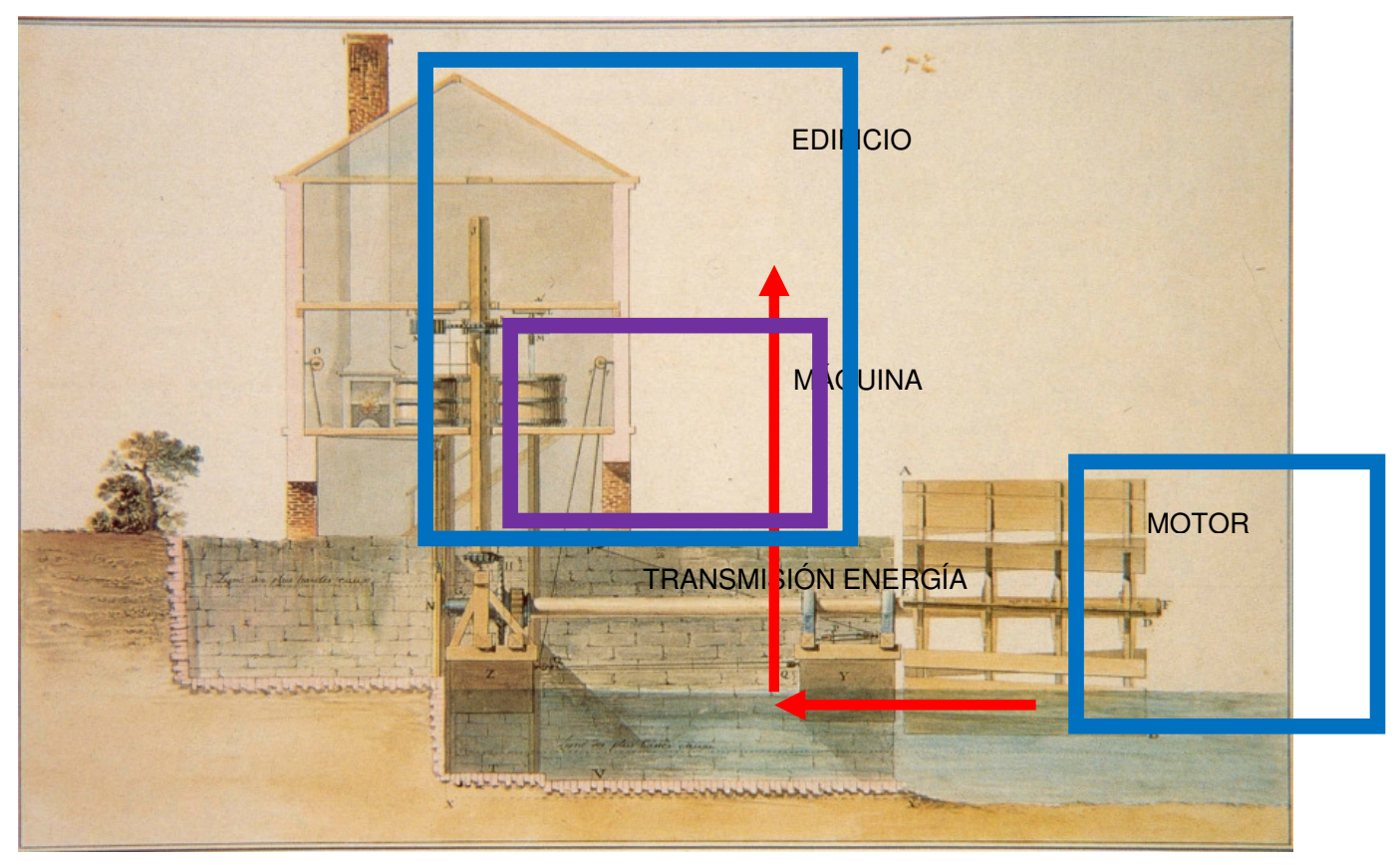

Figura 13. Molino de Betancourt, 1790.

(http://www.museoelder.org/betancourt/indexbiografia.html).

En el proceso evolutivo que siguen las instalaciones molineras, el siguiente paso inmediato será el de la demanda de una mayor dimensión del espacio industrial (Glick, 2000), así como mejores condiciones en las redes de abastecimiento y de comercialización. Todo ello debido al aumento de la productividad y gracias a la llegada de nuevas fuentes energéticas que ayudarán a la mecanización del proceso productivo.

Así pues, evolutivamente, la imagen típica de la fábrica del siglo XIX es la de un edificio-fábrica que sufrió una serie de innovaciones técnicas respecto a su origen como molino, que trajeron una nueva envolvente. Esos inventos directamente aplicados al espacio fabril se resumen a grandes rasgos en: la máquina de vapor y los nuevos materiales y sistemas constructivos, que ayudarán a conseguir la 
fábrica en altura, diáfana y bien iluminada "mill building", a principios del siglo siguiente, tal y como se comprobará en la sucesión de fábricas cronológicamente presentadas en el Capítulo 3 \{confrontar el factor iluminación en apartado 3.6\}.

Así como el origen de los molinos se basa en el principio del motor único que accionaba todas las máquinas (lo cual presuponía ya una serie de conexiones verticales y horizontales que comunicaban el movimiento a cualquier punto de la fábrica, transformándola en un volumen determinado por el enlace ortogonal de las transmisiones), esta tecnología proseguirá también en el siguiente escalón edificatorio, el edificio en altura.

El primer sector industrial en recoger este nuevo sistema de motor-único fue el textil (desde la fábrica de Lombe en Inglaterra hasta incluso las primeras aplicaciones de la máquina de vapor). La tipología de esta nueva fábrica presentaba esencialmente una planta rectangular larga y estrecha, determinada tanto por las dimensiones de las máquinas que debía acoger en su interior, como por la necesidad de ser iluminada uniformemente. Se desarrollaba en altura disponiendo un piso sobre otro por la necesidad de utilizar un solo eje motor vertical conectado a las distintas máquinas mediante un sistema de transmisiones horizontales.

\section{EDIFICIO}

Hay que señalar que los molinos en sí no introdujeron ninguna tipología o innovación constructiva significativa, puesto que simplemente adaptaron las existentes a sus requerimientos funcionales.

A continuación se estudia la tipología de molinos en el ámbito geográfico de la segunda parte de este estudio, en donde existieron interesantes espacios fabriles susceptibles de ser destacados, como es el caso de Alcoi y su comarca (Glick, 2000), los cuales eran movidos por el cauce del río Barxell, Molinar y Serpis. También existieron cuantiosos ejemplos en los municipios de Ontinyent, Albaida, 
Bocairent, etc. En toda esta zona del interior de la provincia de Valencia e interior norte de la de Alicante, el modelo de accionamiento mecánico se basó en sistemas de fuerza que aprovechaban los saltos de agua ${ }^{52}$, destacando en un principio la producción de papel o de harina, y posteriormente su reconversión a la textil, la cual ha perdurado hasta prácticamente la segunda mitad del siglo pasado ${ }^{53}$.

La estructura distributiva de un molino hidráulico de harina es muy sencilla (Glick, 2000) [Figura 14]: el edificio consta de dos niveles o salas claramente diferenciadas. Una superior denominada sala de muelas, que era el espacio propiamente de trabajo donde se molía el grano, y la sala inferior, denominada carcavón, que ocupaba un espacio alargado, generalmente estrecho y de poca altura, por debajo de las muelas. Allí se encontraba el mecanismo motriz y el engranaje que hacía girar la muela superior.

\footnotetext{
${ }^{52}$ Como se ha indicado con anterioridad, se pueden definir los molinos hidráulicos como unos casales que contenían un conjunto de artefactos que servían generalmente para moler productos agrícolas. La energía motriz utilizada para el funcionamiento de la maquinaria es la fuerza del agua, razón por la cual han de estar inevitablemente emplazados cerca de un curso continuo de agua, ya sea natural (como por ejemplo un río) o artificial (una acequia de riego).

${ }^{53}$ La mayor parte de la producción lanera española se situaba en Cataluña, pero el segundo lugar lo ocupaba Alcoi. Valga como ejemplo, que en la Exposición Universal de Paris de 1867, en la sección de 'hilos y tejidos de lana cardada', acudieron 42 expositores españoles, de los que 19 eran alcoyanos.

En lo que respecta a la coyuntura histórica decimonónica, el impulso económico agrario y sus estructuras organizadas en el ámbito comercial y financiero, generarán un ambiente favorable para la inversión industrial. Como ejemplo de esta época está la desaparición de las regulaciones relativas al control de la producción y a las formas de trabajo de los gremios artesanales.
} 


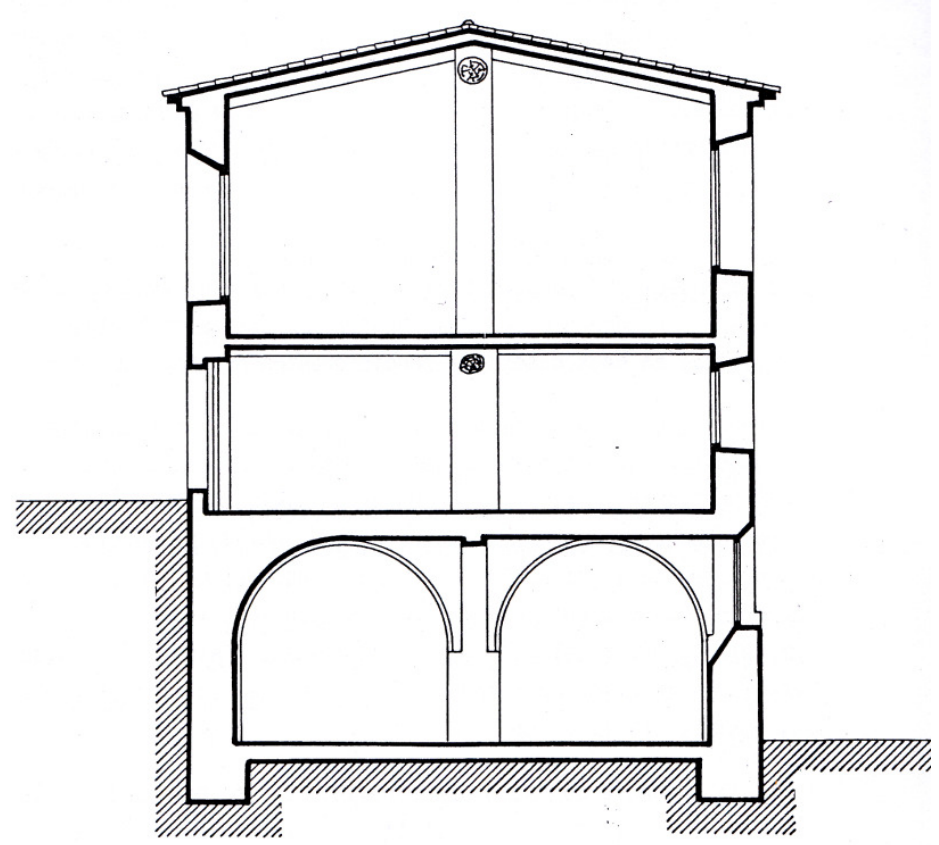

Figura 14. Sección tipo de un molino de la Cuenca el Barxell de finales del siglo XVIII. Dibujo propio según esquema de Olcina (Olcina, 1986). La rueda hidráulica estaba ubicada en la planta baja, externa al edificio, y accionaba un eje (transversal a la fotografía) que hacía girar las muelas, también al mismo nivel.

\section{PRIMERAS CONCENTRACIONES INDUSTRIALES. LOS MOLINOS HIDRÁULICOS \\ VALENCIANOS}

Si durante la segunda mitad del siglo XIII (Glick, 2000) se identificaron cuatro molinos y una almácera en Ontinyent, un molino en Bocairent y tres o cuatro molinos y otra almácera en Alcoi, a principios del quinientos existían de estas instalaciones, como fariners, batanes, almáceras y esmoladors, nada menos que 
cuarenta y uno en Ontinyent, once en Bocairent, quince en Biar, seis en Panáguila y diez en Alcoi $^{54}$.

Por otro lado, también al sur del núcleo urbano de Alcoi se situaba una gran concentración industrial. El río alimentado por la 'font de Molinar' alimentaba el 'riu dels molins', creando una sucesión ininterrumpida de estas instalaciones, tanto dedicada originariamente a la moltura de los cereales como al abatanado de los paños, e incluso a tintorerías ${ }^{55}$.

\begin{abstract}
${ }^{54}$ Al ser totalmente necesarios para la transformación de la producción cerealística, el aumento o la disminución de la cantidad de molinos en una determinada población representa un buen dato para determinar la coyuntura agrícola. Cuanto más crece o más desciende la producción de cereales, es necesario disponer de un mayor o menor número de estas instalaciones.

En el siglo XVI la mayor concentración de molinos se encontraba en Ontinyent, con más de 40 de estos aparatos, de los cuales al menos 17 eran fariners. La Vall d'Albaida y l'Alcoià eran zonas donde además de molins fariners había bastantes molins drapers, batanes donde se realizaba la complicada operación de apresto de los paños dentro del proceso de producción manufacturero textil (Álvaro, 2001).

La concentración de instalaciones industriales y transformadoras de la producción agrícola en estas comarcas molineras, responde no solo a la vitalidad económica de los siglos medievales, sino también es consecuencia de las favorables condiciones naturales, y particularmente meteorológicas, que permiten la proliferación de estos molinos hidráulicos. Disponían de corrientes rápidas e intensas, permitiendo la construcción y la concentración de estos ingenios tanto sobre la misma cuenca de los ríos como sobre las canalizaciones artificiales. En el territorio valenciano, Morella y su comarca también se posicionaron como importantes centros hidráulicos (Cuevas, 1999).

55 En ocasiones, la construcción del molino y su maquinaria hidráulica se implantaba en nuevas localizaciones, apareciendo diseminados, alejados de los núcleos urbanos. Todavía queda constancia de ellos con restos de edificaciones, como es el caso de las ruinas que se encuentran en el río Barxell y Molinar en Alcoi \{confrontar el capítulo 4.3\}, o en la carretera que une Bocairent con Ontinyent.
\end{abstract}

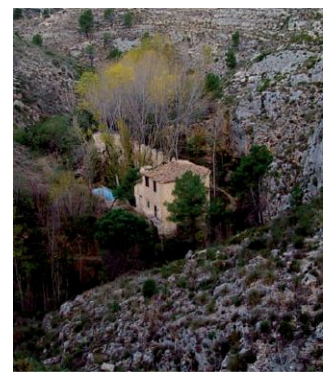

Molino dels Julians. Carretera CV-81, entre Ontinyent y Bocairent 
Estos molinos incluidos en estos sistemas hidráulicos valencianos respondían mayoritariamente a la tipología característica del molino de rueda de eje horizontal, como en todas las regiones mediterráneas.

Según indica Calatayud (Calatayud, 1989), lo que sí parece seguro es que la mayoría de los molinos y batanes de las villas reales de la zona eran instalaciones que albergaban como mucho dos artefactos dedicados específicamente a la moltura o abatanado: una o dos muelas en los 'molins fariners' y una o dos mazas en los 'drapers'.

En algunos casos, los molinos papeleros se diseñaron inicialmente "con una doble perspectiva funcional", puesto que según los caudales de agua disponibles, les permitía transformarse en molinos harineros (Ayuga, 1997) ${ }^{56}$.

\section{VALENCIA}

En la ciudad de Valencia y sus alrededores, la incidencia de la industria textil y papelera también fue relevante a finales del siglo XVIII, pese a que era la provincia de Alicante por aquel entonces la que incluía las comarcas más productoras. La por entonces ya gran ciudad disponía de una tradición sedera muy anterior que fue la que le cedió el paso desde la tradición artesanal a la industria, con todas sus implicaciones: nueva organización del trabajo, el proceso de mecanización y acumulación de maquinaria, etc.

Un ejemplo de fábrica muy interesante que cabe ahora señalar es el de la fábrica de Lapayese, en Vinalesa, cerca de Valencia ${ }^{57}$. Se trata de un ejemplo bastante

\footnotetext{
${ }^{56}$ El río Barxell (Alcoi) disponía de un buen número de molinos harineros y batanes, alcanzando niveles industriales a partir de la segunda mitad del XVIII. Por ejemplo, en el año 1755 apareció el primer molino papelero en la comarca, cuyo origen había sido un batán. Antes de que acabara ese siglo ya había 35 papeleros que crearon una amplia red de presas, acequias y canales. Estos últimos aumentaron su presencia, al autorizar la transformación de los antiguos batanes en molinos papeleros, y gracias a la creación del monopolio del tabaco de América, que disparó la demanda de papel.
} 
posterior al primer edificio en altura del empresario Lombe, en Derby, en 1722, movido también íntegramente por una rueda hidráulica (motor único). Pese a tener una menor importancia en cuanto a tamaño se refiere, es de gran interés, pues como se ha comentado se trata del primer ejemplo de fábrica protoindustrial en la Comunidad Valenciana (Capítulo 4). El edificio fue pensado para tener una producción totalmente en cadena, donde se llegaban a realizar todas y cada una de las operaciones necesarias para la elaboración de la seda, con la utilización de varias máquinas. Tenía una única fuente de energía consistente en una rueda hidráulica instalada en la Real Acequia de Moncada ${ }^{58}$.

También en el resto de España existen innumerables ejemplos de molinos. Es muy interesante por su estado de conservación, su tamaño y su estilo constructivo, el Molino de la Vila de Capellades, en la provincia de Barcelona [Figura 15].

\footnotetext{
${ }^{57}$ Se trata de un edificio que se instaló en este municipio en 1770 , a partir de un privilegio otorgado al comerciante francés que lleva su nombre, para establecer una fábrica de hilaza con las ventajas que le proporcionaban las nuevas oportunidades que ofrecía la tecnología. En este caso, su éxito se corresponderá con la puesta en marcha de las máquinas Vaucanson (Jacques de Vaucanson (1709 1782) fue un ingeniero e inventor francés al cuál se le acredita la creación del primer robot así como la del primer telar completamente automatizado), impulsadas por las aguas de la acequia Real de Moncada a su paso por la población.

${ }^{58}$ Existían sendas entradas a esta fábrica: una central que comunicaba directamente con el patio, y la otra, a la izquierda de la fachada principal, que daba acceso a la casa-habitación y oficinas. En el piso superior estaban los cañizos para guardar los capullos. La 1a y la 2a operación del proceso, consistente en ahogar el capullo e hilar la seda, se realizaban íntegramente en planta baja. En el lado noroeste del edificio, en un espacio estrecho de larga longitud, totalmente diáfano, se ubicaron los treinta tornos dobles para hilar la seda, 15 a cada lado de la pared, y en el centro las balsas de agua para hilar. La 3a y 4 a operación se realizaban en el segundo piso del pabellón de la fachada principal, donde se encontraban las veintidós máquinas para devanar y doblar la seda. En la planta primera se realizaban las dos operaciones del torcido con 22 tornos para torcer la seda. La situación de este pabellón estaba determinado por la ubicación de la rueda hidráulica, que adosada al edificio en su fachada lateral, recibía un impulso de 15 a 20 caballos de un salto de agua de la Real Acequia de Moncada, y daba energía a los tornos de devanar, doblar y torcer la seda. En los laterales de la fábrica estaban las dependencias dedicadas a servicios, es decir, un dormitorio para operarios, la fragua, el taller, las bodegas, etc. No faltaban tampoco las torrecillas de vigilancia en su fachada, imagen evidente del orden y la disciplina de la época.
} 


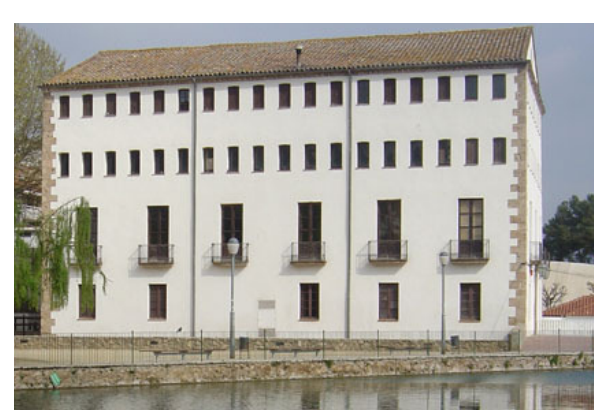

Figura 15. Molino de Capellades, Cataluña ${ }^{59}$ (https://www.google.es/maps)

Es indudable que el precedente arquitectónico de estos molinos son las masías, en el que se mantiene la solución tipológica de edificio concentrado y aislado, con cubierta a dos aguas con mucha ventilación, para secar el papel ${ }^{60}$.

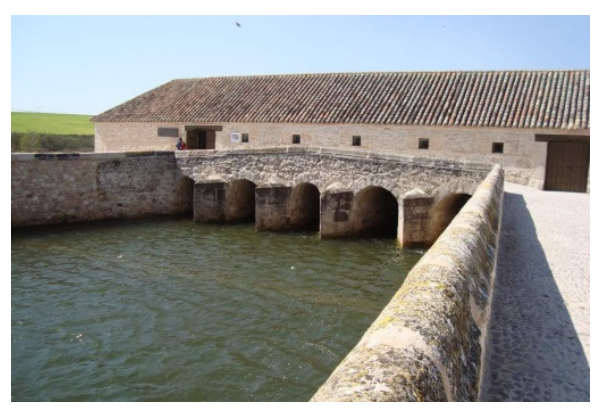

Figura 16. Molino del Molemocho, en el Parque Nacional de Las Tablas de Daimiel, entre Daimiel y Villarrubia de los Ojos.

(https://www.google.es/maps).

\footnotetext{
${ }^{59}$ Se trata de una estructura preindustrial ya existente en el siglo XVII. Está ubicado en el centro de la población, y obtenía su fuente de energía de una gran balsa, perteneciente al canal de la costa, a través de unas ruedas de madera que movían las máquinas de producción de papel. Los dos pisos superiores servían de secaderos del papel, de ahí su menor altura y el gran número de ventanas repartidas uniformemente en toda la fachada.

60 Lo mismo se podría decir de las ferrerías, molinos y astilleros artesanales, tan frecuentes en el país vasco, como el molino de papel 'La Soledad', en Aduna, el molino de 'Rezusta' en Airnazabal, el astillero 'Bedua', en Zestoa, o la ferrería de 'Egurbiola' en Azkoitia, o los molinos hidráulicos de Castilla-La Mancha, como el 'Molino del Molemocho' [Figura 16], y el del 'Puente Navarro' en Ciudad Real, el 'Molino Alto' en Almansa, o el 'Molino de San Gregorio' en Alpera (Cañizares, 2007).
} 


\section{7. $\underline{A L C O I}$}

Remarcable es el conjunto industrial establecido en Alcoi a lo largo del barranco del Molinar. Este conjunto estaba formado en sus orígenes (segunda mitad del siglo XVIII) por seis molinos destinados a la industria textil y papelera, que partían de la "fábrica de primera agua" (Vidal, 1981), que era donde se iniciaba el aprovechamiento hidráulico antes de ser canalizado ${ }^{61}$ [Figura 2, Figura 17 y Figura 18].

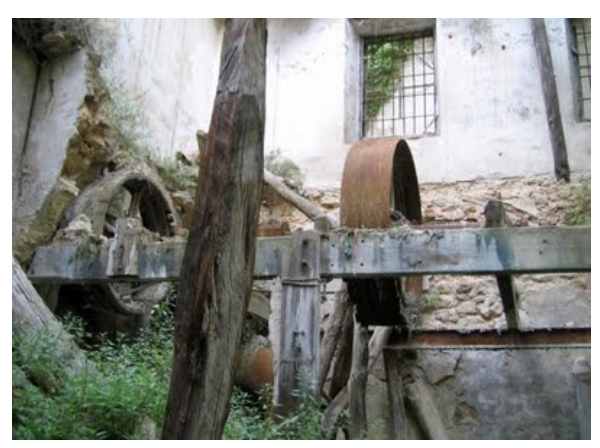

Figura 17. Sistema hidráulico de transmisión de eje horizontal de un molino en el río Molinar de Alcoi (Fotografía propia. Julio 2012).

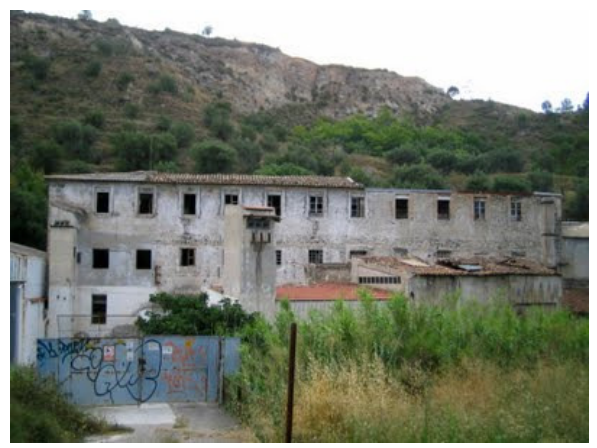

Figura 18. Molino dels Pepets en Alcoi (Fotografía propia. Julio 2012).

${ }^{61}$ Desde la razón social Soler Hermanos, hasta los establecimientos de Octavio Reig, Molino de Tort, Fábrica del Xurro, Fábrica de Benavent y Fábrica de Antonio Llorens. 


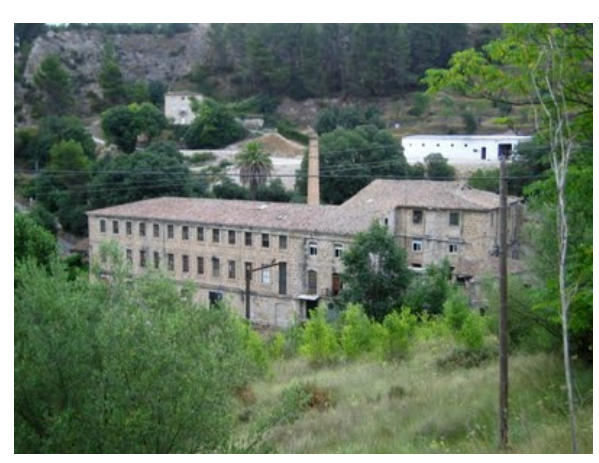

Figura 19. Molino de Francisco Moltó en Alcoi, segunda mitad del XVIII (Fotografía propia. Julio 2012).

En estos molinos generalmente se puede apreciar una analogía en el número de plantas (edificios de planta baja más doble altura), y un aspecto exterior similar a los mill buildings ingleses de principios del siglo XVIII, con ventanas alineadamente distribuidas de igual tamaño. Asimismo, las cubiertas son de teja árabe mayoritariamente a dos aguas. Otro rasgo característico es su planta alargada, como la de Francisco Moltó [Figura 19], que debido al terreno escarpado en la que se ubica, tiene la necesidad de tener bloques a distinta altura. Estos edificios no tienen una anchura excesiva, ya que se requería de cuanta más iluminación natural interior fuera posible, para una producción cada vez más continuada, y un sistema de transmisión de ejes y poleas que imponía una distribución lineal.

El terreno obligaba a adaptarse al abrupto relieve de la zona, que no permitía explanaciones de gran amplitud, y que condicionaba la construcción de molinos como máximo de tres y cuatro pisos (solo en algunos casos) de planta cuadrada o rectangular, constituidas incluso a veces por sendos edificios separados por un patio. Por su parte, el motor hidráulico y la transmisión de la potencia estaban determinados, en general, por:

1. Un conjunto industrial dependiente de la difícil orografía,

2. El aprovechamiento máximo de los recursos hídricos, y

3. Los conocimientos técnicos de la época 
La arquitectura de Alcoi es una arquitectura regional en cuanto a su disposición estructural, similar a otras a las que se construían en toda la Comunidad Valenciana. También del mismo modo fue introduciendo progresivamente avances constructivos derivados del uso de los materiales portantes de fundición. Posteriormente, en cuanto a la fuente de energía, se adaptó a la máquina de vapor como fuente de energía, aunque no de forma generalizada, puesto que el aprovechamiento de la energía hidráulica prosiguió durante mucho tiempo.

En este sentido, como la transmisión de la fuerza mecánica fue uno de los principales escoyos en el desarrollo de todas estas industrias, obligó a los sistemas constructivos a evolucionar. La caracterización de estos edificios responde al empleo de:

1. Materiales clásicos para conseguir altura, como sillería y mampostería para los muros de carga

2. Piedra en cimentaciones

3. Ladrillo en los pisos intermedios, y

4. Madera para las estructuras de cubrición

Las solicitaciones de carga (flexión y compresión) son superadas mediante los sistemas tradicionales de arcos y bóvedas, con relleno o sin él, utilizados en la arquitectura civil del XIX, como se verá en el apartado correspondiente \{confrontar el capítulo 3.5 más adelante $\}^{62}$.

\footnotetext{
${ }^{62}$ También en el término municipal de Alcoi, aguas abajo del río Barxell y Serpis, se construyen otros establecimientos industriales, caracterizados mayormente por una planta lineal de tres crujías, ocupando cada vez espacios mayores debido a la disponibilidad de solar y las mejoras en los accesos, como sucede en la Fábrica dels Pepets [Figura 18], la de Francisco Moltó [Figura 19] y la de Santiago Blanes. En esta zona baja de confluencia de estos dos ríos, se origina un espacio útil para la ampliación de la industria que permitirá la construcción de más factorías textiles, como la de Hijos de S. García, donde aparecen separados los espacios destinados a batanes, tisaje e hilados, conectados por calles de apariencia urbana (Olcina, 1986).
} 
En estos ejemplos de finales del siglo XIX, ya se puede hablar de la implantación de los nuevos sistemas constructivos europeos a partir de las estructuras mixtas de fundición y acero (Knowles, 2003).

\subsubsection{Manufacturas y reales fábricas - renovación tipológica}

La manufactura fue una práctica habitual en Europa durante un largo periodo de tiempo comprendido entre los siglos XIV y XVII, aunque también se pueden encontrar ejemplos posteriores. La sociedad feudal ${ }^{63}$ había estado cambiando de una forma muy rápida desde el descubrimiento de América: el mercantilismo y el desarrollo en paralelo del comercio y la exportación recupera el trabajo a domicilio, pero también aparecen las "primeras sociedades", cuyos fines principales inicialmente se centran en la "división del trabajo" y en las "mejoras tecnológicas". Como primer resultado de estas renovaciones económicas aparecerá la acumulación de capitales en manos de los empresarios y de la aristocracia. Sin embargo, y según este autor, hay que destacar que este movimiento se produce, por diversos motivos, "de una forma tardía en España respecto al resto de Europa" (Sobrino, 1996).

Paralelamente se origina una revolución científica ${ }^{64}$, en donde investigar, descubrir y difundir serán los objetivos básicos en la mayoría de los países avanzados. En estos el Estado va a actuar como una máquina movida por una clase social cuyo objetivo fundamental será precisamente promover el progreso.

\footnotetext{
${ }^{63}$ Feudalismo es la denominación del sistema político predominante en la Europa occidental de los siglos centrales de la Edad Media (entre los siglos IX al XV, aunque no hay acuerdo entre los historiadores sobre su comienzo y su duración, y ésta varía según la región).

${ }^{64}$ La Revolución Científica es un periodo comprendido principalmente entre los siglos XVI y XVII, en el que nuevas ideas y conocimientos en física, astronomía, biología, medicina y química transformaron las visiones antiguas y medievales sobre la naturaleza y sentaron las bases de la ciencia moderna. Se inició en Europa aproximadamente hacia el final de la época del Renacimiento y continuó a través del siglo XVIII, con la llustración.
} 
La influyente ilustración ${ }^{65}$ pretende iniciar reformas para una mejora general de la enseñanza, formando técnicos fuera del país y buscando expertos extranjeros cualificados.

Por otro lado, en el siglo XVIII en España, los centros industriales ya se denominan fábricas o manufacturas, con predominio de la primera acepción. Antonio Carbonel, bibliotecario del Real Seminario de Nobles de Madrid, en 1794 cita en su libro 'Enciclopedia metódica de fábricas, artes y oficios':

"Nosotros traducimos fábrica [...] porque tomados estos objetos por mayor, resulta una serie de operaciones diversas, contenidas en un recinto y gobernadas por factores, directores o empresarios del establecimiento."

En cuanto a las Reales Fábricas estas constituyen un objetivo primordial para las monarquías absolutas del siglo XVIII, principalmente francesas, al considerarlas como un extraordinario instrumento intervencionista capaz de producir bienes para que sus naciones progresen y eliminen al mismo tiempo las costosas importaciones de productos de lujo demandados por la aristocracia y la propia monarquía (Markus, 1993) ${ }^{66}$.

\footnotetext{
${ }^{65}$ Es a partir de la segunda mitad del siglo XVIII cuando se producen una serie de cambios sociales motivados por una reactivación económica. Es lo que se conoce como la ilustración, la cual fue una época histórica y un movimiento cultural e intelectual europeo, que se dio especialmente en Francia e Inglaterra y que se desarrolló desde finales del siglo XVII hasta el inicio de la Revolución Francesa, aunque en algunos países se prolongó hasta incluso los primeros años del siglo XIX.

El aumento demográfico y el cultivo extensivo de cereal en este periodo necesitan la construcción de molinos, más grandes y tecnológicamente más avanzados. Ello conllevará consigo la transformación del paisaje y de las zonas urbanas, y que a su vez, traerá también la construcción de molinos hidráulicos textiles y papeleros.

${ }^{66}$ En España fue la monarquía borbónica, con Fernando VI (1713 - 1759) y Carlos III (1716 - 1788), la que puso en marcha un programa de renovación económica para producir objetos de lujo en fábricas dependientes de la Corona. Ambos promovieron una nueva política económica con el fin de cambiar la situación precaria en la que estaba inmerso el país, y en el que abundaba un sistema de trabajo primitivo, de escasos rendimientos, de ausencia de capitales, de máquinas y de espíritu empresarial.

Si bien la principal financiación de estas reales fábricas procedía de la realeza, también tuvieron cierto interés en la fabricación de productos de calidad la aristocracia, las grandes familias de
} 
Eso sí, para alcanzar el máximo aprovechamiento establecieron un control absoluto, tal y como tendrían algunos años después las primeras factorías industriales (Pevsner, 1979).

En cierto modo, el origen del orden en las fábricas de producción provendría ya de los monasterios medievales, es decir, de las estrictas rutinas seguidas por los religiosos (Sánchez, 1998) ${ }^{67}$.

Para asegurarse que no se perdía tiempo en el trabajo diario, en las reales fábricas se requería una vigilancia constante, la cual quedaba perfectamente establecida mediante largos ejes visuales controlados por el director desde su propia casa. Esta distribución visual sería precisamente la base en la que se diseñarían las grandes factorías del siglo XVIII. Con esta metodología se elaborarán principalmente tres productos: primero, artículos preciosos, extraños y lujosos para la aristocracia y la clase propietaria de las plantas. En segundo lugar, géneros exclusivos para la realeza, y en tercer lugar, alimentos como el azúcar, el tabaco, el algodón y la madera ${ }^{68}$.

Por otro lado, no sólo se construyeron reales fábricas en Francia y España, sino también en otros países como Polonia, Lituania, Bulgaria, etc, las cuales se especializaron en artículos con la seda como materia prima (Agreda, 2002). En este sentido, lo que dio a esta última un interés especial fue la temprana

mercaderes, los propietarios de tierras, la iglesia y los papas, etc. Como se ve, los que disponían de capital invertían en este tipo de factorías, lo que en principio ya les dio un cierto poder efectivo.

67 Los sonidos de las campanas estructuraron el tiempo anticipándose a los relojes de las organizaciones fabriles. La relación espacio-disciplina en el sistema fabril, también tenía sus correlaciones espaciales en el exterior. Para llegar a la fábrica desde el hogar, se tenía que emplear el menor tiempo posible, por lo que ambos lugares tenían que estar próximos entre sí.

${ }^{68}$ Asimismo, con la financiación del Estado se pretendía que en el sector industrial las fábricas del reino aumentaran su producción, como en el caso del sector textil, que debía dar respuesta a la constantemente creciente demanda de los géneros que habían de ir al Nuevo Mundo. Sin embargo, la política de reformas borbónicas no afectó por igual a todos los núcleos industriales textiles de España. Valencia y Cataluña, las menos favorecidas políticamente por los soberanos, fueron sin embargo las que disfrutaron de mayor éxito industrial (Weston, 2005). 
aplicación de la fuerza del agua para que la producción fuera viable, antes incluso de que se aplicara a otras fábricas textiles.

En cuanto a la tipología de edificio, seguía casi siempre las mismas directrices: uno o varios talleres, también llamados obradores, y una tienda donde se exponían los productos que se realizaban. En ellas se agrupaban diferentes oficios, por lo que empezaba a cobrar fuerza el concepto de organización del espacio (Sánchez, 1988) [Figura 20].

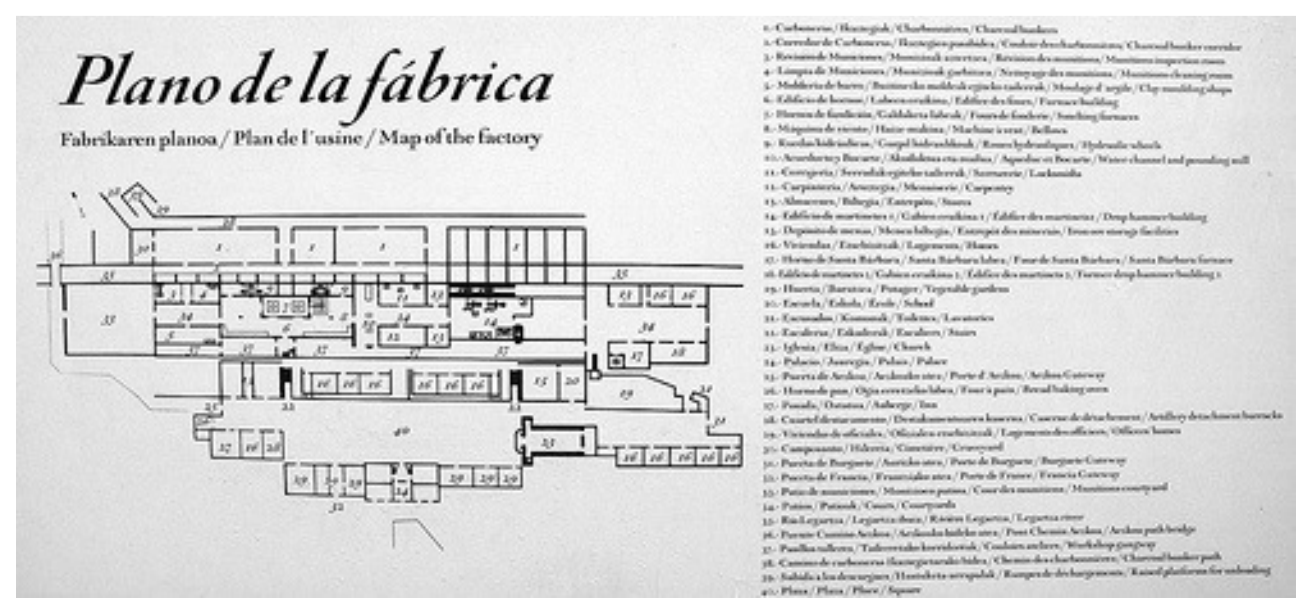

Figura 20. Real Fábrica de armas de Orbaiceta, instalada por orden de Carlos III de España en 1784, (http://www.euskomedia.org/ImgsAuna/40011501.gif). 


\section{TIPOLOGÍAS: LAS REALES FÁBRICAS COMO PALACIO PARA PRODUCIR}

Uno de los problemas fundamentales con que se encontraron los primeros encargados de construir fábricas fue que no tenían referentes. Eran nuevos espacios para nuevas necesidades, que carecían de antecedentes clásicos y que tampoco figuraban en ninguno de los manuales de construcción que se venían siguiendo desde la antigüedad (Sebastià, 2007).

La documentación más valiosa que se disponía para ello era la de Vitruvio, del siglo I a.C., paradigma de la formación del arquitecto y modelo de los diferentes tipos de edificios durante los siglos XV y XVI. Su importancia fue tal que todavía en el siglo XIX continuó siendo el manual de referencia ${ }^{69}$.

Por ello, los primeros espacios fabriles de trabajo tuvieron que basarse en modelos de otros tipos de construcciones, ampliándolos y adaptándolos para intentar servir a ese nuevo objetivo: conseguir un espacio para la producción.

Así, los modelos más utilizados inicialmente fueron las construcciones populares: masías, barracas, alquerías, etc, y que gracias a constructores anónimos fueron modificadas para dar cabida a trabajos cada vez más sofisticados, como más tarde para la instalación de máquinas. Se trataba, en términos generales, de una arquitectura utilitaria y funcional, y sobre todo práctica.

En el caso de las Reales Fábricas, vistas desde el exterior, se parecían más a un palacio que a un centro de trabajo. Casi todas ellas seguían un esquema prefijado: un gran cuerpo central con alas laterales dispuestas alrededor de un patio. Según este autor, "como emblema real, no podían renunciar a los ornamentos y atributos del poder, lo que les daba un acentuado carácter monumental, no

69 En sus diez volúmenes se recogía tanta información que se podía estudiar desde el comportamiento de los diferentes materiales hasta la planificación de las ciudades, pasando por la construcción de puentes y edificios tan variados como templos, teatros, bibliotecas y molinos, etc. No obstante, no se encontraba información sobre fábricas. 
correspondiendo con la funcionalidad que se esperaba de un centro productivo"70 [Figura 21, Figura 22, Figura 23, Figura 24 y Figura 25]. En definitiva, estas fábricas se construyeron de forma que se garantizara el orden y la disciplina, tal y como se aprecia en las fotografías citadas anteriormente, en las que más bien, por su distribución, sus pasillos, sus escaleras, su disposición, su simetría y regularidad, su rigor, y en general, por su magnitud, se asemejaban perfectamente a un "palacio para producir" (Sebastià, 2007).

Con referencia al caso español, la creación de reales manufacturas también formó parte de la nueva política económica de la dinastía borbónica, la cual potenció una renovación industrial desde principios del siglo XVIII, especialmente en edificios palaciegos herederos del modelo francés ${ }^{71}$.

\footnotetext{
${ }^{70}$ Su construcción es realmente lo que adquiere importancia en esta tesis: se trataba de espacios institucionalizados donde el trabajo quedaba esencialmente unido al orden, la moral y la disciplina. En todas ellas existían una serie de dispositivos de control que recuerdan a los de las fortalezas militares de la época (Sebastià, 2007). No se debe olvidar que el cuerpo de ingenieros, una figura que empieza a definirse como ahora se conoce, sería la responsable de la construcción de una buena parte de estas factorías, por lo que se puede decir que procedían de tradición militar. De hecho, muchos de los que planearon fábricas reales realizaron también construcciones de defensa.

${ }^{71}$ Un ejemplo muy claro del poder de vigilancia que estas factorías ejercían sobre sus obreros se encuentra en la Real Fábrica de Tabacos de Sevilla, un soberbio edificio proyectado por el ingeniero militar Ignacio Salas en 1725, acabado en 1775, 50 años después. La dinastía borbónica, que se había instalado en España tras la Guerra de Sucesión (1700-1714), puso en marcha una serie de profundas reformas que imitaban en todo a la política de sus parientes franceses: centralización, proteccionismo, y también, impulso de la industria con la creación de las Reales Fábricas (Gutiérrez, 2001).
} 


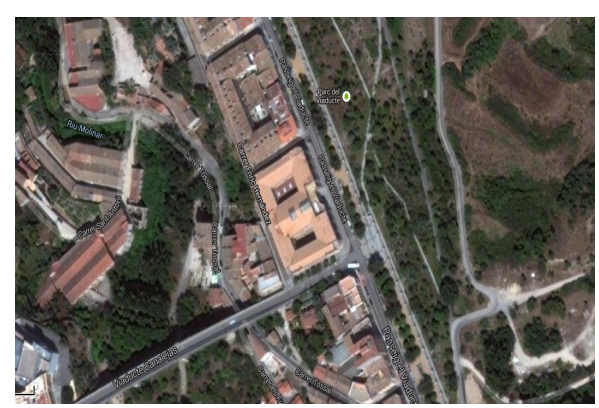

Figura 21. Real Fábrica de Paños de Alcoi: organización del siglo XVIII de fabricantes que elaboraba tejido que se utilizada en los ejércitos reales del Rey Carlos IV de España. Su aspecto se asemeja más a un gran palacio a lo que realmente es: una manufactura (https://www.google.es/maps).

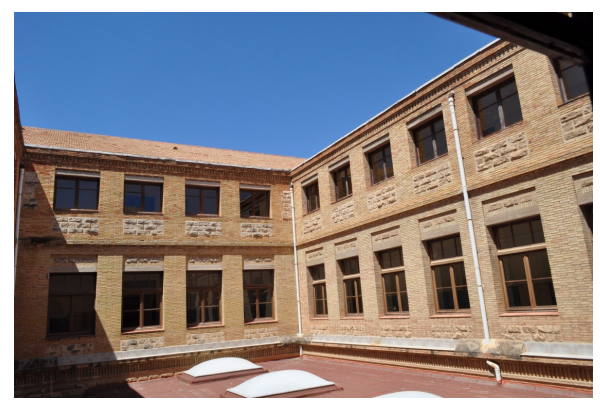

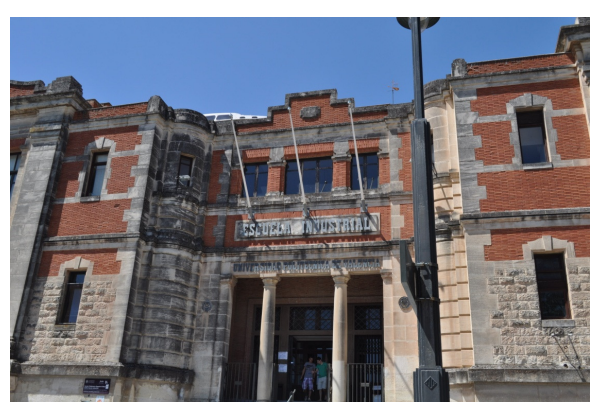

Figura 22. Real Fábrica de Paños de Alcoi. Fachada principal, acceso. Se trata de un edificio de dos plantas que ocupaba una gran superficie. Actualmente pertenece a la Universitat Politècnica de València, con uso docente durante unos años. Solo por la fachada, ya se podría juzgar que no tiene apariencia fabril (Fotografía propia. Julio 2012).

Figura 23. Real Fábrica de Paños de Alcoi. Patio interior. Fachada de mampostería que permitía huecos considerables para iluminación y ventilación.

(Fotografía propia. Julio 2012). 


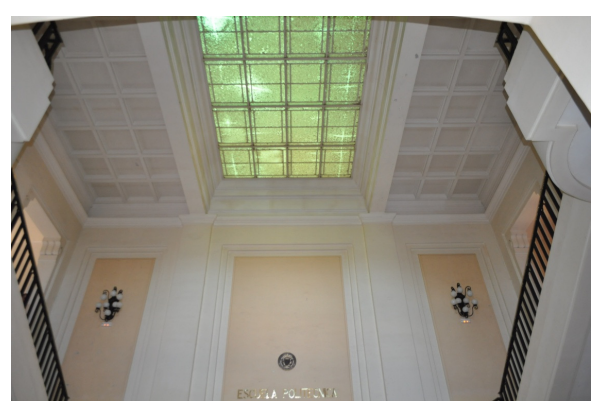

Figura 24. Real Fábrica de Paños de Alcoi. Escalera principal de distribución, acceso a la planta primera desde el vestíbulo. Su tamaño conduce a deducir su relevancia (Fotografía propia. Julio 2012).

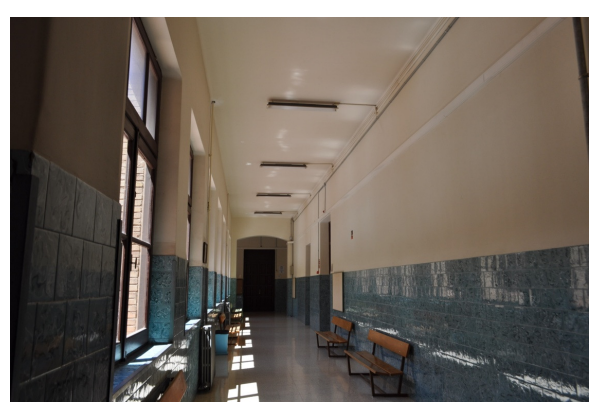

Figura 25. Real Fábrica de Paños de Alcoi. Pasillo distribuidor (Fotografía propia. Julio 2012).

A pesar de que las reales fábricas constituyeron una minoría respecto a los talleres de base popular, menores en tamaño pero mucho más abundantes, su huella tendría cierta influencia en el nacimiento posterior de las fábricas modernas. La concentración y la racionalización del trabajo, el severo control y la construcción de naves especiales para albergar la maquinaria son sus características principales.

Así, las Reales Fábricas establecen un nuevo modelo tipológico de edificio, inédito hasta entonces para usos industriales, al concentrar en un solo espacio los procedimientos y máquinas que permitían un trabajo colectivo en cadena. Este nuevo edificio era ya la fábrica ${ }^{72}$.

Como ya se ha comentado, las reales fábricas eran edificios cuya base arquitectónica fue copiada de los palacios y edificios burgueses, en los que fundamentalmente predominaba la decoración y la ostentación. Aunque estaban

72 Los ingenieros y arquitectos de la Corona pretendían dar una respuesta a estas nuevas necesidades. Se requería en primer lugar una solución arquitectónica exclusivamente fabril, y en segundo lugar, una solución económica que respondiera a un nuevo modelo de producción que empezaba a ser vital. La fábrica real, imitando las manufacturas francesas, será el tipo que eligieron. 
escasamente mecanizadas, su tamaño fue creciendo en planta a medida que fue cobrando importancia la industrialización y la necesidad de una distribución energética adecuada. Un ejemplo de esto último lo demuestra la instalación temprana de ejes horizontales giratorios para el accionamiento de maquinaria.

Estas manufacturas tenían que se ser capaces de:

1. Obtener la organización del espacio alrededor de un proceso productivo completo.

2. Ahorrar tiempo y facilitar el trabajo ininterrumpido.

3. Organizar racionalmente las diversas fases de trabajo.

4. Establecer un control eficaz sobre el producto y los trabajadores. 


\section{EDIFICIO: LAS FÁBRICAS COMO ORIGEN DE LAS PRIMERAS CONCENTRACIONES} FABRILES

A grandes rasgos, en Europa habría que distinguir entre dos claras tendencias en los sistemas productivos industriales: la de Gran Bretaña, marcada por los industriales, ingenieros, empresarios e inventores ilustrados (como Richard Arkwright, los Strutt y los Wedgwood), y la de los países de la Europa continental, donde la iniciativa empresarial residía en los autócratas que detentaban el poder.

A pesar de esta diferencia, tanto en las formas arquitectónicas de los espacios fabriles de una como de otra, como en los aspectos económicos y sociales, los edificios fabriles tenían algunas cosas en común, como por ejemplo, la organización de la producción y la jerarquización de los poderes dentro de la empresa ${ }^{73}$.

Las manufacturas reales tenían una configuración mediante un sistema totalmente ordenado, siempre supervisado por el director desde su vivienda estratégicamente ubicada, y donde las largas horas de la jornada laboral eran controladas por un enorme reloj, elemento muy destacado en sus entradas.

\footnotetext{
${ }^{73}$ Si se toma como ejemplo la real fábrica de LeCreusot, en la borgoña francesa, que data de 1781, se observa que el complejo industrial giraba en torno a la casa del director, enorme, a modo de "château", con inmensos jardines, ubicada en uno de los vértices de una planta en forma de herradura, alejada de los humos, calor y ruidos de la fundición y los talleres. Por su parte, lo que había albergado la granja y el alojamiento de la servidumbre, se transformó directamente en dependencias para los trabajadores, con huertos para su propio uso.
} 


\section{LA VIGILANCIA EN LAS REALES FÁBRICAS Y LOS PANÓPTICOS}

En esta época de la ilustración y de la aristocracia europea, en el siglo XVIII, en la que empezaban a surgir importantes cambios sociales (Pevsner, 1976), la eficacia y la cantidad de la producción preocupaba a los dos sectores implicados: tanto aquel que proporcionaba el trabajo en sí, que como ya se ha dicho eran artesanos especializados en la manufactura y operarios encargados de funciones diversas, como a los propios promotores, obsesionados en la calidad de sus productos. Por ello, para asegurar que no se perdía tiempo en la producción, se necesitaba una permanente vigilancia visual, que dependía de ejes focales que abarcan incluso sombras en espacios de trabajo ${ }^{74}$.

Esto también lo podemos encontrar en los edificios panópticos (Darley, 2010). Bentham fue un joven ingeniero inglés, que en 1784 fue llamado por Potemkin ${ }^{75}$, un príncipe ruso que estaba ideando unos ambiciosos planes para convertir la población de Krichev en un importante centro industrial. La solución la encontró en la "organización de los operarios y de la producción, de naturaleza compositiva: si la supervisión pudiese realizarse desde el centro de un espacio común, en un punto de vista elevado, la tarea resultaría mejorable". Desde ese lugar, una sola persona podría vigilar a un gran número de trabajadores [Figura 26] ${ }^{76}$.

\footnotetext{
${ }^{74}$ Como regla general, estas manufacturas a menudo tenían una escala gigantesca. De hecho, algunos palacios, incluso fueron empleados como industria pesada.

${ }^{75}$ Gregorio Aleksándrovich Potemkin $(1739$ - 1791), estadista, militar y político ruso.

76 Su hermano Samuel Bentham, construyó en 1807 un panóptico en Ochta, cerca de San Petersburgo. Se trataba de un edificio rígido de planta central, pero que resultó ser totalmente inadecuado para cambiar los procesos de fabricación y traslado de la maquinaria. Esto es un ejemplo más de que pese a todas las esperanzas puestas en su forma, el panóptico nunca demostró ser un modelo físico reproducible para la industria, aunque sí lo fue como prisión u otros usos (Darley, 2010).
} 


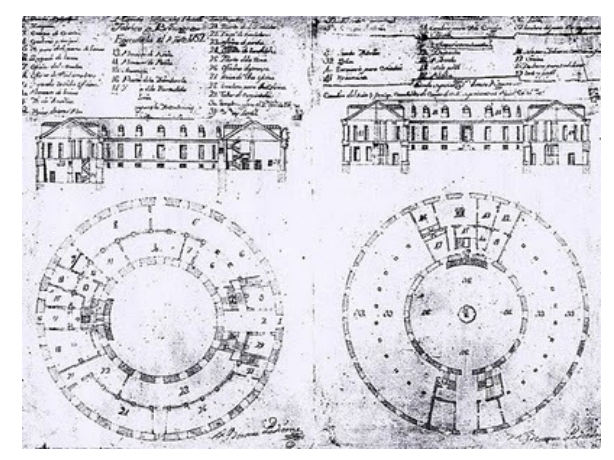

Figura 26. Real Fábrica de Guadalajara (http://4.bp.blogspot.com/ _sLD86kdht94 /Blog_redonda.jpg).

En paralelo, como producto de esta organización económica y social en las que se intenta racionalizar el proceso productivo (Aguilar, 1998), el historiador Villa Selvafolta define las fábricas reales como:

"Unidades productivas en las que el poder central figuraba como único y primer empresario y que, como tales, junto a los requisitos funcionales dictados por las necesidades de fabricación, debían incorporar requisitos simbólicos capaces de transferir visiblemente los signos de la autoridad derivada del monopolio económico."

Con todo ello, se desprende una primera conclusión que se podría obtener de estas primeras grandes estructuras y centros de manufactura industrial: la producción era inseparable del orden, y el "trabajo de la moral"77.

\footnotetext{
${ }^{77}$ Así, se puede establecer una clara similitud entre todos aquellos edificios en los que la regularidad y la disciplina son características principales: hospitales, prisiones, cuarteles, monasterios, etc.

En este último caso, se pueden encontrar numerosos edificios en los que tras la desamortización, se convirtieron en fábricas, como por ejemplo, La Cartuja, en Sevilla.

Este Monasterio de Santa María de las Cuevas, fundado en 1399 por D. Gonzalo de Mena, tuvo en el siglo XIX distintas funciones, convirtiéndose primero en cuartel de las tropas napoleónicas y pasando posteriormente a la Junta de Enajenación de Conventos suprimidos de la provincia de Sevilla en 1835. En 1841 se instaló en él la fábrica de loza de La Cartuja, mediante la reutilización de los edificios existentes, ampliaciones, etc, comenzando así a parecerse más a un edificio fabril hasta la actualidad, que ya ha dejado de serlo para convertirse en un museo (Gutiérrez, 2001).

- Blondel \{(1705 - 1774), arquitecto, urbanista y teórico francés. Nieto del también arquitecto François Blondel, conocido como François Blondel el Grande, arquitecto de la
} 


\section{ARSENAL DE VENECIA}

Vale la pena hacer aquí un inciso cronológicamente puntual, aunque muy anterior a las reales fábricas, sobre uno de los hitos comerciales y logísticos más importantes de toda la historia, según la bibliografía general sobre arquitectura industrial: el Arsenal de Venecia [Figura 27 y Figura 28].

Villa de París, autor de la Puerta Saint-Denis en 1672$\}$, en su curso de Arquitectura Civil, de 1771 , sólo hace una mera indicación sobre las factorías indicando que deben parecer sencillas y sólidas: aconsejaba amplios espacios para contener hombres, mercancías e instrumentos de trabajo, y que deben construirse en la periferia de la ciudad junto a un río, sin embargo antepone como requisito esencial: "alojamientos para los directores $e$ inspectores encargados de velar por el orden, economía y perfección de cada uno de los objetos".

- Milizia \{Francesco Milizia (1725 - 1798), arquitecto y tratadista de arte italiano. Gran defensor del gusto neoclásico, su pensamiento como crítico de arte quedó expuesto en las obras: Memoria de los arquitectos antiguos y modernos, de 1768, Principios de la arquitectura civil, de 1781, y Arte de saber ver en las Bellas Artes del diseño, de 1781. Sus ideas y teorías fueron puestas en práctica en las ciudades del siglo XIX. Entre sus preocupaciones urbanas estaban: la higiene, la grandes plazas, edificios públicos desahogados (principalmente las iglesias) y los espacios verdes integrados en la malla urbana\}, en sus Principios de Arquitectura Civil, de 1785, planta a Bondel: "Las manufacturas deben ser sencillas pero grandes y deben estar alejadas de las ciudades".

- Quatremère de Quincy $\{(1755$ - 1849) arqueólogo, filósofo, crítico de arte y político francés\}, en su "Diccionario Histórico de Arquitectura", dice: "Una fábrica es un edificio cuya primera condición es la utilidad. De aquí su simplicidad y ausencia de lujo y decoración".

Bien es cierto que existe una clara diferencia entre la definición de Blondel más próxima a las necesidades de una Real Fábrica o manufactura típica del siglo XVIII frente a la definición de Quatremère de Quincy más específica de una fábrica del XIX.

Estos autores, aunque de forma muy sucinta, indican los principios mínimos básicos de las manufacturas o fábricas: economía, simplicidad, grandes espacios y vigilancia. 


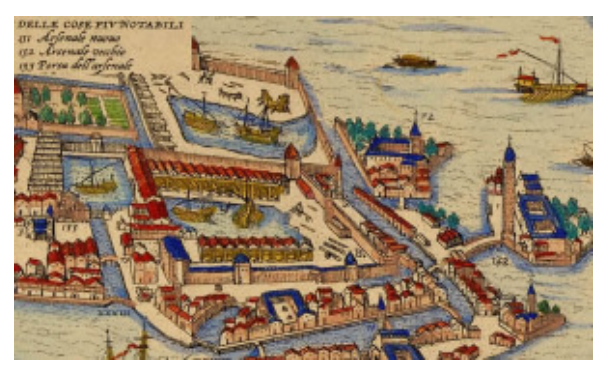

Figura 27. Arsenal de Venecia. Grabado del siglo XVIII.

(http://veneziavive.wordpress.com/2011/05/ 20/larsenale-torna-ai-veneziani/).

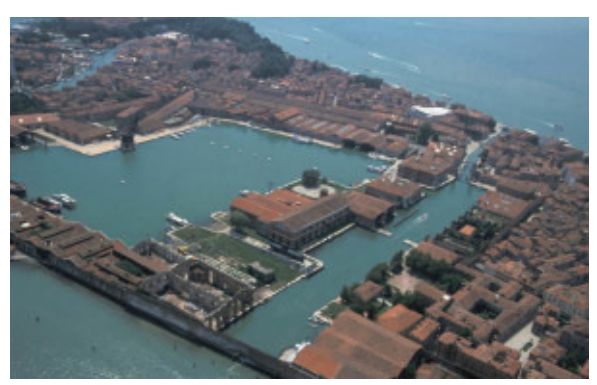

Figura 28. Arsenal de Venecia en la actualidad

(http://hiperlinkOplugin.wordpress.com/2/).

$\mathrm{El}$ arsenal ${ }^{78}$ fue fundado, según consta en los manuales de historia, a principios del siglo XII, concretamente en el año 1104, y posteriormente ampliado entre el siglo XIV al XVI. En ese momento llegó a ser el astillero más grande del mundo con sus talleres, almacenes, fundiciones, cordelerías y fábricas de velas.

Se puede considerar una verdadera fábrica de la era preindustrial, en el sentido actual de la palabra, ya que era un buen ejemplo para definir un complejo productivo, en el que llegaron a trabajar hasta 5.000 operarios o "arsenalotti".

La estructura del arsenal se mantuvo constante a través de los años, excepto algunas variaciones algunos siglos después, con la introducción de naves para velas de mayor tamaño y altura ${ }^{79}$.

78 RAE: Establecimiento militar o particular en el que se construyen, reparan y conservan las embarcaciones, y se guardan los pertrechos y géneros necesarios para equiparlas.

${ }^{79}$ Incluso algunos edificios como las cordelerías llegaban a los $371 \mathrm{~m}$ de largo según necesidades específicas. 
Su ubicación, en Venecia, junto al lado del mar, fue pensada tanto por motivos estratégicos, para su defensa ante posibles ataques exteriores, como logísticos, en lo que se refiere a la llegada de la madera de la tierra firme.

Al comienzo del 1300 se construyó el Arsenal Nuevo, con sus fundiciones, las fábricas de remos, las cordelerías (fábricas de cabos) y el sector de artillería.

Ya en el 1400 era el complejo industrial más importante del mundo, consiguiendo construir 6 galeras por mes, gracias a su organización moderna y a la capacidad de gestión en todos sus aspectos, desde el aprovisionamiento de madera y otras materias primas hasta la modularidad de las construcciones.

Por otra parte, desde el 1473 hasta el 1570 se realizó la tercera fase de su desarrollo, con la construcción de viviendas externas para los obreros, y depósitos de cereales ${ }^{80}$.

En un grabado de finales del siglo XVIII, a vuelo de pájaro, se puede intuir una distribución de tareas en las distintas zonas del Arsenal, lo que se entiende como una perfecta organización fabril [Figura 27].

Finalmente, como dato histórico, en el siglo XIX hubo un cambio en su utilización como base naval, apareciendo ya el concepto de línea de montaje, en este caso para naves de combate. Se entiende como una organización merecedora del calificativo de "moderna".

\footnotetext{
${ }^{80}$ En este momento, cuando la Serenísima se enfrentaba a la amenaza turca en Chipre, tenía la capacidad de construir una galera en poco más de 24 horas, debido a la fabricación de naves iguales y a la estandarización de los elementos. Desde principios del siglo XVI los cascos botados en el Arsenal Nuevo se remolcaron a lo largo de los edificios del Viejo Arsenal, donde se colocaban los aparejos y se las abastecía de los equipos necesarios, alimentos y municiones.
} 
FACTORES DETERMINANTES DE LA ARQUITECTURA DE LOS "MILL BUILDINGS" Y SU INFLUENCIA EN LA ARQUITECTURA INDUSTRIAL VALENCIANA

$96 / 525$ 


\section{LOS "MILL BUILDINGS"}

Lo que en realidad se persigue en esta tesis no es simplemente la descripción técnica de los mill buildings como edificios fabriles para establecer una mera semejanza entre ellos, sino la extracción de la información que en ellos reside como desencadenante del desarrollo que han tenido los espacios de trabajo a lo largo de la historiografía industrial. De sus orígenes, por su diseño eminentemente empírico en la mayoría de los casos, se pueden obtener conclusiones valiosas acerca del comportamiento de su estructura y de su funcionamiento como recinto productivo. Ello ayudará a desvelar cómo se extendió la voluntad de conseguir superficies más diáfanas con un mayor aprovechamiento.

En este Capítulo 3, se va a proceder al estudio detallado de esos espacios industriales, para lo que se procederá inicialmente mediante la clarificación de unos aspectos generales y más tarde, mediante el estudio de unos casos concretos que se constituyeron como hitos en la arquitectura industrial de la 
revolución industrial británica. Seguidamente, basado en estos mismos edificios, se establecerán unos factores que estipularán las características de los "mill buildings". Estos constituyen el cuerpo central de este estudio, y será con los que se podrá establecer similitudes con otros espacios industriales de otras regiones, incluso con aquellos que fueron construidos bien posteriormente, bien a otra escala socioeconómica. 


\subsection{ASPECTOS GENERALES.}

Los mill buildings se convirtieron en el tipo de espacio fabril preferido por los industriales ingleses a partir de la segunda mitad del siglo XVIII [Figura 29].

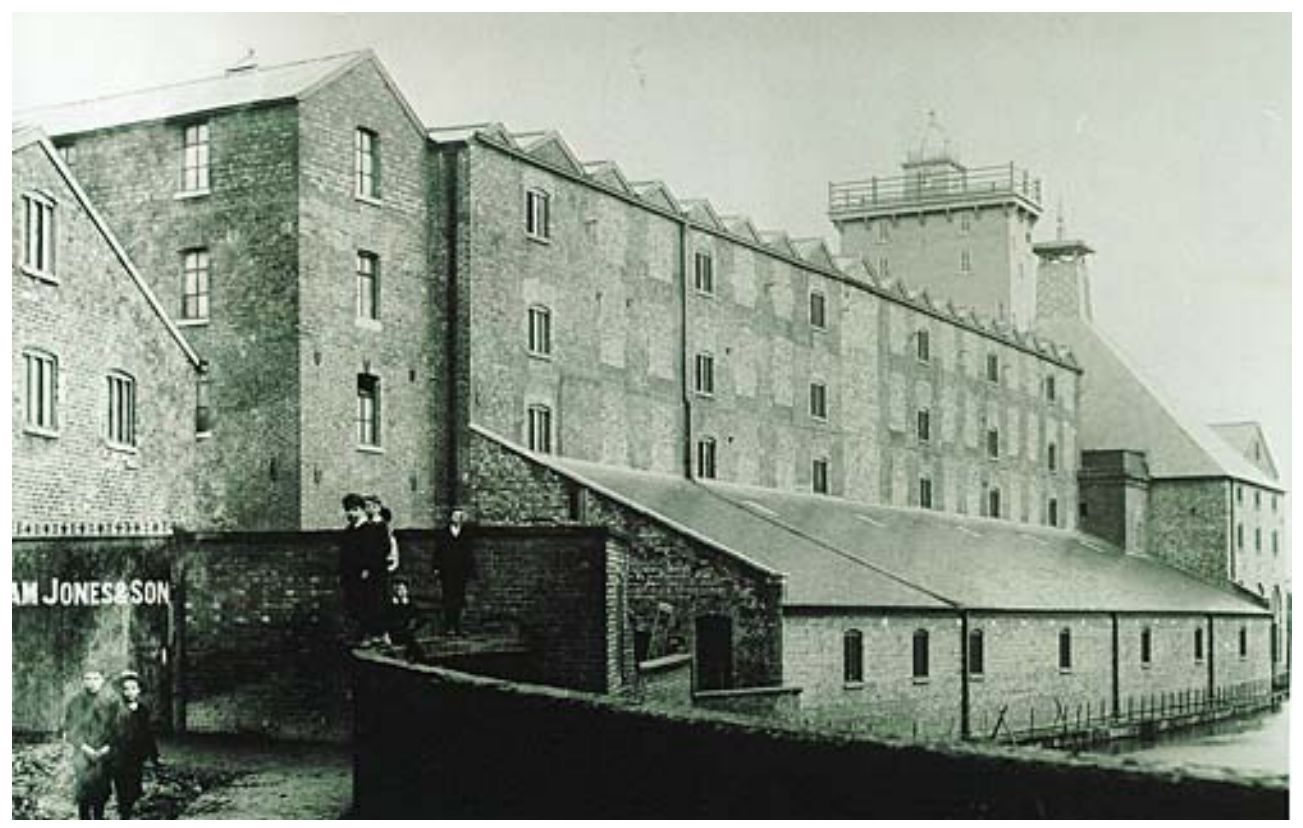

Figura 29. Ditherington Flax Mill o Marshall, Benyon and Bage, Shrewsbury, 1796, Arquitecto: Charles Bage (http://www.search.revolutionaryplayers.org.uk).

\section{INGLATERRA, ORIGEN DE UNA REVOLUCIÓN INDUSTRIAL. LOS MILL BUILDINGS}

La Revolución Industrial, iniciada en Inglaterra a finales del siglo XVIII, encontró en la mecanización textil (Darley, 2010), favorecida por la invención de la máquina de hilar de Richard Arkwright ${ }^{81}$, como posteriormente por la fuerza motriz de la

${ }^{81}$ Sir Richard Arkwright (1732 - 1792) fue un industrial inglés que patentó el marco giratorio movido por agua (water frame) en 1769, y fundó la primera factoría de algodón hidráulica del mundo en 
máquina de vapor de James Watt (alrededor de 1780), el elemento básico y fundamental que condujo a la transformación industrial. A partir de la máquina "spinning Jenny" de James Hargreaves ${ }^{82}$, de 1764, la "water frame" de Arkwright, de 1769, y la "mule Jenny" de Samuel Crompton ${ }^{83}$, de 1779, y su conexión en un gran número de ellas a un sistema de accionamiento por ruedas hidráulicas, se pasó a la construcción de un tipo de edificio fabril de varios pisos, que constituiría el modelo estándar de hilatura y fábrica textil de las primeras décadas industriales [Figura 29]. Este modelo perduró porque demostró ser desde un principio el que mejor respondería a la exigencia de máxima eficiencia productiva, objetivo en el que se sustentaba la sociedad productora industrial (Crump, 2010).

ETIMOLOGÍA: Debido a su origen vinculado a los molinos, aparentemente la primera vez que aparece escrita la palabra 'factory' en un manual técnico, según se tiene constancia, es en el libro 'Life and Times of Samuel Crompton', cuyo autor es Gilbert J. French, publicado en Manchester en 1862 (French, 1862). También es verdad que este dato es poco fiable, porque mucho antes, la legislación inglesa de 1802 se refiere a ella cuando se trata el tema de la salud física y moral de los aprendices en las "fábricas". En esta época, las palabras en inglés 'mill' y 'factory' se utilizaban indistintamente ${ }^{84}$.

En estas instalaciones industriales, cabe destacar principalmente cuatro características particulares que marcarían su desarrollo \{página 15\}. El primer rasgo identificativo viene definido por la utilización del sistema de accionamiento

Cromford, Derbyshire (Inglaterra) en 1771, siendo uno de los catalizadores de la revolución industrial.

82 James Hargreaves (1720 - 1778) fue un tejedor y carpintero de Lancashire (Inglaterra).

${ }^{83}$ Samuel Crompton (1753 - 1827) fue un inventor inglés. Los defectos de la Spinning-Jenny le inclinaron hacia la idea de concebir algo mejor. Sobre 1779 le llegó el éxito con la producción de una máquina apta para el hilado y uso en la manufactura de la muselina, que en un principio fue conocida como la hiladora de muselina, y más tarde como la Spinning-mule.

${ }^{84}$ Se trataba de edificios de tipología característica inglesa, si bien el edificio fabril en altura ya contaba con algún antecedente, como por ejemplo la fábrica de seda ya mecanizada de los hermanos Lombe, en Derby, de 1722. 
motriz de su maquinaria, generalmente a modo de motor único. La segunda propiedad está vinculada a aspectos relacionados con la utilización de materiales y métodos constructivos, que en cierto modo son novedosos en el campo de la construcción. En cuanto a la tercera diferenciación, es que generalmente se trata de un edificio en altura, de varias plantas; y la cuarta hace referencia a su forma característica, de planta estrecha y alargada.

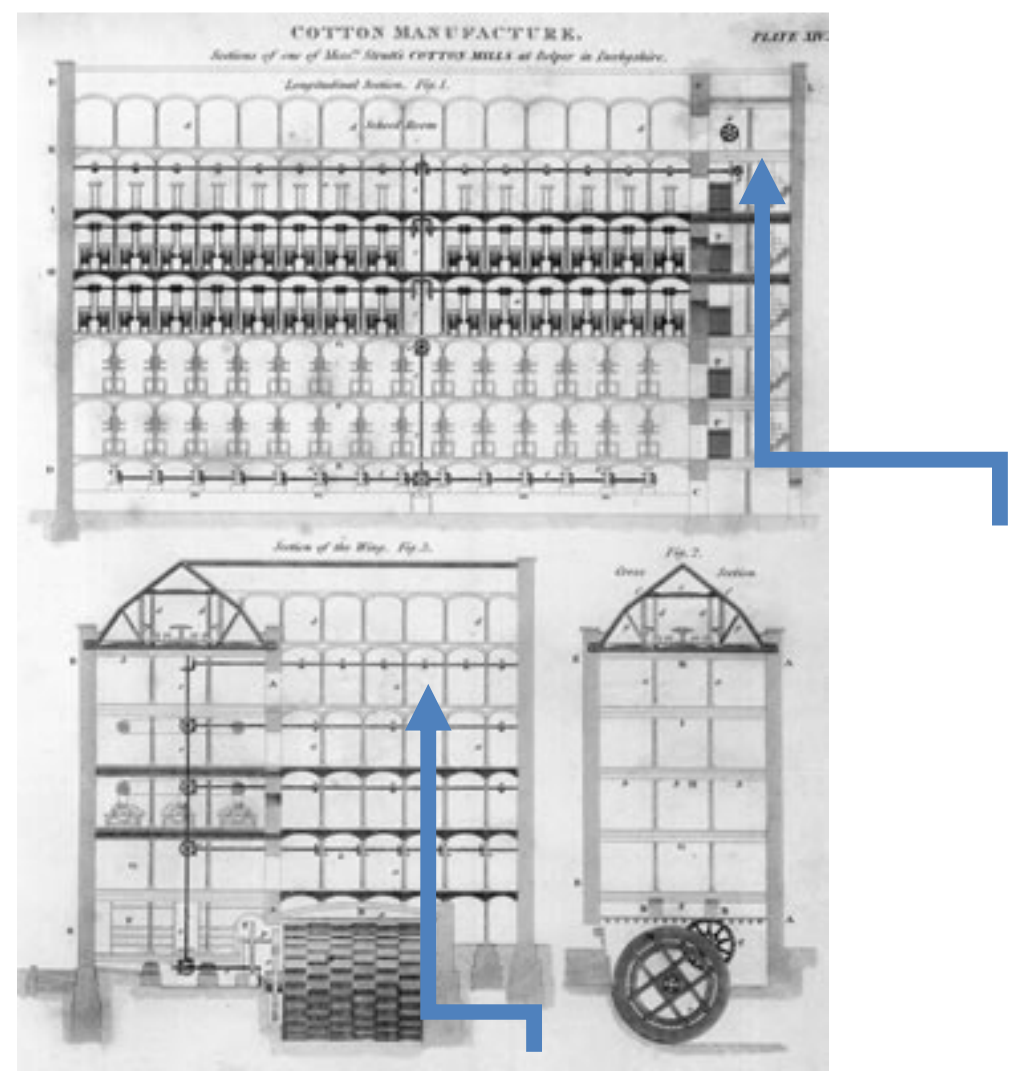

Figura 30. Strutt's North Mill, 1804, Belper. Ejemplo de "mill building" donde la flecha azul determina el recorrido del esfuerzo motriz por las diversas plantas del edificio proveniente de la rueda hidráulica, quedando accionados todos los elementos del sistema productivo (el edificio en sí) (http://commons.wikimedia.org/wiki). 


\section{$\underline{\text { MILL BUILDING }}$}

Dentro del contexto histórico que se trata en esta tesis, que comenzaría en los orígenes de la Revolución Industrial en la 2a mitad del siglo XVIII en Inglaterra, se presenta un "mill building" inglés según:

\section{1) SISTEMA DE ACCIONAMIENTO Y TRANSMISIÓN DE LA ENERGÍA MOTRIZ:}

Estos edificios fabriles se caracterizan por ser un conjunto con edificio-motor único-varias máquinas, diferenciándose del molino cronológicamente predecesor que era edificio-motor-máquina. Esta agrupación coincide con la envolvente de todo un complejo sistema de transmisión de la energía, mediante ejes giratorios, engranajes, poleas, correas, etc, todo ello funcionando armónicamente, de forma sincronizada y de forma continua, como si de un todo se tratara.

\section{2) ASPECTOS CONSTRUCTIVOS:}

Generalmente los "mill buildings" estaban construidos mediante muros de carga perimétricos de ladrillo con aberturas repetidas. Una de sus primeras evoluciones en el sistema constructivo fue el cambio desde un entramado interior de madera a otro parcialmente metálico. Este cambio se produjo en primer lugar en los soportes, con la utilización de hierro macizo de sección cruciforme, como el utilizado por primera vez por William Strutt en 1792-1793, en Derby [Figura 30], y en la fábrica de lino Ditherington Mill, en 1796.

Más tarde, por la necesidad de conseguir el denominado "a prueba de fuego", se pasaron a utilizar también vigas metálicas con bóvedas de ladrillo tabicadas entre vigas formando los forjados, aunque se continuó construyendo el pavimento con gruesos tablones de madera de pino sin ninguna protección ignífuga durante mucho tiempo. 


\section{3) EDIFICIO DE VARIAS PLANTAS:}

Diversos son los condicionantes que llevan a construir edificios para producir en varias plantas, especialmente después de la 2 a mitad del siglo XVIII, incluso de hasta 7 o 8 alturas en el cambio de siglo:

- Su ubicación cerca del punto de accionamiento hidráulico, con poca disponibilidad de terreno.

- La máxima longitud en función de la torsión máxima de los ejes motrices, tanto verticales como horizontales.

- Los sistemas constructivos y su avance tecnológico.

- Conocimiento del comportamiento de los materiales, como la madera o el hierro.

\section{4) FORMA CARACTERÍSTICA:}

Se trata de edificios específicamente en altura, con exterior escasamente ornamentado, estrechos y alargados, condicionado exclusivamente por las posibilidades de la estructura y la captación de iluminación interior para el trabajo, así como por la máxima torsión a la que podían estar sometidos los ejes de transmisión del movimiento. 


\subsection{LOS PRIMEROS MILL BUILDINGS}

A continuación se hace una breve descripción de los primeros edificios fabriles que nacieron como consecuencia de lo que en la historiografía tradicional se ha venido a llamar como Revolución Industrial.

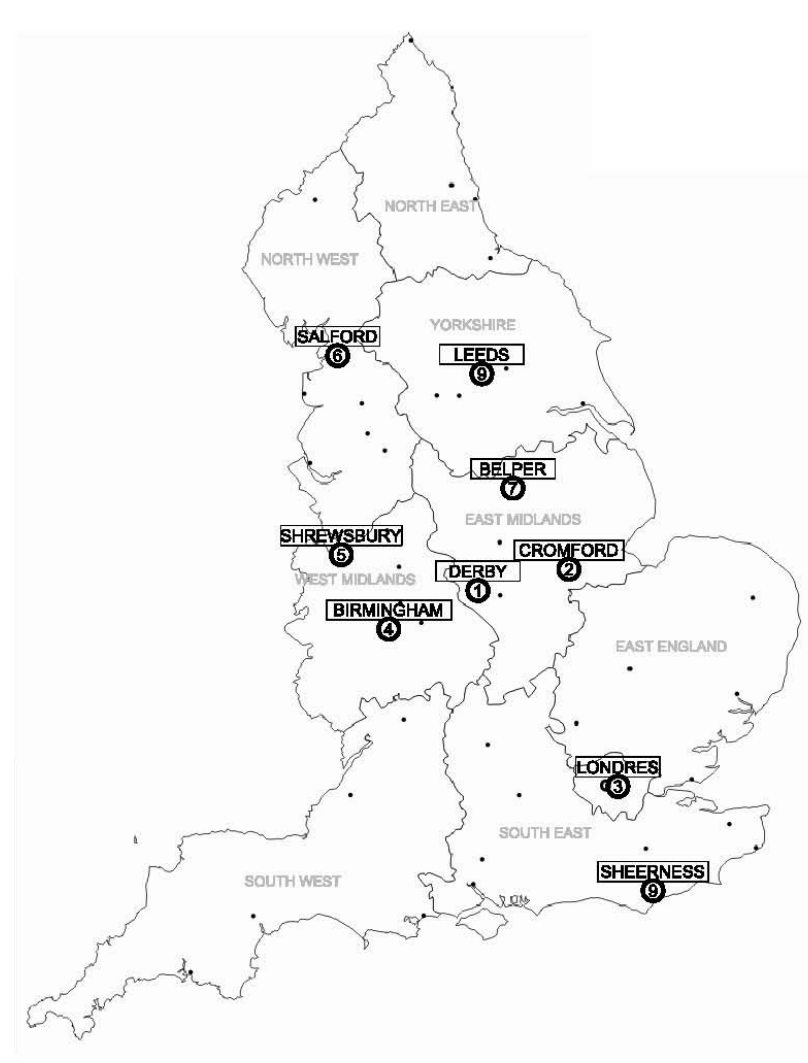

La elección de este tipo de fábricas que ya incluían uno o varios motores accionados bien por una rueda hidráulica, bien por una máquina de vapor ${ }^{85}$, ha sido motivada principalmente por la importancia que tuvieron en el momento de ser construidas. La mayoría de ellas fueron diseñadas para producir, como un nuevo concepto más allá de la manufactura popular [Figura 31].

Figura 31. Mapa de Inglaterra con la localización de los edificios estudiados en el Capítulo 3.2.

\footnotetext{
${ }^{85}$ La palabra mill proviene del inglés y su traducción literal es la de molino, o triturador, si bien se le asocian en el contexto al que se refiere este estudio acepciones como watermill o posteriormente factory. Se trata de un edificio en altura donde se realiza la producción industrial de algún producto, como textil, harina, algodón, lino, etc (Palabras relacionadas: spinning mill, flour mill, lumber mill, paper mill, wollen mill, etc).
} 
La numeración aparecida en la Figura 31 se corresponde con los siguientes edificios:

\begin{tabular}{|c|l|c|l|}
\hline 1 & Lombe's Mill & 1722 & Derby \\
\hline 2 & Factoría de Arkwright & 1771 & Cromford \\
\hline 3 & Albion Mill & 1786 & Londres \\
\hline 4 & Soho Foundry & 1795 & Birmingham \\
\hline 5 & Ditherington Flax Mill & 1796 & Shrewsbury \\
\hline 6 & Phillips, Wood \& Lee & 1799 & Salford \\
\hline 7 & Strutt's North Mill & 1804 & Belper \\
\hline 8 & Marshall's Temple Mill & 1842 & Leeds \\
\hline 9 & The Boat Store & 1858 & Kent \\
\hline
\end{tabular}

Entre ellos se destacará en primer lugar el molino sedero de los hermanos Lombe, en Derby, que fue el primero en ser considerado en la bibliografía realmente como una fábrica en altura. Esta fue la manufactura original destinada a la producción de tejidos de seda, mucho antes de la invención de la máquina de hilar de Arkwright.

Su aspecto exterior, del primer cuarto del siglo XVIII, es muy parecido a los "mill buildings" originarios que se construirán medio siglo después. Es por ello que su elección no ha sido casual.

En segundo lugar, se estudiará las factorías de algodón hidráulicas que el propio inventor de la máquina de hilar, Arkwright, construyó en Cromford, Derbyshire, en 1771. Se califica como el origen de la industria inglesa desde el punto de vista de la mecanización y la producción a gran escala (Derry, 1980). Estaba considerada primero como el prototipo nacional inglés de fábrica, y posteriormente modelo de desarrollo de la industria del algodón. Su estructura, como era usual en los molinos anteriores, estaba realizada mediante forjados y 
vigas de madera ${ }^{86}$, apoyadas sobre los muros de carga en piedra, suficientes para sostener las cuatro alturas que habían por encima de la planta baja.

Por otro lado, se ha escogido también como referencia de edificios fabriles en las primeras etapas de la revolución industrial, una de las primeras fábricas de harina que se construyó en 1786, en el centro de Londres. Se refiere a la Albion Mill, que fue la primera en emplear el vapor como fuerza motriz. Este emblemático edificio era uno de los más grandes construidos hasta el momento y simbolizaría de alguna manera el comienzo de la producción industrial de la harina, con tecnología inusual en ese momento. Es por ello que le surgieron tantos admiradores como detractores, los cuales siempre estuvieron bajo sospecha de provocar su incendio, pese haber estado considerado como fortuito en 1791, tan solo 5 años después de su inauguración. El final trágico de este emblema fue la gran frustración de aquellos que habían depositado tanta esperanza en la revolución económica incipiente.

En cuarto lugar, se han escogido como referencias notables las fundiciones que primero Matthew Boulton construyó en 1766 en el barrio de Smethwick de Birmingham, la Soho Manufactory, y posteriormente junto con James Watt en 1796, la Soho Foundry, a las afueras de la ciudad, donde fabricarían las primeras máquinas de vapor que serían utilizadas para el accionamiento principalmente de los telares mecánicos de los molinos textiles.

Más que por su importancia como edificios en sí, estas fundiciones reflejaban cómo se entendían las grandes empresas tecnológicas del momento, así como la trascendencia de estos dos inventores y empresarios, que se ha ido manteniendo a través de la historia: la máquina de vapor aparece en toda la bibliografía del siglo XIX como la que realmente provocó el inicio del verdadero cambio en la producción industrial.

${ }^{86}$ Usualmente de $45 \times 45 \mathrm{~cm}$ de sección. 
La Soho Manufactory era un edificio grande, de 3 plantas, con distribución simétrica y con muros de ladrillo rojo exterior. La Soho Foundry, incorporaba algunos pilares y vigas de hierro, y su fachada ya presentaba algunos rasgos ornamentales.

Con el quinto edificio en estudio se llega al máximo exponente de lo que significó la revolución industrial: la gran producción textil, caracterizada entre otros originariamente por el Ditherington Flax Mill, o la fábrica de lino de John Marshall, de los hermanos Benyon y del arquitecto Charles Bage, de 1796. Como en cualquier manual de historia o de arquitectura industrial no podría quedar fuera de las referencias de este estudio, sobre todo por el cambio en el concepto de edificio fabril.

El Ditherington Mill, construido en Shrewsbury, Shropshire, fue un icono de la arquitectura de la revolución industrial inglesa, entre otros motivos por ser el primer edificio completamente construido con estructura de hierro fundido (en inglés "cast iron frame"). Todavía en la década de 1790, los intentos por controlar los riesgos que podía provocar un incendio eran inútiles, y el sucedido en la Albion Mill era demasiado reciente. Sus fachadas de ladrillo rojo no posibilitaban tener más del $20 \%$ de su superficie acristalada \{confrontar el factor iluminación en apartado 3.6 más adelante\}. Sus pilares eran esbeltos con sección cruciforme, también de hierro fundido.

Hay que considerar que la construcción en hierro fundido requería de mayor precisión, tanto en el diseño como en su ejecución, puesto que la madera se podía ajustar al tamaño requerido en cada momento mediante su corte y puesta en obra.

En sexto lugar, se ha estudiado la fábrica de hilos de Salford, o Phillips, Wood \& Lee, molino de 1799, por su completa estructura en hierro y forjados en bóvedas de ladrillo, revolución por su técnica constructiva. 
Seguidamente, cuatro años después del cambio de siglo, William Strutt construyó la fábrica algodonera North Mill, en Belper. Este icono de la Revolución Industrial británica es un imponente edificio de planta baja y 4 alturas, que ya fue considerado como a prueba de fuego, al utilizar nuevos materiales diferentes a la madera y a los tradicionales. Es conocido por ser uno de los molinos más impresionantes y tecnológicamente avanzados de su tiempo, motivo por el cual aparece en un gran número de bibliografías, formando parte del patrimonio del conjunto industrial del Valle del Río Derwent.

Su estructura permitió alcanzar crujías de $7 \mathrm{~m}$ y cerchas de $14 \mathrm{~m}$. Sus forjados de ladrillo en bóvedas apoyaban sobre vigas de hierro, pero sus viguetas eran todavía de madera, como las utilizadas habitualmente, pero forradas con una chapa de hierro para conseguir la necesaria resistencia al fuego, absolutamente indispensable.

La North Mill, como las anteriores, con sus muros de carga perimetrales y sus numerosas ventanas distribuidas perimetralmente, consiguió ser prototipo para otras fábricas textiles, almacenes y otras construcciones que requerían de una mayor resistencia al fuego y gran iluminación interior. Pese a que 84 años antes la fábrica de los hermanos Lombe ya había marcado tipología fabril inglesa, la North Mill consolidó el aspecto exterior de las hilanderías industriales: inmensos edificios con forma de prismas cuadrangulares esbeltos, con planta tal que uno de los dos lados era mucho mayor que el otro, y con grandes superficies de fachadas lineales en albañilería, muy característicos. En cuanto a su fuente de energía, tenía una inmensa rueda hidráulica accionada por las abundantes aguas del río Derwent, alojada bajo un enorme arco de ladrillo. La máquina de vapor fue instalada más tarde.

El hito industrial reflejado por la Marshall's Temple Mill, de 1842, un molino de una única planta con iluminación cenital, viene motivado también por su fachada, que fue expresamente diseñada como reclamo comercial, con motivos egipcios y 
de tamaño monumental, y cuya imponencia llamaba extraordinariamente la atención, no solo en Leeds, donde fue construido, sino en todo el país.

Pero del también llamado Temple Works, pese a no tratarse de un edificio en altura y no poderse calificar estrictamente como un "mill building", todavía aún es más destacable si cabe su diafanidad, conseguida gracias a su estructura a base de pilares metálicos muy esbeltos, repetidos en cuadrículas de forma seriada, así como la calidad ambiental proporcionada por su cubierta perforada por más de 60 cúpulas acristaladas, en un intento de optimizar la luz natural. En estos huecos se colocaron incluso válvulas capaces de controlar la temperatura y la humedad ambiente, fundamentales en las manufacturas de fibra de lino.

Dos de los últimos edificios industriales que se verán son el Boat Store, cerca de Kent, y la fábrica de chocolates Menier, cerca de París. Se trata de sendos edificios prácticamente coetáneos, con estructura de hierro fundido, pero completamente diferentes en su aspecto ${ }^{87}$. El primero de ellos, que data de poco antes de 1860 , no tiene un carácter productivo, sino que se trata de un almacén de embarcaciones en un astillero. En sí mismo, posee una imagen de modernidad, sencillez, diafanidad y rigidez envidiable por cualquier edificio actual, construido nada más y nada menos que 150 años después.

Por su parte, la fábrica de chocolates Menier, tan solo 11 años posterior, refleja la belleza conseguida mediante el uso del hierro, como reflejan sus fachadas, extraordinariamente ornamentadas al rellenar los huecos con ladrillos coloreados encajados en la estructura. La piel del edificio de ladrillo y placas cerámicas de estilo clásico tradicional aparentemente no tenían nada que ver con la ingeniería interior, puntera para su momento.

87 La sensación producida al observar simultáneamente las imágenes de las dos fábricas es extremadamente difícil de calificar. 
Su reconocimiento por la arquitectura industrial se debe al sencillo método empleado en su construcción y por la acertada utilización de los materiales en obra $^{88}$.

El siguiente paso constructivo viene de la mano del hormigón, alrededor del cambio de siglo, del XIX al XX, acompañado del estallido económico producido por la industria automovilística americana. Una de las generalidades más destacables a lo largo de toda esta tesis doctoral se ve reflejada en ella, por la posibilidad de la entrada de luz natural en su interior, todo ello ampliado por la llegada de la estructura a la fachada. Esta época se aproxima al advenimiento de lo que será la fábrica diáfana y bien iluminada, que constituirá el final del periodo en estudio, eligiendo como el último edificio una fábrica de vehículos de Albert Kahn de principios del siglo pasado.

Una vez descritos y valorada su importancia para la historiografía de la arquitectura industrial, se justificará cual ha sido su verdadera influencia en la generación de las tipologías industriales. Por medio de unas variables, llamadas en esta tesis "factores", se intentarán caracterizar las formas, los volúmenes, las fachadas, la apariencia, los sistemas constructivos y el empleo de los materiales de construcción, y en general la configuración de los espacios fabriles, los cuales en el fondo, son el reflejo de la propia sociedad de los países medianamente industrializados.

${ }^{88}$ Actualmente, es una de las sedes sociales de la compañía multinacional Nestlé, y pertenece a la World Heritage Site de la Unesco. 


\subsubsection{Lombe's Mill, Derby, 1722, John Lombe}

La fábrica de los hermanos Lombe, en Derby, se considera en términos generales el primer edificio en altura destinado a la producción de tejidos de seda. De hecho, se le reconoce también por introducir el primer sistema fabril en Inglaterra, medio siglo antes de la invención de la máquina de hilar de Arkwright. Es por ello que se deriva la elección de este molino en esta tesis doctoral.

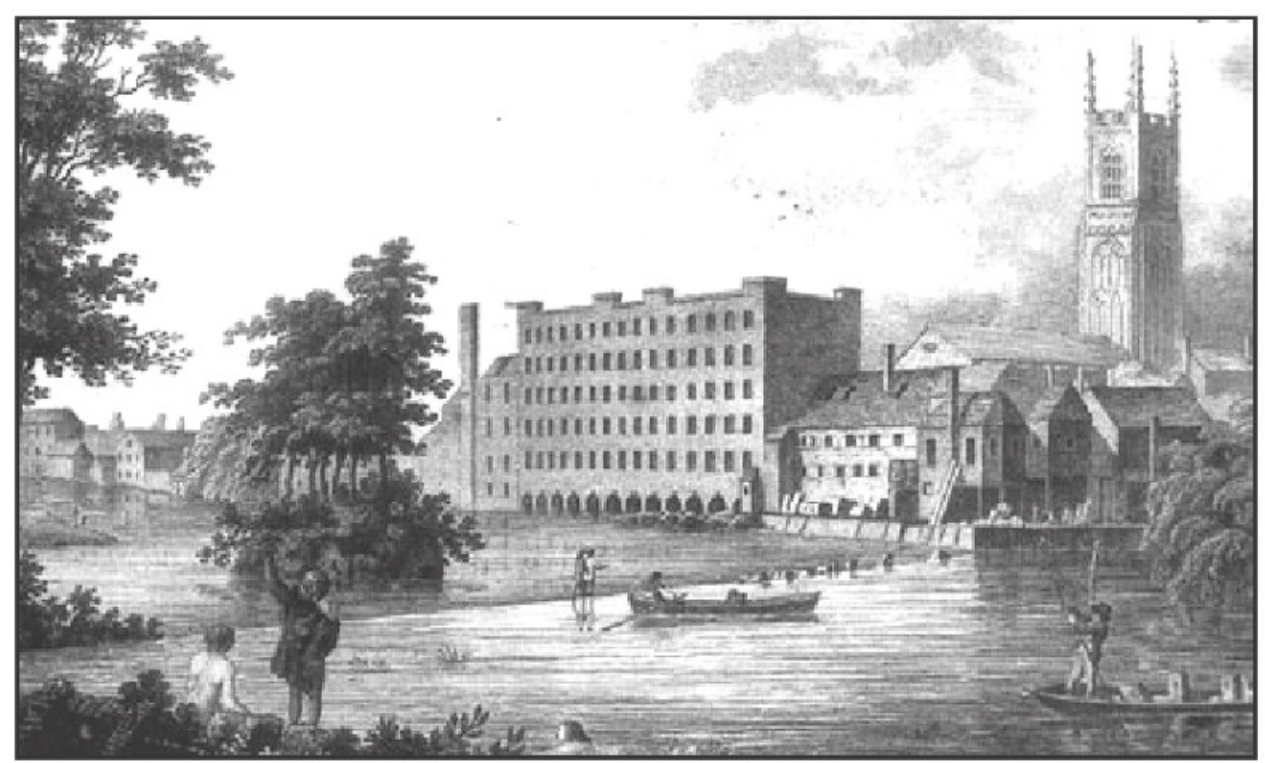

Lombe's Derby silk mill, 1793

Figura 32. Cuadro de la fábrica de seda de los hermanos Lombe, visto desde el río Derwent, a finales del siglo XVIII, 71 años después de su construcción (http://www.estherlederberg.com/Elmages/). 


\section{LOCALIZACIÓN}

La fábrica de seda de los hermanos Lombe estaba situada en una isla que formaba el río Derwent, a su paso por Derby, condado de Derbyshire, en los Midlands del Este [Figura 32$]^{89}$.

Alrededor de 1717, John Lombe ${ }^{90}$, motivado por el porvenir de su hermano ${ }^{91}$, viajó a Italia donde había también una gran tradición en la fabricación de este tejido $^{92}$ (Crump, 2010). Su intención no era más que la de observar cómo se trabajaba en ese país: encontró trabajo en una de las tiendas en las que había instalada una maquinaria especial para trabajar la seda, y de donde se dice que dibujó los croquis de su funcionamiento ${ }^{93}$ (University of the West of England. Dep. Architecture, 2014). Justo a su vuelta, contactó con Sorocold ${ }^{94}$ para que le construyese un edificio en el que pudiera fabricar telas de este material, tal y como había aprendido, con la misma maquinaria ${ }^{95}$, junto con unos cuantos artesanos italianos que le acompañaron (Chaloner, 1963).

\footnotetext{
${ }^{89}$ Esta región se había convertido a principios del siglo XVIII, en un centro productor textil de seda para los mercados de Londres.

${ }^{90}$ John Lombe (1693 - 1722), hilandero de seda de Derby, Inglaterra.

${ }^{91}$ Se trataba de Thomas, que trabajaba en un molino de Derby, por mediación del reputado arquitecto, George Sorocold $(\approx 1668-\approx 1738$, ingeniero de Derby del siglo XVIII, hijo de James Sorocold, y que construyó una de las primeras ruedas accionadas hidráulicamente desde el río Támesis). El sitio donde fue a trabajar estaba localizado justo a las orillas del río Derwent. Se trataba de uno de los primeros ejemplos en el que varios trabajadores se encontraban en un mismo edificio sin que el movimiento de las máquinas se debiera a un accionamiento mecánico a sangre.

${ }^{92}$ Las ruedas hidráulicas fueron usadas ya para impulsar las manufacturas italianas desde el XIII. A pesar de ello, mucho después, se puede afirmar que lo que realmente impulsó la mecanización del molino de los hermanos Lombe fue la temprana aplicación de la fuerza del agua para la producción textil.

${ }_{93}$ De forma tal que ahora se podría considerar como espionaje industrial.

${ }^{94}$ George Sorocold (1668 - 1738) fue un ingeniero inglés del siglo XVIII que trabajó en diversos molinos de Derby.

${ }_{95}$ Según una leyenda de los Midlands del Este, el Rey de Sicilia envió una mujer a Inglaterra encargándole la muerte de John Lombe por traición.
} 
La ubicación elegida fue el río Derwent, justo aguas abajo pero muy próxima, a otra de las primeras construcciones destinadas al trabajo textil en Derby, la del empresario Thomas Corchett, datada de $1702^{96}$ (Hills, 1973), muy referenciada en los libros sobre historia general de la Revolución Industrial.

A la fábrica de los hermanos Lombe se le atribuye, entre otras particularidades, la condición de ser el primer edificio que generó un estilo arquitectónico propio, seguido durante muchos años por otros edificios fabriles: el molino en altura (Darley, 2010). Con él la forma de la factoría industrial quedó definida: en general consistía en construcciones alargadas de varias plantas, con fachadas regulares que disponían de ventanas en cada planta dispuestas uniformemente y construidas con muros de carga a base de mampuestos (University of the West of England. Dep. Architecture, 2014). Esta constitución marcó referencia posterior, por lo que se le considera de gran importancia en el estudio de los "mills" textiles ${ }^{97}$. $Y$ ello pese a su maquinaria rudimentaria de muy poco rendimiento, que no lograba que su sistema productivo obtuviera grandes beneficios, pese a los grandes volúmenes manufacturados. Esta misma tipología se siguió copiando 50 años después pero ya con la máquina de hilar de Arkwright, mucho más eficaz.

\footnotetext{
${ }^{96}$ Aunque esta fábrica no obtuvo resultados productivos satisfactorios, puesto que necesitó de tres ruedas hidráulicas como la que tenía instalada inicialmente. Los hermanos Lombe decidieron emprender su idea con el mismo sistema motriz e incluso con un edificio de mayor envergadura, pero con un mejor sistema de accionamiento.

${ }^{97}$ La idea del edificio en altura se basa principalmente en la tradición molinera, al facilitarse la transmisión mecánica de la energía en su interior. Los molinos actuaban como envolvente de la maquinaria, según un básico proceso productivo (en el caso harinero, regido por la ley de la gravedad: desde su parte superior hacia abajo). Además, pese a que el valor del suelo no era excesivo, en los edificios en altura se aprovechaba el terreno, y se conseguía mayor espacio para la producción. El alargamiento se permite gracias a la instalación de árboles de transmisión, accionando más cantidad de máquinas, dispuestas en cada planta, y como mayoritariamente en los molinos, desde un único punto de accionamiento: la rueda hidráulica. De este hecho y de su condición prematura, se deriva la elección de este edificio en este apartado de la tesis doctoral, como se ha indicado al principio de este apartado (University of the West of England. Dep. Architecture, 2014).
} 
Poco queda ya del molino original, más que un museo levantado sobre su cimentación. Todas sus características conocidas se han obtenido casi exclusivamente del grabado que se conserva.

\section{DESCRIPCIÓN}

Tal y como queda reflejado en un cuadro pintado por Nixon a finales del siglo XVIII [Figura 32], de la poca información gráfica que se dispone del Lombe's Mill, se sabe que se cimentó sobre unos arcos de piedra que permitían el paso de las aguas del río Derwent (Chaloner, 1963), de forma que el accionamiento de la maquinaria quedara asegurado gracias a su abundante caudal. Sus máquinas eran tan altas que en algún punto del edificio incluso ocupaban dos plantas, habiéndose practicado huecos entre los forjados para poderlas instalar. Por su parte, las de bobinar el hilo de menor tamaño estaban ubicadas en las 3 últimas plantas.

El edificio, ideado por los propios hermanos Lombe, tenía una planta rectangular alargada de 32×12 metros (Darley, 2010) (ó $35 \mathrm{~m}$ de largo según (University of the West of England. Dep. Architecture, 2014)), con cinco pisos, y $17 \mathrm{~m}$ de altura total, cuyos forjados se apoyaban sobre muros de carga, con cubierta a dos aguas ligeramente inclinada, y cuya estructura interior era completamente de madera (pisos, vigas y pilares).

Según esta misma autora (Darley, 2010), esta tipología fabril será la que adoptarían la mayoría de los "mills" textiles ingleses, de finales del siglo XVIII y parte del siguiente, cuya principal fuente de energía para el accionamiento de su maquinaria es la hidráulica. Su forma se corresponderá esencialmente con una planta rectangular, larga y estrecha, que vendrá determinada por las dimensiones de las máquinas instaladas en su interior, así como por la condición irrenunciable de ser iluminada con carácter uniforme, para poder trabajar de forma mejor. 
Los Lombe quisieron levantar un piso sobre otro para poder así transportar la energía mecánica giratoria por medio de un único eje motor vertical que la transmitiría al respectivo eje horizontal de cada planta. De este modo, las máquinas de hilar la seda para las telas podrían funcionar de modo continuo.

\section{ESTRUCTURA}

La estructura de este edificio se basaba en soportes interiores y vigas de madera, cuyos extremos apoyaban en muros de carga que conformaban la envolvente del edificio. Estos estaban construidos mediante mampuestos, colocados de manera que se podía establecer una distribución uniforme de los huecos en fachada para las ventanas de cada planta, aportando la iluminación natural necesaria para su funcionamiento durante las horas de sol.

\section{CERRAMIENTOS}

En cuanto a los cerramientos de la fábrica, como se expresa en el párrafo anterior, estaban realizados con piedra de mampostería a modo de muros de carga con mechinales en los que apoyaban las vigas de madera. Debido a su necesaria capacidad portante para las 5 plantas de todo el edificio, no disponía de huecos de excesiva superficie para la entrada de luz natural, aunque en el grabado de Nixon se aprecia un ritmo en su distribución, lo que le confiere una cierta distinción exterior, prototipo atípico de las construcciones dedicadas a la industria textil de todo el siglo XVIII, generalmente poco ornamentadas, muy irregulares a base de adiciones y ampliaciones sucesivas (configuración organicista).

Del mismo modo, la anchura de los edificios no podía ser muy grande, porque las vigas de madera no tenían posibilidad de alcanzar luces considerables.

La cubierta era a dos aguas, tal y como se realizaba en general en los edificios y cobertizos de la época. 


\section{FUENTES DE ENERGÍA}

Uno de los factores más determinantes en la configuración de estos edificios de producción textil a mayor escala que la artesanal fue el sistema que disponían para el accionamiento de su maquinaria. Por ejemplo, la fábrica de los hermanos Lombe respondía al principio del motor único (Aguilar, 1998) ${ }^{98}$, o sea, disponía de una sola rueda hidráulica de $7 \mathrm{~m}$ de diámetro y $2 \mathrm{~m}$ de anchura que podía accionar todas y cada una de las máquinas del edificio a la vez, mediante la conexión de un eje vertical y diversos horizontales que transferían la energía a cualquier punto de la fábrica, cubriendo toda la longitud del edificio. Esos árboles de transmisión y las máquinas de tejer serán las que configurarán el volumen del edificio, $y$ en definitiva su forma.

Así, de este modo, se puede deducir directamente que la arquitectura de los "mills" textiles estaba fuertemente influida por variables muy concretas. Lo mismo ocurriría tiempo después con el establecimiento de las primeras máquinas de vapor (Crump, 2010) ${ }^{99}$, que provocaron que muchos de los "mills" en los que iban a ser instaladas, fueran construidos pensando especialmente en su alojamiento.

\footnotetext{
${ }^{98}$ Según Inmaculada Aguilar (Aguilar, 1998), la imagen característica de una fábrica del siglo XVIII se corresponde con la de un edificio adaptado a unas innovaciones tecnológicas, ajustando su envolvente de forma que se pueda realizar un proceso productivo con un rendimiento adecuado. Este periodo que aquí se contextualiza, está lleno de descubrimientos, en el que en este estudio destaca sobre todo el del motor único: la rueda hidráulica, más tarde la máquina de vapor y posteriormente la electricidad, así como los nuevos sistemas constructivos y materiales, como el hierro.

${ }_{99}$ Uno de los primeros de ellos fue el Ditherington Flax Mill, Shrewsbury, condado de Shropshire, construido en 1796, como se verá después de la descripción de 3 edificios más.
} 


\section{DATOS CARACTERÍSTICOS}

- El molino de Lombe no fue el primero en construirse realmente como fábrica de hilado de seda, puesto que hubo otro previamente construido aguas arriba del río Derwent, a su paso por Derby, propiedad de Thomas Cotchett, de 1704 (Hills, 1973), si bien este no alcanzó ningún éxito industrial de relevancia (Posener, 1972). Para su funcionamiento se levantó una presa aguas arriba de su ubicación, ya que este río no tenía de por sí un caudal de agua abundante y de suficiente energía.

- Daniel Defoe ${ }^{100}$ en la década de 1720 , mientras hacía un largo viaje por Gran Bretaña, destacó en su libro de viajes que cuando al cruzar el río Derwent, en Derby, vio una gran hilandería de seda recién construida, con una gran rueda hidráulica que accionaba la maquinaria (Crump, 2010). Este mecanismo no era en principio ninguna novedad en sí, pero la escala del edificio y el funcionamiento de la manufactura sí lo entendía como un nuevo concepto social: la fábrica no elaboraba artículos hechos a mano, sino que llevaba a cabo otra labor realizando el "trabajo de muchas manos" (Darley, 2010). Eran los comienzos de la mecanización y los procesos en cadena.

\footnotetext{
${ }^{100}$ Daniel Defoe (entre 1659 y 1661 - 1731). Escritor y periodista inglés, mundialmente conocido por
} su novela Robinson Crusoe. 
3.2.2. Factoría de algodón hidráulica, Cromford, Derbyshire, 1771, Richard Arkwright

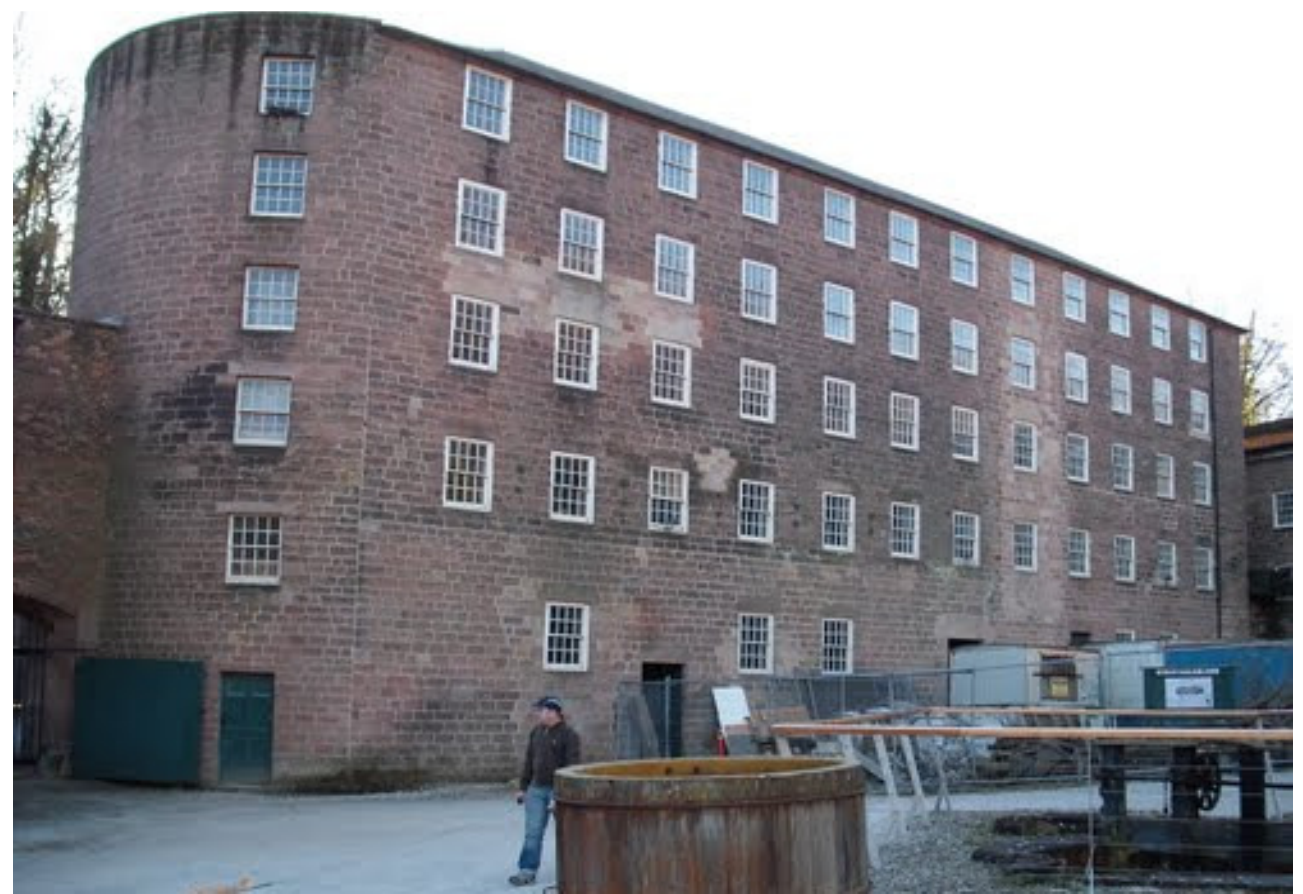

Figura 33. Mill de Arkwright en Cromford, finales del siglo XVIII (http://www.belperresearch.com/people/arkwright/arkwright.html).

La fabricación de tejidos textiles en grandes cantidades de forma mecanizada ya existía desde principios del siglo XVIII, como lo hacía Sorocold \& Cotchett, alrededor de 1704, tal y como se ha visto en el apartado anterior. Pero muchos de 
estos intentos fracasaron y dejaron de funcionar al poco de sus comienzos (Watts, $2008)^{101}$.

En 1771, Richard Arkwright construyó un edificio fabril en Cromford, Derbyshire, que utilizaba el agua del río Derwent para mover una rueda hidráulica de accionamiento superior (University of the West of England. Dep. Architecture, 2014) [Figura 33]. Con este, se puede afirmar que Arkwright, con su nueva

\footnotetext{
${ }^{101}$ La causa de esos malogros se debió principalmente a la falta de maquinaria especializada para tejer las fibras de algodón, aunque sin embargo, es cierto que la fábrica de seda de los hermanos Lombe funcionó durante algún tiempo de forma eficaz gracias a los conocimientos adquiridos durante su estancia en Italia y a la mano de obra más o menos traída de ese país. De hecho, esta fábrica, impulsada mecánicamente por ruedas hidráulicas, fue el inicio de la implantación de la industria textil en el sentido estricto de la producción a gran escala, con respecto a la manufactura en pequeños talleres artesanales predominante hasta ese momento (University of the West of England. Dep. Architecture, 2014). Y más teniendo en cuenta que la patente de los hermanos Lombe caducó en 1732, conllevando la expansión del sector al construirse varios molinos para la fabricación de seda tal cual o parecido al original. De hecho, este edificio fue el prototipo nacional inglés de la industria de la seda: 50 años después todavía seguía siendo el modelo de desarrollo de la industria del algodón, como lo fue para las fábricas de Arkwright y de los Strutt, en el mismo valle del río Severn (Watts, 2008).

En lo que se refiere a las fábricas de Arkwright, estas estaban ubicadas en el condado de Derbyshire, aunque la industria textil se desplazó hacia Lancashire y Yorkshire por varios motivos, entre otros (Watts, 2008): 1) Los vientos húmedos de los Peninos, mejores para las fibras de algodón; 2) EI terreno para la construcción de edificios era más barato; y 3) La potencia mecánica accesible para el accionamiento de las máquinas de hilado por las corrientes naturales de agua era muy abundante. La mayoría de los procesos de producción de hilado textil se mecanizaron en Gran Bretaña durante la $2^{\text {a }}$ mitad del siglo XVIII, gracias a las sucesivas invenciones y patentes que surgían (Hills, 1973). Por esto, Richard Arkwright, el inventor del "water frame", o marco giratorio movido por agua, se mudó de Lancashire en 1768 evitando las manifestaciones de sus obreros [el nombre de "waterframe" se debe a su accionamiento por movimiento mecánico proveniente del curso de un río. Este nombre se conservó muchos años después, incluso cuando la maquinaria se accionaba por vapor]. Su primer "mill building", accionado a sangre por caballos y del que se conoce muy poca información, lo estableció en Nottingham, una zona hasta el momento muy poco industrializada, pero donde la fuerza laboral era considerada menos conflictiva. Data de alrededor de 1772 y tenía cuatro pisos de altura, aunque en 1781, como tantos otros "mills", fue destruido por el fuego. Muy pronto, volvió a ser reconstruido por Arkwright, también accionado a sangre. Ya en 1790, Arkwright \& Co instaló el vapor (Crump, 2010).
} 
maquinaria ${ }^{102}$ y su socio Jeddediah Strutt ${ }^{103}$, fueron los verdaderos iniciadores del sistema fabril para la producción centralizada de algodón, y así, del desarrollo de los "mills" textiles en el valle del Derwent (Chaloner, 1963). La elección de los edificios de Arkwright se considera necesaria en esta tesis por su relevancia histórica como catalizador de la Revolución Industrial, pero de todos los edificios que este empresario construyó fue el Masson Mill, de 1783, el que sí aportó realmente una importante novedad constructiva: incluyó un pilar metálico a la mitad de los vanos, ayudando a la viga a aumentar su luz ${ }^{104}$.

Pero, ¿por qué se eligió precisamente Cromford, en pleno centro de Inglaterra, para construir el primer molino? En un principio podría parecer inadecuado por su lejanía a los núcleos industriales incipientes ${ }^{105}$, pero el río Derwent disponía de caudal de agua todo el año ${ }^{106}$, y que según Hills "nunca congelaba, y además, disponía de mano de obra dócil y bastante tolerable a las nuevas inversiones tecnológicas" (Hills, 1973). De esta manera, Arkwright podía poner en marcha su nueva hiladora mecánica protegido de las revueltas sociales que se estaban produciendo al prescindir de mano de obra ${ }^{107}$.

\footnotetext{
102 Este edificio, construido unos 50 años después del de los hermanos Lombe en Derby, no aporta aparentemente ninguna novedad en cuanto a su aspecto exterior, si bien su importancia radica especialmente en que fue justo el lugar donde se instaló la primera máquina de hilar accionada hidráulicamente, lo que mecanizó el proceso productivo del tejido textil.

${ }^{103}$ Después de su relación con Jeddediah Strutt*, que acabó en 1781, la familia Strutt se concentró en el desarrollo de los "mills" en Belper, Derbyshire, como se verá en apartados sucesivos (Hills, 1973).

*Jedediah Strutt (1726 - 1797), fue un calcetero y lencero ingles de Belper, padre de William Strutt, constructor del North Mill que se verá más adelante. También fue socio de Richard Arkwright.

104 Del Masson Mill se hablará en sucesivos apartados por la relevancia de su tecnología constructiva, si bien, el aumento de la luz de la viga no debido a la colocación del soporte de hierro, puesto que ello ya había sucedido con otros materiales, como las pilastras de ladrillo.

${ }_{105}$ Lancashire y Yorkshire (Watts, 2008).

${ }^{106}$ La ingeniería hidráulica era también una parte inseparable del paisaje industrial que se estaba configurando.

${ }^{107}$ Se construyeron allí casas baratas para los trabajadores, con una distribución tal que en su planta de cubierta pudieran instalar máquinas tejedoras para completar el trabajo diario. Arkwright
} 
El molino de Cromford tenía 5 alturas, muy bien iluminadas, con ventanas en toda su fachada distribuidas longitudinalmente. Estructuralmente era similar a los molinos que había en Derby, muy conocidos por Jeddediah Strutt, sugiriéndole su diseño para este nuevo edificio ${ }^{108}$ [Figura 34, Figura 35 y Figura 36] ${ }^{109}$.

también levantó un hotel y una capilla, creando la primera ciudad industrial, que sirvió de modelo de muchas otras posteriores.

${ }^{108}$ Una gran parte del cual existe todavía en la actualidad.

${ }^{109}$ Por otro lado se encontraban los relojeros "clockmakers", que jugaron un papel primordial en el diseño, la fabricación y el montaje de las primeras ruedas dentadas de las máquinas hidráulicas para el hilado de las fibras de algodón. En la construcción de los primeros molinos, a finales del siglo XVIII, toda la maquinaria debía ser construida "in situ", por lo que se debía cortar y ajustar los dientes y piñones de conexión, vitales para los ejes de transmisión de los "waterframes".

La carta que Richard Arkwright envió a Strutt preguntándole por ciertos detalles de acabado del "mill" el 2 de marzo de 1772, confirma la finalización de la obra. La forma en la que está escrita da idea de su satisfacción con la utilización de su maquinaria (Hills, 1973).

De la misma manera, se puede deducir el avance de su fábrica cuando en diciembre de 1771 aparece el primer anuncio en el Derby Mercury, en el que se buscaban relojeros "o cualquier otros que entendieran bien dientes de ruedas dentadas y piñones", tejedores del pueblo, carpinteros, constructores de ruedas de accionamiento, etc. Ello da clara cuenta de la centralización que iba a producirse en el trabajo, todo ello en los nuevos espacios fabriles. 


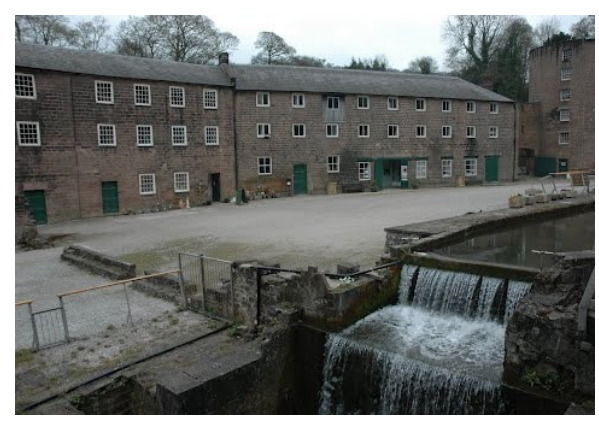

Figura 34. Mill de Arkwright en Cromford, cuna de la Revolución Industrial inglesa y mundial, con la cascada que proporcionaba la potencia mecánica para el accionamiento de su maquinaria.

(http://www.geograph.org.uk/photo/1155444).

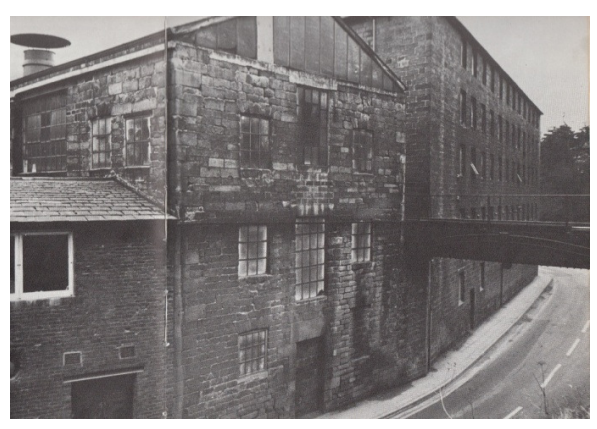

Figura 35. "Mill" de Arkwright, con el canal que drenaba el agua desde el río Bonsall Brook o Cromford Sough, que abastecía de agua también a algunas minas aguas arriba. (Hills, 1973).

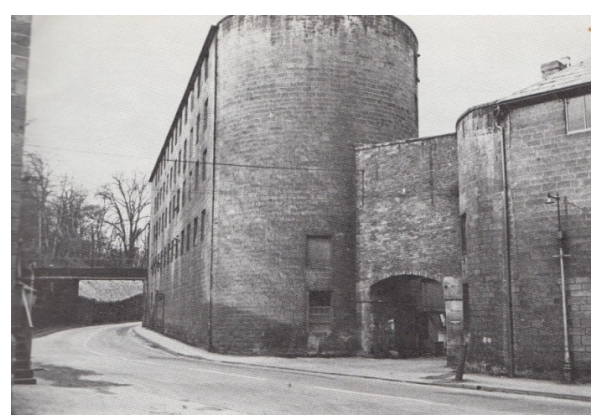

Figura 36. Entrada principal de los "mills" de Arkwright en Cromford. A la izquierda la canalización hidráulica de accionamiento de la maquinaria de hilar (Hills, 1973).

En cuanto a la distribución interior de los edificios de Arkwright, se basaba exclusivamente en la colocación de su nueva maquinaria, básicamente distinta a sus antecesores que era mucho más rudimentaria, de movimiento y ubicación libre. Todo ello en un intento de mecanizar la producción con la supervisión de la menor cantidad de trabajadores. Pero por su parte, la anchura del edificio era la 
que su estructura de madera podía ofrecer, ceñida exclusivamente a la instalación de dichas máquinas, con las que se podían producir muchos ovillos de hilo con relativamente pocos operarios, dando simples vistazos a su funcionamiento.

Se trataba de prácticamente una mecanización de la producción, que se produjo en pocos años después del invento del "waterframe"

\section{ESTRUCTURA}

La estructura de los primeros edificios que Arkwright construyó sigue siendo de madera en vigas y pilares que apoyaban sobre muros de carga, excepto el Masson Mill, que incluía un pilar metálico intermedio ${ }^{111}$. Aparte de esta circunstancia, todavía no se ha producido ninguna innovación tecnológica del sistema constructivo que pudiera evitar el incendio, como el que ocurrió en 1781 en una de sus primeras construcciones. Además, como era habitual a finales del siglo XVIII, incluso los suelos solían ser de madera, lo que no ayudaba en nada a evitar el constante riesgo al que estaban expuestas las fábricas textiles (University of the West of England. Dep. Architecture, 2014) $)^{112}$.

\footnotetext{
${ }^{110}$ Resaltar la diafanidad de la fábrica, necesaria en este tipo de industria, así como la superficie de huecos de ventana que proporcionaban una gran iluminación. Este grabado es un fiel reflejo del cambio producido en los espacios de trabajo: de los "cottages" artesanos a la producción en masa. Los edificios no podían ser ajenos a este cambio tecnológico, económico y social.

${ }^{111}$ Este edificio es clave en la evolución de la tecnología constructiva, por lo que será tratado en un apartado específico posterior, en el análisis de la influencia de los materiales en los espacios fabriles. ${ }^{112}$ Cuando se quemó la fábrica de harina Albion de Londres en 1791 se llevó a un punto extremo la necesidad de reducir el riesgo de incendio que presentaban los edificios con estructura de madera. No hacía mucho que se habían declarado otros incendios graves, en particular la pérdida en 1781 de las primeras construcciones de Arkwright, así como la del Palais Royal de París ese mismo año (Hills, 1973).

La lucha por conseguir edificios fabriles menos vulnerables se vio impulsada especialmente por sus propietarios, que querían proteger sus bienes, así como por el Movimiento Filantrópico, que se preocupaba por las condiciones y la seguridad de los trabajadores en las fábricas. Una de las soluciones fue la construcción de suelos ignífugos, con bóvedas de albañilería, aunque estas eran caras pesadas, e imposibilitaban que los edificios tuvieran muchas alturas.
} 
Sin embargo, plenamente consciente de ello, según esta misma fuente, enfoscó el intradós de los muros de sus primeros edificios con 2 o 3 capas de mortero de cal. La capa interior incorporaba "pelaje" o crin de caballo para mejorar su resistencia a tracción y reducir la fisuración.

Por su parte, las escaleras eran de madera con descansillo intermedio, separadas del edificio por unos muros de piedra, probablemente como forma de separación de lo que se entiende como "sectores de incendios".

\section{FUENTES DE ENERGÍA}

Uno de los méritos más importantes que se le puede atribuir a Richard Arkwright fue claramente la invención de la máquina automática de hilar accionada de forma hidráulica, lo que unió la fábrica de hilados a un curso de agua. De hecho, la mecanización textil surgió espontáneamente a partir de su patente de 1769. En las primeras fábricas de Arkwright el éxito provino de la eficaz conexión de su "telar de agua", de grandes requerimientos de superficie, a un sistema de transmisión movido por una rueda hidráulica ${ }^{113}$ (Hills, 1994) [Figura 37 y Figura 38].

\footnotetext{
${ }^{113}$ En el primer molino que él decidió poner en marcha no disponía de suficiente caudal de agua para accionarlo. Cuando tenía pocas máquinas no tenía este problema, pero conforme fue mecanizando las diferentes partes del proceso, se necesitó mayor cantidad de energía. Fue ampliando su fábrica y construyendo nuevos diques de retención en el curso del río (aunque esto le trajo severos problemas con los mineros aguas abajo que veían perjudicado su trabajo, al restarles energía hidráulica para sus trabajos) (Darley, 2010).
} 


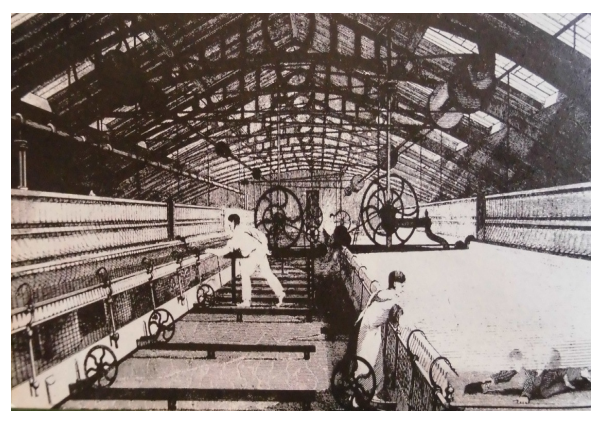

Figura 37. Máquina giratoria de hilar extendida en la industria algodonera, alrededor de 1835 (Hills, 1973).

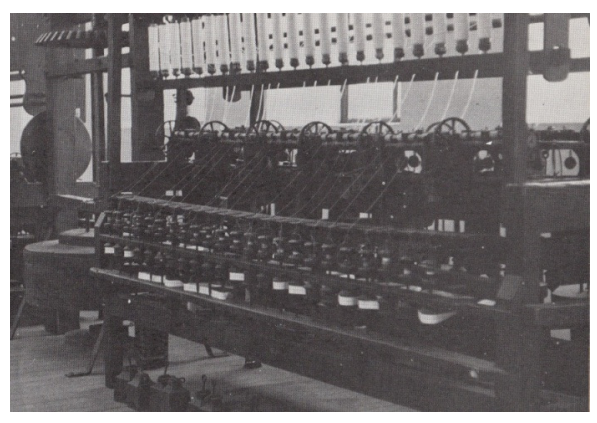

Figura 38. El "water frame" o marco giratorio movido por agua similar al de Richard Arkwright que instaló en su factoría de Cromford (Hills, 1973).

Su siguiente idea fue la posibilidad de usar el vapor como fuente de accionamiento de su maquinaria. En 1777 (Hills, 1973), Arkwright escribió a James Watt para pedirle consejo, aunque hasta ese momento, las máquinas de vapor solo se estaban utilizando para bombear agua y direccionarla hacia las ruedas hidráulicas para producirles el movimiento. La idea de accionar este tipo de maquinaria por medio del vapor, fue el desencadenante de una nueva forma de producción y organización empresarial.

\section{DATOS CARACTERÍSTICOS}

- En 1782, Richard Arkwright muere, dejando lo que quedó de sociedad a su hijo. Este construyó dos nuevos molinos en Holywell, en 1783 y 1785 (Crump, 2010).

- "Mills" de Arkwright (Hills, 1973):

1. Lumford Mill, Bakewell, antes de 1786. Tuvo problemas con el abastecimiento del agua y con sus vecinos próximos.

2. Cressbrook, 1779. Este duró poco tiempo en funcionamiento porque en 1785 sufrió un incendio. 
3. Wirksworth, 1780.

4. Masson, 1783. Edificio "impresionante" también sobre el río Derwent, con una entrada muy ornamentada, inusual en esa época para ese tipo de edificios, y con pilares metálicos.

5. Tutbury Mill, Rocester, 1781.

6. Keighly; West Rding, Yokshire, 1780.

7. Ashbourne, Derbyshire, 1780.

8. Bromsgrove, Worcestershire, 1783.

9. Shudehill, Manchester, 1783. En este caso, como el riachuelo no era suficiente para su accionamiento, y todavía en esta época no existían las máquinas rotativas de vapor totalmente desarrolladas, un motor de energía de vapor bombeaba para elevar el agua y "colisionar" sobre la parte alta de la rueda hidráulica.

- En Gran Bretaña los que definieron de alguna manera las primeras mecanizaciones para la fabricación de tejidos de algodón fueron los primeros industriales como Arkwright, Strutt, Wedgood (Crump, 2010), y todos los socios que con ellos colaboraron. Pero en los países de la Europa continental, los espacios fabriles eran más bien competencia de los autócratas que detentaban el poder. Por eso, en las formas arquitectónicas, eran más bien diferentes (Darley, 2010).

- Los diversos socios de Arkwright establecieron nuevos molinos por todo el país (Hills, 1973). Esta expansión del negocio textil en constante auge, animó a muchos empresarios a retirar licencias de la máquina de Arkwright, y construir a su vez nuevos molinos, pero este no supo sacarle el máximo rendimiento a la patente de su máquina hiladora, puesto que muchos empresarios la copiaron clandestinamente. 


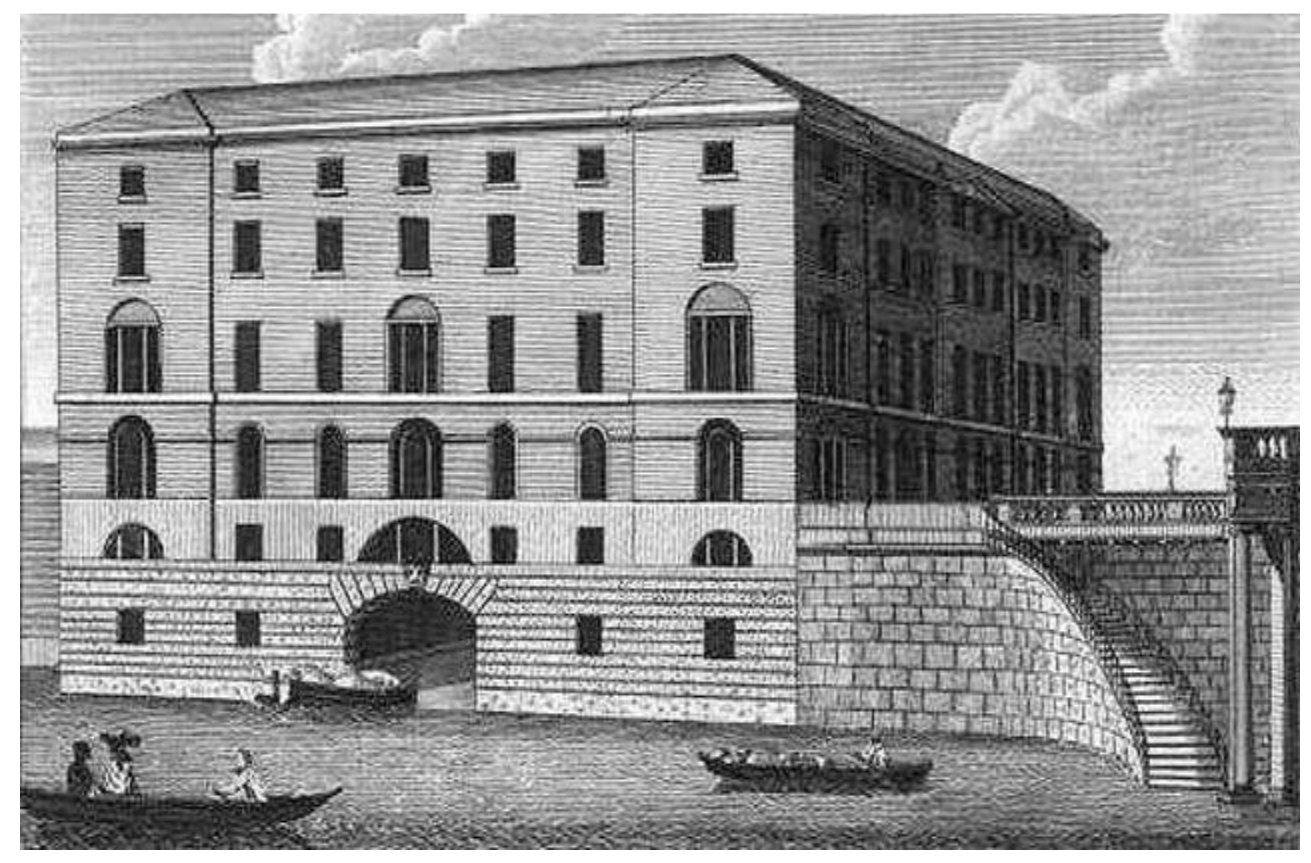

Figura 39. Albion Mill, 1786, sobre el río Támesis.

(http://www.lostindustry.org.uk/walkblackfriars.htm).

En la Figura 39, si se toma como referencia el tamaño de las personas se percibe la magnitud de este edificio, cuyas fachadas de sillería lo agrandan si cabe aún más. Esta fábrica en altura no presentaba exactamente el mismo aspecto que los mills de Arkwright, estudiados en el apartado anterior, ya que, entre otros aspectos, no tenía una planta rectangular alargada, y tenía ciertas pretensiones ornamentales, como la piedra tallada de la fachada principal que daba al río Támesis. 


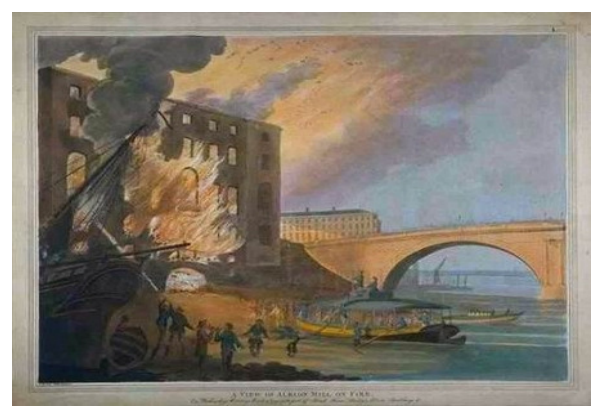

Figura 40. Incendio de la Albion Mill en 1791. (http://www.lostindustry.org.uk/ walkblackfriars.htm).

La fábrica de harina de Albion Mill es un ejemplo de los fracasos que hubo entre tantos avances tecnológicos, sociales y económicos durante la revolución industrial. Así lo deja patente la historiadora Gillian Darley, en su libro La fábrica como arquitectura, en el que señala que esta fue una etapa de la historia "Ilena de esperanzas, pero repleta asimismo de desengaños y frustraciones, que desembocaron entre otras cosas en grandes preocupaciones". $\mathrm{Y}$ pone como ejemplo, la corta y catastrófica historia de la fábrica de la Albion Mill [Figura 39 y Figura 40] (Darley, 2010).

Por un lado, por su vulnerabilidad al fuego, y por tratarse del primer molino en el que se instaló una máquina de vapor de Boulton y Watt (Smiles, 1904), se merece su inclusión en esta tesis ${ }^{114}$. Sendos aspectos son de mención irrenunciable, si bien el edificio en sí no aporta ninguna novedad constructiva respecto los estudiados anteriormente.

\footnotetext{
${ }^{114}$ Concretamente la 3ạ que su fundición construyó.
} 


\section{LOCALIZACIÓN}

El emplazamiento de esta fábrica de harina, conocida con el nombre de Albion Mills, es en las orillas del Támesis, cerca del puente Blackfriars, en pleno centro industrial de Londres de finales del siglo XVIII. Disponía de un embarcadero tanto para exportar la harina producida, como para ser abastecida del carbón que alimentaría su maquinaria, pues como se ha comentado la Albion Mills fue la primera fábrica de harinas en emplear el vapor como fuerza motriz (Pelham, 1957).

Su construcción finalizó en 1786, siendo por entonces considerado uno de los mayores edificios fabriles de Londres, cuya inauguración tuvo un eco internacional (Strike, 2004). La amplia difusión y publicidad de esta fábrica no solo se debía a su innovadora construcción, sino también todo lo que allí se estaba fabricando, por su tecnología y por la cantidad de harina procesada, un conjunto de características inéditas hasta el momento. Por todo esto, se encontraba en el punto de mira tanto de admiradores como también de detractores, como se ve en el párrafo siguiente.

Contemporáneos al Albion Mills, fueron los hornos para la fundición de hierro, en Coalbrookdale, inseparables en la construcción de la máquina vapor ${ }^{115}$. La energía generada a partir del vapor calentado por el carbón se había convertido en sinónimo de "modernidad y de dominio de la tecnología", pero también de una gran agitación social por la pérdida de puestos de trabajo que provocaría (Crump, 2010). Muchos empresarios las instalaron en sus manufacturas pensando en las grandes ventajas que les podían ofrecer, pero sin embargo, el estilo arquitectónico que escogieron para estos edificios continuaría siendo "clásico, conservador y tradicional", que es lo que la gente continuaría visualizando desde

\footnotetext{
${ }^{115}$ Como ya le decía Matthew Boulton a James Watt, todo el mundo se estaba volviendo "loco por la fábrica de vapor". Debido a la locura de las máquinas de vapor, más tarde se sugirió el nombre que se les dio a las locomotoras, puesto que las máquinas eran como "bestias aterradoras, desconocidas" (Darley, 2010).
} 
fuera, disimulando ese avance tecnológico interior y evitando así posibles enfrentamientos.

\section{DESCRIPCIÓN}

El edificio fue concebido desde el principio como una gran envolvente para todo un sistema industrial de producción de harina a gran escala, con un conjunto que aprovechaba la energía del vapor desde su innovadora maquinaria ubicada en el centro del mismo [Figura 41 y Figura 42]. En ella radica el interés, al ser ahí donde aportó una mejora del sistema productivo.

En cuanto a la Figura 41, esta no muestra más que la inseguridad de los molinos de finales del siglo XVIII. Tanto su tamaño como su capacidad de producción centralizada causaron tanto impacto social y económico que estimuló a otros inversores a buscar cómo construir edificios con otros materiales y otras técnicas que fueran a prueba de incendios.

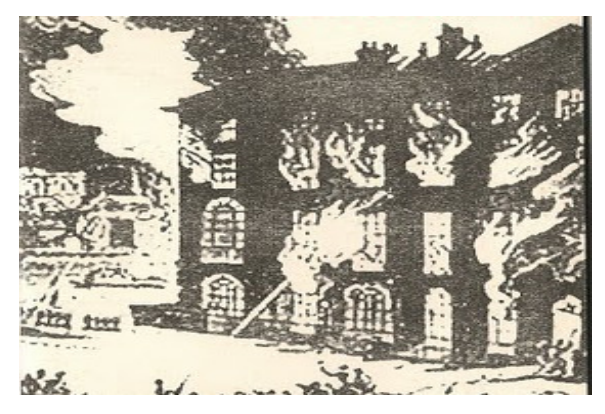

Figura 41. Aspecto del edificio de la Albion Mill en llamas, en 1791 (http://www.1st-art-gallery.com). 


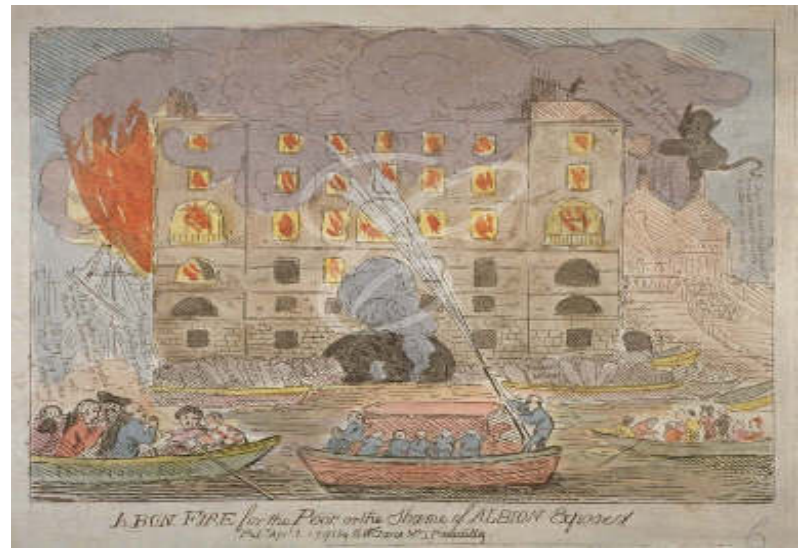

Figura 42. Aspecto del edificio de la Albion Mill en llamas, en 1791 (http://theprintshopwindow.wordp ress.com/2013/11/15/albions-darksatanic-mill/).

La utilización de bombas hidráulicas de agua manuales desde los botes reflejados en la Figura 42, impulsando agua a presión, también es una gran innovación tecnológica en sí.

Al observar las figuras precedentes, ya se ve una preocupación por la fachada, mucho más elaborada que en los casos anteriores. De hecho, se aprecia una cierta inquietud por el aspecto exterior ${ }^{116}$.

Su distribución interior era como la de un molino tradicional de trigo, cuyo proceso se basaba en el desplazamiento del grano por gravedad, en donde los pisos superiores eran los graneros, desde donde estos descendían por su propio peso hasta la planta donde se realizaba el molido, aunque el proceso de molienda estaba mucho más mecanizado.

\footnotetext{
${ }^{116}$ Según Darley (Darley, 2010), la forma de disimular su innovación tecnológica interior, para no levantar los recelos de los muchos pequeños molineros del área industrial de Londres, era mediante una fachada clásica, que al fin y al cabo, era el estilo preponderante hasta el momento en los edificios públicos y las mansiones.
} 


\section{ESTRUCTURA}

Se trataba de una construcción tradicional de aspecto externo robusto, deducible por su fachada, con columnas de piedra, con una cimentación a base de arcos invertidos, además de unos pesados muros interiores capaces de resistir los pesos de la nueva maquinaria [Figura 43].

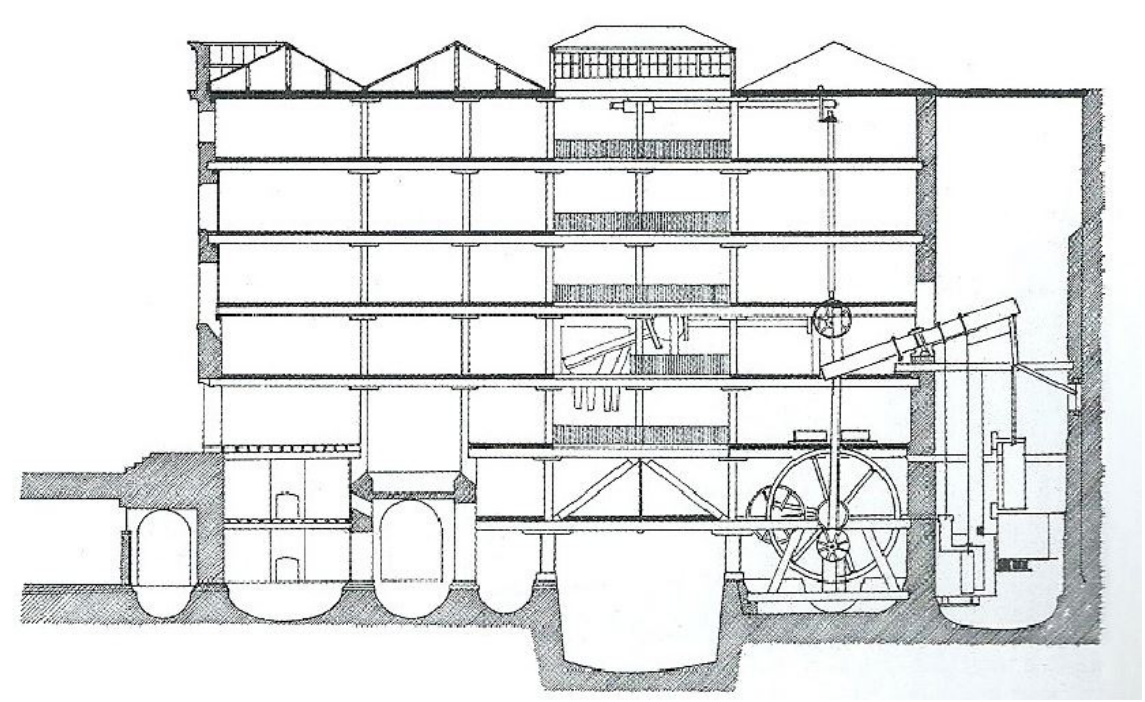

Figura 43. Sección de la Albion Mill a la altura de la máquina de vapor. Se aprecia el volumen donde se ubicó respecto el espacio de producción. Percíbase también todo el sistema mecánico de transmisión vertical y horizontal (Darley, 2010).

Su parte inferior, en contacto con el agua, estaba construida mediante piedra almohadillada, permitiendo el paso de las aguas del río Támesis en la parte central, por el que circulaban asimismo los barcos con el cargamento. Además de esta planta baja, había 5 plantas más, con una ventana en fachada por cada crujía de la estructura, la mayoría de ellas de gran tamaño. Se puede comprobar fácilmente como todavía predomina la parte de cerramiento de piedra con respecto al de los huecos (alrededor del $20 \%$ \{confrontar el factor iluminación en apartado 3.6 más adelante\}). Como se verá en los siguientes edificios estudiados, 
esta tendencia revertirá según la posibiliten los materiales y los sistemas constructivos que vayan apareciendo.

\section{CERRAMIENTO}

En cuanto a su fachada, su arquitecto, Samuel Wyatt, se inspiró en el Somerset House, diseñado por Sir William Chambers, en 1776, de estilo neoclásico victoriano, y muy próximo a la fábrica Albion (Watts, 2008) ${ }^{117}$. Se trataba de uno de los museos más importantes e influyentes de la ciudad, por lo que de este modo, lo que Wyatt pretendía era darle la importancia arquitectónica que esta inversión requería ${ }^{118}$.

Pese a no seguir escrupulosamente todas las características propias de un "mill building", a saber: no tiene una planta rectangular alargada o incluso su tecnología novedosa para su producción a gran escala, sirvió de referencia para otros edificios que se construyeron posteriormente. Del mismo modo, su incendio al poco tiempo de su inauguración ${ }^{119}$, se llevó detrás tantas expectativas puestas

\footnotetext{
${ }^{117}$ Albión es el nombre más antiguo conocido de la isla de Gran Bretaña. Hoy en día, todavía se utiliza a veces de forma poética para referirse a la isla, e incluso por extensión, para hacer referencia al Reino Unido o Inglaterra.

118 Los primeros edificios industriales de comienzos del siglo XVIII se habían construido expresamente para cada uso (Darley, 2010): el patio trasero de una casa se podía convertir en un horno primitivo, una forja o incluso una fundición, con tan solo una pequeña ampliación de un cobertizo. Sin embargo, la nueva industria de finales de siglo pretendía reflejar su importancia en la propia construcción, de manera que pudiera rivalizar constructivamente con una iglesia, una casa aristocrática o cualquier castillo de las inmediaciones. Independientemente de lo que ocultaran sus fachadas, se trataba generalmente de tecnología puntera para la mecanización de la producción, estas incorporaban entre muchos aspectos, óculos en los frontones, mamposterías que resaltaran los huecos de ventana o para la formación de los esquineros, etc.

${ }^{119}$ El motivo del incendio del 2 de marzo de 1791 nunca quedó totalmente clarificado. Algunos lo atribuyeron a las iras de los numerosos artesanos y pequeños molineros de alrededor, y de sus trabajadores que temían perder sus trabajos y sus medios de vida, puesto que se publicó en los periódicos locales que el incidente ocurrió justo cuando la demanda de agua en la ciudad era punta y no había suficiente presión para sofocarlo. A estos se les llegó a llamar "destructores de máquinas" (Darley, 2010).
} 
en la Revolución Industrial. Ello explícitamente obligó forzosamente a la sustitución de materiales de construcción combustibles.

En cambio, el ingeniero que lo diseñó y su arquitecto, John Rennie y Samuel Wyatt respectivamente (Strike, 2004), pensaron que el fuego fue causado accidentalmente por la falta de engrase de alguna máquina cercana al horno, y del sobrecalentamiento de unos cojinetes ${ }^{120}$. Este incendio se puede decir que significó un punto de inflexión en las expectativas puestas en la modernidad en general y constructiva en particular, así como en la nueva tecnología, y en definitiva en las posibilidades de la incipiente revolución industrial británica, cuestión que nunca había suscitado tanto interés entre los empresarios del país.

\section{FUENTES DE ENERGÍA}

La fábrica de Albion fue la primera en ser mecanizada del mundo, en el sentido de que se instaló en ella la primera máquina de vapor construida por Boulton y Watt en 1786, para accionar sus máquinas (Crump, 2010), como se ha comentado al principio de este apartado.

Como ocurre en la mayoría de las ocasiones, a toda novedad, idea o innovación le acompaña la incertidumbre, especialmente en materias tecnológicas, y más aún cuando la maquinaria a instalar, no ha podido ser previamente testada. Esto es precisamente lo que ocurrió en la Albion Mill con aquella máquina de vapor. Se trataba de la tercera máquina que fabricaban los de Boulton y Watt, que eran los líderes del momento de la ingeniería pesada y del diseño de este tipo de máquinas, y fue traída expresamente de sus talleres de la Soho Foundry de Birmingham (Smiles, 1904).

La máquina de vapor se instaló en la planta baja, justo en el centro del edificio, de modo que podía accionar con mayor facilidad sendos ejes de transmisión, uno hacia cada lado del edificio [Figura 43].

\footnotetext{
${ }^{120}$ Se basaban en que Wyatt quería "llevar al máximo la producción" tratando de justificar la gran
} inversión requerida. 
Esto en sí era una novedad tecnológica, ya que hasta el momento de su instalación en la Albions Mill, desde la década de 1770 con la máquina de Newcomen, lo que se hacía era simplemente utilizar esas primeras máquinas para bombear agua y provocar así el giro de una rueda mecánica, cuya fuerza era transmitida a toda la fábrica (Crump, 2010). Aquí, el acoplamiento máquina de vapor y sistema de accionamiento interior era directo ${ }^{121}$.

La máquina de Boulton y Watt podía hacer funcionar varios pares de piedra al mismo tiempo moliendo el grano, así como las máquinas necesarias para tamizar y para preparar la harina. Todo ello condicionaba directamente la forma que había adoptado esta manufactura durante su construcción ${ }^{122}$.

\section{ILUMINACIÓN}

En lo que respecta a la iluminación natural interior, Matthew Boulton ya resaltó la importancia de su calidad a finales de siglo XVIII. Justificó lo importante del encalado de las paredes, tanto para mejorar la salubridad interior como para la reflexión de la luz (Crump, 2010).

Según los pocos grabados que se conservan en los que aparecía este edificio, se puede observar cómo en la cubierta correspondiente a la parte de la escalera, había una claraboya que permitía cenitalmente la entrada de luz natural, si bien no se han encontrado más referencias acerca de esta novedad constructiva en otros edificios de la misma época [Parte central de la Figura 43].

\footnotetext{
${ }^{121}$ Otro ejemplo de bombeo lo fue la Matthew Boulton's Soho Factory, en Birmingham, en la que una bomba impulsaba agua a una rueda de 6 metros de diámetro para los rodillos que fabricarían el metal.

${ }^{122}$ Se las empezó a conocer como "máquinas de fuego" (Darley, 2010), y desde su invención, inquietaban a los 500 pequeños molinos de maíz que existían en la zona de Londres, todos ellos accionados como hasta el momento por el viento y el agua. Cuando llegó el monopolio de la gran fábrica y el temor a perder sus puestos de trabajo, empezó el revuelo social. Como se ve, esta nueva tecnología implantada en los grandes molinos, no parecía tener en principio mucha aceptación.
} 


\subsubsection{Soho Manufactory, 1766, y Soho Foundry, 1795, Birmingham, Inglaterra}

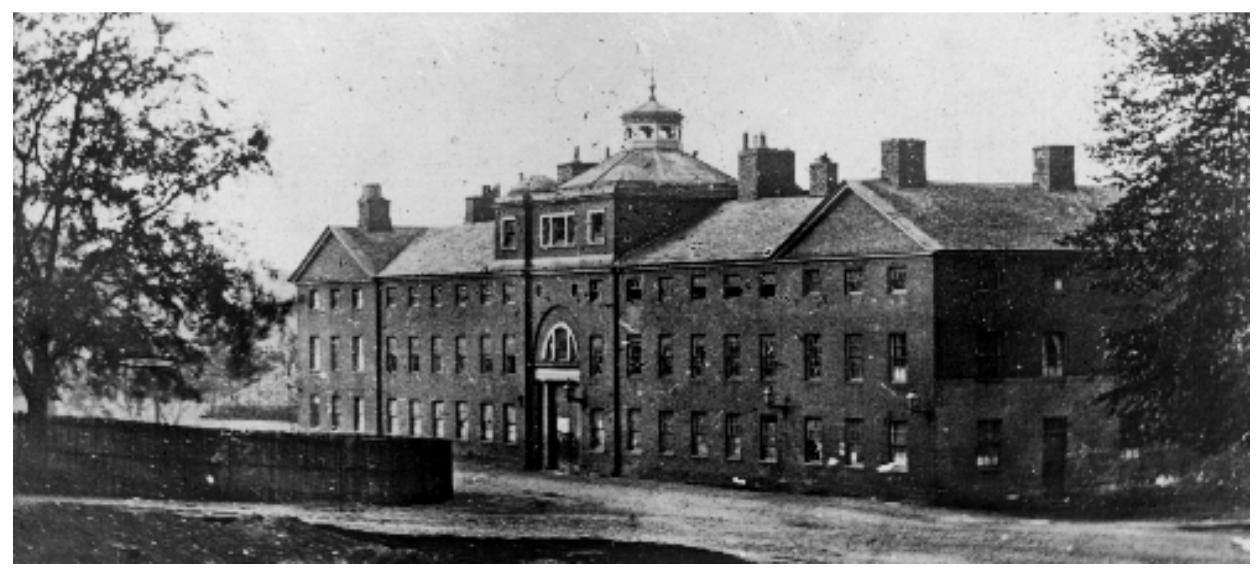

Figura 44. Soho Manufactory, 1766. Fachada noreste.

(http://en.wikipedia.org/wiki/Soho_Manufactory).

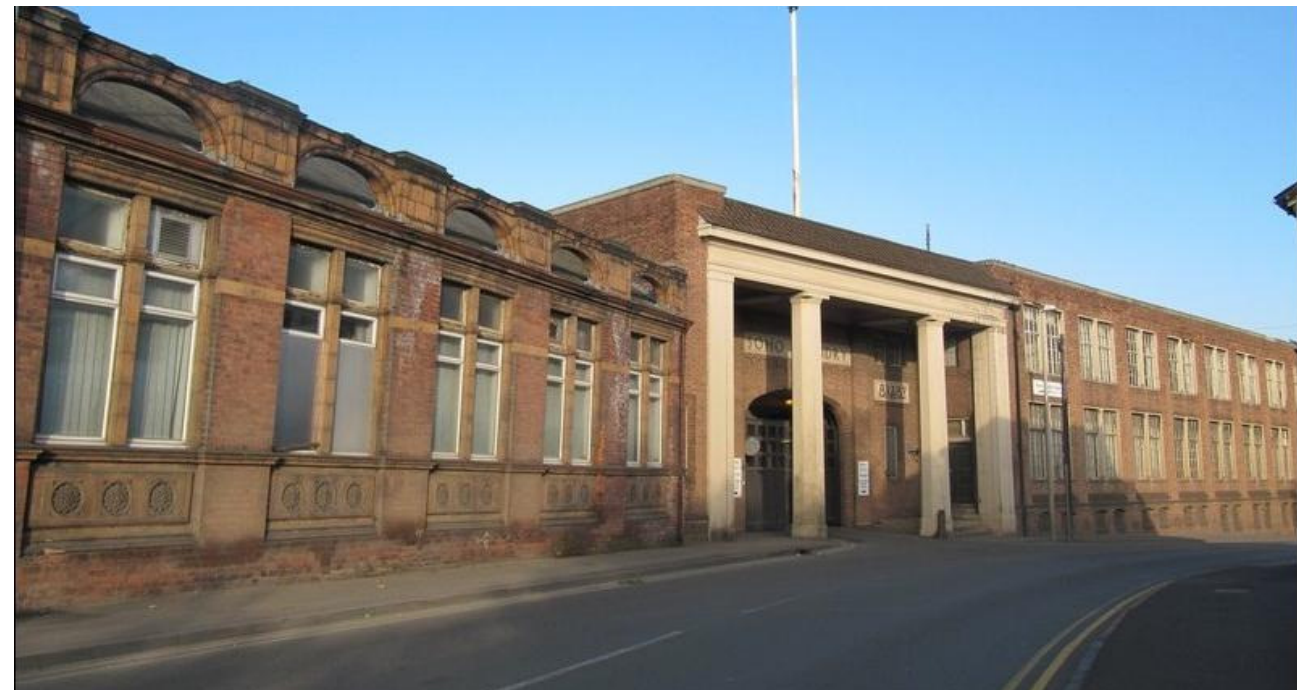

Figura 45. Soho Foundry, 1796. Estado actual (https://www.google.es/maps). 
A continuación se pasa a estudiar los edificios que albergaron las fundiciones de Boulton y Watt. Puesto que el sector de las fundiciones no solía ejercer su actividad en edificios en altura, por tratarse de industria pesada, no podrían considerarse explícitamente como mill buildings: su tipología de fábrica se correspondía con grandes superficies de producción, generalmente con distribución en única planta, o con alguna más en algunos casos. También tenían gruesos muros portantes, pero con posibilidad de mayores superficies de hueco, si bien todavía con poca iluminación interior y ventilación.

No obstante, por su trascendencia industrial y económica, además del uso temprano de la máquina de vapor para el accionamiento de los rodillos de fabricación de las planchas de metal, y su transmisión mecánica a base de ejes y correas, junto con su carácter significativo en la producción de hierro en los comienzos de la revolución industrial, justifican su inclusión en este estudio. Pese a que este estudio se centra explícitamente en los mill buildings (edificios en altura con una transmisión mecánica del giro para accionamiento en todo su volumen), si se dejara de considerar la Soho Foundry o la Soho Manufactory, este podría quedar huérfano.

Es reseñable la utilización de parteluces en los huecos de ventana ejerciendo una función estructural que posibilitan la ampliación de la superficie para un mayor paso de iluminación natural. De esta manera se consigue la estabilidad lateral de los distintos paños. Probablemente, esta solución constructiva fue obtenida casi de forma inconsciente, a modo de ensayo prueba-error, como una especie de conocimiento empírico ${ }^{123}$ [Figura 45].

\footnotetext{
${ }^{123}$ Si bien también es cierto que la carga que tenían que soportar estos muros era mucho menor que aquellos con más alturas, y eso permitía directamente huecos más grandes.
} 


\section{LOCALIZACIÓN}

Las fundiciones, y en general aquellas manufacturas que necesitaban de grandes cantidades de energía para su funcionamiento, como por ejemplo carbón, estaban localizadas cerca de las zonas de extracción de los minerales, a diferencia de los molinos textiles o de harina que empleaban la fuerza hidráulica para su movimiento ${ }^{124}$. Uno de esos lugares más importantes de Inglaterra por la cantidad de materia prima obtenida es Coalbrookdale ${ }^{125}$ (Giedion, 1978), asentamiento en el valle del Ironbridge Gorbe, en el distrito de Telford y Wrekin del condado de Shropshire, Inglaterra ${ }^{126}$.

En estas zonas, donde el carbón era más barato, las máquinas de Newcomen ${ }^{127}$ se instalaban para bombear agua (Watts, 2008), que en tiempos de sequía realimentarían los pequeños caudales de agua de los riachuelos para tener así suficiente fuerza mecánica para accionar las ruedas hidráulicas de las fábricas

\footnotetext{
${ }^{124}$ Con la máquina de vapor, la fuerza hidráulica de los ríos ya no es necesaria, por lo que se libera al edificio de su dependencia a ellos.

${ }^{125}$ Coalbrookdale está considerado en una amplia bibliografía como uno de los lugares donde empezó a producirse la Revolución Industrial inglesa.

${ }^{126}$ En el siglo XVIII, más que cualquier otra ciudad de los Midlands del Este, Birmingham (Midlands del Oeste) se convirtió en un gran centro industrial y de negocios. A finales de ese siglo, y gracias a la Soho Foundry, resultó en un importante centro de ensamblaje de máquinas de vapor de Watt. Asimismo, esta fundición, como en muchas otras de la ciudad, ayudaron a la expansión de la manufactura del hierro y el acero, para convertirlos en materiales para la construcción, como vigas y pilares.

${ }^{127}$ La máquina de Newcomen, o máquina de vapor atmosférica, fue inventada en 1712 por Thomas Newcomen. Esta máquina supuso una considerable mejora tecnológica frente a las máquinas existentes que trabajaban con el vapor: creaba el vacío en un depósito a base de enfriar vapor de agua. Pese al rendimiento conseguido, que era aún bajo, y su todavía poco uso en la industria durante el siglo XVIII, en la extracción de agua de las minas sí se consideraba como un gran avance técnico. Posteriormente James Watt ya ideó la nueva máquina que contaba con un condensador independiente, de modo que cada parte de la máquina se mantenía a una temperatura determinada, evitando los sucesivos calentamientos y enfriamientos del vapor de agua en un único depósito que provocaba su rotura constante. Otros ingenieros y constructores de molinos estuvieron interesados también en la mejora de la máquina de Newcomen, como James Brindley y John Smeaton (Chaloner, 1963).
} 
próximas. Con esta máquina no se accionaba directamente la rueda motriz sino que se daba energía potencial al agua para moverla. En la década de 1780, con la máquina de Watt, se accionará directamente la maquinaria desde un punto motriz.

Hay dos manufacturas atribuidas a Matthew Boulton ${ }^{128}$ : la que hizo con su socio John Fothergill ${ }^{129}$, en 1766, conocida como la Soho Manufactory, en el barrio de Smethwick (Smiles, 1904); y la que hizo en sociedad con James Watt ${ }^{130}$, para la construcción de su máquina de vapor, la Soho Foundry, que databa de 1796 (Hills, 1973) [Figura 44 y Figura 45].

${ }^{128}$ Matthew Boulton (1728 - 1809), comerciante e industrial de Birmingham propietario de un pujante negocio de prendas de vestir. Fue uno de los pilares de la Sociedad Lunar, que reunía a los industriales, inventores y científicos de su país.

${ }^{129}$ John Fothergill $(1712-1780)$, médico inglés.

${ }^{130}$ James Watt (1736 - 1819), ingeniero de origen escocés. Las mejoras que realizó en la máquina de Newcomen dieron lugar a la conocida como máquina de vapor, uno de los hechos más fundamentales en el comienzo de la Revolución Industrial, tanto en el Reino Unido como en el resto del mundo.

En la Soho Manufactory, 600 operarios altamente cualificados producían juguetes con una gran popularidad entre los empresarios de Birmingham. Dos años después de su inauguración, recibió precisamente la visita de James Watt, de la que quedó totalmente impresionado, por lo que tuvo la intención de establecer una relación técnico-comercial con el que 30 años después sería su socio para la construcción de un negocio de construcción de máquinas de vapor, la Soho Foundry, situada cerca de allí, a 1 milla, en el barrio de Handsworth. James Watt y Matthew Boulton, como grandes empresarios e inventores invirtieron en la mejora de la máquina de Newcomen, la cual todavía tenía muchas limitaciones, pese a su gran ventaja en el bombeo para la minería. Watt, cuando conoció a Boulton ya había empezado a trabajar con la idea de una nueva máquina de vapor con un mayor rendimiento.

Una vez ambos se mudaron a Birmingham, empezaron con el perfeccionamiento de una máquina traída desde Escocia. Para ello, necesitaban espacio, instalándose en la Soho Manufactory.

Su primer destino fue Cornwall, donde existían numerosas minas de cobre y donde Watt deducía que podía haber mercado para su nueva maquinaria, puesto que la máquina de Newcomen había estado fallando allí.

Así empezó el éxito, que se extendió por los alrededores de Birmingham, Londres, toda Inglaterra, Francia, y en general, en toda Europa continental. 


\section{DESCRIPCIÓN}

Aunque de las manufacturas de Soho no se tiene excesiva información relevante desde el punto de vista de sus edificios, se pasará a describir de manera somera cómo eran estas manufacturas de Boulton y Watt.

Si bien ambos tienen una diferencia entre ellos de 30 años (uno fue construido en 1766 y el otro en 1796), en uno y otro existen ciertas analogías, considerando su actividad como fundiciones. Como ejemplo, que el complejo industrial estaba compuesto por varios edificios independientes entre sí.

\section{SOHO MANUFACTORY [Figura 44, Figura 46 y Figura 47]}

El edificio principal era de tamaño considerable. Tenía 3 plantas con distribución simétrica visto desde la fachada principal, en cuyo centro se encontraba el acceso principal de doble altura. De esta forma podían acceder los carruajes que transportaban las materias primas provenientes de las afueras de Birmingham (Crump, 2010).

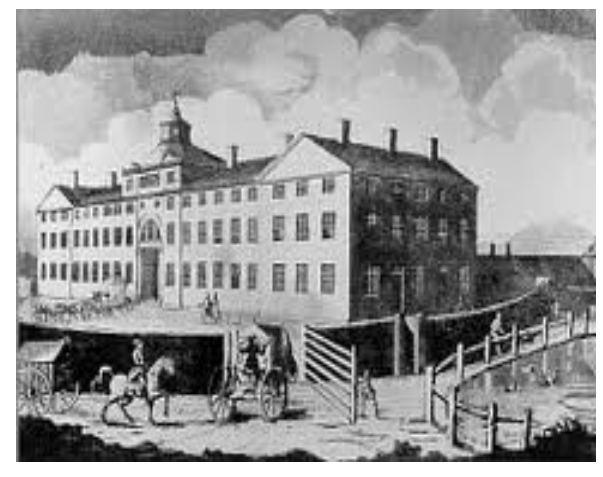

Figura 46. Soho Manufactory, 1766. Fachada noreste

(http://visitbirmingham.com/files/2012-0312/SohoManufactoryBMAH.jpeg).

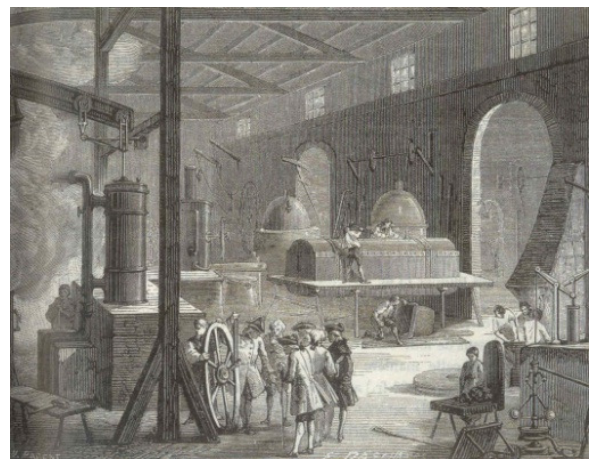

Figura 47. Interior de la Soho Manufactory (http://www.hevac-

heritage.org/images/image_8/Boultons\%20B oilers.jpg). 
La cubierta era a dos aguas con la cumbrera en los extremos en sentido perpendicular a la alineación de la fachada, y en el centro, paralela a esta. Desde el exterior se podían apreciar chimeneas que sobresalían de la cumbrera del edificio, expulsando los humos de los hornos en los que se realizaba la combustión de carbón para la fundición del hierro.

Las fachadas de todo el edificio disponían de varios huecos de ventana, de gran superficie, y distribuidas de forma uniforme, tanto en alineación horizontal como vertical. Los muros exteriores eran de ladrillo rojo, haciendo la función de muro portante.

El resto de edificios del complejo, los cuales también desaparecieron, eran de única planta.

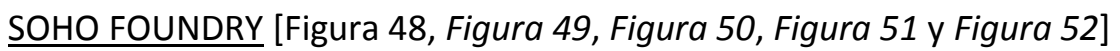

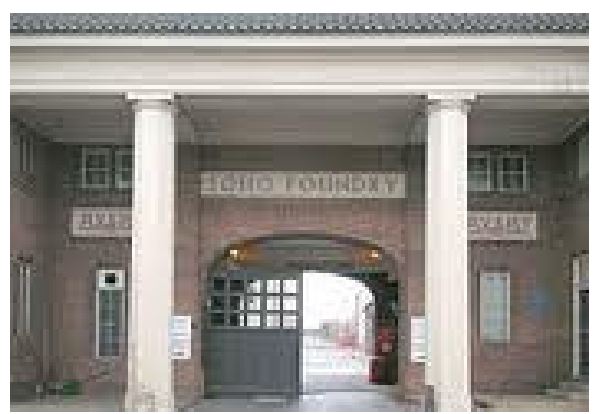

Figura 48. Soho Foundry. Acceso principal. (http://en.wikipedia.org/wiki/Soho_Foundry) 


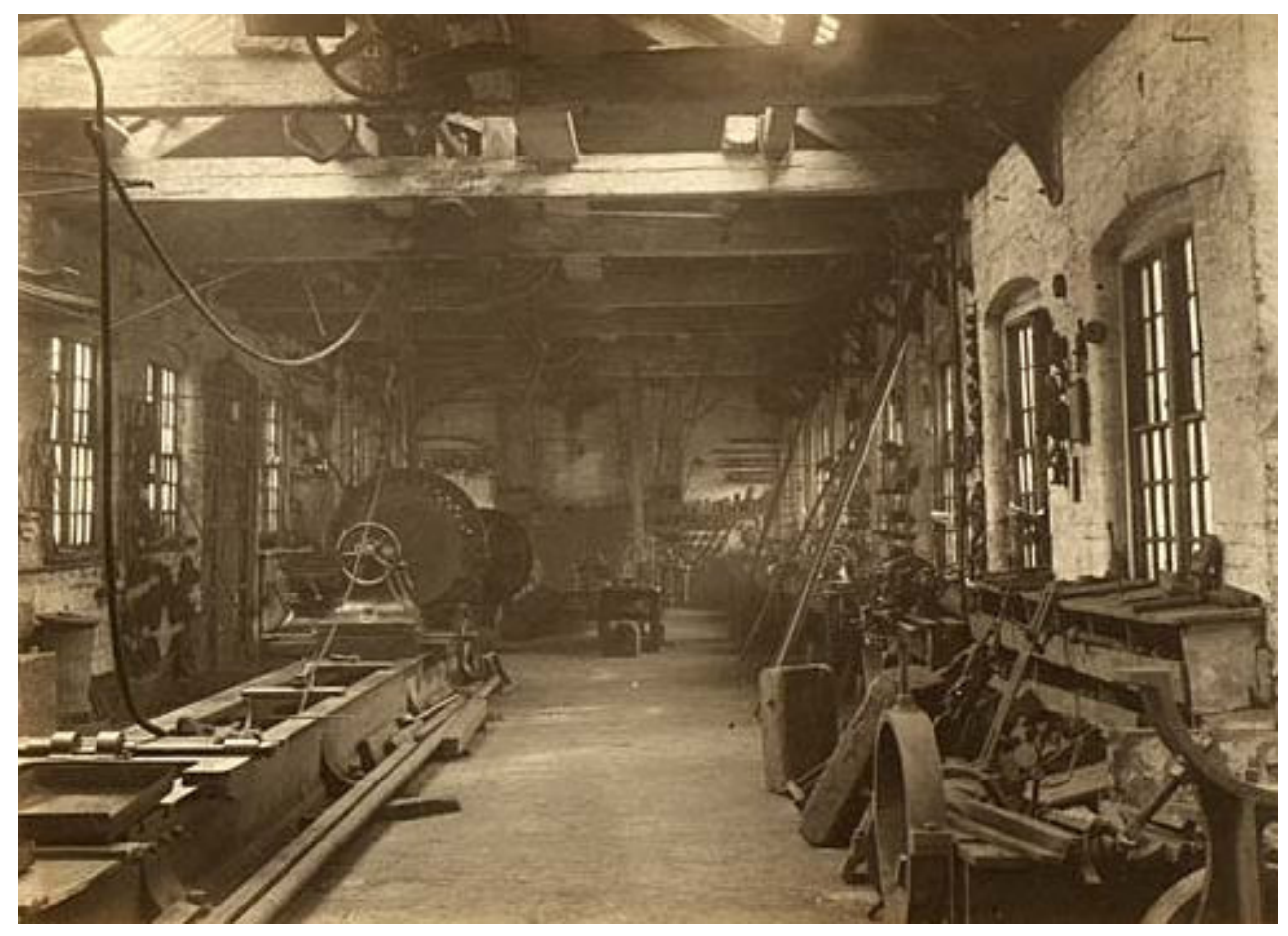

Figura 49. Soho Foundry: Fotografía tomada en 1895 del taller de máquinas, correspondiente a la colección Boulton \& Watt, de los Archivos de Soho, de Birmingham City Archives (www.search.digitalhandsworth.org.uk.engineresourcedefault).

En la Figura 49 se aprecian las cerchas de madera que apoyan de lado a lado sobre los muros de carga, en los que se disponen de grandes ventanales para iluminación y ventilación. 


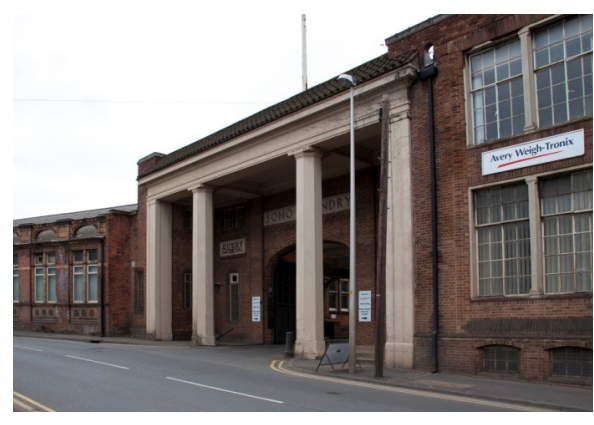

Figura 50. Soho Foundry, Birmigham. Acceso principal, con fotografía tomada de la actualidad (https://www.google.es/maps)

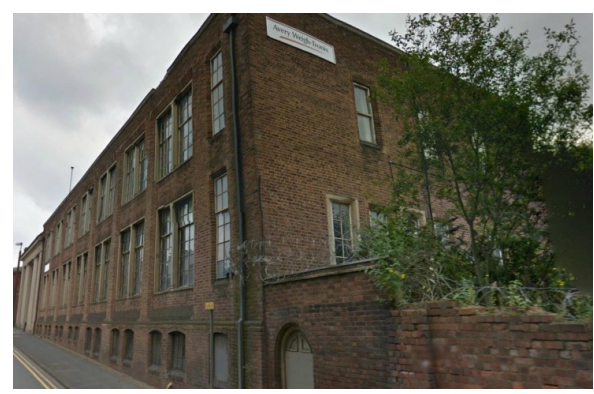

Figura 51. Soho Foundry, en la actualidad. Fachadas de cara vista, y ventanales de gran tamaño.

(https://www.google.es/maps)

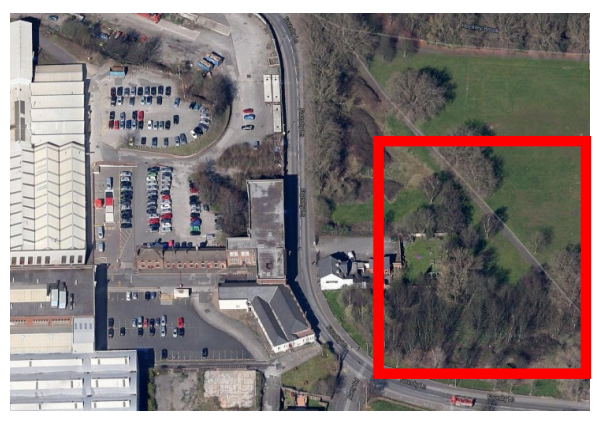

Figura 52. Soho Foundry, en la actualidad. Vista aérea del complejo.

(https://www.google.es/maps)

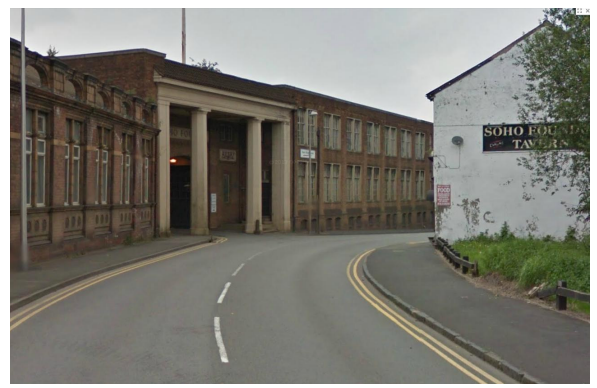

Figura 53. Soho Foundry, en la actualidad. La composición del edificio no es simétrica, con una altura o varias.

(https://www.google.es/maps)

Se trata de un conjunto también de varios edificios en los que cada uno de ellos se realizaba un trabajo diferente [Figura 50, Figura 51, Figura 52 y Figura 53].

El edificio principal no es simétrico, y seguía la alineación curva de la calle desde donde se realizaba el acceso, el cual tenía una mayor altura que la planta baja y cuyo dintel tenía unas dimensiones sobresalientes respecto los edificios adyacentes a ambos lados. Este estaba soportado por 4 grandes columnas, 
cuadradas, con capitel sobre el fuste a modo dórico, que bien recordaban la entrada a una gran mansión palaciega de la época (Crump, 2010).

La evolución constructiva respecto a la predecesora del socio Matthew Boulton es evidente, puesto que en este segundo caso, los soportes de los pórticos estaban realizados con pilastras de ladrillo de forma tal que el hueco estaba totalmente cubierto por grandes ventanales acristalados que permitían la iluminación interior de forma natural. En su interior, los pilares de fábrica tenían sección rectangular (Smiles, 1904).

\section{$\underline{\text { ESTRUCTURA }}$}

\section{SOHO MANUFACTORY}

Este edificio no destaca por ninguna novedad constructiva en su estructura, puesto que pese a sus dimensiones, y dada la fecha de su construcción, está compuesto de pilares de ladrillo macizo, muros de cerramiento con función portante y vigas de madera de no demasiada longitud.

Las cubiertas, a dos aguas, estaban realizadas con cerchas de madera.

\section{$\underline{\text { SOHO FOUNDRY }}$}

La solución constructiva es similar a su predecesora, si bien, la diferencia estriba en la utilización hierro en algunas de sus vigas. No existe documentación al respecto de la utilización de este material, por lo que pese a su innovación, no hay elementos de juicio suficientes para su valoración. 


\section{CERRAMIENTOS}

En ambos casos se trata de muros con función portante en ladrillo macizo, que resistía las cargas provenientes de las plantas superiores ${ }^{131}$.

Ventanales con distribución en serie, que proporcionaban una gran iluminación interior.

Sin embargo, Schinkel en su viaje a Gran Bretaña, plasmó una visión acerca de los edificios ingleses industriales que en muchas ocasiones no era muy positiva, e incluso los calificaba de "carentes de todo estilo" (Posener, 1972):

"The enormous masses of buildings build of red brick by the contractor without any thought of architecture make a most uncanny impression."

"Las enormes masas de los edificios, construidos en ladrillo rojo por el contratista sin idea alguna de arquitectura, causan una impresión bastante extraña."

\section{FUENTES DE ENERGÍA}

En ambos casos, la fuente de energía que usaban era el carbón para los hornos de fundición, y para la alimentación de las máquinas de vapor (Smiles, 1904).

${ }^{131}$ En el caso de la parte derecha del Soho Foundry, de única planta, directamente de la cubierta. 


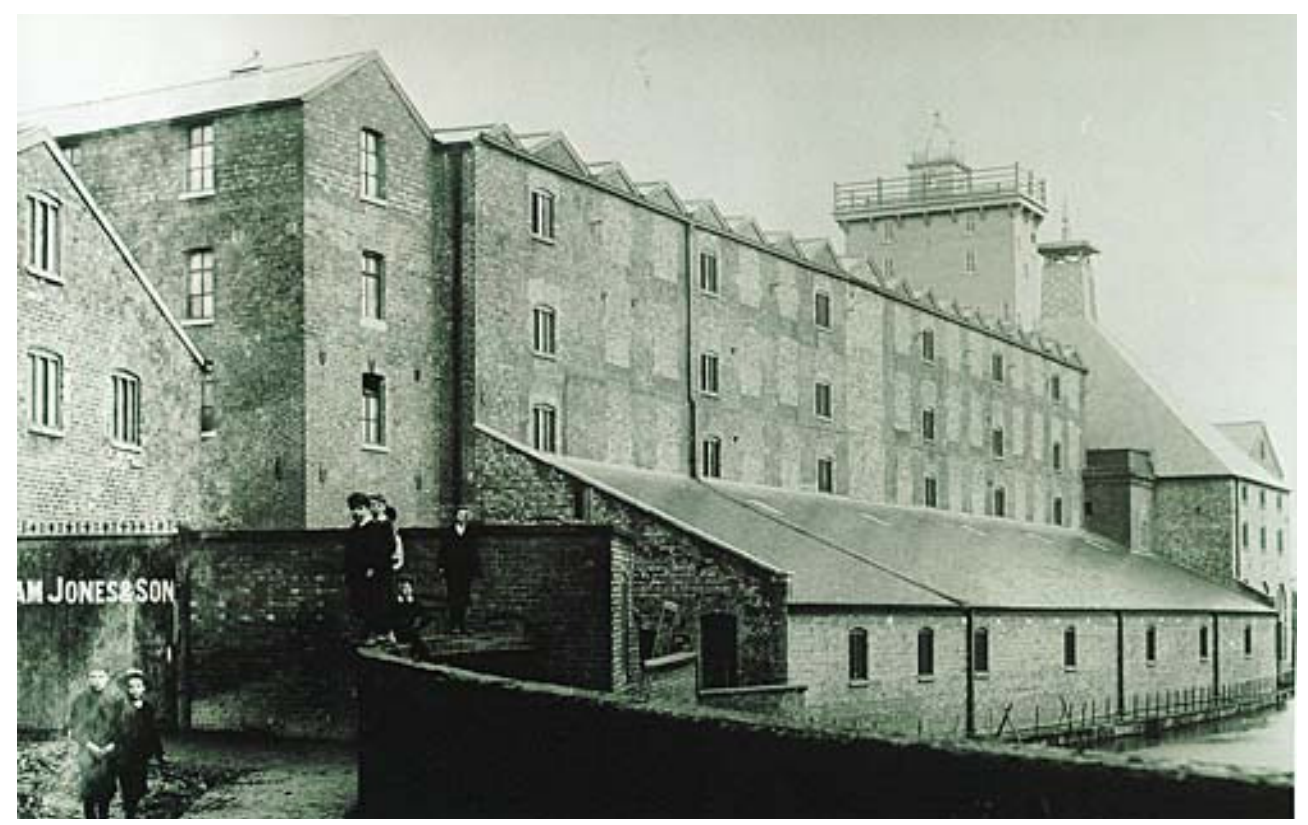

Figura 54. Ditherington Flax Mill o Marshall, Benyon and Bage, Shrewsbury, 1796, Arquitecto: Charles Bage. Fachada sureste (http://news.bbc.co.uk/local/shropshire).

El edificio Ditherington Flax Mill, localizado a las afueras del norte de Shrewsbury, en el condado de Shropshire, fue construido en 1796 por el arquitecto inglés Charles Bage ${ }^{132}$. Está considerado como icono de la revolución industrial inglesa, entre otros motivos por ser el primer edificio completamente construido con estructura metálica de hierro fundido, a excepción de la fachada que todavía continua siendo portante (en inglés cast iron frame) (Strike, 2004) [Figura 54 y Figura 55].

\footnotetext{
${ }^{132}$ Charles Woolley Bage (1751 - 1822), arquitecto inglés nacido en Derby, Derbyshire.
} 


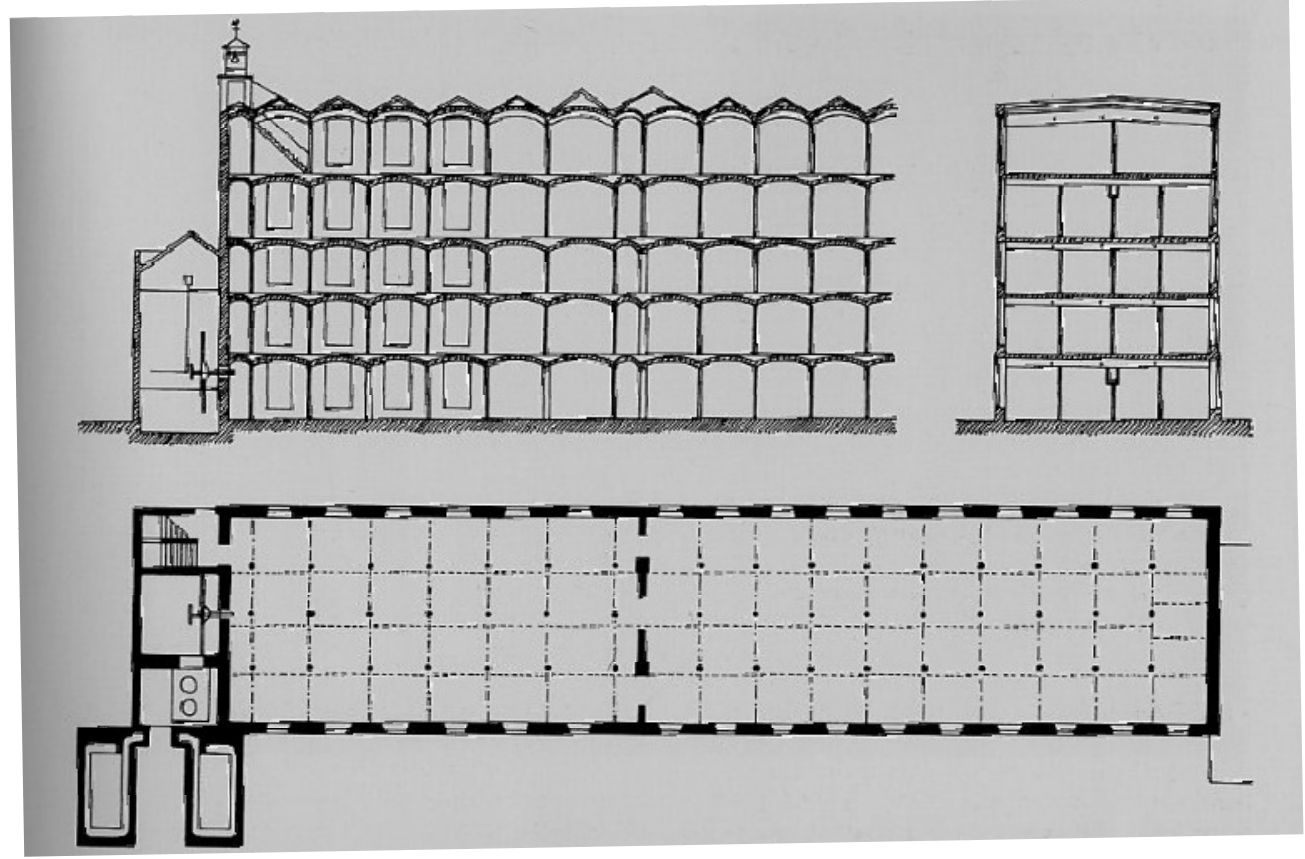

Figura 55. Sección longitudinal y planta baja del Ditherington Flax Mill (http://quod.lib.umich.edu/cgi).

Durante el siglo XVIII, Shrewsbury era un importante centro comercial de lana, que fabricaba y vendía para mercados del norte del país. La mecanización ${ }^{133}$ en la industria y los negocios textiles se extendían en la región de los West Midlands, donde la producción de lino iba en aumento, y gracias también a la máquina de Arkwright (Darley, 2010).

La sociedad de John Marshall con los hermanos Benyon surgió con la construcción de esta manufactura ${ }^{134}$. Su localización era estratégica: cerca del río Severn, con

133 El Water Frame de Richard Arkwright fue patentado en 1769 en el condado de Derbyshire, cercano a los West Midlands.

${ }^{134}$ Más tarde y a partir de este molino, los hermanos Thomas y Benjamin Benyon, y John Marshall, conformaron una nueva sociedad para la construcción de otra manufactura de lino en Leeds, la 
una gran capacidad hidráulica ${ }^{135}$ en un camino de paso entre Shrewsbury y Whitchurch, que aparte de ser un gran centro comercial era cercano a la zona productora de materia prima para el tejido de lino ${ }^{136}$ [Figura 56].

El Ditherington Flax Mill se estima que fue también de las primeras fábricas pensadas para la instalación del vapor como fuente de energía mecánica para su maquinaria. Este mill fue construido en un periodo en el que ocurrieron muchos cambios importantes en la localización y la distribución de la industria, en particular, en la construcción de factorías en los alrededores de las ciudades, gracias a la implantación de las máquinas de vapor (Smiles, 1904).

Temple Mill, muy renombrada desde el momento de su construcción (1842), y que se estudiará en un apartado posterior.

${ }^{135}$ Aunque principalmente fue accionada por máquina de vapor.

${ }^{136}$ Hay que resaltar que la revolución industrial inglesa tiene sus orígenes en la industrialización de las zonas rurales, como la de Coalbrookdale, a $20 \mathrm{~km}$ de Shrewbury, que disponía de grandes cantidades de carbón, necesario para la fundición del hierro, que se emplearía tanto para la edificación de fábricas como para la máquina de vapor. 

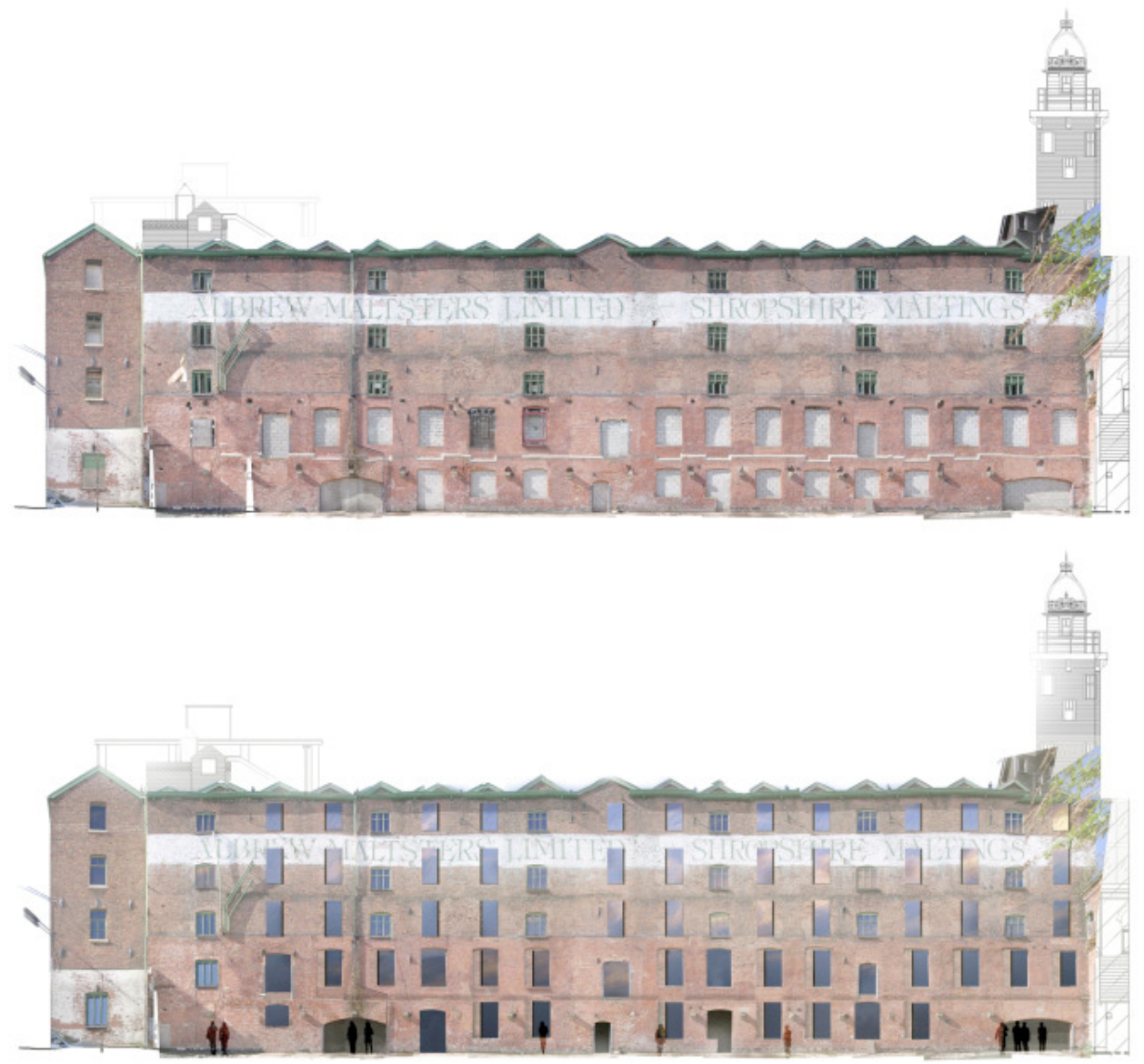

Figura 56. Fachadas principales. SE. Ditherington Flax Mill o Marshall, Benyon and Bage, Shrewsbury, 1796, Arquitecto: Charles Bage (http://www.bbc.com/news/uk-england-shropshire-24971978). 


\section{DESCRIPCIÓN DEL EDIFICIO: LOS PIONEROS DE LAS ESTRUCTURAS DE HIERRO}

Cuando en 1791, la fábrica de harina Albion Mill sufrió un incendio que la destruyó prácticamente en su totalidad, se tuvo la necesidad de reducir el riesgo de incendio que tenían los edificios compuestos de suelos y estructura de madera (Strike, 2004). Previamente a este suceso, había habido varios siniestros en Inglaterra, aunque no tan conocidos popularmente y reflejados en la bibliografía como este ${ }^{137}$.

El accidente de la fábrica Albion, en el núcleo industrial de Londres y centro mundial de todas las miradas del progreso del momento ocurrió tan solo cinco años después de su construcción, lo que motivó el aumento desorbitado de las primas de riesgo que demandaban las compañías aseguradoras, cuyas tarifas abusivas se aplicaron a todas las construcciones similares de madera. Todavía en la década de 1790 los intentos por controlar los riesgos que podía provocar un incendio eran inútiles.

Los que comenzaron inicialmente esta lucha contra el fuego fueron los propios promotores de los negocios, puesto que realmente ellos eran los primeros interesados en proteger sus edificios.

Una manera que disponían para conseguir más resistencia al fuego era mediante la albañilería en la construcción de bóvedas de entrevigado, pero aparte de ser excesivamente caras para un edificio fabril eran muy pesadas, lo que en principio dificultaba la construcción de edificios de varias plantas (Crump, 2010). Aquí se aprecia una clara relación directa entre el uso de materiales ignífugos y el tamaño del edificio ${ }^{138}$.

\footnotetext{
${ }^{137}$ Como el que ocurrió en 1781 a las primeras construcciones de Arkwright, en Derbyshire, o al teatro del Palais de París en ese mismo año.

${ }^{138}$ Algún ejemplo existe en el que para evitar este riesgo se revistieron las vigas y viguetas de madera con planchas de hierro clavadas en la parte inferior del entablado, pero no resultaron muy efectivas.
} 
La introducción gradual de la fundición como sustituto de columnas, vigas y suelos de madera se puede seguir a través de una serie de edificios fabriles construidos a partir de los primeros años de la década de 1790, como es el caso del Ditherington Mill ${ }^{139}$ (Gale, 1952). Es por ello que esta fábrica se ha incluido en este desarrollo de la arquitectura industrial.

Pero es muy importante destacar que la implantación del hierro como material estructural en los edificios fabriles, sin embargo, no generó por sí misma una nueva tipología arquitectónica. La forma del edificio ya venía marcada previamente por la de la fábrica de seda de John Lombe, en Derby, que data de 1722 aproximadamente ${ }^{140}$ \{confrontar el edificio en apartado 3.2.1 más atrás\}.

Como otros primeros mill buildings, su forma evoluciona a partir del molino, del que toma la forma a partir del accionamiento energético (rueda hidráulica), si bien, probablemente coja también de las reales fábricas la diafanidad, e incluso, el control de la producción.

\footnotetext{
139 Otro ejemplo de fábricas de varios pisos construidas en la misma época que el Ditherington Mill son las de Murray's New Mills, en Ancoats, en la ciudad de Mánchester. La primera de ellas data de entre 1798 y 1802, con una planta a nivel del suelo y 7 alturas. En este complejo, que se convirtió en el más grande de Mánchester a comienzos de su industrialización, trabajaban miles de personas, lo que podría dar una idea de su magnitud. Su apariencia exterior es robusta, con fachadas portantes de ladrillo rojo, perforadas con múltiples ventanas distribuidas de forma uniforme en todos sus edificios. Su estructura interior también estaba realizada con pilares de hierro fundido de sección maciza cruciforme, como la Ditherington, la cual estaba situada a casi $150 \mathrm{~km}$. Su planta era estrecha y alargada, por lo que gracias a la disponibilidad de terreno que ofrecían estas incipientes ciudades, no hubo problemas en su ampliación, tan solo un par de años después de su inauguración. El conjunto terminará con las fábricas Sedgewick Mill, que se estudiarán en el siguiente apartado, y la Beehive Mill, en la década de 1820, las cuales ya se comentaban como "fireproof", o resistentes al fuego.

Reseñar que también fue accionada por una pequeña máquina de vapor de la factoría de Boulton y Watt.

${ }^{140}$ Como se vio en el apartado correspondiente, cabe recordar que esta era una caja de $12 \times 33 \mathrm{~m}$, con muros rectos de albañilería, con cinco pisos de altura y con estructura de columnas, vigas y suelos de madera, diseño que se mantiene con la única distinción del material estructural.
} 
Lo que sí es cierto es que estos edificios incipientes sufren su proceso evolutivo al mecanizarse, adaptándose a la máquina de vapor, consolidando la fábrica de pisos como el espacio fabril por excelencia ${ }^{141}$. El factor de la transmisión mecánica, desde el punto de accionamiento bien hidráulico bien por vapor, también resulta fundamental a la hora de justificar la continuación del edificio en altura, que como se acaba de decir, venía construyéndose desde hacía más de siete décadas.

En la construcción pues de la fábrica de lino de Shrewsbury de Benyon, Marshall \& Bage ${ }^{142}$, la fundición no solo se usó para las columnas, sino también para las vigas esbeltas que sostenían las bóvedas de ladrillo revoltón que constituían el forjado.

Sus dimensiones interiores alcanzaban los $53 \mathrm{~m}$ de largo $\times 11$ de ancho ${ }^{143}$, con 4 vanos, sin muros de carga interiores, y con una ligereza y diafanidad poco habitual a finales del siglo XVIII. Las luces conseguidas con sus vigas alcanzaban los 2,65 m, con un perfil ligeramente ensanchado en la parte inferior para ofrecer apoyo a esas bóvedas de ladrillo que configuraban el forjado. Todavía no se ha abandonado la estructura muraria exterior, por lo que la iluminación natural sigue sin poder entrar dentro del edificio en grandes cantidades (Strike, 2004) [Figura 55].

Con su diseño consiguió de alguna manera también superar el problema del riesgo de incendio, debido a las atmósferas potencialmente explosivas por el alto contenido de polvo en suspensión procedente de las fibras del lino y las llamas de

\footnotetext{
${ }^{141}$ Como se ve con el estudio de sucesivas fábricas, el mill building se adapta a la aparición de nuevas tecnologías, como la electricidad para el accionamiento de la maquinaria, o a los nuevos materiales, liberando la fachada de su función estructural y creando la fábrica diáfana bien iluminada. Posteriormente evoluciona con el hormigón a fábricas mucho más grandes, gracias a las oportunidades que ofrece este material, junto al acero laminado, como se irá viendo a lo largo de todo el recorrido de este material.

${ }^{142}$ Charles Bage, como arquitecto, tuvo tanto interés en la utilización del hierro de fundición, que hasta incluso las ventanas de la fábrica las hizo de este material.

${ }^{143}$ Que formaban una caja de $55 \times 12$ m de cerramiento de fábrica.
} 
las velas que iluminaban esos espacios. Con ello adquirió una gran ventaja respecto a sus precedentes factorías textiles.

\section{EDIFICIOS DEL COMPLEJO INDUSTRIAL}

Este complejo fabril estaba compuesto por varios edificios:

- Edificio principal (en inglés, main mill), ya referido anteriormente [Figura 54, Figura 55, Figura 56 y Figura 57].

- Edificio de tinte y secado del textil.

- Escuela o edificio para el aprendizaje (en inglés, apprentice house).

- Preparación del lino y de la materia prima (en inglés, cross mill) y,

- Almacén (en inglés, warehouse).

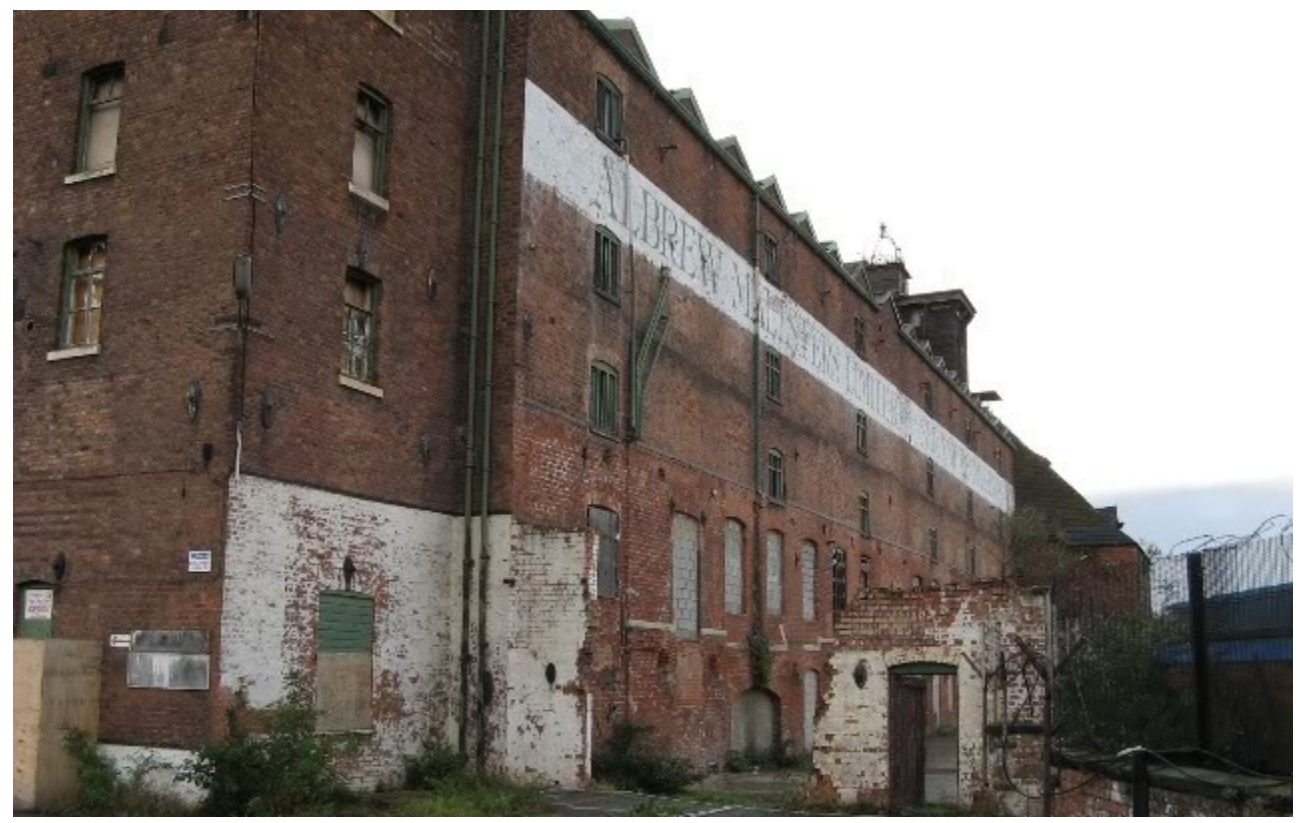

Figura 57. Edificio principal. En la actualidad en restauración (https://www.google.es/maps). 
1. Main mill (“mill” principal) [Figura 57]:

El edificio principal tiene 5 alturas, compuesto de 18 crujías, de 4 vanos cada una [Figura 55], con forjados de bóvedas de ladrillo apoyando sobre vigas y soportes de hierro fundido de sección cruciforme [Figura 58, Figura 59, Figura 62], con cubiertas mediante cerchas [Figura 60 y Figura 61]. Posteriormente se amplió tanto en su extremo norte como en el sur con una crujía adicional, conformando unos espacios suficientes para ubicar la maquinaria.

A la izquierda del plano reflejado en la Figura 55 quedaba instalada la máquina de vapor. Por su parte, se aprecia claramente como apoyan las bóvedas de ladrillo sobre los pilares de hierro fundido. Constatar además la relación entre la altura de los forjados y la distancia entre pilares, lo que da una idea de la luz alcanzada por las vigas.

La distribución de las ventanas en cada planta sigue una disposición regular, con 16 huecos, algunos de los cuales fueron tapiados o vieron reducida su superficie de abertura, ya que así era requerido en su posterior uso como maltería. Este cambio se produjo en 1886 después de su venta, y por lo que podría ser más reconocido en la actualidad.

La hilera central de pilares de la planta baja, la tercera y la cuarta tenían un detalle en su parte superior para disponer los ejes de transmisión de la maquinaria, ubicada en la extensión realizada al edificio en su parte norte y sur. 


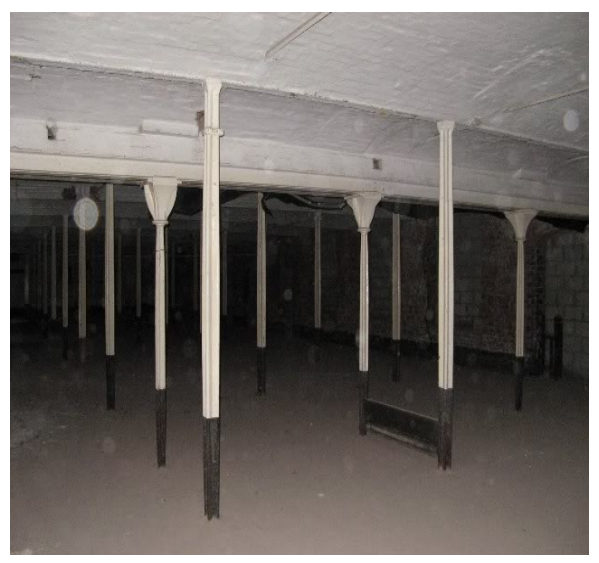

Figura 58. Vista interior con sus vigas y soportes de fundición.

(http://www.28dayslater.co.uk/forums/industrialsites/3632-ditherington-flax-mill-shrewsbury.html).

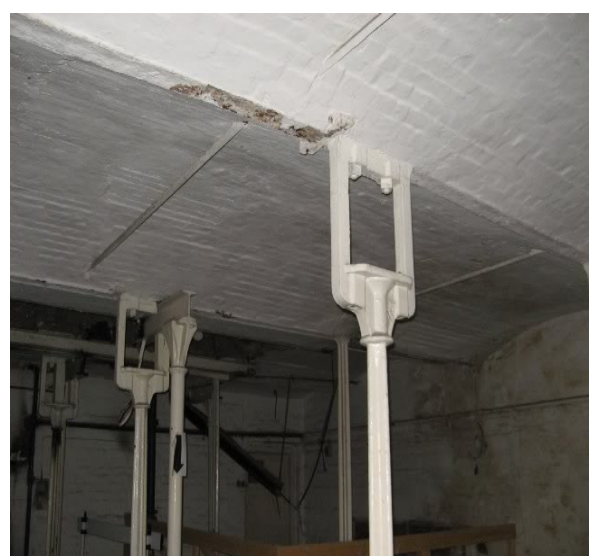

Figura 59. Vista interior con sus vigas de fundición, con el detalle de la cabeza de las columnas del primer piso para alojar los ejes de transmisión (http://www.shrewsburylocalhistory.org.uk/ bage.htm).

En la Figura 58 y Figura 59 se aprecian las tres hileras de columnas de sección cruciforme conformando cuatro vanos, así como los muros exteriores de carga, de gran espesor para poder soportar todo el peso del edificio. En la parte central se pueden ver también los huecos en las cabezas de los pilares para alojar el eje de transmisión longitudinal para el movimiento de la maquinaria. 


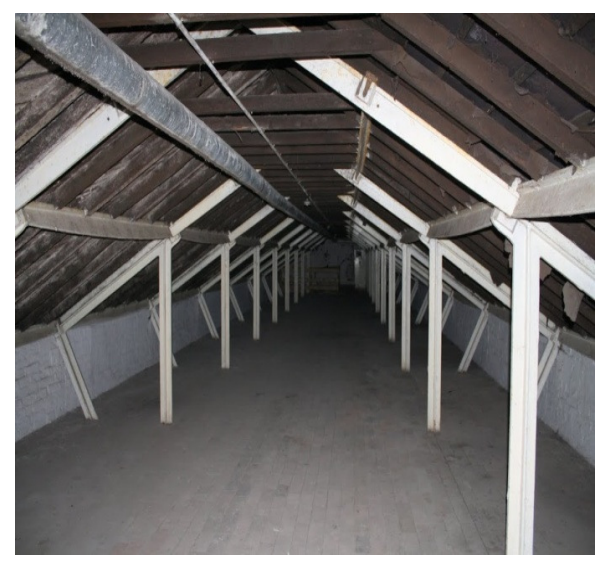

Figura 60. Vista interior de la cubierta, hasta la que llegaban los pilares metálicos de sección cruciforme.

(http://www.28dayslater.co.uk/forums/ industrial-sites/3632-ditherington-flax-millshrewsbury.html)

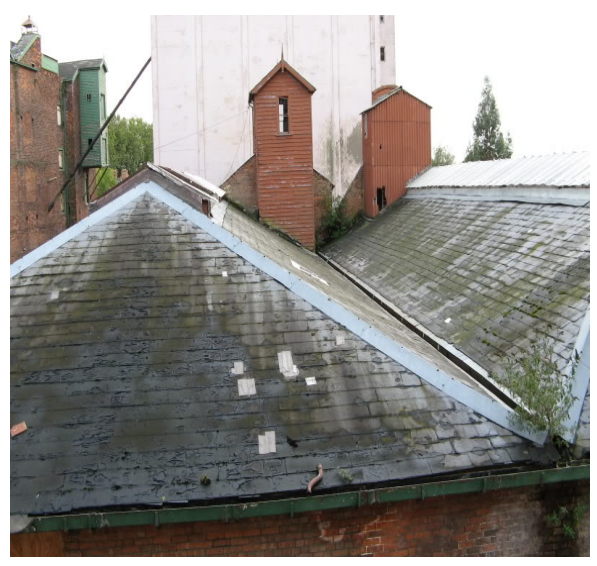

Figura 61. Cubiertas.

(http://www.stoneroof.org.uk/historic/

Historic_Roofs/Ditherington_Flax_Mill.html).

La cubierta, aunque de altura no es excesiva, se le asignó un uso para el aprendizaje de los niños que durante el día trabajaban en la fábrica [Figura 60 y Figura 61].

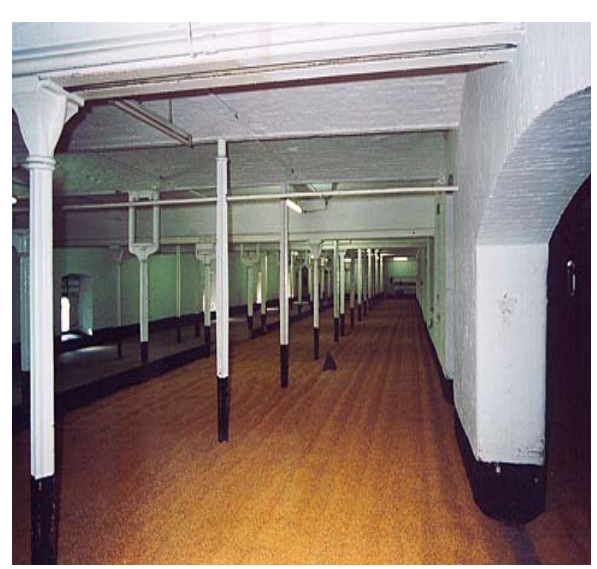

$156 / 525$
Figura 62. Vista interior.

(http://www.search.revolutionaryplayers.org.uk/ engine/resource) 
En la vista interior de la Figura 62 se aprecia la diafanidad conseguida con las tres hileras de pilares interiores, valor estimable para el alojamiento de la maquinaria textil, generalmente de gran tamaño. En esta figura se aprecia también el grosor de los muros de carga donde apoyaban las vigas de todos los forjados.

2. Cross mill:

Inicialmente era el único del conjunto de edificios que conformaban el complejo textil de producción de lino con vigas de madera. Estaba dedicado a la preparación de la materia prima para la producción del hilado. Este edificio fue reconstruido parcialmente después de un incendio sufrido en 1811, razón por la cual el mismo arquitecto Bage se encargó de rehacerlo en hierro.

Tenía planta rectangular, también 5 alturas, con 11 ventanas en la fachada de cada una ${ }^{144}$.

Sus cerramientos exteriores eran también de fábrica de ladrillo rojo y su cubierta tenía una inclinación sur, también con vigas de hierro fundido.

3. Warehouse o almacén:

Sus cerramientos eran de ladrillo con cubierta inclinada de pizarra galesa (Darley, 2010). La estructura también era de hierro, con 4 plantas que se componían de 9 crujías, con ventanas distribuidas homogéneamente, cuyas dimensiones fueron también reducidas posteriormente debido a su reconversión en maltería.

Por su parte, tenía tres hileras de pilares de hierro fundido que soportaban los forjados del edificio, y en cuanto a la estructura de la cubierta, también era de hierro fundido.

\footnotetext{
${ }^{144}$ Las aberturas al norte y al sur fueron tapiadas o parcialmente reducidas en tamaño al cambiar el
} uso inicial del edificio a fabricación de malta. 
Se le considera el tercer edificio más antiguo construido con hierro, y el segundo del complejo, después del edificio principal ${ }^{145}$.

Este edificio albergaba principalmente niños y mujeres que trabajan en la manufactura, como era habitual al principio del siglo XIX.

Pese a que no aumentó el número de alturas de las fábricas textiles respecto a sus predecesoras, el avance de los edificios hacia la condición de a prueba de incendios o fire proof, cambió para siempre la forma en que fueron diseñados y construidos, al haber logrado una mayor flexibilidad constructiva que con el uso de la madera, y una mayor capacidad estructural al estar protegida su estructura contra el fuego ${ }^{146}$.

\section{$\underline{\text { ESTRUCTURA }}$}

Previamente a la construcción del Ditherington Mill, ya se habían utilizado los pilares de hierro (Masson Mill de Arkwright, de 1786) y los techos abovedados de ladrillo soportados con vigas de madera, si bien este edificio está considerado como el primero en utilizar en su totalidad vigas de hierro fundido.

Por lo que respecta a su diseño novedoso, el arquitecto Charles Bage buscó consejo en otros industriales con más experiencia, como William Strutt de Derby (Darley, 2010). Además, estaba totalmente al día de los desarrollos tecnológicos que se estaban produciendo en la arquitectura y la ingeniería de los West Midlands, así como de las técnicas de construcción en hierro que se estaban extendiendo de forma muy rápida en la década de 1790 [Figura 63].

\footnotetext{
${ }^{145}$ También tenía otro cobertizo anexo que tenía un uso de almacén.

${ }^{146}$ Al haberse producido este avance mayormente en las factorías textiles, como el caso que se ocupa, se perciben las fábricas en altura de este sector como icono tipológico y símbolo de la revolución industrial.
} 
Los soportes de hierro fundido con sección maciza cruciforme ya fueron empleados en una fábrica de los Strutt en Derby (cerca de Belper), donde las retículas que se alcanzaban eran de 2,74 metros, mientras que en la Ditherington Flax Mill de Shrewbury, eran de 2,74×3,30 m [Figura 55]. Este tipo de soportes se convertirán en los habituales para la tecnología de fundición $\mathrm{n}^{147}$, soportando las vigas de sección tipo $Y$ invertida donde apoyarán las bóvedas de ladrillo fire proof.

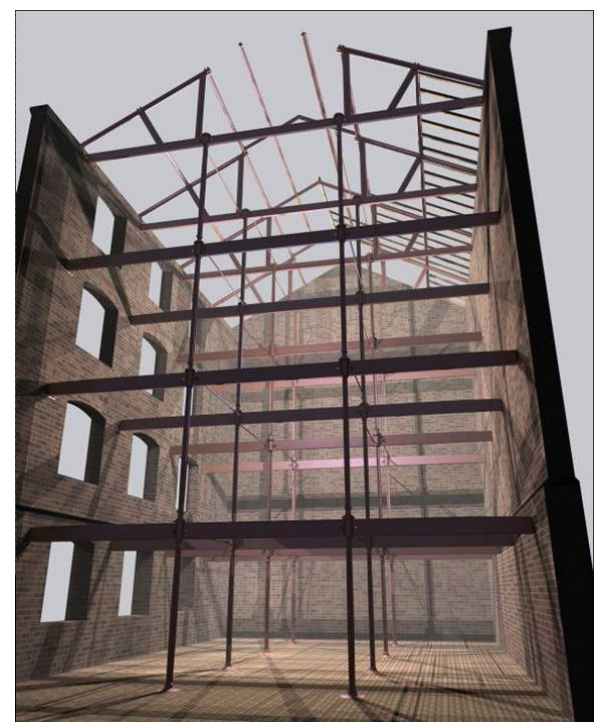

Figura 63. Detalles de la estructura original de la fábrica.

(http://8late.wordpress.com/2012/06/10/regenerat ion-for-the-fun-of-it/)

\section{CERRAMIENTOS}

Mayoritariamente, los diversos edificios que componían el complejo fabril estaban realizados con cerramientos de ladrillo de color rojizo y las cubiertas de pizarra, como se ha señalado con anterioridad.

\footnotetext{
${ }^{147}$ A pesar de esto, como se verá, en la fábrica de Salford, de la firma Phillips, Wood \& Lee (1799, 3
} años después) ya se moldearon columnas con forma circular hueca. 
Esta fábrica tenía alrededor de un $25 \%$ de superficie acristalada en su fachada principal, del mismo orden que sus antecesoras, como la Albion Mill o los primeros mills de Arkwright. Como dato comparativo, posteriormente, la fábrica de Stanley, en Stonehouse, de 1813, no llega a 20 años después, contaba ya con el $40 \%$ [Figura 64 y Figura $65^{148}$ ]. Cuando la estructura de hierro acabó con la necesidad de que la envolvente exterior fuese totalmente portante, se aprovecharon totalmente las posibilidades para la entrada de luz de las grandes superficies acristaladas ${ }^{149}$.

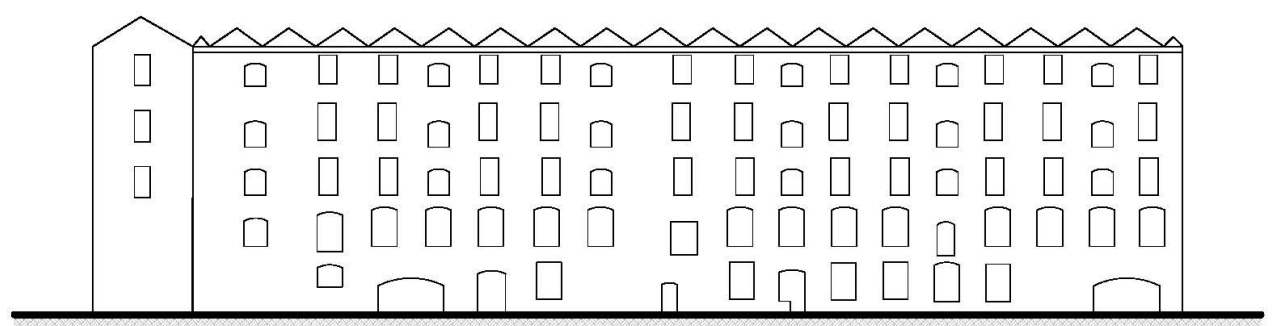

Figura 64. Alzados de la planta actual (S/E).

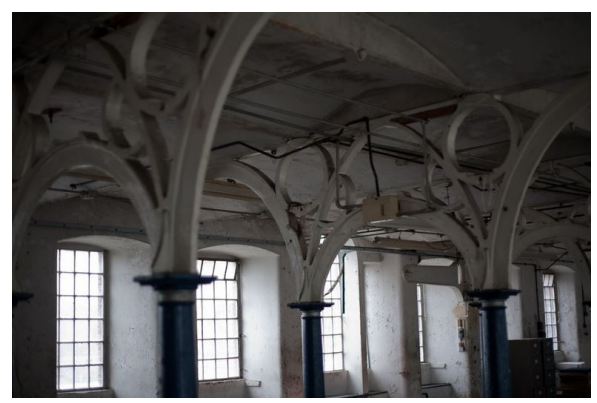

Figura 65. Stanley Mill, Stonehouse (Inglaterra), 1813.

(http://www.whateversleft.co.uk/industrial/stanleymill-king-stanley).

\footnotetext{
${ }^{148}$ En la Figura 65 se aprecian los detalles en las cabezas de pilares de la Stanley Mill, también de hierro fundido de sección cruciforme, los forjados en bóvedas de ladrillo apoyando sobre vigas metálicas, y las ventanas con jambas en cuña para mejorar el paso de iluminación natural.

${ }^{149}$ Las estructuras de hierro tuvieron un efecto muy directo sobre el aspecto externo de los edificios. Entre otros, el más interesante, por su influencia más directa, resultó ser el aumento de la superficie de ventana en fachadas, acristalada, que proporcionó una mayor posibilidad de aprovechamiento de la iluminación natural.
} 


\section{FUENTES DE ENERGÍA}

En general, la arquitectura de los "mill" textiles estaba fuertemente influida por el tipo de accionamiento mecánico utilizado y por la forma de transmisión a la maquinaria, así como posteriormente por la implantación de las máquinas de vapor. Los "mills" que se construían exclusivamente para la mecanización textil a finales del siglo XVIII eran pioneros en la instalación de estas últimas, siendo el Ditherington Flax Mill uno de los ejemplos más antiguos todavía existente al que se le instaló una máquina de vapor (Smiles, 1904) [Figura 66 y Figura 67].
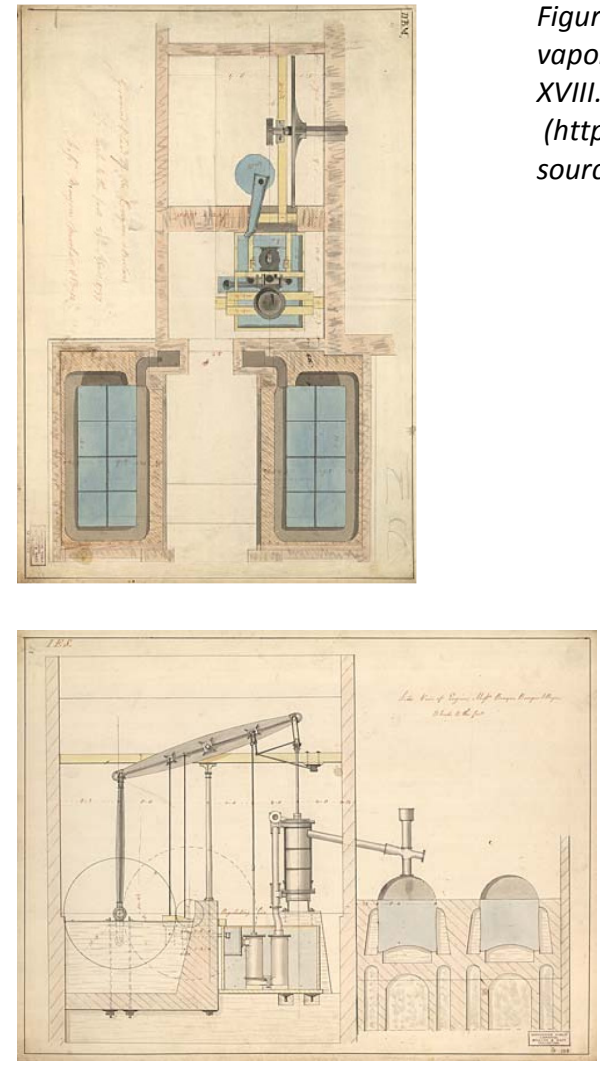
XVIII.

Figura 66. Detalles de la transmisión de las máquinas de vapor y de calderas en la Ditherington Mill. Finales del siglo

(http://www.search.revolutionaryplayers.org.uk/engine/re source/exhibition/standard/child.asp?)

Figura 67. Detalles del funcionamiento de las máquinas de vapor y de su transmisión a las plantas para el accionamiento de las máquinas de hilar el lino.

(http://www.search.revolutionaryplayers.org.uk/en gine/resource/exhibition/standard/child.asp?) 
En febrero de 1797 se le compró una máquina de vapor a la Boulton \& Watt, la cual fue trasladada desde Birmingham por el río Severn y el canal, vía Stourport. Esta máquina accionaría toda la maquinaria de la fábrica (Darley, 2010) ${ }^{150}$.

\section{DATOS CARACTERÍSTICOS}

- Los principales molinos de finales del siglo XVIII ya empezaron a considerarse resistentes al fuego, "fireproof", pero fue en el siglo XIX el de la gran evolución de las estructuras, desde los suelos de madera resistentes al fuego de la década de 1790 hasta el de la tipología de construcción con vigas de hierro y suelos de ladrillo del siglo XIX, todo ello pasando por las estructuras y las teorías de Fairbairn, como se verá en el capítulo siguiente \{confrontar el capítulo de factores en apartado 3.3 más adelante\}.

- Hasta la década de 1790, en la que fue construido el Ditherington Flax Mill, no se empezó a considerar al hierro como elemento estructural en la construcción. Se toma como referencia esos años porque ocurrieron dos acontecimientos importantes: uno fue la construcción del Coalbrookdale (Crump, 2010), conocido precisamente como el Ironbridge, de 1777, y la fábrica de harina Albion, de Londres, de 1791, en la que debido al incendio sufrido, impulsó hacia una mayor aplicación de la fundición para conseguir construcciones resistentes al fuego. El puente de hierro sobre el río Severn, en Coalbrookdale, representa un avance considerable en el uso estructural de la fundición.

- Thomas y Benjamin Benyon, junto con Charles Bage, después de la disolución de la sociedad con John Marshall, construyeron en 1804 otro "mill" en Castlefields, Shrewsbury. Se trataba de un edificio iluminado con

\footnotetext{
${ }^{150}$ Como datos representativos, en 1799 se instaló una pequeña máquina de vapor en un lado del
} edificio, en 1811 otra, y más tarde se reemplazó la primera por una más potente. 
luz de gas, también proporcionado por la empresa de Boulton \& Watt, tal y como se empezaban a hacer otras fábricas de principios del siglo $X I X^{151}$

- A mediados del siglo XX, el Ditherington Mill fue uno de los primeros en ser reconocido como de importancia histórica internacional, símbolo de la arqueología industrial moderna ${ }^{152}$. Su significado internacional ha estado ampliamente reconocido, y en general, se está de acuerdo en afirmar que fue el primer paso en el largo y complicado desarrollo de las estructuras de hierro y acero en los edificios.

- En el libro de viajes del arquitecto Karl Friederic Schinkel (Polsener, 1972), destaca uno de los realizados a Gran Bretaña junto con el ministro prusiano de comercio, B. C. W von Beuth, en 1826, 30 años después de la construcción de esta fábrica, en la que ambos mostraron mucho interés por los sistemas constructivos utilizados en esos primeros edificios fabriles, así como en las fábricas de algodón de Manchester. El político se llevó esas experiencias a Alemania, donde su posición influyente le facilitó publicar los conocimientos que había adquirido (Strike, 2004).

- Un periódico local elogió la terminación del primer edificio del mundo que usaba el hierro fundido tanto para los soportes como para las vigas (Strike, 2004):

"La firma Benyon \& Bage [...] acaba de terminar una espaciosa fábrica de hilados de lino, que es resistente al fuego. Los materiales usados son exclusivamente el ladrillo y el hierro; los forjados tienen bovedillas, y las vigas y los pilares están hechos de hierro fundido."

\footnotetext{
${ }^{151}$ Uno de los principales negocios de Charles Bage, además de la construcción en hierro, fueron las aplicaciones del gas. Sus principales clientes fueron los "mills" textiles de Lancashire y Escocia. El Ditherington Mill también fue pronto iluminado con gas de agua en unas instalaciones anexas.

${ }^{152}$ Pertenece al listado considerado del English Heritage, institución sostenida con fondos públicos del Gobierno británico, de dicada a la catalogación, conservación y puesta en valor de los edificios más relevantes arquitectónica e históricamente del país.
} 


\subsubsection{Fábrica de hilos de Salford, o Phillips, Wood \& Lee, 1799; Boulton \& Watt. Salford (Greater Manchester, Inglaterra)}

Giedion (Giedion, 2009) concede a esta fábrica el honor de ser la primera construida completamente con estructura de hierro, pese a que no cita a la Ditherington Mill, que lo había sido prácticamente en su totalidad 3 años antes. Se da el caso de que en muchas ocasiones, diferentes autores atribuyen informaciones contradictorias acerca de edificios industriales. En este caso, Giedion se basa en que a su vez, Fairbairn atribuye en su libro de 1857 (Fairbairn, 1857) esta cualidad a la fábrica de hilos de Salford, cuyo promotor fue la firma Phillips, Wood \& Lee, construida entre 1799 y 1801. Su inclusión en este estudio se basa precisamente en este hecho histórico, convertido en hito de la arquitectura industrial [Figura 68 y Figura 69]:

"[...] el pionero de ese sistema de construcción resistente al fuego que ahora caracteriza los distritos fabriles de este país. Durante un cuarto de siglo, esta factoría fue un modelo para los edificios similares. Desde 1801 hasta 1824, hubo muy poca o ninguna variación en la forma de las vigas." 


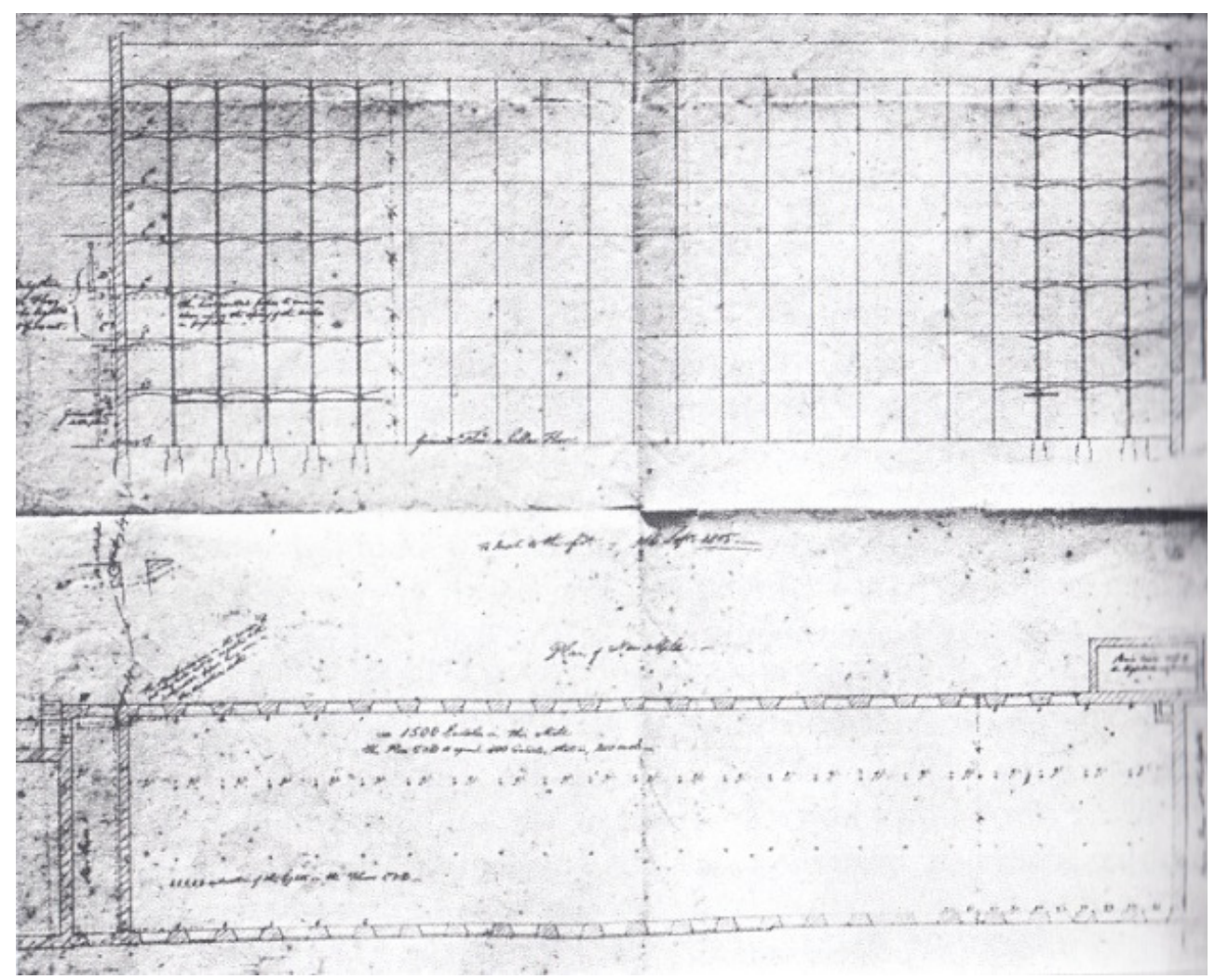

Figura 68. Boulton y Watt, planos de ejecución, Salford (Manchester), 1801 (Giedion, 1978).

En la Figura 68, se aprecian los mismos rasgos constructivos que en su predecesora, la Ditherington Flax Mill: pilares metálicos (hierro fundido), bóvedas de ladrillo apoyando en vigas metálicas, muros de carga a base de mampuestos, cimentaciones de piedra, etc, así como otros aspectos arquitectónicos como la distribución uniforme de ventanas a lo largo de las dos fachadas principales, jambas en cuña, planta alargada y estrecha, simetría, edificio anexo al principal para la máquina de vapor, etc. 

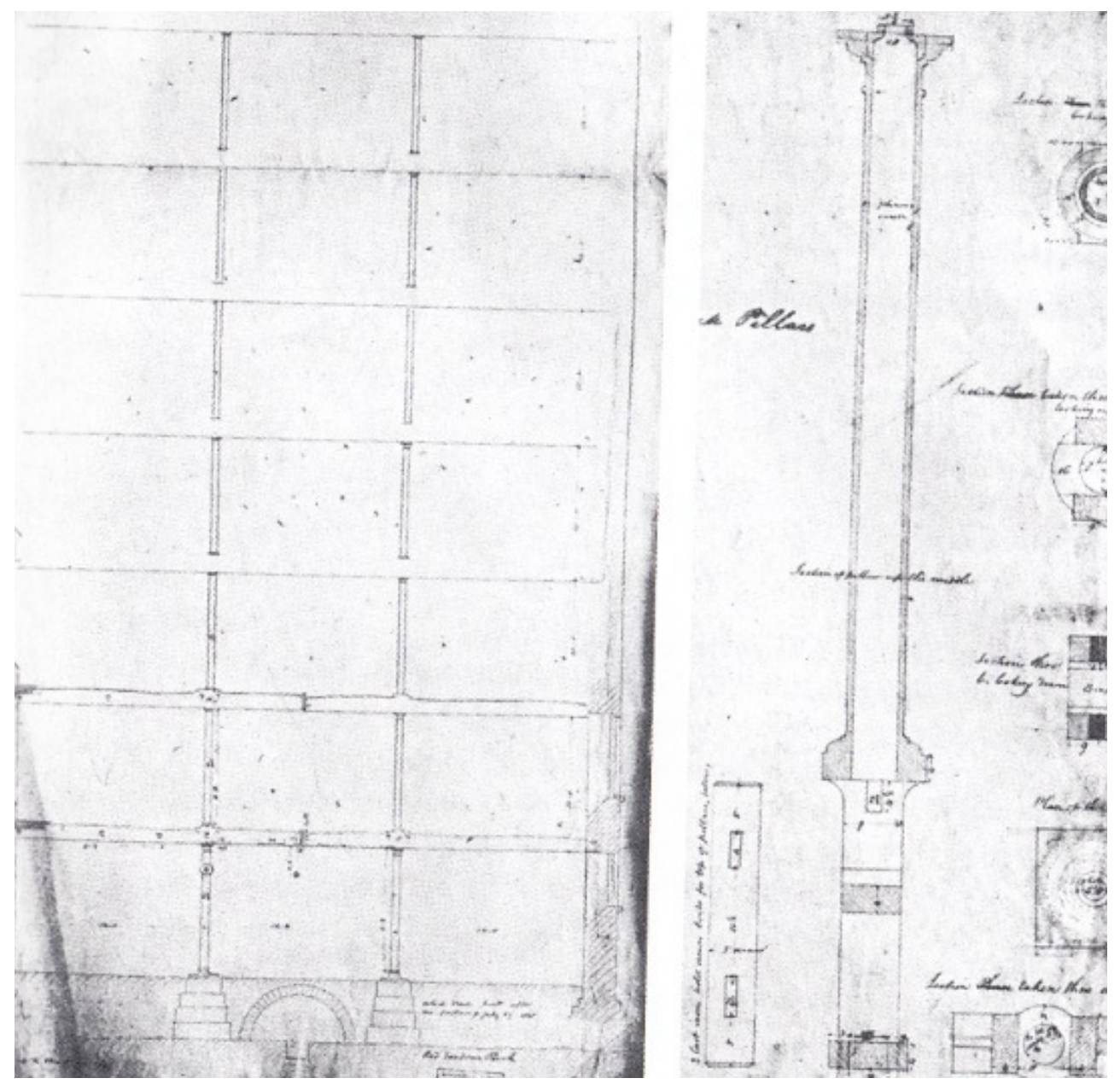

Figura 69. Planos de sección y detalles constructivos, Salford (Manchester), 1801 (Giedion, 1978).

En la Figura 69 están los planos que Boulton y Watt realizaron para la instalación de la que sería su fuente motriz: la máquina de vapor. En la sección transversal se aprecian perfectamente las vigas y pilares metálicos, por primera vez circulares huecos, gracias a su despiece, a la derecha del plano. En este edificio se entiende claramente el concepto de "mill building" textil de comienzos de la revolución 
industrial inglesa: edificio en altura con pilares metálicos, manifiestamente diáfano y construido expresamente para la concentración de la producción.

Probablemente, la razón de esta confirmación de Giedion fue la falta de información respecto a los edificios que se construían en ese momento, o que la documentación disponible no era suficientemente fiable por falta de pruebas y ensayos de los nuevos materiales: no todos los edificios se diseñaban con estructuras y materiales a los que se les había realizado prueba alguna o ensayo previo.

Según este autor, el edificio de Salford de siete pisos, con su esqueleto de fundición rodeado por muros exteriores de fábrica de albañilería, llegó a ser como de tipología "habitual en los almacenes a lo largo de todo el siglo XIX", y que también fue adoptado por algunos edificios públicos relevantes (Giedion, 1978).

En este edificio se utiliza prácticamente por primera vez la columna de hierro tubular, cuyo origen podría derivarse de la tecnología militar para la realización de cañones. En esta fue donde se moldearon las columnas con forma circular hueca, en lugar del perfil cruciforme como el utilizado en el Ditherington. Sus pilares tenían un diámetro de $165 \mathrm{~mm}$ en los dos primeros pisos de altura y de $140 \mathrm{~mm}$ en los superiores. Eso sí, pese a que esta fábrica sigue el esquema de las anteriores construcciones en madera, consiguió aumentar tanto el número de plantas como la distancia entre columnas.

Su comportamiento estructural fue perfecto, por su capacidad a compresión, si bien, su fabricación, por su ocacidad, resultó complicada, más que nada teniendo en cuenta las posibilidades tecnológicas de la época.

La garantía del correcto comportamiento de esas nuevas técnicas constructivas queda avalada por su larga vida, concediéndoles en muchas ocasiones el reconocimiento y el prestigio que merecen. Algunas edificaciones del siglo XVIII y XIX lo lograron, como el que se ocupa en este apartado, e incluso algunos autores 
lo consideran como un hito en la construcción con hierro fundido (Strike, 2004) $)^{153}$. Su construcción se convertirá en "la verificación del nuevo material y de la nueva técnica constructiva". En todo caso se podría decir que algún otro edificio anterior hubiera podido servir de "banco de pruebas" para una determinada novedad, pero en estos edificios es en los que fácilmente se puede encontrar un indicador de fiabilidad.

La fábrica de hilos de Salford, tan solo tres años posterior a la de lino de Ditherington, consiguió una luz de 4,2 m. Las vigas fueron diseñadas por la fábrica de Boulton y Watt, similares a las que utilizó Bage en aquel primer mill, pero con un mayor saliente en el ala inferior del perfil, de forma que pudieran apoyar mejor las bóvedas de ladrillo. Esta viga y las de la fábrica de Houldsworth en Glasgow, de 1802 , se calificarían como de entre las pioneras en utilizar este sistema estructura de perfil en ' $T$ ' invertida, como también se vio en el edificio del Ditherington Mill [Figura 70]:

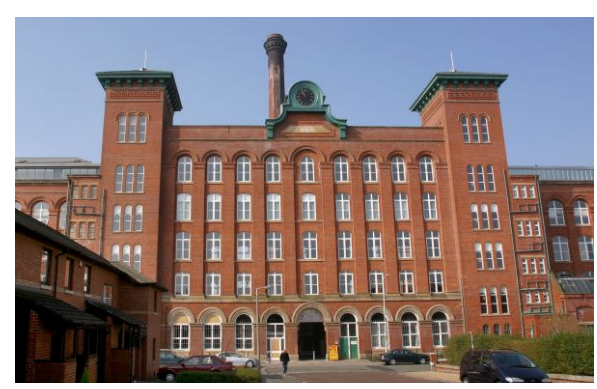

Figura 70. Houldworth, Glasgow, 1802. (http://en.wikipedia.org/wiki/Cotton_mill).

\footnotetext{
${ }^{153}$ Como del mismo modo lo fue para el vidrio, la Great Stove de Chatsworth, de entre 1836 y 1840 ,
} o el almacén naval de Sheerness, de 1858, para la construcción funcional, según este autor. 


\subsubsection{Strutt's North Mill, 1804, Belper}

Este edificio en altura de principios del siglo XIX marca un punto de inflexión con referencia a numerosos aspectos constructivos, pero es especialmente remarcable el diseño de su fachada y su estructura interior, como también lo eran otros edificios coetáneos, como el visto en el apartado anterior. La inclusión en este trabajo se debe principalmente a este hecho, así como a la utilización del hierro como material estructural y a las bóvedas de ladrillo para la formación de los forjados. Esta novedad constructiva refleja un claro desarrollo hacia el sistema de los molinos "fire proof", o a prueba de incendios, que como se ha dicho en reiteradas ocasiones sucedían con elevada frecuencia [Figura 71].

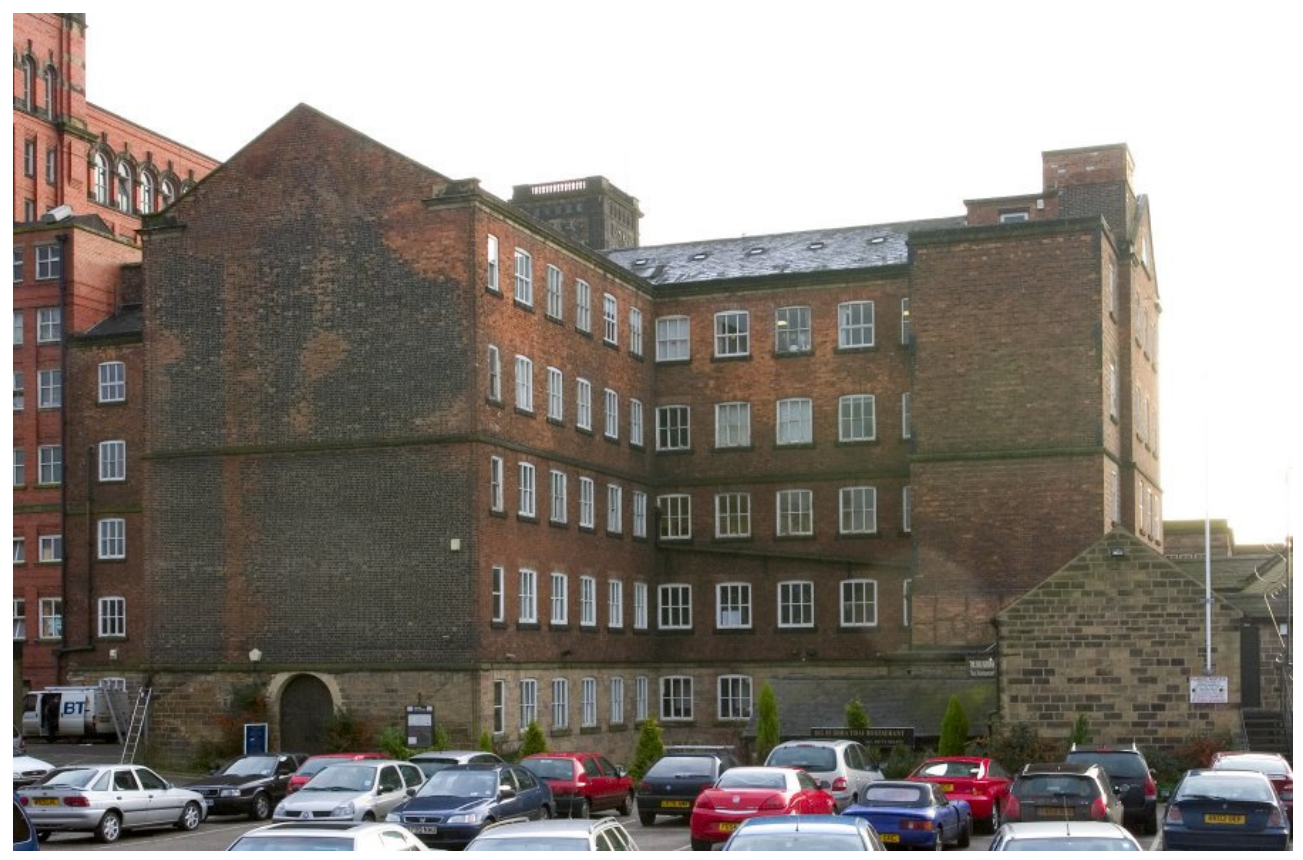

Figura 71. North Mill, 1804 (University of the West of England. Department of Architecture and the Built Environment. http://www.uwe.port.ac.uk/commercial/vic_mills/index.htm). 
Como rasgo importante, ya en su día fue descrito como "uno de los edificios más impresionantes y tecnológicamente avanzados de su tiempo", motivo por el cual aparece en una amplia bibliografía (Darley, 2010) ${ }^{154}$.

\section{LOCALIZACIÓN}

Esta fábrica textil está localizada en Belper, una pequeña ciudad del centro de Inglaterra que formaba parte del subconjunto industrial del valle del Derwent [Figura 72]. En esta zona de Derbyshire, en el condado de los East Midlands, se instalaron diversos edificios a lo largo del curso del río del mismo nombre, conformando lo que se puede considerar como uno de los primeros asentamientos industriales, muy cercano a otros que se encontraban en los condados lindantes, como el de Manchester, Yorkshire, Leicestershire o Cheshire (Watts, 2008) ${ }^{155}$.

\footnotetext{
${ }^{154}$ Además de por estar considerado como parte del patrimonio dentro del conjunto industrial del Valle del Derwent.

${ }^{155}$ Estos molinos están considerados como parte del patrimonio industrial mundial desde el año 2001, ubicados precisamente donde nació en el siglo XVIII el periodo conocido como revolución industrial, cuya base es la fábrica moderna que hoy entendemos, y que da a conocer con su nombre inglés "mill" el espacio donde se albergaba la nueva tecnología para el hilado del algodón, desarrollada, como se ha dicho anteriormente, por Richard Arkwright, y que hizo posible producir tejidos y telas en grandes cantidades de una forma constante.

Este sistema fue adoptado en todo el valle, extendiéndose de forma tal que en 1788 se contabilizaron más de 200 "mills" con la maquinaria de Arkwright en Gran Bretaña. Esta nueva tecnología promovió una organización laboral totalmente diferente, que fue exportada posteriormente al resto de Europa y a los Estados Unidos (Darley, 2010).
} 


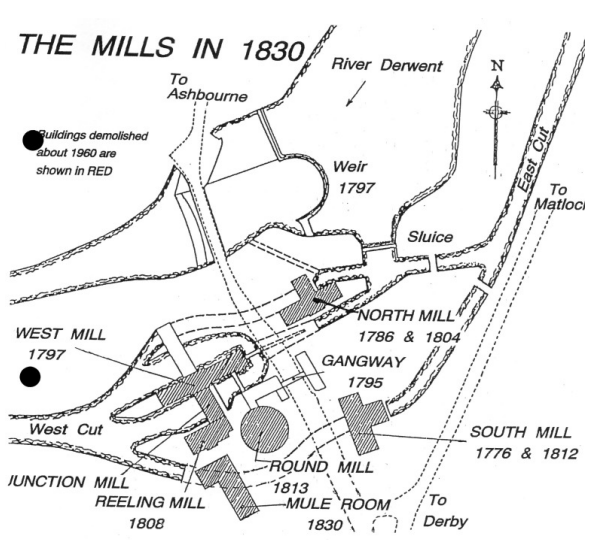

Figura 72. Los "mills" de Belper en 1830.

El North Mill es un edificio de planta baja y 4 pisos [Figura 71], con planta en forma de L, con 17 vanos en la parte principal y 6 en la otra ala ${ }^{156}$. Fue diseñado para disponer de mayor superficie donde ubicar toda la maquinaria necesaria para la producción textil, la cual crecía en número y tamaño conforme aumentaba la demanda.

Inicialmente se construyó un edificio en Belper en 1792, con estructura de vigas y soportes de madera, material tradicional por excelencia, pero que sufrió un incendio en 1803 que lo destruyó prácticamente por completo, a excepción de la planta baja que fue sobre la que unos años después, en 1804, se erigió el edificio actual. Como otras fábricas contemporáneas, respondía a una tipología de construcción voluminosa y de apariencia exterior pesada.

Aunque las propiedades mecánicas de la madera eran sobradamente conocidas por los constructores de "mills", estos mostraban reticencias a su utilización, porque los incendios se sucedían constantemente. Estos numerosos sucesos y concretamente el de la North Mill, condujo a William Strutt ${ }^{157}$, su constructor, hijo

\footnotetext{
${ }^{156}$ La construcción en altura ya era habitual en los mill textiles en el cambio de siglo.

157 William Strutt (1756 - 1830), fue un hilandero de algodón, inventor e ingeniero civil de Belper, Inglaterra.
} 
de Jedediah Strutt ${ }^{158}$, a levantar el segundo edificio con estructura en hierro fundido (Watts, 2008). De esta forma se encuadraría dentro de lo que se denominaba ya por aquel entonces como a prueba de fuego (Darley, 2010).

Hay que tener en cuenta que uno de los principales riesgos a los que se sometían los operarios y en general todas estas instalaciones, que suponían una gran inversión para los empresarios, se debía a que lo que allí se manufacturaba eran materiales y sustancias muy inflamables, como la lana, el algodón y la seda. Al mismo tiempo, se utilizaba aceite y grasas para lubricar las máquinas, que en muchas ocasiones era derramado por el suelo, que junto a las velas para alumbrar los espacios, provocaban numerosos incendios ${ }^{159}$.

\section{DESCRIPCIÓN}

Destacan sus enormes fachadas de ladrillo cara vista, y especialmente sus numerosas ventanas, de gran superficie, en las que la luz del sol entraba al entorno del trabajo, lo cual representa un cambio tipológico evolutivo ${ }^{160}$ [Figura 73].

\footnotetext{
158 Jedediah Strutt (1726 - 1797), calcetero de Belper, Inglaterra, a quien se debe el invento de la "stocking frame", o máquina de hilar calcetines.

${ }^{159}$ William Strutt, como empresario algodonero siempre preocupado por este problema, construyó poco después del primer North Mill un almacén en Milford (Derbyshire) en 1793, y otro molino en Derby en 1795, utilizando el nuevo sistema con hierro fundido para la estructura y suelos soportados mediante arcos de ladrillo y vigas de madera, aunque forradas de hierro.

Después de estos dos edificios, se construyeron varios "mills" durante los años siguientes, siguiendo la misma solución constructiva. Es muy importante señalar, que por estas fechas también, Charles Bage estaba planeando su "mill" cerca de Shrewsbury, manteniendo una comunicación constante con William Strutt.

${ }^{160} \mathrm{El}$ interés por las estructuras resistentes al fuego le fue inspirada a su constructor, entre otras cosas, por su participación en la construcción de la fábrica de lino de Shrewsbury, del arquitecto Charles Bage, tal y como se ha dicho en la descripción de este edificio descrito anteriormente. De hecho, William Strutt está considerado por muchos (Darley, 2010) el primer ingeniero que abordó directamente y de forma muy práctica el asunto de los incendios que ocurrían de forma demasiado habitual en los "mill" textiles.
} 


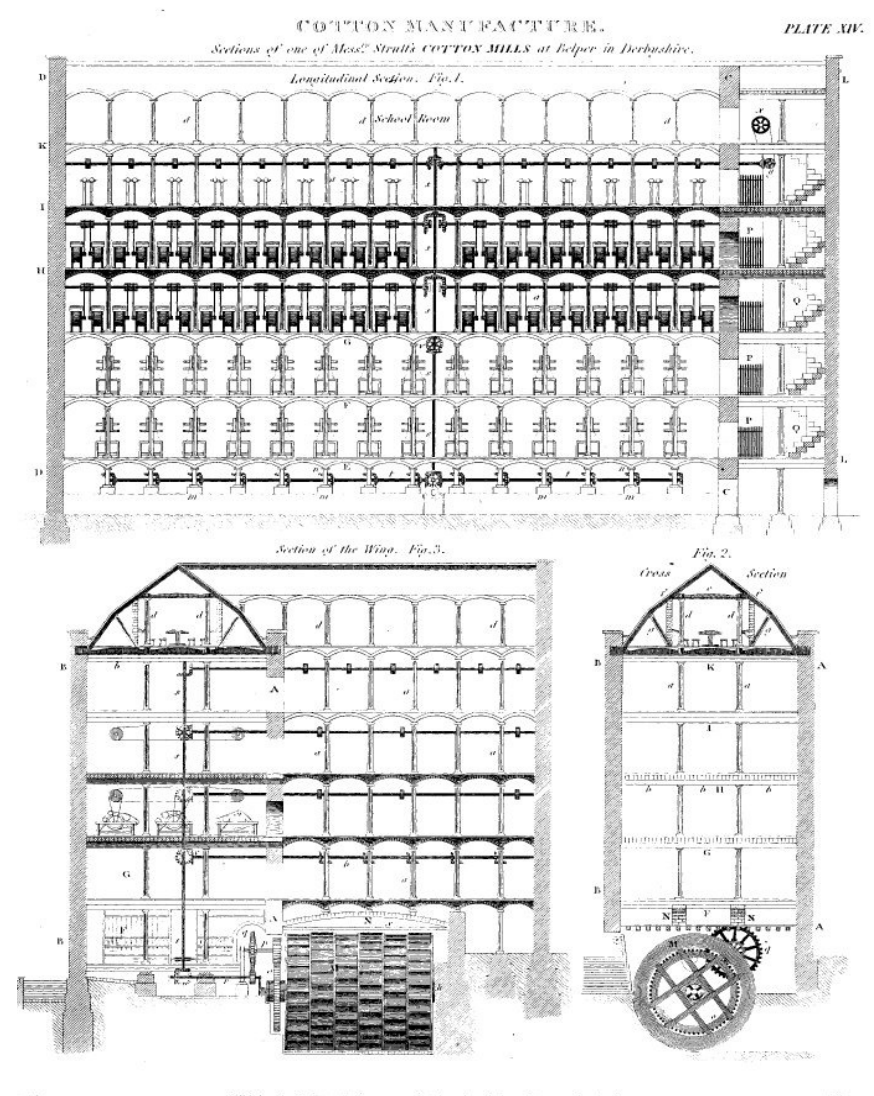

Figura 73. North Mill, secciones. Esta fotografia fue publicada por primera vez en Ree's Cyclopedia, alrededor de 1819, y muestra la disposición del molino y su sistema de transmisión. El eje de la rueda transmitía la potencia a la maquinaria por medio de un eje vertical, el cual se conectaba a los ejes horizontales de cada planta. Cada máquina se conectaba a estos mediante correas de cuero (University of the West of England. Department of Architecture and the Built Environment. http://www.uwe.port.ac.uk/commercial/vic_mills/index.htm).

Este tipo de construcciones, con gruesos muros de carga en su perímetro, llegaron a ser muy habituales en su época, a principios del siglo XIX. La estabilidad lateral 
de estas enormes estructuras, típicamente de cinco o seis alturas, fue solventada mediante muros exteriores de gran sección ${ }^{161}$ (Falconer, 1993) [Figura 74].

Además de una edificación principal existían otros talleres con otros oficios relacionados en el proceso de elaboración textil, como el ubicado transversalmente al eje longitudinal del edificio principal, de menor altura, y otro de una única planta con cubierta en diente de sierra [Figura 72] ${ }^{162}$. Destacan ahora ya las luces alcanzadas en el edificio metálico central: dos crujías de $7 \mathrm{~m}$ de ancho, y cerchas de $14 \mathrm{~m}$, aproximadamente.
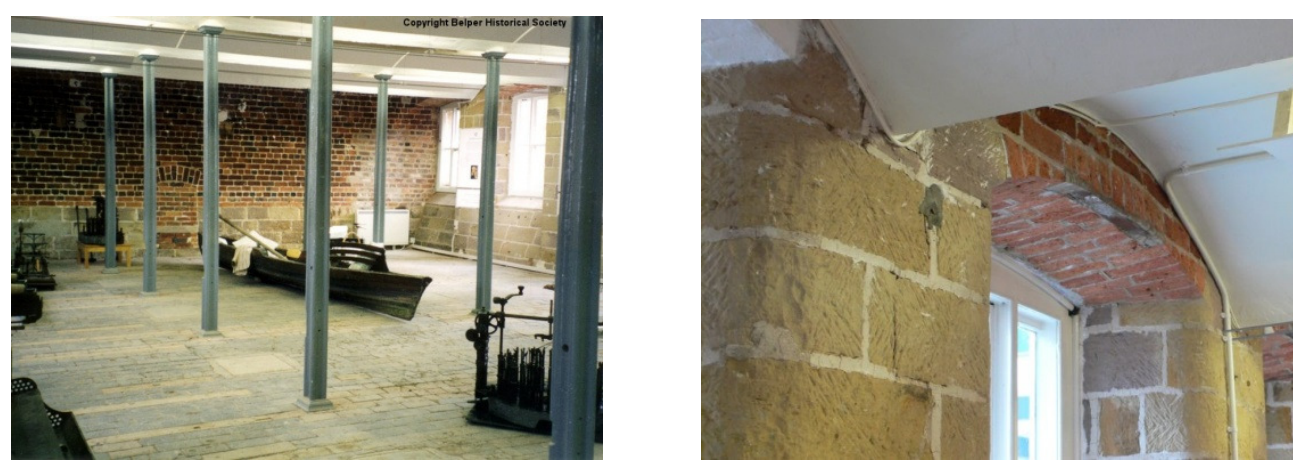

Figura 74. North Mill, 1804 (University of the West of England. Department of Architecture and the Built Environment. http://www.uwe.port.ac.uk/commercial/vic_mills/index.htm).

A la izquierda de la Figura 74 se aprecian los pilares de hierro fundido de sección maciza cruciforme, con las vigas también metálicas cruzando de lado a lado del edificio y apoyando en sus extremos sobre las pilastras, tal y como se ve en la fotografía de la derecha. Los forjados estaban construidos mediante arcos de

\footnotetext{
161 No fue hasta pesados unos años después de Shrewsbury y Belper que los edificios con estructuras de hierro con peso moderado tuvieron más rigidez gracias a los "portal bracing", o arriostramientos laterales, como se verá unos párrafos después, siguiendo la teoría de Fairbairn.

${ }^{162}$ A ello hay que añadirle el East Mill [Figura 80], un edificio gigantesco construido mucho después, en 1912, y del que después se hablará en un subapartado al final de esta sección.
} 
ladrillo que apoyaban en dichas vigas, rellenados con una especie de argamasa de cal para la formación horizontal del suelo. Para compensar el empuje de estas bóvedas, se dispuso embebido en el propio forjado hierro forjado a modo de tirantes [Figura 46 y Figura 75].

En el caso del gran arco que albergaba la rueda hidráulica se emplearon en lugar de ladrillo trozos de cazos y tiestos huecos de arcilla como material de relleno, de forma que se aligeraba el peso de dicho forjado [Figura 73 y Figura 76].

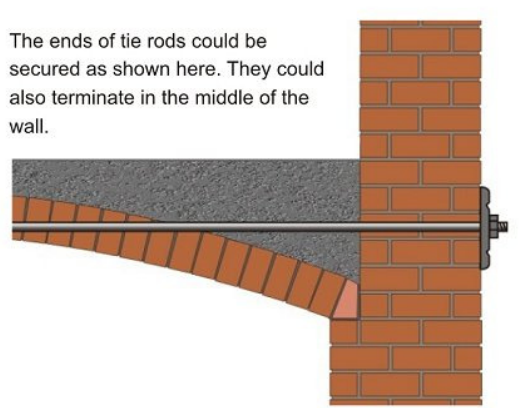

Figura 75. Aunque este forjado se corresponde con una construcción alrededor de 40 años posterior a la North Mill, sirve como detalle explicativo de la solución empleada con tirantes de hierro forjado que impedían la apertura de las bóvedas, y como se fijaban sus terminales anclados en fachada. Este sistema ya fue empleado en aquel edificio de 1804 (University of the West of England. Department of Architecture and the Built Environment).

\section{FUENTE DE ENERGÍA}

La North Mill original aplicaba la fuerza hidráulica para accionar la maquinaria textil. En los planos con secciones transversales, se muestra la construcción de unas bóvedas de descarga estructural para alojar su gran rueda hidráulica (de alrededor 5,5 m de diámetro y $7 \mathrm{~m}$ de ancho), así como el sistema de ejes de engranajes para el accionamiento de los telares, el cual consistía en un eje vertical al que se acoplaban ejes horizontales en cada planta, todo ellos de hierro forjado, y a los que finalmente se embragaban las máquinas a base de correas de piel ${ }^{163}$ [Figura 73 , Figura 76 y Figura 77]:

\footnotetext{
163 Las ruedas hidráulicas estaban hechas con un eje de hierro fundido de sección cruciforme, diseñadas en muchas ocasiones más bien empíricamente que por cálculos. Existían unas conexiones a través de diversas ruedas dentadas que hacían la relación de transmisión, variando las velocidades
} 


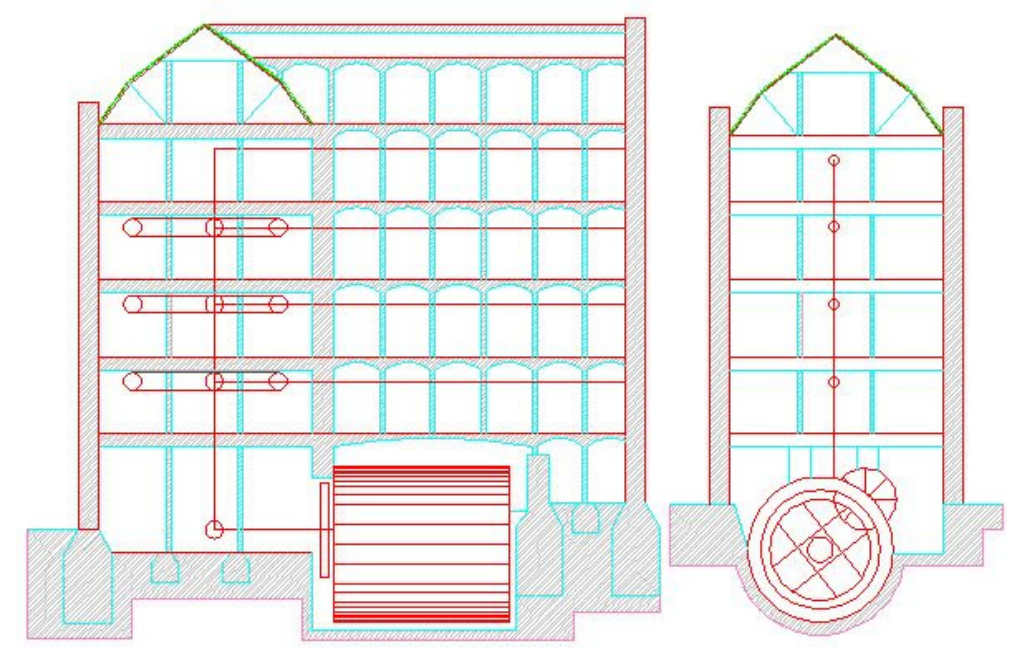

Figura 76. Secciones North Mill, S/E.

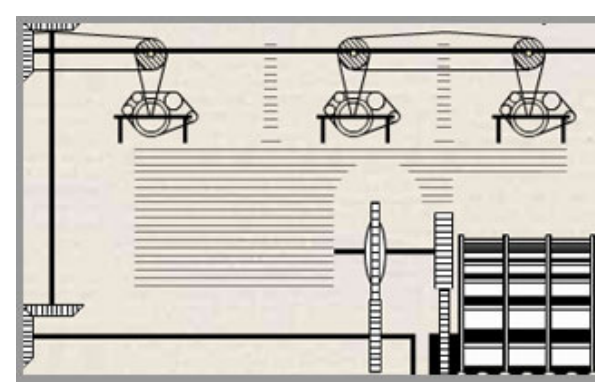

Figura 77. North Mill, detalles de las transmisiones mecánicas y sus relaciones de transmisión (University of the West of England. Department of Architecture and the Built Environment. http://www.uwe.port.ac.uk/commercial/vic_mills/i ndex.htm).

desde ruedas con grandes diámetros hasta las de pequeño diámetro, lo que era muy provechoso para la maquinaria textil, que requería de grandes velocidades. Esto es lo que se dio a llamar como "suspension wheels", de las que se instalaron 2 en la fábrica de Belper entre 1804 y 1810 (Watts, 2008).

Esta idea se debe principalmente a W. Strutt, aunque la puesta en práctica y su desarrollo se debe al ingeniero textil Thomas Hewes (1768 - 1832) (Watts, 2008). La primera rueda fue sustituida en 1823. 


\section{$\underline{\text { EAST MILL, } 1912}$}

A pesar de ser muy posterior, al North Mill se le añadió otro edificio de grandes dimensiones, que conformaría el complejo textil de Belper que se conoce en la actualidad. Su inserción en este apartado se debe a su presencia inseparable en la bibliografía consultada, y por tratarse de un edificio pionero en su sistema constructivo por la utilización del acero.

Como se aprecia en la fotografía [Figura 80] se sustituyen los espesos muros de carga envolvente de las manufacturas anteriores del siglo anterior por pilastras de menor sección. Entre ellas se disponen los ventanales cubriendo asimismo toda la altura entre forjados, de forma que la superficie para la entrada de luz natural al interior del edificio es la máxima que permite la fachada, muchísimo mayor que la de sus edificios precedentes.

Por otro lado, destaca como la obra de ladrillo que soportaba las cargas en este momento se desplaza a las esquinas, adoptando la forma de torres, y ejerciendo ahora otra función estructural de arriostramiento del edificio. Dicho de otro modo, se han eliminado los ladrillos que cubrían la mayor parte de la fachada hasta el momento, y se han reubicado en los extremos. Además, se consigue una doble funcionalidad: localizar las escaleras y los núcleos de comunicación en esas esquinas. Ambas características definirán estas grandes fábricas a partir del siglo XIX.

Esta idea ya la consideró Fairbairn ${ }^{164}$ en su libro publicado en 1863 [Figura 78 y Figura 79] (Fairbairn, 1863):

\footnotetext{
${ }^{164}$ En la primera edición de su libro Treatise on Mills and Milwork, de 1861, Fairbairn trató diversos temas sobre molinos, como los accionados por la fuerza del viento, las ruedas hidráulicas, que ya venía construyendo hacía más de 30 años, y muchos otros aspectos relacionados con la ingeniería e la producción (Watts, 2008). Se considera un referente en la innovación tecnológica y constructiva de la Revolución Industrial británica.
} 


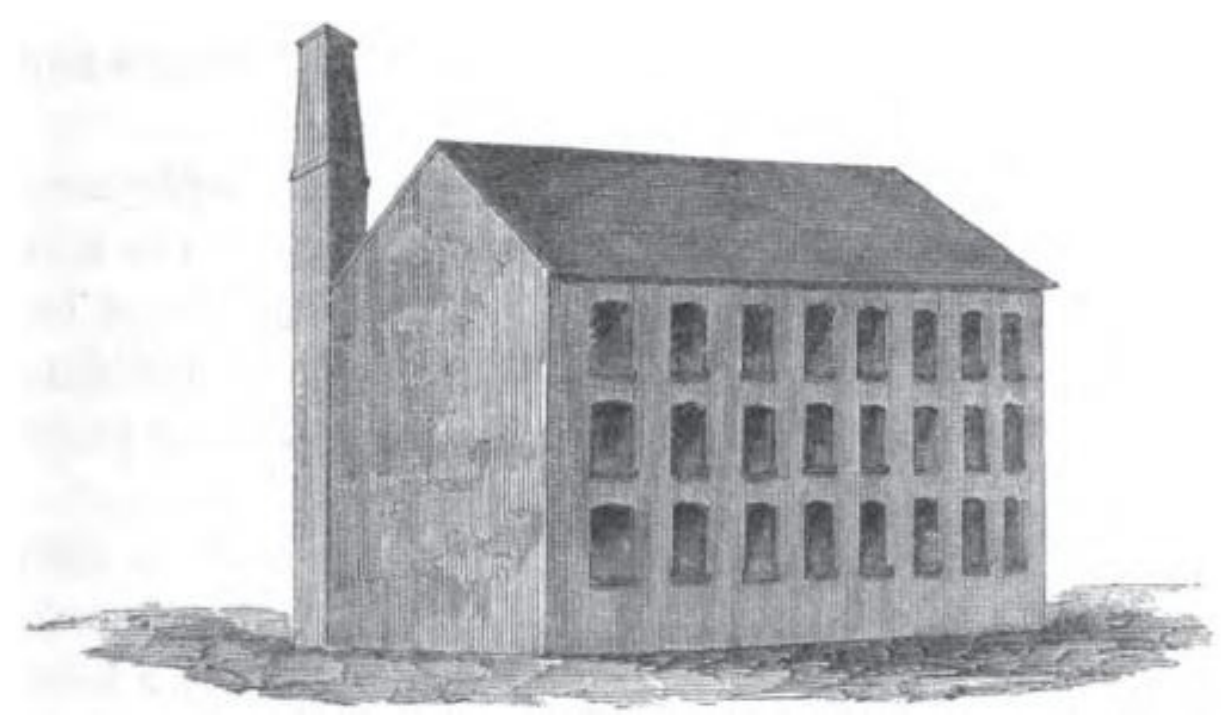

Figura 78. "Mill" tipo para Fairbairn, anterior a 1784 (Fairbairn, 1863).

"Antes de 1784, no había factorías [...] pero las mejoras en la maquinaria para el algodón introducidas por Arkwright y Crompton, necesitaron de espacios mayores en edificios separados, y los grandes beneficios que se obtenían en este tipo de manufacturas en esa época, motivaron a los propietarios a construir "mills", alguno de ellos considerado de dimensiones colosales.

Al principio, estos "mills" eran espacios cuadrados construidos con ladrillo, sin ninguna pretensión arquitectónica.

Esta descripción de los edificios con muros de carga fue muy característica durante muchos años, con la misma forma en toda Inglaterra. Pero alrededor de 1827, ya di diseños para un nuevo "mill", y persuadí al propietario hacia una cierta derivación respecto a las formas monótonas generalmente usadas. Consistía principalmente en convertir las esquinas en pilastras, con una cornisa ligera alrededor del edificio.

Este ligero cambio le dio un nuevo ímpetu a los edificios de las manufacturas. Se copió rápidamente en todas las partes del país con pequeñas modificaciones, pero siempre con el mismo efecto mejorado, y con un mejor gusto tanto para los propietarios como para el público. 
Esta intención de mejora condujo a la contratación de arquitectos [...], que junto con otros edificios públicos e instituciones, consideraron a las fábricas como obras de arte, tanto por el poder y la armonía de su composición como por su apariencia.

[...] se debían introducir mejoras en el funcionamiento del edificio y adaptaciones a la diferente maquinaria, a la seguridad contra el fuego y a otros requisitos, y así poder llevar a cabo un gran proceso de manufactura"

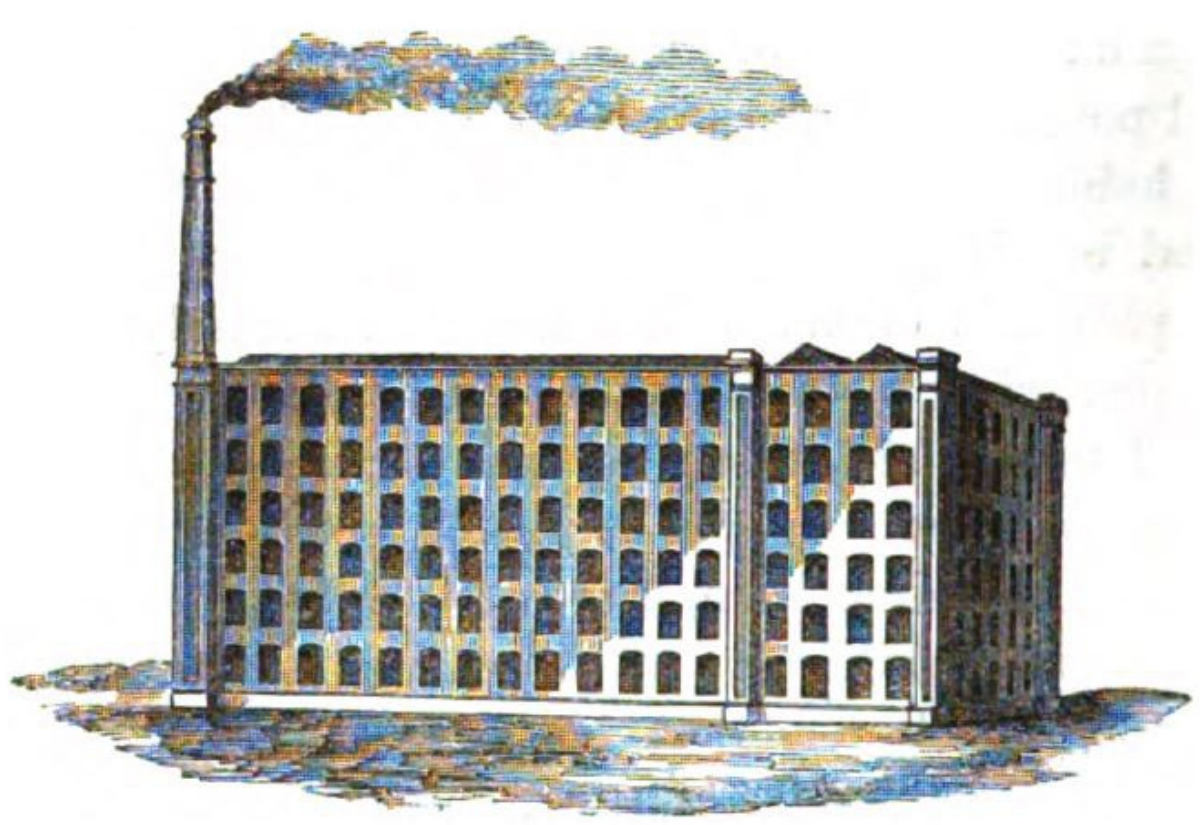

Figura 79. "Mill" tipo para Fairbairn, a partir de 1827 (Fairbairn, 1863).

Por último, reseñar que en este edificio de principios del siglo XX hay una intención compositiva clara, como el remate en su cumbrera, detalle muy usual en edificios de gran tamaño, así como los arcos de los huecos de la última planta [Figura 84]. 


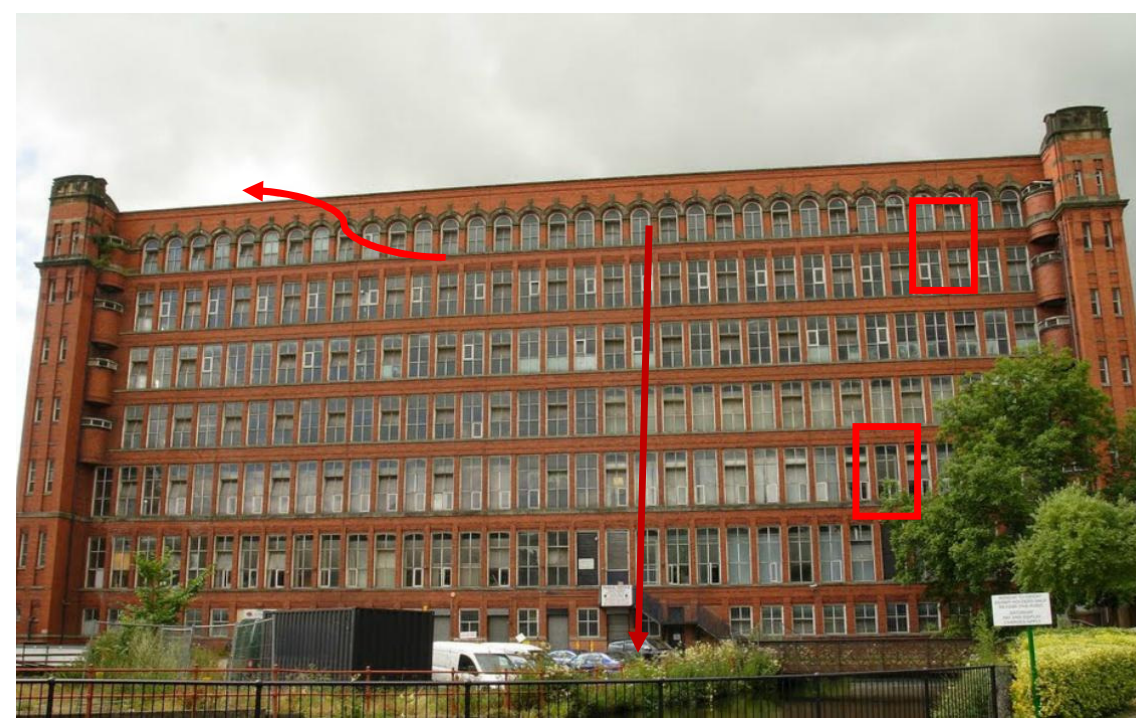

Figura 80. East Mill, Belper, en la actualidad (https://www.google.es/maps).

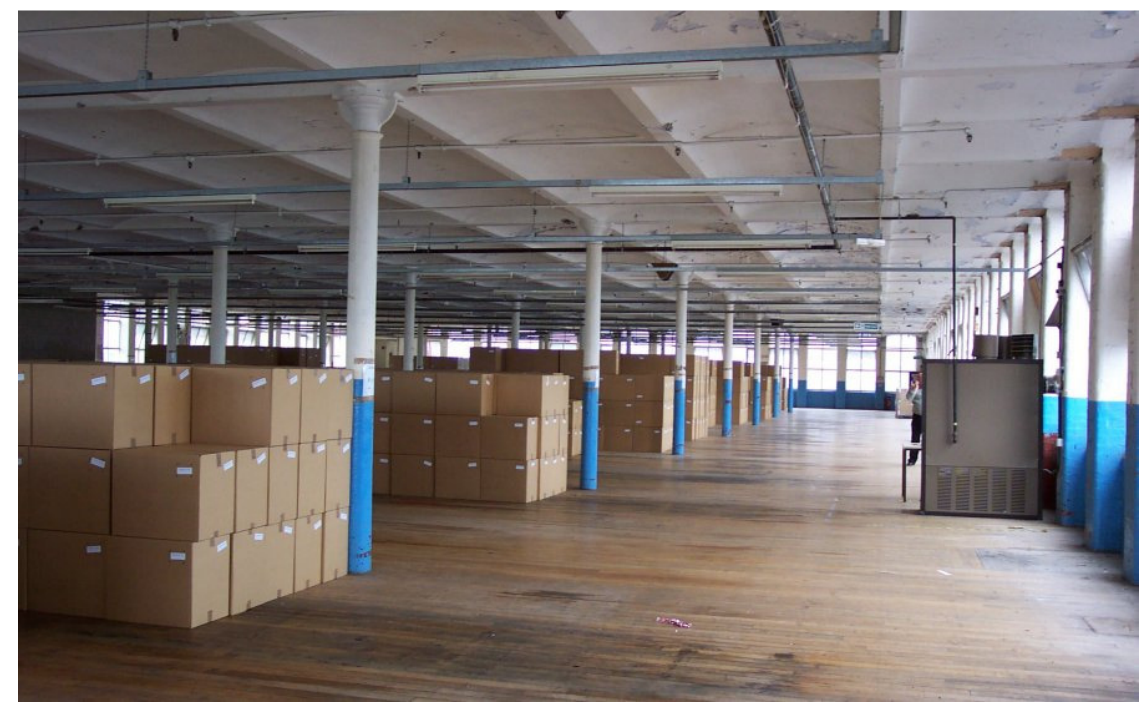

Figura 81. Belper East Mill, 1912. Esta foto da cierta idea de la escala de estos edificios a principios del siglo XX. Importante reseñar su estructura de acero, su fachada y ante todo, su diafanidad (University of the West of England. Department of Architecture and the Built Environment. http://www.uwe.port.ac.uk/commercial/vic_mills/index.htm). 
Otros ejemplos que avalarían la teoría de Fairbairn sobre la estandarización de los mill buildings con torres en sus esquinas son la New Mill de John Woods, en Bradford, de 1825, 20 años posterior a la North Mill (el proyecto respondía al diseño de Boulton y Watt, con estructura a prueba de fuego); y la India Mill, construido unos cuantos años después, con la extensión de esta idea (Darley, 2010) [Figura 82 y Figura 83]:
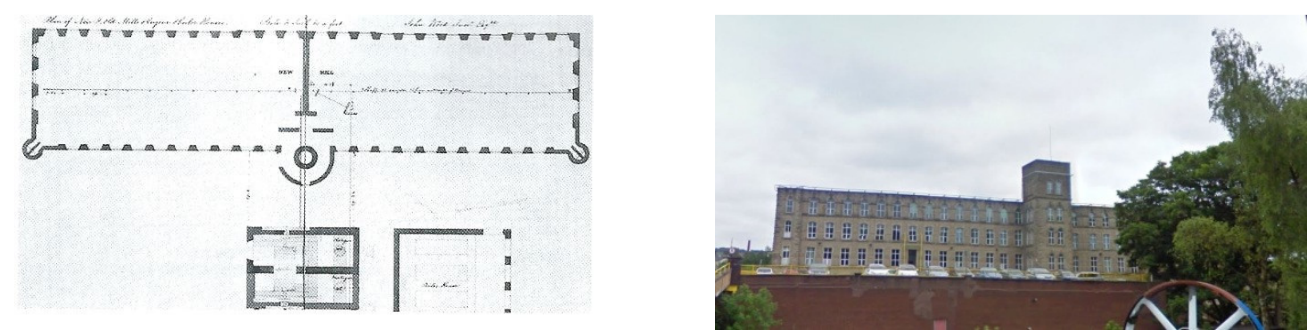

Figura 82 (izquierda). India Mill, $1859 \div 1871$, Darwen, Lancashire (Inglaterra) (http://www.google.es/imgres?imgurl=http\%3A\%2F\%2FsO.geograph.org.uk y http://www.indiamill.com/ respectivamente).

Figura 83 (derecha). Planta de la New Mill de John Woods, en Bradford, de 1825 (Darley, 2010). 


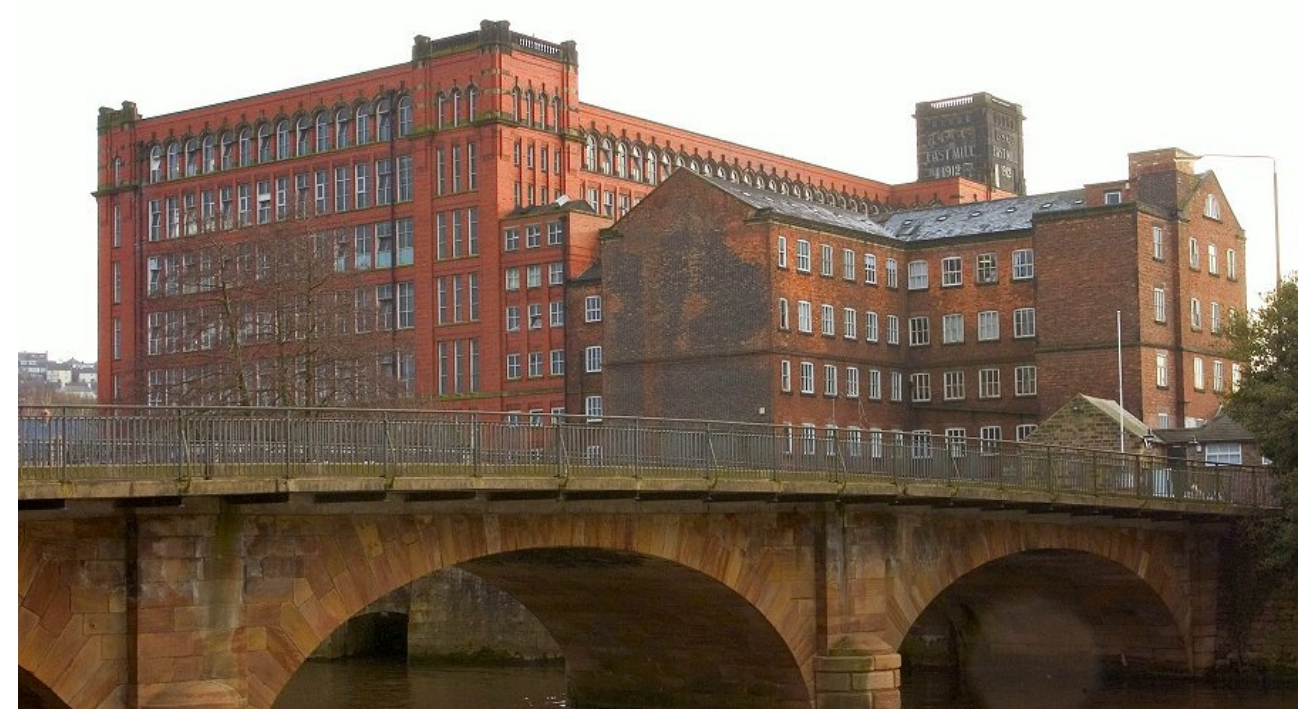

Figura 84. North Mill, en plano principal a la derecha, de 1804, y detrás, el East Mill, de 1912, un siglo posterior (University of the West of England. Department of Architecture and the Built Environment. http://www.uwe.port.ac.uk/commercial/vic_mills/index.htm).

\begin{tabular}{|c|c|c|c|c|c|c|c|c|}
\hline \multirow[b]{2}{*}{ AÑO } & \multirow[b]{2}{*}{ MILL BUILDING } & \multirow[b]{2}{*}{$\begin{array}{l}\text { NÚMERO } \\
\text { DE PISOS }\end{array}$} & \multirow[b]{2}{*}{$\begin{array}{l}\text { DIMENSIONES } \\
\text { APROXIMADAS }\end{array}$} & \multirow{2}{*}{$\begin{array}{c}\text { PISOS } \\
\text { MATERIAL* }\end{array}$} & \multicolumn{2}{|c|}{ PILARES } & \multicolumn{2}{|c|}{ VIGAS } \\
\hline & & & & & MATERIAL & \begin{tabular}{|c|} 
ALTURA \\
ENTREPLANTAS \\
\end{tabular} & MATERIAL & LUZ \\
\hline \multicolumn{9}{|c|}{ "FIRE-PROOF MILLS" } \\
\hline \begin{tabular}{|l|}
$1792-93$ \\
\end{tabular} & DERBY, COTTON MILL & 6 & $35 \times 9,50$ & BRICK ARCH & HIERRO & 3,00 & MADERA & 2,75 \\
\hline 1792-93 & MILFORD, ALMACÉN & 4 & $27,50 \times 9,50$ & BRICK ARCH & HIERRO & 3,12 & MADERA & 2,75 \\
\hline 1793-95 & BELPER, WEST MILL & 6 & $27,50 \times 9,50$ & BRICK ARCH & HIERRO & 3,00 & MADERA & 4 \\
\hline \multicolumn{9}{|c|}{ "IRON FRAMED MILLS" } \\
\hline 1803-04 & BELPER, NORTH MILL & $5+A$ & $37,5 \times 9,50$ & BRICK ARCH & HIERRO & 3,10 & HIERRO & 2,75 \\
\hline 1805-06 & MILFORD, EAST WING & 5 & $14,30 \times 9,50$ & BRICK ARCH & HIERRO & 2,67 & HIERRO & 2,75 \\
\hline 1807-08 & BELPER, REELING MILL & 6 & $27,50 \times 12,20$ & BRICK ARCH & HIERRO & 3,00 & HIERRO & 2,75 \\
\hline 1811-12 & BELPER, SOUTH MILL & $5+A$ & $36 \times 12,20$ & BRICK ARCH & HIERRO & 3,05 & HIERRO & 4 \\
\hline
\end{tabular}

*BRICK ARCH = Forjados a base de bóvedas de ladrillo

Tabla 2. Resumen de los edificios a prueba de incendios "fire-proof mills" y con estructura de hierro "iron framed mills" de William Strutt en el condado de Derbyshire. 
3.2.8. Marshall's Temple Mill o Marshall's One-Storied Mill, Holbeck, West Yorkshire, 1842, I. Bonami

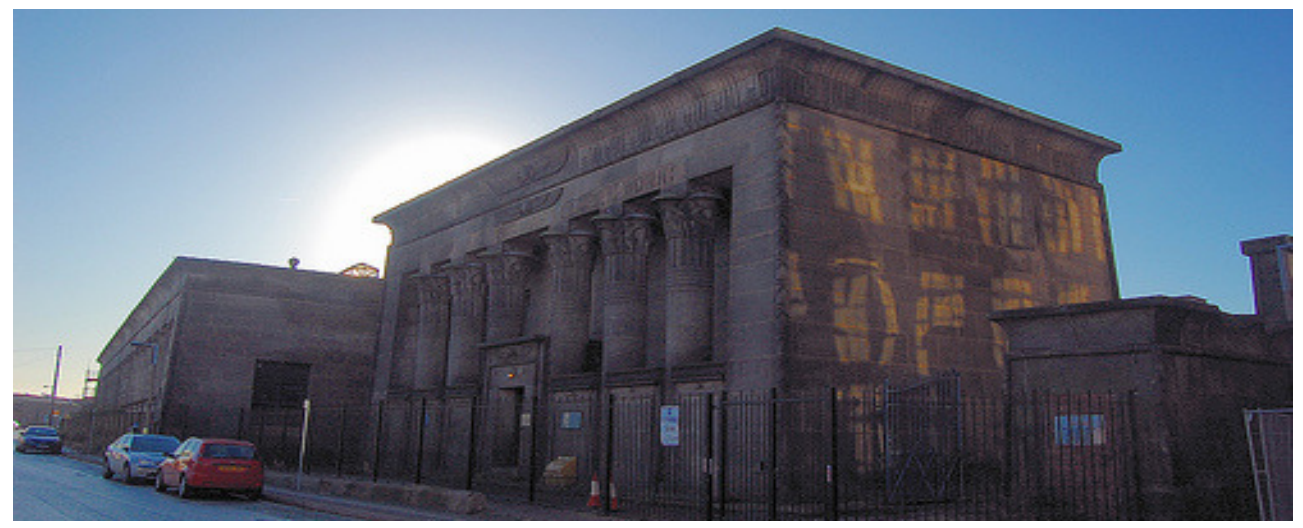

Figura 85. Marshall's Temple Mill o Marshall's one-storied Mill, Holbeck, West Yorkshire, 1842. Fachada este (https://www.google.es/maps).

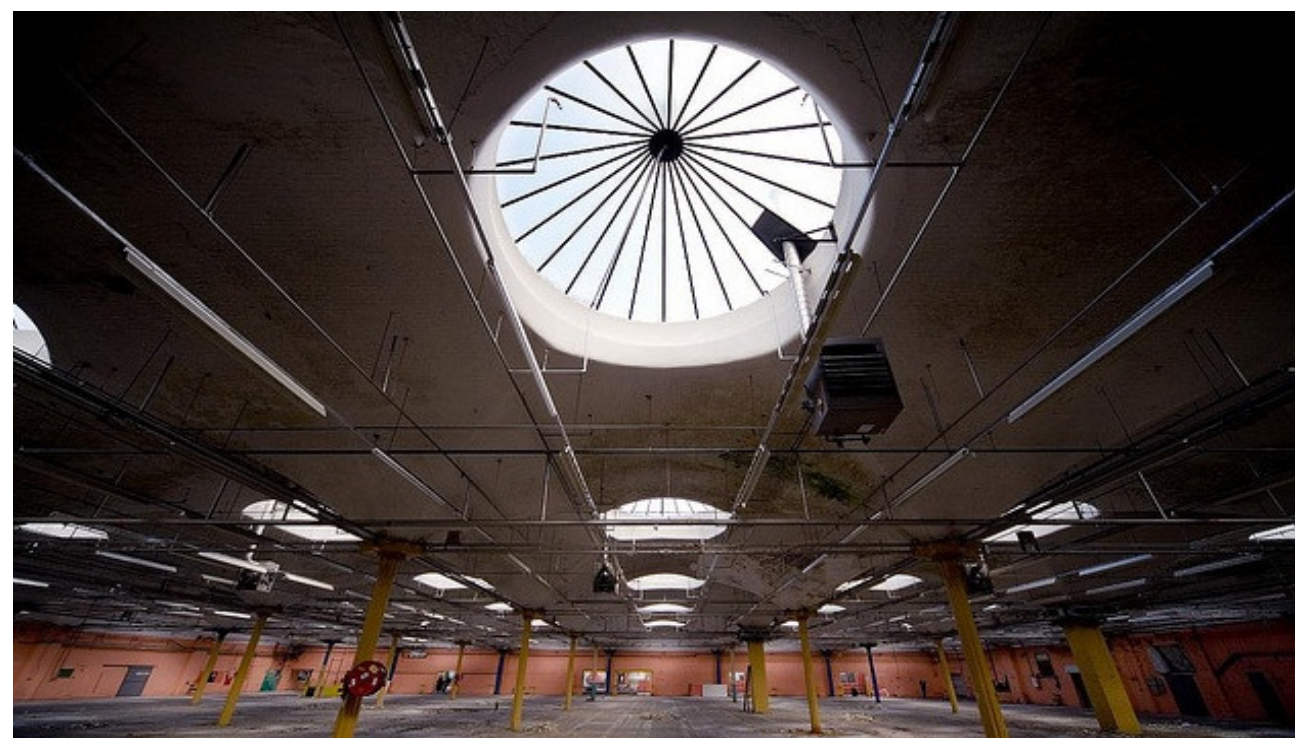

Figura 86. Interior de la fábrica: logro de la diafanidad e iluminación cenital (http://www.britishlistedbuildings.co.uk/en-466044-temple-mill-/photos). 
Este edificio es otro resultado de la evolución de la tecnología en la construcción pero en planta única, como ya lo hicieron las fundiciones de Boulton y Watt de principios y de la segunda mitad del siglo XVIII. Entre otros, incorpora pilares de fundición sobre los que apoyan bóvedas de arista, recibidas por medio de capiteles también de hierro fundido.

De hecho, una forma de conseguir mayor diafanidad interior, aumentando la distancia entre pilares, pasaba por disminuir la carga que estos tenían que soportar. Una medida drástica consistía en disminuir el número de alturas del edificio, y este es un claro ejemplo de ello: solo disponía de una única planta. Ahora bien, su superficie era considerablemente grande, tanto en anchura como en longitud. Esta particularidad contradecía la idea de los edificios en altura que venían construyéndose: para conseguir mayor iluminación natural las fábricas tenían que ser alargadas y estrechas, proporción relativa que precisamente el Marshall no cumplía.

La solución adoptada por Bonami ${ }^{165}$, su arquitecto, que motivó su consideración de hito de la arquitectura industrial, fue la de disponer de iluminación natural de forma regular en toda la superficie. Así logró lo que se pretendía con su diseño: establecer en una única altura todo el proceso productivo [Figura 86].

${ }^{165}$ Joseph Bonomi the Younger (1796 - 1878). Arquitecto y egiptólogo ingles. 


\section{LOCALIZACIÓN}

Una de las primeras referencias que se hace sobre las hilaturas de la familia Marshall aparece en el diario que escribió Karl Friedrich Schinkel (Posener, $1972)^{166}$ durante su viaje a Inglaterra, en 1826 , en el que se indica expresamente que quedó "fuertemente impresionado" por la cantidad de chimeneas (él las llamaba "altos obeliscos") que había en el país. Es en el apartado que relata su camino hacia el norte, concretamente cuando se dirige hacia Leeds, donde se percata entre otros de los talleres mecánicos circulares de Frenton Murray ${ }^{167}$, y de las famosas hilaturas de lino de John Marshall, que eran entonces el antecedente a lo que sería posteriormente la famosa manufactura de la Temple Mill [Figura 85, Figura 86 y Figura 88].

La Temple Mill, también llamada Temple Works, está ubicada en la calle Marshall de Leeds. Su fachada principal, recayente a esta vía pública [Figura 87], tenía desde su concepción una intención claramente promocional, lo que le funcionó perfectamente como tal a la familia promotora y a sus sucesivos propietarios, reclamo que consigue incluso en la actualidad.

\footnotetext{
${ }^{166}$ Karl Friedrich Schinkel (1781 - 1841), fue un arquitecto y pintor alemán, siendo el más destacado autor del neoclasicismo en su país, y uno de los diseñadores de la ciudad de Berlín en su periodo prusiano. Como jefe del departamento de obras del estado y arquitecto de la familia real, diseñó la mayoría de los edificios importantes de su época. Visitó varios países europeos durante su carrera profesional, entre ellos Inglaterra, en plena revolución industrial, donde escribió su famoso diario, en el que detallaba y dibujaba innumerables edificios fabriles.

${ }^{167}$ Fenton Murray fue una empresa dedicada a la fundición en Holbeck, Leeds (Inglaterra), creada en la década de 1790, especializada en producir piezas de fundición para la maquinaria textil, así como para las máquinas de vapor.
} 


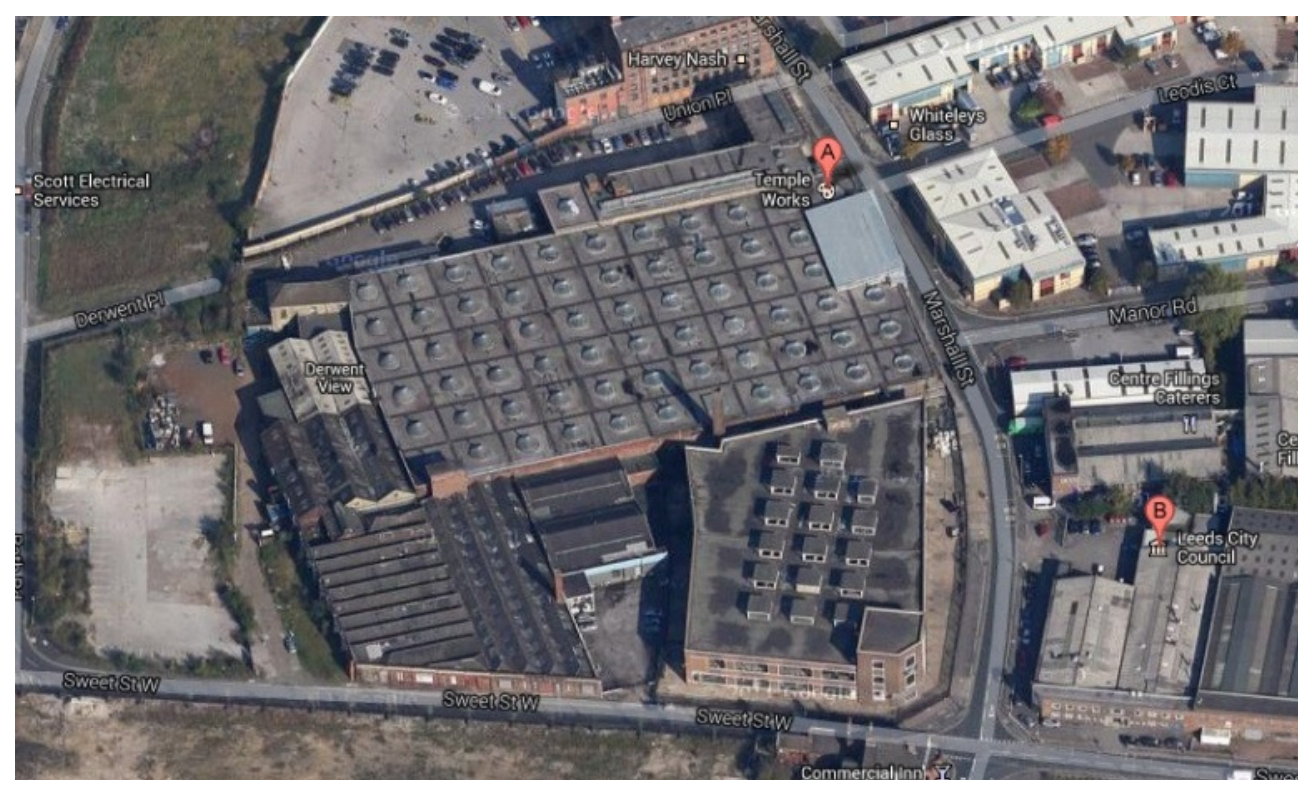

Figura 87. Localización actual en la trama urbana de Leeds, Inglaterra. (https://www.google.es/maps).

Su aspecto recordaba a los edificios más imponentes del antiguo Egipto, tanto en lo que era la parte del almacén como el del bloque anexo destinado a las oficinas, las cuales se conformaban en un edificio cuanto menos llamativo en la zona industrial del distrito de Holbeck. Este módulo administrativo, refleja de una forma muy clara la creciente complejidad que iba adquiriendo la gestión fabril de la floreciente industria textil inglesa durante el siglo XIX (Darley, 2010). Desde sus comienzos el uso que se le dio al edificio fabril era el de la producción de tejidos a partir de fibras de lino ${ }^{168}$.

\footnotetext{
${ }^{168}$ El primer encargo que la familia Marshall hizo para su nueva manufactura en Holbeck fue para el ingeniero local de su empresa, James Combe, si bien la idea que les presentó no les satisfizo en absoluto. Y se pusieron en contacto con Robert Hay, un egiptólogo y viajante que había estado en las tierras del río Nilo con Joseph Bonomi, diseñador y delineante, hijo del arquitecto también llamado Joseph Bonomi.
} 
La familia Marshall propuso unos proyectos para su nueva hilatura de lino, cuya condición principal impuesta era que esta tenía que estar relacionada con Egipto $^{169}$.

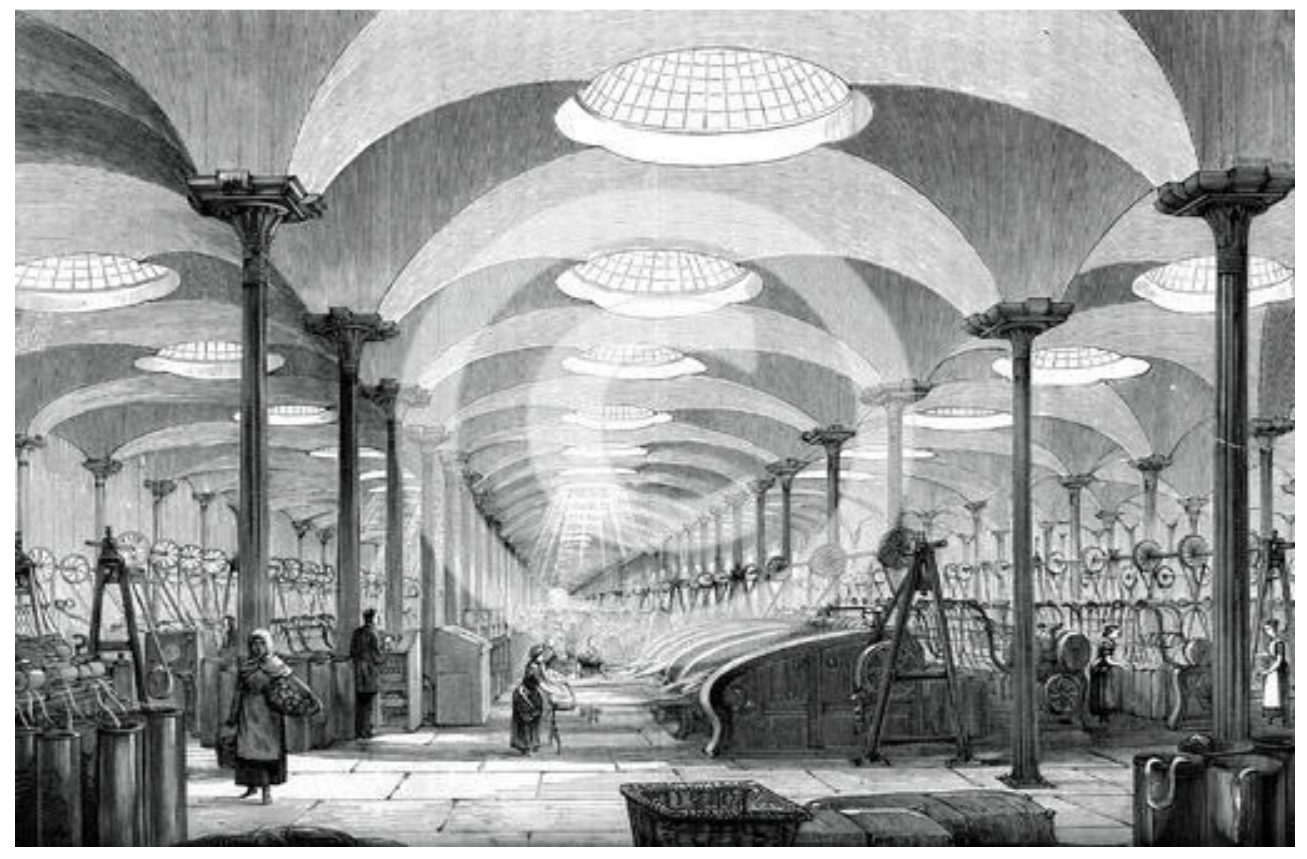

Figura 88. Interior de la fábrica: diafanidad e iluminación (http://templeworks.weebly.com/).

\footnotetext{
${ }^{169}$ Dado que Robert Hay no era arquitecto tuvo que contar con la ayuda de su compañero Bonomi, y es por eso que se le atribuye a este último la autoría del diseño de la fábrica.

Cuando terminaron el edificio en 1842 constaba sólo de una fábrica y un bloque anexo de oficinas: la primera se inspiraba en el Templo de Horus de Edfu y el Templo de Antǽopolis, y el de oficinas procedía de Typhonium de Dendera. Se trataba de una adaptación de templos egipcios a edificios comerciales: por ejemplo, la chimenea representaba un obelisco, e incluso la maquinaria en su interior era también del mismo estilo, porque en el antiguo Egipto usaban la planta de lino para producir fibras y tejidos (Darley, 2010).
} 


\section{DESCRIPCIÓN}

Bonomi proyectó tanto un bloque de oficinas de aspecto egipcio, como la fábrica contigua, cuya fachada estaba construida en piedra, con 18 ventanales y rematada por una gran cornisa (Darley, 2010). Estas características solo las aplicó a las fachadas principales, puesto que el resto no se veían desde el exterior, dejándolas completamente lisas: lo único reseñable era su gran longitud [Figura 89, Figura 90 y Figura 91 y Figura 92].

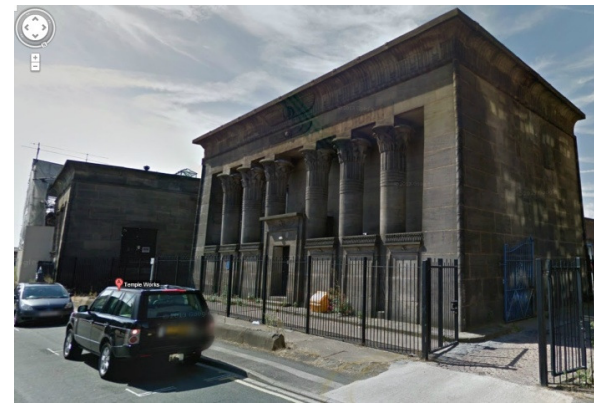

Figura 89. Fachada principal del bloque oficinas, con su acceso con portón de madera, utilizado como material noble, de la misma forma que la piedra tallada con los motivos del Templo Antǽopolis griego, con sus capiteles totalmente decorados (https://www.google.es/maps).

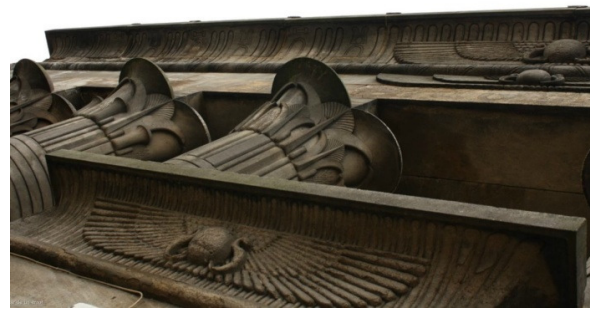

Figura 90. Detalles de la fachada sobre la puerta de acceso principal. Obsérvense los capiteles laboriosamente ornamentados (http://needleprint.blogspot.com.es/2014/04 /around-world-in-80-textiles-ulita.html). 


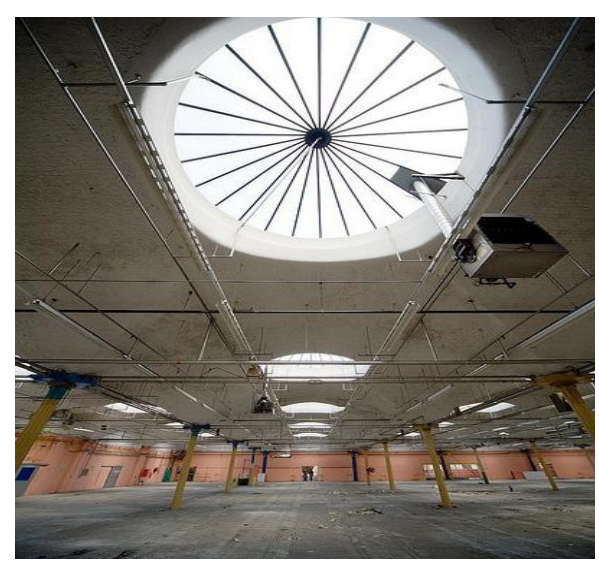

Figura 91. Interior del almacén: diafanidad e iluminación interior.

(http://www.flickriver.com/photos).

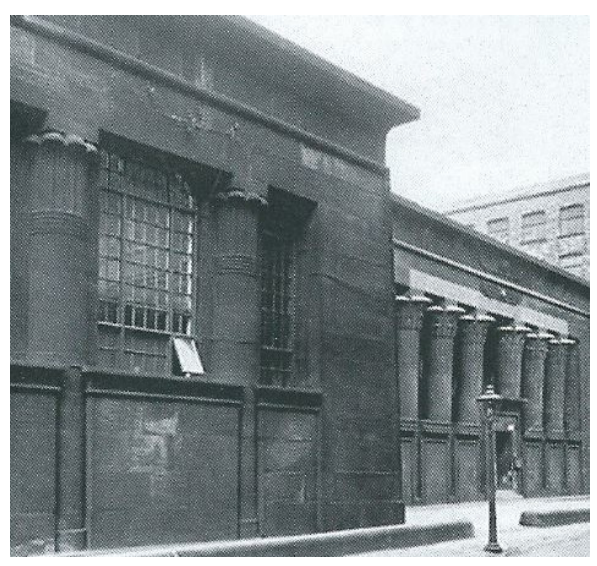

Figura 92. Fachada principal (Darley, 2010).

El almacén es un edificio de gran superficie que, junto con las oficinas, tal y como se ha dicho anteriormente, tan solo tienen una sola altura, lo cual no resultaba muy habitual en la primera mitad del siglo XIX. Pero entre otras ventajas, ello le permitiría un mejor control de toda la producción con tan solo una simple línea visual del vigilante. Asimismo, también permitía disponer de ventanas de mayor superficie al no tener que soportar los muros grandes cargas. Si bien no se le puede considerar como mill building en su acepción de edificio en altura, se ha considerado su inclusión en la relación de los edificios fabriles más interesantes, por cuanto su iluminación cenital y la utilización de una estructura ligera, que abrió nuevas posibilidades para los espacios de producción.

La elección de la estructura de lo que querían los Marshall que fuera su manufactura, tenía en cuenta una serie de consideraciones muy prácticas, como la necesidad de recibir luz por arriba, considerando una inversión lo más económica posible. 
De esta forma lograrían una fábrica que por un lado tendría una iluminación mejor y más uniforme, sin problemas de sombras, y por otro, una mejor organización del trabajo, facilidad en la supervisión, etc. Es precisamente por este motivo, que uno de los condicionantes que establecieron sus promotores fue que todo el espacio fabril se desarrollara en una única planta, disponiendo en la cubierta de numerosas cúpulas de material traslúcido, de forma tal que se permitiera aprovechar de una abundante luz cenital [Figura 93].

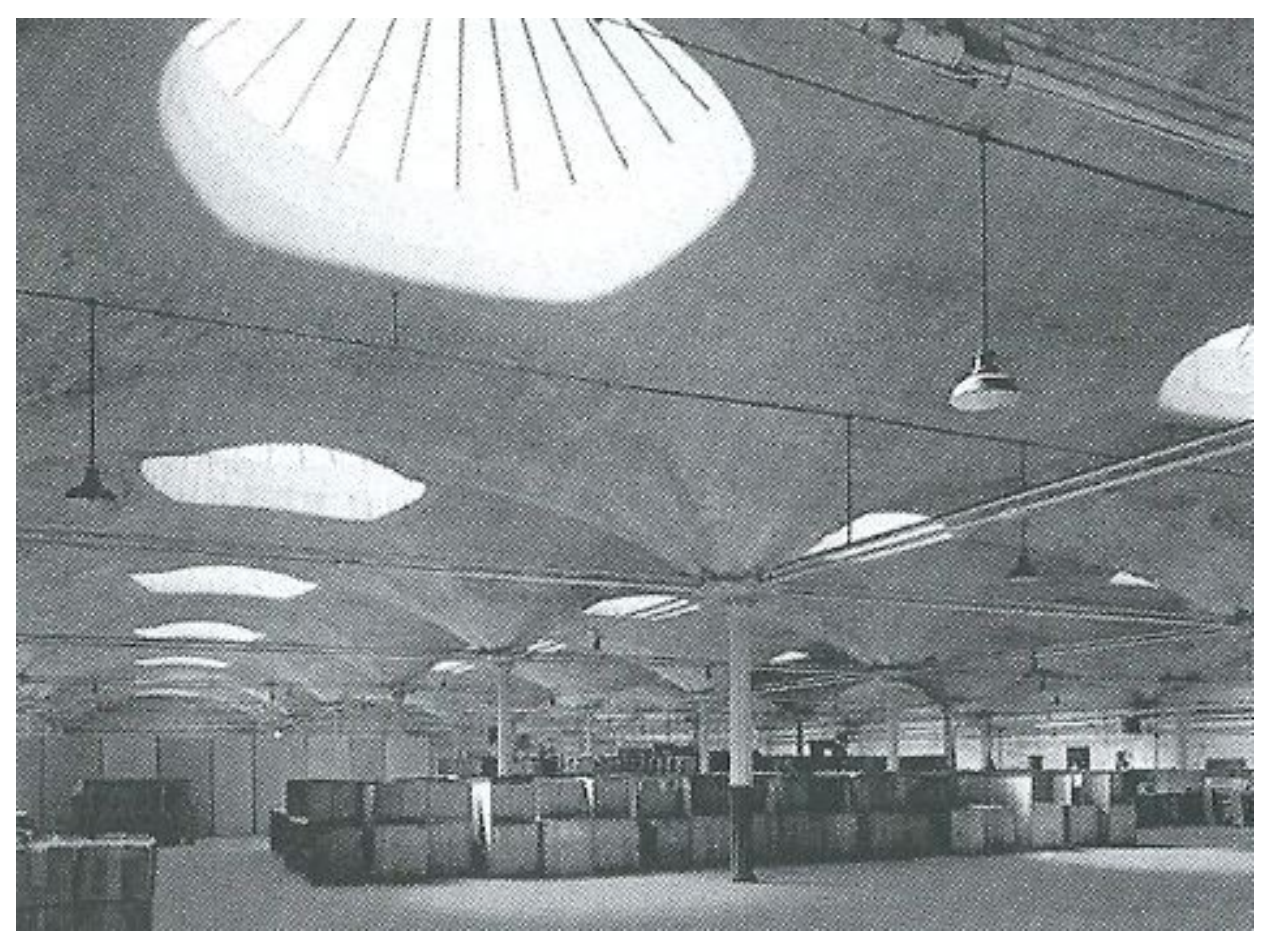

Figura 93. Interior del almacén (Darley, 2010).

Muchos años después esta tipología de manufactura en una sola planta sí lograría ser el esquema más repetido, generado a partir de retículas repetidas por la disposición de las columnas. 
"La originalidad y la extravagancia de este edificio" provocó que se hablara de él en los encuentros de técnicos y entre los artistas, así como en numerosas revistas y publicaciones de la época (Darley, 2010).

\section{ESTRUCTURA}

La estructura interior estaba formada por pilares metálicos tubulares de hierro fundido, repetidos en cuadrículas de forma uniforme. Estos tenían una ornamentación característica, también con motivos egipcios: los capiteles de las columnas estaban rematados con hojas de palma y papiro. Esta misma ornamentación se repetiría también en piezas de la maquinaria [Figura 93].

Disraeli $^{170}$ (Disraeli, 1970) comparaba este edificio con aquellos espacios de producción de las fábricas de varios pisos, que entre otros aspectos se diferenciaban por tener unos techos más bajos. En su libro detalla cómo se realizaba la ventilación, mediante la renovación del aire, de modo que todo el edificio se mantuviera a una temperatura constante, de forma tal que resultara insensible a las variaciones climatológicas. Así, según este autor, se beneficiaba a los trabajadores y facilitaba el movimiento, reducía los accidentes y permitía "una mejor inspección y observación general".

Benjamin Disraeli también dijo ${ }^{171}$ :

"[...] una de las maravillas de la región, incluso podría decirse que de todo el país: un único espacio, de escasos dos acres de extensión [unas 0,8 hectáreas] y con cabida para más de dos mil trabajadores. El techo de bóvedas de arista, iluminado por cúpulas de ventilación situadas a una altura de 18 pies [unos 5,4 metros], estaba sostenido por columnas huecas de fundición, a través de las cuales se efectuaba la evacuación del agua."

\footnotetext{
${ }^{170}$ Disraeli añadía también que el señor Trafford había construido para sus empleados un poblado modélico (dotado de jardines, escuelas, baños públicos e iglesia), que les pagaba bien y que les daba medio día libre para que pudiesen ir al mercado.

${ }^{171}$ Benjamín Disraeli (1804 - 1881), Conde de Beaconsfield o Lord Beaconsfield, fue un político, escritor y aristócrata británico.
} 


\section{CERRAMIENTOS}

Las fachadas estaban realizadas con piedras talladas de forma regular, colocadas en hiladas paralelas de igual tamaño, de gran dimensión, de una forma tal que se demostraba una enorme consistencia y solidez en el edificio. De hecho, más allá de las reales fábricas de la Europa continental, no era habitual la decoración ni el ornamento en fábricas, ya que el principal interés era la obtención del máximo beneficio con la mínima inversión. Esta idea de adornar su cara exterior se puede entender como prematura, puesto que la intención comercial premeditada de unión del producto con su marca se parece más bien al marketing propio de la $2 \stackrel{0}{\circ}$ mitad del siglo XX, 100 años después de su diseño.

La cornisa es de tamaño considerable. En ella destacan también unas inscripciones con el nombre de la fábrica Temple Works, demostrando el interés de sus propietarios por promocionar la marca [Figura 92].

En cuanto a la cubierta estaba perforada por más de 60 cúpulas acristaladas (claraboyas), como se ha dicho anteriormente (de 14 pies de diámetro $\approx 4,2 \mathrm{~m}$ ) (Darley, 2010), en un intento clarísimo de optimizar la luz natural ${ }^{172}$. Cada claraboya estaba rematada por una "válvula" como uno de los diversos dispositivos empleados para controlar los niveles de temperatura y humedad, necesarios en la manufactura de las fibras de lino [Figura 94].

\footnotetext{
${ }^{172}$ Según una descripción de la época parecían "invernaderos de pepinos en un jardín".
} 

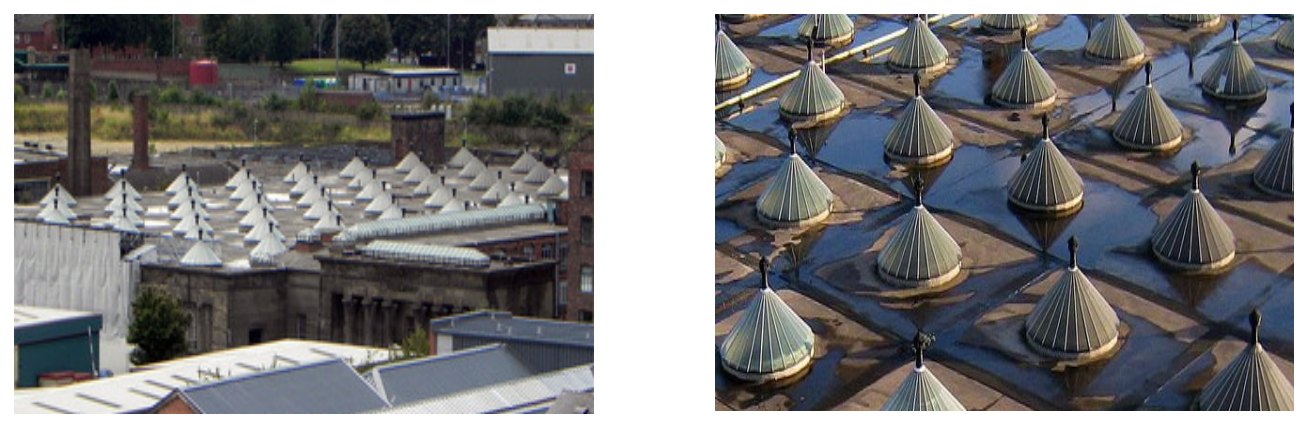

Figura 94. Cubierta (http://www.flickriver.com/photos/tags/templeworks/interesting/).

Bonomi tenía extensos conocimientos sobre iluminación. Conocía a Sir John Soane ${ }^{173}$ a través de su padre, que indudablemente le produjo cierta influencia en el tratamiento de la luz, y más concretamente sobre el sistema de iluminación cenital (tanto cúpulas acristaladas como ventanales altos), a través de sus obras residenciales, o la del Banco de Inglaterra (Strike, 2004). Es muy probable que esta manufactura de Leeds estuviera inspirada en este arquitecto ${ }^{174}$, considerada por la mayoría de la bibliografía la primera nave industrial no shed del mundo con iluminación cenital (Darley, 2010) ${ }^{175}$.

Además, en cuanto al proceso industrial, las manufacturas de lino necesitaban temperaturas estables, y eso se lograba, aislando térmicamente la cubierta con

\footnotetext{
173 John Soane (1753 - 1837) fue un arquitecto británico de estilo neoclásico. En 1788 fue nombrado arquitecto conservador del Banco de Inglaterra, y al final de su carrera profesional se dedicó a su actividad como coleccionista.

${ }^{174}$ Según Giedion (Giedion, 1978), muchos de los "mejores arquitectos ingleses del siglo XVIII e inicios del XIX", como John Soane, "eran al mismo tempo constructores, artistas y especuladores". Ello nos conduce a deducir que todavía el papel del ingeniero, del empresario, del inversor y del arquitecto, coincidía en muchas ocasiones, también como asegura Julián Sobrino (Sobrino, 1996), tal y como se ha aseverado en reiteradas ocasiones.

${ }^{175}$ Afirmación que es discutible si se compara con la Fábrica de Tabaco de Sevilla, de finales del siglo XVIII, que utilizaba linternas para la iluminación por la cubierta (Sobrino, 1998).
} 
tierra. En el caso de la Temple Mill esta capa tenía un espesor de unos $20 \mathrm{~cm}$, sembrada con hierba que era segada con ovejas que pastaban ${ }^{176}$.

Por último, la evacuación de las aguas pluviales se realizaba por el interior de los pilares huecos de hierro fundido, que actuaban como bajantes.

\section{FUENTES DE ENERGÍA}

El accionamiento de esta manufactura se producía mediante máquinas de vapor (Darley, 2010), que accionaban los ejes de transmisión de la maquinaria textil. Estaban ubicadas en un sótano con techo de bóvedas de ladrillo, que soportaban el peso de la planta baja, que era donde se realizaba toda la producción. Asimismo, alimentaban la calefacción que proporcionaba los niveles de calor y humedad requeridos para realizar todo el proceso.

Esta misma autora, afirma en su libro que la chimenea original era un obelisco egipcio, pero poco después de su construcción, en 1852, se agrietó, reemplazándose por otra más convencional y más práctica.

Como se aprecia en la Figura 93, la diafanidad lograda supera con creces la de los "mill buildings" en altura, al conseguirse un espacio que condiciona mínimamente la producción. Asimismo, se permite la gestión y el control del sistema.

La cubierta se realiza mediante bóvedas de ladrillo con base cuadrangular que apoyaban sobre vigas y soportes metálicos, de hierro fundido, capaces de soportar el peso inicial de la capa vegetal que se ideó el aislamiento térmico. Las linternas se realizaron mediante estructura metálica con acristalamiento, dotadas de válvulas para su apertura parcial para el control de la temperatura interior, cuyas exigencias marcaba el proceso de producción del lino. Este sistema se podría considerar tecnológicamente novedoso (Darley, 2010) [Figura 94].

\footnotetext{
${ }^{176}$ Se comentó en prensa de la época de los inicios de funcionamiento de este edificio, un suceso ocurrido que provocó el cambio en el mantenimiento del cuidado de la hierba que hacía las veces de aislante térmico. Una oveja cayó por uno de los lucernarios sobre una máquina en funcionamiento. Ello provocó la inmediata retirada de la capa vegetal.
} 


\subsubsection{The Boat Store, Sheerness, Kent, $1858 \div 1860$, Colonel Greene}

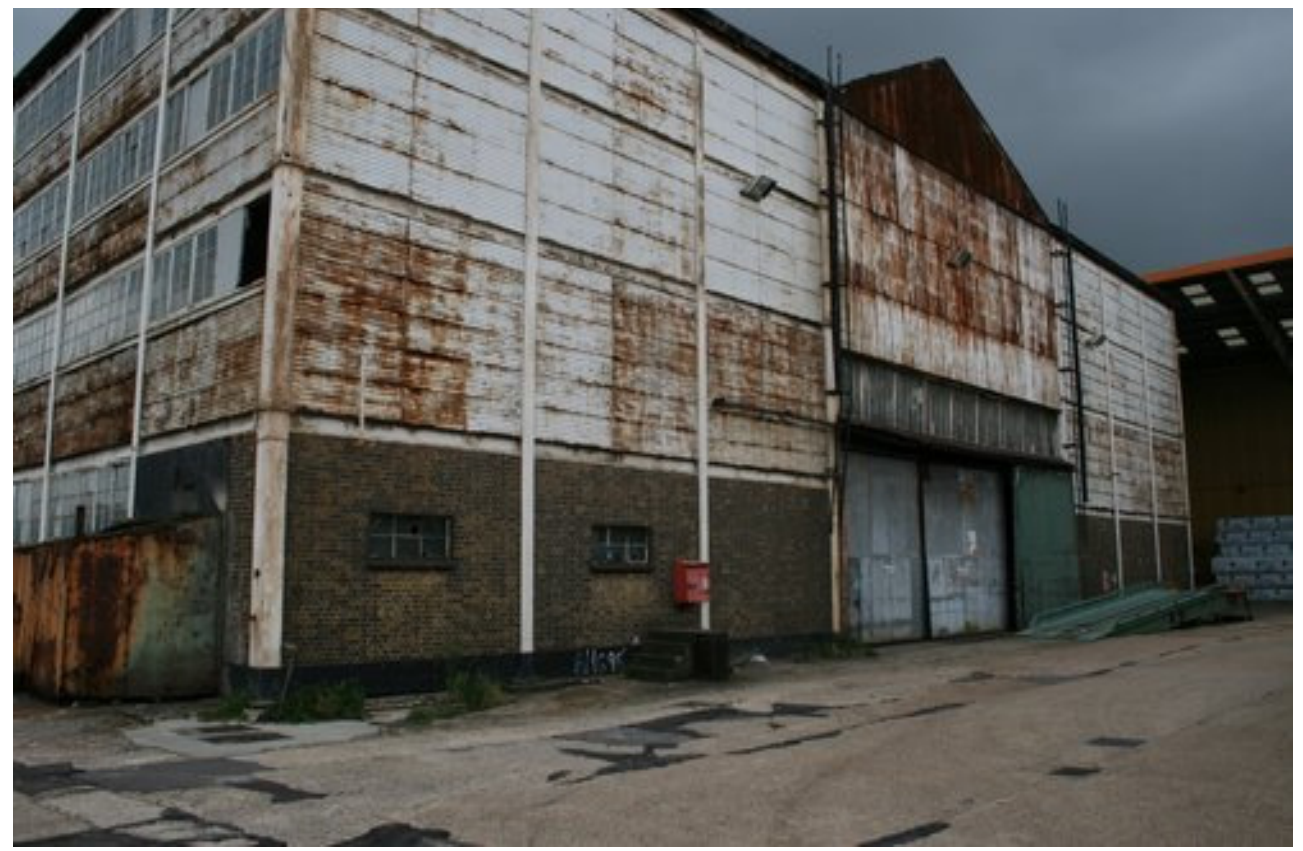

Figura 95. Astillero de Sheerness, Inglaterra, 1858. Fachada principal mayoritariamente metálica. Con este edificio se constata que el hierro ya ha llegado a la fachada (http://www.panoramio.com/photo/27899360). 

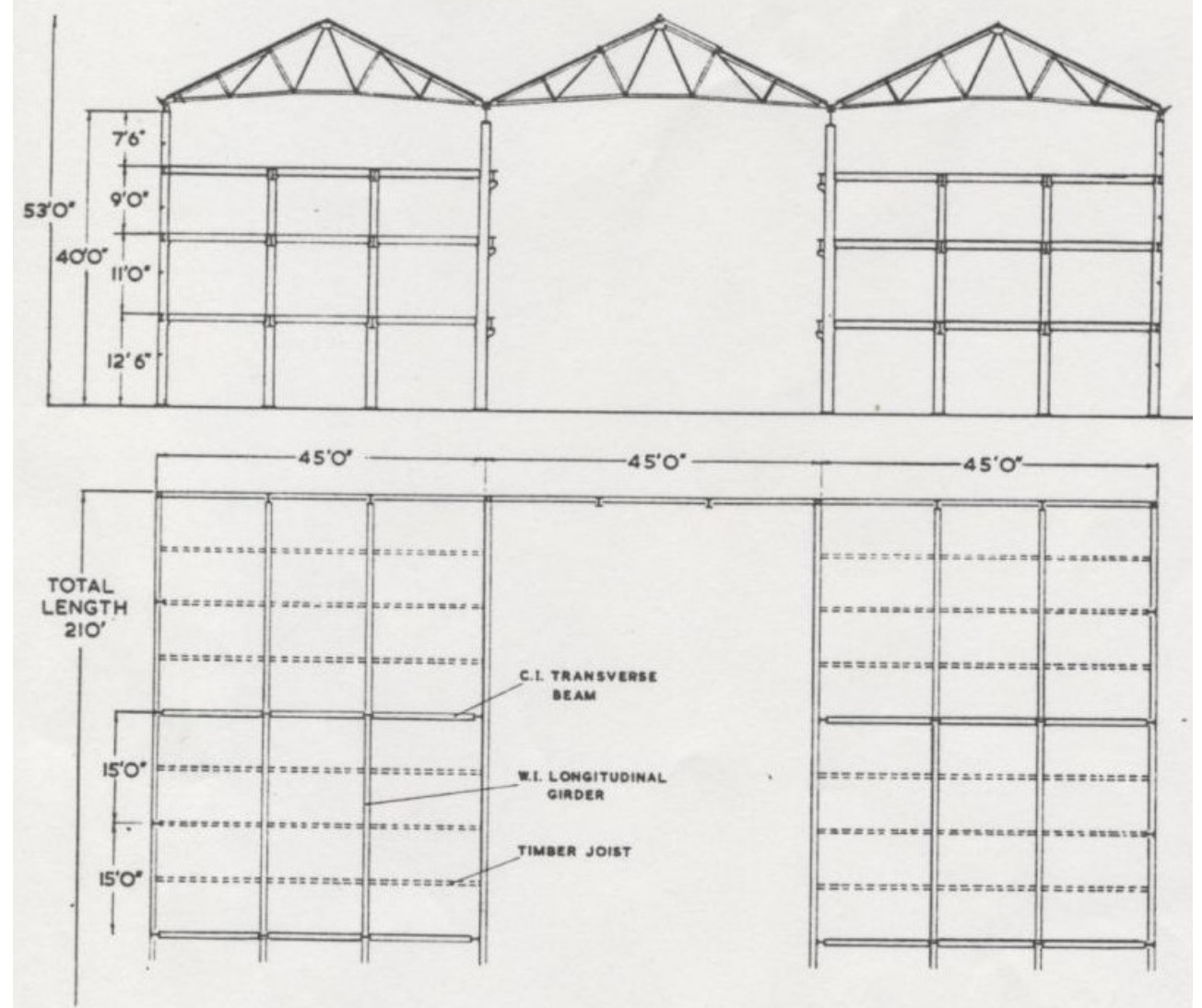

BOAT STORE, SHEERNESS (1858 60)

Figura 96. Astillero de Sheerness, Inglaterra, 1858. Planos de ejecución (Skempton, 1960). 


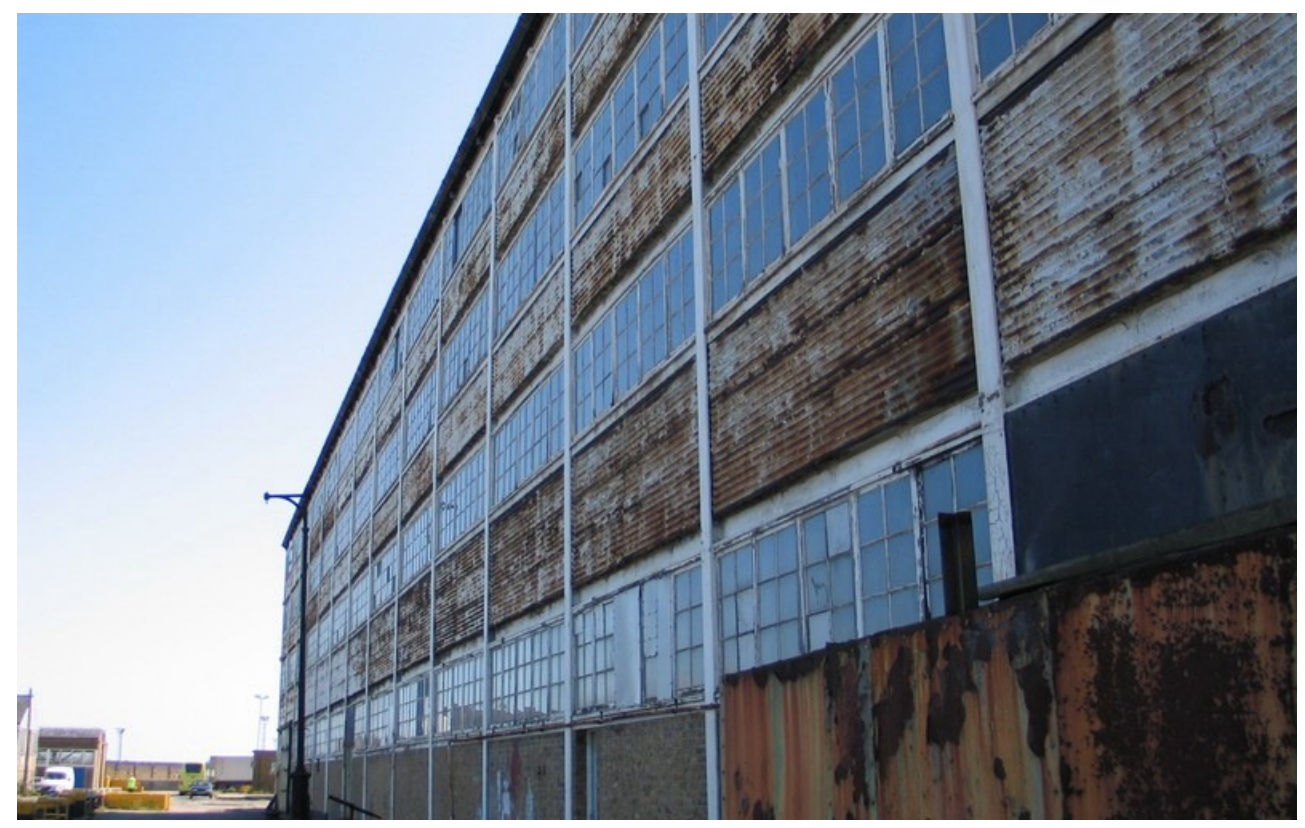

Figura 97. Astillero de Sheerness. Fachada lateral, con sus ventanales dispuestos de forma corrida en toda su longitud. Su carácter actual no se corresponde con sus más de 150 años de antigüedad (http://www.built.org.uk/photographs/south-east.html).

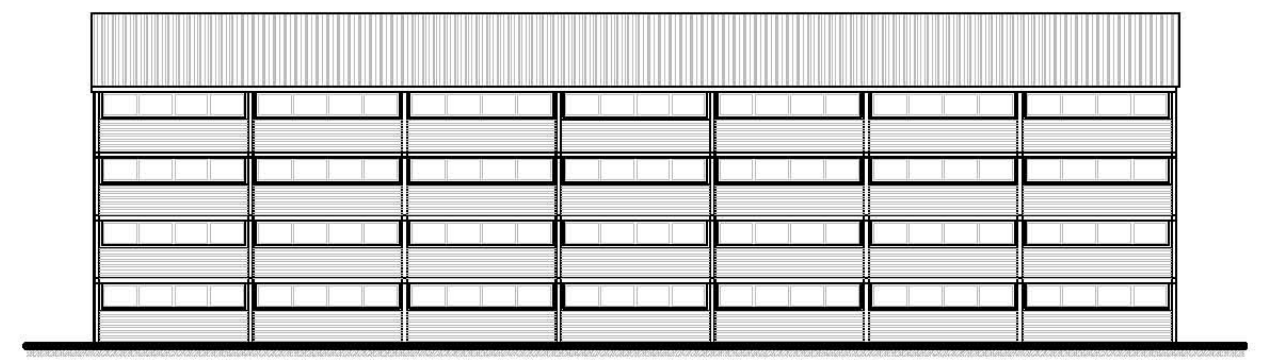

Figura 98. Alzados de la planta actual (S/E). 
El interés suscitado por este edificio en esta tesis doctoral tiene su origen en la presencia de estructura metálica en su fachada [Figura 95, Figura 96, Figura 97 y Figura 98]. Este almacén de barcos, de principios de la segunda mitad del siglo $\mathrm{XIX}$, es una derivación de la arquitectura industrial en cuanto a la utilización del hierro fundido directamente en la fachada. Este es un hecho significativo que confirma por primera vez la llegada de este material a la envolvente del edificio (Skempton, 1960), ya que no está realizada a base de muros de carga de mampuestos, donde anteriormente se hacía descansar todo el peso del edificio.

La formación de fachadas con pilares metálicos vistos es en sí una novedad en todos los sentidos: estructural, estética, funcional, etc. Su envolvente ligera, a base de chapa metálica ondulada, y sus ventanas corridas a lo largo de todas las fachadas longitudinales, constatan su diferencia respecto a los edificios en altura hasta ese momento, a las fundiciones y la Temple Mill, estas últimas de una sola planta.

Específicamente, no se trata de un "mill building", como está definido en el Capítulo 1 de este trabajo: no es un molino en altura, y ni siquiera existe un proceso productivo en él, pero sí es una buena referencia como sistema constructivo y en la utilización de los materiales estructurales, en la evolución cronológica de los espacios industriales del siglo XIX. Hay que señalar también que no hay influencia de este edificio sobre otros, puesto que no hubo mención directa sobre él, hasta un tiempo después, tal y como se indica en el párrafo siguiente.

Encuadrando este astillero en la historia, según A. W. Skempton (Skempton, 1960) este edificio realmente pasó desapercibido durante muchísimo tiempo, y no fue hasta que en la revista Architectural Review, editada por J. M. Richards, el 
fotógrafo Eric de Maré ${ }^{177}$, en julio de 1957, publicó una de sus investigaciones fotográficas sobre la arquitectura industrial en Inglaterra, en un número especial dedicado exclusivamente a este almacén de barcos. Junto a él, el profesor Skempton realizó un estudio muy completo que publicó en ese interesante artículo, y en el que principalmente se expusieron ciertos datos relevantes a partir de los cuales muchos autores comenzaron a considerarlo como el primer edificio de pisos (en sus naves laterales) con estructura completamente a base de hierro, aunque todavía los forjados entre plantas de estas dos naves adjuntas continuaban siendo de viguetas de madera, material que también conformaba los pisos $^{178}$.

Una de las primeras conclusiones que se obtuvieron según este artículo fue, principalmente gracias a algunos de los dibujos y documentos que todavía se conservan en Sheerness, su fecha de construcción: efectivamente en 1858 "en estricta concordancia a los planos", y que además fueron diseñados por el Coronel Greene $^{179}$

\footnotetext{
${ }^{177}$ Eric de Maré (1910 - 2002) fue un fotógrafo británico. En el obituario que el periódico The Times publicó el 5 de febrero de 2002, se describe como uno de los mejores fotógrafos de arquitectura del país.

${ }^{178}$ Pocos estudios e investigaciones existen que hayan tratado este edificio con suficiente rigor. Destaca una tesis de Charlotte Baden Powell, "History of Sheerness Dockyard", de la Architectural Association School, de 1959.

${ }^{179}$ A este ingeniero se le atribuyen otros edificios del astillero de esa ciudad inglesa y de su alrededor, muchos de ellos también diseñados con alguna de sus partes en hierro. Es por ello, que se deduce que el coronel disponía de nociones y experiencia más que suficientes como para construir edificios con este material.

Entre alguno de estos diseños se puede citar el almacén Smithery, en Portsmouth, de 1851, cuyos constructores fueron Fox, Henderson \& Co, y que está considerado como el prototipo del Boat Store, así como un cobertizo en Chatham, en Kent, de 1852, que incluso lograba una luz en su parte central de $25 \mathrm{~m}$, cuyos constructores, los hermanos Grissell, lo fueron también del Boat Store. A Green se le reivindican también otros edificios en Sheerness, como el Gun-mounting Store, de 1862, también con estructura de hierro, y otros con muros de carga pero con estructura interior también de hierro. Por todo ello, a este ingeniero se le debería reconocer como una figura relevante en el desarrollo de la estructura de hierro, siendo el Boat Store su diseño más relevante.
} 
Su apariencia exterior recuerda perfectamente a una nave industrial del siglo XX, pues es muy similar a fábricas que incluso fueron construidas 100 años después. Pero su interior no desmerece ser considerado, por sus innovadores pilares en $\mathrm{H}$, vigas en doble T, con uniones remachadas y Cruces de San Andrés [Figura 99].

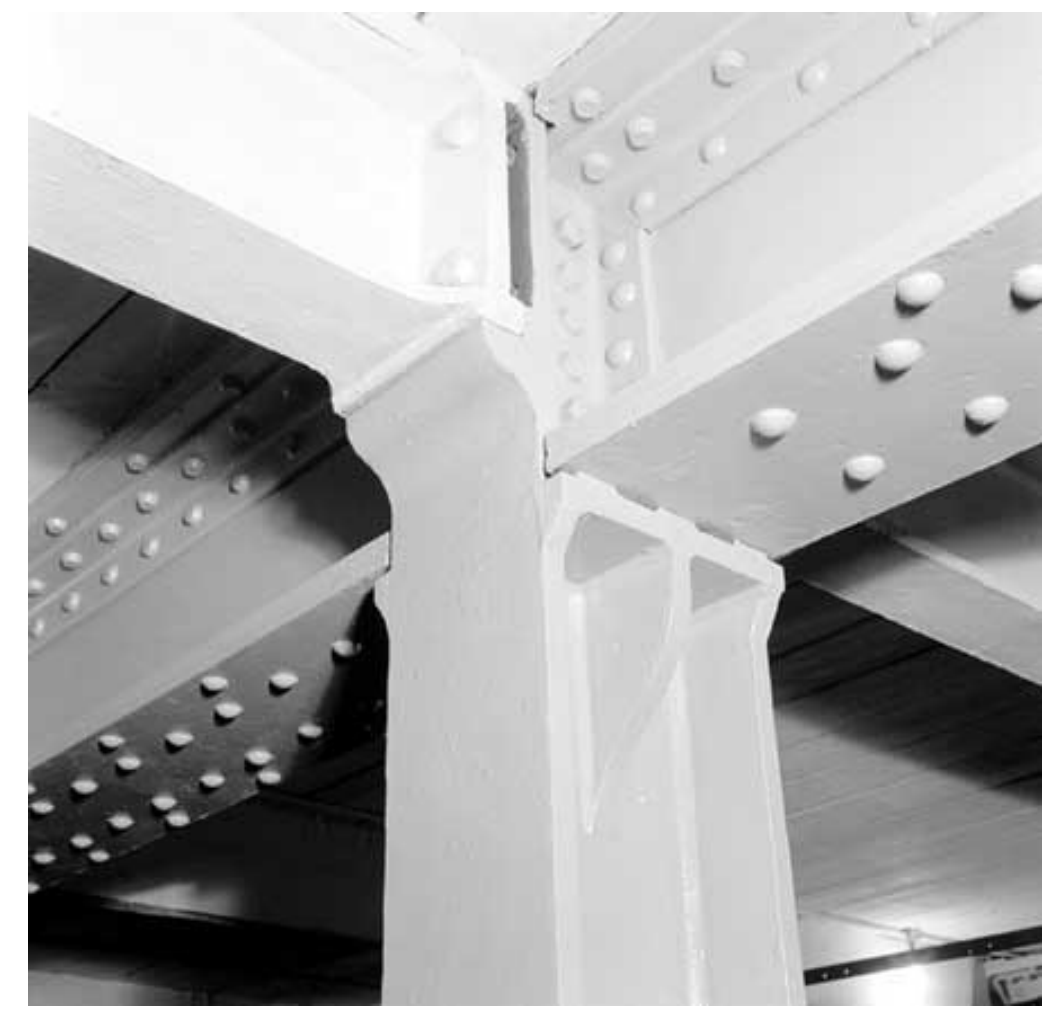

Figura 99. Astillero de Sheerness. Detalle de la unión en la estructura metálica interior, toda ella roblonada (http://www.viewfinder.english-heritage.org.uk).

Se considera en este estudio como un edificio emblemático, representativo de la revolución arquitectónica, hito y símbolo de una era marcadamente industrial, al menos en Inglaterra (Strike, 2004). Siendo tan solo 8 años posterior al Crystal Palace parecen de distinta época, a pesar de la modernidad de aquel, y tan solo 
12 años anterior al famoso edificio de los chocolates Menier, en Francia, el cual ha sido tradicionalmente considerado de forma incorrecta como el primer edificio de múltiples pisos con estructura de hierro.

Según este artículo citado:

"El Boat Store:

1) Es un ejemplo temprano de lo que es un edificio de varias plantas en hierro.

2) Es tal vez el primer edificio de ese estilo en utilizar pilares de sección en $H$, en contraste con las formas típicas del periodo, más elaboradas y decoradas.

3) Con elevaciones proporcionadas y un uso sensato de los materiales, tiene un valor estético comparable con su interés estructural: se puede considerar como un edificio prototipo de la arquitectura moderna."

Si nos remontamos unos 60 años antes de su construcción, encontraremos la fábrica de lino Ditherington Flax Mill, de Charles Bage, de 1796, que a su vez había seguido las directrices de William Strutt en el "cotton mil" de Belper, de 1792. Este tipo de construcciones con gruesos muros de carga en todo su perímetro, que llegaron a ser prototipo de edificio en la época de las primeras fábricas textiles, almacenes y otras construcciones en las que la resistencia al fuego era necesariamente requerida, no se parecen al Boat Store. Anteriormente, los suelos y los forjados entre plantas se sostenían gracias a las bóvedas de ladrillo, y la estabilidad lateral de este tipo de estructuras, típicamente de cinco o seis alturas, estaba garantizada por sus gruesos muros de carga. No fue pues hasta pasados unos años después de Shrewsbury, con la aparición de estos nuevos espacios industriales con estructura prácticamente de hierro de peso moderado, que se garantizó una mayor estabilidad gracias a sus arriostramientos longitudinales y/o transversales, cuyo término en español se acuña a Cruces de San Andrés, 
mediante tirantes o perfiles que se disponen en forma de cruz, y que a su vez son mucho más sencillas de ejecutar ${ }^{180}$.

Por su parte, también existe un pequeño molino diseñado y construido por Fairbain en 1840 y reconocido por Bogardus, que tenía paredes de chapa metálica rigidizadas por pilares de hierro huecos y vigas, y una estructura interior que soportaba dos pisos. Pero es difícil de saber si hubo algún edificio siguiendo el mismo sistema constructivo que el Boat Store antes de 1858. Incluso existen varios edificios posteriores al de los astilleros de Kent que tenían algún lateral en muro de ladrillo para solucionar la estabilidad y con forjados de madera (University of the West of England. Dep. Architecture, 2014), precisamente porque no fue un edificio conocido hasta un siglo después de su construcción.

\section{DESCRIPCIÓN}

La apariencia exterior de este edificio recuerda a la de una nave industrial perteneciente a cualquier momento de la segunda mitad del siglo XX. De hecho, podría calificarse cuanto menos de actual, evitando así la subjetividad que conlleva la palabra moderno. Dicho de otro modo: a primera vista resultaría difícil determinar su fecha de construcción. Lo mismo ocurriría si intentáramos determinarla basándonos en su estructura, completamente distinta a la que se estaba empleando en las fábricas textiles inglesas de su misma época, puesto que sus planos datan, como se ha comentado anteriormente, de $1858^{181}$. Así, se puede deducir que se ejecutó de forma muy rápida.

Asimismo, sus ventanas de guillotina estaban distribuidas de forma corrida, de lado a lado de los cerramientos laterales y en cada piso [Figura 100].

\footnotetext{
${ }^{180}$ Probablemente el primer edificio de múltiples plantas de este estilo fue erigido entre 1848 y 1849 en Duane Street en Nueva York, por James Bogardus, de 4 alturas. También es conveniente citar a este respecto el Crystal Palace, que albergó la Gran Exposición de Londres en 1851.

${ }^{181}$ El mismo año en el que empezaron los trabajos de su construcción, y probablemente su entera ejecución.
} 
El almacén consta de 2 edificios en los extremos de 4 plantas (incluyendo la planta baja), distribuidos de forma simétrica respecto una nave central cuya altura es la total de aquellas, y con un lucernario que atraviesa toda la longitud de la cubierta de esta parte interior, permitiéndole una gran iluminación cenital en todo el almacén [Figura 101].

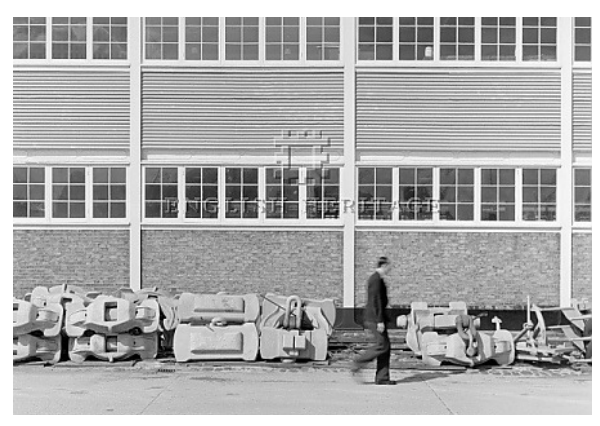

Figura 100. Astillero de Sheerness, 1858 (http://www.english-heritage.org.uk.).

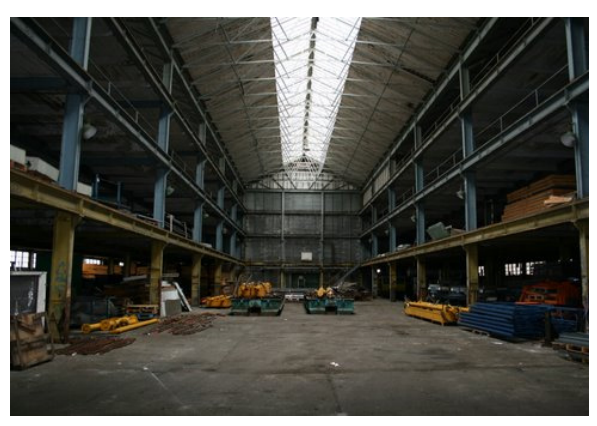

Figura 101. Astillero de Sheerness (http://www.viewfinder.englishheritage.org.uk).

\section{ESTRUCTURA}

La totalidad de la planta tiene unas dimensiones de $64 \mathrm{~m}$ de largo $\times 41,1 \mathrm{~m}$ de ancho, con una altura de 15,15 m. Los pórticos de cada nave lateral están unidos por vigas de gran tamaño, una para cada altura, y que en su parte interior servían también para la sujeción y el traslado de un lugar a otro de los barcos que allí se fabricaban o reparaban ${ }^{182}$ (Skempton, 1960).

\footnotetext{
${ }^{182}$ Los botes eran maniobrados a una determinada posición dentro del edificio, y posteriormente elevados, apoyándose en las citadas vigas.
} 
Cada nave lateral tenía 4 columnas, separadas una distancia de 4,42 m transversalmente, y 9,14 m longitudinalmente, excepto en su parte más exterior, en los cerramientos, donde esta distancia se reduce a la mitad. Cada columna apoya sobre 4 pilotes de madera de $0,3 \mathrm{~m}$ de diámetro con una profundidad respecto el nivel del suelo de 18,29 m [Figura 96].

Estos pilotes estaban compuestos de: una placa de granito de $30 \mathrm{~cm}$ de espesor que descansaba sobre una pilastra de ladrillo de $90 \times 90 \mathrm{~cm}$, apoyando sobre un encepado de hormigón, de donde nacían, a una profundidad de 3,66 m, los 4 pilotes de madera anteriormente mencionados [Figura 102].

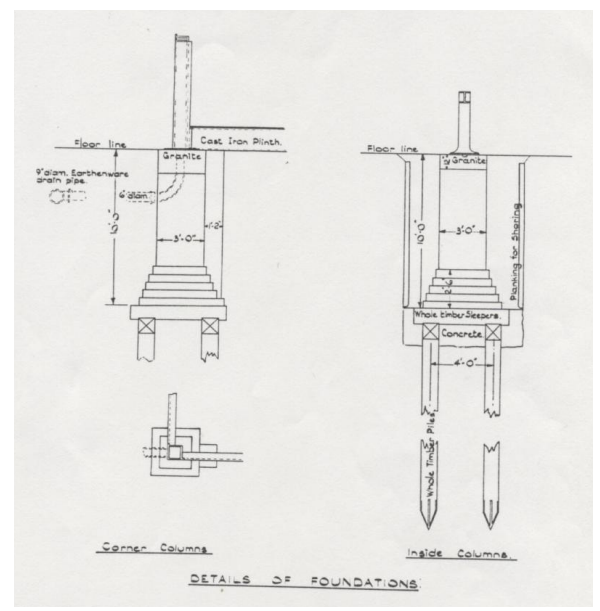

Figura 102. Astillero de Sheerness. Detalle de las cimentaciones (Skempton, 1960).

La solera estaba realizada en una especie de mortero, pero los tres pisos restantes de las naves laterales, consistían de tablones de alcornoque de $23 \mathrm{~cm}$ de ancho $\times$ $8 \mathrm{~cm}$ de espesor. Estos forjados apoyaban sobre vigas de hierro transversales. Como se ve, todavía la madera está presente, pese a la vulnerabilidad al fuego.

\section{ARRIOSTRAMIENTOS Y FIJACIONES}

La fijación de las vigas con los pilares se resuelve en cada unión mediante 4 tornillos de $20 \mathrm{~mm}$ de diámetro, siendo la estabilidad de todo el edificio 
totalmente mediante cruces de San Andrés, que son los arriostramientos de los pórticos, y que a su vez deriva de la rigidez de todas las uniones. De todo ello se desprende que las vigas de hierro fundido eran consideradas por Green como un componente esencial en la estabilidad del edificio.

Por último señalar que los apoyos de las vigas a los pilares también se resuelven a través de ménsulas [Figura 96].

\section{VENTANAS, CERRAMIENTOS Y CUBIERTA}

Generalmente las ventanas descansaban sobre angulares de hierro de $150 \times 100$ $\mathrm{mm}$, siendo originalmente de tipo guillotina, aunque posteriormente fueron sustituidas por ventanas batientes (Darley, 2010).

Los paños de cerramiento estaban hechos de chapas de hierro ondulado, que se fijaban a la estructura mediante anclajes de hierro forjado a las alas de los pilares en H [Figura 103]. 


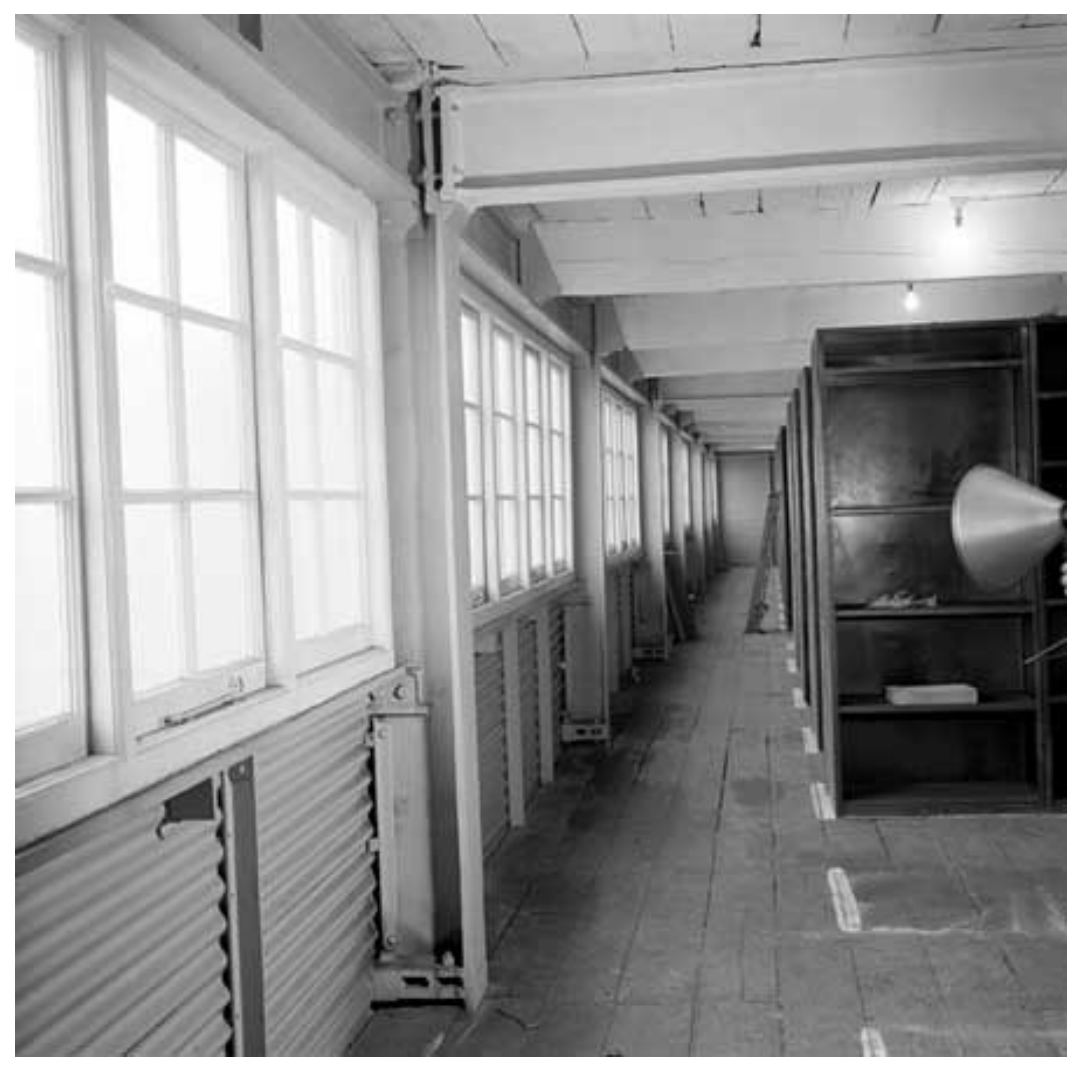

Figura 103. Astillero de Sheerness. Vista desde el interior de los cerramientos de chapa ondulada, de las ventanas y de los suelos de madera (http://www.viewfinder.english-heritage.org.uk).

En cuanto a la cubierta del edificio, inclinada, estaba realizada con estructura de hierro forjado a modo de cerchas, y con cubrición de pizarra. Las bajantes de las aguas pluviales se recogen mediante canalones que desaguan por el interior de los pilares esquineros (Strike, 2004) [Figura 104]. 


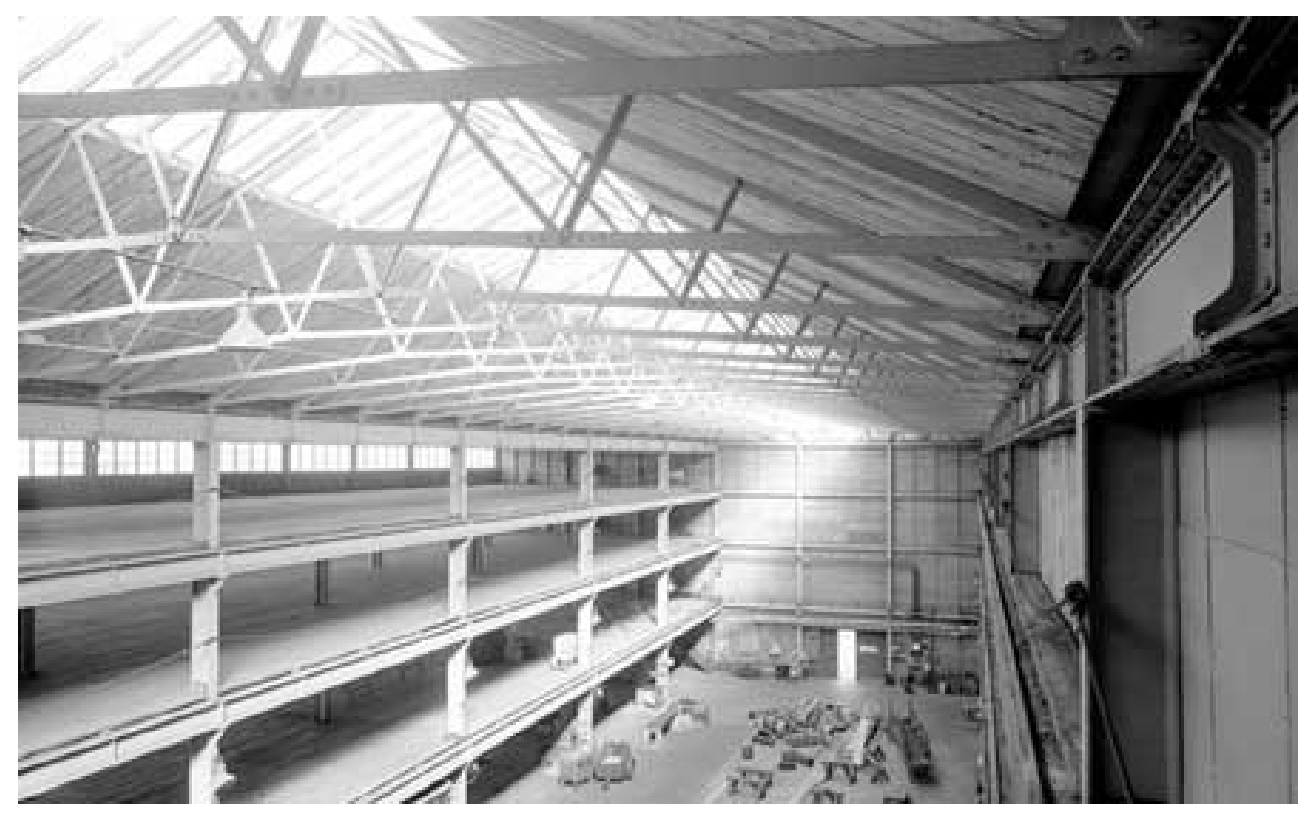

Figura 104. Astillero de Sheerness. Vista desde el interior de la cubierta (http://www.viewfinder.english-heritage.org.uk).

Así, según este autor, los detalles estructurales estaban "brillantemente pensados y posteriormente ejecutados" (Skempton, 1960).

Ahora bien, las razones que llevó a adoptar una estructura de hierro no se reflejan en ningún documento. Hay, sin embargo, al menos tres evidencias en el artículo que lo hacen prevalecer sobre los edificios con muros de ladrillo:

\section{"En el boat store:}

a. Velocidad de construcción.

b. Mayores ventanas, proporcionando mejor iluminación a las plantas.

c. Menores cimentaciones."

Tal vez este último punto sea el más importante. Los edificios ingleses anteriores y coetáneos, con muros de carga, tenían cimentaciones mediante arcos invertidos soportados por un gran número de pilotes en los casos cercanos al mar, como 
astilleros y edificios navales o marítimos. Tal y como se señala en la revista de abril de 2011 del English Heritage, "Designation. Listing Selection Guide. Maritime and Naval Buildings":

"Hubo una rápida expansión en la construcción de dársenas desde 1770 auspiciadas por el desarrollo clave en la construcción y en la ingeniería, como las primeros de John Smeaton (1724 - 1792) y John Rennie (1761 1821), que incluían el uso del cemento hidráulico utilizado bajo el agua, y las bóvedas de ladrillo invertido usados para formar los suelos de los muelles y resistir la presión del terreno [...]"

En cuanto a la chapa ondulada metálica de cerramiento, esta se une a las vigas exteriores de la estructuran mediante tornillos de $19 \mathrm{~mm}$ ( $3 / 4$ inch). Esos paneles de chapa de hierro ondulado, colocados detrás de las alas de los pilares y soportados por pequeños ángulos de hierro forjado, tal y como se ha comentado en párrafos más arriba [Figura 103]. Las todavía presentes viguetas de madera son exclusivamente para soportar el suelo.

En la Figura 101 aparece una vista interior en la que destaca la diafanidad requerida para el mantenimiento de los barcos de gran tamaño, con el lucernario de la cubierta central que iluminaba toda la nave. 


\subsubsection{Fábrica de Chocolates Menier, 1871, Noisel-Sur-Marne, Francia}

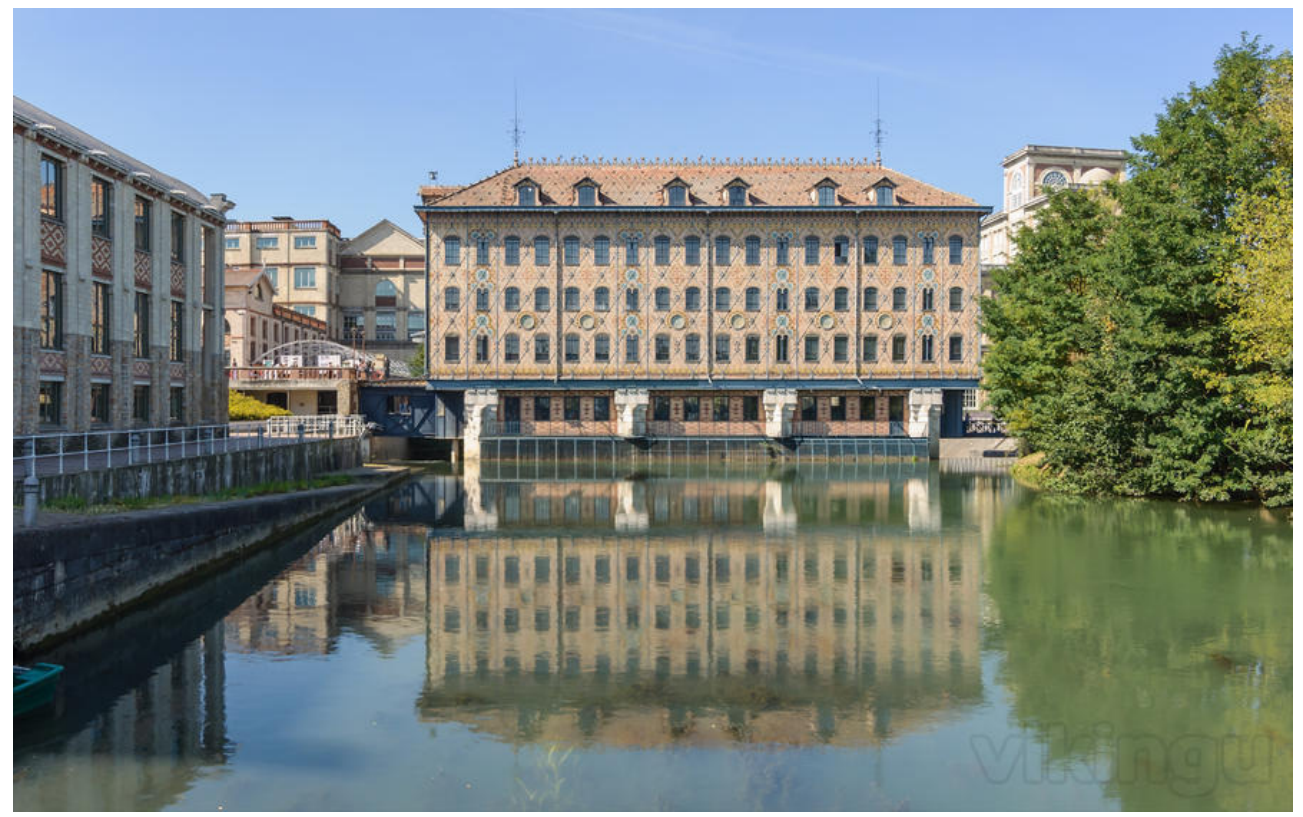

Figura 105. Fábrica de chocolates Menier, 1871. Fachada este. Este edificio se ubica dentro del propio río Marne, de forma que la energía de sus aguas consigue mover las turbinas hidráulicas, como evolución mecánica de la rueda hidráulica (http://es.wikipedia.org/wiki/Chocolat_Menier).

Si se compara este edificio con el de los hermanos Lombe, de 1722, se obtienen similitudes destacables, pese a haber transcurrido casi 150 años. De ellas, la más evidente se centra en su aspecto exterior [Figura 105 y Figura 106]. 

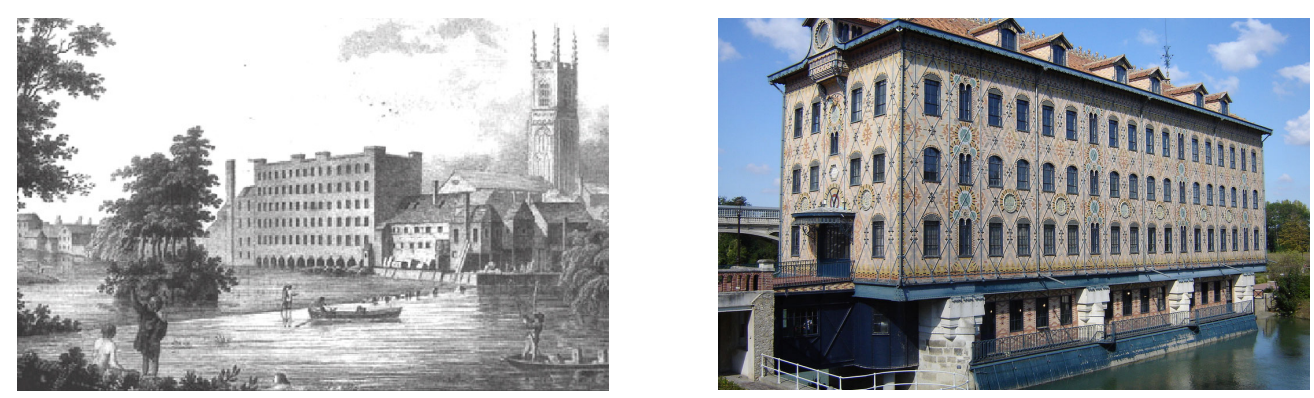

Figura 106. Edificio de los Hermanos Lombe, de 1722 y la fábrica de chocolates Menier, de 1871, vista por su fachada sureste (http://es.wikipedia.org/wiki/Chocolat_Menier).

En cuanto a las fachadas, después de tanto tiempo transcurrido entre la construcción de sendos edificios, continúan siendo de un tamaño similar, con proporciones semejantes y distribuidas con una relación hueco/cerramiento de obra del mismo orden (alrededor de 0,25 \{confrontar el factor iluminación en apartado 3.6 más adelante\}).

En lo que sí difieren, debido principalmente al gran periodo de tiempo que las separa, es en la utilización de diferentes materiales en su estructura: el de Lombe estaba realizado en madera, tanto vigas como soportes y forjados, y el de Menier, con hierro fundido. La segunda gran diferencia reside en la forma de accionamiento mecánico, teniendo en cuenta la evolución tecnológica habida entre la rueda hidráulica utilizada por el primero hasta la turbina hidráulica en el segundo de los casos, aumentando considerablemente la eficiencia del sistema energético. De esta comparación, y su evidente innovación tecnológica y constructiva, surge la necesidad de su inclusión en este estudio evolutivo, aparte de su indudable reconocimiento arquitectónico. 


\section{LOCALIZACIÓN}

La popularidad a nivel mundial que alcanzaron ciertos edificios molino se fundamenta en diversas características y peculiaridades. La mayoría de ellos consiguieron destacar por su novedad tecnológica, bien en su proceso de producción bien por el método empleado en la construcción del propio edificio, o incluso por la adecuada utilización de los materiales en la obra.

Muchos de estos edificios, se han considerado como hitos también de la arquitectura industrial, siendo uno de ellos la fábrica de chocolates Menier, ubicada sobre el lecho del río Marne, en Noisiel, Francia ${ }^{183}$. En este caso coinciden las tres particularidades mencionadas anteriormente, que lo motivan para la inclusión en esta tesis doctoral. Todavía hoy Noisiel es sinónimo de Menier, que fue un importante fabricante de chocolate que pretendió construir una fábrica automatizada para la producción de este producto en grandes cantidades ${ }^{184}$ [Figura 105 y Figura 106].

Pero, ¿cómo pudo llegar a influir el material utilizado en la forma y la distribución de este edificio? Evidentemente en tantos aspectos como para lograr haber conseguido ser icono de la arquitectura incluso reconocido hasta nuestros días, y ser uno de los más aparecidos en la bibliografía sobre arquitectura industrial ${ }^{185}$.

\footnotetext{
${ }^{183}$ Localidad está situada a unos $20 \mathrm{~km}$ al este de París.

${ }^{184}$ Como promotora, la familia Menier también construyó viviendas e instalaciones para sus trabajadores. La factoría estuvo operando hasta 1993, convirtiéndose posteriormente en museo del chocolate y luego como oficinas centrales de la compañía multinacional Nestlé, actuales propietarios. El Gobierno francés lo calificó como monumento histórico, y pertenece a la lista del World Heritage Site de la Unesco.

185 Este edificio ha sido muy referenciado por relevantes y renombrados autores de libros de arquitectura, como Giedion, Ragon, Frampton, Lemoine, etc.
} 


\section{DESCRIPCIÓN}

La fábrica de chocolates Menier fue diseñada por el arquitecto Jules Saulnier ${ }^{186} \mathrm{y}$ el ingeniero Armand Moisant ${ }^{187}$, entre 1871 y 1872 (Giedion, 1978).

Levantada sobre un afluente del río Sena llamado Marne, que le proporcionaba la energía mecánica para accionar las turbinas hidráulicas ${ }^{188}$, y que a su vez movían la maquinaria, la mayoría de ella ubicada en la última planta del edificio.

Su emplazamiento estaba ideado para que su eje longitudinal cruzara el río, de forma que el aprovechamiento de la corriente de agua por las 3 turbinas fuera máximo.

El edificio tiene la planta inferior sobre el nivel del agua del río, para alojar las turbinas, y tres plantas superiores más, donde se realizaba la producción. Su planta es rectangular y se accede al mismo desde el nivel del suelo por sus dos laterales, que se corresponden con la planta primera, tal y como se puede apreciar en las fotografías [Figura 107].

\footnotetext{
${ }^{186}$ Jules Saulnier (1817 - 1881).

${ }^{187}$ Armand Moisant (1838 - 1906).

${ }^{188}$ Las turbinas hidráulicas, a diferencia de las ruedas hidráulicas, tienen dos puntos de impulsión, uno sometido a sobrepresión y el otro a depresión. Ello favorece el aumento del rendimiento energético.
} 


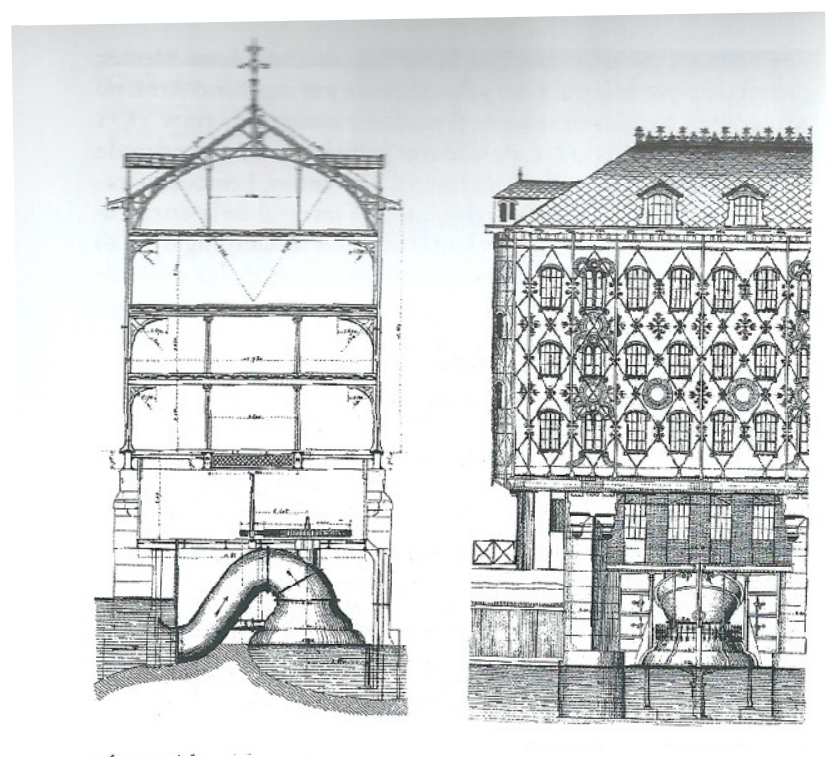

Figura 107. Fábrica de chocolates Menier, Noisel-sur-Marne, Francia, construida por el arquitecto Jules Saulnier y el ingeniero Armand Moisant en $1871 \div 1872$ (Darley, 2010).

La cubierta es a dos aguas, sobresaliendo los faldones respecto de las fachadas, planas simétricas, con 54 ventanas uniformemente distribuidas en las de mayor tamaño y 10 en las otras dos, donde se encuentran las puertas de acceso. En la principal dispone en su parte más alta de un gran y exageradamente adornado reloj, que marcaba las horas de entrada, salida y cambio de turno de los trabajadores.

\section{ESTRUCTURA}

La fábrica Menier fue otro de los primeros edificios con verdadero esqueleto realizado completamente en hierro fundido. Descansa sobre 4 pilones de piedra apoyados sobre el lecho del río Marne, cuya corriente atravesaba los 3 huecos formados entre ellos para mover las turbinas hidráulicas. 
El edificio se levanta sobre 4 jácenas huecas de hierro o "iron box girders" (Darley, 2010), todas ellas de sección cuadrada, de $72 \mathrm{~cm}$ de canto. Estas vigas forman la base completa del edificio, y por ello ha sido calificado por muchos autores como el primero en emplear los principios del esqueleto (Giedion, 1978), es decir, el precursor para el que se diseñó una estructura de hierro para soportar todo su peso. Este esqueleto puede verse desde el exterior, en la superficie de los muros, los cuales están realizados con ladrillos huecos, que funcionan simplemente como un mero relleno [Figura 108].

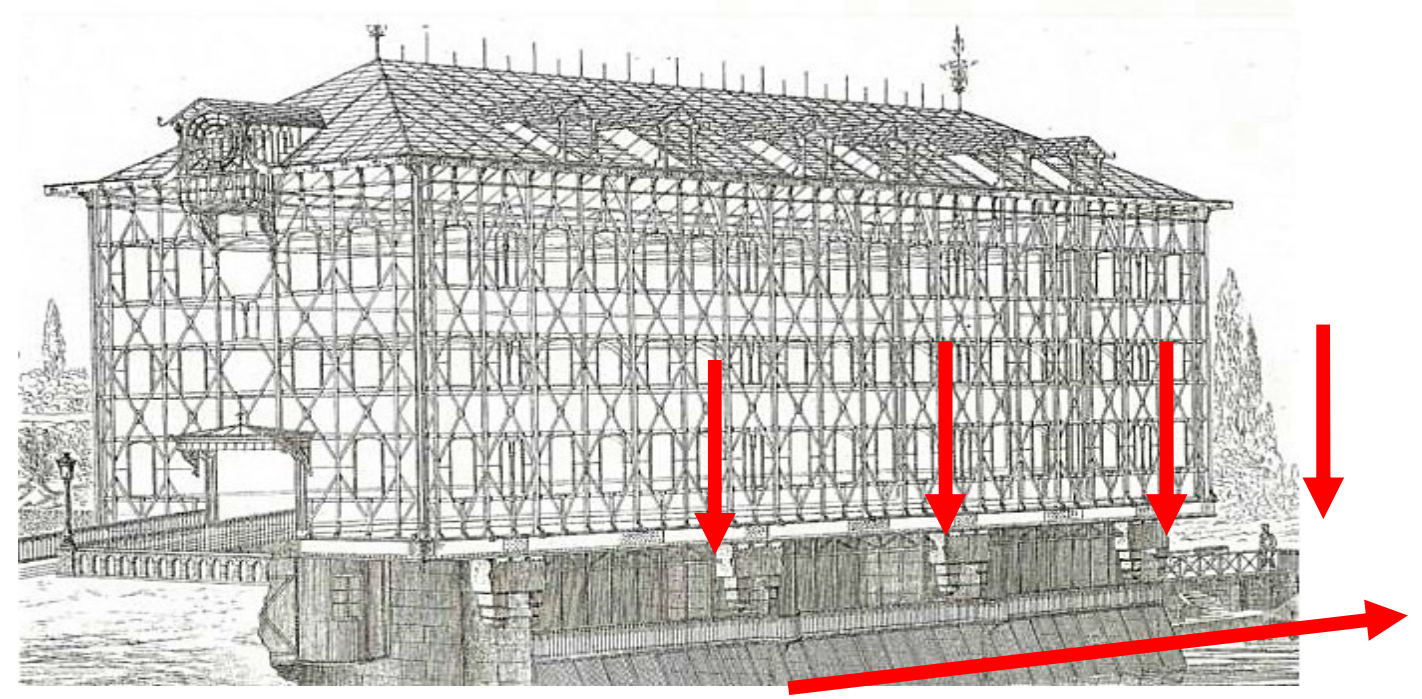

Figura 108. Esqueleto de la fábrica de chocolates, con sus cuatro grandes pilares apeados sobre la viga principal, en la base del edificio.

(http://pone.lateb.pagesperso-orange.fr/moulin\%20saulnier.htm).

La estructura vertical está compuesta por una serie de pilares muy esbeltos arriostrados diagonalmente, formando una retícula a base de rombos. De esta manera, la estructura se concibe como una "gran jaula autoportante" (Darley, 2010). 
Según esta autora, este tipo de construcción, en sus orígenes, cuando fue utilizado por Saulnier, era considerablemente más caro que cualquier otro realizado hasta el momento, por lo que además de admiración entre los arquitectos e ingenieros del sector, generó muchas expectativas en cuanto a su funcionamiento práctico y técnico.

Los planos se publicaron con todo detalle en las más conocidas revistas francesas del momento, si bien, la obra de Saulnier resultó "completamente desconocida en Estados Unidos" (Darley, 2010). Es por ello que Darley considera que este sistema constructivo no tuvo ninguna influencia en el desarrollo de los rascacielos norteamericanos ${ }^{189}$.

Pero volviendo a Europa, hasta que no se tuvo conciencia de la importancia del almacén de embarcaciones de Sheerness (Kent, Inglaterra) del coronel Greene, que fue construido antes de 1860, se pensaba que la fábrica de chocolates de Menier era el primer edificio cuyas vigas y pilares de fachada eran todos ellos de hierro (Skempton, 1960).

Por otro lado también, en la introducción de su artículo leído en el Museo de la Ciencia de Londres, el 3 de febrero de 1960, dijo: "To anyone at all conversant with the history of nineteenth-century building construction it will be obvious that the Boat Store provides a challenge. A mere 8 years later than the Crystal Palace, it seems to belong to a different age, in spite of the advanced technique of that work. Moreover, the Boat Store was completed 12 years before the famous Menier factory in France, traditionally though quite incorrectly considered to be

\footnotetext{
${ }^{189}$ Aunque los métodos de Saulnier diferían en varios aspectos de los que proponía Buffington*, el constructor francés se había anticipado al norteamericano: había levantado casi una década antes un edificio cuyas fachadas estaban sostenidas exclusivamente por jácenas de hierro forjado. En esencia, había que entender la factoría de Noisiel como un entramado de hierro revestido de albañilería (Banham, 1989).

* Leroy Buffington patentó en los Estados Unidos, en 1888, la forma de construir estructuras mediante una estructura de celosía (pilares, vigas y losas) para reemplazar las paredes portantes, y tener la función de cierre, revolucionando la forma de proyectar y construir edificios.
} 
the first multi-storey iron-framed building. Also, the Menier factory is far less elegant structurally, whilst architecturally it is altogether typical of the late Victorian period" ("A todo aquel familiarizado con la historia de la construcción del siglo XIX, le será trivial considerar que el Boat Store contrajo un reto. Tan solo 8 años posterior al Crystal Palace, parece pertenecer a otra época, gracias a sus avances técnicos. Además, el Boat Store se ejecutó 12 años antes que la famosa Factoría de Menier, en Francia, generalmente conocida, si bien incorrectamente, como la primera de varias alturas con estructura de hierro. También, la factoría de Menier es muchísimo menos elegante estructuralmente, mientras que arquitectónicamente es al mismo tiempo típica del periodo Victoriano").

Por otro lado, a diferencia del edificio de Saulnier, el almacén de embarcaciones de Sheerness no tenía la necesidad de mostrar ningún ornamento (Skempton, 1960). Estaba escondido en un astillero naval de una ciudad no demasiado importante desde el punto de vista industrial o económico. En este la apariencia externa estaba totalmente en consonancia con la ligereza de su estructura novedosa de hierro, al contrario de lo que ocurría con la de Saulnier. En cambio, ambos diseñadores prescindieron de la solución constructiva de los muros de carga, liberando las fachadas de todo esfuerzo portante al haberles llegado también a ellas la estructura. Del mismo modo, al aligerar todo el peso de la estructura y de los cerramientos, las cimentaciones eran de un menor tamaño.

Por su parte, sendos entramados de hierro tenían claras ventajas frente a los sistemas constructivos convencionales: eran más rápidos de construir y tenían la capacidad de tener mayores superficies de ventana, consiguiendo una mayor iluminación natural (Darley, 2010). Lo ingenioso surgió de la utilización de unos nuevos perfiles estándar recién ideados y unas carpinterías metálicas más resistentes. Se deduce que claramente, cuando la estructura alcanzó las fachadas, la fábrica cambió. De hecho, este sistema ha conservado su tipología hasta la actualidad. 
La cubierta estaba realizada con cerchas metálicas que permitían una gran diafanidad para la instalación de maquinaria.

En este sentido, por todo lo dicho en los anteriores dos párrafos, al estar construido en hierro, también se puede considerar como una fábrica moderna resistente al fuego.

\section{CERRAMIENTOS}

Aquellos edificios coetáneos que pretendían tener un carácter formal o representativo, tenían las fachadas sobrecargadas de decoración. En este caso, se trataba de muros de entramado metálico, rellenos de ladrillo hueco coloreado formando motivos ornamentales, de $18 \mathrm{~cm}$ de espesor total, encajado entre los elementos verticales metálicos. No tienen función portante, únicamente funcionando como envolvente.

Estas fachadas del edificio de Saulnier eran totalmente planas (Giedion, 1978). El sistema de construcción usado "producía una superficie enteramente homogénea y nivelada de arriba abajo, sin saliente alguno, ni horizontal ni vertical". Pero, pese a la novedad tecnológica de su construcción no pudo ir en contra del gusto europeo de los años 1870, "empleando aparejo de ladrillo con dibujo de azulejos multicolores". La piel era sumamente decorativa (Darley, 2010), construida mediante ladrillo y placas cerámicas, y "que parecía estar sumamente en desacuerdo con la habilidosa ingeniería interior". El muro exterior no refleja pues en sí la organización interior [Figura 110, Figura 111 y Figura 112].

Pero a pesar de todo, la ornamentación era realmente muy económica, puesto que en el fondo se trata de una simple variación de color del ladrillo. Esta está en correspondencia con la estructura metálica, pasando por detrás de ellas. También dispone de elementos decorativos singulares como paneles de terracota esmaltada con el símbolo de la empresa o con referencias a la planta del cacao. 
La fachada también por su parte ejercía su papel comercial (Sebastià, 2007). Las empresas habían sufrido un gran cambio durante la segunda mitad del siglo XIX, Y buscaban obtener el máximo beneficio tratando de aumentar su mercado. Había cada vez más donde elegir, por lo que la calidad del producto entró en juego, así como la publicidad. "La fábrica-edificio hizo su función como elemento propagandístico". Para muchos fabricantes, como es el caso de Menier, esta se convirtió en un modo de prestigiar sus productos y construir una imagen de empresa: "el edificio comenzó a tener un valor comercial además del estrictamente funcional como espacio de trabajo, por lo que indiscutiblemente cabía preocuparse de su estética"190.

\section{FUENTES DE ENERGÍA}

Un ejemplo notable de "moderna propulsión por turbinas de eje vertical" es la fábrica de chocolates de Menier (Darley, 2010), diseñada por el ingeniero Armand Moisant ${ }^{191}$. Estas turbinas hidráulicas, aumentaban considerablemente la eficiencia del sistema mecánico respecto de las ruedas hidráulicas utilizadas con anterioridad. Estaban ubicadas en la parte inferior del edificio en contacto con el lecho del río, y que como se aprecia en la Figura 109, apoyaban en los pilares de piedra referidos en el párrafo dedicado a la descripción de su estructura.

\footnotetext{
190 Según George M. Price (Price, 1914), en algunas compañías había gratificaciones a los trabajadores por sus servicios, como el caso de la fábrica de Menier, en la que se daba dinero extra a aquellos trabajadores que habían estado empleados durante al menos 20 años (un total de $8 \mathrm{f}$ cada año añadido al salario).

Otro dato característico es que según George M. Price (Price, 1914), la fábrica de Menier había construido una colonia residencial de 312 casas pareadas, escuelas, un restaurante y diversos locales de ocio, así como un hogar para jubilados, lavanderías y baños públicos.

${ }^{191}$ Armand Moisant (1838 - 1906), es un ingeniero estructural y un industrial francés que destacó a partir de 1870 por las principales obras de construcciones metálicas de Francia como el Bon Marché, el Gran Palacio y otros trabajos para la Exposición Universal de París. Se consideró como uno de los principales competidores de Gustave Eiffel.
} 


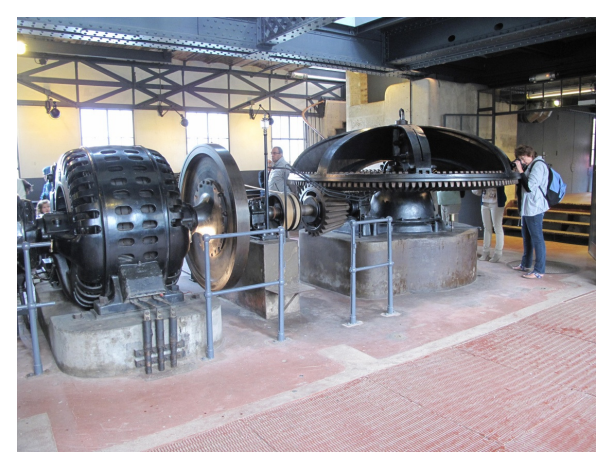

Figura 109. Relativo a la fotografía Figura 195.

(http://pone.lateb.pagespersoorange.fr/Batiments.htm).

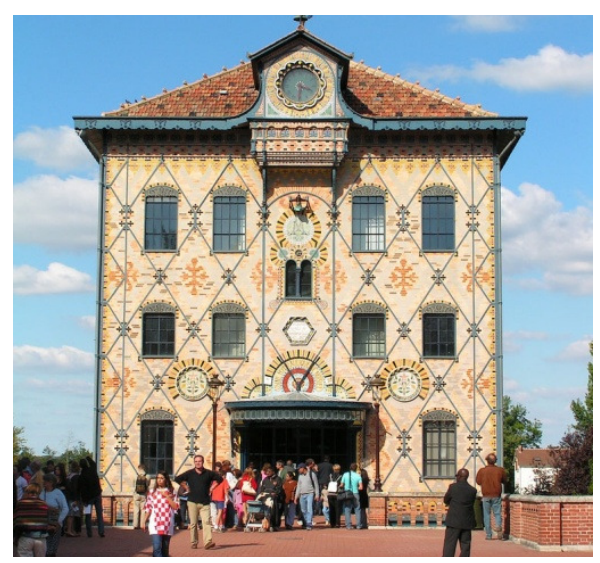

Figura 110. Fachada principal, acceso (http://www.arqueologiaypatrimonioindustri al.com/2008/11/francia-mulin-saulnierfotografias.html).

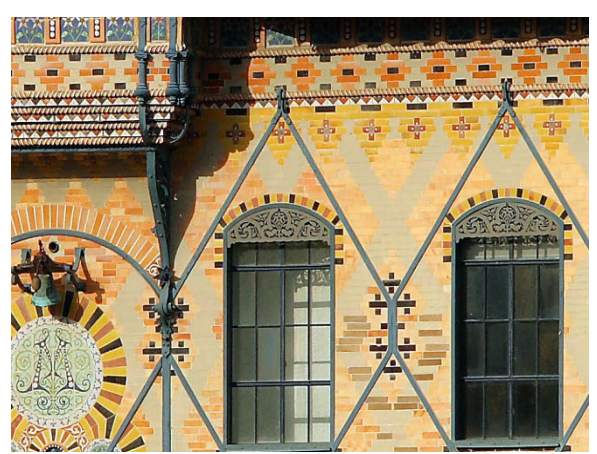

Figura 111. Detalle de fachada (http://unapizcadecmha.blogspot.com.es/20 13/06/fabrica-de-chocolates-menier-ennoisiel.html).

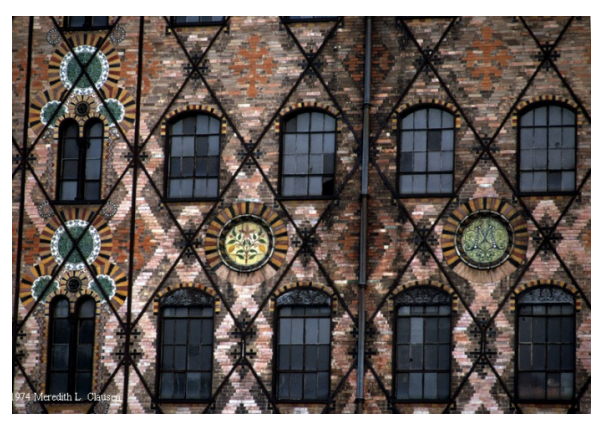

Figura 112. Detalle de fachada (http://unapizcadecmha.blogspot.com.es/20 13/06/fabrica-de-chocolates-menier-ennoisiel.html). 


\subsubsection{Packard Motor Car Company, 1905, Detroit, Estados Unidos}

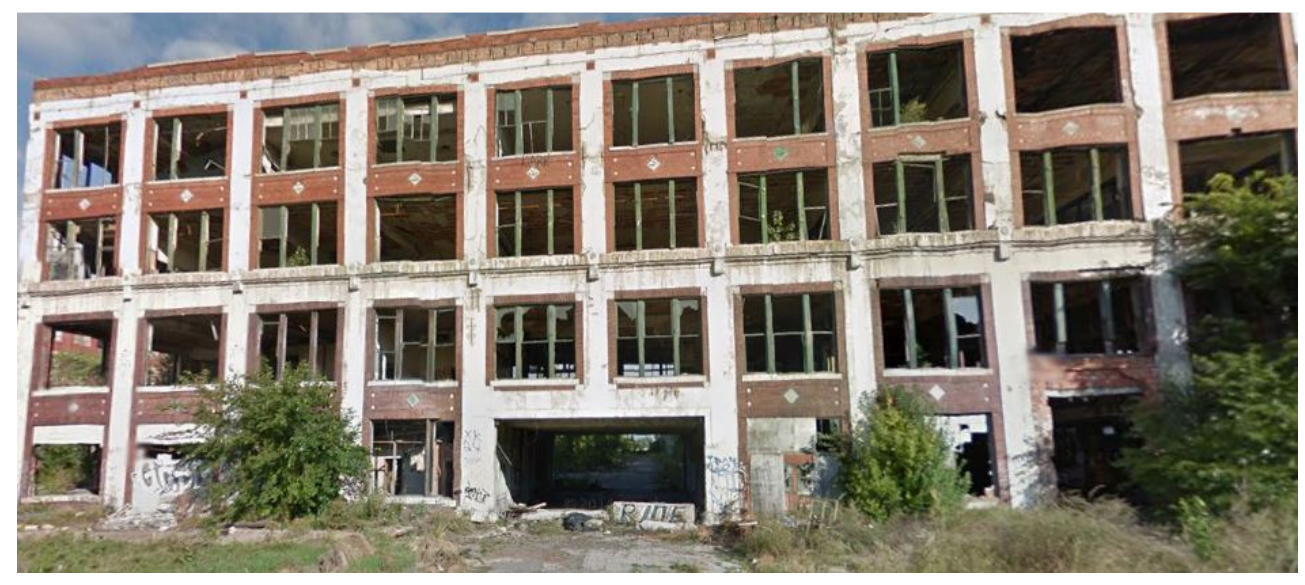

Figura 113. Vista actual de la fachada de la Packard Motor Car Company, Detroit, 1905 (https://www.google.es/maps).

La primera gran fábrica de la Packard, conocida por su nombre en inglés como la Packard Motor Car Company's Factory, fue construida entre 1903 y 1905 por el arquitecto Albert Kahn. Fue el primer edificio diseñado por este arquitecto en hormigón, aunque también se le conoce como Edificio 10 porque fue el décimo que diseñó para la firma de automóviles Packard. Ello le permitió tal reconocimiento que cuando en 1908 Henry Ford lo visitó, Kahn se convirtió en el arquitecto de todos sus nuevos edificios (Moritz, 1969) ${ }^{192}$ [Figura 113 y Figura 114].

\footnotetext{
${ }^{192}$ A Albert Kahn se le conoce por haber diseñado más de 1.000 edificios en EEUU, aunque no todos ellos tenían un origen industrial.
} 

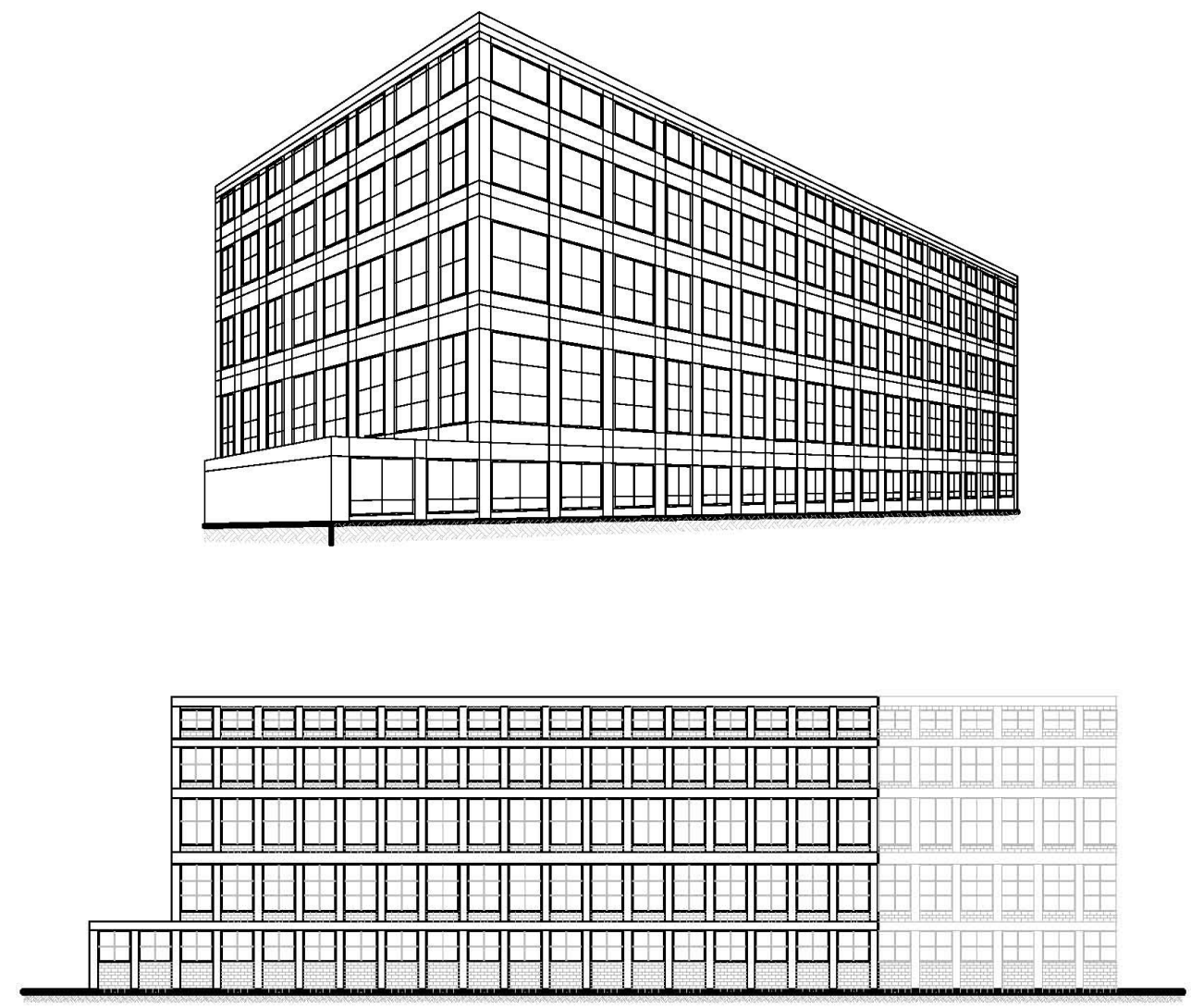

Figura 114. Alzados de la planta actual (S/E). 


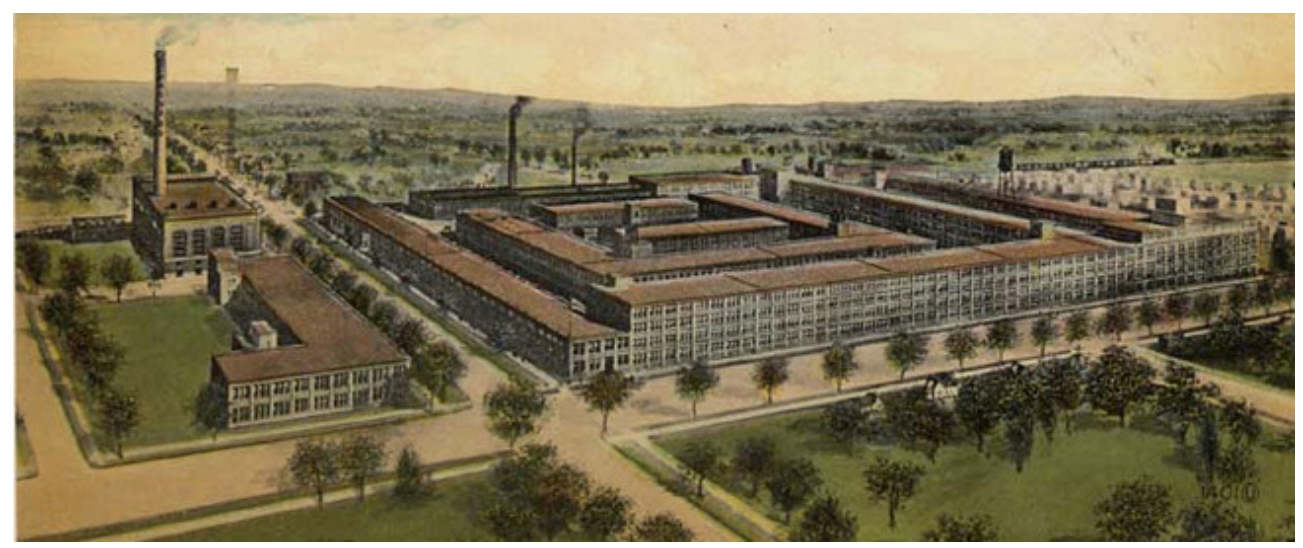

Figura 115. Vista de pájaro de la Packard Motor Car Company, Detroit, a principios de siglo (http://www.cca.qc.ca/en/collection/1958-the-site-of-the-packard-motor-company).

\section{LOCALIZACIÓN}

El complejo industrial se ubica en al este de la ciudad de Detroit, en una parcela de unas $14 \mathrm{Ha}$. La construcción en su totalidad ocupa alrededor de $350.000 \mathrm{~m}^{2}$, la mayoría de ellos realizados con hormigón armado. Su fecha de inauguración fue a principios del siglo $X X$, aunque su funcionamiento completo como manufactura de automóviles solo duró unas 6 décadas. Fue en ella donde empezaron a trabajar el mayor número de operarios para la producción en cadena, lo que da cuenta de las medidas necesarias (Frampton, 1989) [Figura 115]. 


\section{DESCRIPCIÓN}

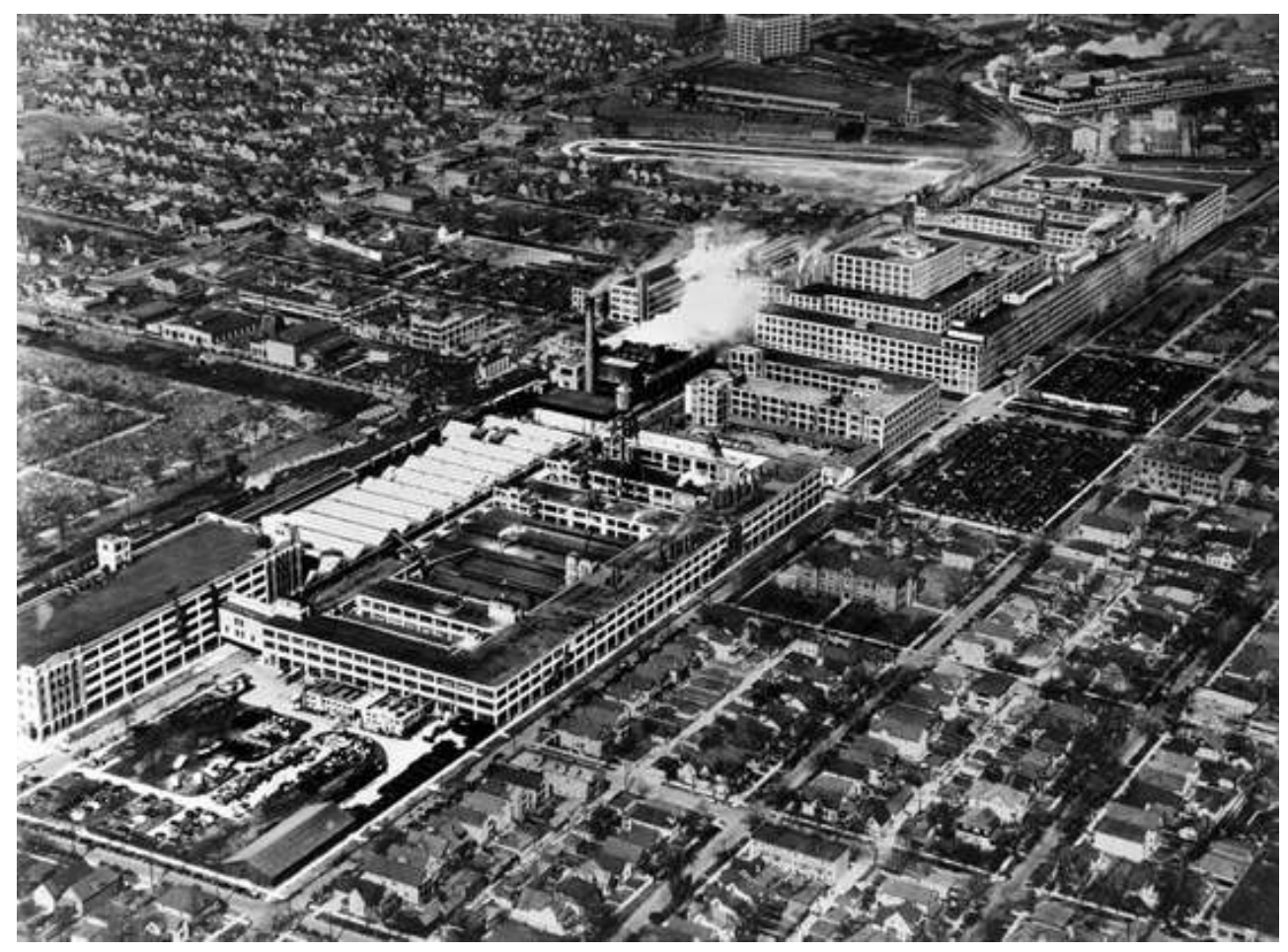

Figura 116. Vista aérea del complejo industrial de la Packard Motor Car Company, Detroit, cuyas dimensiones eran gigantescas (http://theoldmotor.com/?tag=the-packard-motor-car-companyplant).

El complejo estaba compuesto de varios edificios [Figura 116], de diferente número de plantas, aunque lo que se repetía era la disposición de las fachadas: generalmente soportes de hormigón y ventanas de carpintería metálica de pilar a pilar y desde un pequeño antepecho al forjado superior, aprovechando al máximo la cantidad de luz que podía entrar a los espacios interiores de trabajo [Figura 117]. 


\section{ESTRUCTURA}

La estructura que conformaba la mayoría de los edificios estaba ejecutada con hormigón armado, siendo por primera vez utilizado en estas dimensiones por Albert Kahn [Figura 117, Figura 119 y Figura 120].

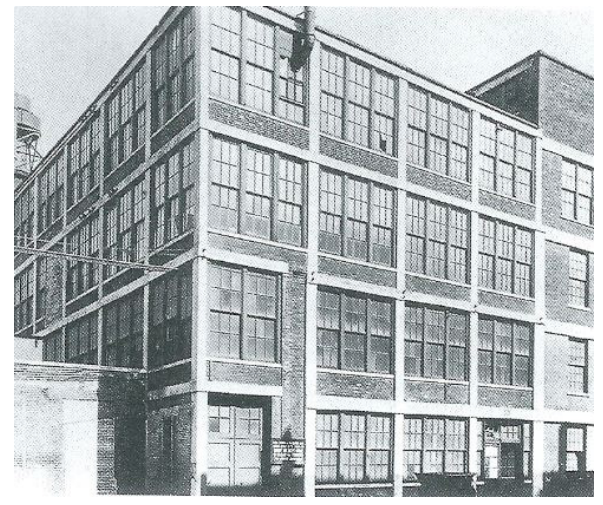

Figura 117. Parte del Edificio 10 que fue ampliado en dos alturas (Darley, 2010).

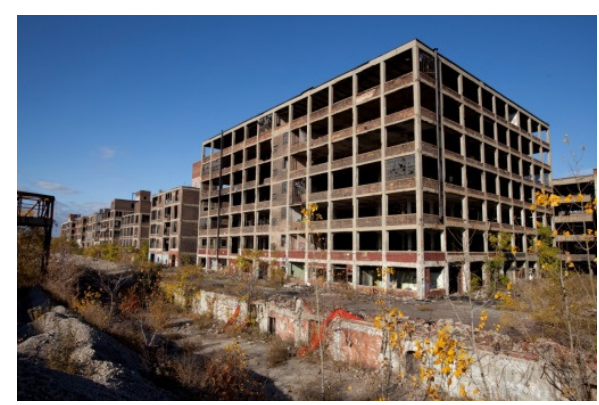

Figura 118. Estado actual de abandono de los edificios que conforman el complejo industrial de Albert Kahn, que dejó de producir a principios de la segunda mitad del s. $X X^{193}$ (https://www.google.es/maps).

Con esta construcción se consigue la fábrica diáfana bien iluminada, gracias a las propiedades estructurales del hormigón, y es precisamente esta idea, la que ha conducido a su elección para la inclusión en este estudio. Precisamente la tesis acaba en el tiempo cuando la estructura de hormigón alcanza la fachada, en las primeras décadas del siglo XX.

Albert Kahn, además de este complejo industrial, diseñó un numeroso repertorio de obras industriales y residenciales durante la primera mitad del siglo XX, incluso

\footnotetext{
${ }^{193}$ Se percibe la secuencia de pilares uniformemente distribuidos, con antepechos en cada planta quedando unos huecos de ventana de gran superficie.
} 
llegando a representar, en 1938, el $20 \%$ de las factorías construidas en EEUU, según los datos que la página web de Ford indica [Figura 119 y Figura 120].

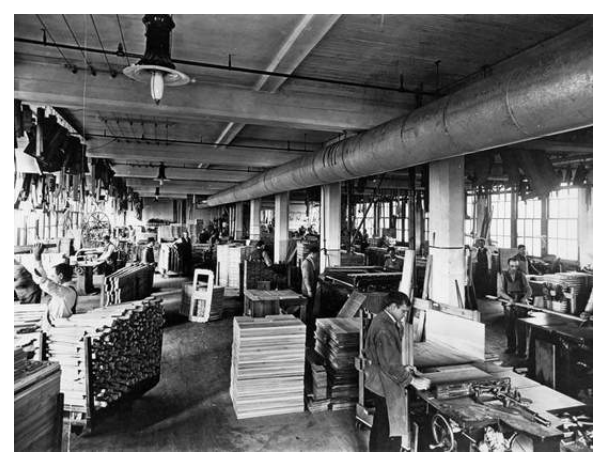

Figura 119. Vista interior de la fábrica, con los pilares y forjados de hormigón.

(http://www.abandonedamerica.us/packard-handassembly-c-1910).
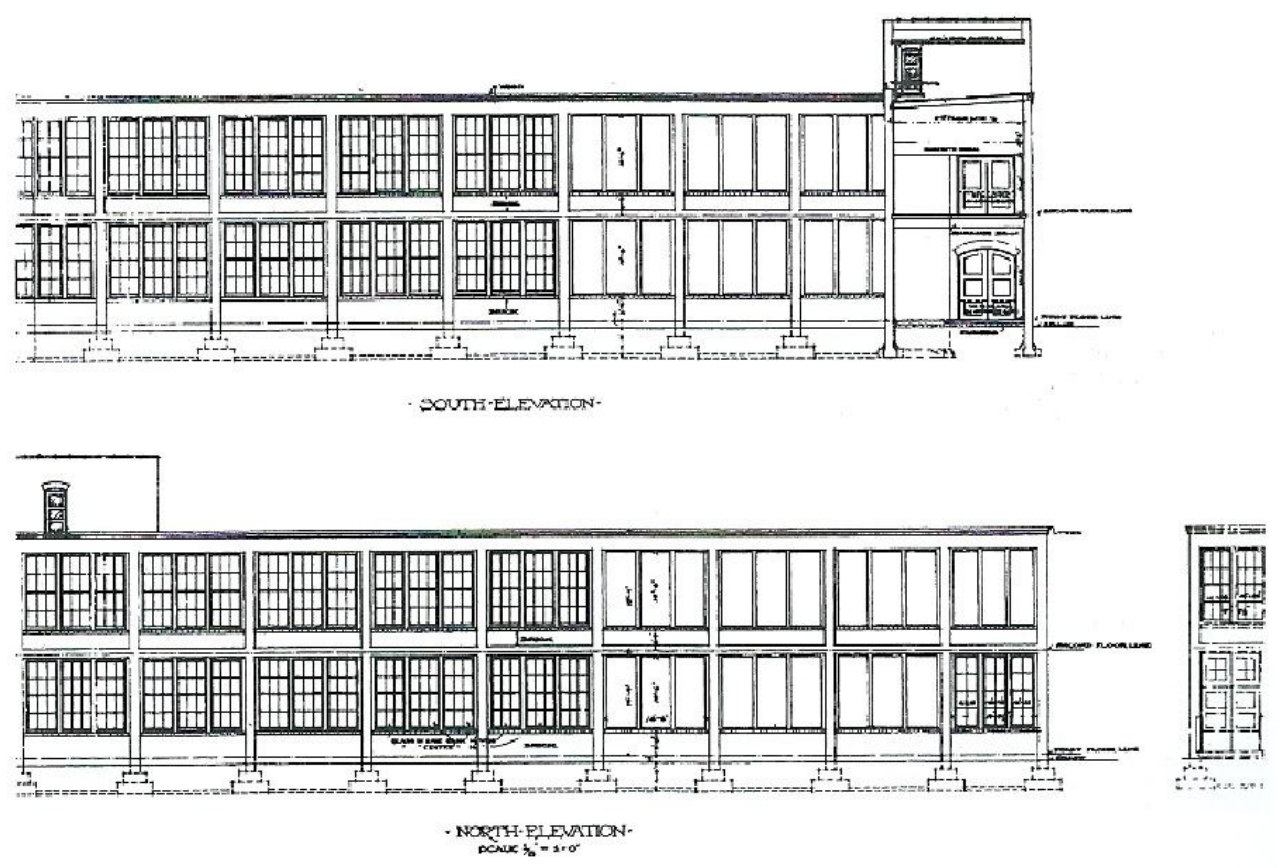

Figura 120. Edificio 10 de Albert Kahn, alzados y planos de cerramientos y fachadas principales (Darley, 2010). 
En esta misma época de principios del siglo pasado, en Inglaterra también se estaban construyendo grandes fábricas con hormigón, como la New Little Mill (1908), la Paragon Mill (1911) o la Royal Mill (1913), de la extensión industrial de la Ancoats de Manchester, si bien estas tenían una apariencia exterior completamente diferente (Price, 1914). Sus fachadas eran a base de ladrillo rojo cara vista, con grandes ventanales separados por pilastras de cierto espesor, y su estructura interior utilizaba vigas acero para apoyar los forjados. De hecho, el hierro fundido todavía estaba presente en detalles constructivos de muchas construcciones fabriles europeas (Martínez, 2006) ${ }^{194}$.

${ }^{194}$ Eso sí, ya solían disponer de sus edificios adyacentes para suministrar la energía eléctrica necesaria para el accionamiento de sus maquinarias. 


\subsection{FACTORES}

Una vez analizados desde el punto de vista del trinomio edificio-motor-máquina los principales mill buildings que han existido a lo largo del periodo en estudio, después de haber presentado los principales hitos que la revolución industrial dejó como insignias, y antes de poder analizar los edificios valencianos dedicados a la producción, es necesario disponer de unas herramientas que ayuden a caracterizarlos [Figura 121].
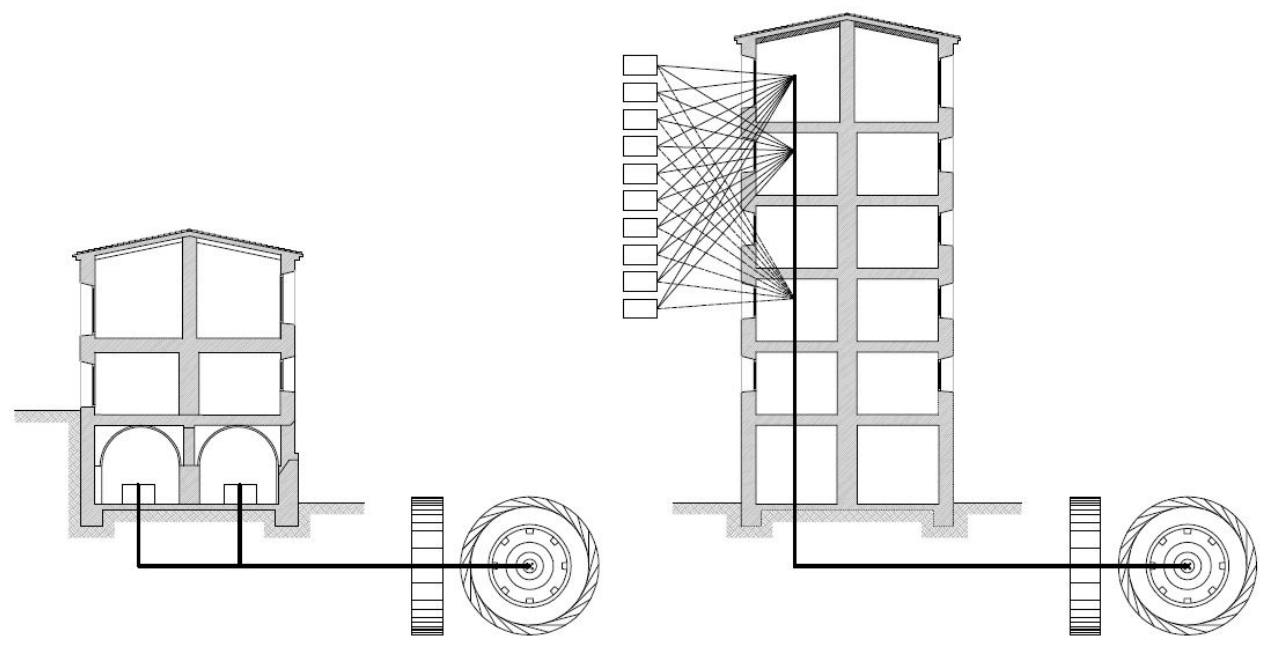

Figura 121. Comparación entre el esquema general del trinomio edificio-motor-máquina y el del edificio-motor-máquinas: la figura de la izquierda se corresponde con las serrerías, herrerías, batanes, harineros, papeleros, almazaras, etc, habituales antes de la construcción de molinos de varias plantas (figura de la izquierda), tipología que salvo excepciones (como la fábrica de los Hermanos Lombe), no se comenzó a extender hasta las últimas décadas del siglo XVIII.

Del conjunto de variables o factores que definirían las características de un edificio industrial hay tres que destacan [Figura 122]. A saber: 1) El sistema energético utilizado en todas sus formas para el accionamiento de los artefactos primero, y posteriormente la maquinaria de los diferentes procesos productivos; 2) Los materiales de construcción utilizados, por su comportamiento mecánico y 
estructural, y por su manera de resistir frente al fuego; y 3) La iluminación como requisito indispensable para trabajar.

Elegidos estos como fundamentales para la caracterización de los espacios industriales, se pasa a correlacionarlos, previamente mediante una sucinta presentación, y después, más detalladamente.

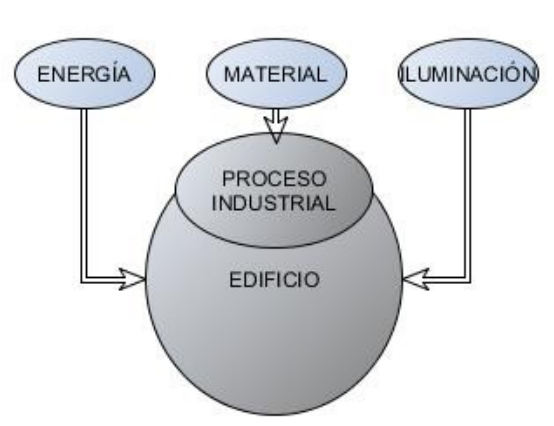

Figura 122. Los espacios industriales se definen, como las tres patas de un taburete, en tres factores fundamentales: la energía para su funcionamiento mecánico, los materiales de su construcción y la iluminación.

En primer lugar, se hablará de la fuente de energía y la forma de transmitirla a los diferentes puntos del espacio de producción [Figura 123]. Si la alimentación energética es hidráulica, eólica o mediante el vapor de las máquinas de Boulton y Watt, no solo condicionará su localización ${ }^{195}$ sino la distribución interna, entre otros por la longitud máxima que podían someter a torsión sus ejes de madera o metálicos, que a su vez determinó la forma de los edificios fabriles. De este modo, la solución del edificio de múltiples plantas parecía la más adecuada conforme las necesidades de producción iban aumentando.

Y así, esta tipología de edificios enlaza con el aumento de la relación entre la superficie de fachada con respecto a la de la planta, con el propósito prioritario de conseguir la mayor cantidad de iluminación natural posible, otra de las variables en estudio.

\footnotetext{
${ }^{195}$ Industrial history farm to factory 1720-1900 (http://industryinform.co.uk/earlyyears.aspx)
} 
Mientras tanto, para iluminar la parte central de estos edificios altos y alargados, el alumbrado mediante velas provocaba innumerables incendios. En los primeros años de la revolución industrial, el constante peligro de siniestro provocaba un aumento exorbitante de las primas de las compañías aseguradoras (Fairbairn, 1863). Evitar esos riesgos se convertirá en uno de los principales objetivos de los empresarios textiles, buscando el mejor edificio a prueba de incendios o "fireproof".

Por otro lado, los edificios fabriles no hubieran podido evolucionar tan rápidamente sin los primeros cálculos de resistencia de materiales y sin la apuesta por unos sistemas estructurales y constructivos capaces de darles forma (Fairbairn, 1857). Es por ello, que esto último se convertirá para este estudio también en factor clave: la madera, el hierro fundido, el hierro forjado, el acero, el hormigón y también los mampuestos para la formación de muros de carga, son los materiales que se analizarán en el apartado correspondiente.

Se acabará el estudio analizando cómo se implantaron estos avances en los "mill building" sobre la industria valenciana, qué influencia tuvieron y cuáles fueron sus ventajas en la etapa de resurgimiento industrial, tal y como se argumenta en los párrafos previos al estudio de los edificios valencianos escogidos \{el estudio de los edificios valencianos se realizará en el capítulo 4 más adelante\} [Figura 123]. 


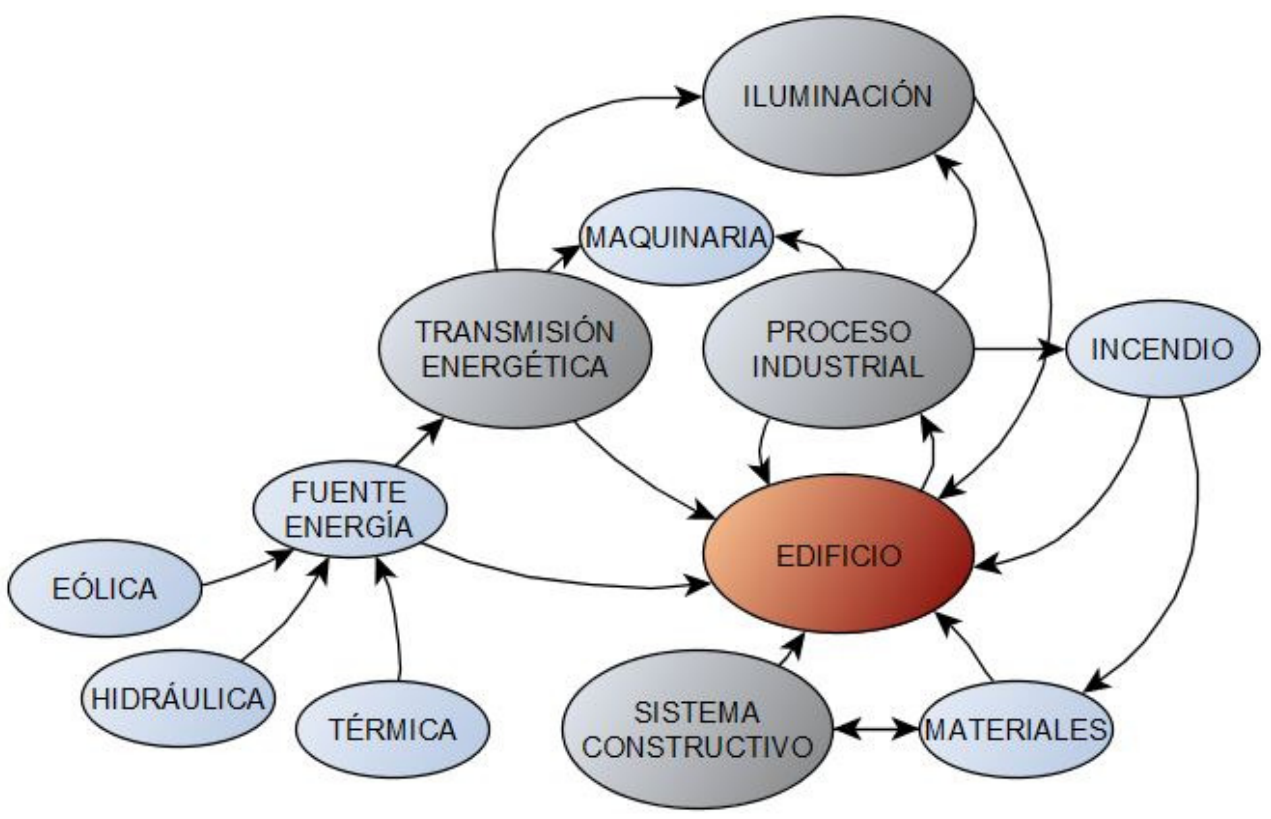

Figura 123. Esquema general de los factores influyentes en la evolución de la forma de los edificios industriales, donde además se refleja su interrelación. Apréciese además la importancia que adquiere el proceso industrial en la configuración del espacio. 


\subsection{EL EFECTO DE LA ENERGÍA DE ACCIONAMIENTO EN LOS EDIFICIOS FABRILES}

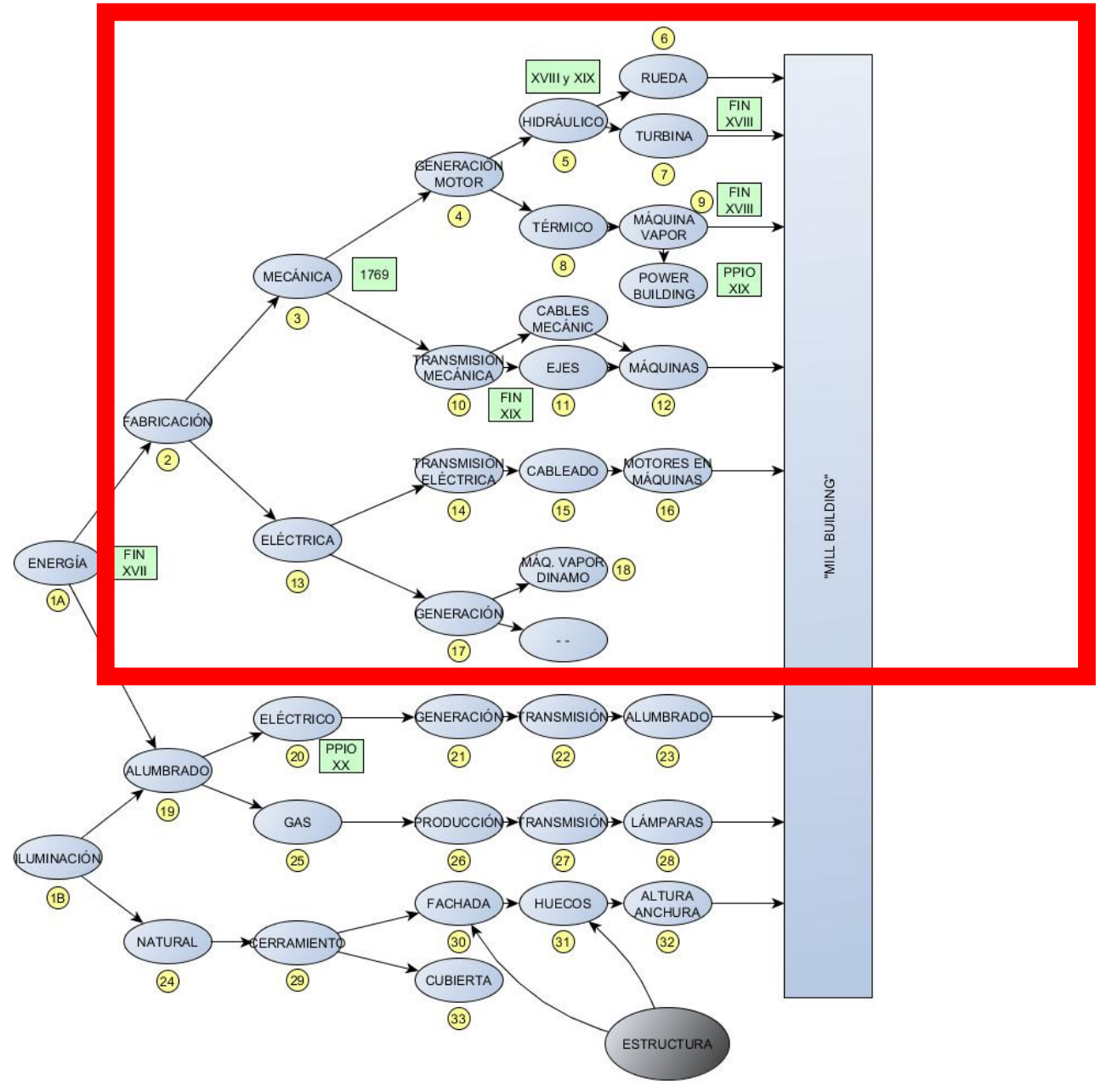

Figura 124. Esquema conceptual del factor energético como base del desarrollo evolutivo de los espacios fabriles. Los sistemas productivos están compuestos de tres elementos básicos: materiales, máquinas y operarios, pero la energía constituye un elemento clave para el accionamiento de su maquinaria. En este modelo aparece también la iluminación como variable esencial íntimamente ligada a la energía en cualquier régimen industrial, y cuyo efecto será valorado en próximos apartados \{página 348$\}$. 
El estudio de la fuente de energía y su transmisión en la mecanización industrial resulta imprescindible para poder abordar el estudio de las transformaciones que han ido sufriendo los edificios fabriles como envolvente de los procesos productivos [Figura 124].

La energía ha sido necesaria desde siempre tanto para el accionamiento de la maquinaria (Geijo, 2005), desde los orígenes de la mecanización [Estado $1 A$ de la Figura 124$]^{196}$, como para la iluminación. Será pues necesario evaluar la trascendencia que esta tuvo sobre los espacios fabriles.

Su manifestación en la producción industrial fue inicialmente de forma mecánica [Estado 3], y posteriormente eléctrica [Estado 13]. Con esta última, además se consiguió que una misma fuente proporcionara iluminación en las fábricas durante la noche y en días de poca luz [Estado 19], evitando los constantes riesgos de incendio provocados por la combustión de sustancias como el gas o el aceite. Su mejora en lo referente al transporte, provocó un cambio radical en la interdependencia entre el edificio y la maquinaria [Estado 14].

Pero como se ha dicho, hasta ese momento, a principios del siglo XX, el accionamiento de la maquinaria había sido totalmente mecánico [Estado 4], bien hidráulico [Estado 5], bien eólico, o térmico mediante el uso de la máquina de vapor. Las ruedas hidráulicas [Estado 6] y las turbinas [Estado 7] actuaban en la mayoría de los casos como motor único, esto es, impulsando por todo el volumen fabril desde un solo punto, arranque de la energía mecánica que se transmitía mediante ejes, poleas y correas a las máquinas ${ }^{197}$.

\footnotetext{
${ }^{196}$ Es la máquina de hilar de Arkwright la que se establece en la bibliografía industrial como uno de los mayores hitos tecnológicos.

${ }^{197}$ La primera mecanización arrancó en América alrededor de 1790 de la mano de Samuel Slater (1768 - 1835), cuya experiencia provenía de Gran Bretaña, de donde no se podía obtener información gráfica pero sí práctica. Este comienzo se iba extendiendo, hasta que en 1820, con la Boston Associates Company, en Massachusetts, el inventor americano Paul Moody (1779 - 1831)
} 
Con la invención de la máquina de vapor de Boulton y Watt ${ }^{198}$, poco antes del cambio de siglo del XVIII al XIX, si bien continuó existiendo el sistema de motor único $^{199}$, lo que se consiguió fundamentalmente fue un cambio de la fuente de energía que desligaría la localización del edificio de los cursos de agua ${ }^{200}$. Ello condicionó por sí mismo la forma y el tamaño de las manufacturas: en el primero de los casos debido a su nueva forma de construir siguiendo unos parámetros urbanísticos que condicionarían su planta y volumetría (Blasco, 2003), y en el segundo, por las posibilidades de ampliación de la producción que proporcionaban las modernas máquinas de grandes potencias ${ }^{201}$. Así de este modo, se ampliaría en general el volumen de las fábricas, como se demuestra con los casos estudiados en los que se instaló la máquina de vapor (Ditherington Flax Mill, Philips y Lee, y sucesivas, y las "fábricas mamuth" [Figura 125] (Darley, 2010)). Pero pese a ello, la transmisión mecánica en el interior de las mismas seguirá realizándose durante bastante más tiempo a base de ejes horizontales y verticales que cubrirán todos los espacios hasta donde se pudiera instalar una máquina, que de algún modo vendría limitado por la máxima capacidad a la torsión de estos [Estado 10].

\footnotetext{
instaló el primer sistema de transmisión de la energía por cableado mecánico del mundo, habiendo superado a Europa en evolución tecnológica (Biggs, 1996).

${ }_{198}$ Patentada por Watt en 1769, aunque la primera en construirse lo fue en 1774.

199 El concepto de motor único no se atribuiría a aquellos molinos que utilizaran más de una rueda hidráulica para su accionamiento, si bien, existen muy pocos ejemplos documentados (uno de los más renombrados es el complejo industrial de Saltaire en Bradford, de 1853, que disponía de sendas ruedas ubicadas en sus extremos longitudinales, y del que más adelante se hablará).

200 La máquina de vapor de Boulton y Watt tenía unos rendimientos aceptables para grandes potencias. En molinos de poca entidad no se llegaron a instalar hasta mucho después, hasta que no se mejoró su tecnología.

${ }^{201}$ Así pues, el aumento de plantas y la longitud ya se había hecho manifiesto en las primeras grandes fábricas de Manchester, como la Sedgewick Mill, de 1818-1820, o en las denominadas fábricas "mamut", de alrededor de 1830, con ejemplos como la Fishwick Mill, en Preston, de 1830; Travis Brook Mill, de 1834; o Shaddon Mill, de 1835-1836, considerada la más grande de la época.
} 

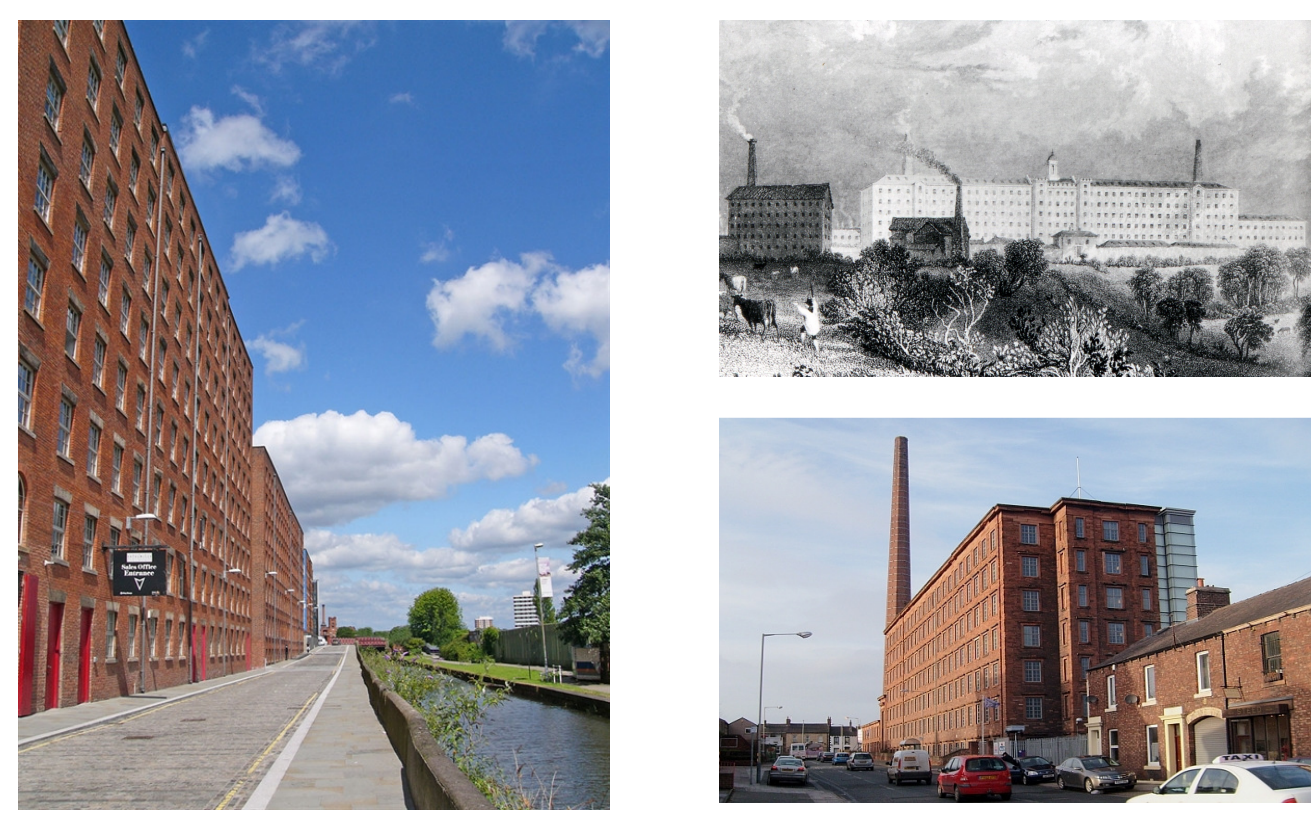

Figura 125. Ejemplos de fábricas "mamut", de izquierda a derecha: 1) Sedgewick Mill, de 1818-1820 (http://www.granitelettings.com); 2) Fishwick Mill, en Preston, de 1830 (http://www.dunkerleytuson.co.uk); 3) Shaddon Mill, de 1835-1836, considerada la más grande de la época (http://media.rightmove.co.uk). Al fondo sus chimeneas caracteristicas.

No es de nuevo hasta la utilización de la electricidad como fuente de energía [Estado 13 de la Figura 124] que los originales sistemas de transmisión primero (gruesos, pesados, de articulación rígida y muy ruidosos [Figura 126]), y el sistema de cableado mecánico que reparte la energía mediante cuerdas y poleas en cada una de las plantas segundo [Figura 127], se convertirán definitivamente en conductores eléctricos delgados flexibles, capaces de llevar la energía hasta todos los puntos de la fábrica [Estado 15 y Estado 16] ${ }^{202}$. Es por ello, que tras un periodo de mejoras tecnológicas, desaparece el concepto de motor único y aparecen varios motores en las manufacturas, llegando incluso a instalar uno por cada

\footnotetext{
${ }^{202}$ La máquina de vapor era cara y requería una escala o tamaño mínimo para amortizar la inversión, debido a que su rendimiento era aceptable solo a partir de una determinada potencia.
} 
máquina [Figura 121]. Más tarde, ello se convertirá en la técnica general de las instalaciones mecanizadas hasta la actualidad ${ }^{203}$. Esta última idea, y su influencia sobre los edificios, se detallará en el punto 1). "El accionamiento hidráulico" del siguiente apartado \{página 247\}.

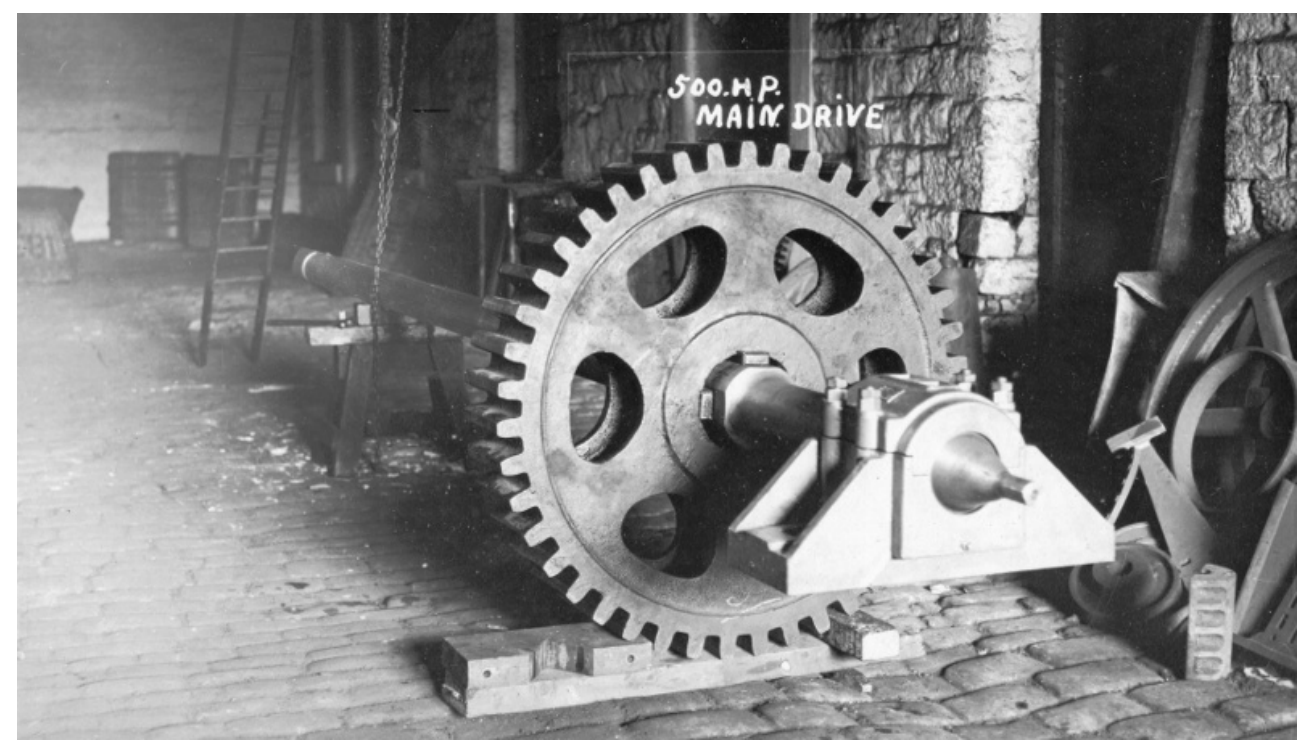

Figura 126. Fábrica textil en Lancashire, de alrededor de 1925, donde se puede apreciar las dimensiones del eje principal como el "driving spindle".

(http://Itp2013.oneguyfrombarlick.co.uk/www.pluggy.me.uk).

\footnotetext{
203 Una consecuencia inmediata de la electrificación fue la desaparición del "power building", o edificio que albergaba la máquina de vapor, así como sus chimeneas de los gases de combustión, lo que de alguna manera modificará los paisajes industriales de las ciudades industriales.
} 


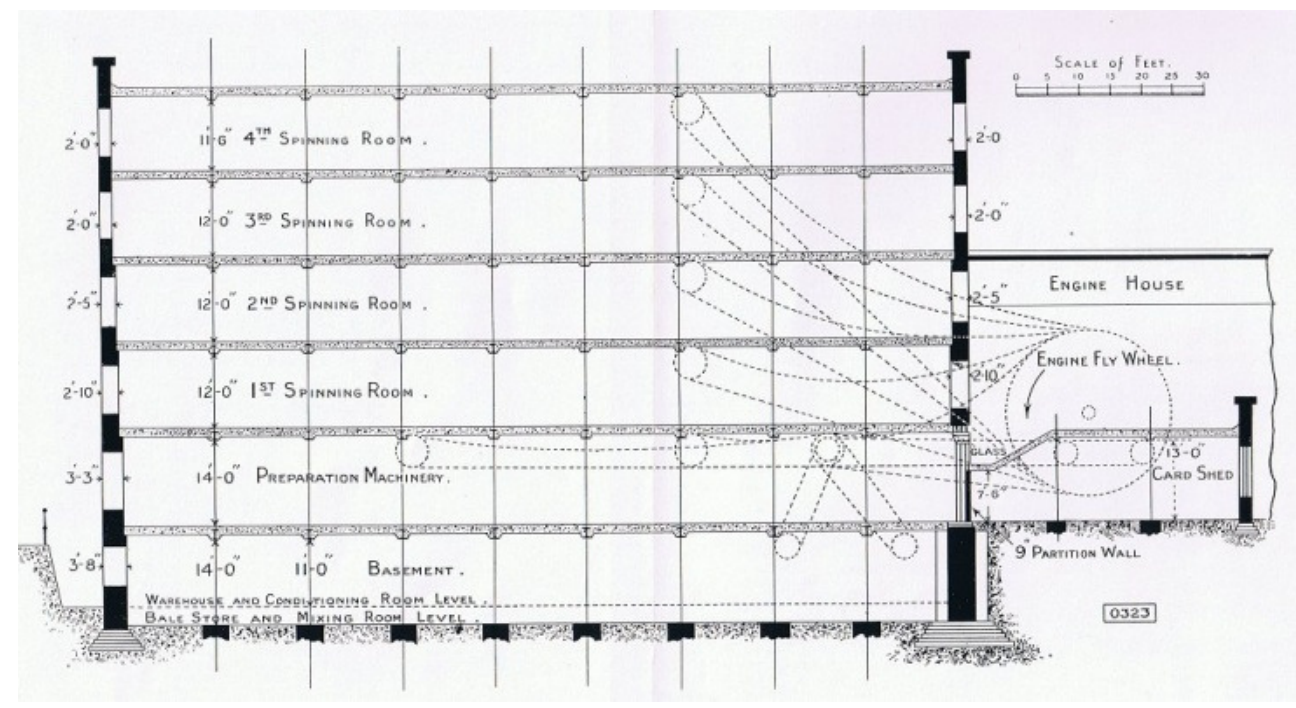

Figura 127. Ejemplo de distribución por cables mecánicos. Este modelo sucedió al de los ejes rígidos verticales (http://es.wikipedia.org/wiki/Transmisi\%C3\%B3n_mec\%C3\%A1nica).
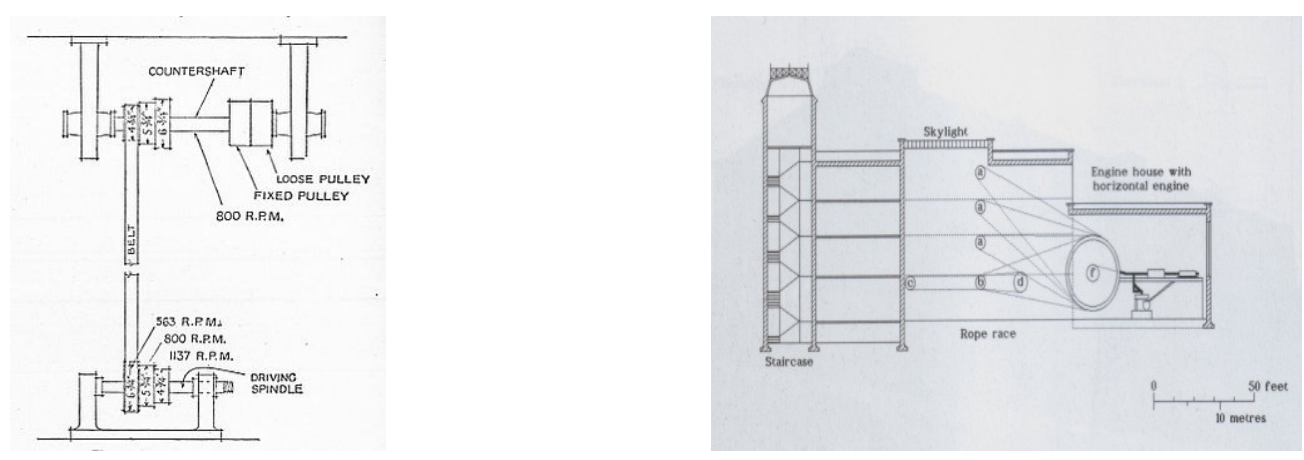

Figura 128. Mecanismos para la velocidad variable de ejes de transmisión mecánica para el accionamiento de maquinaria rotativa. \{http://en.wikipedia.org/wiki/Line_shaft\}. 
En la Figura 128 se aprecian los ejes, contraejes, partes fijas y móviles, cuerdas, poleas y el sistema de embragado de la maquinaria. La polea que aparece a la derecha con el nombre "Loose pulley" permitía parar la máquina de forma aislada, con independencia del sistema accionador. También se distinguen los engranajes para el cambio de velocidad de giro, en función de las necesidades. En cuanto a la figura de la derecha, se observa cómo la máquina de vapor accionaba una serie de cables mecánicos de forma que se independizaba el conjunto de las máquinas de cada planta.

Pero hasta que no se solucionó el problema de su generación y transporte, la máquina de vapor fue la encargada de proporcionar la energía, tanto para alumbrado como posteriormente para fuerza, mediante el uso de dinamos eléctricas accionadas precisamente por máquinas de vapor [Estado 17 y Estado 18].

En cuanto al alumbrado [Estado 19], este sigue su camino paralelamente al accionamiento mecánico: en las primeras décadas del siglo XX no había distinción entre las líneas eléctricas que proporcionaban la iluminación artificial [Estado 23] de las encargadas de la fuerza de la maquinaria [Estado 22]. El proceso pasó de las velas, lámparas de aceite o de gas (como el gas de agua, fabricado en la propia fábrica, que podía hacer funcionar pequeños motores o lámparas de poca potencia), y que eran realmente peligrosas por el riesgo de incendio que entrañaban, pasando por el arco eléctrico (de corriente continua, patentadas por Humphry Davy en las primeras décadas del siglo XIX), y por último, a la incandescencia (Thomas Alva Edison en 1880) [Estado 25]. Así pues, con la capacidad de la electricidad de proporcionar luz de forma segura y económica, y con el surgimiento al mismo tiempo de los nuevos materiales que mejoraron los sistemas constructivos, los edificios dejaron de tener esa tipología necesariamente estrecha y alargada, tan característica. Este proceso resultó dilatado en el tiempo, no consolidándose la electricidad al menos hasta el primer cuarto de siglo XX, lo que se detallará en el apartado correspondiente a la valoración de la influencia ejercida por el factor iluminación en la forma del edificio \{Apartado 3.6\}. 


\section{FORMAS DE TRANSMISIÓN ENERGÉTICA}

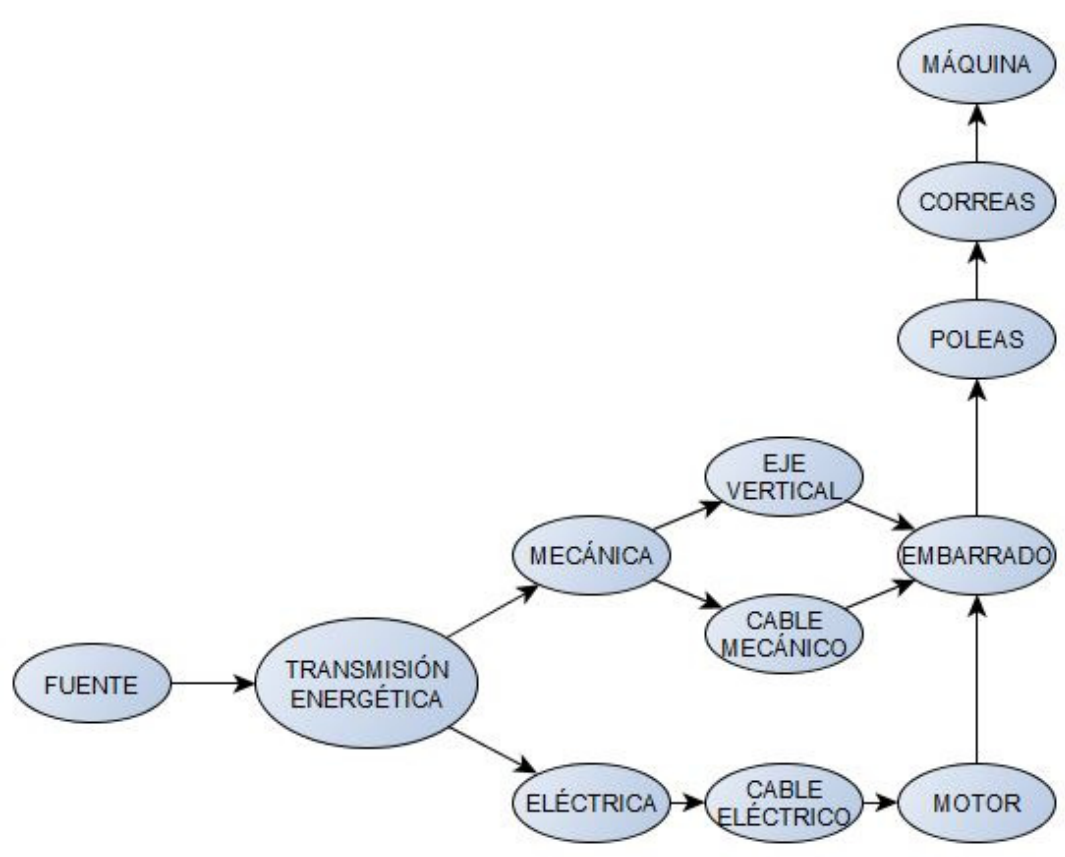

Figura 129. Formas de transmisión energética en el interior de los espacios fabriles.

Centrándose ahora en cómo se realizaba la transmisión mecánica en el interior de las fábricas [Figura 129], cabe partir de la premisa que durante el largo periodo comprendido entre los primeros molinos de grano y batanes que golpeaban los paños de principios del siglo XVIII hasta finales del siglo XIX, las máquinas de producción estaban conectadas mediante unión directa a las fuentes de energía que las accionaban [Estado 5 de la Figura 124]. En la mayoría de las manufacturas, una única fuente centralmente localizada, generalmente una rueda hidráulica o una máquina de vapor [Figura 130, Figura 131 y Figura 132], movían los ejes de transmisión de hierro a través de engranajes, ejes, poleas y correas de cuero que accionaban la molienda o el movimiento de la maquinaria. Estos árboles [Figura 133], normalmente de hasta 3 pulgadas de diámetro (Newbold, 1934), estaban 
suspendidos del techo o apoyados en pilares, y se extendían a lo largo de cada una de las plantas de la factoría ${ }^{204}$. La energía se distribuía entre las plantas por medio de ejes que transcurrían por patinillos o huecos realizados a los forjados. Como estos huecos eran pasos por donde se podía propagar fácilmente el fuego en caso de incendio (por el efecto chimenea), los cables mecánicos que iban entre plantas eran a menudo encerrados en una especie de patinillo de instalaciones. Las líneas de ejes giraban vía poleas y correas, y contraejes (en inglés "line shafts"), que eran ejes más pequeños también suspendidos del techo y paralelos a la línea de ejes principal. La maquinaria de producción generalmente estaba unida a estos contraejes y ubicada en hileras paralelas a la línea principal de accionamiento mecánico ${ }^{205}$ [como se verá también en la Figura 134].

En la Figura 130, se puede apreciar la rueda hidráulica y las conexiones horizontales y verticales para el accionamiento de la maquinaria del North Mill, en Belper $^{206}$, de principios del siglo XIX, y en la Figura 131, el esquema de un accionamiento hidráulico en un sistema único edificio-motor-máquina [Estado 6].

\footnotetext{
${ }^{204}$ Incluso en algunas ocasiones hasta el exterior del propio edificio, para repartir su energía a otros recintos.

${ }^{205}$ Como apunta Biggs (Biggs, 1996), la "evolución natural" de los edificios fabriles a lo largo los siglos XVIII y XIX hacia la "racionalidad" se "retroalimentaba" de los mismos problemas que se generaban como consecuencia de la propia producción que ellos mismos albergaban. Valga como uno de los mayores logros en la percepción visual en las plantas de fabricación, la menor necesidad de pilares cuando comenzaron las estructuras de hormigón, al poder aumentar considerablemente la luz de las vigas. Asimismo, con este material, también se eliminó la trasmisión de las vibraciones causadas por la maquinaria, muy perjudicial para los edificios de varias alturas, que se traducía a su vez en falta de confort (este término todavía no se utilizaba en la bibliografía del momento), y que perjudicaba tanto a las máquinas como a los ejes de transmisión mecánica, que siempre necesitaban de constantes reajustes. Y uno de los aspectos que más destacan en este trabajo, fue la consecución de una mayor resistencia al fuego, característica que tuvo como alcance más inmediato la reducción, e incluso la eliminación, de las primas de los seguros. Esta fábrica diáfana aportó además una extraordinaria ventaja: no depender de las paredes exteriores para soportar todo el peso del edificio, siendo sus muros envolventes de mucho menor tamaño, lo que a su vez permitió grandes huecos libres de ventanas y una mayor iluminación.
}

${ }^{206}$ Confrontar Apartado 3.2.7. 


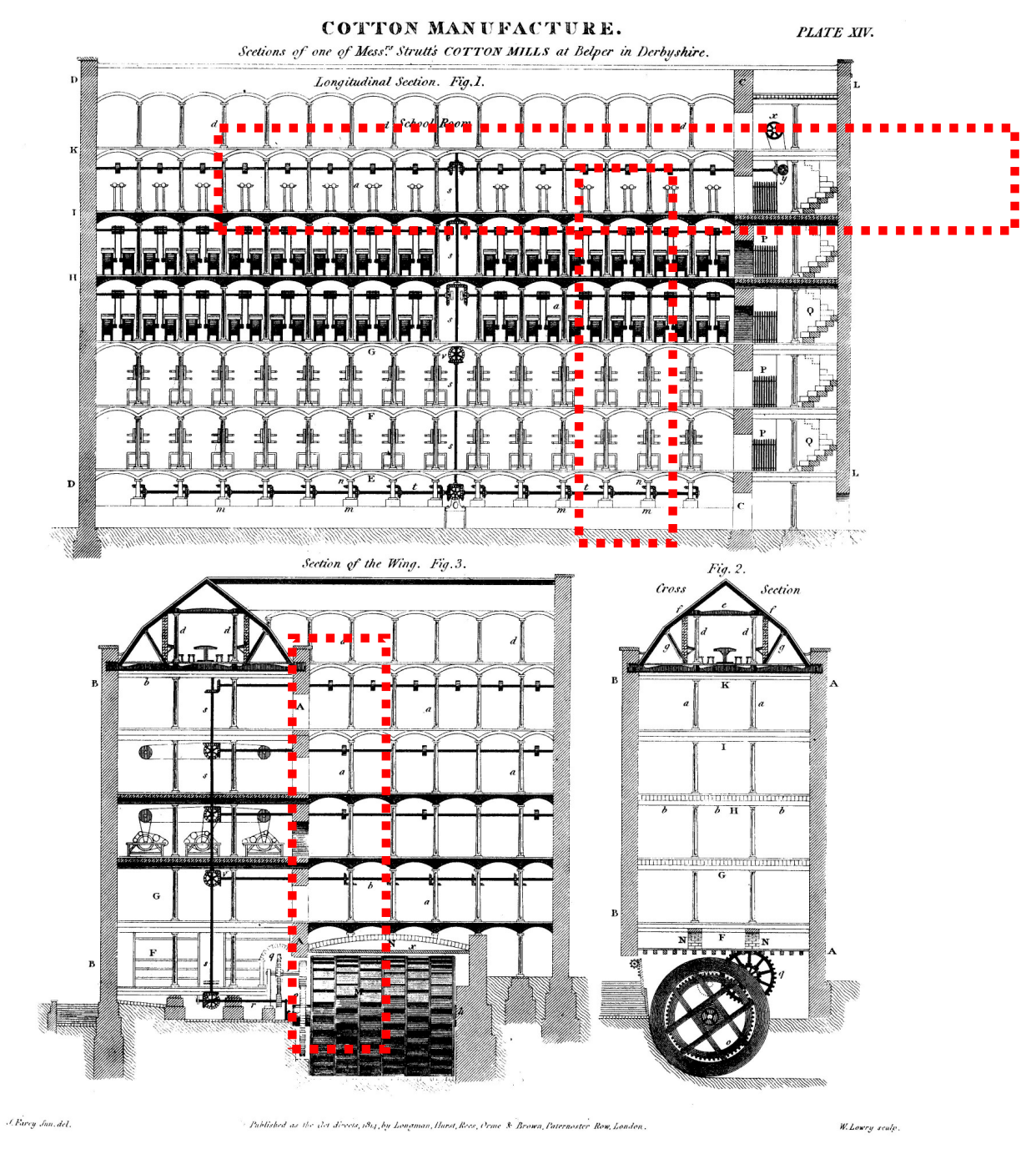

Figura 130. North Mill, Belper, 1803 - 1804. Se comprueba la relación de tamaño entre la rueda hidráulica de motor único y el propio edificio. Esta fábrica coincide en el tiempo con la instalación de las primeras máquinas de vapor (Enciclopedia de Rees de 1820). 


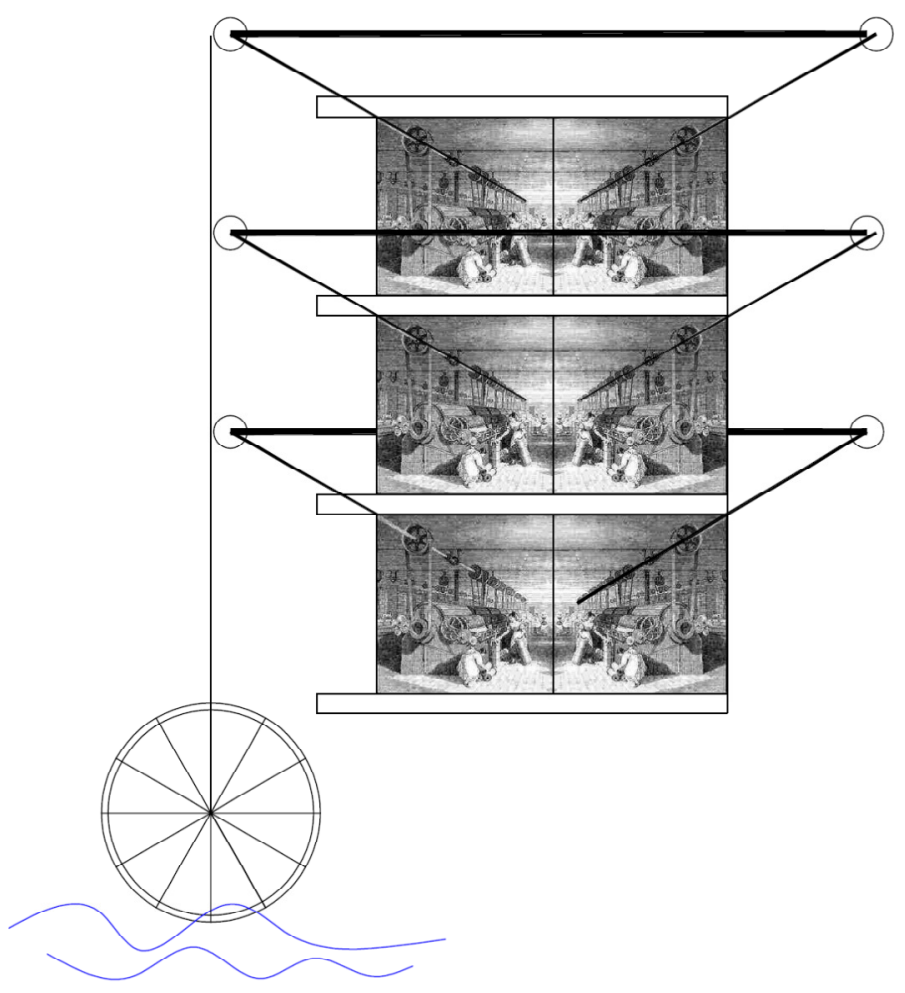

Figura 131. Esquema de un motor único hidráulico accionando una fábrica textil.
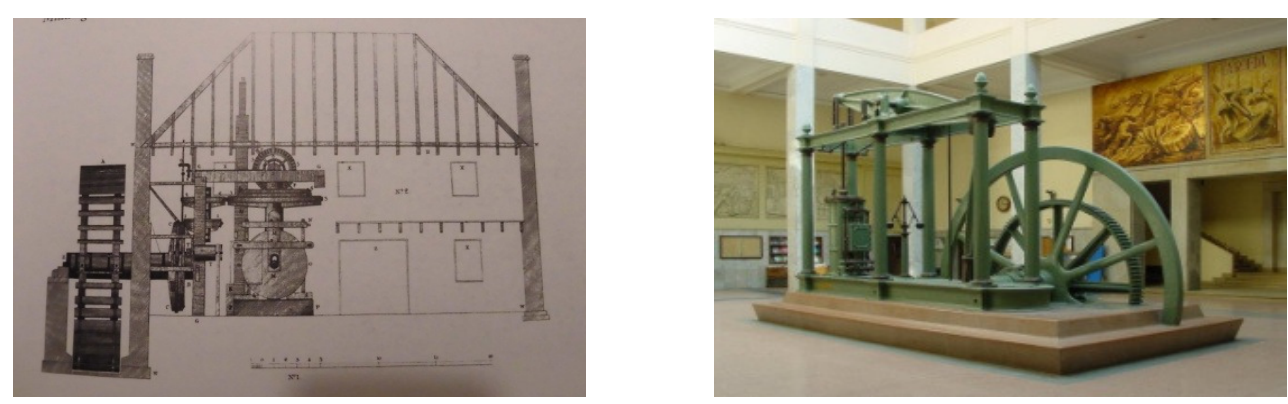

Figura 132. Figura de la izquierda: rueda hidráulica en una almácera de aceite, de alrededor de 1800 (Watts, 2008); Figura de la derecha: máquina de vapor accionando una rueda motriz, en el Hall de la Escuela Técnica Superior de Ingenieros Industriales de Madrid.

\{http://commons.wikimedia.org/wiki/File:Maquina_vapor_Watt_ETSIIM.jpg\} 


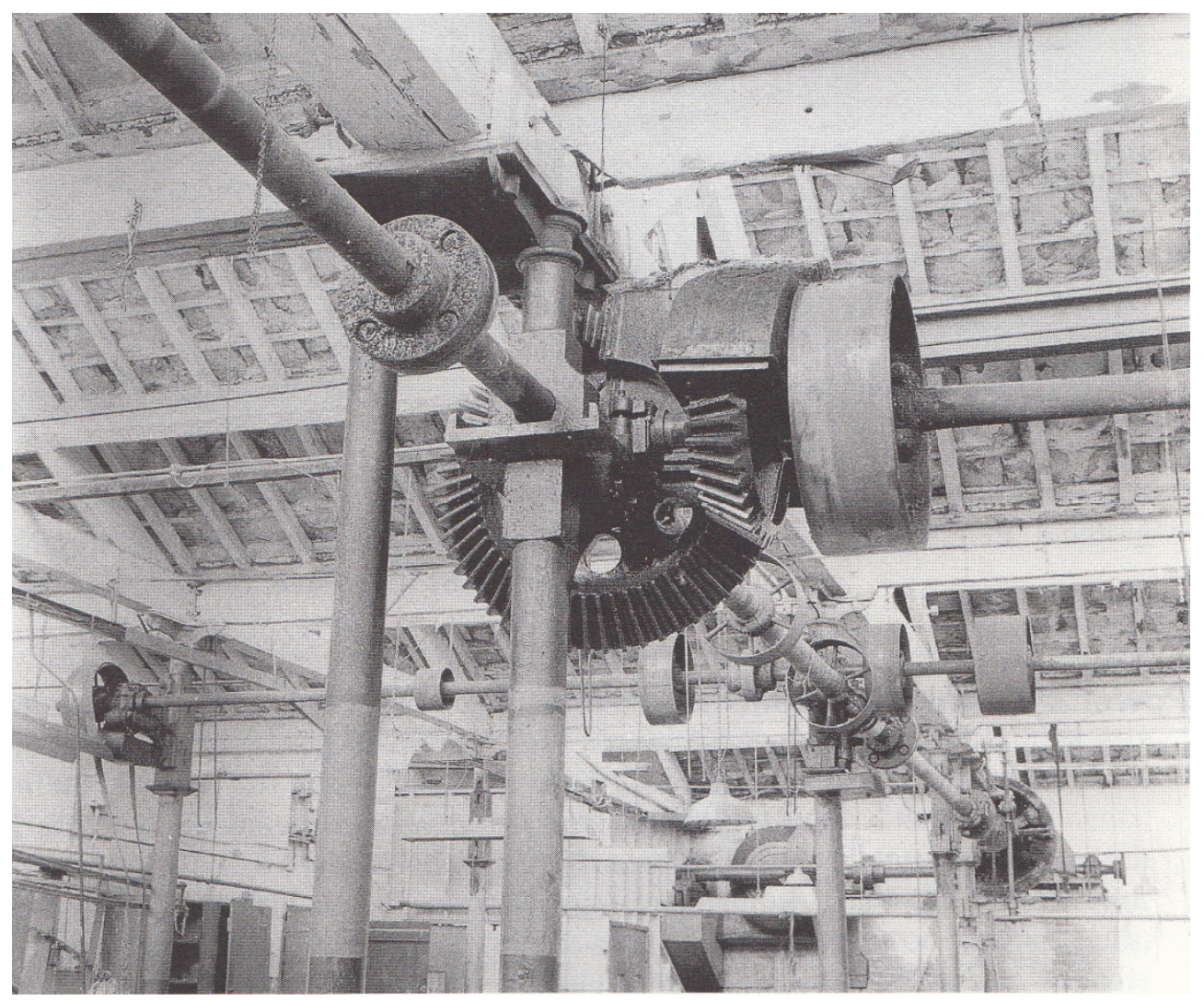

Figura 133. James Walker Blanket Mill, Mirfield, West Yorkshire (Inglaterra), de alrededor de 1820 (Swailes, 1998).

Por su parte, en la Figura 133 aparece una transmisión mecánica mediante ruedas dentadas cónicas fijadas sobre estructuras de madera. Estos cambios de dirección mecánicos tenían la misma función que las actuales cajas de derivación y cuadros eléctricos, de donde se derivan las líneas que alimentan los motores eléctricos. Destacan las columnas de fundición intermedias que soportan las vigas de madera que consiguen una gran amplitud (hacía más de 40 años que Arkwright colocó el primer pilar intermedio de apoyo a las vigas del Masson Mill), así como los sistemas de transmisión energética, habituales en el cambio de siglo XVIII al XIX. 


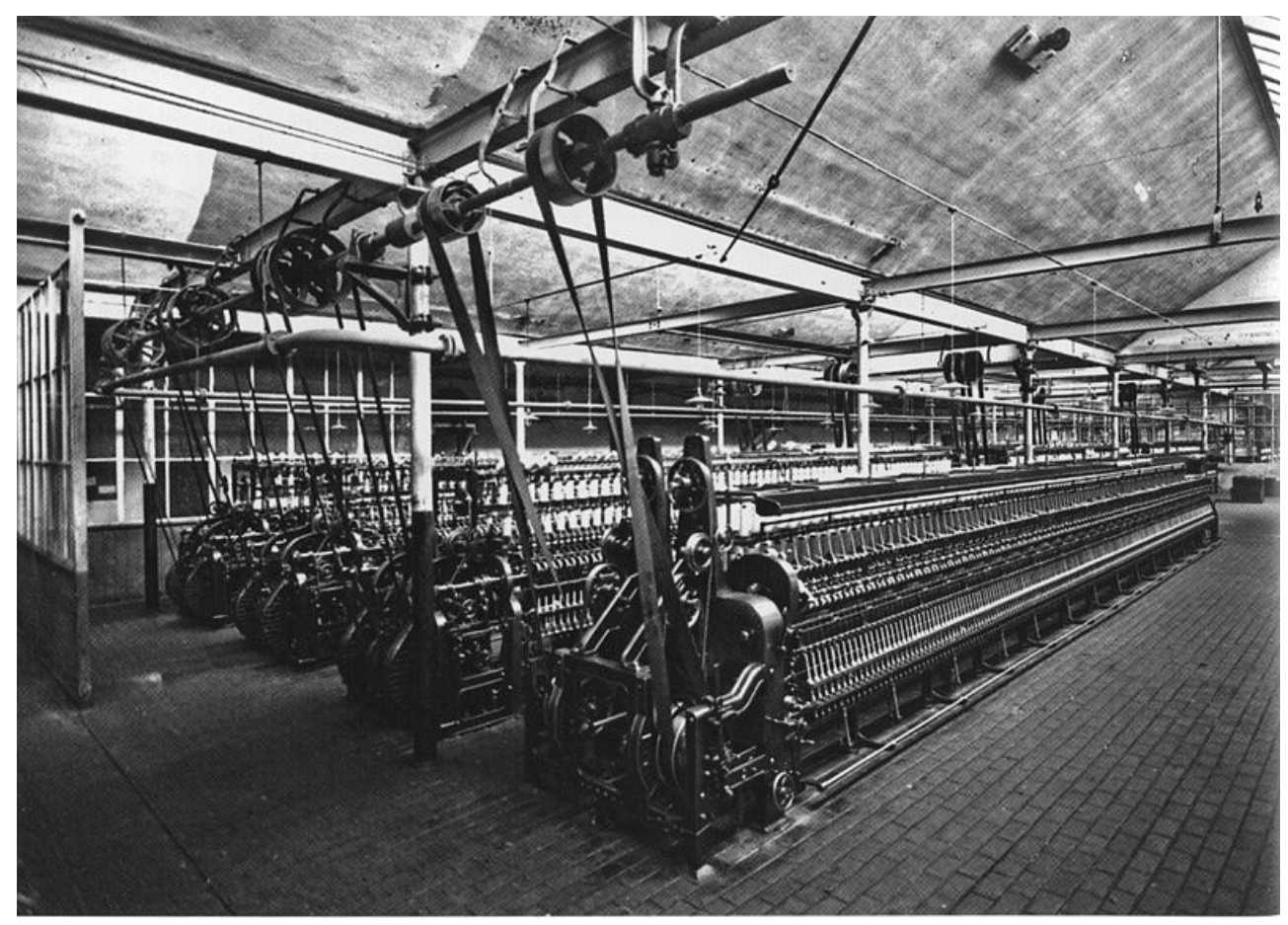

Figura 134. Máquinas de hilar accionadas por correas instaladas según el sistema Möbius (Leipzig, Alemania, hacia 1925). \{http://en.wikipedia.org/wiki/Line_shaft\}.

En lo que respecta a la Figura 134, esta muestra 4 máquinas de hilar accionadas por correas instaladas según el sistema Möbius, alrededor de 1925, unidas al eje mediante poleas dispuestas en la parte superior. Se aprecia también claramente la interconexión que existe entre la transmisión de la energía en el interior de una fábrica y la estructura del edificio. Concretamente en este caso se trata de un sistema tardío, probablemente accionado mediante electricidad.

A continuación se presenta una tabla cronológica en la que se aparecen los diferentes logros de los sistemas de transmisión de la energía basándose en los mill buildings que se estudiaron en el apartado anterior [Tabla 3 y Figura 135]. 


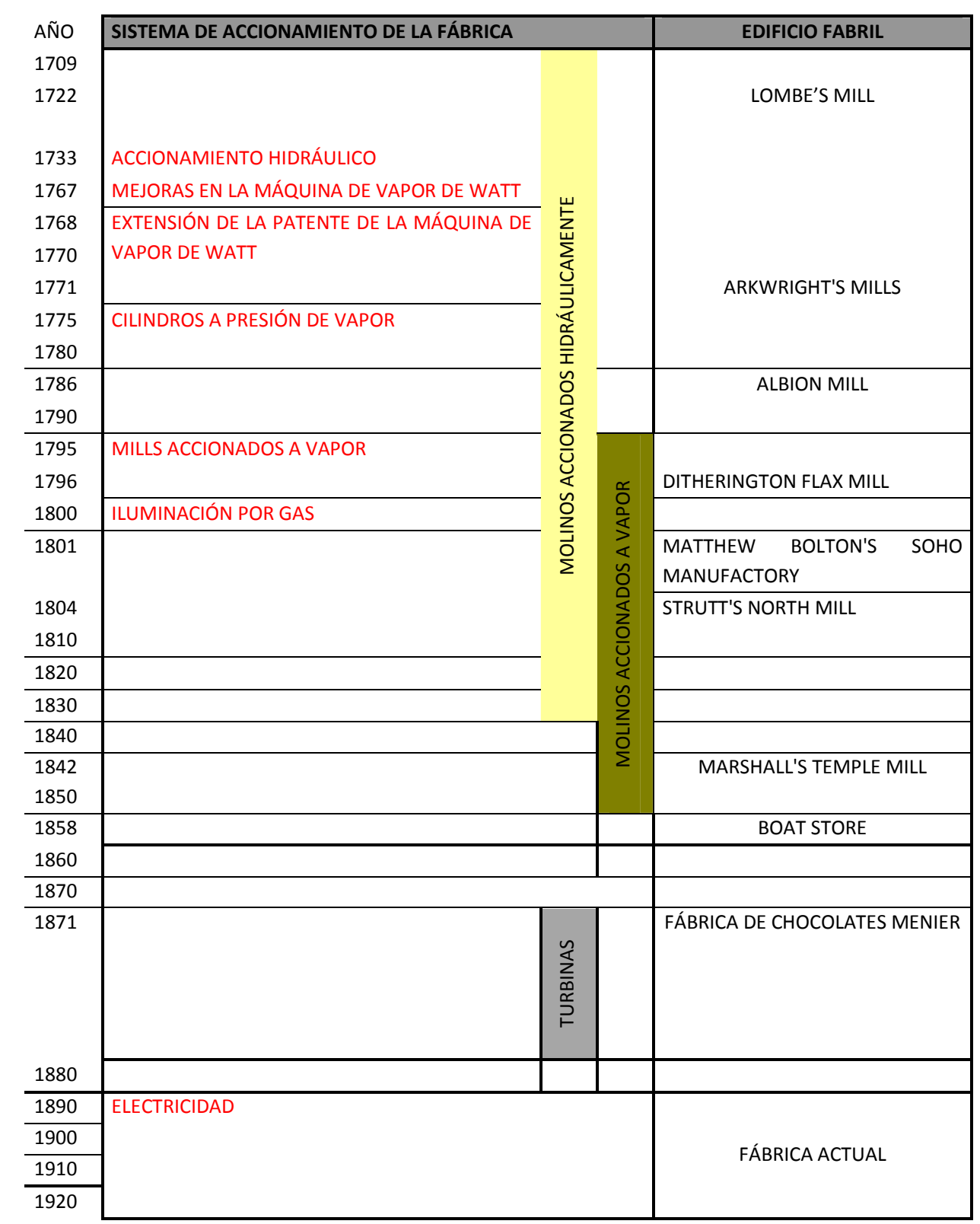

Tabla 3. Cronología de los sistemas de transmisión energética en el interior de los edificios fabriles. 


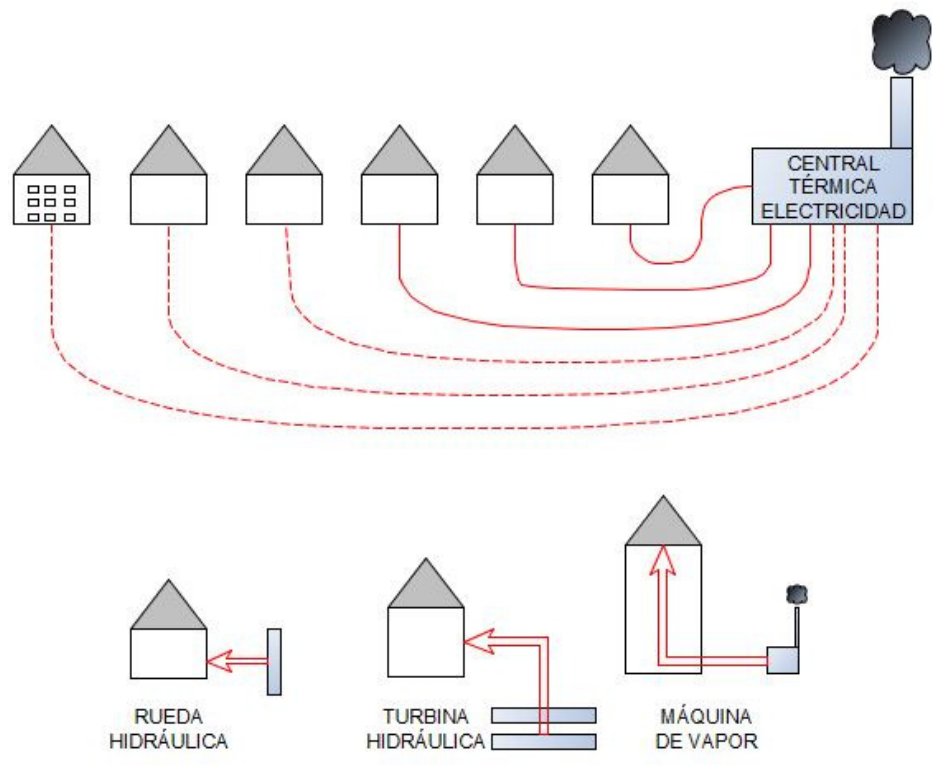

Figura 135. Diferentes formas de accionamiento mecánico en los sistemas fabriles, desde la rueda hidráulica de los molinos próximos a los cursos de los ríos, hasta las centrales térmicas de principios del siglo XX, que alimentaban a la vez varias fábricas independientes, pasando por la turbina hidráulica o la máquina de vapor. Nótese como tanto en los sistemas alimentados por vapor como en el eléctrico, la producción mecánica quedaba separada, la mayoría de las veces, del edificio industrial en sí. En el primero de estos casos, la conexión resultaba ser el propio vapor que seguía accionando el motor único, quedando la caldera totalmente separada. En cuanto a la producción de electricidad, el generador se hallaba bastante más alejado de los diferentes puntos de consumo.

Pero, ¿qué relación existe entre el tipo de fuente energética utilizada con la forma de los espacios fabriles? Como se verá en los párrafos siguientes, hay una estrecha dependencia entre la manera de suministrar la fuerza motriz al conjunto de la maquinaria y el número de plantas del edificio. En este apartado se trata de analizar estas correspondencias, aunque de partida, se plantea la dificultad de separar este estudio de la secuenciación cronológica de los diversos inventos, desde los primeros molinos harineros o textiles hasta las "daylight" americanas de principios del siglo XX. 
En este apartado se va a analizar cómo las propias fuentes energéticas para el accionamiento de la maquinaria y su distribución interior provocaron por sí mismas que los edificios se tuvieran que adaptar a ellas [un ejemplo claro lo constituye la North Mill, en la Figura 130, de principios del siglo XIX].

\section{EL MOTOR ÚNICO:}

La energía generada por los "mill buildings" para su propio accionamiento, como se ha comentado en los párrafos anteriores, puede dividirse en hidráulica o térmica, o finalmente eléctrica [Figura 135]. Si se trata de la primera de ellas, desde la Edad Media ${ }^{207}$ hasta prácticamente la 2 a mitad del siglo XIX, el accionamiento se realizaba mediante una rueda hidráulica, aunque ya habían aparecido las primeras turbinas hidráulicas alrededor de 1827, gracias a Benoît Fourneyron $^{208}$ [Estado 7].

En cuanto a la utilización de la energía térmica como fuente de accionamiento, una de las primeras máquinas de vapor instaladas por Boulton y Watt, como mejora de la de vapor atmosférica utilizada para bombear agua del ingeniero Newcomen en la década de 1730 (Johnson, 1957) ${ }^{209}$, fue para la fábrica de harinas de la Albion Mill de Londres, en 1786 [Estado 9 de la Figura 124], la cual, desafortunadamente, sufrió un incendio que la destruyó completamente a los pocos años de su construcción.

\footnotetext{
${ }^{207}$ Vitruvio, en el siglo I antes de Cristo, ya plantea artilugios hidráulicos, como la primera rueda hidráulica citada en su Libro X de De Architectura.

${ }^{208}$ Las turbinas hidráulicas mejoraban energéticamente a las ruedas hidráulicas porque no solo tenían un punto de accionamiento, sino que el agua actuaba en toda la circunferencia que conformaba la rueda, de forma que se beneficiaba de un aumento de la velocidad de rotación y con el que se conseguían potencias específicas mayores. A grandes rasgos, en la rueda hidráulica, el agua no recorre un camino dentro del rodete, sino que solo golpea las palas, mientras que en las turbinas, el agua entra dentro de la máquina para aprovechar al máximo no solo el punto de entrada sino la impulsión proporcionada a la salida.

Gracias pues a su mayor aprovechamiento de la energía hidráulica de las Corrientes que las ruedas abiertas, podía girar mucho más rápido.

${ }^{209}$ En el sudoeste de Inglaterra.
} 
Una particularidad que trajeron las máquinas de vapor fue el establecimiento de un tipo de edificio exclusivo para su instalación en el interior, que consistía en un pequeño local que en la bibliografía inglesa aparece como "power building", con su chimenea inequívocamente unida [Figura 135].

Las fuentes de energía, hidráulica y térmica, repartían el accionamiento mecánico de distintas maneras: el primero de ellos consistía en una serie de ejes mecánicos accionados por engranajes, poleas y correas [Figura 133], si bien, con la aparición de la máquina de vapor, esa transmisión también se realizó mediante la sustitución de los ejes rígidos por cableado mecánico ${ }^{210}$ (tal y como se expuso ya en este Apartado 3.4 sobre la caracterización de los "mill building") [Figura 127].

La evolución de la maquinaria, junto la de la transmisión energética y la forma de accionamiento, conforman un conjunto que caracterizará la evolución en sí del espacio fabril, como se expone a continuación ${ }^{211}$.

\section{EL ACCIONAMIENTO HIDRÁULICO:}

La fuerza de los cursos fluviales paralelamente al uso del viento como energía motriz en los molinos y batanes, fueron los sistemas utilizados durante muchos siglos [Figura 130] hasta la aparición de la máquina de vapor, antes de 1800, que

\footnotetext{
${ }^{210}$ En 1824, Paul Moody desarrolló un sistema en los Estados Unidos, que consistía en la utilización de correas de piel y poleas para accionar la maquinaria, y que solo se utilizó en América. Este modelo de transmisión resultó ser más económico y requería de un menor mantenimiento que los sistemas de ejes rígidos y engranajes, generalmente usados en la cuna de la Revolución Industrial, Inglaterra.

${ }^{211}$ Todas las tipologías de suministro energético mencionadas corresponden inicialmente a un accionamiento basado en el motor único, definido anteriormente como un único punto que transforma la energía en el movimiento de todo el espacio fabril, que no es más que la envolvente de un grupo de maquinaria que funcionaba toda ella al mismo tiempo.
} 
es el momento a partir del cual se puede decir que los molinos, como espacios de producción, se convierten en los prototipos de fábricas ${ }^{212}$.

Pero no todos los espacios fabriles respondían al patrón del North Mill. Generalmente, los primeros espacios fabriles solían ser variaciones, rehabilitaciones o ampliaciones de edificios existentes con anterioridad, sin una base arquitectónica específica en muchas ocasiones, en los que en absoluto predominaba la ornamentación, ni estaban caracterizados precisamente por la inversión de grandes capitales para su construcción (Aguilar, 1998). Además, solían estar escasamente mecanizados, si bien, su tamaño fue creciendo en planta a medida que aumentaba la cantidad a manufacturar, necesitando para ello una adecuación de la distribución energética en el conjunto interior. Como ejemplo de esta paulatina evolución se tiene la instalación de un entramado de ejes horizontales y verticales giratorios en todo su volumen [Figura 136].

\footnotetext{
${ }^{212}$ Si bien este no fue precisamente única y exclusivamente el momento clave en el que se les pueda llamar fábricas a los espacios de producción. Algunos de ellos fueron fábricas sin estar alimentadas de la máquina de vapor, sino por ejemplo, de turbinas hidráulicas, como la fábrica de chocolates de Menier, o algunos de los molinos textiles de Alcoi, del siglo XIX.
} 


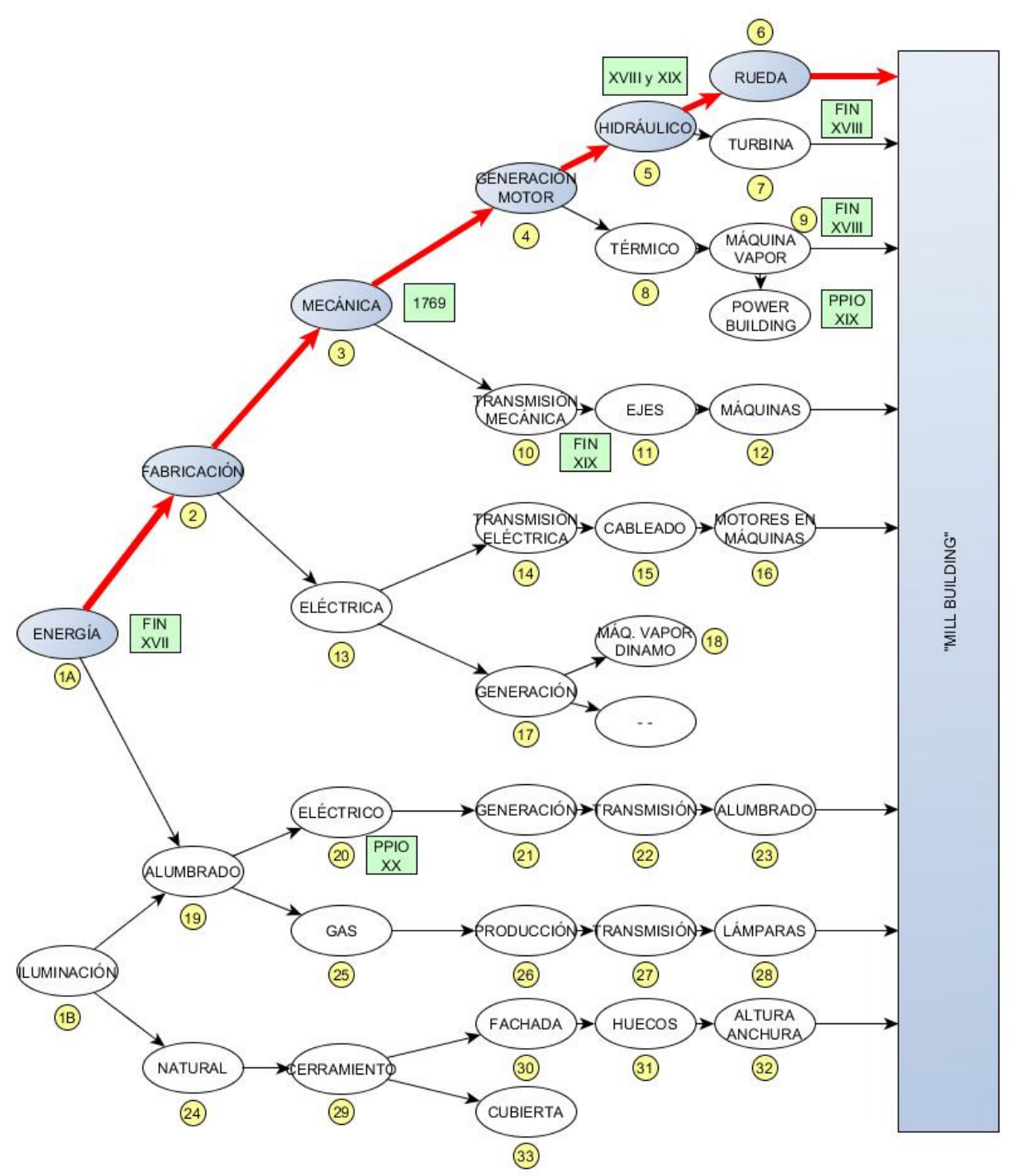

Figura 136. Evolución mecánica hacia la rueda hidráulica. 
Lo que sí está claro es que las fábricas textiles de nueva planta son un evidente ejemplo del empleo de este sistema de motor único durante el siglo XVIII y principios del XIX (Ej. Lombe Mill, Ditherington Mill [Figura 137] y North Mill [Figura 130], estudiados en el apartado anterior \{confrontar estos edificios en apartado 3.2 más atrás\}). Solían ser de planta rectangular y estrecha, sobre la que se construían varios pisos para poder utilizar un solo eje motriz en vertical, desde el que arrancaban las conexiones horizontales y luego las poleas y correas que accionaban todas las máquinas, estas últimas generalmente gobernadas por un operario, también encargado tanto de su embrague como de su engrase.

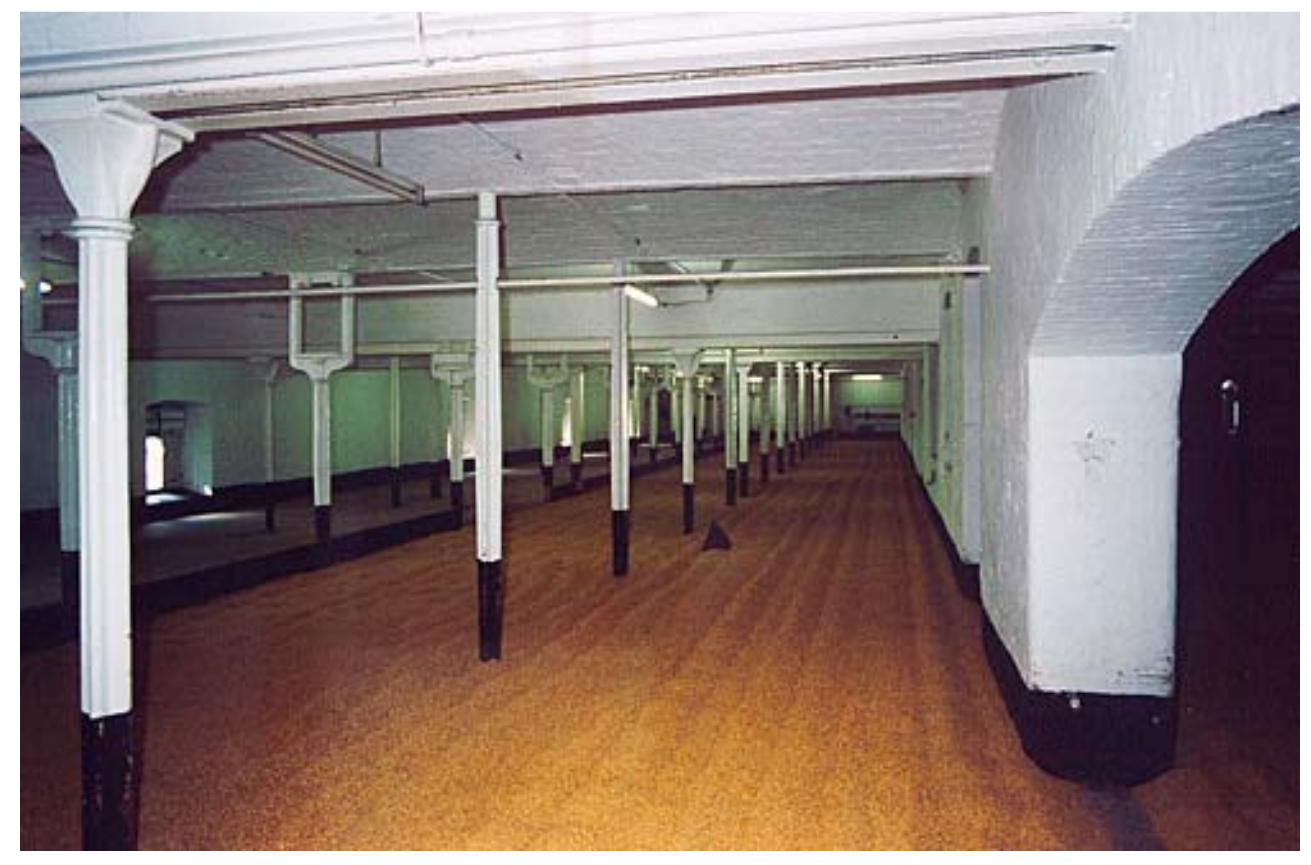

Figura 137. Planta primera del Ditherington Mill, Shrewsbury, de 1796.

(http://www.28dayslater.co.uk/forums/showthread.php/3632-Ditherington-Flax-Mill-Shrewsbury). 
En una de las líneas de pilares que se muestran en la Figura 137, las cabezas disponían de un hueco para ubicar el eje motriz de transmisión. Esta es una forma de demostrar cómo existe una interacción directa entre el sistema de trasferencia de la energía y la estructura del edificio.

Así pues, los objetivos de la industria y las características del motor único gestaron el que se puede considerar como primer tipo original de fábrica moderna: la fábrica de pisos. 


\section{EL ACCIONAMIENTO POR VAPOR:}

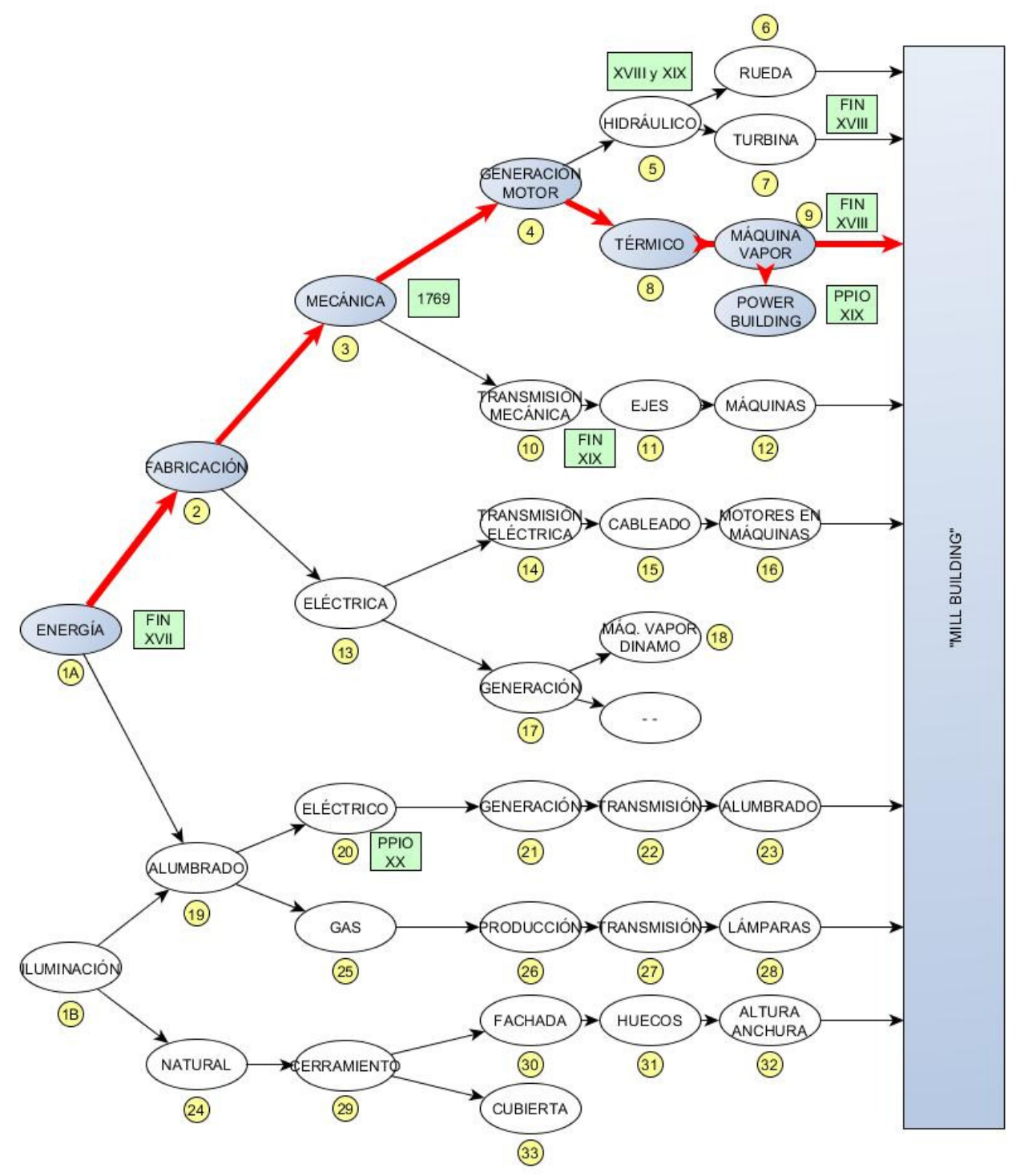

Figura 138. Evolución mecánica hacia la máquina de vapor. 
En cuanto la máquina de vapor [Estado 9 de la Figura 138], que empezó a extenderse desde la última década del siglo XVIII, permitió a las industrias situarse lejos de los cauces de los ríos, su estructura ya no quedó condicionada por las pendientes de las laderas de los valles de los ríos, sino por el alto precio del suelo que controlaban los especuladores. Los propietarios, por tanto, intentaron aprovechar al máximo los solares, edificando más alturas.

Otras dos consideraciones, aparte de la nueva localización, tuvieron también una gran importancia a la hora de definir la forma del edificio y sus características intrínsecas (Banham, 1989): cómo se realizaba la distribución de la energía dentro de la planta, y la disponibilidad de luz en cada puesto de trabajo individual. Entre otros aspectos, la distribución por medio de ejes, poleas y correas, conllevaba pérdidas muy importantes de energía debidas a la fricción, y consecuentemente un calentamiento excesivo de los equipos, lo que se debía limitar reduciendo el número de ejes a un mínimo, que en el mejor de los casos sería un único árbol principal por cada planta de máquinas. Ello inevitablemente fomentaba la construcción de edificios alargados (tanto como la resistencia a la torsión del propio eje transmisor podía soportar, dependiendo del material, madera o hierro, y de su sección), de sección estrecha, con las máquinas dispuestas a lo largo de esos ejes. Asimismo, la necesidad de una iluminación adecuada también hacía necesaria la construcción de edificios estrechos, puesto que así un mayor número de puestos de trabajo estarían cerca de la envolvente exterior y por tanto, cerca de las ventanas.

Es interesante asimismo observar la disposición de las nuevas salas de máquinas o "power buildings", separadas luego de las de calderas, a fin de reducir en lo posible las longitudes de los árboles de transmisión. La New Mill [Figura 139], de 1825, en Bradford, con estructura de Fairbairn y maquinaria de Boulton \& Watt, es un buen ejemplo de lo que fue la ubicación totalmente simétrica de la sala de máquinas con respecto al cuerpo de la fábrica, mientras que en el complejo de Saltaire, de 1851-1853, había dos salas de máquinas distribuidas en simetría para 
el esfuerzo torsor de los ejes de movimiento que se accionaban desde los extremos ${ }^{213}$.

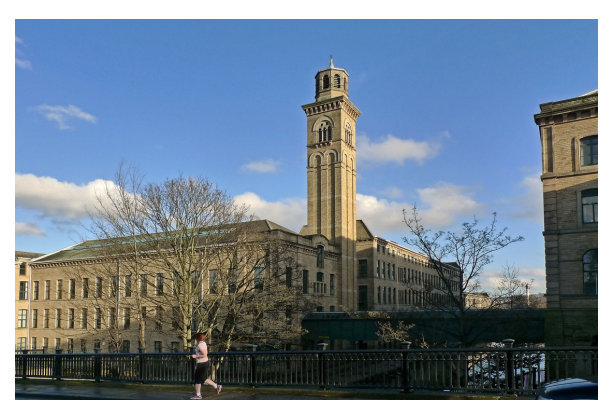

Figura 139. New Mill de Saltaire, Bradford. La torre identifica la división del edificio en dos cuerpos, que coincidía con sendos accionamientos que aumentaban el rendimiento mecánico.

\{https://www.google.es/maps/@53.8375073,-

$1.7779637,17 z$ ?hl=es\}

${ }^{213}$ Muy destacable también es la introducción de la máquina de vapor de doble émbolo que garantizaría una actuación más equilibrada sobre la rueda y que estaba instalada, por ejemplo, en la Gidlow Mill, en Wigan, de 1865, proyectada por George Woodhouse. 


\section{EL ACCIONAMIENTO ELÉCTRICO:}

Pero de los 3 elementos que caracterizan el factor energético, accionamiento, transmisión mecánica y maquinaria, destaca el primero de ellos, el de la forma de suministro, especialmente en cuanto aparece la electricidad, a finales del siglo XIX.

Aunque la primera generación eléctrica fue propia y destinada exclusivamente a la iluminación ${ }^{214}$, su rápida evolución tecnológica pronto posibilitó que esta ya no tuviera que ser generada por el propio "mill building" para su autoconsumo, sino que se produciría en centrales térmicas, a una cierta distancia de la fábrica, lo que en definitiva marcó una primera diferencia respecto a las formas anteriores. El transporte de la energía se realizaba mediante líneas eléctricas y conductores hasta el motor eléctrico único ${ }^{215}$. En este tercer punto del apartado, se presentará

\footnotetext{
${ }^{214}$ Cuando se utiliza este término para referirse a la electricidad, se refiere a la generación mecánica, puesto que la química estaba limitada en cuanto a la potencia y al tiempo.

${ }^{215}$ En 1831, el profesor Joseph Henry, de la Universidad de Princeton, en EEUU, escribió un artículo: "On a reciprocating motion produced by magnetic attraction and repulsion", \{publicado en el Silliman's Journal, vol. 20, págs. 340-343\}, en el que se exponía el principio de funcionamiento de uno de los primeros motores eléctricos. Ello fue probablemente el origen en el que se basó pocos años después un prototipo de motor giratorio, que serviría de inicio para la mecanización textil.

En cuanto a los generadores eléctricos, fue a partir de alrededor de 1860, que su evolución fue paralela a la de los motores eléctricos (Fraile, 2004), ya que desde que se había enunciado el Principio de la Transformación de Energía Eléctrica en Mecánica (rotación electromagnética, de 1821 por Faraday), sus desarrollos habían sido independientes.

En tercer lugar, en la Exposición Internacional de Viena de 1873 fue presentado el transporte de energía eléctrica desde una dinamo a un motor de corriente continua, que era expresamente el mayor condicionante que impedía apreciar la utilidad de este tipo de energía. Fue en ese momento ya, que los fabricantes se interesaron en la construcción de motores eléctricos destinados precisamente a la tracción eléctrica.

En cuanto a la construcción de los motores de corriente alterna, en 1879 Walter Baily demostró frente a la Physical Society de Londres la posibilidad de rotación mediante corrientes inducidas. Este mismo descubrimiento se hizo casi a la vez por Nikola Tesla (1856 - 1943), que fue el primero que construyó y patentó este tipo de motores en octubre de 1887, y por el que se considera el inventor de los mismos, y el que demostró las ventajas frente al motor de corriente continua.

La compañía Westinghouse los comercializó cuatro años después, y ya por 1900, muchos ingenieros habían asegurado su eficiencia en el control de velocidad, convirtiéndose así en el "ideal workshop"
} 
además la distribución eléctrica en el interior de las manufacturas, que había favorecido el suministro eléctrico a los motores, los cuales se iban aproximando a la maquinaria, apareciendo el "accionamiento en grupo" (Devine, 1983) (o a conjunto de máquinas con un mismo objetivo productivo dentro de la cadena de producción). Más tarde, para finalizar, la alimentación se realizará independientemente a cada una de las máquinas que componían el proceso productivo. Este avance tecnológico supone el paso de la manufactura rígida en forma y localización, a una localización libre y una distribución flexible que no depende tanto de la ubicación de la maquinaria: el edificio-motor-máquina se ha convertido en motor-máquina, porque el proceso ha perdido vínculo con el edificio.

\section{EVOLUCIÓN TECNOLÓGICA}

Como se acaba de decir en los párrafos anteriores a grandes rasgos, según este mismo autor (Devine, 1983), aproximadamente en el periodo comprendido entre 1880 y 1930 en Estados Unidos, la producción y la forma de distribución de la energía mecánica necesaria para el accionamiento de la maquinaria de producción de los edificios fabriles, evolucionaron de una forma "cualitativa y cuantitativa", desde las primeras formas de transmisión mecánica con sistemas acoplados mediante ejes y poleas, generalmente de motor único en toda la fábrica, hasta la coexistencia de diversos motores eléctricos accionando las máquinas individualmente [Estado 16 de la Figura 140].

en la primera década del siglo XX. La electricidad y su aplicación en motores alcanzó a ser el método más usado por las manufacturas en el accionamiento de las máquinas herramienta. 


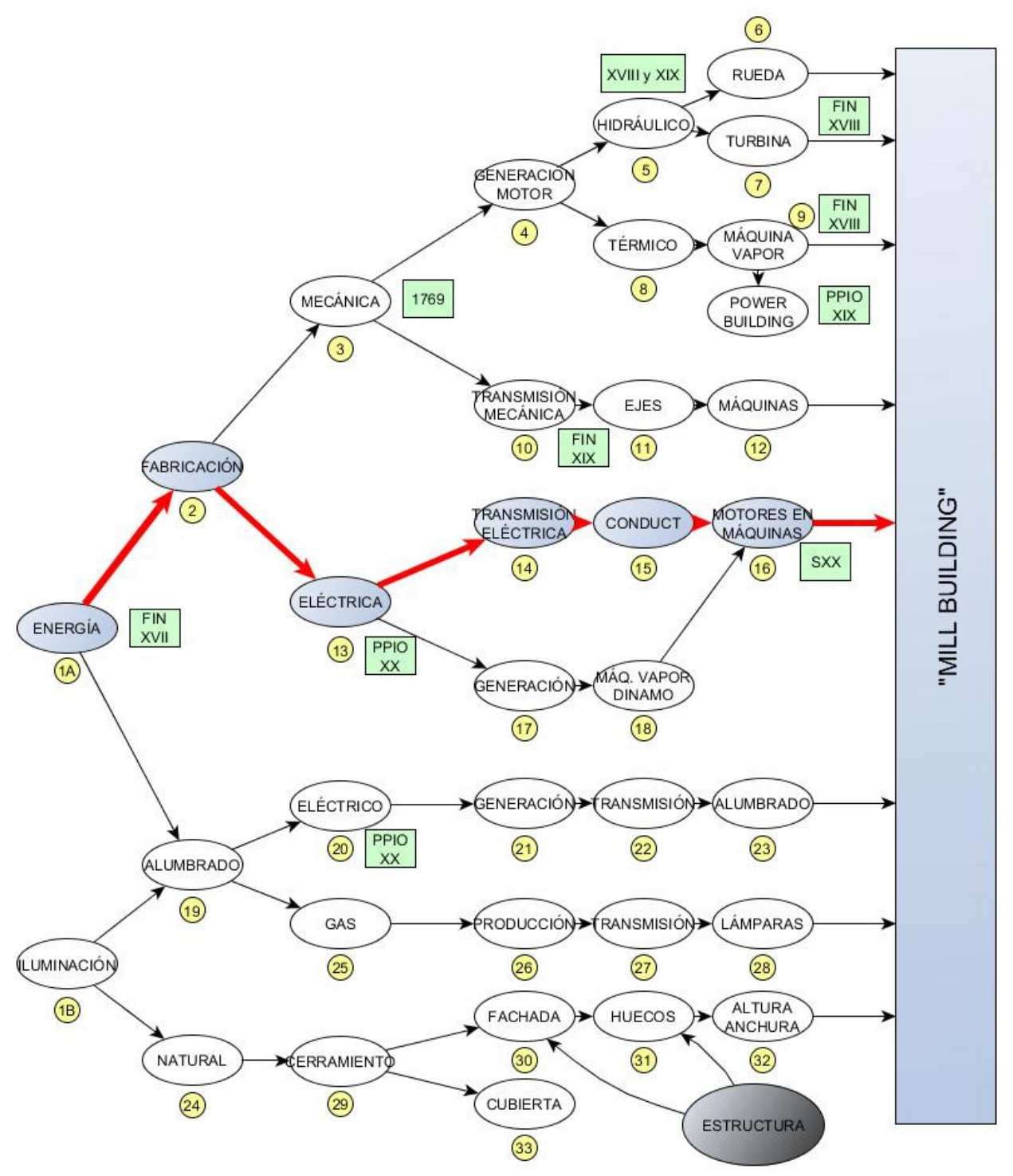

Figura 140. Evolución eléctrica de la transmisión mecánica. 
En términos energéticos, el anterior autor señala que al final de este periodo, hacia 1930, con la implantación de la energía eléctrica, se observó que se redujo la cantidad de materia prima necesaria, considerando la propia energía para mover toda la maquinaria de producción, obteniendo una mayor producción “output" por capital y por mano de obra "input"

Se había cambiado los combustibles utilizados: se pasó del carbón al petróleo y al gas, y del uso directo de formas de energía primitivas (energía hidráulica y carbón) al de energía transformada, como la combustión interna y la electricidad ${ }^{217}$.

\section{EL PRINCIPIO DEL USO DE LA ELECTRICIDAD COMO ELEMENTO MOTRIZ}

Hasta finales del siglo XIX, las máquinas de producción estaban conectadas mediante unión directa a las fuentes de energía que las accionaban. El accionamiento desde la fuente motriz era independiente del número de máquinas en funcionamiento en cada momento, y los ejes y contraejes giraban permanentemente. Si en una línea de ejes se producía algún tipo de avería, la producción paraba en su totalidad, hasta que se hubieran realizado las reparaciones oportunas ${ }^{218}$.

\footnotetext{
${ }^{216}$ El estudio se basa en que al reducir esas cantidades de energía e incrementar la productividad en las manufacturas, disminuyó la relación entre el consumo de energía y el producto nacional bruto de EEUU durante este tiempo.

${ }^{217}$ Según el autor de este artículo, una de las razones por las que se produjo este cambio energético era que el gas, la combustión interna y la electricidad tenían una mayor eficiencia con respecto a las energías que estaban reemplazando, como la hidráulica y el carbón. A principios del siglo XX, las cuestiones meramente económicas primaron en la necesidad de buscar nuevas fuentes energéticamente más eficientes a la hora de su conversión de energía primaria a calor y trabajo mecánico.

${ }^{218}$ Para arrancar cualquier máquina el operario accionaba un embrague o unía los contraejes de su aparato por medio de correas, con un rodillo tensor hasta una polea, utilizando una palanca. Existían multitud de poleas, ejes y correas para el accionamiento y para los cambios de velocidad o de potencia. Los lubricadores suspendidos del techo goteaban aceite de forma constante, siendo rellenados diariamente por los mismos trabajadores, que a su vez alineaban y tensaban las correas.
} 
Pero todo ello cambiaría cuando se desarrolló la ingeniería eléctrica en el cambio de siglo, con la que las máquinas eléctricas desempeñarían un papel trascendental, gracias a sus posibles aplicaciones en los campos de la generación, transformación y utilización de la energía para la producción industrial ${ }^{219}$.

Su utilización por primera vez para accionar maquinaria en una factoría, fue en 1883, año posterior a su comercialización ${ }^{220}$ [Figura 141]. Por entonces, los primeros motores funcionaron en corriente continua, puesto que era la única forma de energía eléctrica que generaban las centrales eléctricas. Estos primeros motores tenían una potencia menor de 1 caballo, y por supuesto, estaban limitados en sus aplicaciones (Fraile, 2004).

\footnotetext{
Si las correas se rasgaban o aflojaban tenían que ser acortadas, uniendo sus extremos y ajustándolas.

${ }^{219}$ Como apuntan varios libros sobre los orígenes de la electricidad (Fraile, 2004), se puede considerar como punto de partida para el estudio de las máquinas eléctricas, mucho antes de su aplicación industrial, el principio de inducción electromagnética, descubierto por Michael Faraday en 1831. Los experimentos posteriores de este investigador ya demostraron de un modo evidente el principio de conversión de la energía eléctrica en mecánica y viceversa (principio dinamoeléctrico). Esta ley de inducción de Faraday fue el detonante para que muchos científicos e ingenieros buscaran una máquina eléctrica que generase electricidad de un modo diferente al que se conocía en aquellos tiempos, la pila de Volta. La ingeniería eléctrica se puede decir que nace en aquel momento, y evidentemente, ello transformó desde un primer momento la manera de mover las máquinas en las fábricas de producción.

${ }^{220}$ La primera central eléctrica moderna apareció en 1882 en Nueva York, de la mano de Thomas Alva Edison.
} 


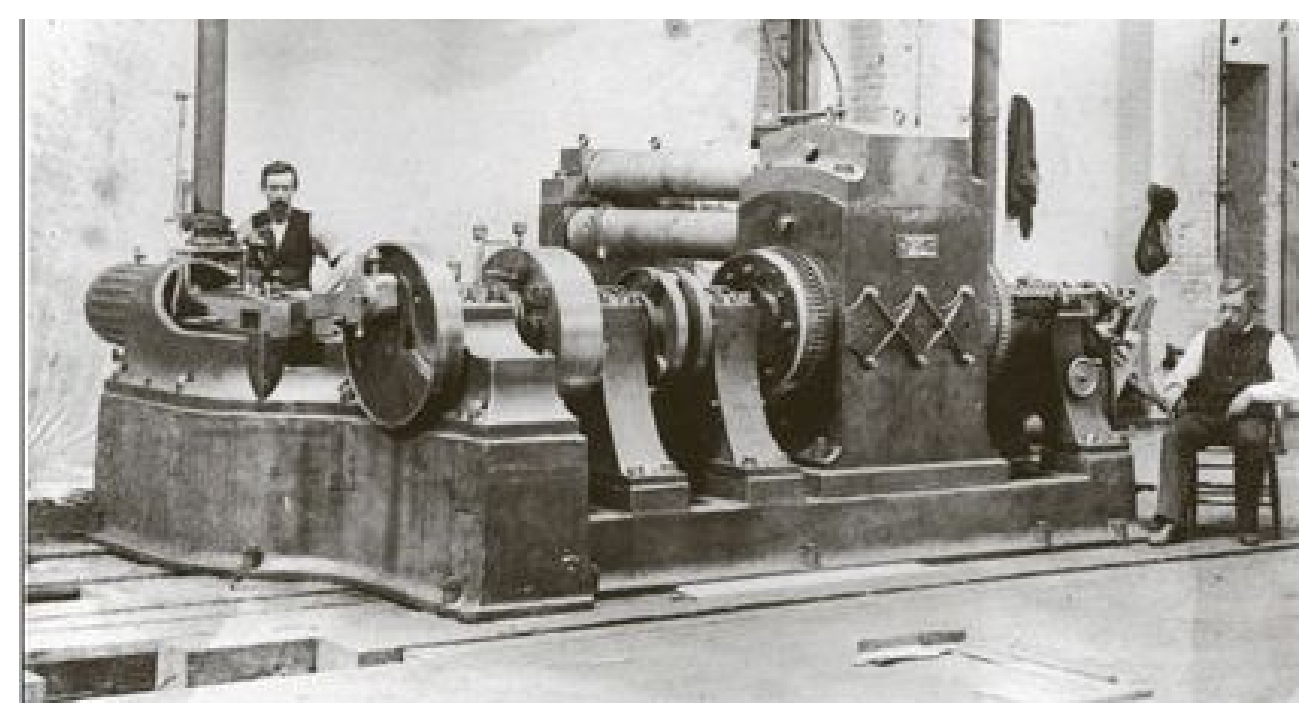

Figura 141. Primera central eléctrica de Edison, de 1882, accionada por una máquina de vapor de pistón que accionaba los generadores de corriente continua.

\{http://www.laaventuradelahistoria.es/2012/09/04/los-85-primeros-hogares-de-ee-uu-con-luzelectrica.html\}

Asimismo, según este autor, la primera mecanización directa por medio de electricidad fue la de las industrias textiles y de papel norteamericanas, en donde la limpieza, la potencia y la velocidad constantes, así como la facilidad de control, eran los aspectos críticos. Pero en un principio no se alteró la forma de transferir esa nueva energía a las máquinas, sino lo que se cambió fue el motor único, ese que hacía girar las líneas de ejes. En el primer sistema eléctrico, llamado por Devine "electric line shaft drive" (Devine, 1983), todos los contraejes, correas, poleas y embragues, seguían perteneciendo al mismo sistema de transmisión del movimiento. Así, en los mill textiles se instalaron grandes motores de cientos de caballos de potencia que llegarían a accionar en poco tiempo, hasta más de mil telares. Según esta idea, el edificio no necesitaba cambiar todavía, puesto que no se había producido ninguna alteración al alimentar a ese motor único mediante electricidad. 


\section{COSTES DE LA IMPLANTACIÓN DE LA ELECTRIFICACIÓN Y CREACIÓN DE LOS} PRIMEROS DEPARTAMENTOS:

A partir del cambio de siglo XIX a XX (Devine, 1983), muchas fábricas comenzaron a confiar en la energía eléctrica como forma para suministrarse energéticamente ${ }^{221}$. Sus posibilidades de transporte y de distribución crecían, y cada vez había más centrales generadoras según crecía la demanda. Por este motivo, el precio de la electricidad bajaba, llegando a compararse con respecto al coste del carbón y el gas. Pero todavía en el interior de los edificios la transmisión mecánica se realizaba de la misma manera: simplemente las ruedas hidráulicas y las máquinas de vapor habían sido reemplazadas por motores eléctricos, que seguían accionando las mismas poleas y correas. Todavía es patente la existencia del motor único: la electricidad era vista como una forma de suministro

\footnotetext{
${ }^{221}$ En 1891 ya fue examinada la variación de costes entre accionar la maquinaria de una fábrica mediante máquinas de vapor o con motores eléctricos. El Dr. Louis Bell del Franklin Institute, ya expuso que cuando se necesitaban pequeñas cantidades de energía, generalmente era más barato usar electricidad que vapor. Esto era debido a que las pequeñas máquinas de vapor eran mucho menos eficientes energéticamente hablando que las grandes, y también porque generar pequeñas cantidades de corriente continua era más factible por entonces que hacerlo en grandes cantidades en estaciones centrales, en las que además esta debía ser derivada al punto de consumo, con los inconvenientes que tiene la corriente continua para ser transportada.

Por el contrario, en las plantas en las que se necesitaban grandes cantidades de energía, continuó siendo más barato mover la maquinaria con máquinas de vapor que con motores eléctricos. Utilizando el mismo razonamiento anterior, las grandes máquinas de vapor eran relativamente más eficientes energéticamente, y grandes cantidades de corriente continua eran caras de obtener, o simplemente, poco disponibles para las utilidades eléctricas iniciales.

Pese a ello, esta tendencia fue cambiando conforme la ingeniería eléctrica fue perfeccionando la máquina eléctrica, y como se verá posteriormente, al aparecer la corriente alterna como la única perfectamente viable para ser transportada en redes sin excesivas pérdidas. La corriente alterna, como energía motriz de la maquinaria en la industria de finales del siglo XIX, fue consolidándose como medio perfectamente útil, sin prácticamente pérdidas en comparación con las anteriores formas energéticas. Gracias a ella, las grandes factorías no tenían que estar localizadas cerca de las fuentes de energía hidráulica, ni tenían que estar diseñadas para ser provistas en todo momento de carbón. En cambio, esta energía podía estar producida en embalses a una distancia considerable, por su facilidad de transporte.
} 
energético a las factorías, pero no como una forma de distribución de la energía dentro de las mismas ${ }^{222}$.

Según este autor, fue a principios del siglo XX cuando empezaron a diseñarse plantas con varios motores eléctricos repartidos por todo el edificio: esto indudablemente sí afectaría a la distribución y ubicación de la maquinaria y de los operarios $^{223}$. De acuerdo también al ingeniero H. C. Spaulding ${ }^{224}$, los mayores problemas seguían estando en las grandes pérdidas debidas a la fricción en el sistema y a la necesidad de girar todo un conjunto de ejes dentro de la fábrica sin tener por qué tener en cuenta el número de máquinas acopladas en cada instante ${ }^{225}$.

Los montajes en grupo ofrecieron una mayor flexibilidad con respecto a los referidos a un eje global único por todo el volumen del edificio. Una de las ventajas que proporcionaban era la posibilidad de accionar un conjunto de máquinas asociadas a una parte de la producción, siendo así como se

\footnotetext{
222 Así pues, reemplazar una máquina de vapor por uno o más motores eléctricos, dejando el sistema de distribución interior invariable, fue lo habitual con la implantación de esta nueva tecnología, puesto que los manufactureros seguían trabajando con el sistema que realmente conocían a la perfección.

${ }^{223}$ Poco después de la Primera Guerra Mundial, en la segunda década del siglo pasado, el entramado de ejes motrices verticales y horizontales ya no era tan habitual. Primero fueron desapareciendo los ejes mecánicos de planta que accionaban toda la maquinaria, y poco a poco, conforme los motores eléctricos iban mejorando su tecnología y se aumentaba la eficiencia con el empleo de motores más pequeños, los contraejes y los ejes más pequeños también fueron reducidos para dar paso a motores alimentando a un grupo de máquinas. Aún así, a pesar de que cada vez se iban utilizando más los motores eléctricos pequeños para accionar los ejes mecánicos, estos últimos permanecían inalterables en su acoplamiento a las máquinas.

${ }^{224}$ H. C. Spaulding, secretario del Massachusetts Institute of Technology, desde 1887.

${ }^{225}$ Según Devine, la maquinaria de producción debía tender al acoplamiento en grupos pequeños, con cada grupo de máquinas accionado desde un eje corto movido por su propio motor eléctrico. Este grupo funcionaría con mayor rendimiento si las máquinas se movían a la misma velocidad y si en el propio grupo había pequeñas variaciones de carga. Una de las primeras aplicaciones que tuvo el accionamiento de maquinaria por grupos se realizó en la propia General Electric Company, en su fábrica de Schenectady, Nueva York, a principios de siglo. Los propios comerciales de la empresa lo usaron como política de expansión de la propia tecnología que producían.
} 
constituyeron las secciones independientes. Con ello se empezarían a crear los departamentos en las fábricas, con una completa reorganización del sistema productivo. Esta es precisamente la circunstancia que interesa remarcar en esta tesis, ya que de algún modo modificaría la distribución de la producción, y con ello la división interna de los edificios fabriles, su ordenación y clasificación, gracias a la consecución de una mayor flexibilidad y menor dependencia a ejes mecánicos.

Por último, remarcar que la organización de las operaciones de manufactura en lugares específicos o departamentos solo fue posible gracias a lo que Devine llamaba en su artículo como el "acoplamiento de la maquinaria por grupos". Así, la línea motriz del motor y la maquinaria de producción de las diferentes secciones pudo ubicarse en los sitios más idóneos dentro del espacio que el edificio proporcionaba [Figura 142] ${ }^{226}$.

\footnotetext{
${ }^{226}$ En 1897, por ejemplo, la "Keating Wheel Company" construyó una fábrica en Middletown, Connecticut, con departamentos diferentes en 6 alas perpendiculares a la planta. Este edificio no habría podido ser construido en su día sin una distribución de energía por medio de electricidad, pues hubiera sido bastante complejo hacer girar las líneas de ejes en dichas alas desde el eje principal de la manufactura por medio de correas. En esta fábrica de finales de siglo, los motores para los acoplamientos de las máquinas en grupo fueron montados en plataformas suspendidas del propio techo y unidos a la pared [Figura 142].
} 


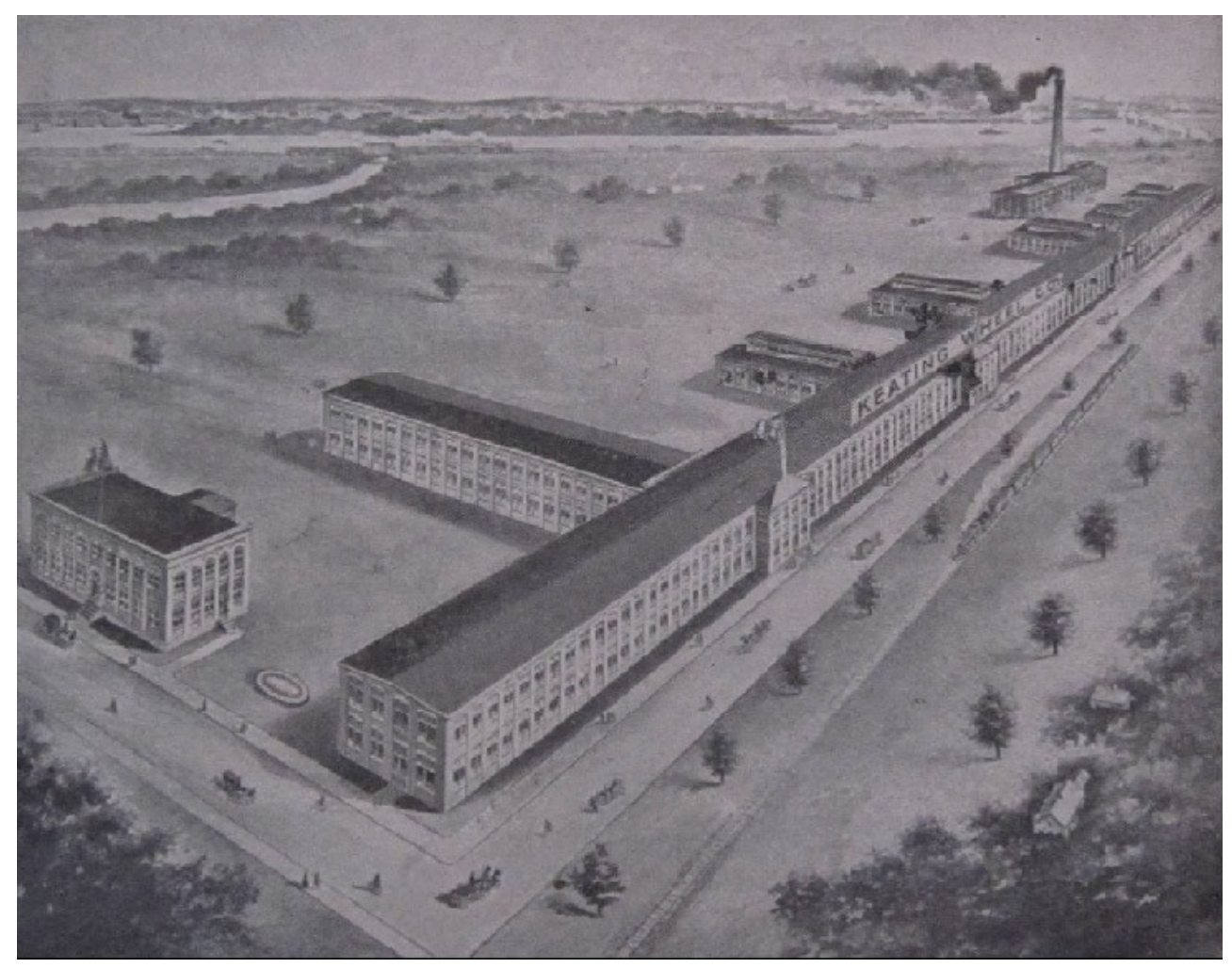

Figura 142. Keating Wheel Company, Middletown, de 1897. Al fondo se distingue perfectamente el edificio separado de maquinaria (en inglés "power building"), y la chimenea para la evacuación de la combustión de la máquina térmica que generaba la electricidad (http://2.bp.blogspot.com/NTWdhc2Z5BU).

Tal y como se mejoraba la tecnología eléctrica y su acoplamiento con las máquinas, se fue reduciendo el número de correas y poleas, así como el de ejes y contraejes, lo que redujo en gran medida las pérdidas en el sistema por rozamiento. De esta manera, los ejes motrices fueron reduciendo su longitud, y así, no fue tan necesario que los edificios tuvieran una forma tan alargada ${ }^{227}$.

227 Según Devine (Devine, 1983), durante la primera década del siglo XX, la transmisión por motor eléctrico aumentó del 5 al $25 \%$ de las fábricas, alcanzando un total de aproximadamente el $70 \%$ de 
Ahora bien, el tamaño de los edificios seguía continuamente aumentando, pero era ya una cuestión meramente productiva, de aumento de la fabricación.

Con todo ello, se puede afirmar que la electrificación y la reorganización de las fábricas fueron a la par. Esta renovación implicó al mismo tiempo el incremento de la especialización de los lugares de trabajo individuales, trayendo consigo un incremento del rendimiento y una mejora en la calidad de la producción ${ }^{228}$.

\section{LA ELECTRICIDAD Y LA "RATIONAL FACTORY":}

Por último, coincidiendo con el final del periodo en estudio (1 1 a década del siglo $X X)$, citar que un cambio en la forma de las fábricas-máquina también se produjo como consecuencia del aumento considerable en la producción textil (Biggs, 1996), ya que "los propietarios de los viejos mills textiles" (en la mayoría de la bibliografía norteamericana consultada se refiere a ellos como los owners), no disponían de espacio suficiente para alojar toda la maquinaria que iban

la capacidad mecánica total (en 1899, el 85\% de la capacidad mecánica de los Estados Unidos procedía de la propia generación en los edificios, mientras que las máquinas a vapor representaban ya menos del $10 \%)$.

Por otro lado, con el sistema de acoplamiento por grupos, hubo una "drástica reducción" del consumo energético, ya que cualquier sección o departamento podía trabajar de forma independiente, parándolo cuando las máquinas no fueran usadas. $O$ inversamente, un grupo podía estar en funcionamiento sin tener que estarlo el eje central de la fábrica. Los ahorros en energía podían ser significativos en aquellas situaciones en las que una parte de una planta necesitara trabajar más de lo normal, o por ejemplo, durante la noche. La posibilidad de arrancar o parar una selección de equipos es hoy en día una aparente obviedad, pero no lo era cuando esta nueva técnica se estaba poniendo en funcionamiento.

Por otro lado, siempre según este autor, hubo además una reducción de entre un 20 y un $25 \%$ en la cantidad de carbón empleado para la máquina de vapor.

${ }^{228}$ Señalar que los costes de capital inicial eran elevados con un motor en cada máquina porque la capacidad total de los motores era de cinco a siete veces la capacidad de un solo motor para toda la fábrica. Con un motor por máquina, cada uno de ellos tenía que ser suficiente para la máxima demanda de este, pero con el acoplamiento en grupo, el motor podía tener el tamaño necesario solo para una diversidad de cargas, o sea, la media del grupo más un margen de seguridad, ya que en raras ocasiones funcionaban todas la máquinas demandando la máxima carga simultáneamente. Resumiendo, con la adopción de un único motor por máquina la capacidad eléctrica aumentaba muchísimo, si bien se disminuía en pérdidas debido a fricción en los ejes y las correas. 
necesitando y a sus operarios correspondientes. El incremento de la producción generó nuevos requerimientos de coordinación de actividades dentro de las fábricas, siendo todo ello cada vez más "racional", concepto que introdujeron los ingenieros de cambio de siglo que se especializaron en la organización industrial ${ }^{229230}$.

Por otro lado, con la instalación del motor eléctrico acoplado a cada máquina, desaparecieron los sistemas mecánicos de ejes, contraejes, poleas y correas ${ }^{231}$. De esta manera, se liberó a la estructura de peso y vibraciones, compensando el coste inicial que suponía la adición de potencia instalada. En todo caso, el coste del cableado eléctrico era bastante inferior al de los ejes giratorios de hierro, o cableado mecánico, así como los costes de mantenimiento. De este modo, con la llegada del único motor, la electricidad empezó a ser vista como un medio económico de distribución de energía en las factorías. Para otros fue una palanca para incrementar la producción.

\footnotetext{
${ }^{229}$ Según Biggs (Biggs, 1996), la transformación que se produjo en los edificios se realizó desde los pequeños mills de finales de siglo, a los enormes complejos industriales de las primeras décadas del siglo XX que dominaron la vida económica y social de las grandes ciudades americanas. Debía vencerse como fuera esa limitación de los anteriores molinos: la energía hidráulica moderada, el espacio reducido, el condicionamiento por los numerosos pilares de la estructura, y la escasez de luz, tanto difusa (o general) como localizada en los puestos de trabajo de los operarios.

${ }^{230}$ También en España, unas décadas después, durante los primeros años del siglo XX fue cuando se pasó de la máquina de vapor a la energía eléctrica, principalmente en la zona mediterránea: "Las compañías Hidroeléctrica Española, Hidroeléctrica Ibérica y otras empezaron su gran despliegue industrial nacional" (Sobrino, 1996).

${ }^{231}$ Esta segunda tercera década del siglo XX coincide con la consecución de la "Daylight Factory" que Benham, en su libro La Atlántida de Hormigón, presenta como la fábrica moderna, diáfana y bien iluminada.
} 


\subsection{EL FACTOR DE LOS MATERIALES DE CONSTRUCCIÓN EN LOS EDIFICIOS FABRILES}

Los diferentes sistemas constructivos y los materiales utilizados para la construcción de un edificio destinado a un uso industrial tienen como objetivo lograr que sea funcional, puesto que su origen es principalmente utilitario, y sólo excepcionalmente, la "componente representativa se ha limitado a ciertos aspectos decorativos de poca o nula incidencia" (Gumà, 1997). Con el fin de ser óptimos para su actividad productiva siempre se trató de idear grandes espacios diáfanos para la disposición de maquinaria, pero intentando al máximo evitar largos recorridos en la transmisión de la energía mecánica, introduciendo asimismo la mejor y mayor cantidad de iluminación natural posible, y de forma adecuada, sin deslumbramientos. Finalmente como es lógico, todo ello con un coste económico mínimo. Para conseguir estos objetivos, los ingenieros, arquitectos e industriales, no sólo incidían en la forma del edificio, sino que también en otros aspectos básicos de la construcción, como por ejemplo en su distribución interior y en la estabilidad de la estructura, la cual inevitablemente estaba relacionada de forma directa con los materiales utilizados.

Según este mismo autor, la estructura de las edificaciones industriales siempre ha estado íntimamente correspondida con la tipología edificatoria. Se le exigía cumplir con el requisito de máxima funcionalidad, dependiendo del uso, y sobre todo, supeditada a encajar dentro de ella la maquinaria necesaria ${ }^{232}$. Pero, para cumplir con estas exigencias había unas limitaciones propias de los materiales.

En un principio, el inicio del periodo de análisis de este trabajo se establece en 1722, con la construcción de la fábrica Lombe's Mill \{confrontar este edificio en apartado 3.2.1\} y finaliza aproximadamente 200 años después, coincidiendo con los primeros edificios con estructura de hormigón \{confrontar este edificio en apartado 3.2.11\}. La evolución que la estructura de los mill buindings experimentó

${ }^{232}$ En los almacenes la maquinaria se quedaría en segundo plano, puesto que lo que simplemente se les exigía era que proporcionaran un espacio cubierto. 
durante este periodo está fuertemente vinculada a la aparición de nuevos materiales estructurales, y por supuesto, al cambio en las necesidades derivadas del proceso industrial y de los requerimientos para cada fábrica. A la hora de valorar estas innovaciones, estos edificios se presentan agrupados por elementos estructurales (muros de carga, pilares, bovedillas, viguetas, forjados, etc), estando ordenados cronológicamente, de forma que al final se pueda apreciar este cambio en la totalidad del edificio. Lo que se persigue concluir es cuales son las modificaciones que han ido introduciendo los diferentes materiales en las estructuras de los edificios fabriles, y por ende, en la forma y el diseño de los mismos.

En la Figura 143 se aprecia con un simple golpe de vista, la comparación entre cuatro edificios construidos con 130 años de diferencia, pudiendo valorar así cual ha sido la evolución de la diafanidad de los espacios fabriles: del edificio a base de muros de carga y pequeños ventanales, pasando por los primeros soportes interiores en hierro fundido, por un almacén con estructura totalmente de hierro fundido, incluso en su fachada (lo que le permite disponer de huecos corridos para una intensa iluminación interior), hasta un inmenso "mill" cuyas fachadas son prácticamente diáfanas gracias a su esqueleto totalmente en hierro, consiguiendo la iluminación natural indispensable para el proceso de fabricación. 

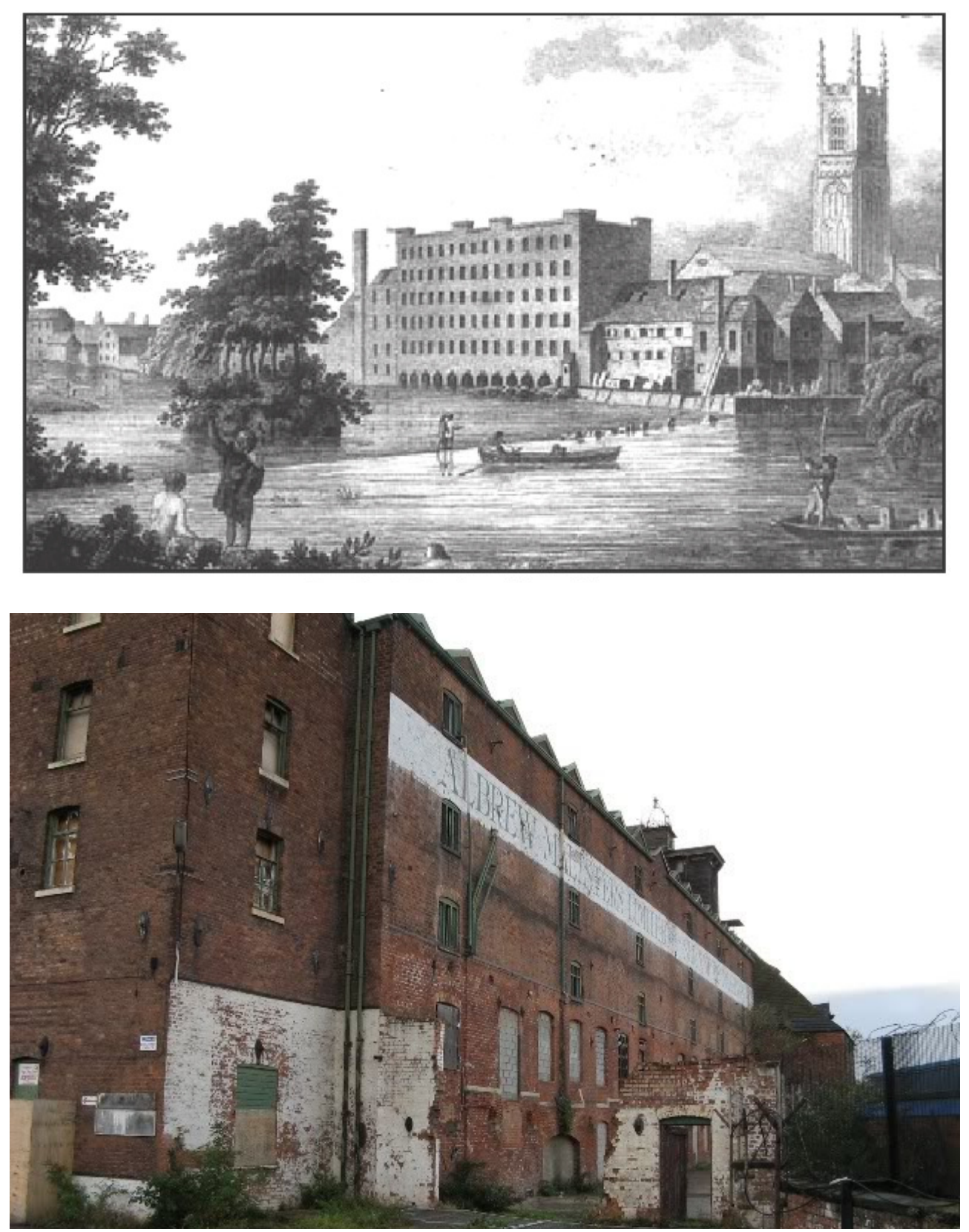

$269 / 525$ 

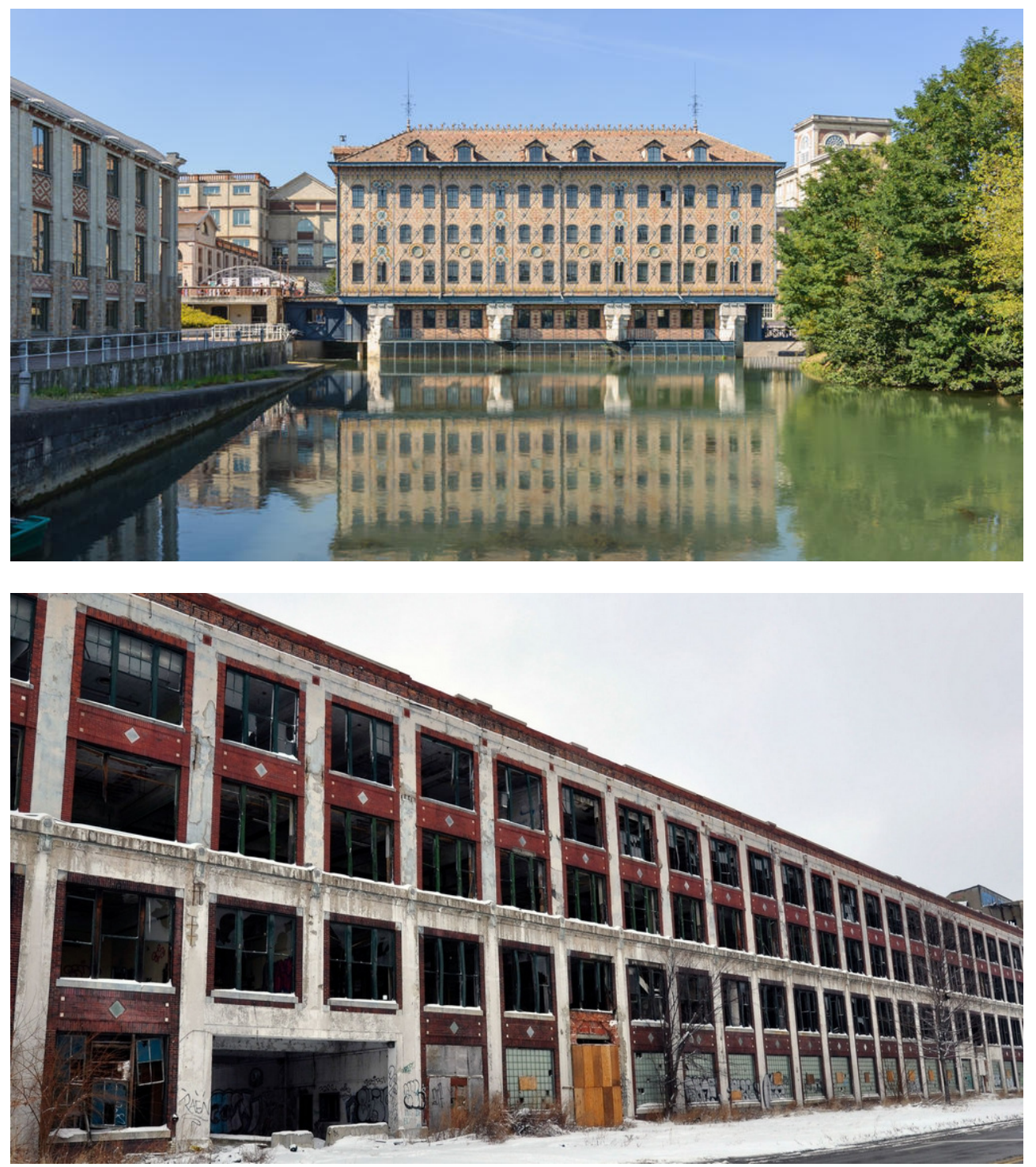

Figura 143. Evolución de los edificios visto desde su exterior: del molino de los hermanos Lombe, de 1722; pasando por el Ditherington Flax Mill, en Shrewsbury, 1796; y la fábrica de chocolates de Menier, en Noisel-Sur-Marne, de 1871; hasta la Packard Motor Company, en Detroit, de 1905 (https://www.google.es/maps). 


\section{CLASIFICACIÓN Y EVOLUCIÓN EN FUNCIÓN DE LOS MATERIALES DE LA}

\section{ESTRUCTURA}

Una de las muchas clasificaciones a las que se puede someter la estructura de los edificios es aquella que distingue entre las que son aporticadas, entramadas, y las que no lo son. En este estudio se tratará de las estructuras que comparten ambas soluciones: las estructuras murarias que evolucionan hacia las de entramado, justo cuando la estructura llega a la fachada, en forma de pilares metálicos o de hormigón. Por otro lado, únicamente se discutirá acerca de los edificios y sistemas constructivos de ámbito industrial, analizándose en detalle esta transformación, desde las primeras ${ }^{233}$ manufacturas de edificios en altura ${ }^{234}$, hasta los primeros ejemplos de armazón en hormigón armado de las primeras décadas del siglo $\mathrm{XX}^{235}$.

Por otro lado, para este análisis se separará la estructura de cubierta del resto de la del edificio, en cuanto que esta siguió una evolución claramente diferenciada, entre otros motivos, por la desigual naturaleza de las solicitaciones y por su función exclusivamente de envolvente, además de utilizar otros sistemas constructivos $^{236}$.

A continuación, en la Figura 144, se muestra un mapa conceptual en el que se refleja visualmente cada uno de los pasos del proceso evolutivo de la tecnología

\footnotetext{
${ }^{233}$ Anteriormente al siglo XVIII se tejía en los talleres artesanales ubicados en las propias casas de los artesanos, por lo que no entrarían en el ámbito de estudio de esta tesis doctoral.

${ }^{234}$ La fábrica de seda de los Hermanos Lombe, estudiada en el apartado anterior, es un buen ejemplo que representa el inicio de los molinos manufactureros o "mill buildings".

${ }^{235}$ Correspondiendo a la parte final del espacio de tiempo en estudio. Como nota de referencia, hay que tener en cuenta que los primeros ensayos de fuego en metales de la construcción se realizaron alrededor de 1914.

${ }^{236}$ A finales del siglo XIX y principios del XX, las cubiertas planas eran escondidas mediante parapetos $\mathrm{o}$ antepechos bajos. Las vigas ya son de acero y hormigón, cubiertas de asfalto natural y betún. En algunos casos concretos de épocas de construcción especificas, estaban incluso cubiertas de agua para mantener la temperatura del local inferior, así como reserva de los rociadores contra el fuego.
} 
de la construcción. En él se incluyen los diferentes materiales empleados, como la madera, el hierro fundido y forjado, e incluso el acero, tanto en los elementos verticales como horizontales de la estructura, y donde las flechas indican la consecución temporal de cada transformación. Uno de los objetivos principales a alcanzar es la obtención de la máxima iluminación en el interior de los espacios de trabajo [Estado 10], la rapidez de montaje, etc, así como la facilidad de la transmisión mecánica de accionamiento por todo el volumen, todo ello en un conjunto seguro y resistente al fuego, en la medida de lo posible. 


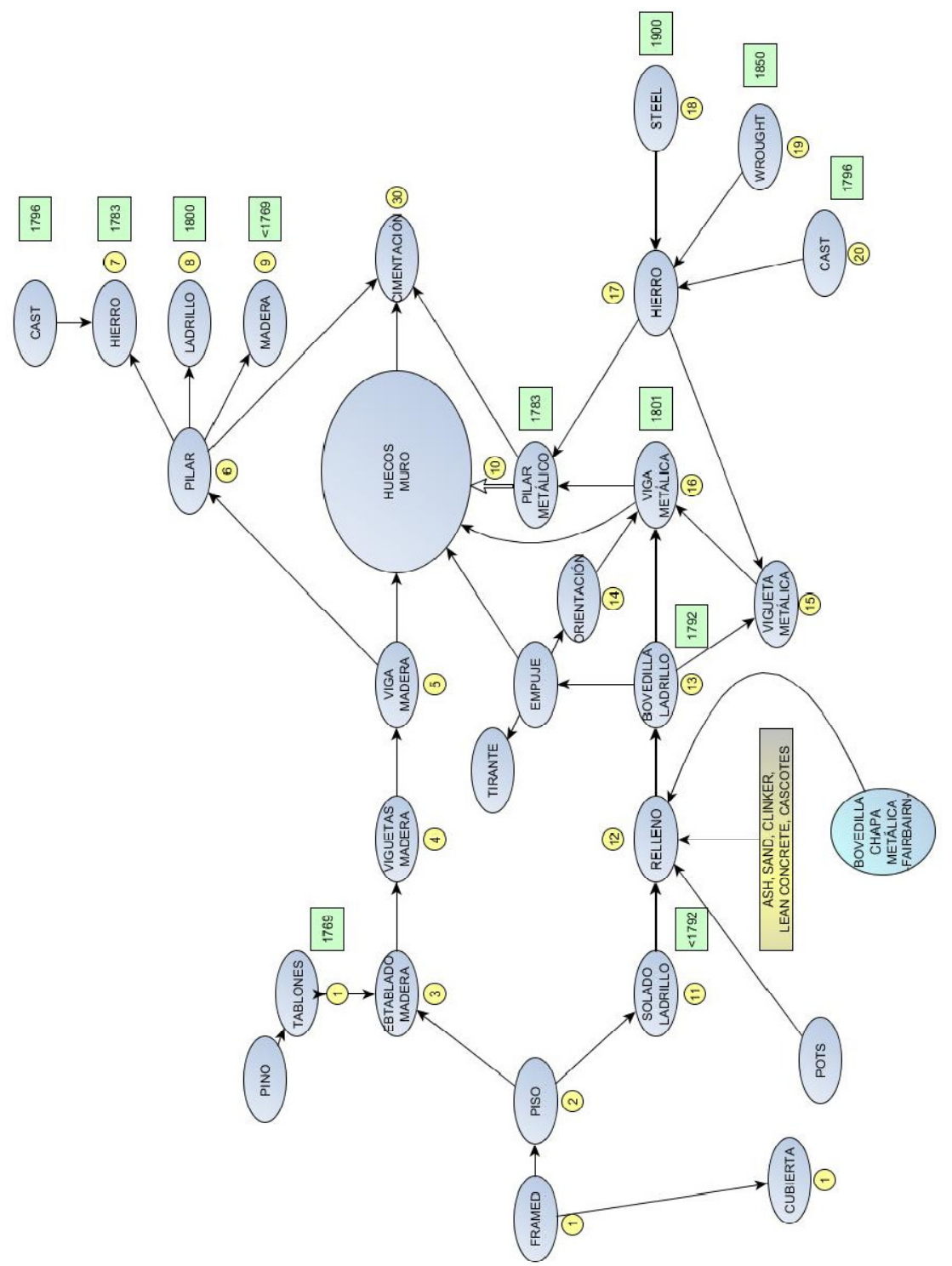

Figura 144. Mapa conceptual para la valoración de la evolución de las estructuras de los "mill buildings" frente al fuego. 
La transformación de los espacios fabriles estuvo íntimamente ligada a la necesidad de ampliar los recintos en los que se producía seda, algodón y lana, que a su vez tenían que adaptarse al incremento de la demanda, indudablemente motivada por el aumento demográfico y la mejora en la calidad de vida en general. Otra causa fue la aparición de nuevas tecnologías que facilitaron la producción en grandes cantidades, y como no también, la existencia de un espíritu emprendedor generalizado materializado en incipientes inversores, que junto con los ingenieros, trataban de descubrir los mejores materiales de construcción con el mejor comportamiento, en función del uso al que iban a destinar a sus edificios y de sus especificaciones.

Se realizaron numerosos estudios, en la mayoría de los casos empíricos, para de alguna manera tender a estructuras más resistentes mecánicamente y con un mejor comportamiento ante el fuego.

Buen ejemplo de ello lo tenemos en las teorías de Fairbairn, que en la 2 a mitad del siglo XIX, aportan un punto de inflexión hacia la consecución de lo que en la bibliografía inglesa se denominaba como "fire-proof", o a prueba de incendios, que era en definitiva el objetivo más deseado.

Pero incluso Fairbairn fue precedido, a finales del siglo XVIII y las primeras décadas del XIX, por otros personajes destacables, a la vez ingenieros, arquitectos, empresarios e inversores ${ }^{237}$. Tal fue el caso, entre otros muchos, del arquitecto Charles Bage o de la familia Strutt, cuyas aportaciones ayudaron en cierto modo a que se produjera el arranque de la llamada Revolución Industrial, no solo como nuevo sistema productivo o como un cambio social radical, sino como la invención de nuevos procedimientos constructivos, que perdurarán durante más de un siglo hasta la aparición del acero laminado o el hormigón armado, lo cual se hará coincidir con el final del periodo de estudio de esta tesis.

${ }^{237}$ Que muchas veces coincidían todos ellos en una misma figura. 
Esta evolución tecnológica y de utilización de los diferentes materiales de construcción referida ha sido dividida en 3 periodos claramente diferenciados: utilización de la madera, del hierro y finalmente del hormigón.

Asimismo, para la mejor comprensión del tema a tratar en este apartado, referente a la evolución de los materiales en la construcción, se ha desarrollado un mapa conceptual, planteado de forma que se pueda asociar un camino determinado en el mismo para cada edificio estudiado en el apartado anterior \{Apartado 3.2\}. El uso de la palabra "camino" se refiere al sentido de las flechas que se reflejan en el esquema, que son las que conducen hacia la construcción de un nuevo edificio tecnológicamente más avanzado en el sentido de estar basado técnicamente en un edificio precedente, o lo que es lo mismo, cronológicamente anterior. A estas líneas del mapa también se les llama "relaciones". 


\section{MADERA}

Si se habla de la constitución de los pisos que dividían las distintas plantas de los edificios en altura [Estado 2 de la página 273], se diferenciará entre aquellos que utilizaban un entablado de madera [Estado 3], y aquellos formados por losas de piedra o ladrillo [Estado 11 $]^{238}$.

Si se sigue el recorrido que parte de los forjados de madera, realizados mediante viguetas y tablones de madera [Estado 4] apoyadas sobre vigas del mismo material [Estado 5], y que a su vez apoyan sobre pilares de madera [Estado 9], obtenemos la tipología de edificio industrial más antigua, y que simplemente se corresponde con los primeros edificios con estructura completamente de madera, a excepción de la envolvente realizada con mampuestos. Ejemplos de esta clasificación se reflejaron en el apartado anterior, como el de los Hermanos Lombe o el de los primeros edificios del mismo Arkwright (1732 - 1792). En ellos, las vigas de madera apoyaban en los muros de carga, en los que se disponían unos mechinales ${ }^{239}$. En dichas vigas se realizaban muescas donde apoyarían las viguetas $^{240}$, generalmente también de la misma madera [Estado 5] [Figura 145, Figura 146, Figura 147, Figura 148 y Figura 149].

\footnotetext{
${ }^{238}$ En el momento del inicio del estudio $(\approx 1700)$ las estructuras de los mills asociados a la industria textil y de molienda de trigo se caracterizaban principalmente por construirse con muros perimetrales portantes, y si existía alguna crujía interior, normalmente era mediante pilares de ladrillo o madera, con lo que los edificios no alcanzaban a ser muy anchos. Los forjados se construyen a base de entarimado de madera yuxtapuestos. Ello no solo ocurre en Gran Bretaña, sino también en la industria textil catalana, pionera española, lo que se deduce de la tesis de R. Gumà (Gumà, 1997).

${ }^{239}$ En los primeros mills de Arkwright, de principios de la segunda mitad del siglo XVIII, la distancia entre los distintos vanos de madera era de alrededor de $2 \mathrm{~m}$, ubicando los huecos de ventana entre ellos (University of the West of England. Dep. Architecture, 2014).

${ }^{240}$ Solución constructiva poco habitual.
} 


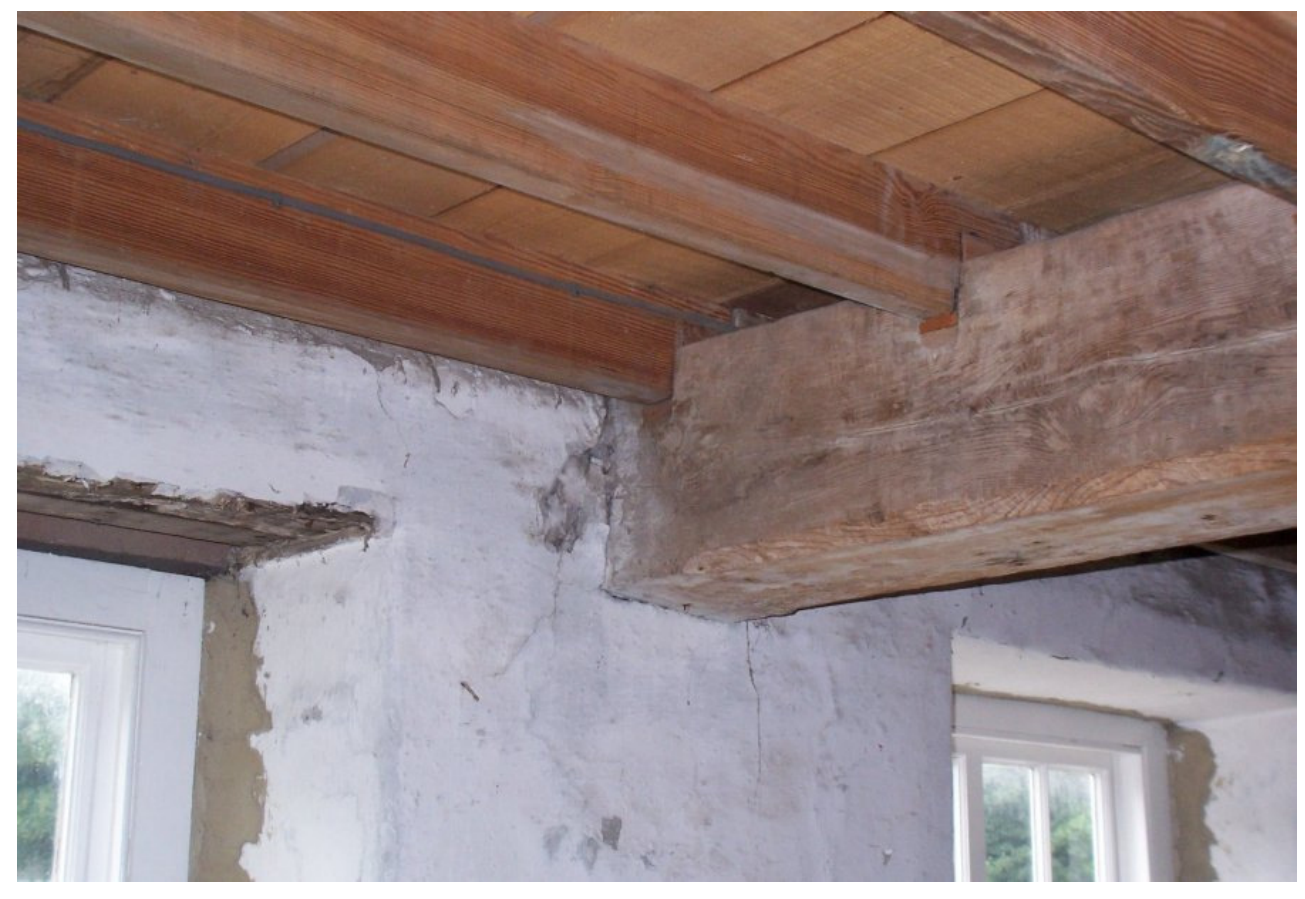

Figura 145. Cromford Mill, primero de los edificios de Arkwright, de 1776: entablado de madera para la formación de los pisos, con viguetas y vigas de madera apoyando en los muros perimetrales (University of the West of England. Dep. Architecture, 2014). 


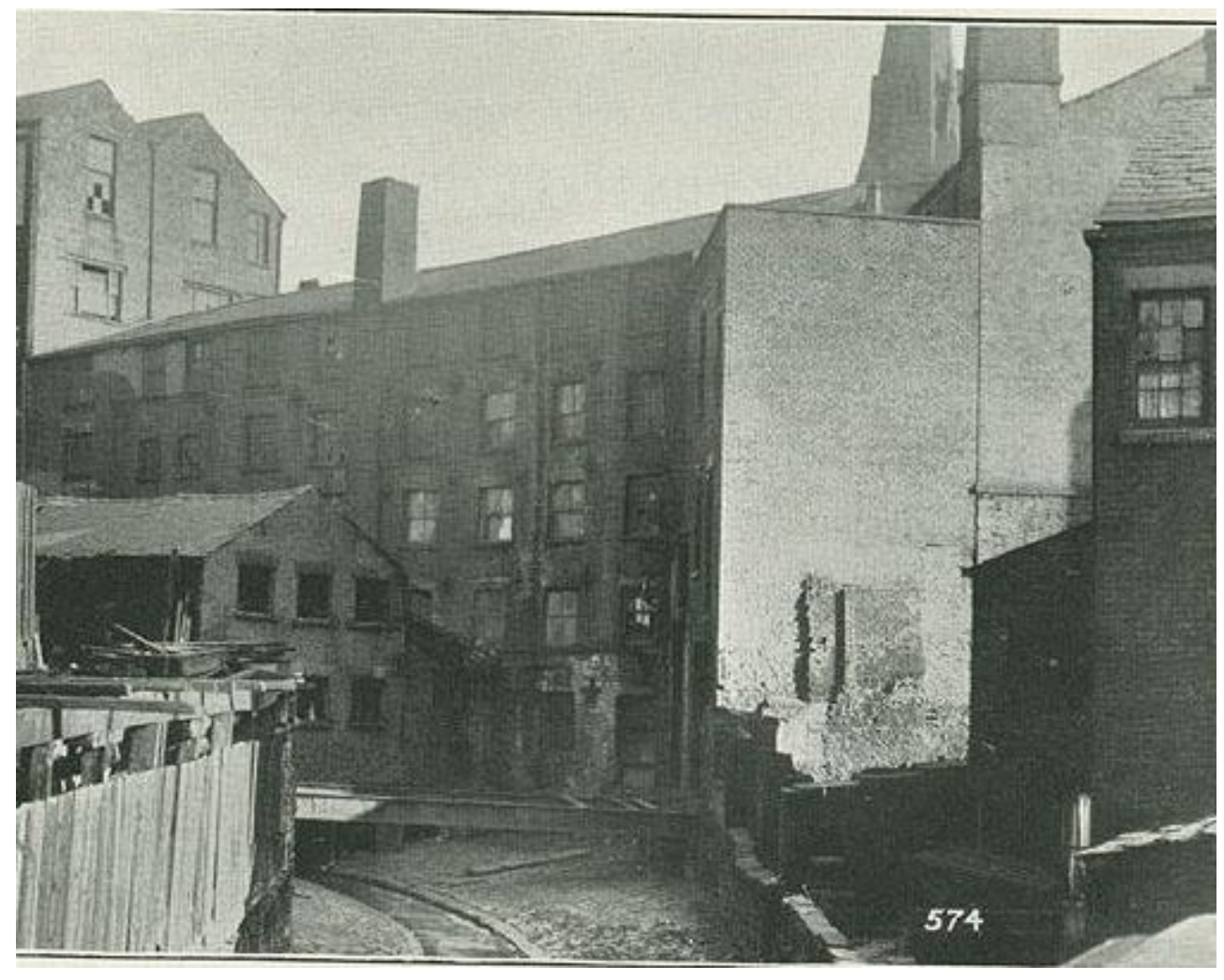

Figura 146. Un "mill" construido en 1782, en Bolton, Gran Mánchester. Este un caso típico de manufactura con estructura completamente en madera, y cuya cubierta estaba realizada con cerchas también del mismo material (Hill, 1927). 


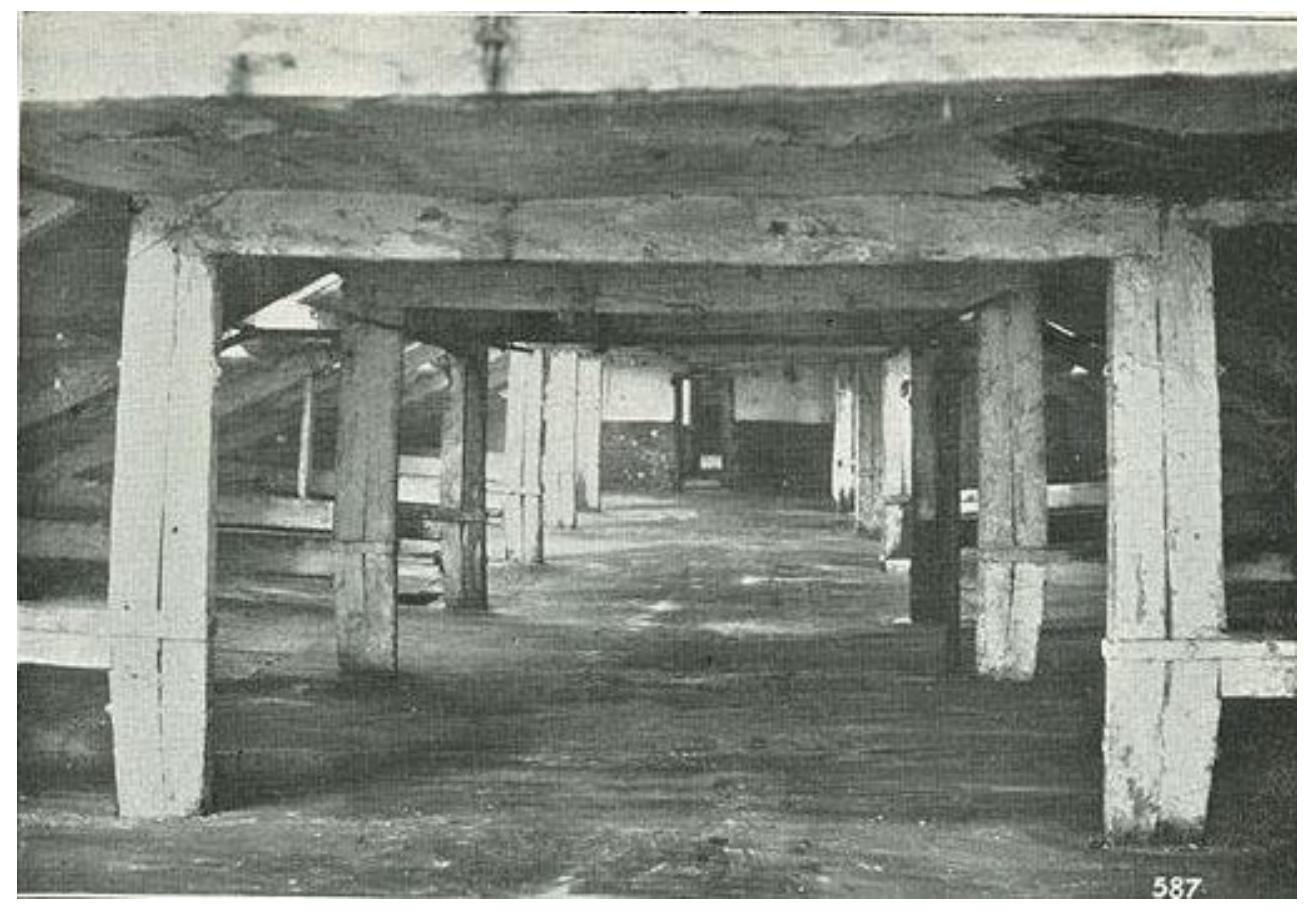

Figura 147. "Típico" ático de un "mill" de finales del siglo XVIII. Las cerchas de madera son de tipo "queen", esto es, de configuración tal que permite un espacio libre central para un uso específico (en muchas ocasiones, concretamente en Inglaterra, servía de escuela para los niños que trabajaban en las plantas inferiores) (Hill, 1927).

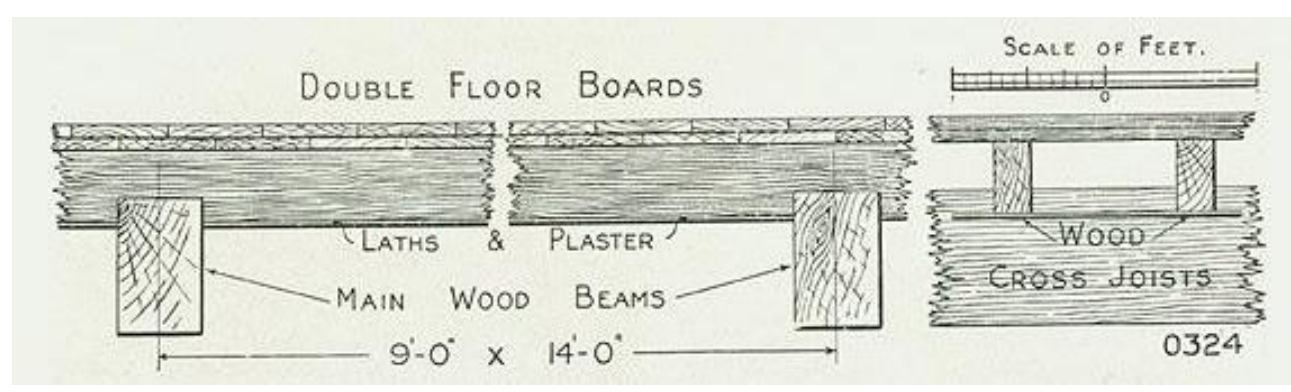

Figura 148. "Mill" de principios del siglo XIX. Vigas (interdistancia alcanzada mayor de $4 \mathrm{~m}$ ), viguetas y suelos de madera. Sección habitual en forjados de principios del XIX (Hill, 1927). 


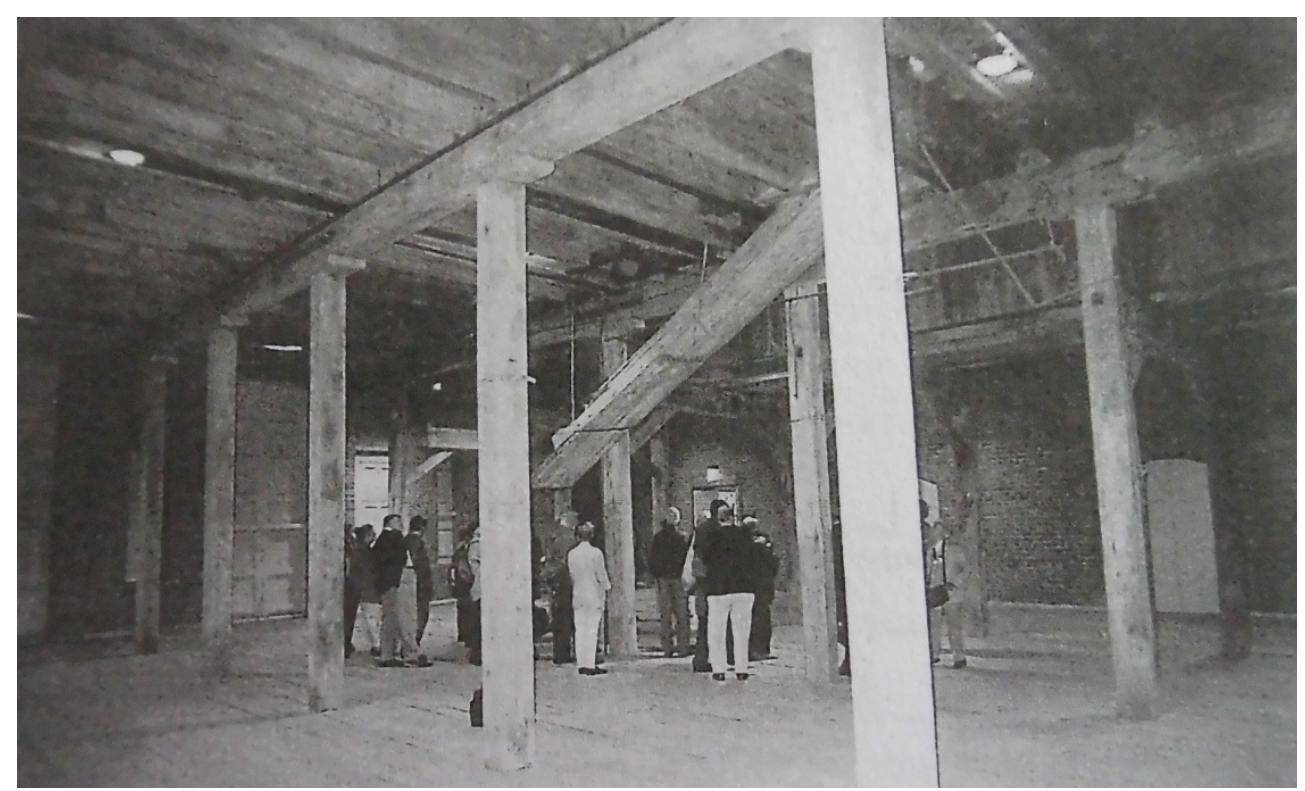

Figura 149. Liverpool Road Station Warehouse, Manchester. Construido en 1830 completamente con estructura interior de madera (Swailes, 1998).

Como regla general, en este periodo comprendido entre el inicio de la llamada Revolución Industrial y las primeras décadas del siglo XIX, también se encuentra la casuística de edificios con estructura de madera y pilares de ladrillo [Estado 8 de la página 273], sobre todo, en aquellos casos en los que se pretendía aumentar la anchura del edificio pero no se disponía todavía del suficiente conocimiento de la forma de trabajo de los soportes metálicos, o que simplemente no se disponía todavía de este material ${ }^{241}$.

\footnotetext{
${ }^{241}$ En Inglaterra se prefería la utilización de la madera frente al hierro, entre otros motivos, por la existencia de numerosos bosques, por lo que la introducción de este segundo material tomó su tiempo.
} 
Por otro lado, la madera comúnmente utilizada era de pino, importada de América (University of the West of England. Dep. Architecture, 2014). La utilización de madera blanda ("softwood") se debía a que su gran contenido en resina evitaba su descomposición y putrefacción, con lo que se garantizaba una gran durabilidad ${ }^{242}$

Para la cubierta, el material predominante es también la madera en forma de vigas o formando cerchas [Figura 147 y Figura 150]. Por su parte, las escaleras también eran igualmente de madera.

${ }^{242}$ Este tipo de madera se usaba para la construcción de barcos, utillaje para la minería, y más tarde, para los durmientes de las vías de ferrocarril. 


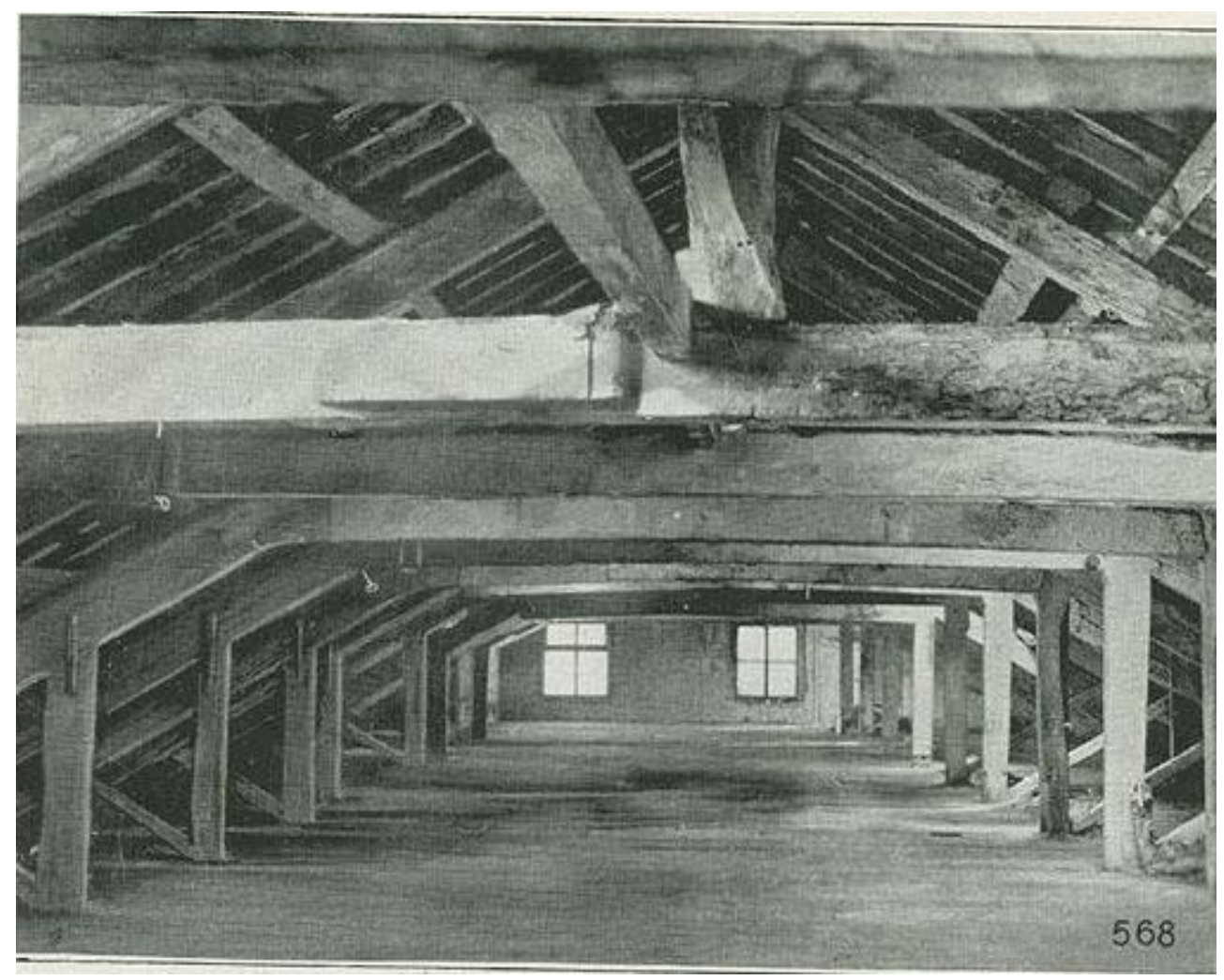

Figura 150. Ático de un "mill" de 1830, con cerchas de madera, al igual que los tablones del suelo. Como se aprecia toda la estructura es de madera (Hill, 1927). 


\begin{tabular}{|c|c|c|c|c|c|c|c|}
\hline MILL & Fecha & Ubicación & Actividad & vigas & soportes & pisos & cubierta \\
\hline $\begin{array}{l}\text { LOMBE'S } \\
\text { MILL }\end{array}$ & 1722 & Derby & TEXTIL (seda) & madera & $\begin{array}{l}\text { muro } \\
\text { perimetral } \\
\text { pilar interior } \\
\text { de ladrillo }\end{array}$ & madera & $\begin{array}{l}\text { cubierta } \\
\text { inclinada, } \\
\text { estructura } \\
\text { básica de } \\
\text { madera }\end{array}$ \\
\hline $\begin{array}{l}\text { CROMFORD } \\
\text { MILL }\end{array}$ & 1783 & Cromford & $\begin{array}{l}\text { TEXTIL } \\
\text { (algodón) }\end{array}$ & madera & $\begin{array}{l}\text { muro } \\
\text { perimetral y } \\
\text { soporte } \\
\text { intermedio } \\
\text { de hierro } \\
\text { fundido }\end{array}$ & madera & $\begin{array}{l}\text { madera } \\
\text { con cercha } \\
\text { tipo King }\end{array}$ \\
\hline ALBION MILL & 1786 & $\begin{array}{c}\text { Orillas } \\
\text { Támesis en } \\
\text { Londres }\end{array}$ & $\begin{array}{l}\text { ALIMENT. } \\
\text { (harina) }\end{array}$ & madera & $\begin{array}{l}\text { muro } \\
\text { perimetral y } \\
\text { pilar interior } \\
\text { de ladrillo }\end{array}$ & madera & $\begin{array}{l}\text { cubierta a } \\
\text { dos aguas }\end{array}$ \\
\hline
\end{tabular}

Tabla 4. Clasificación de los "mill buildings" de referencia estudiados en el Apartado 3.2, según el material empleado en sus elementos estructurales.

Como se ve en la anterior Tabla 4, dentro del grupo en estudio se encuentran las fábricas de Lombe, el conjunto industrial de Arkwright en Cromford y la Albion Mill de Londres, cuya característica común era la distribución interior en alturas y su estructura básica: todos se valían de varias plantas para colocar la maquinaria. Esta condición viene forzada en parte por la imposibilidad de crear grandes luces a base de vigas de madera y muros portantes de mampostería y por el hecho de poder garantizar una buena iluminación en el interior. 
DESARROLLO DETALLADO DEL MAPA CONCEPTUAL de la Figura 144 (página 273) sobre la base estructural de la madera de los "mill buildings" [Figura 151]:

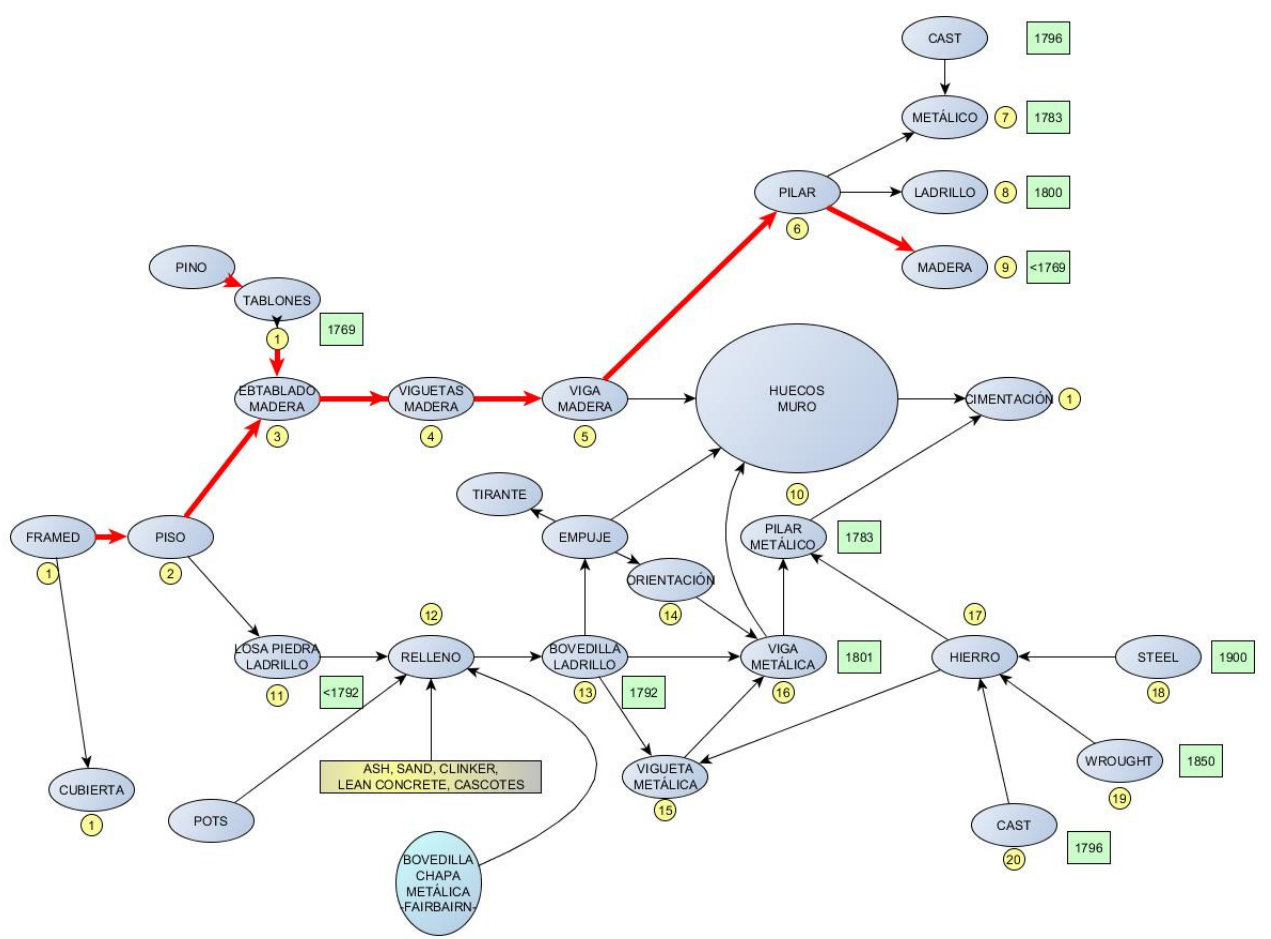

Figura 151. Evolución constructiva de madera.

En la Figura 151 aparecen diferentes referencias que constituyen el proceso evolutivo de la madera como material estructural en los espacios fabriles. Vale la pena comentar cada uno de esos pasos o nudos de una forma más detallada, como complemento a los edificios destacados en los párrafos anteriores: 
1. El sistema constructivo "framed", entramado o aporticado, se diferencia del "non-framed", porque el segundo utiliza los muros de carga, generalmente en toda su estructura. Con el sistema "framed" se consigue una construcción más rápida y mejor arriostrada de los edificios, con toda su estructura trabajando al mismo tiempo, así como una mayor diafanidad al necesitar menor cantidad de soportes interiores, mejorando la distribución interna. Asimismo, se incrementa de forma considerable la posibilidad de ampliaciones futuras tanto en planta como en alturas. En el caso que nos ocupa en este apartado, sobre la construcción a base de madera, las estructuras son mixtas, en tanto en cuanto los edificios están construidos a base de pórticos interiores pero apoyando en envolvente portante.

2. Pisos: la evolución constructiva se separa entre las diferentes formas de pisos: los formados por entablados de madera y aquellos realizados mediante ladrillo, que cronológicamente suceden después [Estado 3 y Estado 11 respectivamente].

3. Entablado de madera para la formación de pisos: pese a la utilización pionera en las fábricas de Belper y Ditherington en el cambio de siglo de XVIII al XIX de las bóvedas de ladrillo, como se verá en el aparatado siguiente, se siguieron utilizando los suelos de madera, incluso 100 años después de la construcción de estos edificios (University of the West of England. Dep. Architecture, 2014). Por tanto, se puede afirmar, que fue un tipo de suelo que se utilizó durante mucho tiempo: desde los primeros edificios en altura, como el de los Hermanos Lombe, en 1722, hasta finales del XIX. Una de las razones principales se debió a la abundancia de este material noble en Inglaterra, y también por el conocimiento empírico de su comportamiento mecánico. Además, en general, los suelos de madera eran muy rápidos de construir y comparativamente baratos. Su principal problema: la combustibilidad. 
En la Figura 148 se presenta la sección de un forjado con doble entablado de listones de madera como piso, apoyado sobre viguetas y vigas del mismo material $^{243}$.

4. Viguetas de madera: se siguieron utilizando en las estructuras de los forjados hasta bien entrada la segunda mitad del siglo XIX ${ }^{244}$.

En la Figura 145 y Figura 148 se aprecian también las viguetas de madera sobre las que descansan los listones de madera.

5. Vigas de madera: hablar de viga de madera puede resultar muy amplio y excesivamente genérico. Este material, noble por excelencia, ha tenido un prolongado uso en construcción residencial y no residencial, por lo que solo se presentará algún caso específico, pudiéndose encontrar numerosos ejemplos en las diversas fotografías de esta tesis.

6. Cubierta: por último, se presentan algunas fotografías de cubiertas de manufacturas textiles del siglo XVIII y XIX. Generalmente, se trataba de cubiertas a 2 aguas, puesto que era la forma más sencilla de evacuar el agua de lluvia. Eran estructuras de madera conocidas como "king or queen roof trusses", aunque durante mucho tiempo fueron de madera, se fueron incorporando tirantes de hierro forjado [Figura 147 y Figura 150].

La aparición de los soportes metálicos fue sin duda el punto de inflexión en la construcción de edificios en altura, junto con las bóvedas de ladrillo para la formación de forjados, y que se pasa a estudiar a continuación. El primero en utilizar este último método constructivo, que se tenga constancia, fue William Strutt, en el Derby Cotton Mill, de Derby, en $1792 \div 93$ [Figura 152].

\footnotetext{
${ }^{243}$ Esta tipología resultó muy habitual en el siglo XVIII y la primera mitad del XIX, pudiéndose encontrar numerosísimos ejemplos.

${ }^{244}$ Como ejemplo de esta última afirmación, se tiene el almacén de barcos Boat Store, en Kent, de 1858, en el que toda la estructura se ejecutó mediante estructura metálica, excepto sus viguetas que eran todavía de madera.
} 


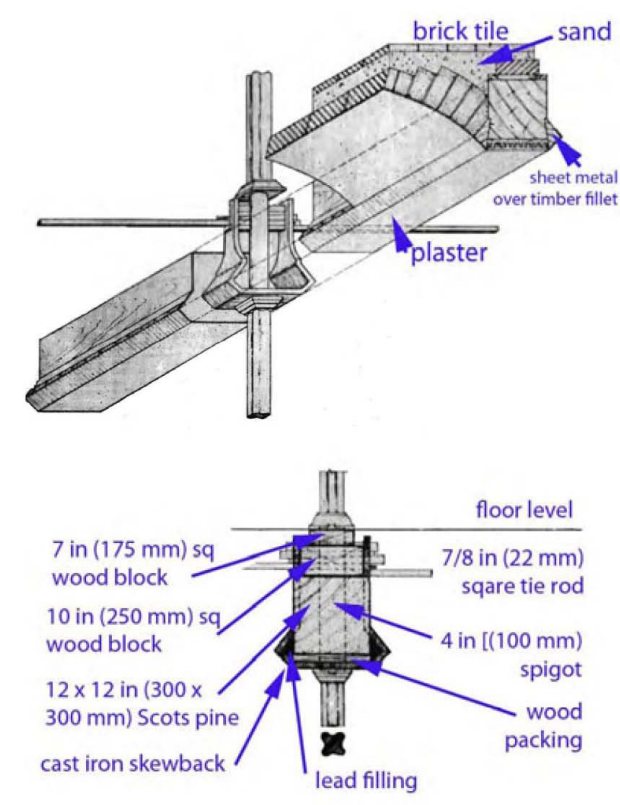

Figura 152. Detalle constructivo de la continuidad de los pilares entre plantas del North Mill, Belper, de finales del siglo XVIII, con vigas principales de madera (analizado en Apartado 3.2.7) (Bryant, 1950). Lo que aparece con el término inglés como "skewback" se refiere a la pieza metálica anclada en la viga de madera donde se recibían los arcos de ladrillo. 


\section{LADRILLO}

La utilización de ladrillo para la formación de bóvedas en lugar de tablones de madera fue una característica que "impresionó" (Johnson, 1955) no solo a los arquitectos e ingenieros de su época, sino especialmente a los constructores, deseosos de tener una alternativa real al principal problema que venían sufriendo sus fábricas, esto es, que no eran capaces de resistir frente al fuego. Es por ello que a este tipo de forjados se les llamó "fire-proof", o a prueba de incendios, desde su primera utilización. Según este mismo autor, ello fue calificado por muchos como el verdadero origen de la estructura moderna [Estado 13 de la Figura 153 y Figura 154].

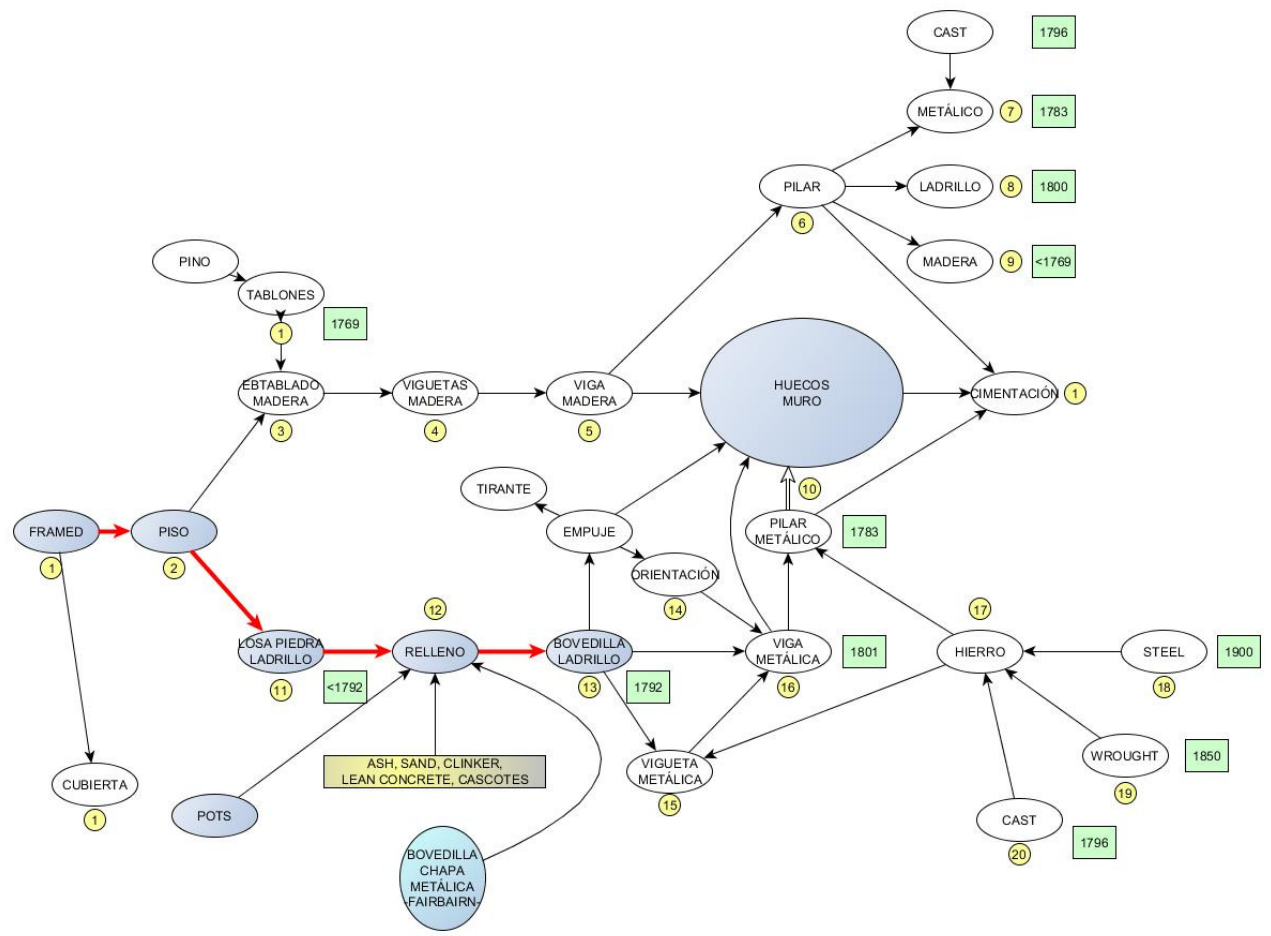

Figura 153. Evolución constructiva de las bóvedas de ladrillo (en inglés "brick archs"). 

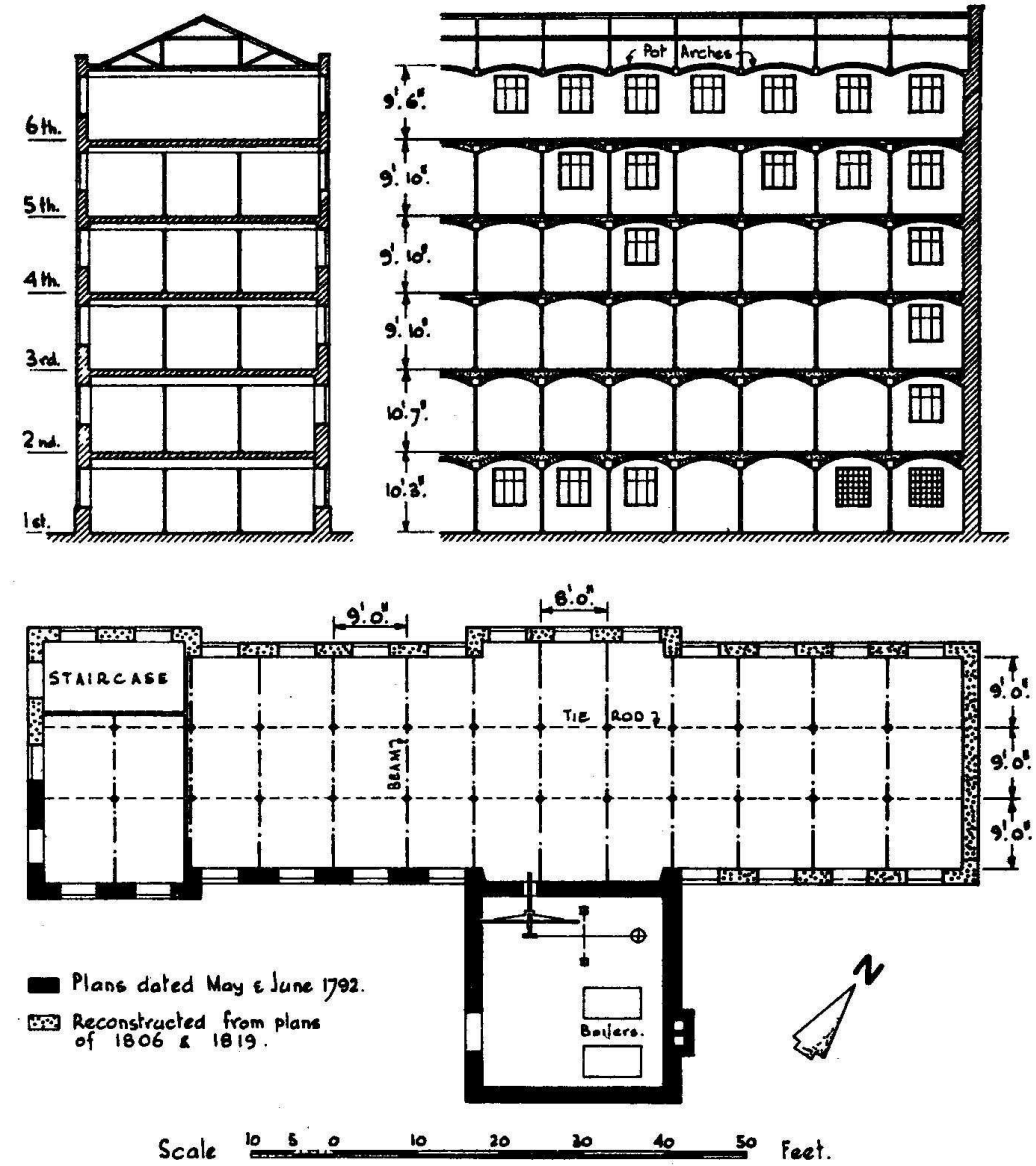

DERBY $B$ COTTON MILL

\section{$1792-93$. J.STRUTT \& SONS.}

Figura 154. Derby Cotton Mill, de William Strutt. Sección y planta, en el que se distingue claramente las bóvedas de ladrillo apoyadas sobre vigas de madera separadas una distancia de $\approx 2,75 \mathrm{~m}$. En la cubierta aparece la palabra "pot arches" en inglés, sistema empleado para aligerar estas bóvedas, cuyo peso en general era considerable porque tenían un gran canto. Estos se pueden apreciar en la Figura 162 (Johnson, 1955). 


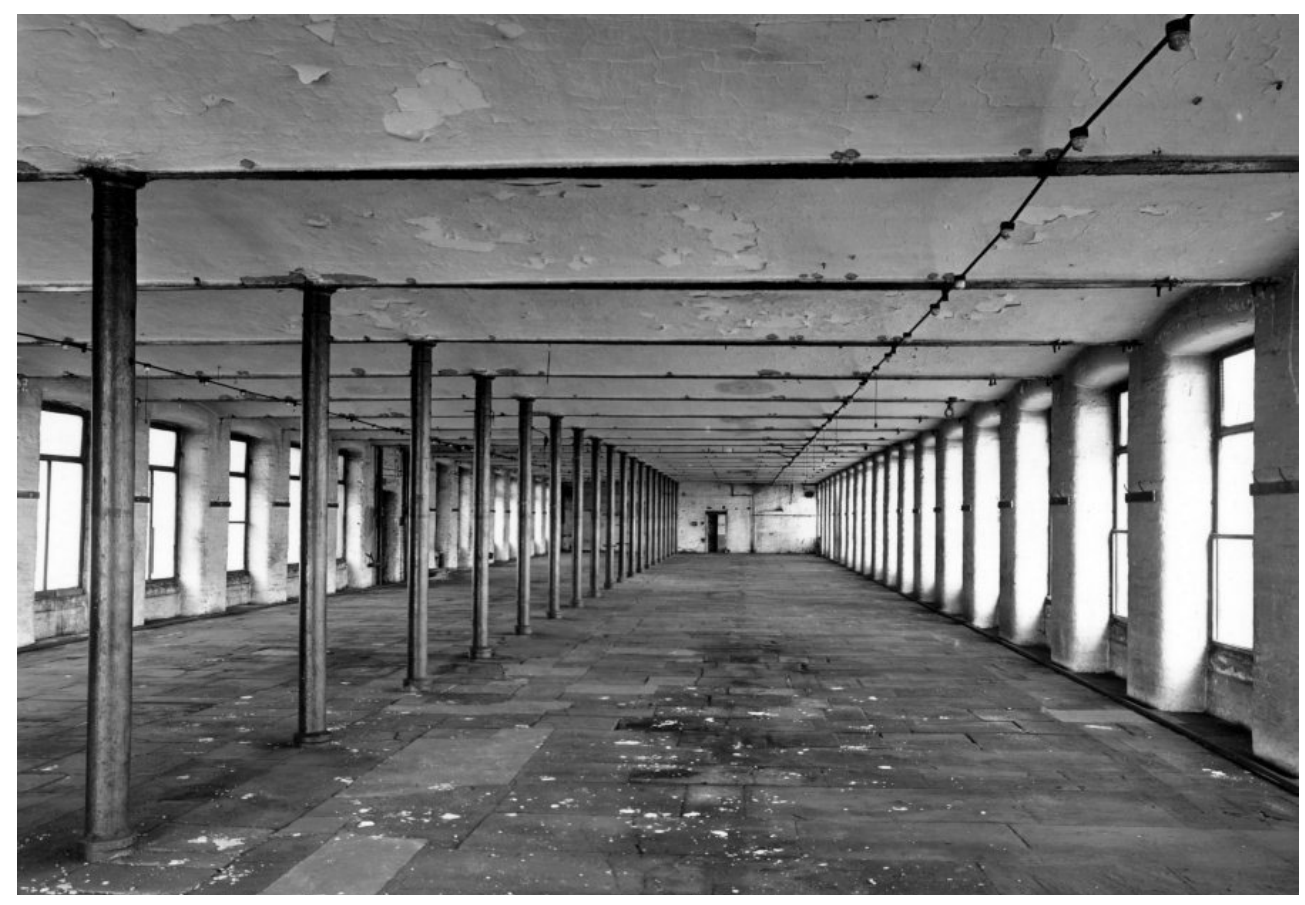

Figura 155. Hunslett Mill, Leeds, construido en 1840 (University of the West of England. Dep. Architecture, 2014).

En la Figura 155 y Figura 156 se distinguen claramente las bóvedas de ladrillo para conformar los forjados, las cuales apoyan sobre vigas de hierro fundido, con una sola hilera de pilares de sección cruciforme en el centro del edificio (material que se estudiará en el apartado siguiente, en la página 308). Por otro lado, el suelo estaba enlosado en piedra, y no con tablones de madera (como los de la Figura 123), lo que podría considerarse también como una novedad. 


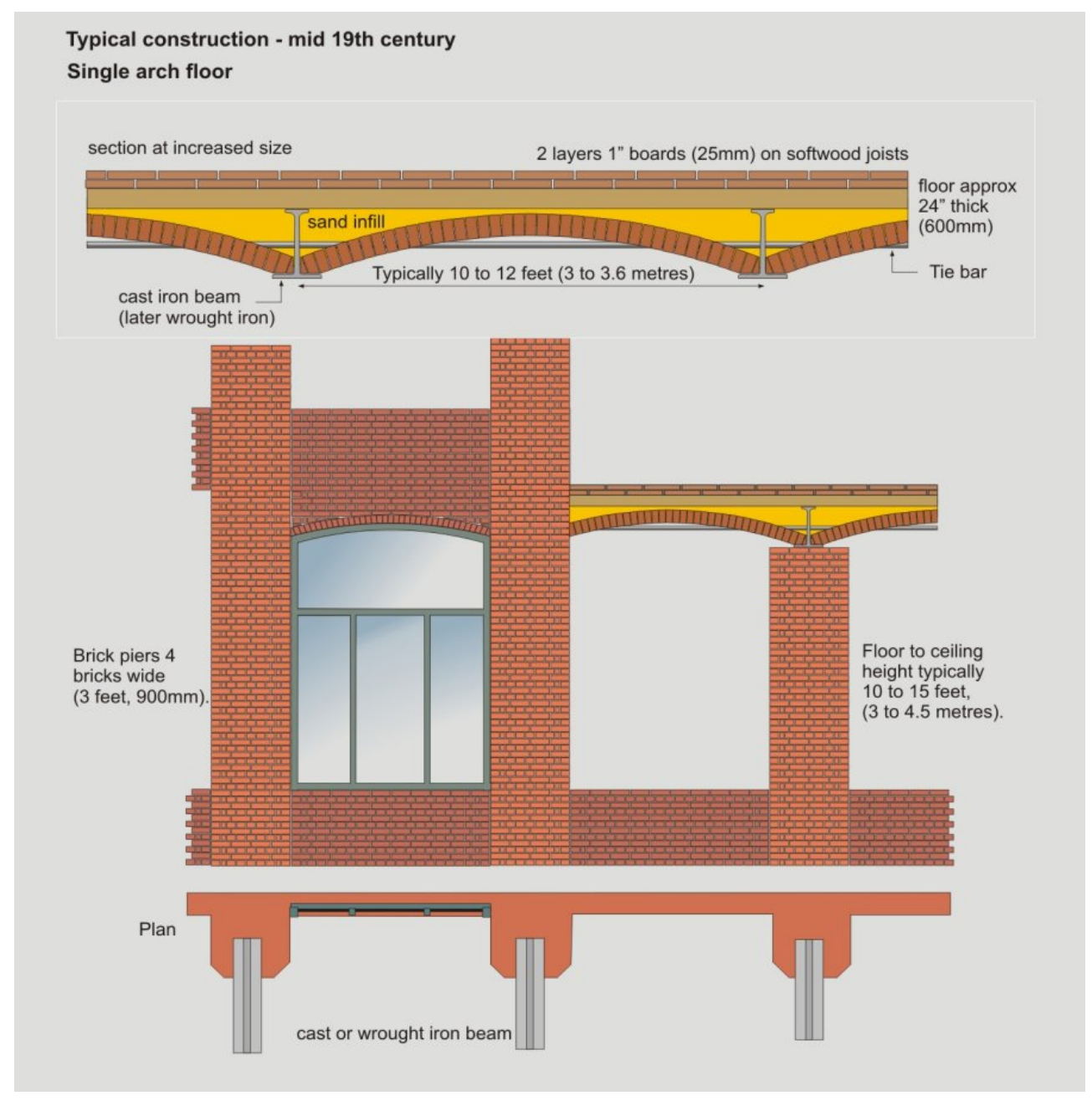

Figura 156. Alzado y sección de un edificio con fachada típica de la primera mitad del siglo XIX, formada por pilastras donde apoyaban las vigas (interdistancia alcanzada hasta los 3,6 m) ${ }^{245}$, y que limitaban el ancho de las ventanas. Las cotas reflejadas son muy ilustrativas para obtener una referencia de las dimensiones que se alcanzaban (University of the West of England. Dep. Architecture, 2014).

${ }^{245}$ La interdistancia alcanzada entre viguetas de madera en la Figura 148, de principios del mismo siglo, era de hasta $4 \mathrm{~m}$. 
Tanto en este ejemplo citado de la Figura 154, el Derby Cotton Mill, como en el del almacén que también el propio Strutt construyó en Milford, cercano a Belper, en $1792 \div 93$, las bóvedas de ladrillo descansaban sobre vigas de madera [Estado 5 de la Figura 153], que se asentaban sobre 2 hileras de pilares de hierro fundido de sección cruciforme ${ }^{246}$.

Como principal novedad, para la formación de los forjados se utilizaba el relleno de arena, cenizas, escorias, arcilla ${ }^{247}$ [Figura 153], y encima el enlosado de piedra como suelo pisable [Estado 20]. De esta forma, se eliminaban los predecesores tablones de madera que al quedar empapados, tanto del lubricante de las partes móviles de la maquinaria como del aceite utilizado por las primeras lámparas para iluminar, se convertían en material que prendía con una gran facilidad.

Además, los forjados de madera, por la abundancia de este material, eran en general mucho más rápidos de construir y mucho más baratos, pero no eran resistentes al fuego. Con las primeras bóvedas de ladrillo en el cambio del siglo XVIII al XIX, además de la mejora en la resistencia al fuego, las distancias que se consiguieron fueron entre 3 y 3,3 m [Figura 157].

\footnotetext{
${ }^{246}$ De este último edificio destacan sobre todo los detalles constructivos de las conexiones entre los pilares y las columnas (Johnson, 1955) [Figura 178], así como el apoyo que las vigas de madera tenían para descansar las bóvedas de ladrillo [Figura 155, Figura 156 y Figura 163].

${ }^{247}$ En ocasiones en la bibliografía aparece la palabra en inglés "pot" refiriéndose no a la arcilla como material, sino a forjados aligerados [Figura 162].
} 


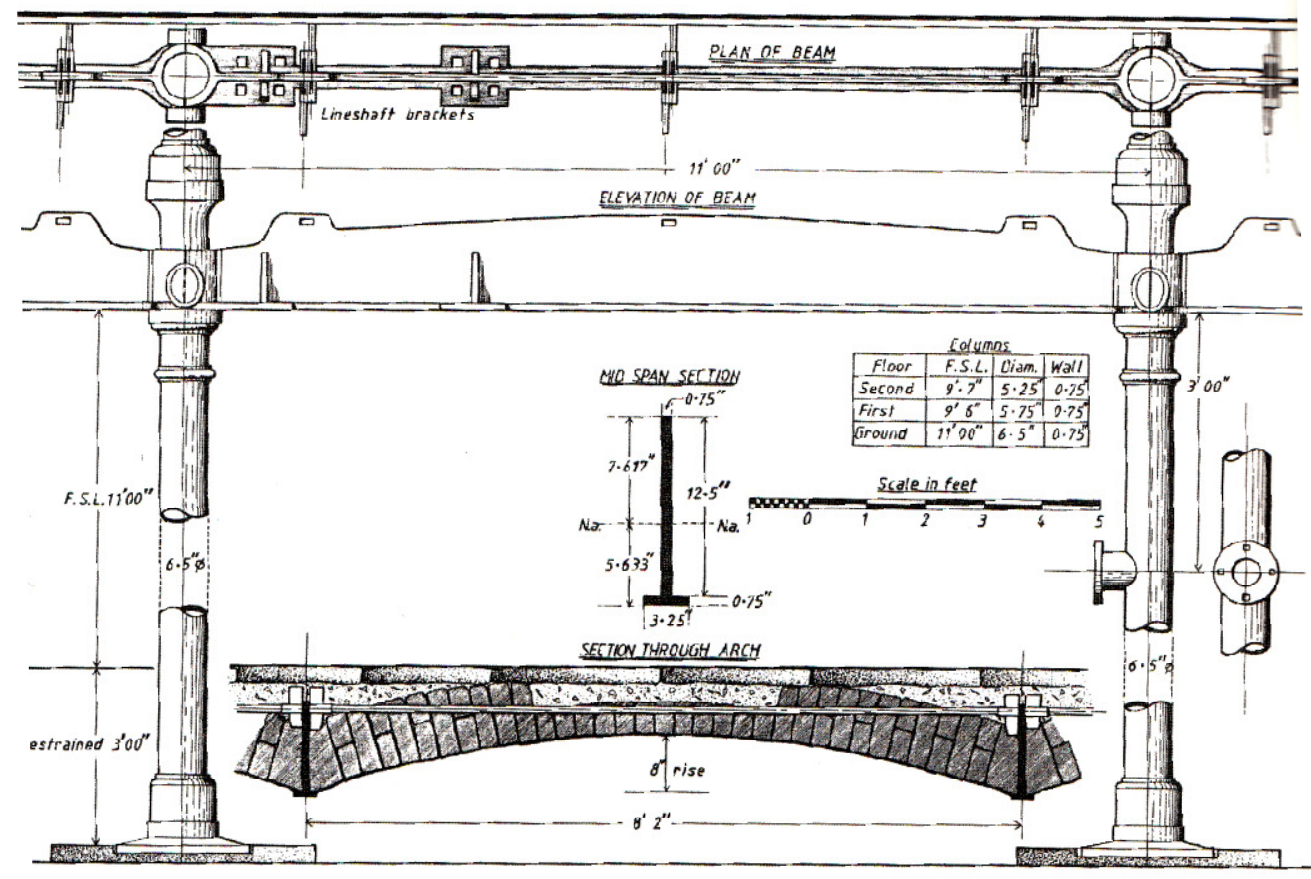

Figura 157. Armley Mill, Leeds, 1804/5, con estructura metálica y bóvedas de ladrillo entre vigas en T invertida, apoyando sobre pilares de hierro fundido. Esta foto reproduce exactamente el tipo de construcción tecnológicamente más avanzado de su época, en el ámbito de las manufacturas textiles entendidas como "fire-proof" (Swailes, 1998). 


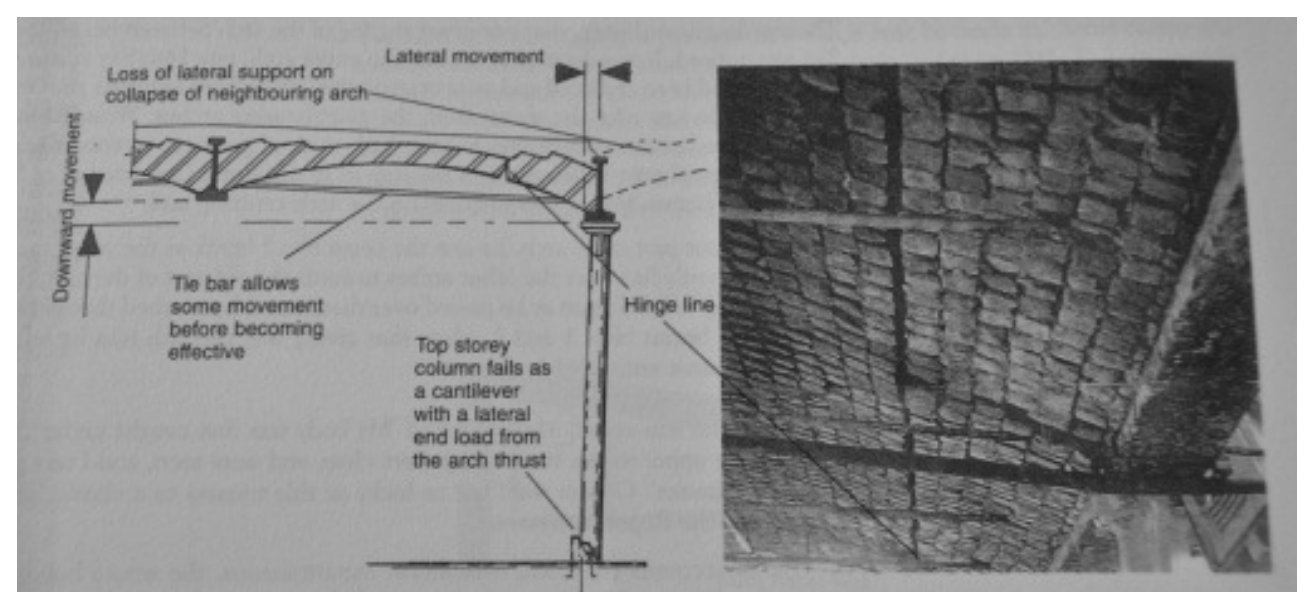

Figura 158. Gourock Rope Works, Escocia, principios del siglo XIX, donde en un momento determinado se produjo el colapso de la estructura por el fallo de un pilar metálico (Swailes, 1998).

Lo que se pretende resaltar en la Figura 158, Figura 159, Figura 160 y Figura 161 son las barras metálicas a modo de tirantes que atravesaban los arcos de ladrillo.

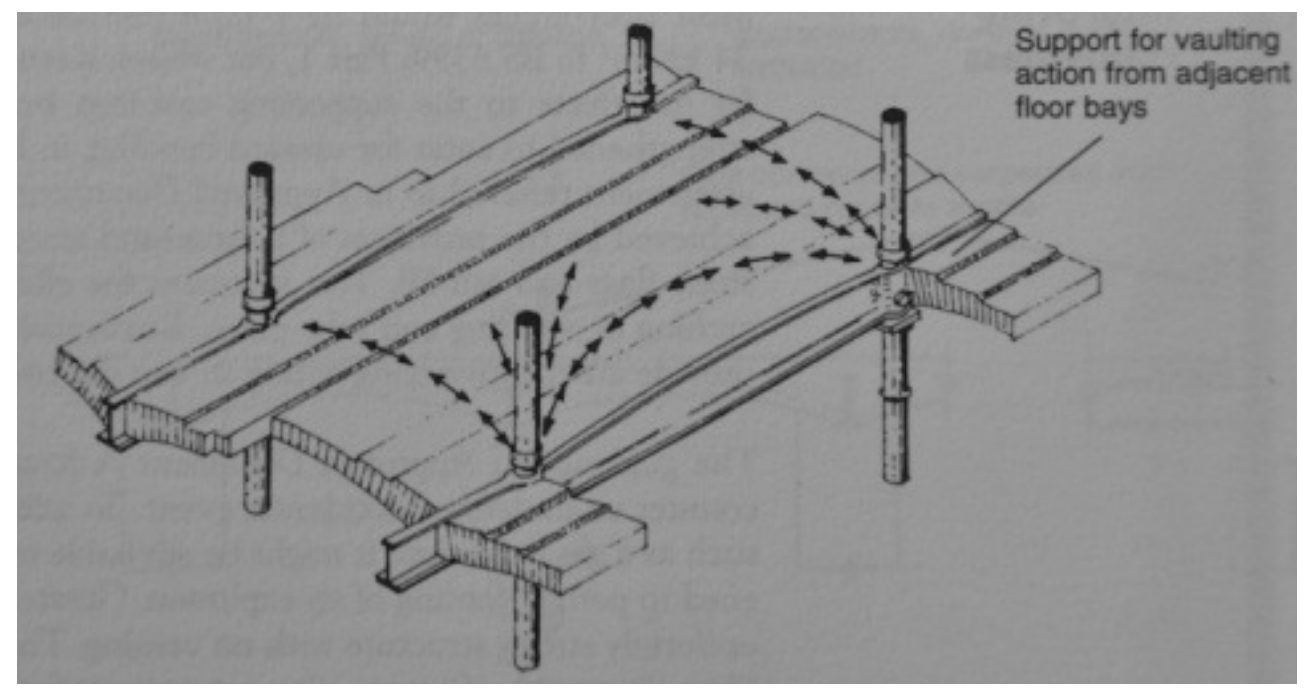

Figura 159. Reacciones en un forjado construido por soportes y vigas metálicas sustentando las bóvedas de ladrillo (Swailes, 1998). 


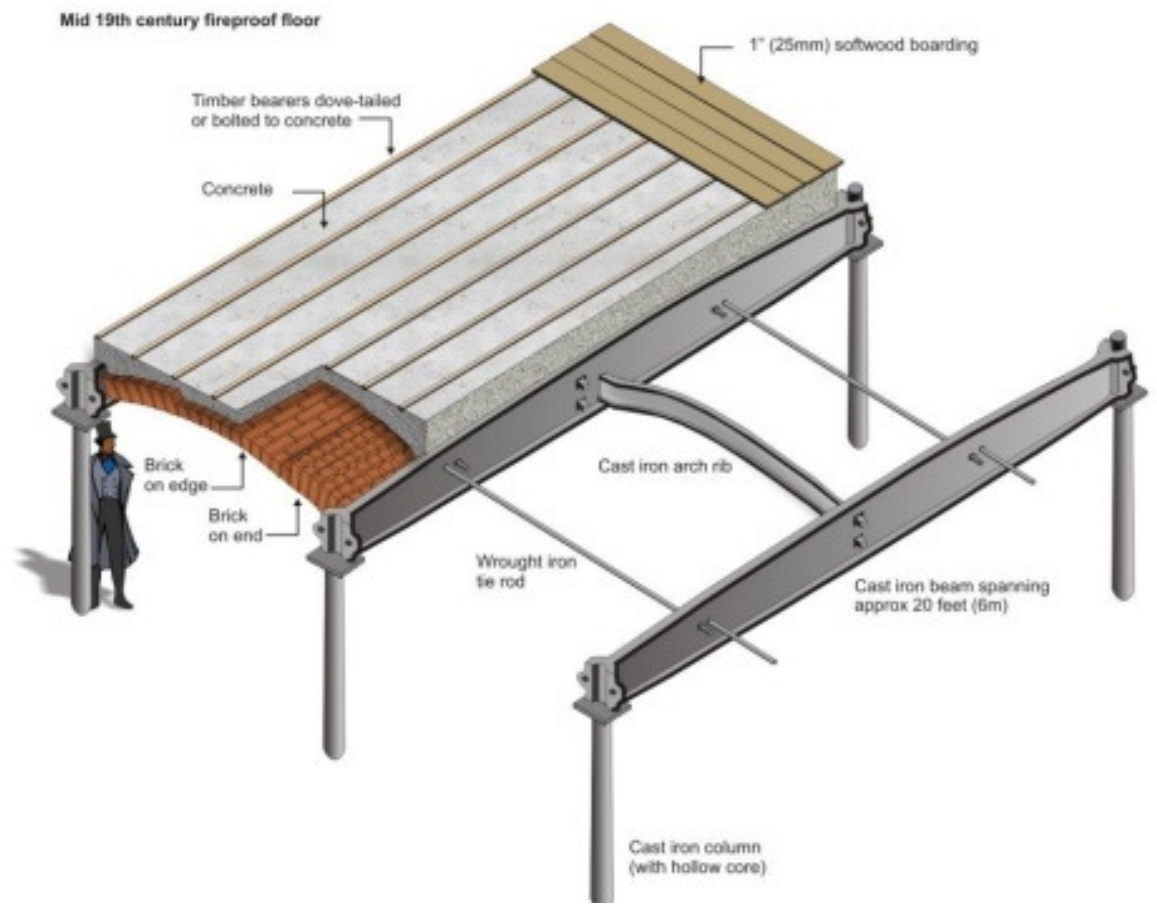

Figura 160. Forjado típico en los "mill" textiles en la segunda mitad del siglo XIX: soportes y vigas de hierro fundido (6 $\mathrm{m}$ de luz) unidas por roblonado, con barras de hiero forjado para evitar la apertura de las bóvedas de ladrillo por las cargas. Aparece la palabra "concrete" como cemento de nivelación para los tablones de madera que conforman el piso (University of the West of England. Dep. Architecture, 2014). 


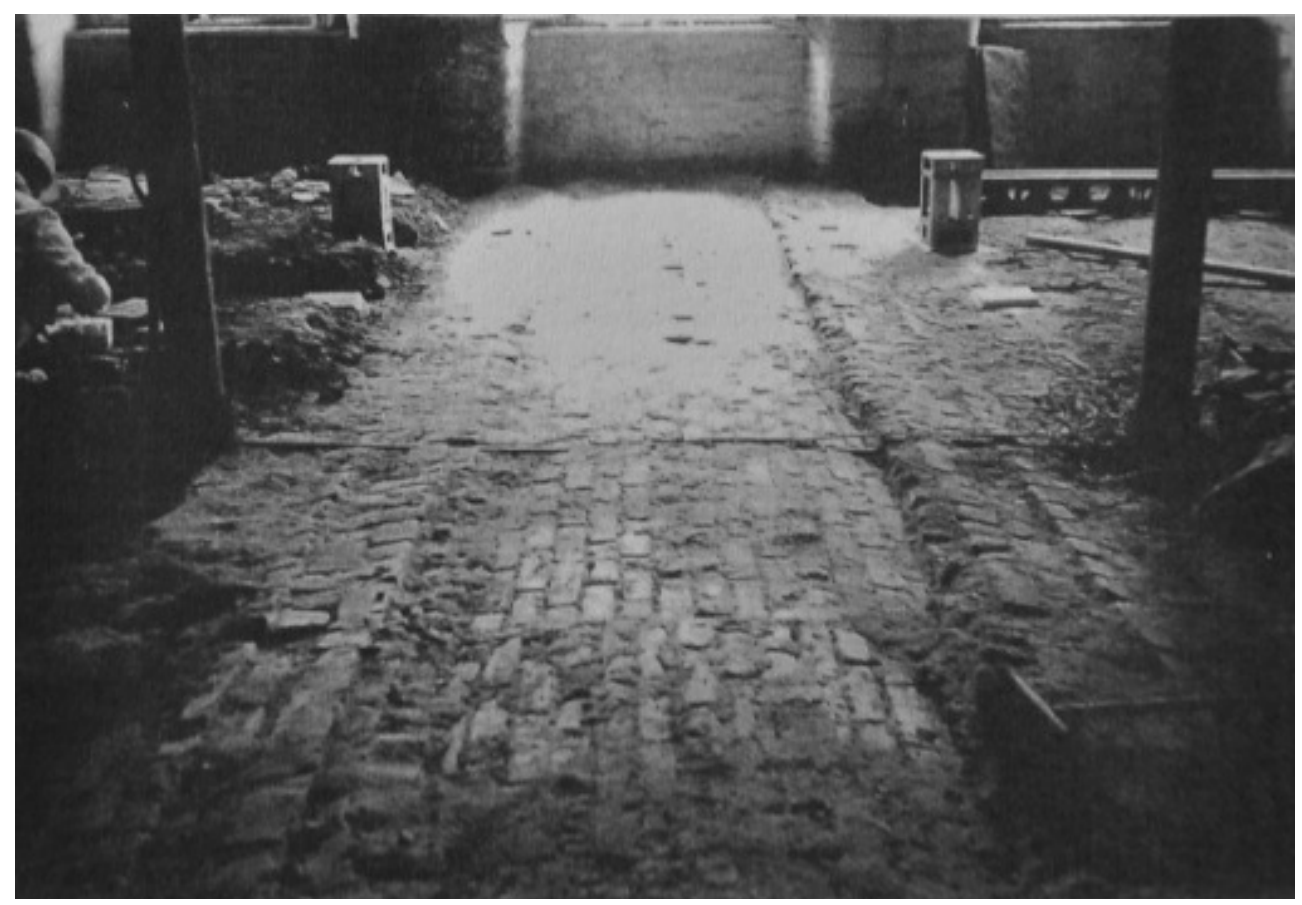

Figura 161. Havelock Cotton Mill, Mánchester, 1845. Estructura metálica: columnas y vigas de hierro fundido atadas entre ellos con barras de hierro forjado entre las bóvedas de ladrillo, las cuales tenían un relleno de ceniza para formar los forjados (Swailes, 1998).

Por otro lado, en algunos casos se aplicaron aligeramientos de estos forjados, generalmente de mucho canto y consecuentemente muy pesados. En la bibliografía aparecían con la expresión "pots", y el resultado era como se aprecia en la Figura 162: 

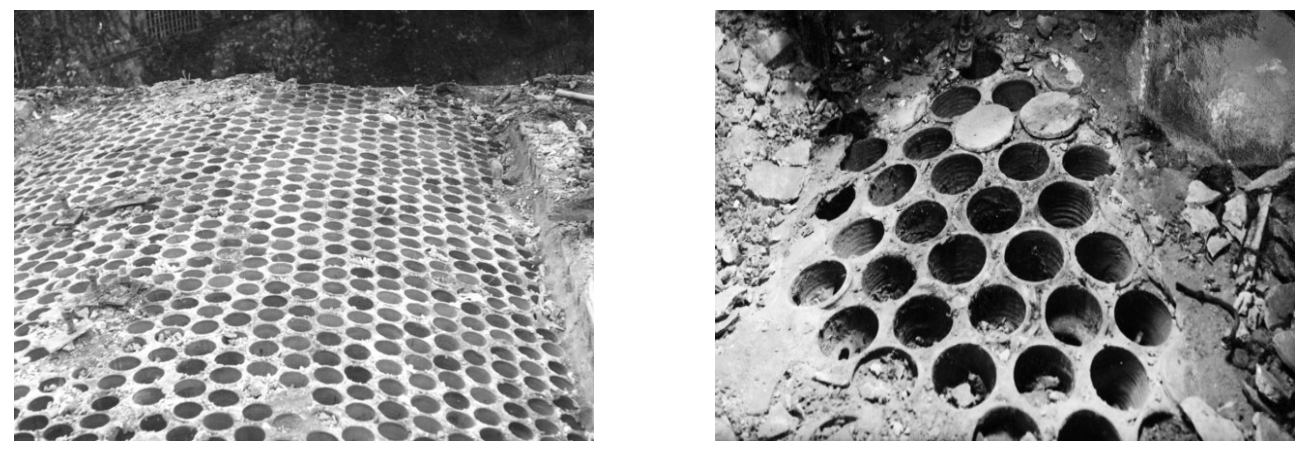

Figura 162. West Mill, 1793-1795. Se trata de un edificio de William Strutt, localizado en Belper, dentro del conjunto empresarial familiar donde también se encontraba el North Mill, en Belper. En esta fotografía, tomada durante una de sus rehabilitaciones, se aprecia el aligeramiento que se le hacía a los forjados, que en la bibliografía escrita en inglés aparece como "pots", aunque cuya traducción al español corresponde a la palabra arcilla, se refiere a las perforaciones en sí. Es un ejemplo gráfico acerca del sistema constructivo utilizado habitualmente en el cambio de siglo XIX.

Destacar también que las primeras bóvedas de ladrillo que apoyaban en las vigas cubrían una gran distancia, lo que obligaba a grandes cantos de forjado. Para intentar reducirlos cabían 3 posibilidades: 1) Reducir el tamaño de los ladrillos intermedios superiores del arco, ejemplos que se presentarán cuando se trate cada una de las nubes del mapa conceptual [Figura 163]; 2) Disminuir la distancia que cubrían los arcos haciéndolos apoyar sobre viguetas, con lo que el esfuerzo que tenía que absorber cada arco más pequeño era mucho menor, invento que ocurrió mucho después, a partir de $1871^{248}$; y 3) Mediante el empleo de tirantes interiores que ayudaban a que los extremos de los mismos no se separaran excesivamente [Figura 156, Figura 157, Figura 158 y Figura 160].

\footnotetext{
${ }^{248}$ Como se verá más adelante [Figura 166].
} 


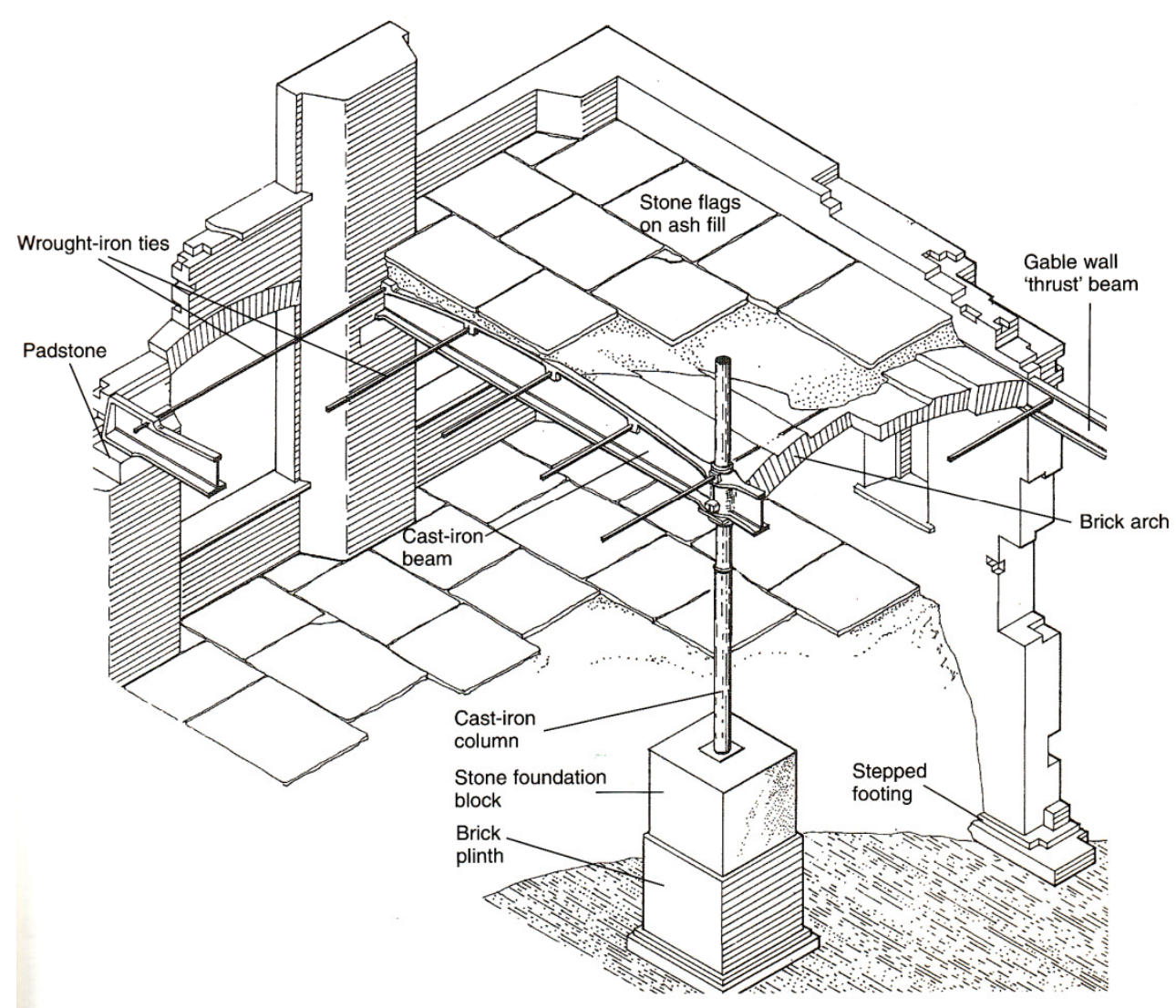

Figura 163. Havelock Cotton Mill, Mánchester, 1845. Estructura metálica: columnas de hierro fundido con bases de piedra, vigas de hierro fundido atadas entre ellas con barras de hierro forjado, bóvedas de ladrillo con relleno de ceniza para formar los forjados, y suelos de piedra ${ }^{249}$ (Swailes, 1998).

En este nuevo tipo de forjados por arcos, los empujes a su vez quedaban minimizados en algunas ocasiones con el cambio de sentido de las viguetas en los vanos extremos del edificio, apoyando sobre los muros hastiales [Figura 164]:

${ }^{249}$ Una típica manufactura textil de las primeras décadas del siglo XIX tenía como mucho 3 vanos de anchura, con unas dimensiones de $33 \times 40 \mathrm{~m}$, y con 6 ó más alturas. 


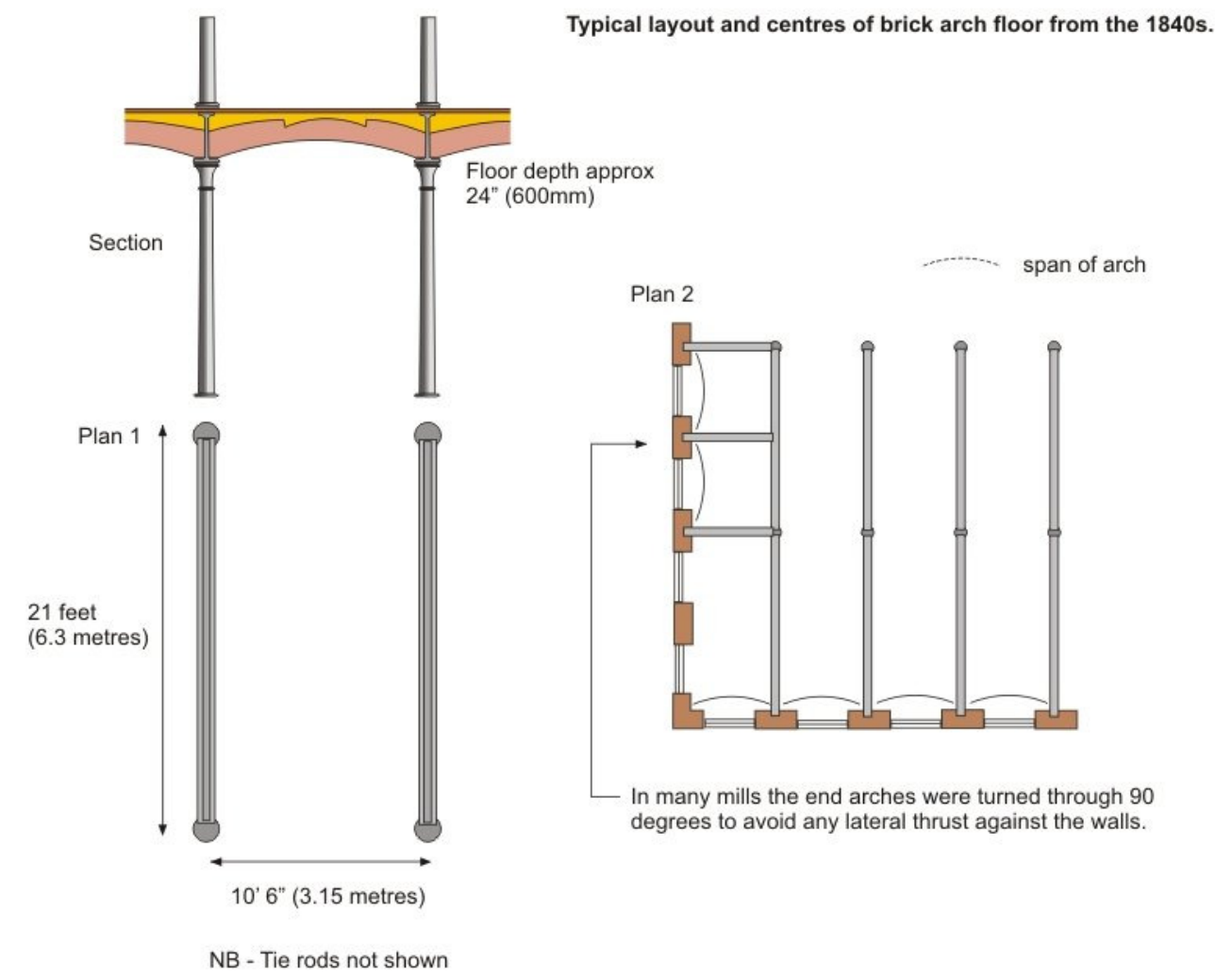

Figura 164. En los extremos del edificio, las bóvedas eran soportadas por los muros hastiales, sobre los que ejercían esfuerzos excesivos, por lo que en ocasiones, se giraba 90 la dirección de estas respecto a la anchura del edificio (University of the West of England. Dep. Architecture, 2014).

Ofreciendo datos concretos, los vanos conseguidos se mantuvieron durante la primera mitad del siglo XIX entre los 3 y los $6 \mathrm{~m}$ (University of the West of England. Dep. Architecture, 2014), con espesores de forjado de unos 0,6 m. Estos valores se identificaban con el tamaño de las máquinas tejedoras, que aunque continuaron siendo más y más largas, su anchura siguió siendo de $3 \mathrm{~m}$, lo que mantuvo fija esa distancia entre pilares, sin que hubiera una secuencia distinta a la propia distribución de la maquinaria, instalada generalmente en 1 única hilera, o en 2 de forma enfrentada, para un mejor manejo del operario. De hecho, la 
distancia entre pilares se correspondía con el layout de la maquinaria y la producción.

Pero con el referido aumento del tamaño de la maquinaria por el incremento del número de husos, y con la consecuente ampliación del tamaño del edificio, estos tenían que elevar su altura, porque esa era la única forma posible de conseguir la iluminación necesaria en el centro de cada planta. De hecho, más cantidad de luz requería ventanas de mayor altura y anchura. Así, ventanas más anchas dejaban menor espacio de muro de carga para el apoyo de las vigas, por lo que la solución pasaba por hacer forjados más ligeros ${ }^{250}$, y ese era el principal inconveniente de las bóvedas de ladrillo, que eran muy pesados [Estado 18; Figura 165].

\footnotetext{
250 Más tarde, el hierro forjado y el acero, se emplearon como alternativos al hierro fundido, evitando así los riesgos asociados a este como material quebradizo, pero ello no ocurrió hasta final de siglo, como se verá en el apartado siguiente.
} 


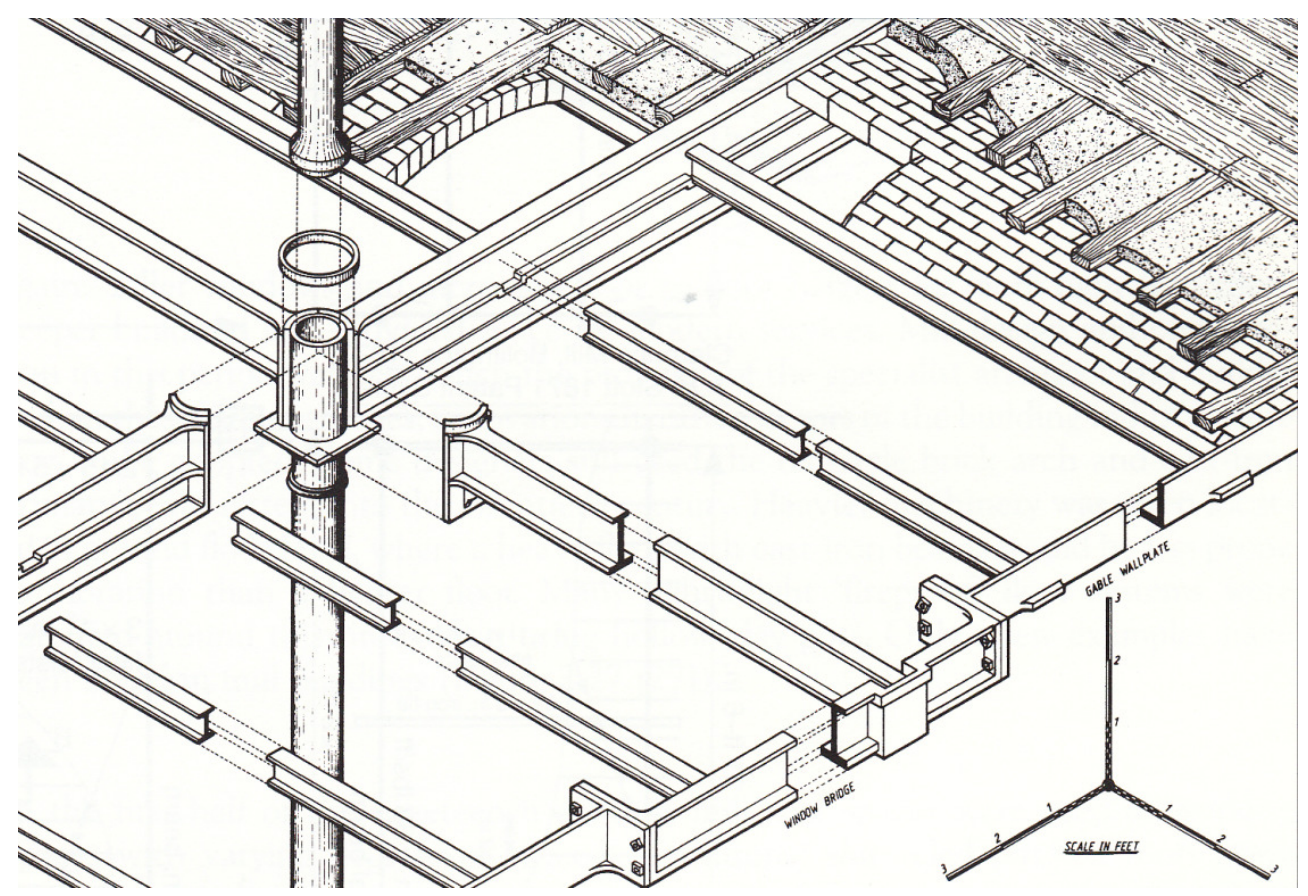

Figura 165. Lee Bank Mills, Halifax, 1863. Estructura metálica de vigas y viguetas de hierro fundido y bóvedas de ladrillo de entrevigado. Apréciese en la parte superior del forjado los tablones de madera (arce canadiense) que conforman el entarimado, lo cual no mejoraba la propagación del fuego en caso de siniestro, si bien, las bóvedas de ladrillo con su relleno evitaban el contacto directo de las Ilamas con las vigas metálicas (Swailes, 1998).

Por último, señalar que las bóvedas inglesas de finales del siglo XVIII, a las que se ha estado refiriendo en los párrafos anteriores, son bóvedas de rosca de ladrillo, constructivamente diferentes de las utilizadas en Valencia, y en general en España y otros países europeos como Francia. Según el artículo de García-Gutiérrez y Santiago Huerta (García-Gutiérrez, 2001), Guastavino diferenciaba entre estas bóvedas de rosca de ladrillo y las bóvedas tabicadas, empleadas en distintos tipos de elementos como forjados o escaleras, especialmente en la segunda mitad del siglo XIX en fábricas textiles. No obstante, se matizará esta diferenciación en el 
apartado correspondiente del Capítulo IV, cuando se trate del caso de las manufacturas valencianas.

Cabe señalar también, que en 1871 aparece la primera patente para reducir la luz entre viguetas [Figura 166 y Estado 14] (University of the West of England. Dep. Architecture, 2014), que conllevó la disminución directa del canto y el peso del forjado, hasta los $0,3 \mathrm{~m}^{251}$.

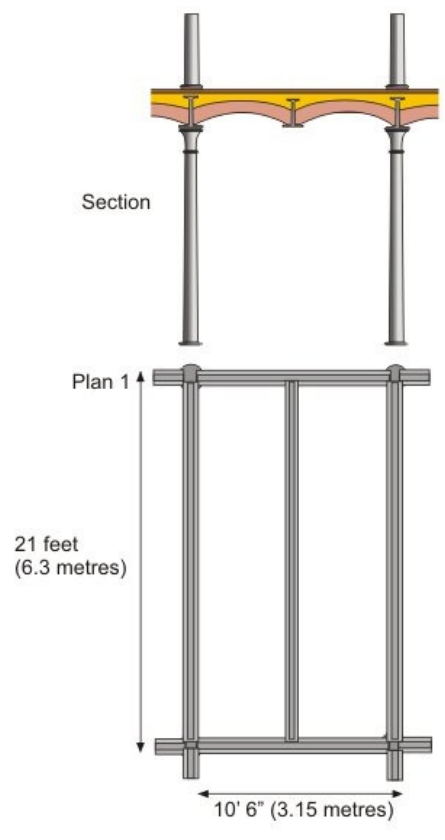

Double brick arch system - mid to late 19th century

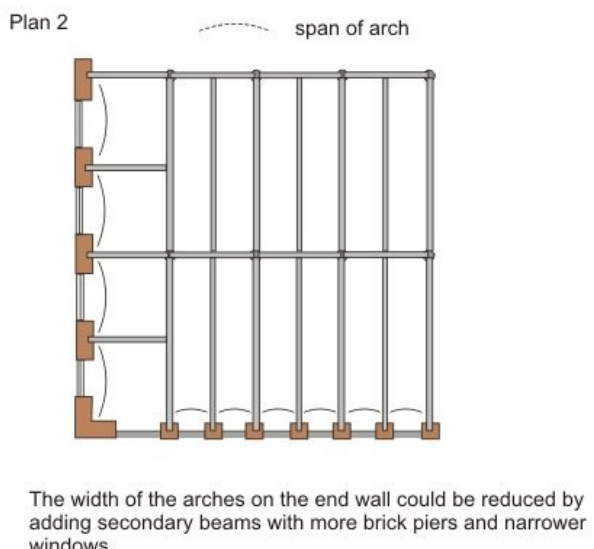

Figura 166. Sistema de doble bóveda de arco para la formación de forjados. Segunda mitad del siglo XIX. La primera patente de ello se registró en 1871 de mano del ingeniero Abraham Stott, familia de arquitectos especializada en el diseño de "mill buildings" textiles en toda Inglaterra. Este modelo, aunque no aumentó el vano sí consiguió disminuir el espesor y aligerar el peso del forjado (University of the West of England. Dep. Architecture, 2014).

${ }^{251}$ En 1880 se triplicaron y cuadriplicaron el número de bóvedas de ladrillo para la formación de los forjados en los edificios industriales. 
En cuanto a la envolvente, inicialmente esta soportaba las cargas del edificio y las propias del uso mediante muros de carga. Este tipo de estructura fue utilizado durante siglos hasta que el pilar metálico fue ganando terreno, no solo en la estructura interior del edificio sino hasta llegar a ser parte de la fachada.

Los muros exteriores de los "mill buildings" tuvieron durante mucho tiempo función estructural (en términos generales, el siglo XVIII y XIX, e incluso gran parte del $X X)$. De hecho, debido a ello, inicialmente los huecos de ventana eran pequeños [Figura 167].

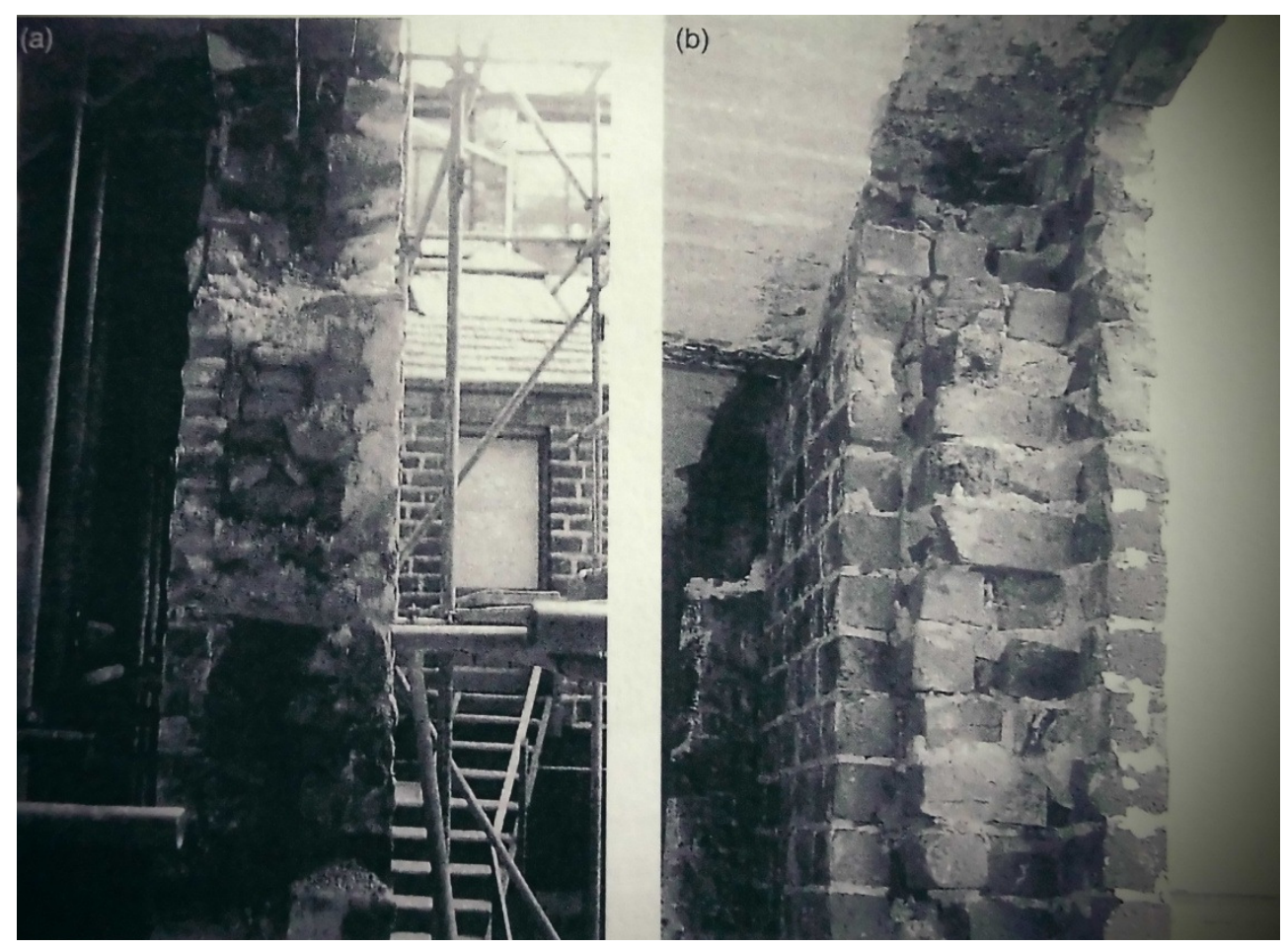

Figura 167. A la izquierda, Greenup's Worsted Mill, 1791. Se trata de un "mill" de 5 alturas. Se distinguen las 3 capas mencionadas, de la que el relleno es escombro. A la derecha, una sección de un muro portante posterior al anterior. La capa intermedia está realizada con fábrica de ladrillo (Swailes, 1998). 
Según (University of the West of England. Dep. Architecture, 2014): "Conforme aumentó el tamaño de la maquinaria, los "mills" tuvieron que ser cada vez de mayores dimensiones. Pero edificios más grandes, tenían que ser a su vez más altos para poder conseguir suficiente luz en el centro. Además, más cantidad de luz requería ventanas más anchas y más altas. A su vez, ventanas más anchas reducía el área útil de los muros de carga. Por otro lado, si los suelos lograran ser más ligeros y delgados, la carga muerta de los muros exteriores podría reducirse. De hecho, forjados más ligeros significaba que el tamaño del vano podría incrementarse, ya que evidentemente vigas menos cargadas podían tener más luz" [Figura 168, Figura 169, Figura 170 y Figura 171].
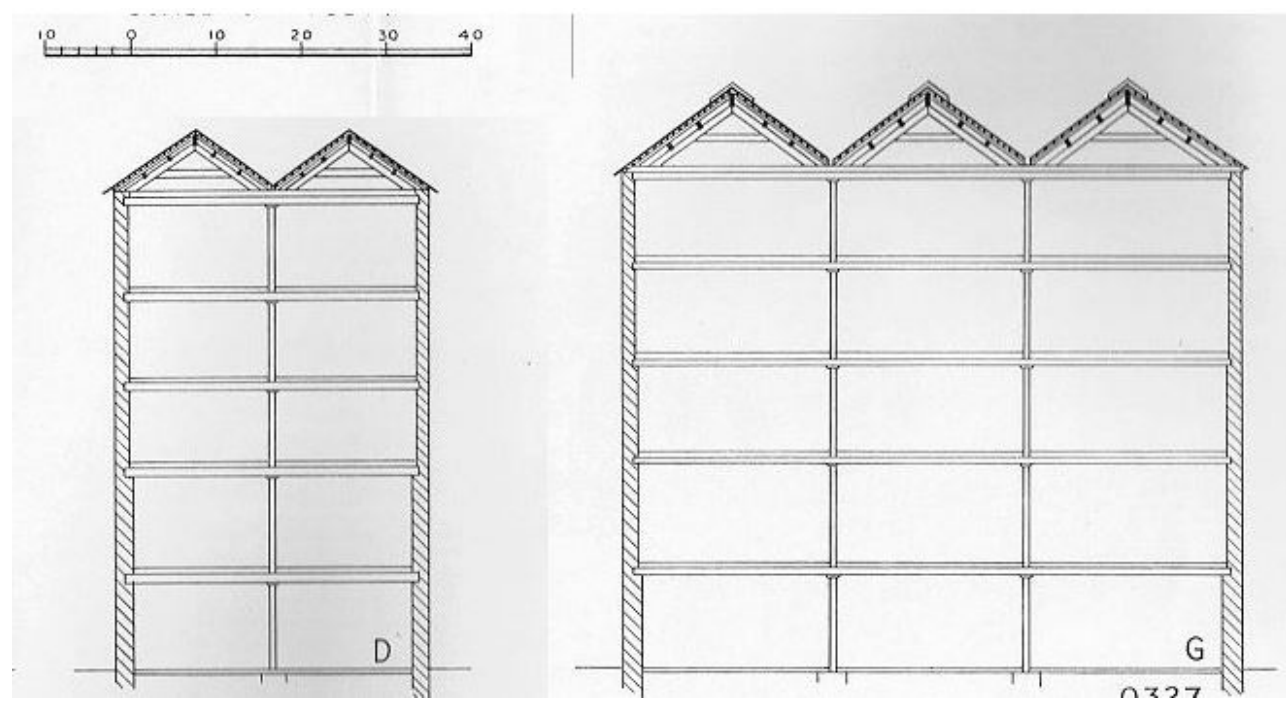

Figura 168. "Mill" construido entre 1820 y 1840 (University of the West of England. Dep. Architecture, 2014).

Como se observa en la figura anterior, los soportes, también metálicos, alcanzaban con los 3 vanos unos $15 \mathrm{~m}$. Apréciese asimismo, los diferentes espesores de los muros exteriores de las plantas más bajas respecto de las superiores. Las cubiertas son generalmente a 2 aguas con estructura de madera. 

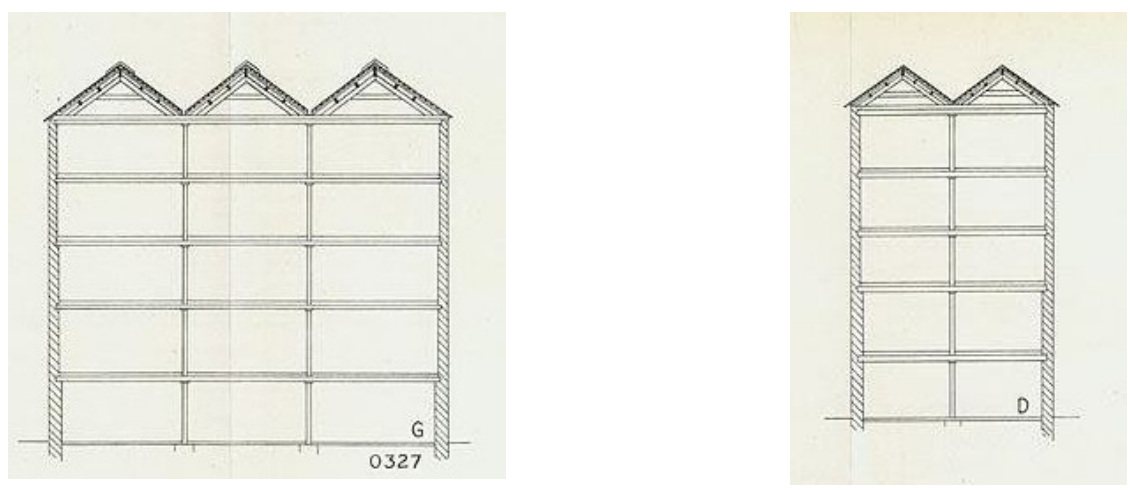

Figura 169. Secciones de un "mill" de la $2^{a}$ década del siglo XX. Se trata de edificio con muros perimetrales de carga, con pilares de hierro fundido, y vigas y forjados de madera (Hill, 1927). 


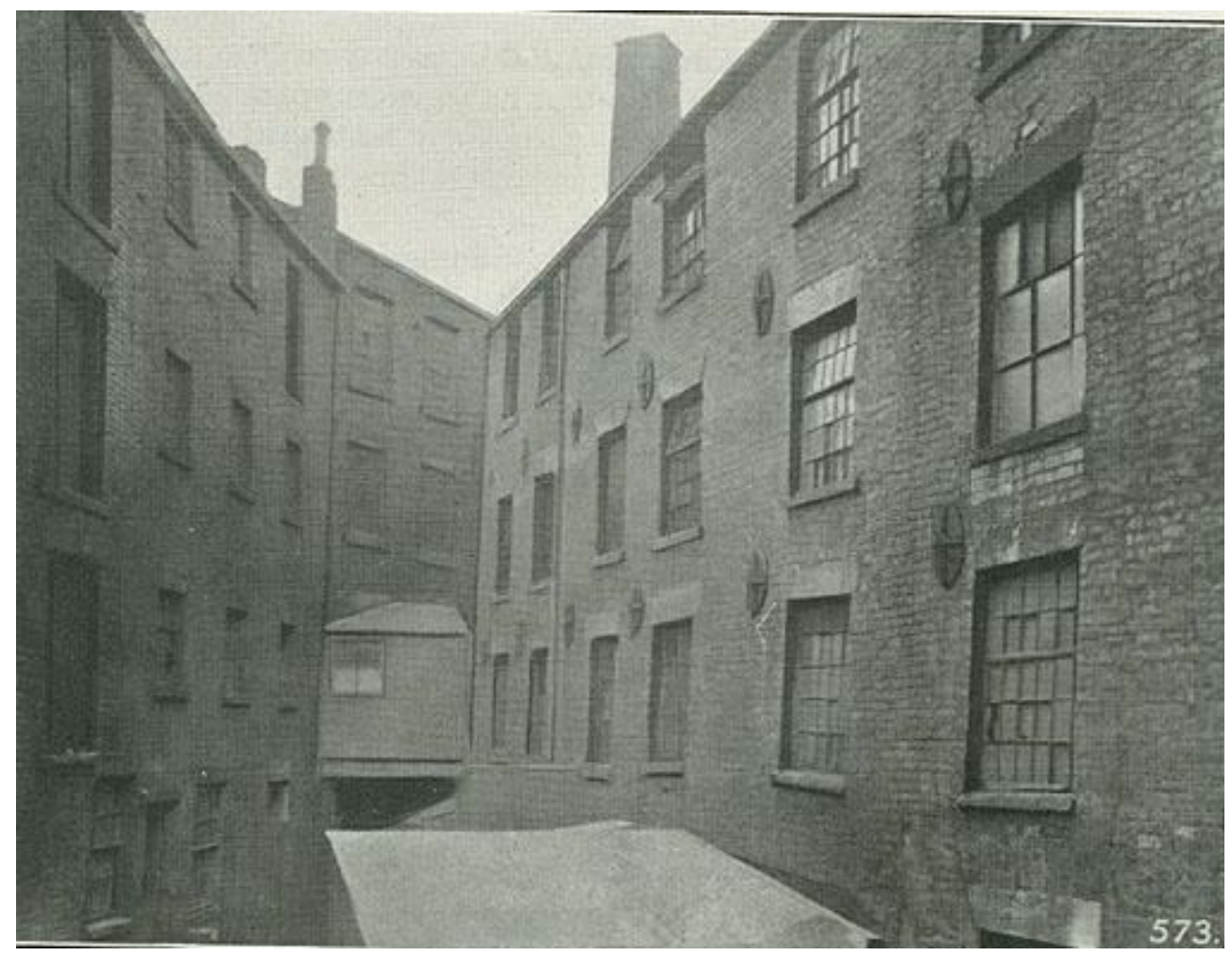

Figura 170. "Mill" construido en 1782, en Bolton, Gran Mánchester (Hill, 1927).

En este caso anterior como en el de la Figura 171 se aprecian perfectamente en el muro exterior de la derecha, y en el hastial para el segundo, caso los anclajes de los tirantes de hierro forjado que atravesaban todo lo largo de los forjados y que evitaban la apertura debida al peso de los primeros bóvedas de ladrillo. 


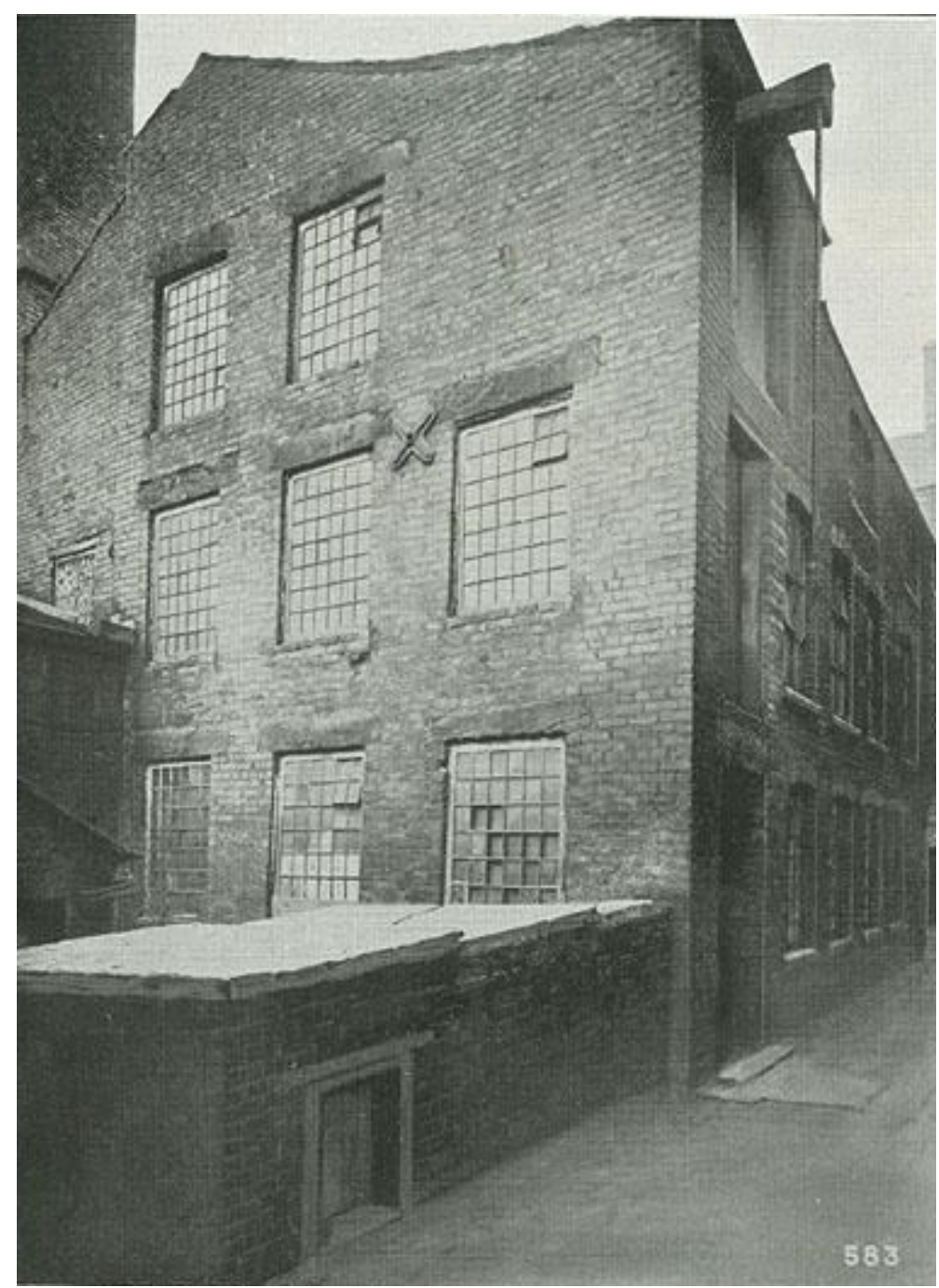

Figura 171. "Mill” construido a principios del XIX, en Bolton, Gran Mánchester (Hill, 1927). 


\section{HIERRO FUNDIDO (“CAST IRON”)}

\section{La introducción del hierro:}

De Arkwright surgió la idea de que las vigas de madera fueran apoyadas por su punto medio mediante pilares de hierro fundido. Concretamente ello ocurrió en 1783 en el Masson Mill, a las orillas del río Derwent que accionaba su maquinaria de producción de algodón \{confrontar el Apartado 3.2.2\}. De esta forma, en lo que se conoce que fue una de las primeras aplicaciones del hierro en la edificación, lo que consiguió fue aumentar de forma considerable la anchura del edificio, y poder así ubicar más máquinas tejedoras, que a su vez habían ido aumentando en tamaño, y al mismo tiempo, disminuir el canto de las vigas de madera. De este modo, se logró ampliar de los poco más de $6 \mathrm{~m}$ del anterior Cromford Mill a los 9 m [Figura 172]. 


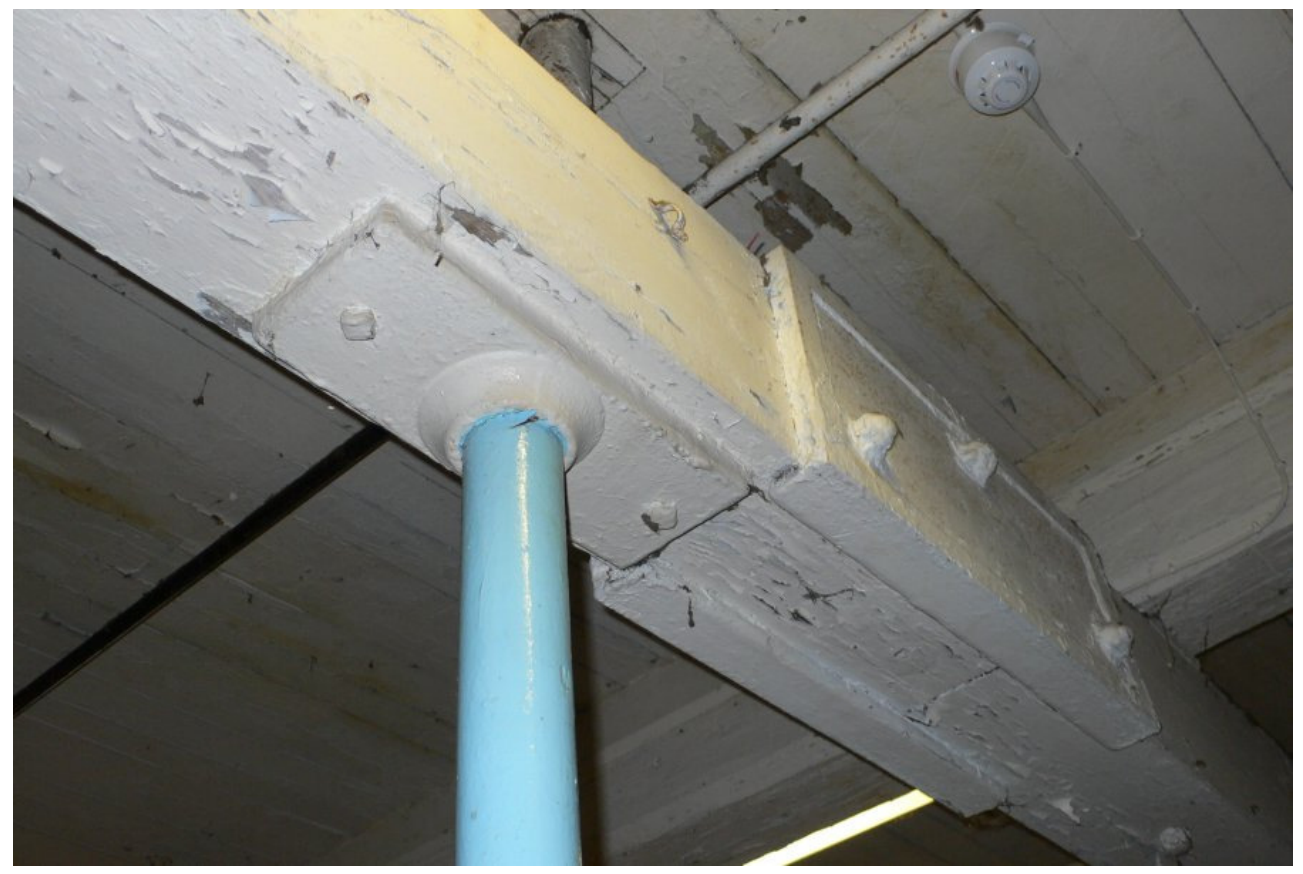

Figura 172. Masson Mill, 1783, sobre el río Derwent. Se trata de uno de los primeros molinos de Arkwright, que en este estudio destaca por su temprana utilización del hierro fundido para el apoyo intermedio de la viga de madera, continua precisamente en ese punto, a modo de junta a medio madera $^{252}$ (University of the West of England. Dep. Architecture, 2014).

Originariamente, los soportes que sujetaban la viga de madera por su mitad no eran huecos, puesto que no había otra forma de fabricación [Figura 172, Figura 173 y Figura 174]. Con esta solución constructiva le siguieron otros edificios como el Ditherington Mill, con sección cruciforme, de 1796, y el North Mill, también de sección circular, de 1804, a los que siguieron otras muchas manufacturas inglesas, especialmente del sector textil.

\footnotetext{
${ }^{252}$ Para la continuidad del pilar a las plantas superiores, la viga de la derecha de la fotografía queda obviamente desplazada respecto el eje de esos soportes, quedando la unión a medio madera de la viga longitudinal del edificio entre estos y esa viga perpendicular. Por su parte, el suelo está formado por entablado de madera, como lo habitual.
} 


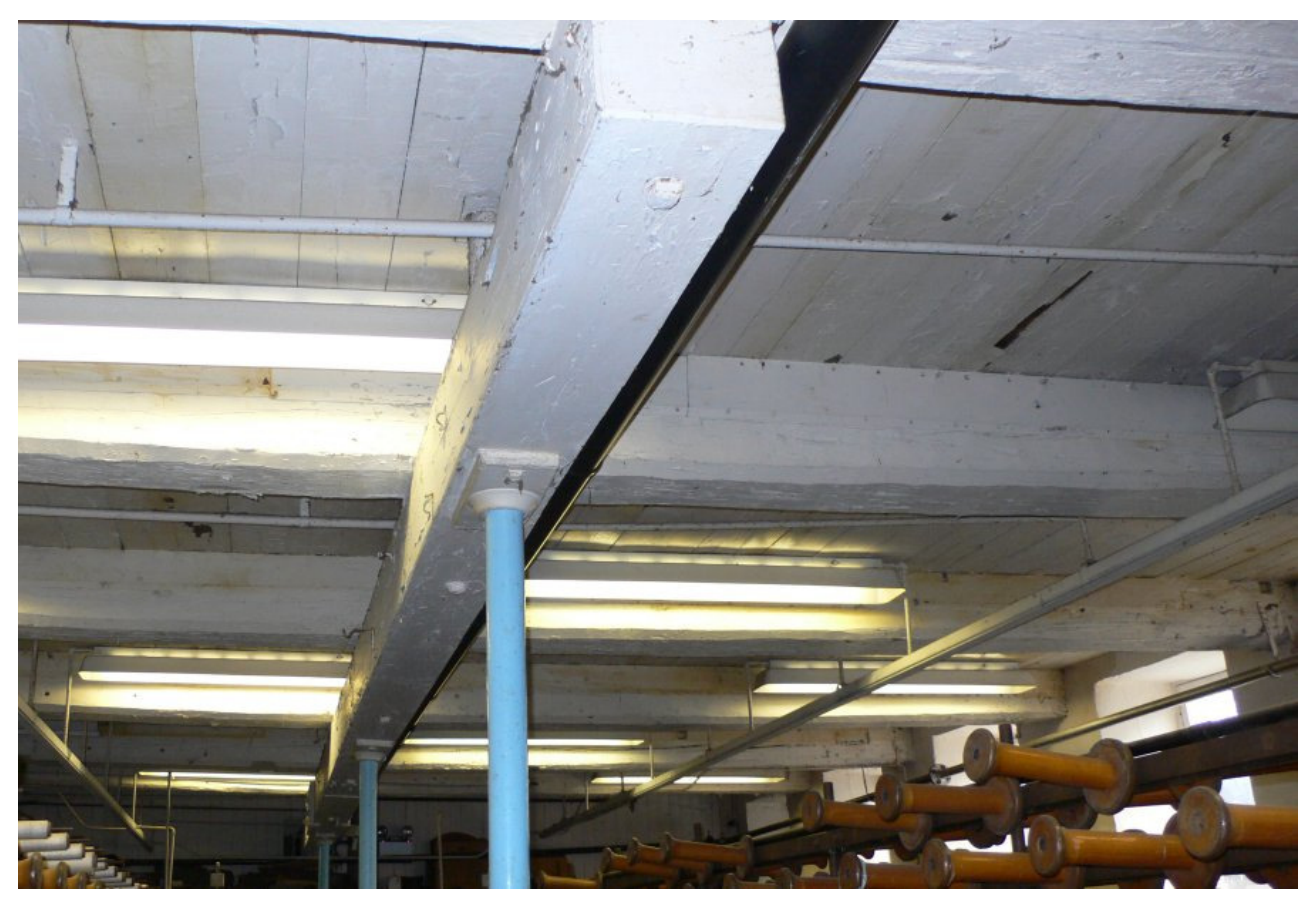

Figura 173. Masson Mill, 1783, sobre el río Derwent (University of the West of England. Dep. Architecture, 2014).

A la derecha de la Figura 173, se aprecian relativamente los espesores de los muros sobre los que apoyaban las vigas de madera. Pese a su aparente sencillez estructural, es totalmente innovadora, habiendo conseguido aumentar considerablemente la anchura del edificio.

Así pues, se presenta una manufactura textil clásica, prototipo de finales del siglo XVIII, con vigas de madera, entablado también de madera, soportes de hierro fundido y muros perimetrales portantes. Como instalaciones, destacan las hiladoras mecanizadas de Arkwright a ambos lados de esta fotografía acabada de citar, accionadas hidráulicamente. 
Este edificio generó por sí mismo un estilo arquitectónico, copiado del residencial: como ejemplo de ello, en las ventanas, de estilo veneciano, se tiene un refuerzo de piedra en los dinteles (con madera en su intradós), así como en las esquinas (mezcla de ladrillo y piedra) [Figura 144].

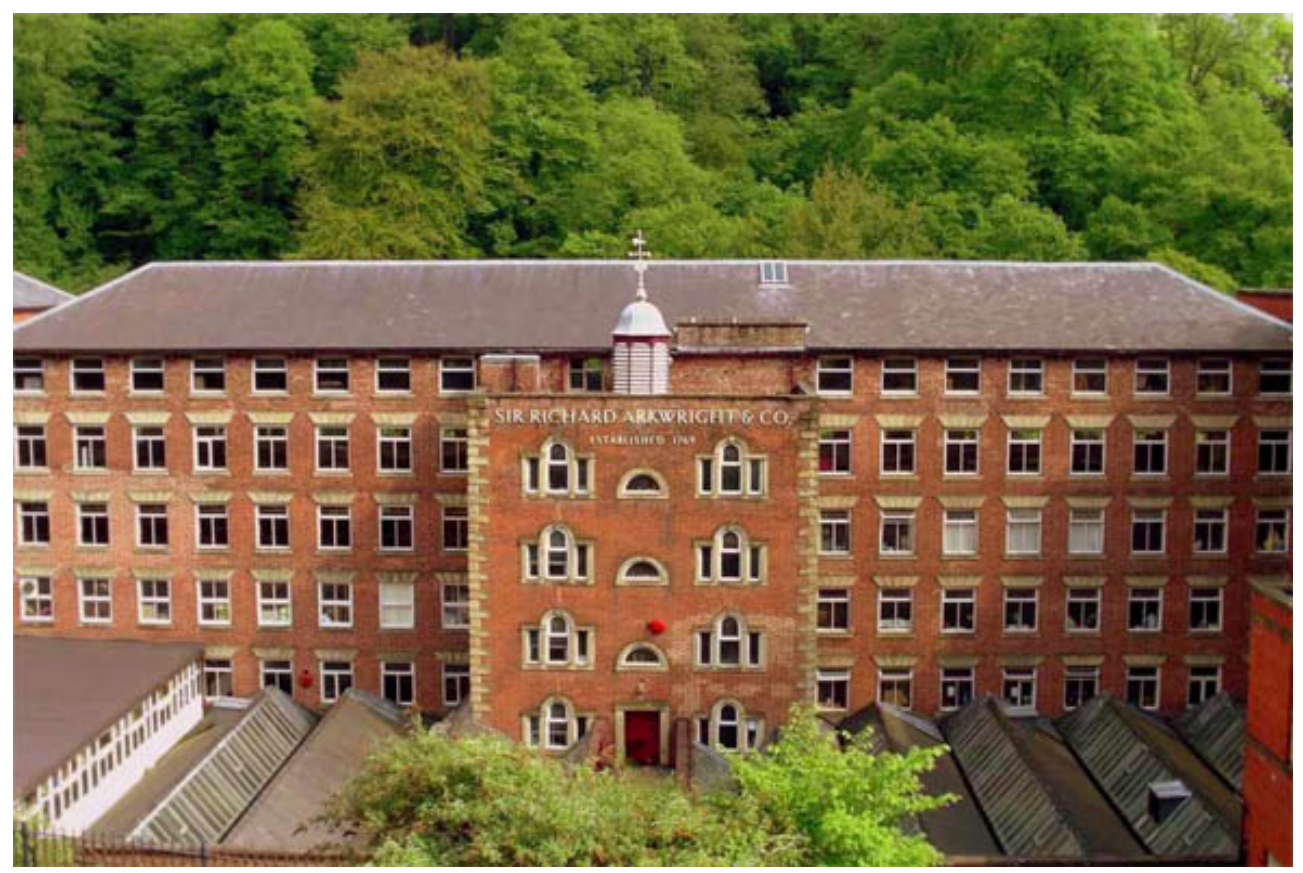

Figura 174. Masson Mill, de Arkwright, 1783.

(http://www.chriscooksey.demon.co.uk/dha/dha30_outing.html).

Durante los 100 años siguientes, esto es, hasta bien pasada la segunda mitad del siglo XIX, la mayoría de los desarrollos en la construcción de molinos se centraron exclusivamente en el diseño de los forjados ${ }^{253}$, y en la introducción y expansión del hierro para la estructura.

${ }^{253}$ Tal es el caso de las bóvedas a rosca. 
Como se ha venido sosteniendo, la introducción de los primeros pilares elaborados con hierro fundido se produce en el último cuarto del siglo XVIII, y a finales de ese mismo siglo, el uso del hierro se traslada también a las vigas ${ }^{254}$ : los forjados se componen de hierro fundido para las viguetas y bóvedas de ladrillo de entrevigado (vistos en el apartado de la página 288), con el objetivo principal de conseguir mayor resistencia al incendio ${ }^{255}$.

Valgan como ejemplos de ello las fábricas textiles inglesas, como la Ditherington Flax Mill, en Shrewsbury, o la Strutt's North Mill, en Belper, en pleno auge de la llamada Revolución Industrial. Además, por necesidad en la protección de las personas y las instalaciones, se ponía mucho interés en alcanzar el denominado "a prueba de fuego". Sin embargo, en este tipo de edificios continuó utilizando como pavimento durante mucho tiempo los gruesos tablones de madera de pino que no tenían absolutamente ninguna protección ignífuga [Figura 175 y Figura 176].

\footnotetext{
254 Entre la última década del 1700 y 1830 la mayoría de los ingenieros y arquitectos experimentaban los nuevos materiales de construcción con ensayos de prueba error. El diseño de los soportes y de las vigas para los nuevos edificios cambiaban de proyecto a proyecto conforme los ingenieros aprendían de sus errores y de sus éxitos, desarrollando nuevas ideas y descubriendo lo que otros técnicos hacían. Es precisamente por esto último que las patentes empezaron a surgir, preservando las nuevas técnicas de construcción que aparecían (University of the West of England. Dep. Architecture, 2014).

${ }^{255}$ En lo que respecta a los materiales utilizados en la construcción de los mill buildings, una de sus primeras evoluciones tuvo lugar al pasar de los forjados de madera a otros parcialmente metálicos, justo en el cambio de siglo del XVIII al XIX. En la estructura de cubierta la introducción del nuevo material se retrasa hasta la segunda década del siglo XIX.
} 


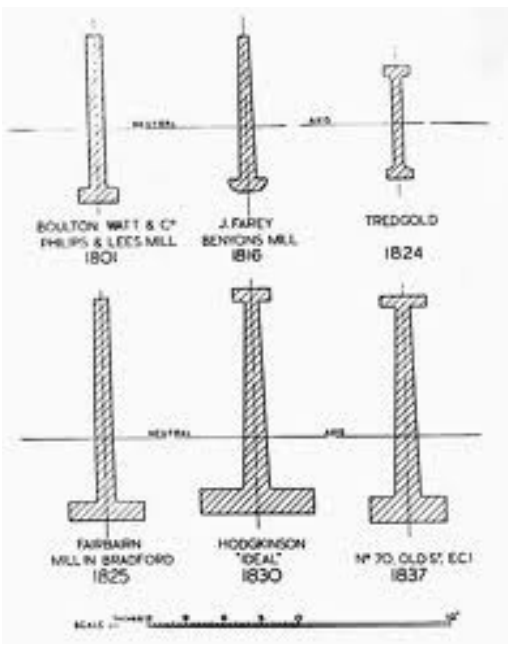

Figura 175. Sucesión de vigas utilizadas en los comienzos de la utilización del hierro en la construcción de "mills" en Inglaterra (Fairbairn, 1864).

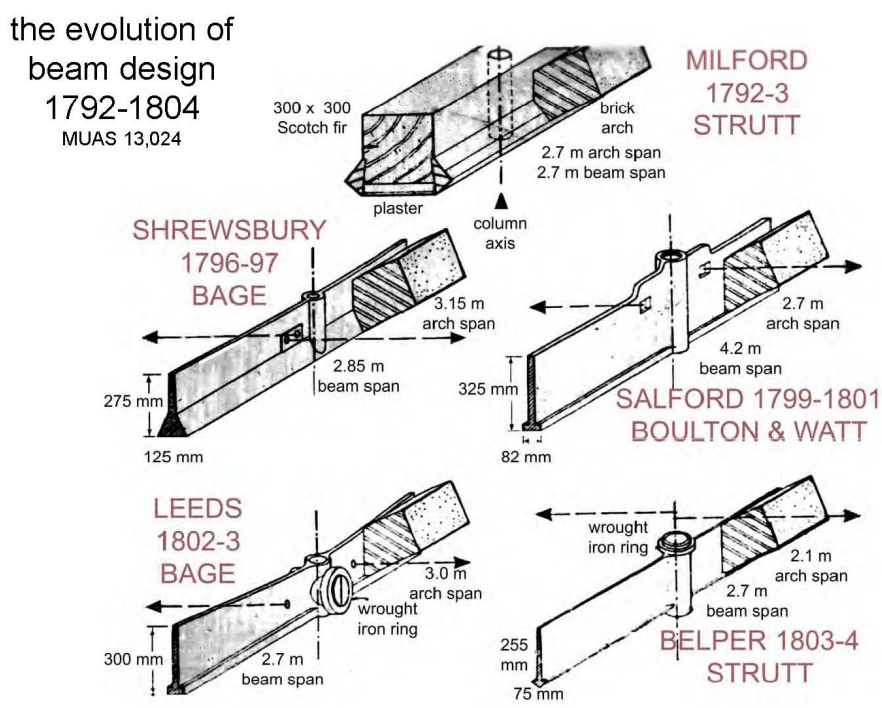

Figura 176. Distintos tipos de vigas empleadas en los diferentes edificios estudiados \{apartado 3.2\}, que demuestra la evolución de los sistemas constructivos empleados en la construcción de espacios fabriles (todos los nombres que aparecen son manufacturas textiles). Más concretamente, refleja el desarrollo de los diseños de las vigas de William Strutt para conseguir la estructura a prueba de incendios (Bryant, 1950). 
Pero todavía durante la década de 1820 a 1830 era común la construcción de "mill buildings" con vigas y forjados de madera. Tal es el caso, como tantos otros, del Spotland Bridge Mill, en Rochdale, ciudad del Gran Mánchester, al noroeste de Inglaterra [Figura 177]. Efectivamente en este ejemplo, por la época de su construcción, los soportes interiores son metálicos (si bien los cerramientos son todavía a base de muros de carga, y lo seguirán siendo hasta que la estructura salga del interior del edificio hacia la fachada, comenzando ello en la $2 \underline{a}$ mitad de siglo).

La anchura de este edificio es de casi $20 \mathrm{~m}$, frente a los 12 del Ditherington, unos 25 años anterior. 

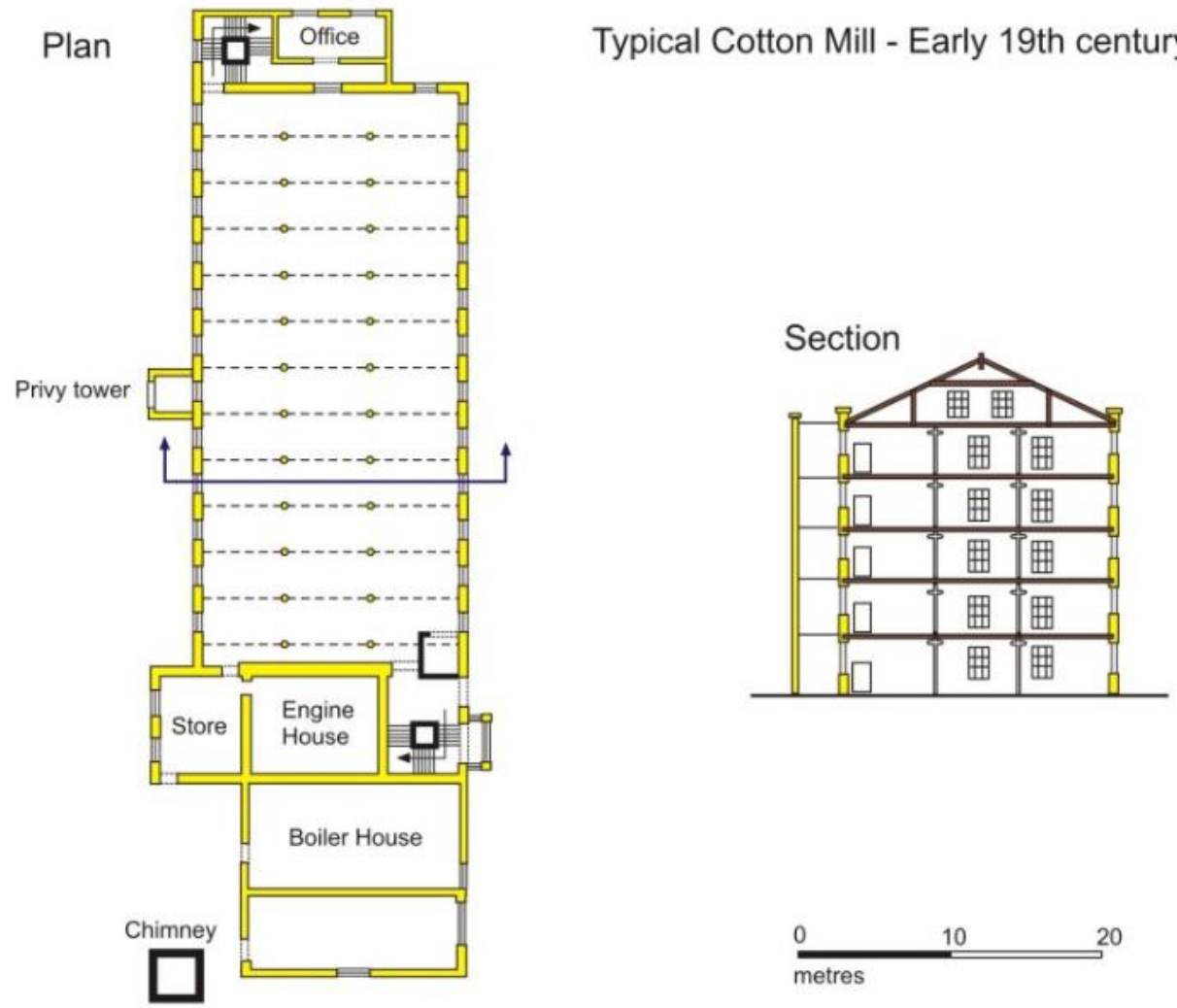

Figura 177. Spotland Bridge Mill, Rochdale, Inglaterra, 1820 $\div 1830$. Edificio de 5 alturas y ático con 13 vanos longitudinales y 3 transversales (University of the West of England. Dep. Architecture, 2014).

La Figura 177 es un ejemplo claro de la permanencia de los forjados de madera frente a la evolución del incipiente hierro como material estructural. La cubierta, por su parte, estaba realizada a dos aguas, con cerchas también de madera, y cerramiento de pizarra. En este caso, se aprecian las 2 hileras de soportes de hierro fundido a lo largo de todo el edificio. Las oficinas o zona administrativa, así como la sala de máquinas, forman parte del edificio. 
Por su parte, en la Figura 178 se muestran las diferentes conexiones entre las vigas de madera y los pilares metálicos, desde alrededor de la $2 \underline{a}$ mitad del siglo XIX hasta finales de siglo:

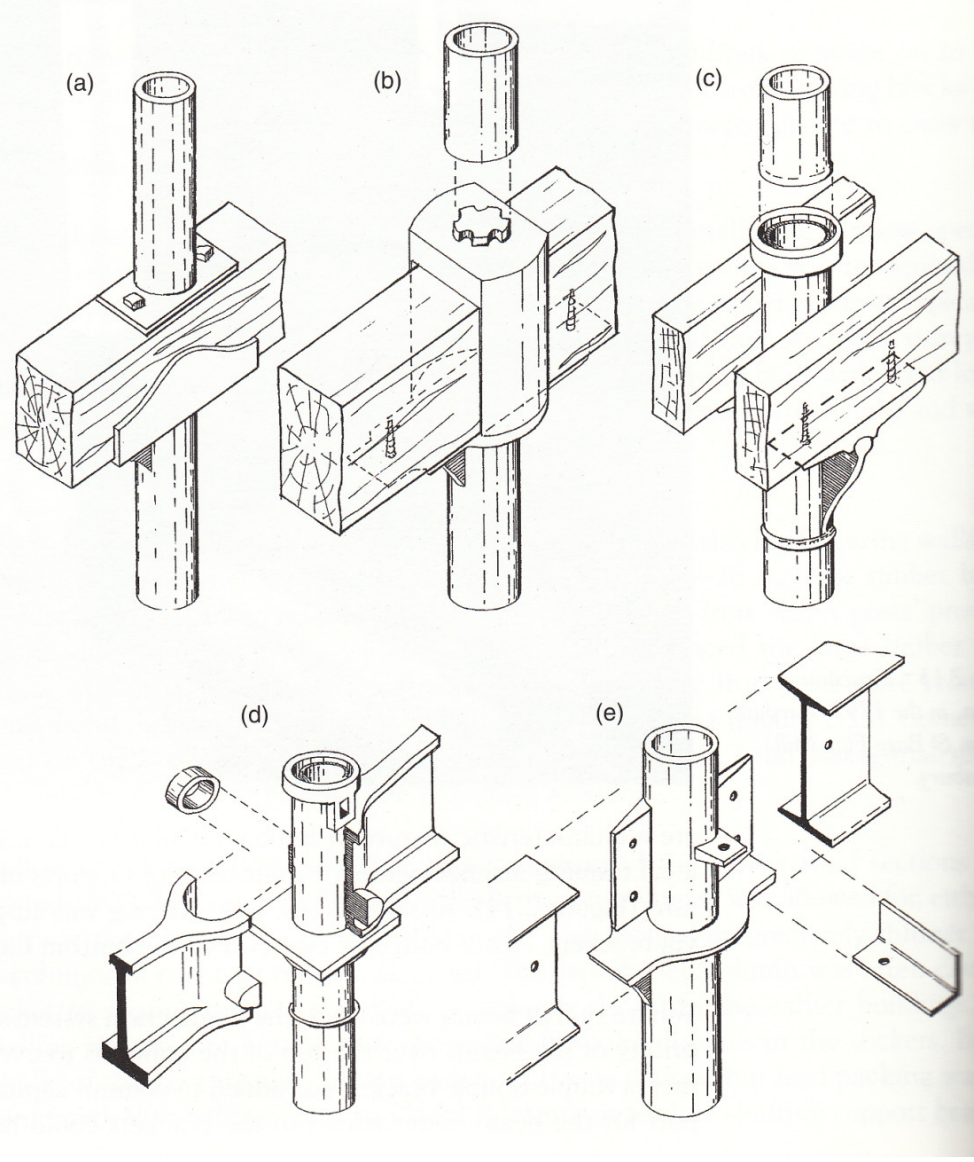

Figura 178. Conexión de pilares metálicos con vigas de madera y metálicas: (a) Viga de maderapilar metálico, solución habitual; (b) Wren's Nest Mill, Glossop, Derbyshire, viga de madera - pilar metálico, alrededor de 1850; (c) Stanley Mills, Perthshire, Escocia, con doble viga de madera soportadas por escuadras de hierro fundido; (d) Havelock Cotton Mill, Mánchester, 1845, con soportes y vigas metálicas; (e) Butterworth Hall Mill, de 1900, con vigas de hierro forjado (Swailes, 1998). 


\section{EL HIERRO:}

El hierro se extrae del mineral de hierro natural ${ }^{256}$, comúnmente como óxido de hierro ( $\mathrm{FeO})$. A principios de la llamada Revolución Industrial su producción requería de altas temperaturas en hornos especiales, produciéndose en lugares donde podía encontrarse en grandes cantidades, como la zona de Derbyshire y Shropshire. Fue precisamente en estos condados donde se empezaron a construir los primeros edificios que usaron este material en su construcción.

El hierro fundido, también llamado de fundición, era muy frágil, aunque tenía un comportamiento excelente a compresión. Esencialmente por ello fue que se comenzó a utilizar en los pilares de grandes edificios. Su fragilidad se debía entre otras razones por su bajo contenido en carbono, menos del $4 \%$.

Como el problema del fuego no quedaba totalmente resuelto, una solución que se adoptó fue proteger las vigas de madera con varias capas de yeso, considerado ignífugo, y sustituir los suelos de madera por baldosas o ladrillos. Un ejemplo de ello ya se había aplicado en 1792 con William Strutt, en las hilaturas de algodón de Derby, Milford y Belper \{confrontar en apartado 3.2 donde se comentan los edificios coetáneos a Arkwright de los Strutt, concretamente el Derby Cotton Mill, de la Figura 154 en la página 289\}, donde introdujeron por primera vez una trama estructural compuesta por pilares y tirantes de hierro y fundición, y las vigas, de madera recubierta [Tabla 5].

\footnotetext{
${ }^{256}$ El hierro es un metal maleable, de color gris plateado y presenta propiedades magnéticas. Es ferromagnético a temperatura ambiente y presión atmosférica. Es extremadamente duro y denso. Se encuentra en la naturaleza formando parte de numerosos minerales, entre ellos muchos óxidos, y raramente se encuentra libre. Para obtener hierro en estado elemental, los óxidos se reducen con carbono y luego es sometido a un proceso de refinado para eliminar las impurezas presentes.

El hierro es el metal duro más usado. En su estado puro (pureza a partir de 99,5 \%) no tiene aplicaciones, salvo excepciones para utilizar su potencial magnético. Tiene su gran aplicación para formar los productos siderúrgicos. Por otro lado, se considera que una aleación de hierro es acero si contiene menos de un $2,1 \%$ de carbono. Si el porcentaje es mayor, recibe el nombre de fundición. El acero es indispensable debido a su bajo precio y tenacidad, especialmente en automóviles, barcos y componentes estructurales de edificios.
} 


\begin{tabular}{|c|c|c|c|c|c|c|c|}
\hline MILL & Fecha & Ubicación & Actividad & Viga & Soportes & Forjado & Cubierta \\
\hline $\begin{array}{l}\text { DITHERINGTON } \\
\text { FLAX MILL }\end{array}$ & 1796 & $\begin{array}{l}\text { Norte de } \\
\text { Shrewsbury, } \\
\text { en el condado } \\
\text { de Shropshire, } \\
\text { Inglaterra }\end{array}$ & Textil & $\begin{array}{l}\text { Metálicas: } \\
\text { hierro } \\
\text { fundido }\end{array}$ & $\begin{array}{l}\text { Columnas de } \\
\text { hierro } \\
\text { fundido de } \\
\text { sección } \\
\text { maciza y } \\
\text { cruciforme }\end{array}$ & $\begin{array}{l}\text { Viguetas de } \\
\text { hierro } \\
\text { fundido de } \\
\text { Y invertida, } \\
\text { revoltones } \\
\text { de ladrillo, } \\
\text { esbeltas de } \\
\text { ladrillo tipo } \\
\text { fire proof }\end{array}$ & $\begin{array}{l}\text { Cerchas } \\
\text { metálicas } \\
\text { (hierro } \\
\text { fundido) }\end{array}$ \\
\hline $\begin{array}{l}\text { FUNDICIÓN DE } \\
\text { BOULTON\&WATT }\end{array}$ & 1801 & $\begin{array}{l}\text { Shropshire, } \\
\text { Inglaterra }\end{array}$ & $\begin{array}{l}\text { Construcció } \\
\text { n de } \\
\text { máquinas } \\
\text { de vapor }\end{array}$ & Madera & \begin{tabular}{|l|} 
Muros \\
perimetrales \\
portantes y \\
pilares de \\
ladrillo
\end{tabular} & - & $\begin{array}{l}\text { Cerchas de } \\
\text { madera }\end{array}$ \\
\hline $\begin{array}{l}\text { STRUTT'S NORTH } \\
\text { MILL }\end{array}$ & 1804 & $\begin{array}{l}\text { Belper, } \\
\text { Inglaterra }\end{array}$ & $\begin{array}{l}\text { Textil: } \\
\text { producción } \\
\text { de algodón }\end{array}$ & $\begin{array}{l}\text { Metálicas: } \\
\text { hierro } \\
\text { fundido } \\
\text { Forjado con } \\
\text { estructura } \\
\text { de madera }\end{array}$ & $\begin{array}{l}\text { Columnas de } \\
\text { fundición }\end{array}$ & $\begin{array}{l}\text { Tablas de } \\
\text { madera } \\
\text { sobre } \\
\text { viguetas de } \\
\text { madera y } \\
\text { revoltón de } \\
\text { ladrillo }\end{array}$ & \\
\hline $\begin{array}{l}\text { MARSHALL'S } \\
\text { TEMPLE MILL }\end{array}$ & 1842 & $\begin{array}{l}\text { Leeds, } \\
\text { Inglaterra }\end{array}$ & $\begin{array}{l}\text { Textil } \\
\text { producción } \\
\text { de tejidos a } \\
\text { partir de } \\
\text { fibras de } \\
\text { lino }\end{array}$ & Metálico & $\begin{array}{l}\text { Columnas de } \\
\text { hierro } \\
\text { fundido }\end{array}$ & $\begin{array}{l}\text { Revoltones } \\
\text { de ladrillo } \\
\text { con } \\
\text { lucernario } \\
\text { en el } \\
\text { centro de } \\
\text { la bóveda }\end{array}$ & \\
\hline
\end{tabular}

Tabla 5. Tabla primer cuarto del siglo XIX. 
Cabe señalar, que la introducción del hierro en las estructuras no generó por sí misma un nuevo tipo arquitectónico, pues se conservó la tipología anterior: edificios de varios pisos con muros rectos de fábrica, a modo de muros de carga.

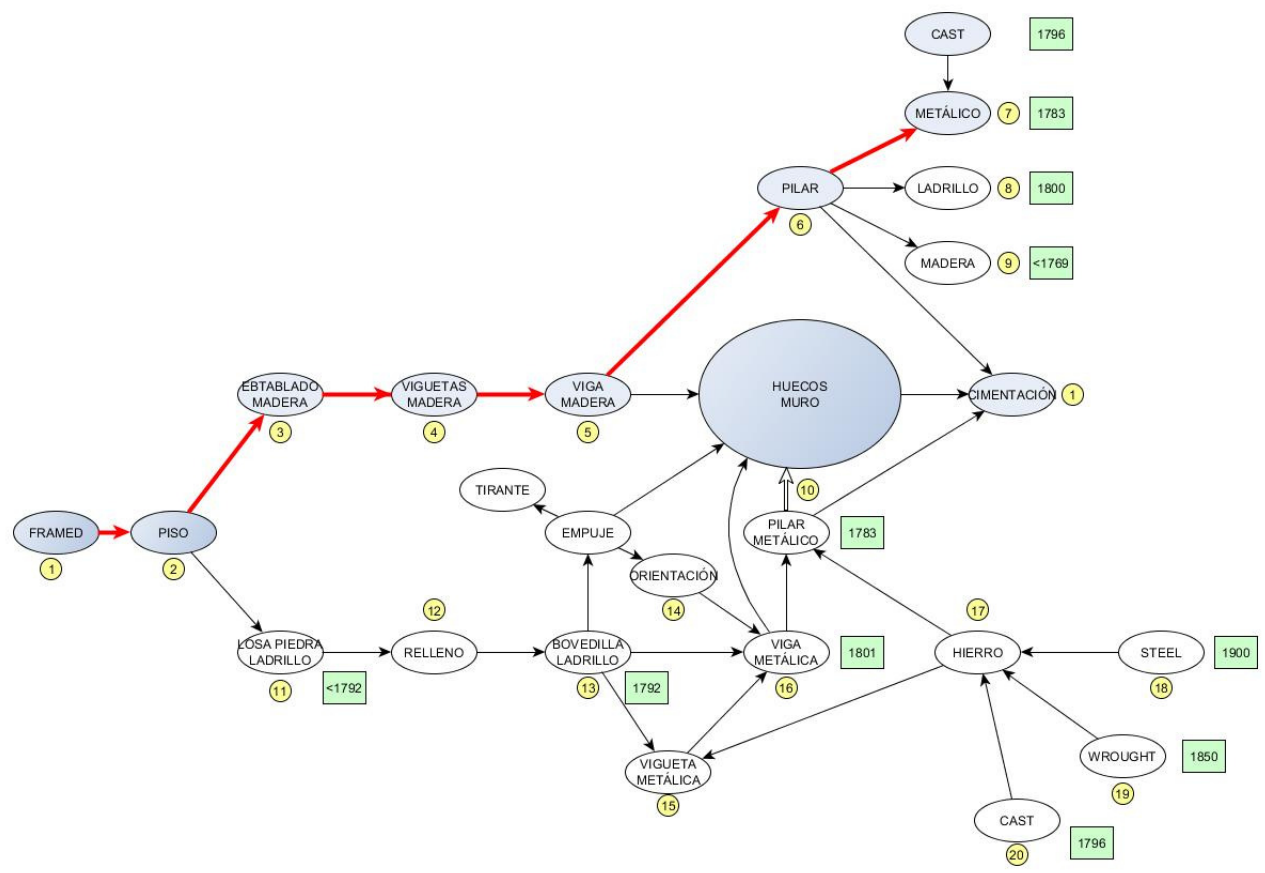

Figura 179. Evolución constructiva de los pilares metálicos.

La introducción del hierro como material se produjo poco a poco. Así, la fundición no solo se usó para las columnas, sino también posteriormente para las vigas y viguetas que sostenían las bóvedas de ladrillo que constituían el forjado (Edificio Ditherington Mill, en el apartado 3.2.5.) [Figura 180 y Figura 181] ${ }^{257}$.

257 Charles Bage, Thomas Telford y el ingeniero William Strutt fueron los responsables de los primeros análisis de la resistencia de los forjados con vigas de sección en $\mathrm{Y}$ invertida donde apoyarán las bóvedas de ladrillo fire proof: Las viguetas de hierro sustituyen a las de madera, que para resistir el fuego se recubrían de yeso y con chapa de hierro, como es en el caso de los forjados de la Strutt's North Mill. 

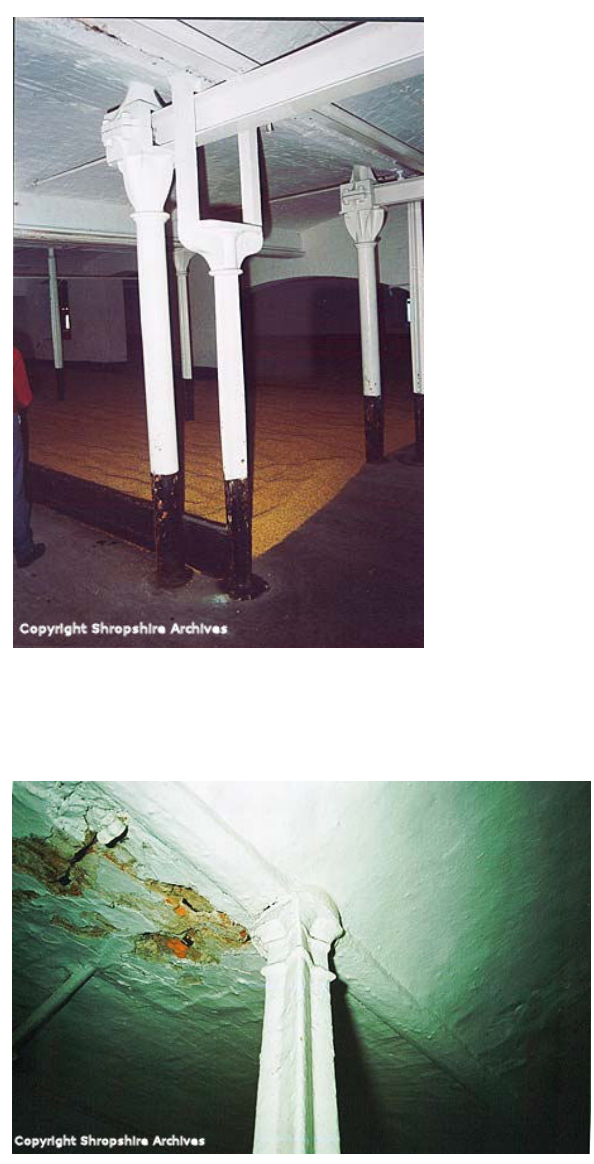

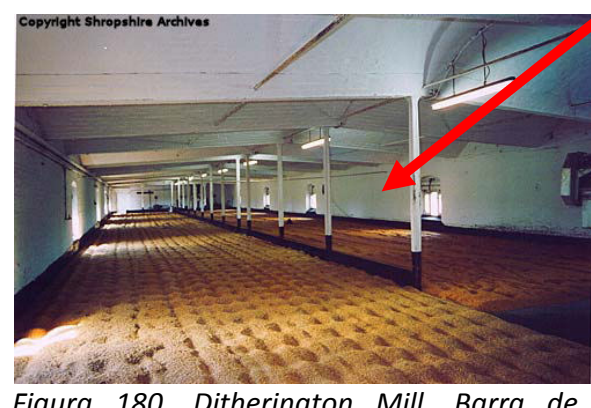

Figura 180. Ditherington Mill. Barra de hierro forjado transversal a la bóveda para evitar que se abra en exceso por el peso (Shropshire Archives).
Figura 181. Ditherington Mill. Pilar de sección maciza cruciforme (Shropshire Archives).

Como se ha comentado líneas más arriba, la novedad de este edificio también residía en la utilización de vigas de hierro fundido [Estado 19 de la página 319] sobre las que apoyaban las bóvedas de ladrillo (en inglés brick barrel vaults o brick arch floors), con barras transversales encastradas de hierro forjado para evitar la

Se trataba de un "método innovador de construcción". También, el hecho por el que Charles Bage inició la utilización del hierro fundido, aparte de su amistad con William Strutt, fue su utilización en el puente de Shrewbury por Telford. Además, Shropshire era el centro de la industria del hierro, con el cercano Coalbrokdale como pionero en fundir con "coke". 
apertura del $\operatorname{arco}^{258}$. Es por ello, que se considera por regla general (University of the West of England. Dep. Architecture, 2014), el primer edificio "fire-proof", puesto que todos los materiales eran incombustibles: estructura, ventanas, escaleras de piedra, etc. Los pilares, que siguen teniendo una sección cruciforme, son ligeramente convexos a mitad altura [Estado 15 de la página 319] ${ }^{259}$. En cuanto a las vigas, apoyan en sus extremos sobre los muros de carga perimetrales, que con sus dos hileras de pilares, alcanza los $12,2 \times 54 \mathrm{~m}$ de planta (es por ello que se considera una estructura mixta "frame" y "no frame" al mismo tiempo). Estas vigas, como sus antecesoras de madera, seguían siendo continuas en sus puntos de apoyo, de forma que mejoraban los momentos negativos, a costa de un ligero incremento de los positivos. Gracias a este edificio como punto de partida (1796), pese a la reticencia en la utilización de la madera para vigas incluso 100 años después (Johnson, 1955) ${ }^{260}$, sí se comenzó a popularizar la utilización del hierro fundido, en especial por sus reconocidas propiedades "fire-proof" 261 [Estado 7 de la Figura 179].

Otros ejemplos de principios del siglo XIX de la utilización del hierro fundido ("cast iron") para los soportes interiores de los forjados [Figura 182 y Figura 183] son:

\footnotetext{
${ }^{258}$ http://list.english-heritage.org.uk/printreport.aspx?img=1\&ld=1

${ }^{259}$ Insistir en el hecho de que todavía las columnas eran cruciformes y no circulares, por la dificultad técnica en la fundición de perfiles huecos, si bien esto no tardará en poder realizarse como se verá en párrafos sucesivos.

${ }^{260}$ Sin embargo, a pesar de la novedad tecnológica del hierro, la madera se siguió utilizado hasta 100 años después porque además de que era más rápida de construir poseía cierta tradición, se conocía su comportamiento frente a los esfuerzos y su puesta en obra, la había en abundancia y era, en definitiva, mucho más barata.

${ }^{261}$ La consideración de "fire-proof" es un concepto que no sería aplicable en la actualidad, porque el hierro no resiste al calor.
} 


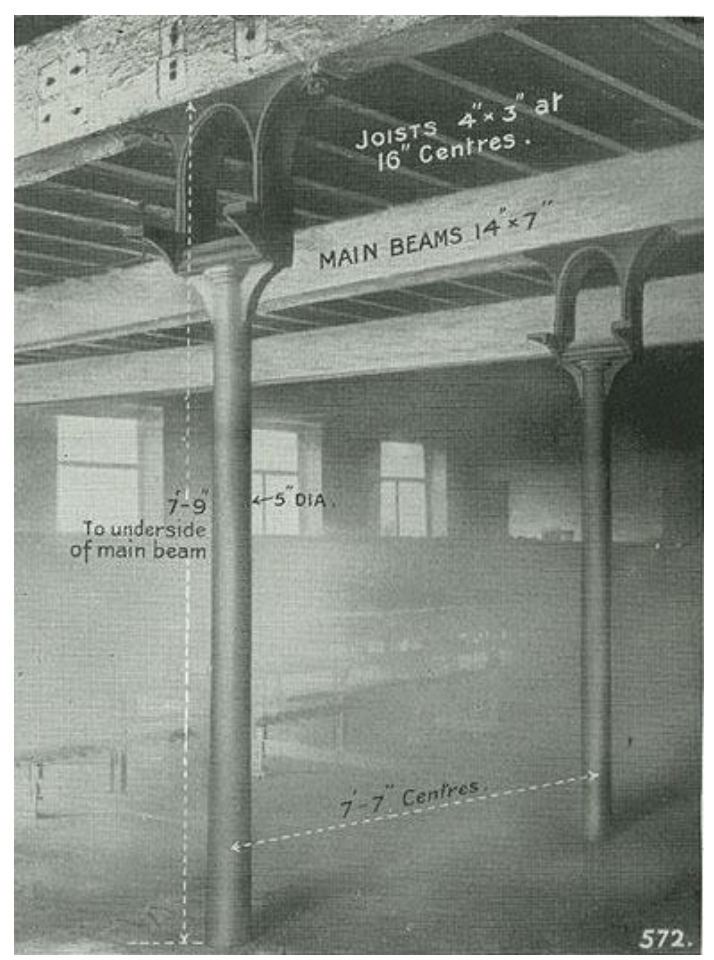

Figura 182. "Mill" construido a principios del siglo XIX, en Bolton, Gran Mánchester. En este caso, los pilares son circulares de hierro fundido, con una particularidad en su cabecera para alojar el eje mecánico de transmisión de la energía que el autor del libro en el que está incluida esta fotografía, califica de "diseño único". Las vigas son de madera, y los muros de carga a base de piedra. Los pisos estaban formados por tablones de madera, apoyando sobre viguetas de madera. La interdistancia entre ejes de pilares era de algo más de $2 \mathrm{~m}$, que coincidirá con la distancia entre los ejes medios de las ventanas. Concretamente esta manufactura también era accionada hidráulicamente (Hill, 1927). 


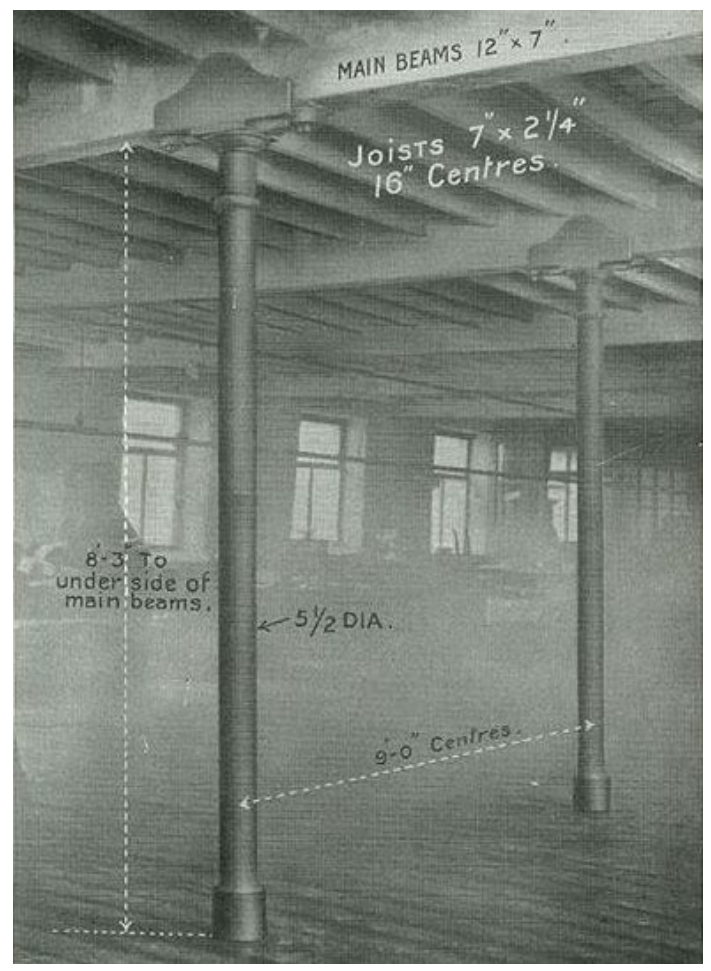

Figura 183. "Mill" de 1830, con pilares metálicos, con dos pestañas que abrazaban la viga de madera para una mejor unión. Vigas, viguetas y forjados de madera, del mismo material que el suelo, realizado con tablones. Se amplía la distancia entre pilares con respecto al de la Figura 182, pese a seguir siendo estructura de madera, si bien está construido 27 años después. Se trata de un edificio todavía estrecho y alargado: 2 vanos frente a 13. Esta conexión aparece en la Figura 178, apartado a) (Hill, 1927).

El siguiente paso en las estructuras metálicas le corresponde al edificio de Salford, de 7 plantas de altura, erigido en 1799 también por Charles Bage para la firma Phillips \& Lee [Figura 184] \{apartado 3.2.6\}. Ello está motivado por la utilización de las vigas con forma de T invertida [Estado 20 de la página 319], de modo que el arranque de las bóvedas de ladrillo se resolvía apoyando en sus alas inferiores. También por el empleo, ahora sí, de pilares de hierro fundido circulares huecos, por donde incluso se hacía pasar vapor de agua de la máquina que Boulton y Watt 
había instalado, con el objetivo de calefactar. Bage empezaba ya a formular sus primeras teorías sobre la resistencia de materiales y el esfuerzo al que las alas de la viga estaban sometidas [Estado 16].

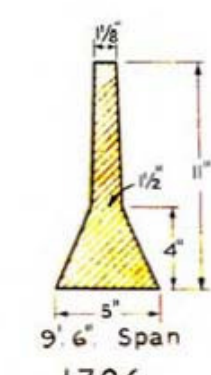

1796

SHREWSBURY

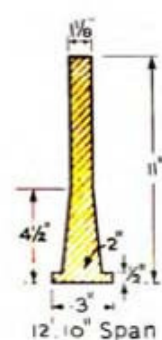

$$
1799
$$

Preliminary design

- salfor
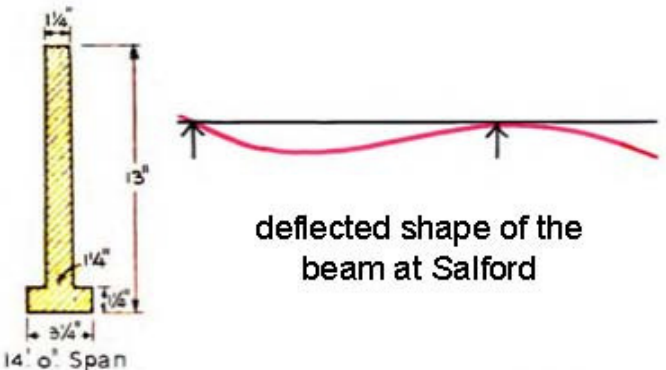

deflected shape of the beam at Salford

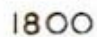

As built

R .

\section{skewbacks and flanges \\ beam sections at \\ Shrewsbury, 1796 \\ Salford, preliminary, 1799 \\ Salford, as built, 1800}

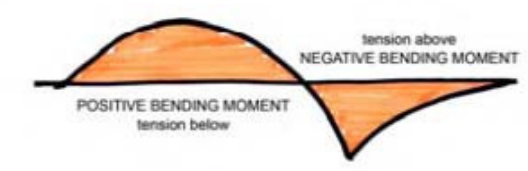

MUAS 12,553

Figura 184. Secciones de las vigas empleadas en el edificio de Salford, alrededor de 1800, y su comportamiento a esfuerzos (Bryant, 1950).

Sin embargo, según Fairbairn (Fairbairn, 1863), se desconoce con exactitud cuándo comenzó a usarse el hierro fundido con alguna aplicación estructural. Señala en su libro que probablemente su origen reside en aplicaciones para artefactos de guerra, como cañones, o para la construcción de las máquinas de vapor o bombas de trasiego de Newcomen ${ }^{262}$, que ya llevaban más de 100 años en funcionamiento, y especialmente en los primeros cilindros para estas máquinas.

${ }^{262}$ Thomas Newcomen (1663 - 1729) 
También el Ingeniero Civil Smeaton ${ }^{263}$, según el químico inglés Tredgold ${ }^{264}$, trató de divulgar y certificar las virtudes de este nuevo material frente a la madera, siempre considerada como un material noble:

"Si no basta con el uso que ha venido teniendo el hierro fundido para la formación de piezas de maquinaria, añadiré que en el año 1755 lo apliqué por primera vez en una estructura. Y así, si la madera más resistente para grandes longitudes no es capaz de soportar grandes pesos, ¿qué le podría pasar al hierro por culpa de su fragilidad? Para contestar, sería suficiente con decir que las pioneras estructuras del norte de Inglaterra han soportado bien, utilizándose de una forma normal, y nunca jamás he oído que hayan colapsado."

A todo ello hay que sumar que Smeaton señalaba que la forma con la que se fundía por aquel entonces el hierro no era totalmente la adecuada, a lo que Fairbairn añadió que para posibilitar también su utilización se tenía que disminuir el precio de su producción. Todavía quedaban dudas de cómo conseguir gran resistencia y pureza, por lo que se desconfiaba para su utilización en vigas. Smeaton, Wilkinson, Watt, Rennie, Murdock, Telford y otros ingenieros prestigiosos contemporáneos sí que confiaron en él para construir máquinas de vapor, algunos "mills", puentes y maquinaria. Simplemente se trataba del comienzo de un nuevo material para estructuras.

En cuanto a material de construcción, según Fairbairn (Fairbairn, 1863), fue también la fábrica de Philips y Lee, en Manchester, de 1801, la primera en utilizar vigas y columnas de hierro fundido. En ella, pese a no haber realizado experimentos previos ${ }^{265}$, Watt sí había conseguido "una aproximación tolerablemente acertada", consiguiendo que soportara el máximo peso para una cantidad de material empleado en su sección. Además, se reconoció en Inglaterra por ser uno de los pioneros "fire-proof".

263 John Smeaton (1724 -1792)

264 John Harfield Tredgold (1798 - 1842)

265 Destacar el discípulo de Fairbairn, Hodgkinson, teorista sobre resistencia de materiales, que empezó con las primeras pruebas publicadas sobre la resistencia de las vigas de hierro, obteniendo los famosos experimentos de Fairbairn, en los que la economía en el uso de material también resultó ser asimismo un factor primordial. 
Según este mismo autor, entre este año y 1824 \{confrontar apartado 3.2.6 más atrás, sobre la Fábrica de hilos de Salford, o Phillips, Wood \& Lee, 1799\} (Fairbairn, 1863) hubo una escasa variación en la forma de las vigas. De hecho, la fábrica de Philips fue el modelo que muchos siguieron durante muchos años más [Figura 175].

Pero a pesar de la confianza depositada en la innovación tecnológica industrial, se detectaron nuevos problemas para el hierro forjado: su fragilidad y su poca resistencia al calor en caso de incendio, fracturándose incluso sin previo aviso.

Siguiendo con los diferentes avances en la tecnología de construcción, el edificio sucesivo al que le corresponderá ser el posterior al de Philip y Lee será el de William Strutt, de 1804 en Belper, conocido como North Mill. Como ya se comentó \{apartado 3.2.7\}, se trata de un edificio de 5 alturas y ático, construido después del incendio que su predecesor había sufrido calcinándolo en su totalidad, a excepción de su cimentación de piedra. De hecho, la idea fue lograr un edificio "fire-proof", con pilares y vigas de hierro fundido donde poner en práctica su teoría sobre el comportamiento de las estructuras metálicas y las cerchas metálicas (Johnson, 1955). Sus pilares son ${ }^{266}$ de sección cruciforme sobre los que apoyan las vigas, que a su vez descansan en sus extremos sobre los muros de carga. Otro "mill" de Belper es el South Mill, de $1811 \div 12$, que llega hasta los $\approx 12 \mathrm{~m}$ de anchura, con 3 hileras de pilares de hierro fundido y con bóvedas de ladrillo, cuyos arranques se ven facilitados por los nuevos diseños de vigas [sección de la viga metálica a la izquierda de la Figura 185] (y todo ello 20 años después del primer "fire-proof" de Strutt). Se consigue así un espacio interior de mayor iluminación y más despejado. Por su parte, la ligereza de estos forjados y vigas permite que no sea tan necesaria la robustez de sus muros de carga, de forma que se permiten mayores dimensiones de los huecos de ventana ${ }^{267}$ [Estado 10 de la página 319, y Figura 186].

\footnotetext{
${ }^{266}$ Este edificio todavía existente.

267 Los pilares metálicos de hierro colado, como se acaba de comentar, tienen muy buen comportamiento frente a los esfuerzos de compresión, además de ser incombustibles y de conseguir mayor diafanidad en los espacios interiores por su menor sección.
} 


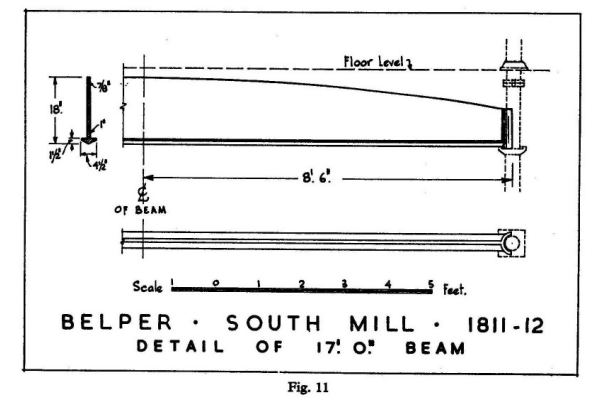

Figura 185. South Mill, de William Strutt, Belper, 1811 - 1812. Detalle de la viga (Johnson, 1955).

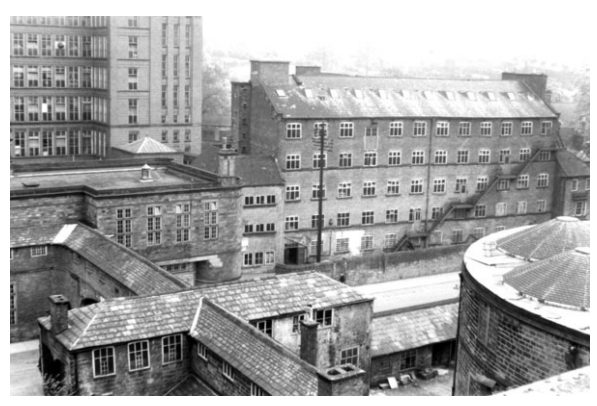

Figura 186. A la derecha el South Mill, con una escalera en fachada para evacuación de incendios posterior. Abajo a la izquierda el Round Mill. Abajo a la derecha, el edificio de oficinas con su pasarela sobre calle adyacente. Arriba izquierda, el East Mill, de 1911/13 (Johnson, 1955).

Gracias a estos primeros edificios, las aplicaciones de los pilares metálicos se regularizan ya en la década de 1830 , siendo ampliamente utilizados hasta la aparición del hormigón armado y el acero laminado (a finales de siglo, como se ve en el siguiente apartado) (Regalado, 1999).

A modo general, se puede concluir que el objetivo buscado es alcanzado con estos materiales: la libertad de planta, con un número muy inferior de soportes intermedios con respecto al periodo anterior (madera o ladrillo), o dicho de otro modo, la consecución de una luz mayor entre pilares.

Como criterio general de cálculo, los diámetros de las columnas estaban dimensionados en función de la carga vertical que soportaban, disminuyendo en función de la planta en la que estuvieran, siguiendo la lógica de la carga vertical que sostenían y la luz de las vigas que apoyaban. 
Por otro lado, en muchas ocasiones, especialmente a partir de la segunda mitad del siglo XIX, se utilizó el hierro fundido como material para colocar los anclajes de los embarrados ${ }^{268}$ giratorios de transmisión de la energía ${ }^{269}$ [Figura 187, Figura 188, Figura 189 y Figura 190].

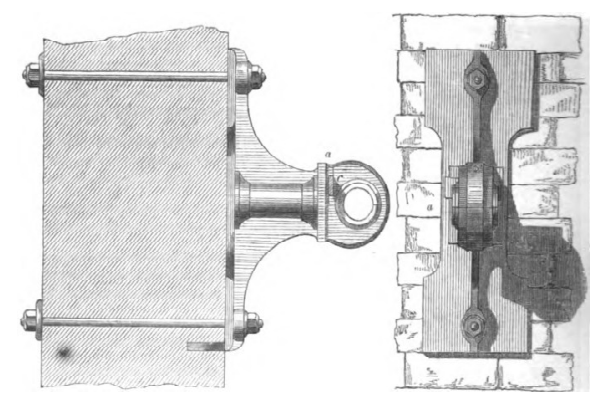

Figura 187. Pedestal en hierro fundido para el paso del eje de transmisión atornillado a muro o pilar de ladrillo, 1864 (Fairbairn, 1863).

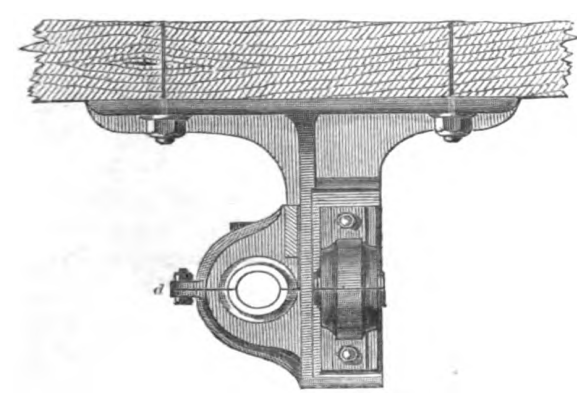

Figura 188. Pedestal en hierro fundido para el paso del eje de transmisión atornillado a viga, 1864 (Fairbairn, 1863).

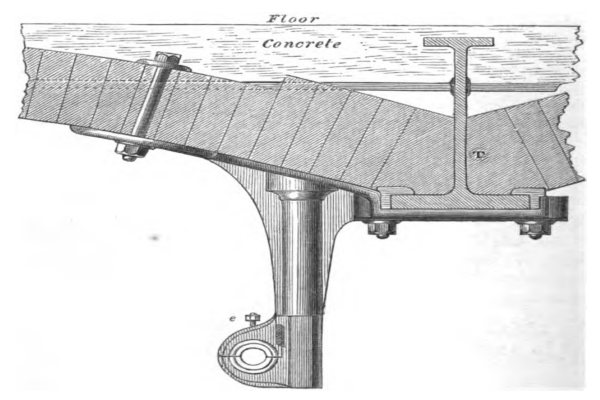

Figura 189. Pedestal en hierro fundido para el paso del eje de transmisión atornillado a arco de ladrillo de entrevigado y a viga de fundición, 1864. Observar además cómo a utiliza en este año la palabra "concrete", refiriéndose al hormigón (Fairbairn, 1863).

\footnotetext{
${ }^{268}$ La palabra embarrado no aparece en el diccionario de la RAE. En todo caso, se refiere a eje de transmisión principal, en el caso de mecanismo mecánico, o pletina a tensión, en el caso de transmisión eléctrica.

${ }^{269}$ Aunque según Gumà (Gumà, 1997), en el siglo XIX en Cataluña (y por extensión, lo mismo se puede deducir de los molinos papeleros de Alcoi), por la distribución del proceso productivo, en las plantas de sótano y en las plantas altas los pilares no solían tener estos apoyos porque no era habitual colocar maquinaria en estas plantas, ya que la primera de ellas se destinaba a almacén y a la instalación de los sistemas de rodamientos, y la segunda, a vivienda o a zona de secado.
} 


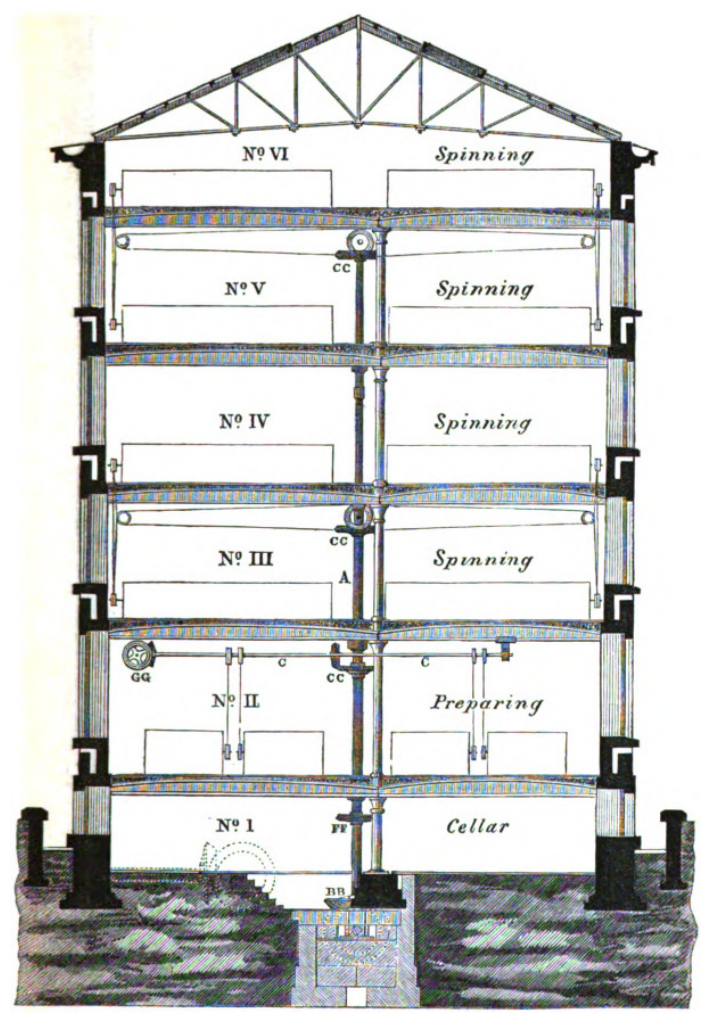

Figura 190. Sección de un edificio diseñado por Fairbairn con soportes interiores metálicos, entrevigado metálico en forjados apoyados en estructura muraría. La estructura todavía no ha llegado a fachada. 1864 (Fairbairn, 1863).

Además, el uso de secciones metálicas permitió introducir la decoración en los elementos estructurales, como los capiteles de las columnas del Marshall's Temple Mill, de 1842, que estaban rematados con hojas de palma y papiro \{Apartado 3.2.8\}. 


\section{HIERRO FORJADO (“WROUGHT IRON")}

En la misma época que aparecen los forjados con doble bóveda para disminuir el canto de los forjados [Figura 166], a principios de la década de 1870, el hierro forjado, y más tarde el acero, fueron tomando presencia, pero solo para vigas [Estado 18 y Estado 19 de la Figura 179] (hasta 1920 las columnas fueron de hierro fundido).

Es pues durante la segunda mitad del siglo XIX que se van sustituyendo las vigas principales de los edificios de madera a hierro forjado, hasta más o menos bien entrado el siglo XX, que al variar la cantidad de carbono de este para mejorar su ductilidad se acabará empleando comúnmente el acero en las estructuras, con el perfeccionamiento de la aleación de hierro y carbono. De esta manera, y gracias a su gran resistencia, y consecuentemente a sus grandes luces (con una distancia media alcanzada de entre 6 y 6,6 m), las construcciones ganan más diafanidad, distribución interna y libertad de diseño de las fachadas, con la consecuente mayor entrada de luz natural. Todo ello junto a la combinación del hierro fundido para los soportes. Además, la estructura se va trasladando consecutivamente desde el interior al exterior, liberándolo de todo exceso portante que le impedía mayor cantidad de huecos [Tabla 6, Figura 191 y Tabla 7]. 


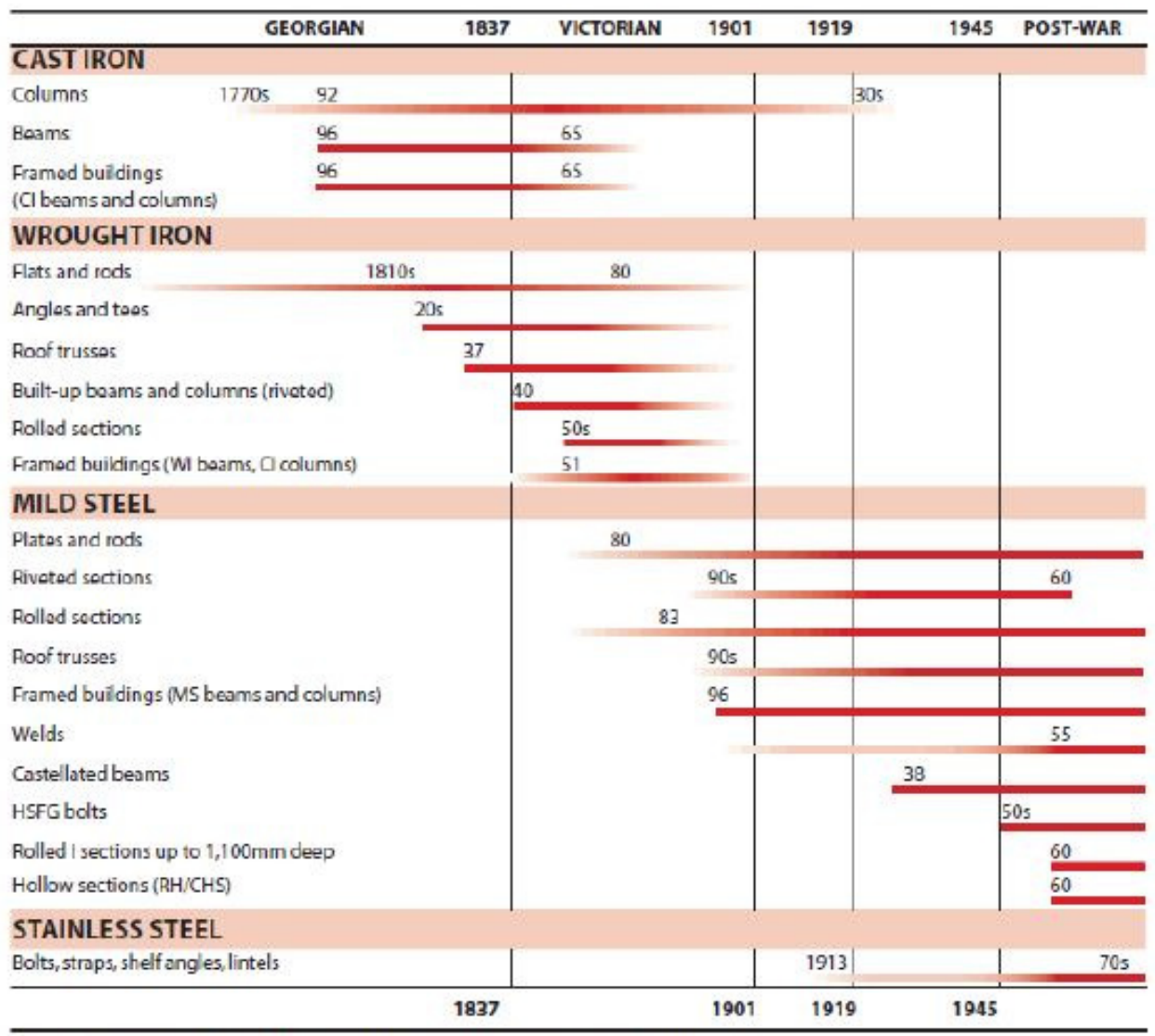

Timelines: knowing the age of a bulding can help in predicting the presence of cast iron beams

Tabla 6. Cronología de la utilización de los distintos hierros como material de construcción (Richardson, 2005). 


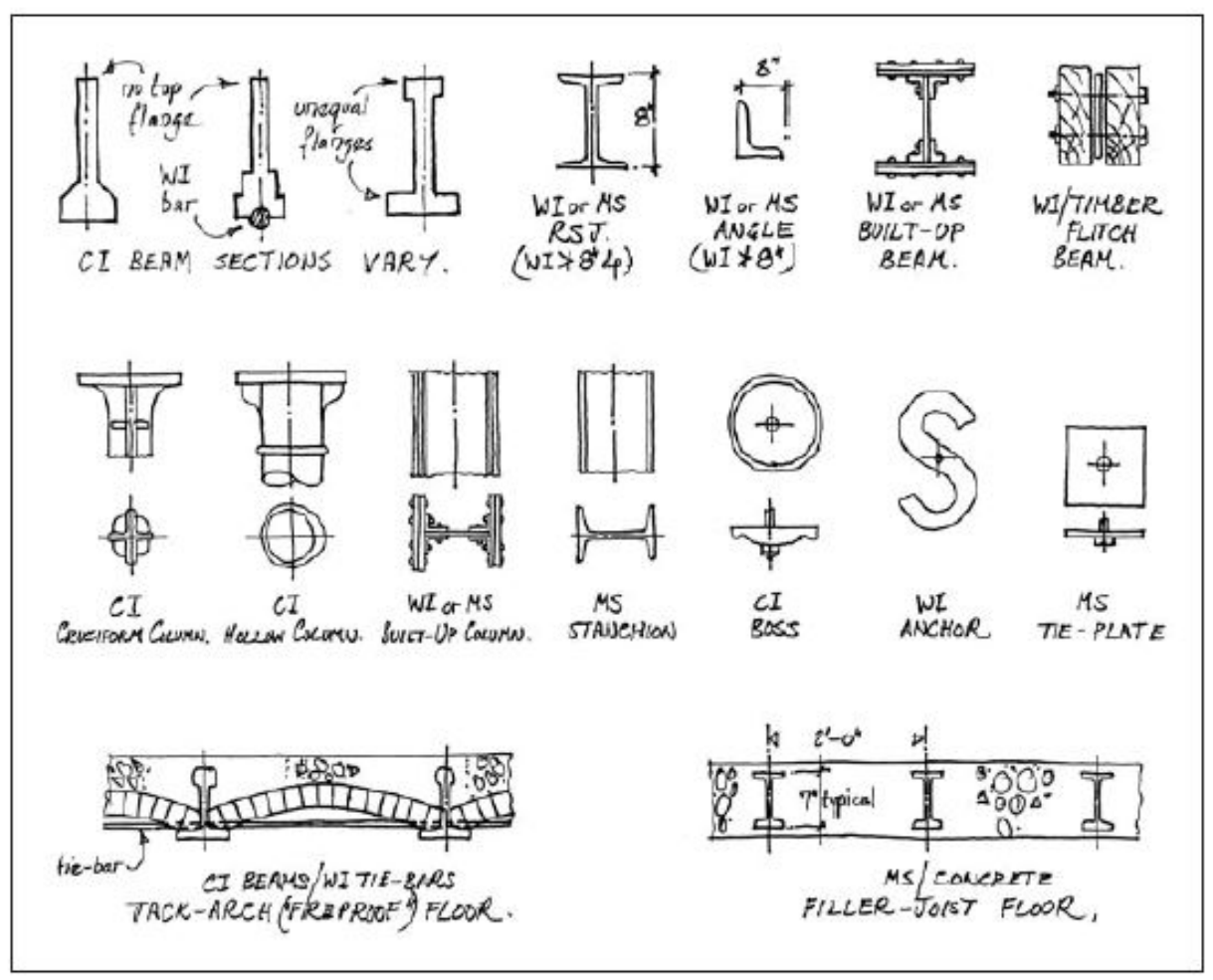

Figura 191. Diferentes secciones constructivas con hierro (Richardson, 2005). 


\begin{tabular}{|c|c|}
\hline 1779 & Puente de Coalbrookdale, en hierro fundido, con distancia de $30 \mathrm{~m}$ \\
\hline 1792 & Edificio de varias plantas con estructura de hierro en Derby (William Strutt) \\
\hline 1796 & Puente de Buildwas, en hierro fundido, con distancia de $43 \mathrm{~m}$ \\
\hline 1796 & Puente de Sunderland, en hierro fundido, con distancia de $79 \mathrm{~m}$ \\
\hline 1801 & Vigas de James Watt en hierro fundido de distancia de 4,3 m \\
\hline 1809 & Puente de Schuylkill, en hierro fundido, con distancia de $103 \mathrm{~m}$ \\
\hline 1820 & Puente de Berwick, en hierro fundido, con distancia de $150 \mathrm{~m}$ \\
\hline 1826 & Puente suspendido de Menai, en hierro fundido, con distancia de $177 \mathrm{~m}$ \\
\hline 1845 & Vigas de hierro forjado en Francia \\
\hline 1848 & Fábrica de 5 pisos en Nueva York (James Bogardus) \\
\hline 1850 & Puente férreo en vigas tubulares de Menai, con distancia de $153 \mathrm{~m}$ \\
\hline 1857 & Invento del ascensor de Otis \\
\hline $1853-58$ & Edificio del Cooper Union de 6 plantas con hierro forjado \\
\hline 1856 & Proceso de producción de hierro de Bessemer \\
\hline 1860 & Boat Store, Sheerness, de 4 alturas con hierro fundido y forjado \\
\hline 1863 & Proceso de forjado de hierro de Butterley \\
\hline 1865 & Producción de acero de Siemens Martin \\
\hline 1877 & Normativa para la utilización del acero en puentes \\
\hline 1880 & Ascensor eléctrico de Siemens \\
\hline 1883 & Puente de Brooklyn, con distancia de $486 \mathrm{~m}$ \\
\hline 1884 & Edificio de 10 plantas, en Chicago, de estructura de acero (W. le Baron Jenney) \\
\hline 1884 & Viaducto de Garabit, de Eiffel, con distancia de $180 \mathrm{~m}$ \\
\hline 1887 & Columnas de acero hexagonales, en Birmingham \\
\hline 1889 & Torre Eiffel, de $300 \mathrm{~m}$ de altura \\
\hline 1896 & Robbinson, en Stockton, primera estructura de acero en Inglaterra \\
\hline 1904 & Hotel Ritz, de Londres \\
\hline 1917 & Puente en Quebec, con distancia de $549 \mathrm{~m}$ \\
\hline 1931 & Puente en Bayonne, de distancia $510 \mathrm{~m}$ \\
\hline 1932 & Puente en el puerto de Sydney, de distancia de $509 \mathrm{~m}$ \\
\hline 1937 & Puente Golden Gate con distancia de 1,280 m \\
\hline
\end{tabular}

Tabla 7. Cronología del empleo de hierro según hitos de la arquitectura y la ingeniería (Richardson, 2005). 
El hierro forjado tiene una menor capacidad a la compresión que el hierro fundido, si bien, su tensión a tracción es considerablemente superior. Es por ello que a partir de la segunda mitad del siglo XIX, con la mejora de su método de producción, se utilizó el primero en vigas, continuando el fundido especialmente en los soportes. Ahora bien, este último era mucho más frágil que el primero, o sea, mucho menos predecible en caso de fallo estructural, por lo que pese a su extendida utilización tenía el peligro de colapso por impacto, sobre todo en espacios llenos de carretillas o elementos móviles (University of the West of England. Dep. Architecture, 2014) [Tabla 8].

\begin{tabular}{|l||r|r|r|r||}
\hline \multicolumn{3}{|l|}{ STRENGTHS ACCORDING TO THE LONDON BUILDING ACTS 1909 } \\
\hline \hline \multirow{2}{*}{ Material } & \multicolumn{4}{|c||}{ Working stresses: Ton/in ${ }^{2}$} \\
\cline { 2 - 5 } & TENSION & COMPRESSION & SHEAR & BEARING \\
\hline Cast iron & 1.5 & 8.0 & 1.5 & 10.0 \\
\hline \hline Wrought iron & 5.0 & 5.0 & 4.0 & 7.0 \\
\hline \hline Mild steel & 7.5 & 7.5 & 5.5 & 11.0 \\
\hline \hline
\end{tabular}

Table 1: Comparative strengths of iron and steel

\begin{tabular}{|c|c|c|}
\hline CAST IRON & WROUGHT IRON & MILD STEEL \\
\hline \begin{tabular}{|l|} 
Surface rust \\
\end{tabular} & Delaminates & Rusts away \\
\hline Brittle & Ductile & Ductile \\
\hline Sandy surface & Hammered/smooth & Smooth surface \\
\hline Mould lines & - & - \\
\hline \begin{tabular}{|l|}
$\begin{array}{l}\text { Monolithic sections } \\
\text { (sometimes decorated) }\end{array}$ \\
\end{tabular} & Riveted sections & Riveted sections \\
\hline Unequal beam flanges & Equal flanges & Equal flanges \\
\hline
\end{tabular}

Tabla 8. Diferentes componentes estructurales del hierro y el acero (Richardson, 2005). 


\begin{tabular}{|l|c|c|c|c|}
\hline \multicolumn{6}{|l|}{ RESISTENCIA DE ACUERDO A LA LEGISLACIÓN EN EDIFICIOS, LONDRES 1909 } \\
\hline \multirow{2}{*}{ MATERIAL } & ESFUERZO DE TRABAJO (T/ $\mathrm{cm}^{2}$ ) \\
\cline { 2 - 5 } & TENSIÓN & COMPRESIÓN & CIZALLADURA & CARGA \\
\hline HIERRO FUNDIDO & 9,68 & 51,61 & 9,68 & 64,52 \\
\hline HIERRO FORJADO & 32,26 & 32,26 & 25,81 & 45,16 \\
\hline ACERO DULCE & 48,39 & 48,39 & 35,48 & 70,97 \\
\hline
\end{tabular}

\begin{tabular}{|c|c|c|}
\hline HIERRO FUNDIDO & HIERRO FORJADO & ACERO DULCE \\
\hline ÓXIDO EN SUPERFICIE & LAMINADO & SIN OXIDACIÓN \\
\hline FRÁGIL & DÚCTIL & DÚCTIL \\
\hline ARENA EN SUPERFICIE & FORJA / SUPERFICIE LISA & SUPERFICIE LISA \\
\hline LÍNEAS DE MOLDE & - & - \\
\hline SECCIONES MONOLIITICAS & SECCIONES REMACHADAS & SECCIONES REMACHADAS \\
\hline PESTAÑAS DESIGUALES EN VIGA & PESTAÑAS IGUALES EN VIGA & PESTAÑAS IGUALES EN VIGA \\
\hline
\end{tabular}

Inicialmente, el hierro forjado era más caro que el fundido, sobre todo por su costoso proceso de producción. Es por ello también, aparte de por sus propiedades mecánicas, que fue preferido por los constructores para vigas pero no tanto para pilares, en el que se siguió utilizando el fundido hasta incluso en las primeras décadas del siglo XX, cuando ya fue reemplazado definitivamente por el acero.

El hierro forjado comenzó a ser popular, especialmente al aumentar el tamaño de las vigas y haber superado los problemas de su fabricación. Con él, apareció el remachado para la formación de grandes vigas a partir de otras de menor tamaño, con lo que se consiguió una mayor facilidad de transporte hasta la obra ${ }^{270}$. En

${ }^{270}$ Rivington, "Building Construction", published in 1875. 
obra, la conexión entre los dos tipos de hierro se hacía de diferentes maneras, dos de ellas representadas en la Figura 192.
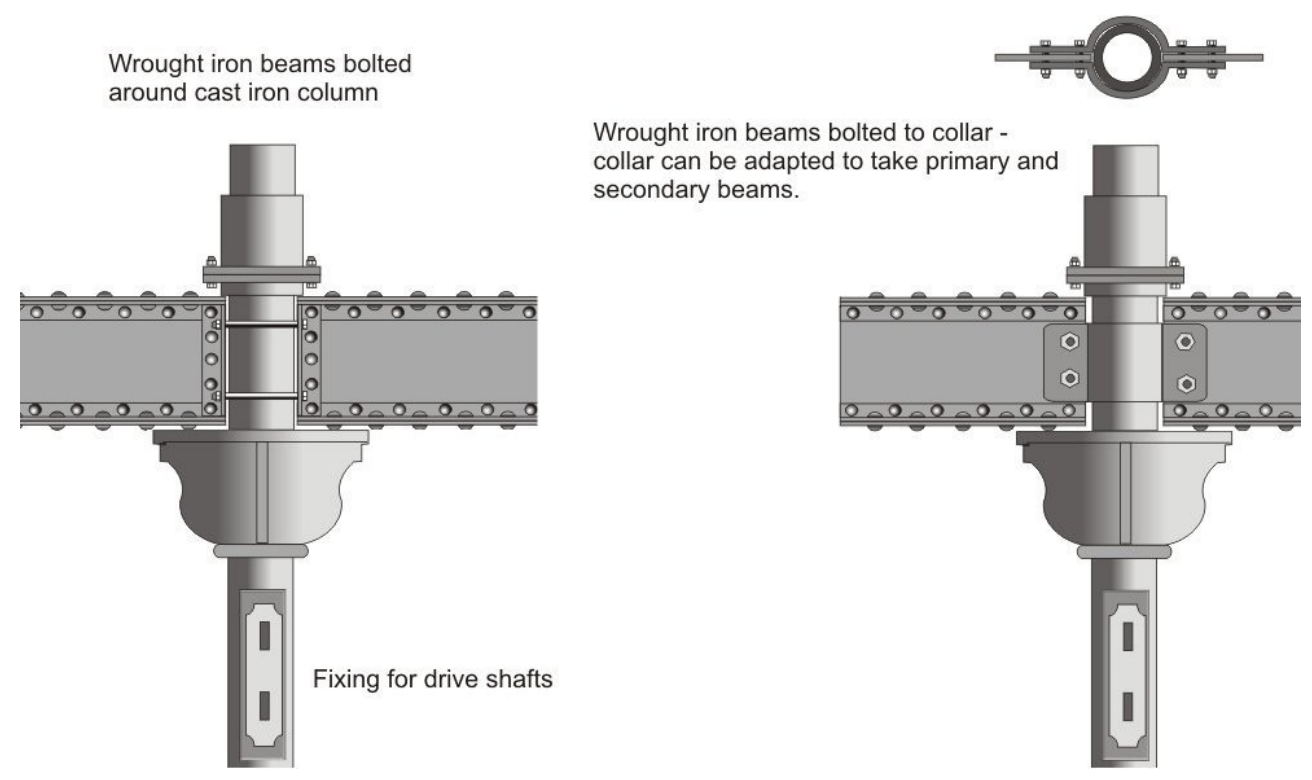

Figura 192. Conexiones habituales entre vigas de hierro forjado y pilares de hierro fundido en la segunda mitad del siglo XIX, especialmente para espacios fabriles con conexiones mecánicas (University of the West of England. Dep. Architecture, 2014).

Como se ha comentado en el párrafo anterior, con la mejora de las técnicas metalúrgicas se optimizó y abarató la producción del hierro forjado, que al principio $(\approx 1850)$, había resultado muy caro de obtener, hasta la llegada de las técnicas de Bessemer, en 1855.

Relativo al factor fuego también, Fairbairn, en 1857 (Fairbairn, 1863) [Figura 193], en su búsqueda en pro de unos edificios incombustibles, estuvo cerca de inventar el hormigón armado. Proponía un sistema de vigas de hierro que sostenían unas bóvedas de planchas metálicas, con hormigón encima. Embebido en este, se insertaron unos tirantes de hierro forjado. Pero el escollo radicaba en dotar de 
elasticidad al material para absorber los esfuerzos producidos por las cargas de la construcción convencional en las vigas y pilares, unos esfuerzos que, si no se tenían en cuenta, llevaban inevitablemente a la fisuración y probablemente al colapso estructural. Esta tipología de forjados no llegó a ser empleada nunca, puesto que no alcanzaron los requerimientos deseados [Figura 193].

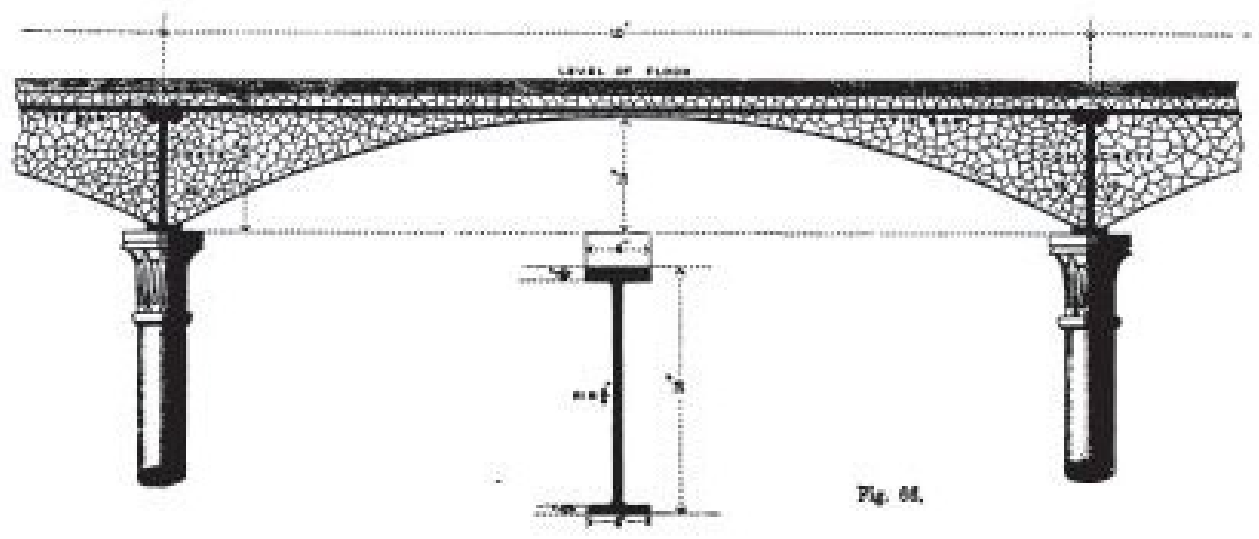

Figura 193. Estructura "fire proof" propuesta por Fairbairn en 1857. Tenía una plancha metálica inferior, con la forma de arco, que servía como encofrado perdido para el hormigón que formaba el forjado en sí, y colocando encima de este, el empisado de losa de ladrillo (Fairbairn, 1863).

Como uno de los edificios que utilizaron el hierro forjado en sus inicios como material en sus vigas (aunque hierro fundido en sus soportes), se tiene el de la fábrica de chocolates Menier, de 1871 [Figura 107, Figura 108, Figura 194, Figura 195 y Figura 196]. 


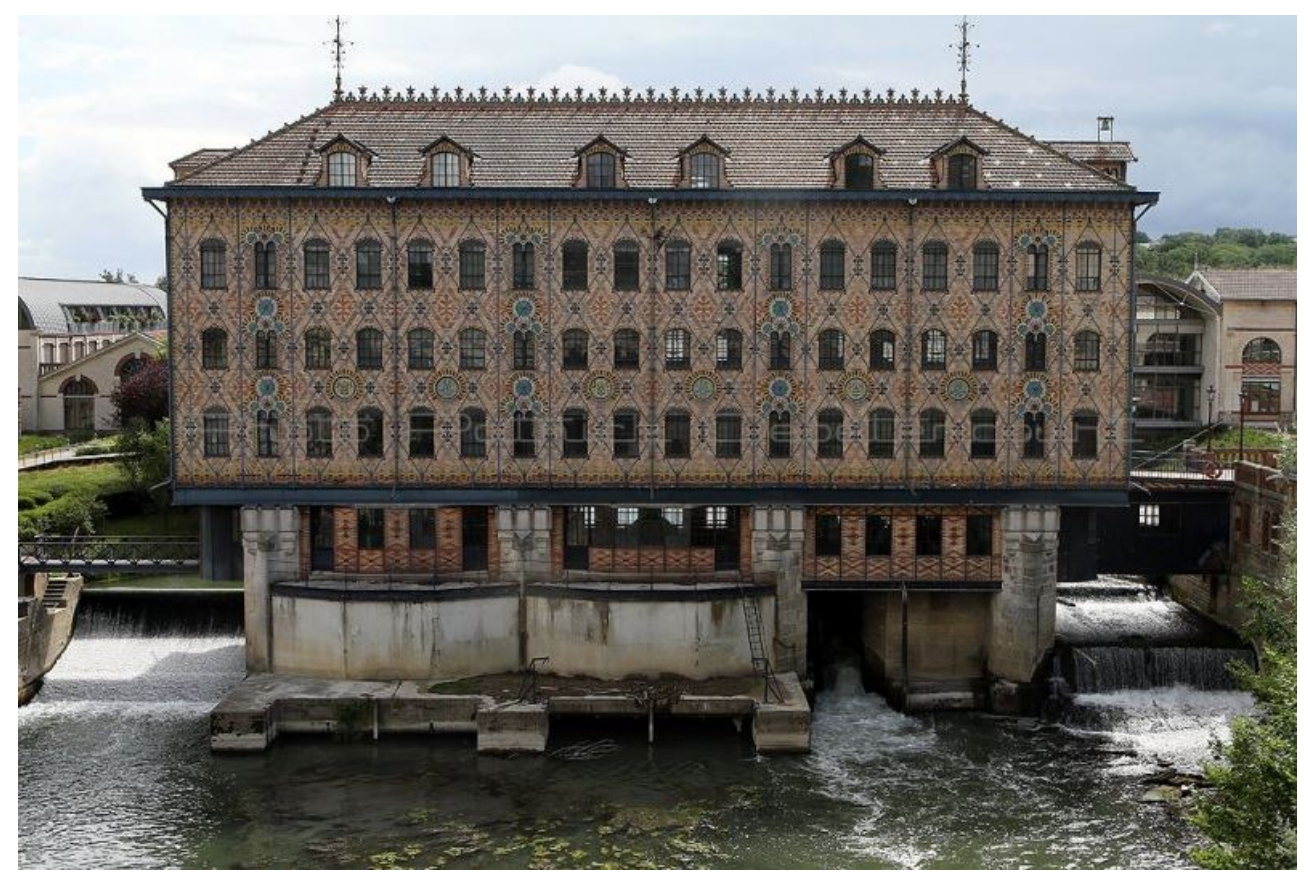

Figura 194. Fábrica de chocolates Menier en la que se perciben las pilastras sobre las que apoya la gran viga de hierro forjado que se corresponde con la planta de acceso desde el nivel de la calle (http://www.lemoniteur.fr/157-realisations/article/retrospective/848731-I-usine-menier-a-noisiel-Iarchitecture-au-service-du-chocolat).

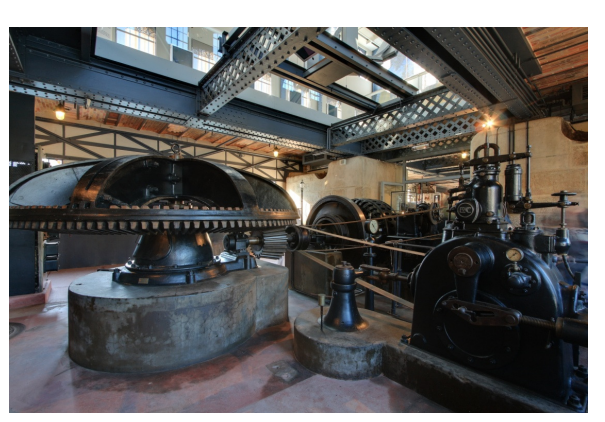

Figura 195. Interior de la fábrica de chocolates Menier, donde se ven las enormes vigas armadas de hierro forjado sobre las que apean las columnas de hierro fundido de los pisos superiores ${ }^{271}$. En esta planta sótano, la más baja del edificio, es donde se encuentra todavía la maquinaria original, incluidas las correas de accionamiento

(http://commons.wikimedia.org/wiki/File:Moulin_Sa ulnier_moteur_hydraulique.jpg).

${ }^{271}$ En inglés son llamadas “lattice girder”, refiriéndose a vigas en celosía, armadas roblonadas. 


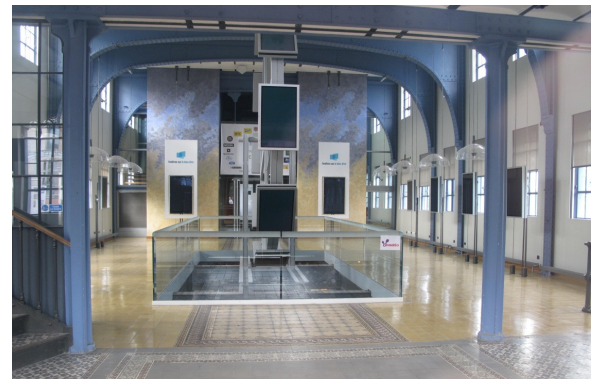

Figura 196. Relativo a la Figura 195.

(http://www.google.es/imgres?imgurl=http\%3A\%2F

\%2Fupload.wikimedia.org).

Resulta interesante en este punto, en el que se acaba de señalar que la estructura portante estaba siendo sustituida por pilares de hierro, añadir el último edificio que la familia Strutt construyó en Belper. Se trata del Belper East Mill, de 1912, más de 100 años posterior al Belper North Mill, uno de los primeros "mills" en tener columnas de acero soportando el perímetro de la estructura del forjado [Estado 18 de la Figura 197]. Como se ve, el uso del acero estructural tuvo un desarrollo lento, puesto que su utilización usual no llegó hasta más o menos 1900. Los procesos fueron mejorando hasta desarrollar las secciones en doble T para la formación de forjados, si bien, los pilares continuaron siendo de hierro fundido [Figura 197, Tabla 9 y Tabla 10].

Por último, resaltar que son varios los edificios en Inglaterra que son señalados como los primeros en utilizar acero en toda su estructura ${ }^{272}$. Esto no es del todo cierto, porque entre otros, en ocasiones durante el cambio de siglo los términos "iron" y "steel" se utilizaron indistintamente (más en los artículos divulgativos y prensa que los específicamente propios de los ingenieros y arquitectos) (University of the West of England. Dep. Architecture, 2014).

\footnotetext{
${ }^{272}$ National Liberal Club, Londres, 1879; The Royal Insurance Building, Liverpool, $1895 \div 96$; Midlan Hotel, Manchester, 1900; Blackpool Tower
} 


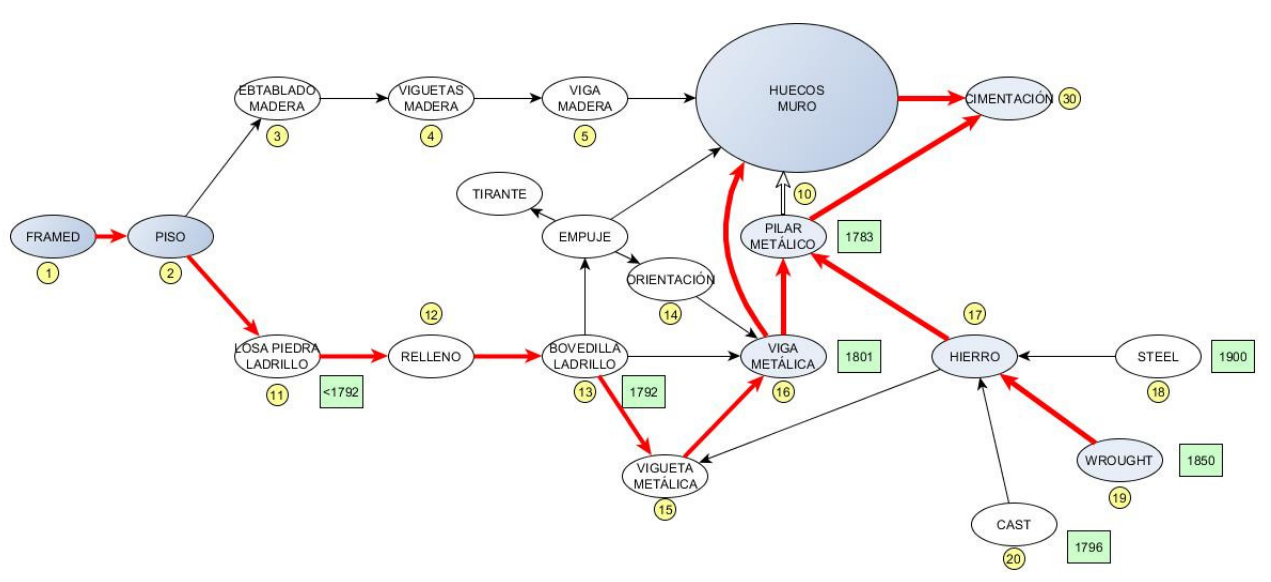

Figura 197. Evolución constructiva de los pilares de hierro forjado, a partir de la segunda mitad del siglo XIX.

\begin{tabular}{|l|l|l|l|l|l|l|l|}
\hline MILL & Fecha & Ubicación & Actividad & Viga & Soportes & Forjado & Cubierta \\
\hline BOAT STORE & 1858 & $\begin{array}{l}\text { Sheerness, } \\
\text { Kent, } \\
\text { Inglaterra }\end{array}$ & $\begin{array}{l}\text { Almacén de } \\
\text { barcos }\end{array}$ & $\begin{array}{l}\text { Vigas } \\
\text { metálicas }\end{array}$ & $\begin{array}{l}\text { Columnas } \\
\text { metálicas }\end{array}$ & $\begin{array}{l}\text { Tablas de } \\
\text { madera } \\
\text { sobre vigas } \\
\text { de madera, } \\
\text { y forjado } \\
\text { también } \\
\text { todavía de } \\
\text { madera }\end{array}$ & $\begin{array}{l}\text { Cercha } \\
\text { metálica. } \\
\text { Cubierta a } \\
\text { dos aguas }\end{array}$ \\
\hline $\begin{array}{l}\text { FÁBRICA DE } \\
\text { CHOCOLATES } \\
\text { MENIER }\end{array}$ & 1871 & $\begin{array}{l}\text { Ubicada sobre } \\
\text { el lecho del río } \\
\text { Marne, en } \\
\text { Noisiel, } \\
\text { Francia. Esta } \\
\text { localidad está } \\
\text { situada a unos } \\
20 \text { km al este } \\
\text { de París. }\end{array}$ & $\begin{array}{l}\text { Alimentación: } \\
\text { fábrica de } \\
\text { chocolate } \\
\text { automatizada } \\
\text { para la } \\
\text { producción de } \\
\text { este producto } \\
\text { en grandes } \\
\text { cantidades }\end{array}$ & $\begin{array}{l}\text { Vigas } \\
\text { metálicas } \\
\text { de hierro }\end{array}$ & $\begin{array}{l}\text { Columnas } \\
\text { metálicas }\end{array}$ & -- & $\begin{array}{l}\text { Cercha } \\
\text { metálica. } \\
\text { Cubierta a } \\
\text { distintas } \\
\text { aguas }\end{array}$ \\
\hline
\end{tabular}

Tabla 9. Tabla con los primeros iconos fabriles con estructura completamente de hierro. 


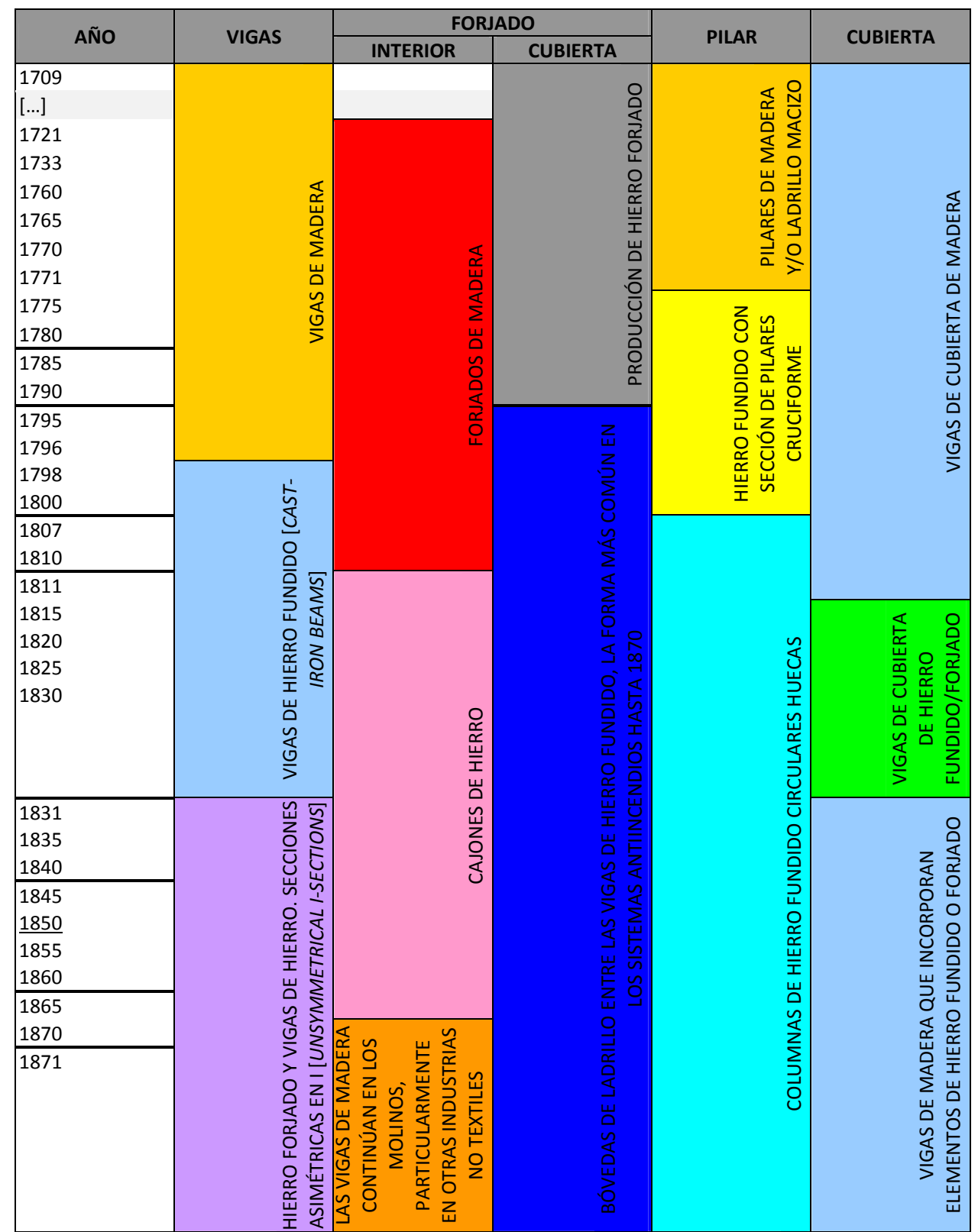

Tabla 10. Tabla cronológica de la utilización de los diferentes materiales. 


\section{HORMIGÓN}

A principios ya del siglo $\mathrm{XX}$, las dimensiones de las fábricas eran considerables, comenzando con cimentaciones de hormigón, pilares de hierro fundido y viguetas de acero para la formación de los forjados, si bien todavía había muchos casos con muros de carga.

El auge del hormigón llegó gracias al llamado "nudo monolítico", inventado por François Hennebique ${ }^{273}$ y patentado en $1892^{274}$.

Otro ingeniero, Maillart, desarrolló en 1910 el forjado plano. Con ambos, a comienzos del siglo XX, la fábrica "moderna" ya podía verse como un edificio perfectamente funcional, en el sentido que los edificios respondían con su forma a la organización específica del proceso industrial (Darley, 2010). Además, como se ha indicado en el apartado correspondiente, se añade la electricidad como base de su funcionamiento \{aparatado 0) de la página 255 \}.

Por su parte, en Norteamérica, Ernest L. Ransome ${ }^{275}$ construyó la fábrica minera Pacific Coast Borax en 1897 [Figura 198], en Bayonne, Nueva York, con su nuevo

273 François Hennebique (1842 - 1921) fue un ingeniero, arquitecto y constructor francés autodidacta, inventor del sistema de construcción con hormigón armado, que permitió la rápida difusión de este material en Europa a principios del siglo XX.

${ }^{274}$ Este nudo singular era relativamente flexible y resistente a las tensiones: consistía en atar las armaduras de refuerzo de los diversos elementos horizontales y verticales de la estructura en sus uniones. La eficacia de este nudo significaba que era posible lograr una estructura de hormigón fiable. Su aplicación en los edificios industriales, reducía el riesgo de incendios, las vibraciones y el coste, y en 1895, Hennebique construyó con él la fábrica de hilados Charles Six, en Tourcoing, Bélgica. Dos años después, junto a un socio suyo, proyectaron el primer edificio de hormigón armado de Gran Bretaña. Hacia 1900, la firma se había convertido en una enorme empresa internacional. Tanto en Europa como en Estados Unidos se desarrollaron también otras patentes, diferenciadas cada una de ellas por la precisa geometría de las armaduras de refuerzo.

${ }^{275}$ Ernest Leslie Ransome (1852 - 1917) fue un ingeniero y arquitecto Americano de origen inglés, innovador en las técnicas de construcción en hormigón armado. Diseñó las más sofisticadas estructuras de la época de los Estados Unidos. Hijo de Frederick Ransome, el cual patentó ya en 1844 la primera piedra artificial. Convenció a la firma de arquitectura Elzner \& Anderson de 
sistema de hormigón armado (Ransome, 1912). Pese a que esta sufrió un grave siniestro en 1902 solo sobrevivió la parte propiamente de hormigón, únicamente con un pequeño daño, de lo que no se pudo decir lo mismo del resto de la metálica. Ello supuso el triunfo y la justificación profesional de Ransome, y convirtió al hormigón en el material ideal de la nueva era industrial americana, con un mejor comportamiento frente a su más directo competidor, el acero y el hierro: "Le dio a la fábrica la caracterización de estructura de hormigón armado, incombustible y con iluminación natural"276 (Banham, 1989):

"The Pacific Coast Borax fire was, it appears, the triumph and vindication of Ransome's professional life. That Company's building at Bayonne, erected in 1897, had been his first work on the East Coast and is also reputedly the first complete reinforced concrete factory to be erected on that side of the country. The fire and Ransome's great and growing reputation as an inventor and constructor combined to give a kind of charisma to reinforced concrete as the material of the new industrial age; and Ransome was only one of a number of forceful new engineering personalities who appeared upon the scene as exponents and exploiters of this miraculous seemingly material.

-R. Banham, A Concrete Atlantis[1]:p.65"

Cincinnati para construir el primer rascacielos de 15 plantas en hormigón, el Ingalls Building, en 1903.

${ }^{276}$ Se pueden plantear dos preguntas: 1) El desarrollo del hormigón, ¿tuvo una evolución en América independiente a la que ocurrió en Europa?, y 2), ¿Tuvo alguna relación con el desarrollo de la estructura de acero?

Con referencia a la primera cuestión, cabe señalar que las primeras patentes de hormigón fueron registradas en los Estados Unidos. Y con respecto a la segunda, determinados autores defienden que los dos materiales, el acero y el hormigón, fueron completamente independientes uno del otro. Según el "Engineering news", durante la primera década del siglo XX, la construcción de acero no se consideraba como un tema de gran interés para el lector, a pesar de la gran cantidad de edificios de ese tipo que se estaban construyendo, pese a que había amentado su presencia en quince veces en los Estados Unidos entre los años 1880 y 1910.

Lo que es cierto es que por razones relacionadas estrictamente con su capacidad de resistencia al fuego, el hormigón se convirtió, desde comienzos del siglo pasado, en un material excelente para la construcción de fábricas, prácticamente en el periodo en que acaba el estudio de esta tesis doctoral, puesto que cumplía con sus expectativas ignífugas. 


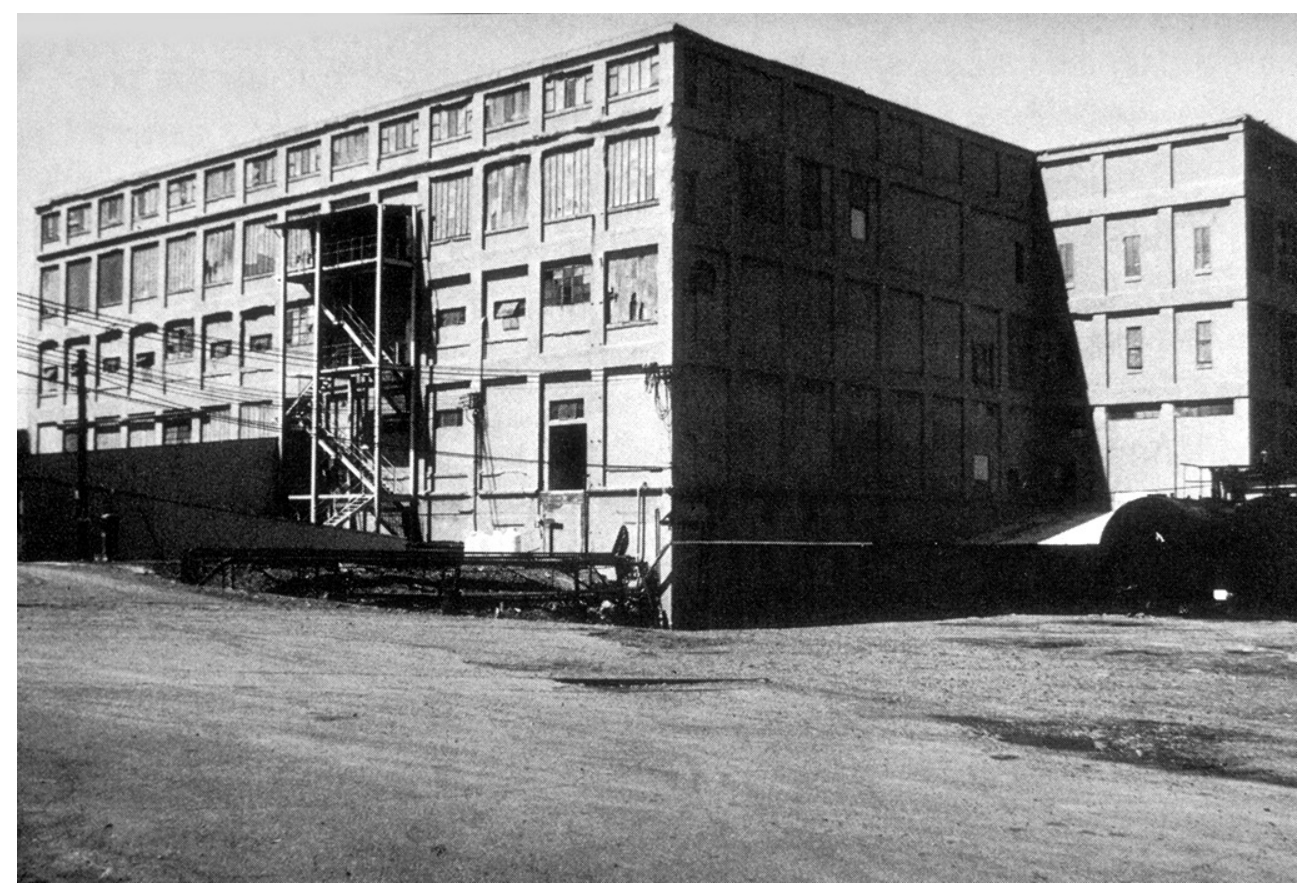

Figura 198. Pacific Coast Borax. Ernest L. Ransome. Bayonne, Nueva York, 1897. Fábrica minera (Banham, 1989).

En 1903, la nueva firma de Kahn fue elegida por la Packard Motor Car Company, para diseñar y construir su nueva fábrica. Hasta el momento, las instalaciones existentes tenían muchas limitaciones para albergar la incipiente industria automovilística, en gran auge desde principios del siglo $\mathrm{XX}^{277}$.

277 Entre estas, los innumerables incendios y la falta de diafanidad que dificultaba el manejo (en inglés "handling") de materiales de un lugar a otro. La primera de ellas se debía principalmente al constante engrase que necesitaba la gran cantidad de maquinaria en movimiento permanente, unida a un complejo sistema formado por ejes, correas y poleas, que provocaba un derrame continuo de aceite que hacía que los suelos entarimados de madera se encontraran incesantemente empapados de grasa y suciedad, una de las causas principales que elevaba el riesgo de incendio, tal y como se ha visto en innumerables puntos en esta tesis. $Y$ en cuanto al segundo de los 
Por ello, el nuevo edificio contratado para la Packard, el llamado № 10 [Figura 113], tenía que ser diseñado precisamente para solventar estos dos problemas, y el hormigón que empezaba a aplicar Kahn en sus obras, reforzado con barras de acero, se presentaba como la mejor alternativa para solucionarlos ${ }^{278}$.

Más o menos al mismo tiempo, apareció otro empresario, Henry Ford, el cual había establecido en Detroit la Highland Park, de la que existen numerosísimas referencias bibliográficas por la entidad que adquirieron esas instalaciones en esa época de cambio de siglo. Como gran hombre de negocios, había observado la reputación que había ido adquiriendo Albert Kahn como arquitecto, y todo lo que había logrado como revolucionario de la arquitectura industrial americana ${ }^{279}$.

La factoría en única planta que quería construir se convirtió poco después en el prototipo de la fábrica industrial del siglo XX, modelo productivo a seguir en todo el mundo.

\footnotetext{
inconvenientes mencionados, una gran restricción que tenía este nuevo sector industrial venía determinada por la corta distancia entre pilares, que acotaba mucho la flexibilidad necesaria.

${ }^{278}$ Tanto su mejor comportamiento al fuego como la mayor separación entre sus pilares que permitía una mejor distribución de la gran cantidad de maquinaria que se necesitaba, convertiría a este material en el más idóneo para las futuras estructuras industriales.

El edificio en cuestión fue diseñado como un gran edificio de planta rectangular con un patio central, con cerramientos repletos de ventanales que, gracias al hormigón empleado, facilitarían una gran iluminación natural en los puestos de trabajo. En la mayoría de la bibliografía acerca del hormigón armado, este se presenta como el primer edificio industrial de la historia en el que se utiliza totalmente. Esta empresa automovilística disponía numerosas cintas transportadoras para soportar grandes pesos, por lo que las losas sobre las que se apoyaban tenían que ser necesariamente muy resistentes. También por ello, este material era el que mejor cumplía con este requisito, puesto que era capaz de soportar grandes pesos por $\mathrm{m}^{2}$ de suelo en sus 4 plantas.

${ }^{279}$ Las dos plantas iniciales del Highland Park habían resultado ineficientes, por lo que Ford pensó en la idea de construir todo el proceso de fabricación de sus vehículos en una única planta, sin patio ni muros separadores, y en tener allí todo el proceso de montaje en cadena. Para ello requería de unas especificaciones particulares para la estructura del edificio.
} 
Y no solo eso, sino que además, con el hormigón armado aumentó la seguridad ante los constantes incendios que se producían en los edificios con estructuras de madera.

Pero para que la construcción de hormigón acabara de triunfar frente a estructuras de acero, tenía que ofrecer unas claras ventajas. Se tenía que demostrar que pese a su mayor dificultad constructiva inicialmente, no tenía un coste económico tan elevado.

Según la revista "The American Architect and Building News" (Banham, 1989), a principios del siglo $\mathrm{XX}$, "la rapidez" ${ }^{280}$ y la economía eran las principales características entre todas las de una lista de mejoras introducidas por las estructuras de hormigón". Estas ventajas del nuevo material eran fundamentalmente:

1. Mayor monolitismo.

2. Economía de mantenimiento.

3. Resistencia al fuego.

Pero todo cambió de forma radical e inesperada cuando en 1906 un terremoto sacudió San Francisco, y el hormigón no dio buenos resultados. En este sentido el acero correctamente diseñado ofrecía mayores ventajas decisivas que el hormigón armado. Así pues, el acero en la construcción de fábricas diáfanas todavía continuó siendo predominante.

Es por ello que como última consideración a la hora de decidir si la deseada fábrica diáfana iba a construirse en hormigón, quedaba la capacidad de resistencia al fuego.

${ }^{280}$ Esta afirmación podría ser discutible. 
Por experiencia se sabía que la construcción metálica tenía generalmente una peor respuesta que la de madera, la cual había merecido el calificativo de material lentamente combustible, porque mantenía su integridad estructural mientras ardía. Por el contrario, los metales que se estaban utilizando en la construcción de las fábricas durante el anterior siglo XIX resultaban peligrosos en circunstancias de mucho calor: el hierro fundido era más frágil, y el hierro forjado y el acero se retorcían y se deformaban ${ }^{281}$.

Por su parte, la estructura de hormigón, al ser intrínsecamente ignífuga, evitaba los gastos derivados de tal protección por ser incombustible, con lo que consiguió ganar la confianza de muchos constructores.

\footnotetext{
${ }^{281}$ Aún así, el acero seguía siendo muy utilizado, al menos en la construcción de rascacielos, pero el coste del revestimiento con material ignífugo para hacerlos resistentes al fuego quedaba compensado por la costumbre arquitectónica de estas construcciones, forradas con ornamentación. Por el contrario, en las construcciones industriales no se tenía tanto interés en la decoración de la fachada, y mucho menos dentro del edificio, por lo que el coste del revestimiento de yeso que cubría el acero en el interior, y el de ladrillo, terracota, cerámica o cemento en el exterior, suponía una parte considerable del presupuesto.
} 


\subsection{EL FACTOR ILUMINACIÓN EN LOS EDIFICIOS FABRILES}

En este apartado se va a estudiar cómo ha influido la iluminación en el proceso de transformación y evolución que han sufrido los edificios fabriles y su interacción. Como en el estudio del resto de factores, aunque se pueda realizar desde varios puntos de vista, hay que tener presente que siempre será el aspecto cronológico el que determinará las directrices a seguir, ya que este no se puede separar del análisis técnico de los diferentes acontecimientos relacionados con la iluminación desde las primeras fábricas [Figura 199].

El día tenía el tiempo limitado para producir. Precisamente por ello, la exigencia de iluminación natural durante estas horas determinaría entre otros aspectos tanto la fachada como incluso la planta de las fábricas. Con la llegada de nuevos materiales, como el cristal, el hierro y el acero, el concepto de fachada portante sufrió un cambio drásticamente radical. La ligereza muraria queda patente en varios sentidos, especialmente por su menor espesor, y como no, por la posibilidad de aperturas que permiten una mayor iluminación natural y, al mismo tiempo, una significativa ventilación. Además, los avances en los materiales estructurales permitieron la apertura de huecos en la cubierta (Navarro, 2006), introduciendo la posibilidad de ensanchar las fábricas. 


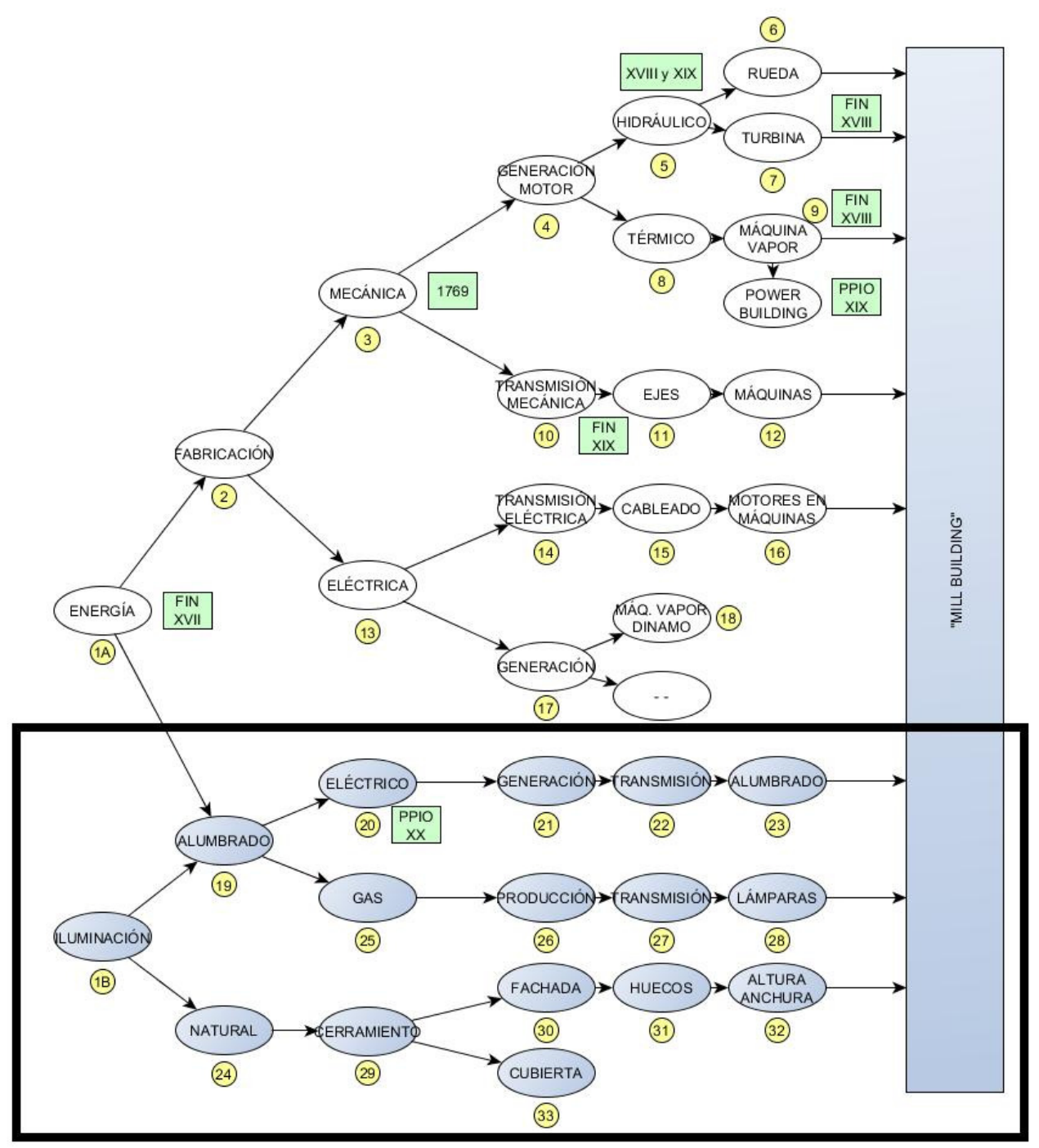

Figura 199. Mapa conceptual para la valoración de la evolución de las estructuras de los "mill buildings" con respecto a la iluminación. 
Se partirá de la premisa de que la iluminación en las fábricas puede ser natural o artificial. Según se observa en el esquema de la siguiente figura [Figura 200], el análisis se hará coincidir con el ámbito de estudio de los "mill buildings", siglos XVIII y XIX, desde el uso extendido del alumbrado mediante lámparas de gas, hasta que comienza a instalarse la electricidad en la industria, a principios del siglo XX.

Sin lugar a dudas, la implantación del aceite y el gas para iluminación fue la que en un principio compensó la falta de iluminación natural. Aunque no se sabe a ciencia cierta, después de los candiles de aceite, la primera fábrica que introdujo la lámpara de gas fue la Boulton y Watt, en la Soho Foundry, en Birmingham, en $1803^{282}$ [Estado 9 de la Figura 199].

Al final del periodo en estudio, y con referencia a la electrificación surgida a finales del siglo XIX, se instaura primeramente la iluminación eléctrica, y posteriormente el accionamiento de los motores (Biggs, 1996). Esta vez sí, con la iluminación más perfeccionada, se mejoró la visibilidad las 24 horas del día, la seguridad, y en general, el entorno de trabajo, pero no mejoró la forma de organizar la fábrica: el mayor impacto en la organización de la planta residió en las nuevas posibilidades que ofrecían los motores eléctricos.

No obstante, a grandes rasgos, la implantación de la iluminación artificial no logra, en general, introducir nuevos cambios en la forma de las fábricas, puesto que siguen siendo muy dependientes de la captación de la natural. Además, la electricidad, en sus orígenes, nació como complemento de la iluminación natural.

282 "The manufactory was the first building to use gas for light in 1802/03" (http://www.handsworthhistory.co.uk/soho-house.html)

De hecho, uno de los principales hechos por los que es conocida la Soho Foundry es porque en ella trabajó el ingeniero William Murdock desde 1777, el cual puso en marcha la iluminación por gas, primero en su casa particular en Cornwall y posteriormente en la fábrica para la cual trabajaba diseñando las máquinas de vapor, en 1802 $\div 1803$ (http://www.averyweigh-tronix.com/AboutUs/History-and-Heritage-/Foundry-History-/\#Murdock's Gas Lighting). 


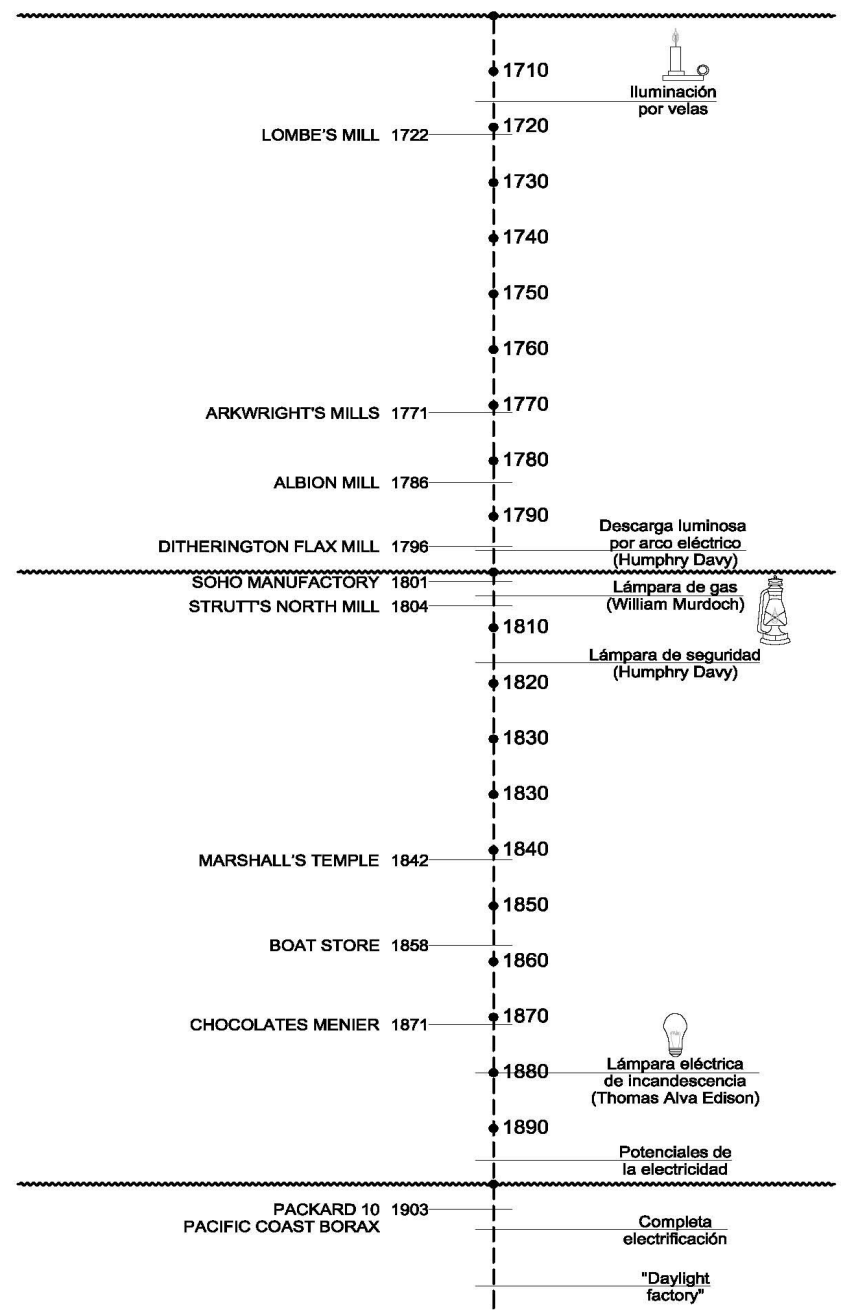

Figura 200 Esquema cronológico de la iluminación en su aplicación a las manufacturas estudiadas en esta tesis. 


\section{ILUMINACIÓN NATURAL}

Los primeros estudios de cierta relevancia y de expansión específicos sobre los beneficios de la iluminación y sus efectos sobre los trabajadores y la productividad no llegan hasta principios del siglo XX, especialmente en América.

Por ejemplo, en 1913, la Industrial Commission of Wisconsin publicó la siguiente opinión ${ }^{283}$ :

"[...] un despertar general está extendido entre todos los manufactureros del país acerca del valor económico que representa conservar el equipamiento humano en sus factorías, pues no ha habido nunca ningún tiempo en que se haya dado tanta atención al alumbrado en los lugares de trabajo."

De hecho, hasta la 2a década del siglo XIX, la discusión acerca de la iluminación se centró exclusivamente y de forma muy intensa, en obtener la iluminación natural a través de las ventanas en fachada. Pero conseguir la luz del día necesaria para trabajar requería innovaciones en el diseño del edificio, y también de los huecos y estructura de fachada. Las consideraciones más importantes que tuvieron los ingenieros americanos y británicos (Banham, 1989) fueron la distribución de la energía dentro de la planta \{confrontar el factor transmisión mecánica en apartado 3.4 más atrás\}, y la necesaria disponibilidad de luz en cada puesto de trabajo individual. El requisito de una iluminación adecuada también alentaba la construcción de edificios estrechos, puesto que así la mayor cantidad de puestos de trabajo podrían ubicarse cerca de las paredes al exterior, y de las ventanas.

Como se acaba de mencionar, ya desde los primeros edificios fabriles, aquellos accionados por fuentes hidráulicas, siempre hubo un gran interés por obtener cuanta más iluminación natural fuera posible, lo que necesariamente siempre estuvo muy presente en la mente de cualquier empresario que pretendiera

${ }^{283}$ http://dwd.wisconsin.gov/dwd/dwdhistory/Year_Pages/wis_indstrl_comm.htm 
maximizar la producción. Como ejemplos, los expuestos en los apartados anteriores \{confrontar espacios fabriles icono en apartado 3.2 más atrás\}.

Banham (Banham, 1989), sin embargo, contrapone los beneficios directos de la requerida iluminación natural abundante y de calidad (la califica de "sensacional" con respecto a "la luz natural aprovechable que entraba por las ventanas del viejo edificio apenas penetraba la profundidad de una crujía de unos cuatro metros" $)^{284}$, con las contraprestaciones que suponía una baja calidad en las condiciones térmicas ambientales, pues señala: "a pesar de su gran pérdida de calor durante los fríos meses de invierno".

Según este mismo autor, en 1911, concretamente cuando la Larkin Company empezó a construir sus nuevos edificios en hormigón en Buffalo, las ventajas de la fábrica diáfana bien iluminada era un tema recurrente en las más prestigiosas revistas de arquitectura, como la The American Architect and Building News, que publicó:

"La pura, clara, incolora luz del día, [...] se está convirtiendo en propiedad del operario fabril americano. Las ventanas con marcos de acero, resistentes a la intemperie, permiten un máximo de iluminación natural."

Asimismo, para posibilitar al máximo la cantidad de luz que entrara al edificio, la estructura de la fachada debía ocupar la mínima superficie de esta, y el hierro, el material con el que ahora se estaban haciendo las fábricas, podía ser un buen material, aunque ello "por razones de seguridad contra los incendios así como por otros motivos menos tangibles, parecía prácticamente inconcebible en la primera década del siglo XX. [...]. En él, cada centímetro cuadrado del exterior que podía, razonablemente, acristalarse aparecía recubierto de este material".

\footnotetext{
${ }^{284}$ Y sigue: "cuando esa misma luz llegaba a través de las cristaleras del edificio $C$ [el de la Larkin Company en Buffalo, Nueva York], que se extendían de pared a pared y del suelo al techo, inundaba un espacio dos veces superior, y deslumbraba mucho menos porque no había un contraste instantáneo de luz y oscuridad que fatigara la vista".
} 
Por su parte, Harry Franklin Porter, un prestigioso ingeniero americano autor de libros como "Concrete - Its composition and use" y "Successful Industrial Management", llegó incluso a decir que, en relación con la iluminación natural y artificial:

\footnotetext{
"Las ventanas acristaladas y la pintura blanca son mejores que las lámparas eléctricas durante el día para suplir la iluminación de las fábricas."
}

Por tanto, la iluminación natural [Estado 24 de la Figura 199], como queda patente en numerosa bibliografía además de los autores citados en párrafos anteriores, siempre ha sido un factor claramente determinante a la hora de diseñar cualquier edificio industrial. Pero al referirse concretamente al alumbrado de fábricas, su máximo aprovechamiento ha sido el principal requisito para conseguir la mayor eficiencia en la producción. Dicho de otro modo: la luz es el componente que más incrementa la posibilidad de producir mayor cantidad de bienes valiéndose de las ventajas que aporta. Según Biggs, (Biggs, 1996), tal y como fue creciendo la demanda de producción (en referencia a los comienzos de la Revolución Industrial y durante todo el siglo XIX), hay unos "nuevos retos en la coordinación de actividades en los molinos:

1) Agua, o energía mecánica en general, para su accionamiento

2) Espacio para las máquinas y los operarios, y

3) Iluminación en cantidad suficiente para que los operarios pudieran hacer bien su trabajo".

Como se ve, eleva la iluminación ( $3^{\text {er }}$ punto del párrafo anterior) a la misma importancia que el espacio productivo e incluso a la energía requerida. 


\section{CONDICIONANTES DE LA ILUMINACIÓN NATURAL}

La iluminación de las fábricas depende básicamente, tal y como se ha ido comentando a lo largo de este estudio, de:

a) Las dimensiones de los elementos de la estructura, de forma que se puede reducir o ampliar la superficie de entrada de luz al interior de las fábricas. O sea, de la envolvente y de la capacidad estructural del edificio.

De hecho, según Biggs, (Biggs, 1996), "se diseñaron los edificios atendiendo a la máxima posibilidad de luz natural, puesto que en edificios anchos, el centro quedaba poco iluminado. El promedio (siglo XIX) estaba en unos 30 pies [algo más de $9 \mathrm{~m}$ ], y la longitud dependía de la producción". Termina esta idea confirmando que los espesos muros complicaban el problema de la iluminación.

b) El tamaño y el espacio de la maquinaria y su distribución en el espacio de producción. Lo que ahora se entiende por layout, venía siempre fijado por la cantidad de luz recibida en los puntos de trabajo.

Según Banham (Banham, 1989), la iluminación en cada puesto de trabajo individual podía aumentar rebajando al mínimo el número de ejes de transmisión, "con el mejor de los casos a un único eje principal", lo que inevitablemente llevaba también a la construcción de edificios alargados. 
A continuación se amplían estos 2 párrafos:

\section{a) Las dimensiones de los elementos de la estructura:}

Hasta finales del siglo XVIII, los gruesos muros de mampostería y las grandes escuadrías de las vigas de madera usuales en las fábricas dificultaban la resolución del problema de la distribución de la iluminación solar, puesto que su sistema constructivo era necesariamente a base de gruesos muros portantes: por ejemplo, tanto desde la Lombe's Mill, terminada en 1722, hasta la Ditherington Mill, de 1796: las cuatro primeras fábricas del estudio se construyeron con estructuras murarias [Figura 202]:

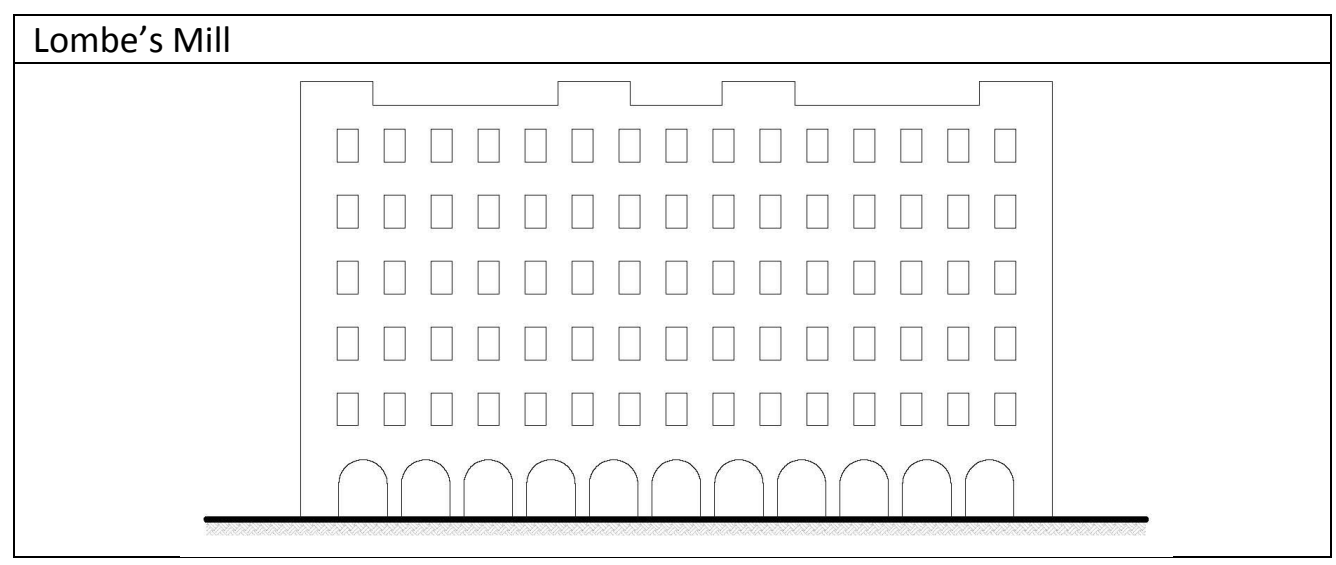

Figura 201. Edificios con fachada de fábrica, de 1722 a 1796. 


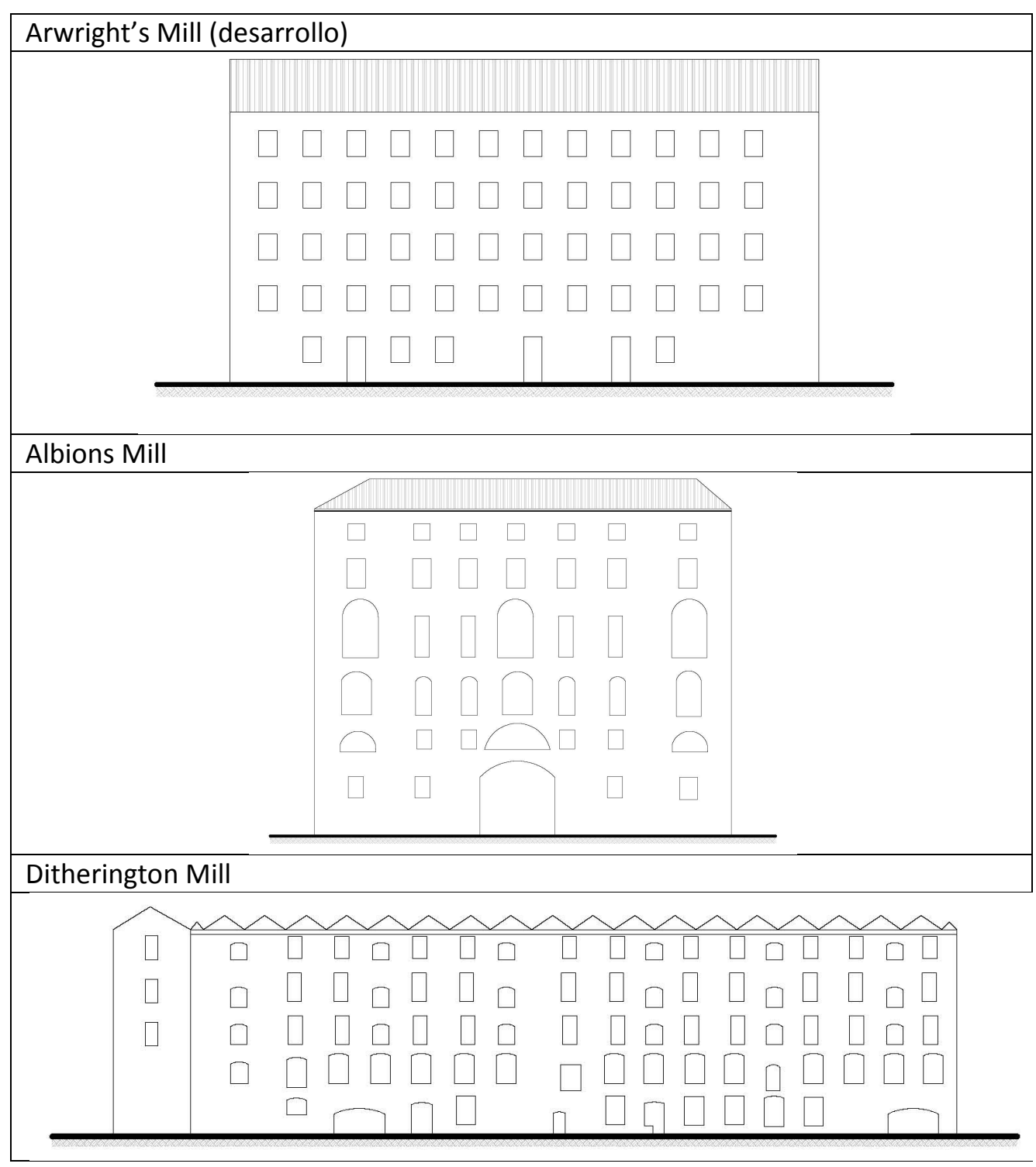

Figura 202 (cont.). Edificios con fachada de fábrica, de 1722 a 1796. 
No es hasta los primeros años del siglo XIX, con la introducción del hierro fundido para los soportes y vigas, que se permitió una mayor diafanidad en el interior de los edificios, que se tradujo en huecos mayores en fachadas y en la cubierta. Este es el caso de las fábricas Strutt's North Mill, de 1804, Marshall's Temple, de 1842, y Boat Store, de 1858 [Figura 204]:

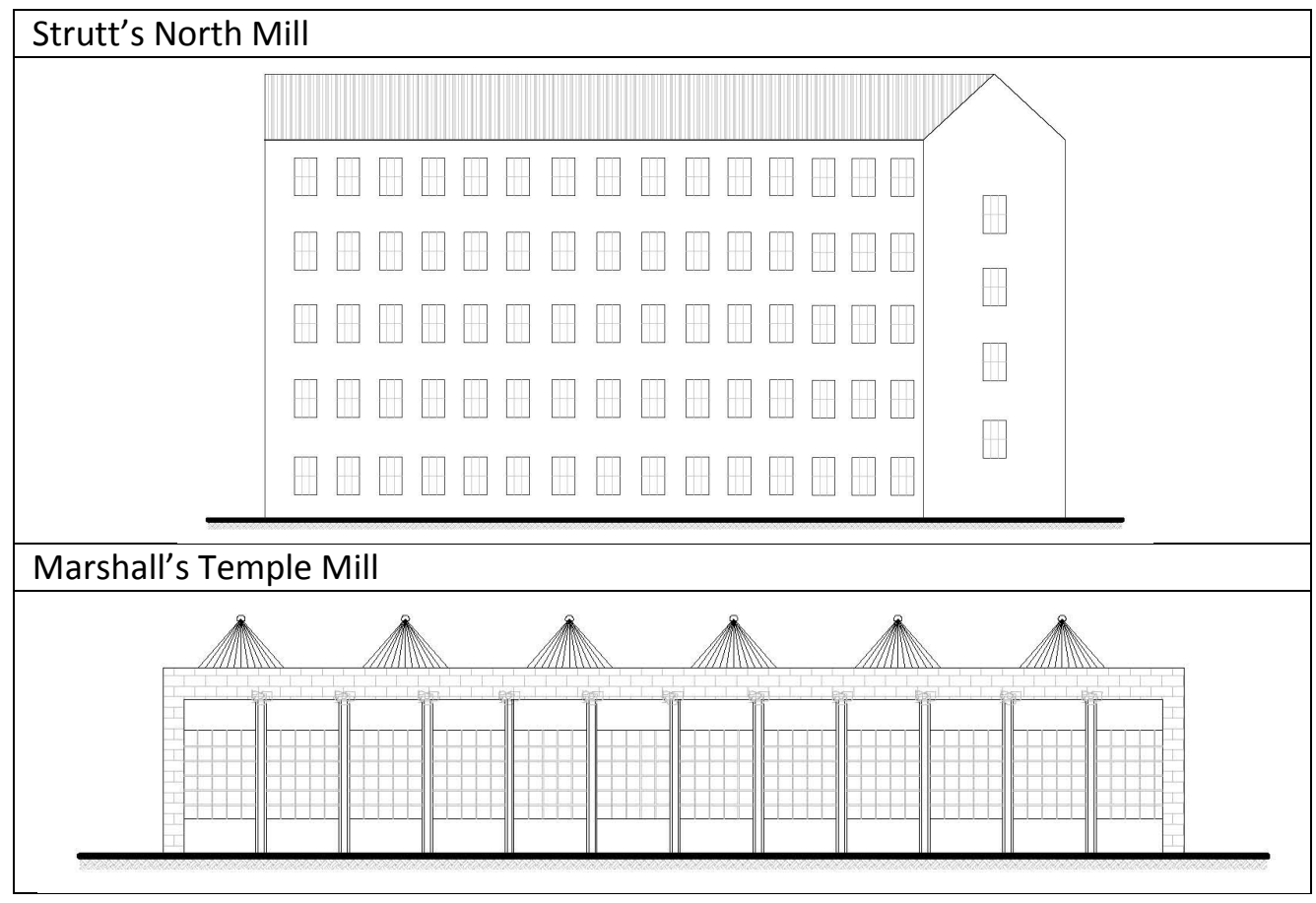

Figura 203. Fábricas con fachadas diáfanas, de principios de siglo XIX hasta principios del XX. 


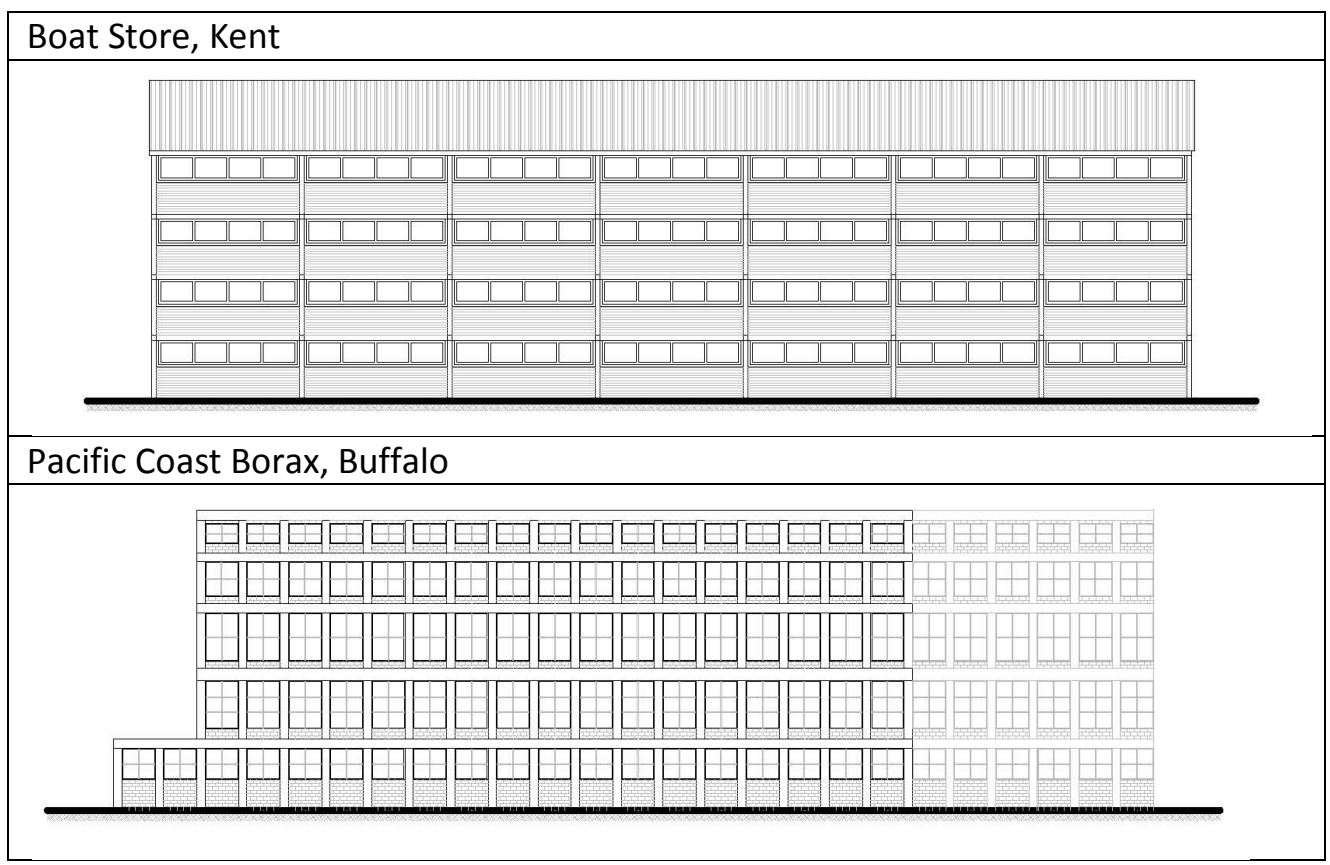

Figura 204 (cont.). Fábricas con fachadas diáfanas, de principios de siglo XIX hasta principios del XX. 


\section{b) La maquinaria en el interior del edificio:}

La forma que adoptaban los mill buildings respondía directamente, en la medida que se les permitía: a las transformaciones de su maquinaria, a las de las fuentes de energía y a las de la tecnología constructiva, si bien, tanto la altura como la longitud estaban limitadas inicialmente, entre otras, aunque de forma muy clara, por la resistencia a la torsión de los ejes de transmisión de madera ${ }^{285}$ \{confrontar edificios en apartado 3.4\}. Referente a la primera condición, la instalación de la maquinaria cerca de las ventanas para el mejor aprovechamiento de la luz solar, y el conjunto de su disposición, las obligaba a tener la máxima superficie que fuera posible.

Una vez vistos estos dos requisitos, el de la estructura y el de la disposición de la maquinaria, y analizando las fábricas estudiadas \{apartado 3.2\}, se ha podido observar que el porcentaje de hueco en fachada ha ido en aumento, principalmente debido a la libertad dimensional que aportaba el uso y el conocimiento de aquellos materiales que resultaban más resistentes con una menor sección.

Así se deduce que es a partir de más o menos 1820, cuando las superficies de ventana se habían incrementado a un $30 \%$ de la superficie total de la fachada, por los avances en los sistemas constructivos y en los materiales empleados, como por ejemplo, con la incorporación del hierro fundido ${ }^{286}$ [Figura 205]:

\footnotetext{
${ }^{285}$ Es totalmente cierto que la ubicación del punto de accionamiento hidráulico o térmico en el centro del edificio permitía incrementar estas longitudes, si bien, la resistencia de los materiales de los árboles de transmisión, de alguna manera, siempre las limitaban.

286 Alrededor de 1850, la sustitución del hierro forjado por fundición permitió incluso mayor aumento en longitud y altura \{confrontar el factor materiales en apartado 3.5\}. Un cambio importante en la estructura ya había ocurrido, incluso 70 años antes, al final del siglo XVIII cuando en la Albion's Mill, de Londres, el hierro forjado reemplazó a la madera en los ejes y mecanismos. De esta manera, los árboles de distribución y los edificios incrementaron su longitud hasta los $100 \mathrm{~m}$, aunque todavía sin un ensanchamiento suficiente (Darley, 2010).
} 


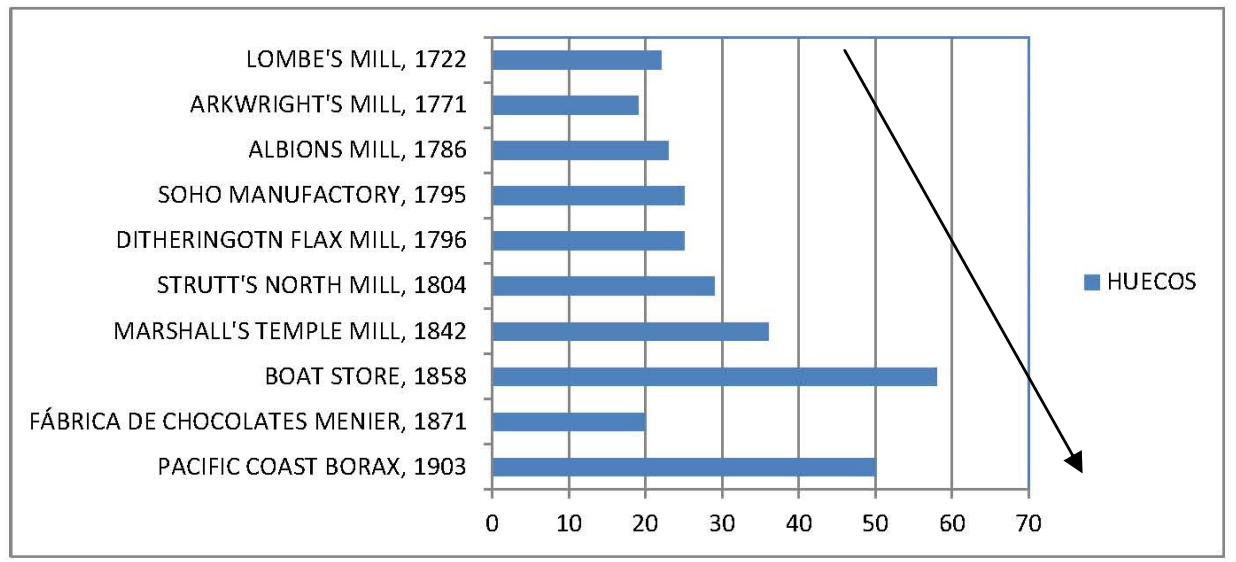

Figura 205. Esquema de la evolución del porcentaje de huecos en los distintos edificios estudiados.

Si la longitud de las fábricas textiles por pisos estaba limitada por los ejes de transmisión, en cuanto a la anchura, tal y como se sostiene en todo este estudio, estuvo condicionada principalmente por la entrada de luz natural. Darley (Darley, 2010) valida una teoría que indica que el ancho mínimo aconsejable para conseguir la máxima iluminación se obtiene bajo un ángulo de entrada de la luz solar de 20 grados desde la fachada. Así, para lograr la máxima cantidad de luz en el interior, solo cabía un incremento de la altura libre entre plantas, ya que la anchura del edificio estaba fuertemente limitada por la luz admisible de las vigas. Este era el único modo en el que la superficie de los ventanales fuera el máximo [Figura 206].

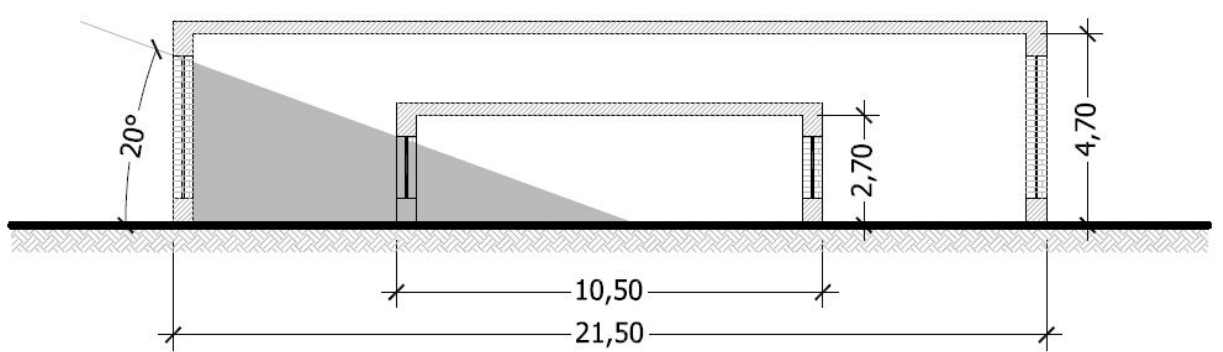

Figura 206. Esquema sección de una fábrica para valorar la entrada de luz natural, bajo un ángulo de 20ㅇ (Darley, 2010). 
De esta teoría se deduce el aspecto tan característico de los "mills" a lo largo de todo el siglo XIX, prevaleciendo sus dimensiones de altura y longitud, frente a la de anchura.

\section{UNA PLANTA VERSUS VARIAS PLANTAS:}

Algunos ingenieros de principios de siglo XX se plantearon la discusión sobre la funcionalidad de una fábrica de una única planta o de varias plantas. Ello estaba íntimamente relacionado con la iluminación natural que alcanzaba el interior de los edificios. Hubo bastantes posiciones que defendían las ventajas del primer tipo de fábrica frente al segundo. Para ello, se centraban en la eficacia a la hora de controlar más fácilmente la actividad de toda la planta en su totalidad. No obstante, la mayoría de las fábricas construidas antes de la segunda década del siglo XX eran las de 'multiple-storey' que, tal y como se acaba de mencionar, era debido a las posibilidades que ofrecían a la entrada de luz por las fachadas. Valgan como ejemplo, en EEUU, los productores de herramientas para maquinaria, armas, ropa, textil, zapatos, etc, que se decantaron por la construcción de edificios de múltiples plantas bien iluminados. Sólo para trabajos pesados, como el caso de fundiciones, industria automovilística, del acero, gran maquinaria y forja se construyeron grandes superficies con una planta única.

En el caso europeo, en el periodo estudiado en esta tesis, todas las fábricas son de varias plantas a excepción de la Marshall Temple Mill, la cual solo tiene una única planta, aunque de una gran superficie.

Pero aparte de esta dualidad, destaca una fábrica con una sección peculiar, la Boat Store, de principios de la segunda mitad del XIX, pues tiene una nave central de una única planta y gran altura, con dos naves adyacentes simétricamente con múltiples plantas [Figura 207]. Este almacén de barcos no solo destaca pues por su novedad en la utilización de materiales para la construcción, y en la combinación de una y varias plantas en un mismo espacio, sino también por la forma de iluminar, aportaciones que lo hacen merecedor de una gran 
consideración en esta tesis. Como se aprecia en esta Figura 207 la forma de iluminar sendos espacios es bastante diferente:
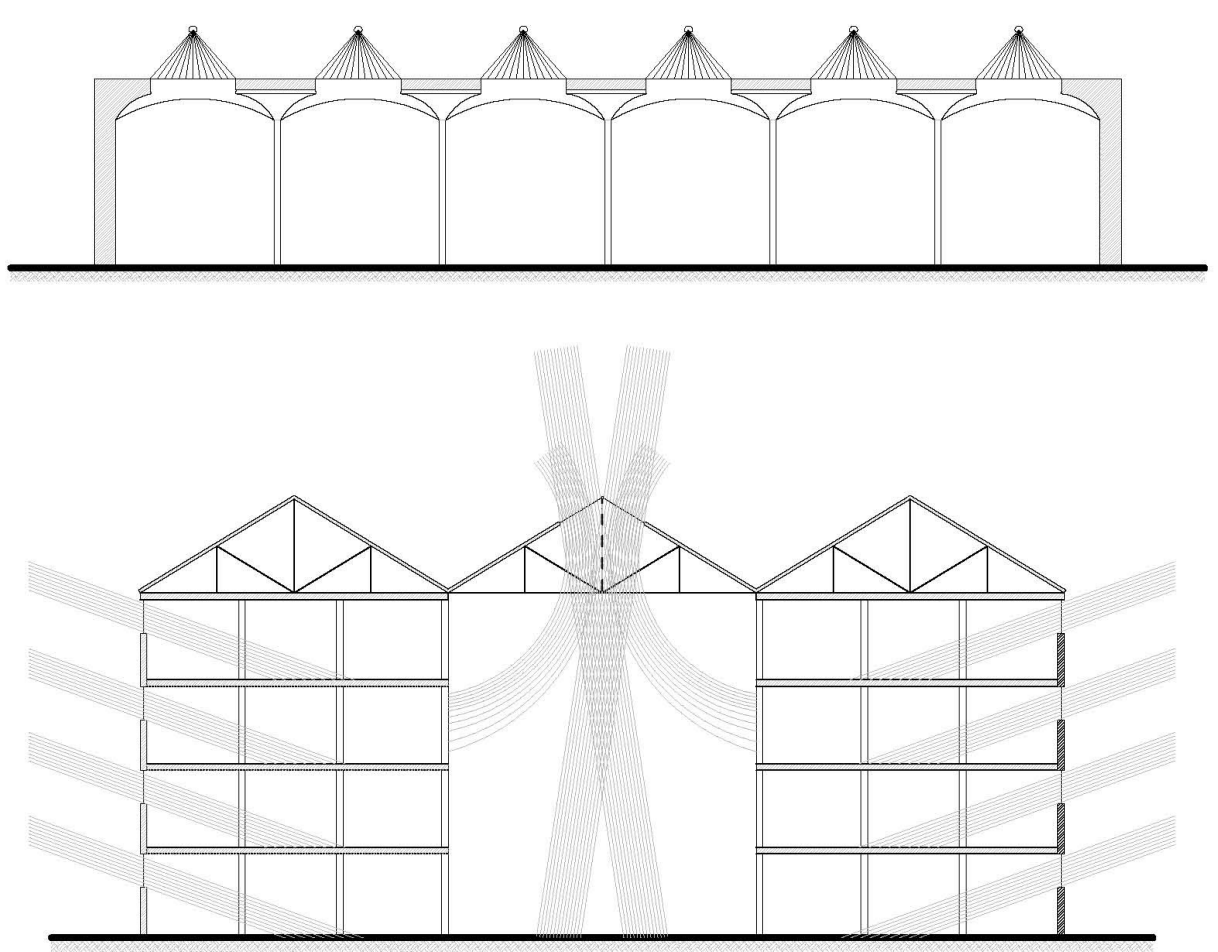

Figura 207. Diferentes secciones de las fábricas: la Marshall y la Boat Store, ambas de principios de la $2{ }^{a}$ mitad del siglo XIX.

Esta reflexión anterior conduce al siguiente tema: las cubiertas.

\section{CUBIERTAS}

Habitualmente, la luz de los espacios fabriles se cubría con cerchas triangulares, que como se ha venido comentando, primeramente eran a base de madera y posteriormente metálicas. De este modo, a principios del siglo XIX, la iluminación 
se conseguía exclusivamente desde los cerramientos de fachada y/o de forma cenital (como es el caso de la Marshall, de la segunda mitad del XIX, en apartado 3.2.8) [Estado 33 de la Figura 208].

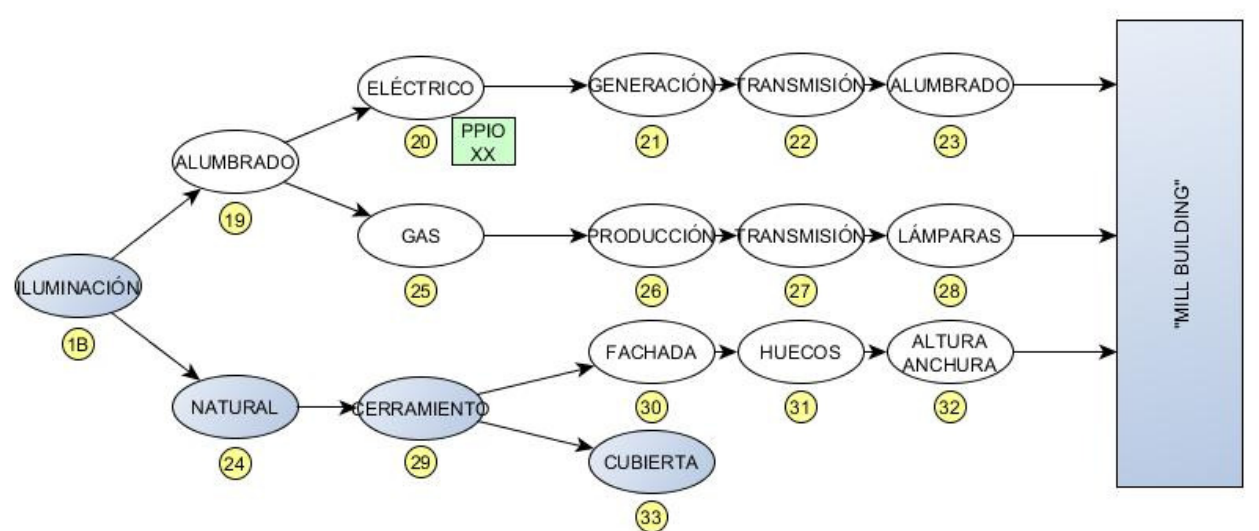

Figura 208. Mapa conceptual para la valoración de la evolución de la estructura de cubierta de los "mill buildings" para iluminación cenital.

La iluminación cenital en cubiertas a dos aguas con estructura de madera y tejas, resultaba difícil de conseguir, por el inconveniente de conseguir la estanqueidad, y de ahí que las primeras 5 fábricas estudiadas: Lombe (1722), Arwright (1771), Albion (1786), Ditherington (1796) y Soho Manufactory (1795), sólo se iluminaran desde las fachadas, y por supuesto, por medio de velas como iluminación $\operatorname{artificial}^{287}$.

No obstante, a partir de la introducción del hierro en las estructuras de cubrición, la aparición de materiales traslúcidos y las mejoras en la estanqueidad de la construcción, se posibilita la apertura de huecos en las cubiertas. Así por ejemplo,

\footnotetext{
${ }^{287}$ Existe una excepción particular en la Albion's Mill, en donde las escaleras se iluminaron con una claraboya, lo cual, en cierto modo resulta sorprendente dada la época de su construcción \{Apartado 3.2.3\}.
} 
la Boat Store (1858) abre un gran hueco en la nave central cerca de la cumbrera, recorriendo toda la longitud de la misma [Figura 207].

Sin embargo, dieciséis años antes de la construcción de esta cubierta, en la Marshall Temple (1842) en el West Yorkshire, y con materiales más tradicionales, se construyen lucernarios en forma de pirámides de base octogonal para iluminar, con la entrada de una cantidad de luz considerable [Figura 207].

Existe un ejemplo de fábrica en España con iluminación cenital peculiar que merece la pena destacar en este apartado. Se trata de la Real Fábrica de Cañones de Sevilla, de principios de siglo XIX. Según Sobrino (Sobrino, 1998), y a diferencia de la tendencia habitual en el ámbito nacional, la iluminación por la cubierta de la Real Fábrica de Cañones de Sevilla se adelanta a los posteriores dientes de sierra $^{288}$.

Como se puede ver en las fotografías, sus elevadas cúpulas abovedadas se levantaban sobre grandes pilares cruciformes en ladrillo, de forma que la ampliación del edificio podía ser posible anticipándose al concepto de flexibilidad, tan deseado por los constructores de la Revolución Industrial, que veían como la producción aumentaba demandando cada vez más espacio.

\footnotetext{
${ }^{288}$ El origen de la Real Fundición de Cañones se sitúa en torno al año 1565 en el Barrio de San Bernardo de Sevilla, junto a la Iglesia del mismo nombre, con el primer taller de fundición del Giraldillo. De aquella primera construcción no quedan restos en superficie, ya que a partir de 1720 las demoliciones fueron constantes hasta conseguir la fábrica actual, con su estructura a base de cuadrículas, la cual fue iniciada con los trabajos de Próspero Verboom (Amberes, 1667 - Barcelona, 1744), noble e ingeniero militar español de origen flamenco, fundador del Real Cuerpo de Ingenieros.
} 

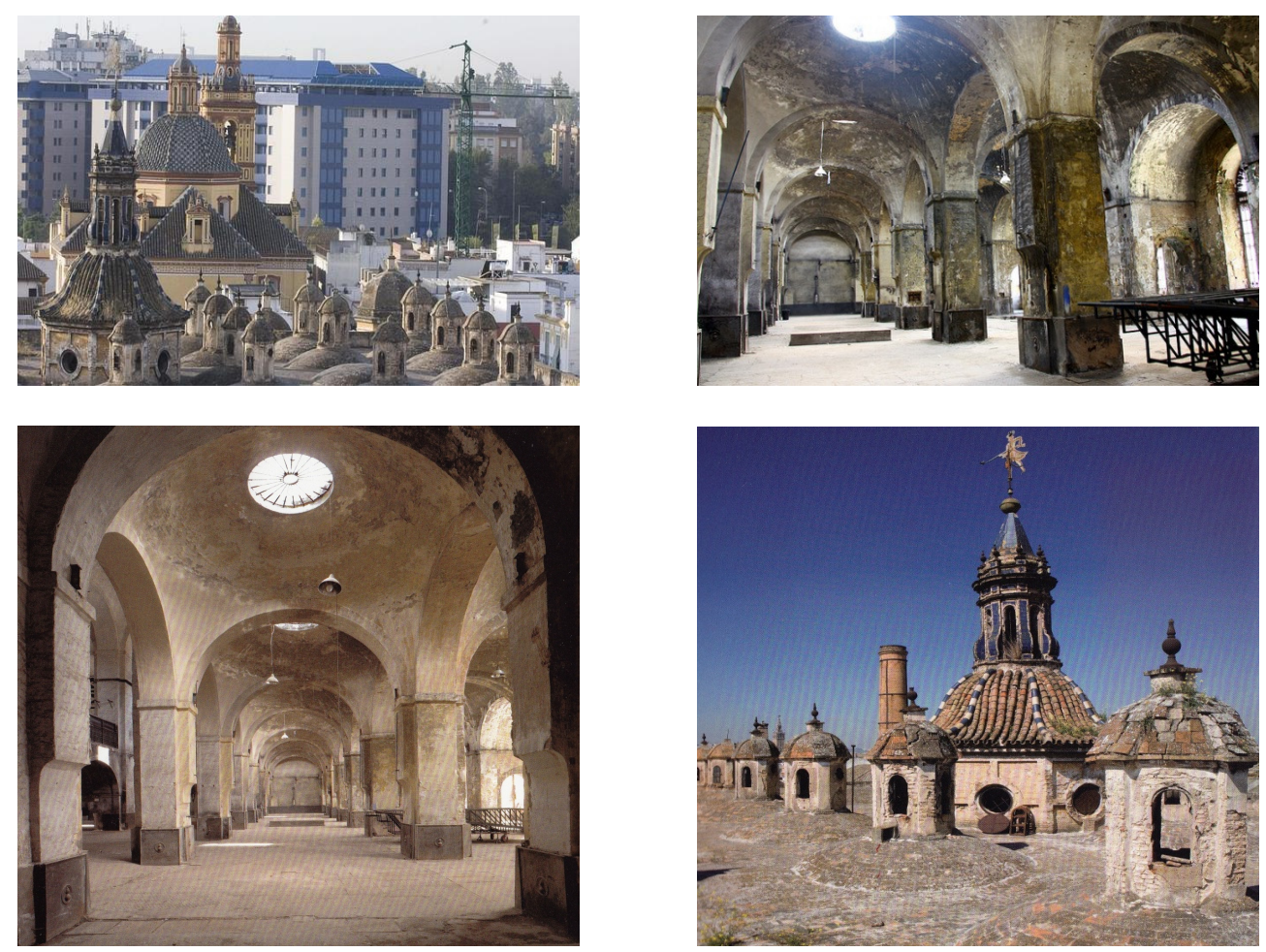

Figura 209. Fábrica Real de Fundición de Cañones de Sevilla, en el Barrio de San Bernardo, de principios del siglo XVIII. Vista de su cubierta (https://www.google.es/maps).

Esta manufactura se describe como una nave, en su mayoría de una sola planta, con un conjunto de pilares dispuestos en retícula sobre los que descansaban las bóvedas de cubierta [Figura 209]. Desde principios del siglo XIX (Aguilar, 1981), a través de esta solución se resolvía también la posibilidad de ampliar lateralmente las naves, sin perder opciones de iluminación y ventilación, imposible en los edificios alargados a dos aguas típicos hasta el momento [Figura 210]. 


\begin{tabular}{|c|c|c|c|c|c|}
\hline 敛 & 战 & 徏 & ) & 㗒 & 綵 \\
\hline 踥 & W & W & 步 & 织 & W \\
\hline 战 & 釈 & 敛 & 㗭 & 的 & W \\
\hline 此 & 䋇 & 踩 & W & 䊝 & W \\
\hline 的 & 步 & 粰 & 焉 & 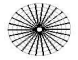 & Wh \\
\hline 彭 & W & W & W & 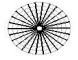 & W \\
\hline 跑 & $\mathbb{W}$ & W & 战 & 步信 & W \\
\hline 步 & W & W & W & 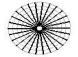 & W \\
\hline 包 & 楼 & W & 步 & 踥 & 跑 \\
\hline 1 & 楼 & W & 音 & 数 & W \\
\hline 橴 & 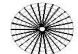 & 涉 & 步 & 新 & W \\
\hline
\end{tabular}

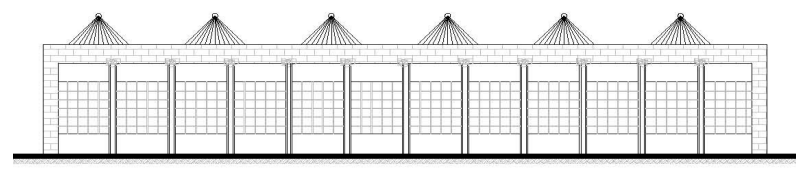

Figura 210. Marshall's Temple Mill, $2^{a}$ mitad del siglo XIX. Proporción estimada entre la altura y la superficie ocupada por su única planta. 


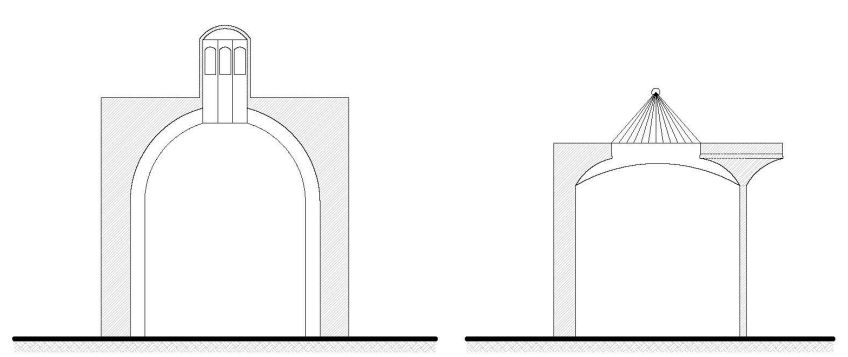

Figura 211. Comparación entre la iluminación cenital de la Fábrica Real de Fundición de Cañones de Sevilla y la Marshall's Temple Mill.

\section{LOS SAW-TOOTH ROOF, SHED O DIENTES DE SIERRA}

Siguiendo con la cubierta, de las diferentes tipologías de fábricas que han surgido atendiendo principalmente a la influencia del factor iluminación, se puede considerar como la que en mayor medida repercutió sobre esta la llamada de tipo shed. Los saw-tooth roof, o cubiertas en diente de sierra, son aquellas que constan de una serie repetida equidistantemente de tramos con la misma forma compuestos de un lado en pendiente y otra parte generalmente en vertical con cerramiento de cristal orientado normalmente al norte ${ }^{289}$ para evitar el deslumbramiento, y obteniendo una iluminación cenital uniforme. Por su parte, las caras en pendiente suelen ser opacas, para proteger a los trabajadores y a la maquinaria de la proyección directa de los rayos del sol [Figura 212 y Figura 213].

${ }^{289}$ En el Hemisferio norte. Orientadas al sur en el Hemisferio Sur. 


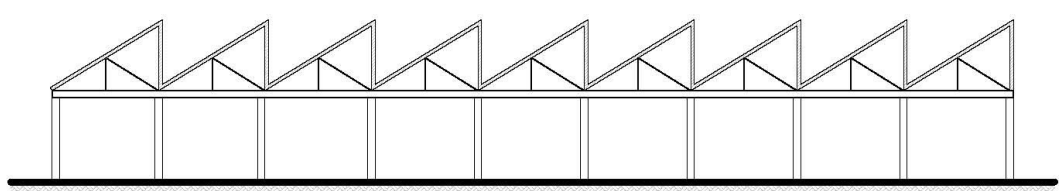

Figura 212. Fábrica de una planta con cubierta de tipo diente de sierra, para posibilitar la entrada de la mayor cantidad posible de luz natural.

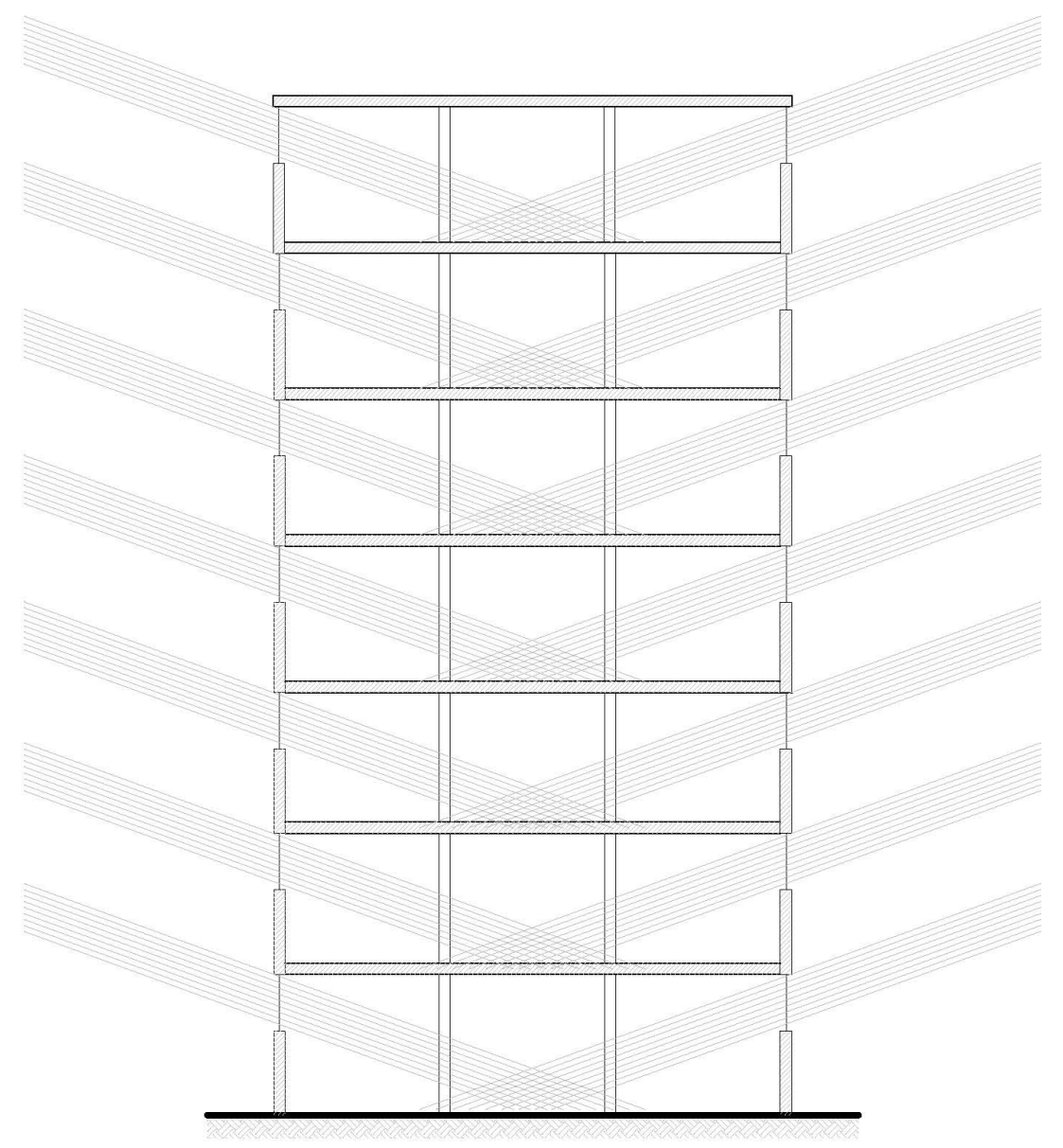

Figura 213. Fábrica de varias plantas con entrada de la luz natural que le permite su fachada, según el esquema de la Figura 206. 
William Fairbairn (Fairbairn, 1857) ya acuñó el término "shed principle" para este tipo de cubiertas (ya existentes) antes de 1825, diseñando ese mismo año una de estas para la ya mencionada New Mill, en Bradford [Figura 139].

A lo largo del siglo XIX este tipo de estructuras para cubierta fue evolucionando estructuralmente, sobre todo en lo que respecta a la eliminación de los pilares intermedios donde apoyaba cada valle de la viga. Ello fue posible gracias exclusivamente a la aparición del hierro fundido para los soportes y el forjado para conformar cerchas de gran altura y más ligeras, lo que se traduce en un escalón más hacia la consecución de la fábrica diáfana (Letkemann, 2000).

Los espacios fabriles con este tipo de cubiertas solían disponer de una única planta, lo que en cierto modo abarató también las pólizas de los seguros de incendios, tal y como Edward Atkinson ${ }^{290}$, un relevante activista político de finales del siglo XIX a favor de la prevención del incendio en la industria textil americana, aseguró en 1879 en la Revista "The Architect and de Building News" (Cruz, 2013).

Por su parte, también se puede encontrar en la bibliografía al ingeniero de principios del siglo XX Horace Arnold ${ }^{291}$ (Arnold, 1919), que con referencia a las cubiertas "saw roof" en la revista "New York: The Engineering magazine company", ya aseveró con contundencia que "nadie que nunca haya visto un espacio de trabajo con cubiertas a base de diente de sierra puede tener una idea real del efecto de la abundante iluminación que asegura".

Asimismo, en estos edificios característicamente fabriles, de una sola planta, y con maquinaria a la que la electricidad (primeras décadas del siglo XX) le había posibilitado mayores cargas de trabajo y a mayores velocidades, las vibraciones

\footnotetext{
290 Edward Atkinson (1827 - 1905) fue un economista Americano, de la Liga Antiimperialista, activamente dedicado, entre otros, a la prevención contra el fuego en las manufacturas de algodón.

${ }^{291}$ Horace Lucian Arnold (1838-1915) fue un ingeniero Americano, inventor y periodista especializado en ingeniería, que fundó las bases de la moderna dirección y gestión de la producción en las empresas, sus costes y otras técnicas específicas de la organización industrial.
} 
podían ser absorbidas mejor que en los edificios en altura. De hecho, los primeros ejemplos de este tipo se asociaron a la industria textil, tanto en América como en los países más industrializados de Europa.

Eso sí, este tipo de cubiertas tenía una serie de problemas, como una construcción más compleja que una cubierta a 2 ó 4 aguas, pero sobre todo, muchos problemas de humedad, por la mayor dificultad de conseguir la estanqueidad. Con ello, por su dificultad estructural, Bradley (Bradley, 1999) las valora como entre 40 y $60 \%$ más caras.

Por último, otro ejemplo muy característico de principios del XX que resulta representativo de la iluminación cenital a base de cubiertas inclinadas orientadas al Norte, que aunque no se trata propiamente de una estructura de diente de sierra, lleva una idea más elaborada de ello, es el de El Vapor Aymerich, Amat i Jover ${ }^{292}$, en Terrassa (Barcelona), de 1907 [Figura 214]. Se trataría de una trasposición de los dientes de sierra a la fábrica modernista, con cubierta de bóveda tabicada catalana para la formación de linternas que permite la entrada abundante de luz natural. El edificio es uno de los principales ejemplos de la arquitectura modernista de Cataluña, siendo diseñado por el arquitecto Lluís Muncunill, y construido entre 1907 y 1908.

\footnotetext{
${ }^{292}$ La denominación de vapor se debe al hecho que la fábrica utilizaba el vapor de agua como fuerza para accionamiento de las máquinas.
} 

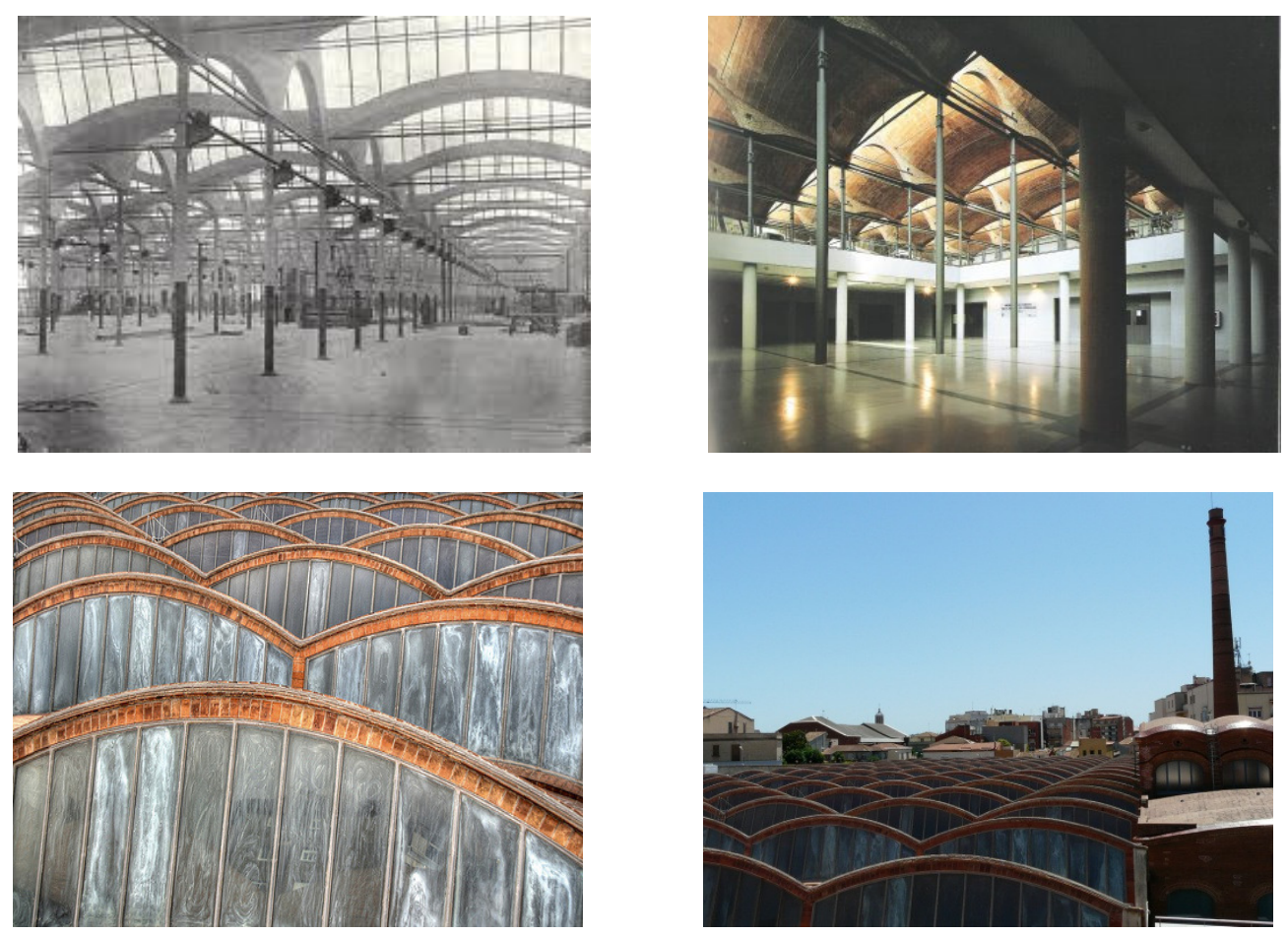

Figura 214. El Vapor Aymerich, Amat i Jover, actualmente sede del Museo de la Ciencia y de la Técnica de Tarrasa (http://es.wikipedia.org/wiki/Museo_de_la_Ciencia).

Así como el de la Filature de la Rodoute, en Roubaix, en el norte de Francia, de 1913 [Figura 215]: 

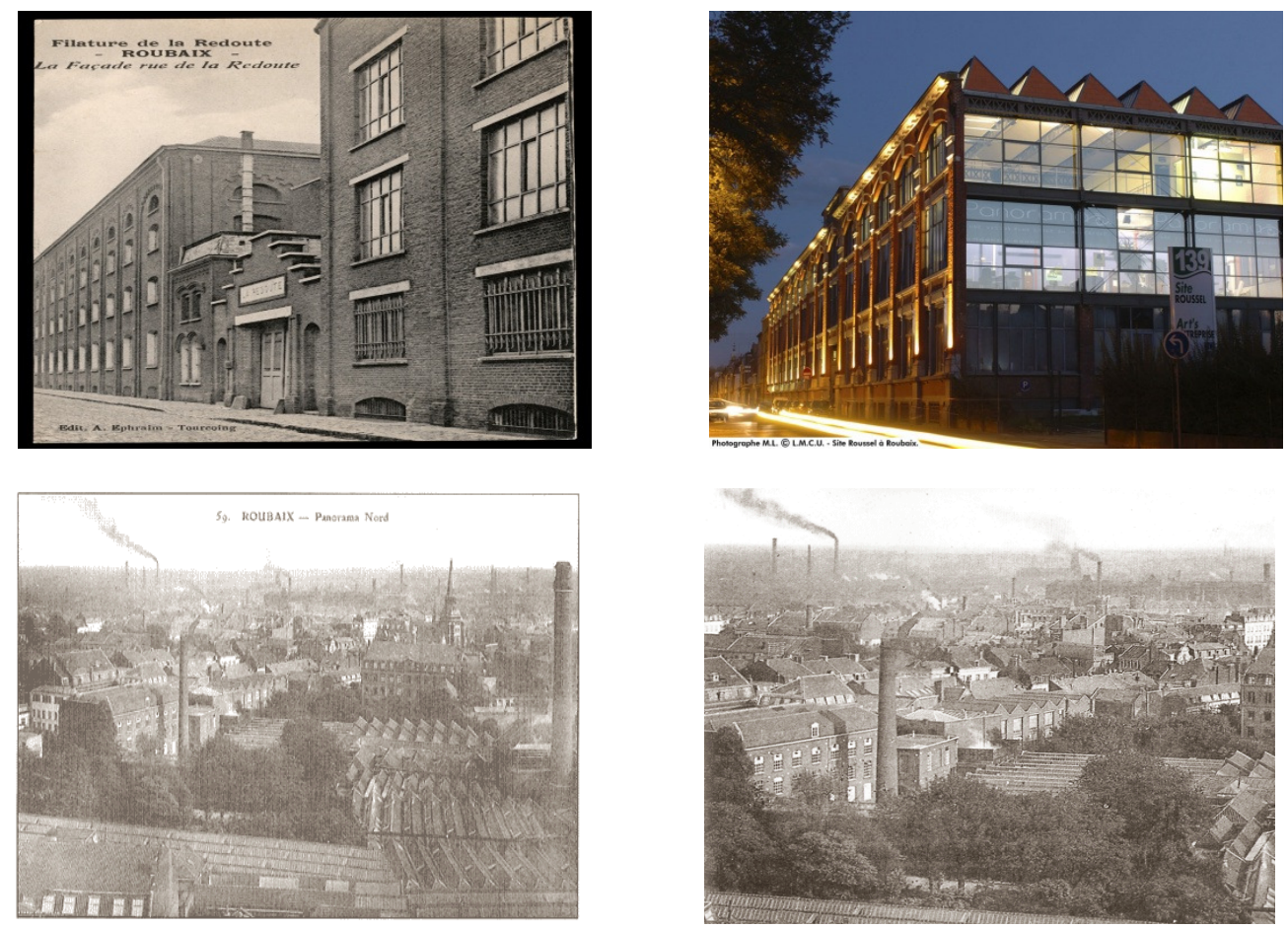

Figura 215. Filature de la Rodoute en Roubaix, con sus numerosas fábricas de la segunda década del siglo XX con cubiertas de tipo "shed" (http://es.wikipedia.org/wiki/Roubaix).

\section{LA ILUMINACIÓN EN LAS FÁBRICAS EN EL PANORAMA INTERNACIONAL}

La mejora en la iluminación de las fábricas fue tomada en consideración por los propietarios de las fábricas desde los primeros edificios en altura, allá por finales del siglo XVIII. Pero ello fue especialmente requerido a partir de la segunda mitad del XIX principalmente por la masa obrera deseosa de alcanzar sus derechos laborales. Según Biggs (Biggs, 1996), el "Industrial Betterment Movement and Welfare Capitalism" fue un movimiento obrero que comenzó a finales de la década de 1880 y permaneció muy activo hasta el final de la Gran Depresión, en 
los años anteriores a la Segunda Guerra Mundial ${ }^{293}$. Aparte de reclamar derechos como vivienda, escuelas, iglesias y hospitales, demandas que podían resultar genéricas, también exigían mejoras en las condiciones laborales, calefacción, ventilación e iluminación en el puesto de trabajo, lo que de forma directa, aseguraban sus demandantes, traería directamente un mejor rendimiento en la producción y un incremento de la adaptación de los trabajadores. Pero todo ello tenía una limitación exclusivamente técnica: mientras los materiales no pudieran liberar las fachadas de su condición de muro de carga, no se podrían alcanzarían sus exigencias.

Como paradigma de la iluminación natural en las fábricas del siglo $\mathrm{XX}$, aunque realmente fuera del periodo estudiado en el Capítulo 3, se considera oportuno incluir unos edificios fabriles que representan ejemplarmente la fábrica diáfana perfectamente iluminada de forma natural. De hecho, estos lograron indiscutiblemente la calificación de hitos en la historia de la arquitectura a nivel internacional, en la mayoría de la bibliografía de la arquitectura industrial.

En primer lugar, la fábrica de turbinas de la AEG en Berlín, que es el edificio "más famoso" (Osuna, 1997) del arquitecto Peter Behrens ${ }^{294}$. Construida entre 1908 y 1909, fue uno de los primeros en participar en el llamado Movimiento Moderno. Desde el exterior refleja una gran solidez, por su tamaño y por su fachada en piedra artificial en piezas grandes, además de por sus inmesos ventanales cuya misión principal era, precisamente, la de proporcionar una intensa iluminación interior perfectamente distribuida.

Construida en hormigón y acero, la nave de montaje tiene 27,50 m de ancho por $123 \mathrm{~m}$ de largo (si bien fue ampliada posteriormente), y la cubierta tiene forma de arco formado por seis segmentos planos, de los cuales, los dos centrales, a lo

\footnotetext{
${ }^{293}$ Estos programas de bienestar laboral sufrieron las consecuencias de la Gran Depresión, cuando la tasa de desempleo aumentó de forma exponencial y la falta de financiación de las empresas.

${ }^{294}$ Peter Behrens, 1868 - 1940.
} 
largo de toda la nave, son un lucernario que asegura la iluminación interior para trabajar.

Este edificio refleja la potencia de la industria alemana de principios de siglo, con una imagen intencionadamente sencilla sin ornamentación (Sebastià, 2007). La iluminación conseguida por Behrens en su interior la convierte en prototipo de "fábrica diáfana bien iluminada" (Banham, 1989). Servirá de modelo para muchos de los incipientes empresarios que querían demostrar ante todo la fuerza empresarial de su marca [Figura 216].

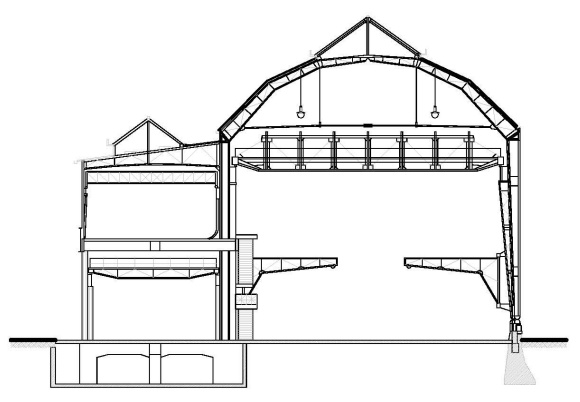

Figura 216. Fábrica AEG, sección.

Otro extraordinario ejemplo de iluminación natural en el interior de espacios fabriles dentro del conocido como Movimiento Moderno es la fábrica de hormas de zapatos Fagus, del arquitecto Walter Gropius ${ }^{295}$ [Figura 217].

\footnotetext{
${ }^{295}$ Fue acabada en 1914 en la localidad alemana de Alfeld an der Leine. Se levantó en una población rural, lejos de ninguna ciudad importante, y a excepción de la imponente chimenea, todos los elementos se ubicaban al mismo nivel. El exterior está construido con tan solo dos materiales: ladrillo y metal, siendo el más famoso de sus pabellones un bloque acristalado, el cual aparece en una amplia bibliografía y es referenciado en muchos manuales de arquitectura del siglo XX.
} 


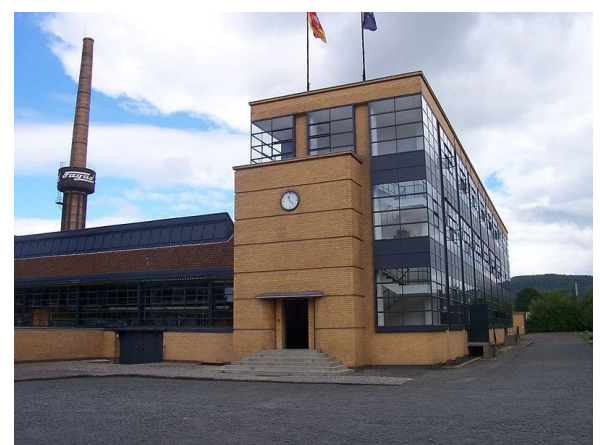

Figura 217. Fábrica Fagus de Walter Gropius (Darley, 2010).

Los ventanales de Fagus son por sí mismos un precedente de los muros-cortina tan extensamente empleados en las construcciones del siglo XX. Evidentemente, proporcionan una enorme luminosidad natural interior, además de contribuir a difuminar los límites entre interior y exterior para sus ocupantes. 


\section{LA INDUSTRIA VALENCIANA}

\subsection{LA DICOTOMÍA INDUSTRIA-AGRICULTURA}

Desde el interés por la cultura, la economía, la arquitectura y la industria valenciana, se comprueba sin dificultad que existe una amplia bibliografía que trata en profundidad cada uno de estos campos. No es difícil encontrar en las bibliotecas universitarias abundantes libros, artículos y revistas de referencia que aportan información y documentación científica de aspectos muy concretos, y al mismo tiempo muy interesantes, para el trabajo del investigador atraído por el estudio de la historiografía local.

Por otro lado, es totalmente cierto que tradicionalmente el modelo social valenciano ha sido constantemente debatido entre muchos sectores de la 
población, y desde puntos de vista bien distintos: político, social, círculos familiares, amistosos, laborales, estudiantiles, etc. La idiosincrasia valenciana, reflejada en la literatura y en la cultura, ha sido siempre un tema de controversia por la dificultad que entraña la caracterización de un pueblo que, entre otros problemas, ha sufrido las dificultades económicas afines a su condición mayoritariamente agrícola (Cucó, 1978). E incluso su progreso industrial siempre ha sido puesto en tela de juicio, entre otros motivos, por la carencia de una burguesía fuerte con intereses económicos más allá del sector agrario (Garrabau, 1985).

Pero pese a ese modelo de "no industrialización", rebatido por nutridos estudios con mayor rigor científico, existen líneas de investigación que aportan modelos teóricos que explican perfectamente la economía valenciana en el periodo de estudio: los siglos XVIII, XIX y principios del XX (Fabra, 2000).

En esta última afirmación se fundamenta la justificación de esta tesis doctoral: el estudio de los "mill buildings" valencianos. Para ello, se opta por la comparación de estos con aquellos que dieron origen a la revolución industrial a nivel mundial, principalmente en Inglaterra a finales del siglo XVIII.

En cuanto a la industria valenciana también, por tratarse de un campo nada despreciable, multitud de investigadores han tratado este tema (Vidal Vidal, Olcina Lloréns, Aguilar Civera, Cano, etc), pero se echa en falta, desde un punto de vista igualmente científico, mayor cantidad de referencias académicas sobre sus edificios fabriles, no solo considerando su perfil histórico, sino un punto de vista más técnico. 


\section{EL MODELO DE NO INDUSTRIALIZACIÓN VALENCIANO}

El modelo valenciano de no industrialización, referenciado a la historia económica del siglo XVIII y XIX, se basa en dos principales supuestos (Sánchez, 2009):

1. No hubo revolución industrial.

2. No hubo burguesía transformadora.

Estas ausencias se han puesto en entredicho en algunas investigaciones que es importante reflejar aquí. Una línea historiográfica, nacida a principios de los años 80 del pasado siglo, acepta la primera de ellas, pero empieza a contradecir la segunda. Esta tesis se acerca a ella para describir si efectivamente existieron inversores más allá de la agricultura, que emplearan su capital en espacios fabriles para la producción. Para ello, en primer lugar se examinará de una manera rápida la economía valenciana de estos dos siglos.

En el paso del Antiguo Régimen ${ }^{296}$ al capitalismo surge una nueva clase social, que principalmente está ligada al capital comercial y agrario (Torró, 1994). En el caso valenciano, esta se encuentra principalmente en la ciudad de Valencia, si bien,

\footnotetext{
${ }^{296}$ El Antiguo Régimen es un sistema político, social y económico por el cual una minoría privilegiada (nobleza y clero) ostenta todos los cargos públicos y no paga impuestos, mientras que la inmensa mayoría de la población (el tercer estado) paga los impuestos y no goza de ningún tipo de privilegio. En lo político se dan las monarquías absolutas, el rey tiene un poder absoluto aunque en el siglo XVIII esté influido por las ideas de la llustración (despotismo ilustrado) y sólo busque el bienestar de sus súbditos. En lo económico la burguesía es el verdadero motor de la economía, tiene el poder económico, pero aspirará a tener el poder político, y eso sólo se puede conseguir por la fuerza (revolución) (http://es.wikipedia.org).

El Antiguo Régimen se da en Europa durante la Edad Moderna, es decir, en los siglos XVI, XVII y XVIII. Durante estos tres siglos todavía perviven, sobre todo en lo social y económico, muchos rasgos propios de la Edad Media. Su fin llegará con las revoluciones liberales o burguesas y con la revolución industrial, y tras él se inicia el régimen liberal y la Edad Contemporánea.
} 
mantenía unas excelentes relaciones con el resto del territorio, sobre todo, con los que poseían tierras agrícolas ${ }^{297}$.

Es interesante también valorar los distintos puntos de vista de otros autores, de forma que quede reflejada esa tímida industrialización valenciana, sobre todo durante el siglo XIX.

En primer lugar, resulta interesante reflexionar sobre la obra "La vía valenciana", de Ernest Lluch (Lluch, 1976), que marca el inicio de esta corriente, y en la que se acuña el término "aristocracia financiera" como aquella clase social dominante en Valencia de mediados del siglo XIX ${ }^{298}$.

Por su parte, Anaclet Pons y Justo Serna constataron en su libro La ciudad extensa. La burguesía comercial-financiera en la Valencia de mediados del XIX (Pons, 1992), la participación de algunos burgueses de Valencia en alguna iniciativa industrial, especialmente en el sector textil.

De alguna manera, con todos estos investigadores, se puede afirmar que la permanencia y el impulso del sector agrícola, no suponía un obstáculo a la modernización, sino una forma distinta de sociedad capitalista ${ }^{299}$.

297 Una vez establecidos los principios del estado liberal, se le podría asociar el nombre de "burguesía", pero "sin renunciar a su predilección agro-comercial", si bien, en determinados casos excepcionales, había ampliado también su margen de acción al sector financiero. Según este mismo autor (Torró, 2002), esta burguesía ciudadana, como se acaba de comentar ligada fundamentalmente a la agricultura, llegó a tener una visión más amplia de lo que se había pensado tradicionalmente, porque entre otras cosas, promovió y organizó la Exposición Regional de 1909.

${ }^{298}$ Otros autores de referencia en la economía valenciana de este siglo son Ródenas (Ródenas, 1978), sobre la banca y la industrialización, y Hernández (García, 1983), sobre el ferrocarril. En sendas obras aparece el aristócrata Marqués José Campo, del que todavía existen numerosas calles que llevan su nombre (Dénia, Algemesí, Carcaixent, Valencia).

${ }^{299}$ En todo caso, no se discutía la concepción de una región sin industrialización, ni de un capitalismo predominantemente agrario con una burguesía que tenía su mirada puesta solo en la agricultura. Según Torró (Torró, 1983) "la economía valenciana parecía haber ahogado sus potenciales 
Por otro lado Lluch (Lluch, 1976) concluía que la agricultura valenciana, a excepción del complicado periodo correspondiente a la Primera República, había llevado a cabo un proceso de modernización. La falta de industrialización parecía así deberse a una agricultura con suficientes incentivos económicos como para desviar la inversión hacia ella, pese al atraso que sufría, por su "poca capacidad de integración entre sus diversos componentes y escasa implicación hacia otros sectores económicos". Es decir, era incapaz de generar demanda interna suficiente como para producir una expansión industria ${ }^{300}$.

Con referencia a otros autores valencianos, en el artículo de LI. Torró y J. Cuevas (Cuevas, 2002), tampoco se discute la coexistencia de una industrialización, sino que del mismo modo constatan que en el sector capitalista y burgués prevalecía el sector agrario.

Con todos estos autores citados, lo que se pretende demostrar es que el sector industrial adquirió cierta relevancia, y por ende, una modernización, aunque principalmente basado en el impulso del sector agrario, muy importante en el siglo XIX. Se trataba de una sociedad capitalista, en cierto modo diferente de otras del resto de España (De Fusco, 1992) ${ }^{301}$.

industrializadores ante las expectativas de beneficio que prometía una agricultura fuertemente comercializada".

${ }^{300}$ Sin embargo, en zonas con agricultura menos rentable, sí se desarrollaron actividades industriales, como en Alcoi (Cuevas, 1999).

${ }^{301}$ También Martínez Gallego (Martínez, 1995), del mismo modo asume la categoría histórica de burguesía en el XIX para el capitalista agrario. Y dice "quienes pretendían observar la industrialización valenciana como un producto del siglo XX, conectado o con los efectos inductivos de la Primera Guerra Mundial o con los del "desarrollismo" franquista, cometían un error de apreciación; pretendí resituar el debate sobre la industrialización valenciana en el ámbito de la difusión de la revolución industrial originada en Gran Bretaña durante el siglo XVIII y extendida en diversos núcleos españoles, una vez la revolución burguesa sentó las bases jurídicas necesarias para ello. [...] continuaron apareciendo monografías sobre industrializaciones locales que ayudaron a establecer los criterios explicativos y a ir desarrollando una topografía, tanto de las zonas con industria, como de aquellas otras sin ella, en el contexto de revolución industrial." 
Con todo ello, se puede concluir que la economía valenciana, aunque basada fuertemente en la agricultura, dejaba paso libre al proceso industrializador.

Por su parte, Martínez Gallego (Martínez, 1995) indica que en el ámbito del capitalismo, agricultura e industria no están enfrentadas. Y recuerda a Thompson, (Thompson, 1977), que dice que durante el siglo XVIII, el de la revolución industrial por excelencia, la inglesa, la agricultura fue la principal industria del país. De ahí que se pueda trasladar lo mismo al territorio valenciano durante los siglos XIX y gran parte del XX.

Así se desprende que las hipótesis que algunos sostenían sobre no industrialización impidió valorar adecuadamente los cambios cualitativos que realmente se habían producido en Valencia durante el siglo XVIII en adelante.

Es en la segunda mitad del siglo XIX cuando hay una relación más estrecha entre agricultura e industrialización (Garrabou, 1985). Al aumentar las exportaciones hay una gran entrada de capital que se invierte en la industria paralela de producción de productos relacionados, como bombas hidráulicas, equipamiento agroindustrial, papel, etc.

\footnotetext{
"Establecí [...] la unidad entre los fenómenos de revolución burguesa, y la revolución industrial; entré en el debate sobre la industrialización valenciana, centrándome en la sedería y mostrando cómo ni siquiera en ese sector se produjo la desindustrialización tantas veces apuntada, sino más bien una honda transformación, que hizo tender a la especialización en tejidos de seda de altísimo valor, y que llevó de una pujante manufactura a una modesta, pero sólida, industria; incidí, además, en la configuración industrial de una serie de sectores distintos a los que tradicionalmente se habian tenido por punta de lanza de la industrialización (textil algodonero y siderurgia), concentrándolos en el textil cañamero y yutero, la confección de alpargatas, alfombras, mantas, sombreros y zapatos, la industria agroalimentaria (del aguardiente a las conservas, pasando por las fábricas harineras), la crucial industria de la madera, las industrias cerámicas (de las tejas y ladrillos a los azulejos, pasando por el vidrio o la piedra tallada), la metalurgia, o la importante química (fósforos, cirios, perfumes y, sobre todo, abonos inorgánicos); terminé con un mapa del País Valenciano donde los puntos señalados eran otros tantos ámbitos de industrialización y los espacios en blanco importaban tanto como las anteriores para entenderla".
} 


\section{EL CONCEPTO DE PROTOINDUSTRIALIZACIÓN VALENCIANA:}

El concepto de protoindustrialización analiza las relaciones entre sector agrario y la elaboración de productos manufacturados, y se puede tomar para el caso valenciano como base del concepto de revolución industrial.

Según Jordi $\mathrm{Nada}^{302}$, el crecimiento agrario valenciano no tuvo por qué ser incompatible con el industrial: se cuestionaba, de una forma muy contundente, si realmente el desarrollo de la economía valenciana había seguido una vía exclusivamente agraria ${ }^{303}$ (Nadal, 1987).

La misma línea sigue Ernest Reig (Reig, 2007): "Con demasiada frecuencia, la historia industrial valenciana del siglo XIX se ha resumido en una constatación, la crisis de la industria sedera, y en una tesis explicativa del retraso con que cuajó la industrialización, basada en la idea de que el esplendor agrario ahogó a una industria incipiente. Sin embargo, la realidad fue mucho más compleja, como se ha ido percibiendo a medida que ha avanzado la investigación historiográfica, y el panorama del que hoy en día disponemos para interpretar lo acontecido ofrece muchos más matices".

\footnotetext{
302 Jordi Nadal i Oller (Girona, 1929 - ) es un economista e historiador español, considerado como muy relevante en la historia del proceso de industrialización en España.

${ }^{303}$ De hecho, en este artículo la presenta como "la tercera región más industrializada de España". Denuncia que "al mantener la tesis de la no-industrialización del País, los historiadores valencianos tienen demasiado presente el ejemplo catalán, centrado en el textil: al norte del río de la Sènia, el éxito del algodón simboliza el triunfo del sistema fabril; al sur del río de la Sènia, el fracaso de la seda, encarnado en el fracaso del esfuerzo industrial. Además de equivocada, esta actitud es estéril. De la misma manera que la industrialización catalana se distingue de la de Lancashire, la Alsacia o Lombardía, la industrialización valenciana no tenía por qué reproducir la del Principado. El desastre sedero, ciertamente innegable, es solo una parte de la historia. Por otro lado, faltan otros muchos sectores, descuidados hasta el momento, que es urgente recuperar. Cuando se haya hecho, se verá que el balance industrial no es tan negativo como se ha dicho, que las ganancias han sido mayores que las pérdidas". Así pues, diversos autores estaban descubriendo que en la Comunidad Valenciana estaba mucho más industrializada de lo que se pensaba.
} 
Como resultado de este proceso de industrialización surgen en la geografía valenciana un conjunto de complejos y edificios fabriles que se recogen en el mapa de Inmaculada Aguilar (Aguilar, 2012) [Figura 218], de los cuales, unos cuantos van a ser objeto de estudio en esta tesis, con el fin de identificar en ellos los factores que se desarrollaron previamente en los "mill buildings" en Europa.

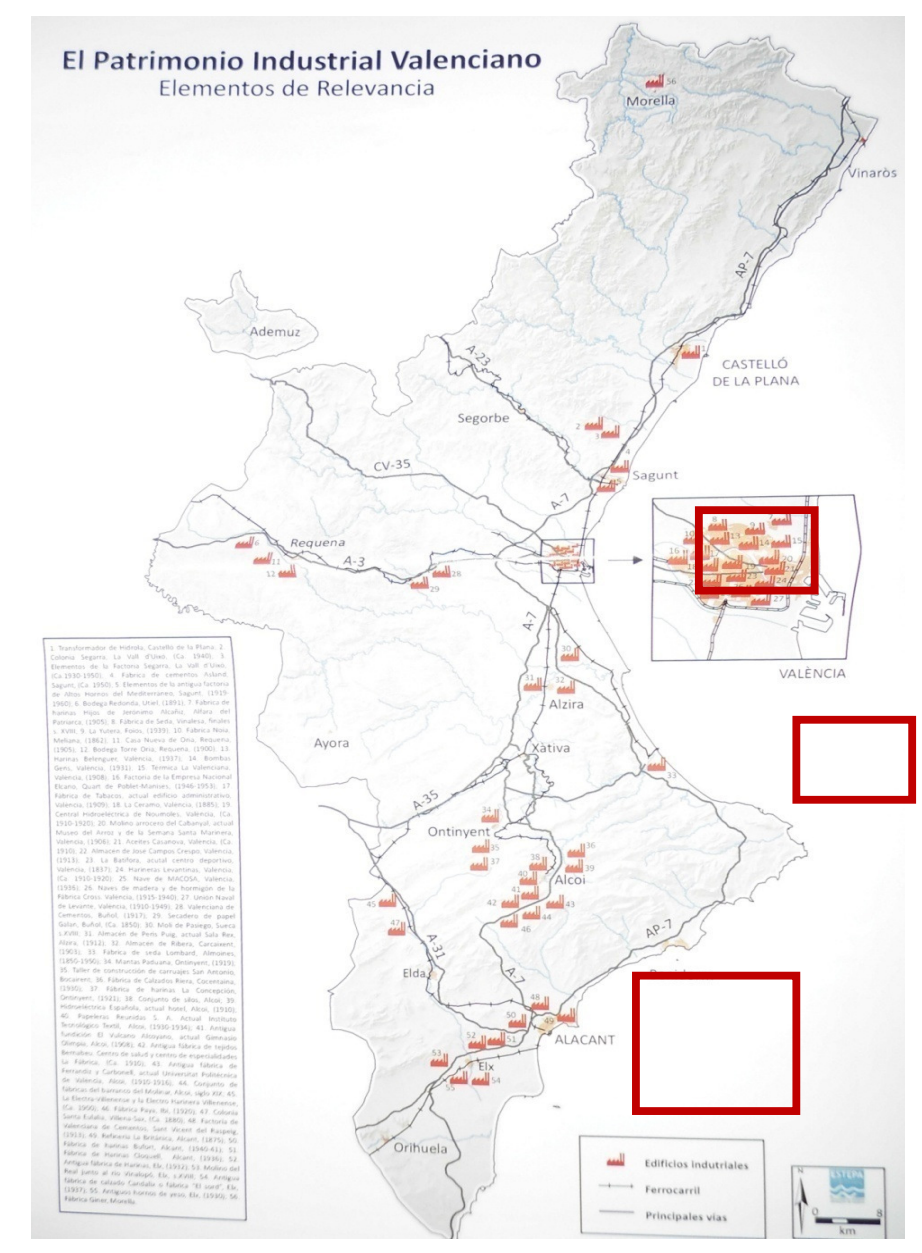

Figura 218. Mapa de patrimonio industrial según Inmaculada Aguilar, 2012. Remarcados en rojo, se señalan los casos más representativos que se detallan en los siguientes apartados. 


\section{2. ÁMBITO DE APLICACIÓN.}

Tal y como se ha visto en el apartado anterior, el territorio valenciano sufre una moderada industrialización desde finales del siglo XVIII y durante el XIX, con una proliferación, entre otros sectores, de edificaciones y complejos fabriles dedicados a la producción de papel y de materias derivadas de la industria textil (hilo, trapos, hilatura, tejido, tinte, etc). En realidad, el fenómeno no abarcó todo el ámbito territorial de la región, sino que se desarrolló principalmente en unos emplazamientos determinados: Alcoi, Morella, Valencia, la Vall d'Albaida, etc (Díez, 1991).

En un principio la localización de las industrias se establece al lado de las cuencas de los ríos, fenómeno motivado por la búsqueda de fuentes de energía barata (el agua); por la mejora de las comunicaciones, con la construcción del ferrocarril (García, 1983); y en un segundo plano, no menos importante, alejándose de las zonas donde empiezan a producirse fenómenos de conflictividad laboral ${ }^{304}$.

Pero además, la evolución manufacturera valenciana resulta muy interesante de estudiar por cuanto no sigue un modelo establecido de desarrollo como lo hicieron otros núcleos industriales como Cataluña o el País Vasco. De hecho, durante la primera mitad del siglo XIX incluso se acentuó el proceso de dispersión de la producción manufacturera, sin que de ello pueda deducirse, según se ha visto en el apartado anterior, una situación general de "desindustrialización". Solo son constatables algunos casos de involución en algunas viejas concentraciones industriales: la sedería en la ciudad de Valencia y la industria de la lana en Enguera y Morella.

\footnotetext{
${ }^{304}$ En Alcoi hubo algún episodio de conflictos, como el ocurrido en 1873, cuando hubo una huelga general en la que, a consecuencia de la represión, murieron dieciséis personas. Si bien, en términos generales, no provocó ningún impedimento al proceso inversor de su burguesía (Mora, I; "Alcoy, Ciudad Industrial", en http://www.raco.cat/index.php/Catalonia/article/viewFile/96767/161466; 1995).
} 
Había industria. Como se ha argumentado en el apartado anterior, las fuertes inversiones en infraestructuras por parte de la aristocracia valenciana, sin olvidar su fuerte vinculación al sector agrario, no demuestran precisamente una sociedad descapitalizada ni exclusivamente volcada sobre la tierra ${ }^{305}$.

Por todo lo anteriormente expuesto, resulta de gran interés delimitar el ámbito de aplicación de este trabajo a una pequeña muestra de edificios de características semejantes a los "mill buildings" que sirvieron de contenedores de actividades de la industria textil, pañería, papelera, metalúrgica o de cualquier sector industrial en el territorio de la Comunidad Valenciana, y que fueron edificados en el periodo comprendido entre finales del siglo XVIII y principios del XX. Pero principalmente, los casos estudiados hacen referencia al primero de estos sectores, por ser el más representativo de la industrialización valenciana durante este tiempo ${ }^{306}$.

Como argumento añadido a lo anterior, se puede decir con claridad que en la industria textil se ven reflejadas todas las tipologías edificatorias que aparecen en la extensión del estudio. En otras palabras, pese a las diferentes características edificatorias derivadas de la adaptación a la actividad, la mayoría de las edificaciones industriales siguen un modelo similar a las de la industria textil ${ }^{307}$ (Gumá, 1996).

\footnotetext{
${ }^{305}$ La familia de Thomas Trénor Keating $(1798$ - 1858) es un buen ejemplo. Se establece en Valencia desde Irlanda, su país natal, e inicia negocios vinculados a la agricultura, como la importación y exportación de pasa escaldada de Dénia, pero también entra en el sector financiero (en 1827 fundó la Banca Trénor), y en la industria de la seda (en 1842 adquirió la Real Fábrica de Sedas de Vinalesa). ${ }^{306}$ Aunque en lo que sí cabe cierta unanimidad, es que la industria valenciana fue muy variada, mucho más de lo que fueron otros focos económicos del país, como Cataluña y el País Vasco. De hecho, se estudian también en este capítulo, diferentes complejos industriales dedicados a la industria alimentaria.

${ }^{307}$ Este argumento es seguido por Ramón Gumà en su tesis sobre la evolución constructiva de los edificios textiles en Cataluña.
} 


\subsubsection{Los orígenes de la industrialización en Valencia.}

La historia de la industria valenciana a menudo se resume en dos conceptos clave, de las que algunas líneas de investigación discuten su total veracidad: la crisis sedera y el auge de la agricultura, y que le confieren a priori una débil presencia a nivel del país, incluso menor a nivel europeo. Como señalaba Jordi Nadal (Nadal, 1987), estas ideas no están totalmente fundamentadas, puesto que la historiografía ha demostrado que en el territorio valenciano, la evolución tecnológica fue mucho más compleja como para apoyarse solamente en esas dos premisas.

El campo valenciano del siglo XVIII tenía una fuerte opresión feudal y sufría un gran atraso técnico (Reig, 2007), que impedía la existencia de excedentes agrarios que pudieran ser comercializados. Los agricultores no disponían de dinero más allá del que necesitaban destinar a su subsistencia, y no se tenía para nada una mentalidad inversora en manufacturas, ni siquiera destinadas al tratamiento de los productos agrarios ${ }^{308}$.

Aisladamente, en el Norte, como por ejemplo en Morella y en las comarcas lindantes, sí existía una producción de hilado y tejidos. En l'Horta de Valencia se concentraba la producción sedera, y en las comarcas de l'Alcoià, el Comtat y la Vall d'Albaida predominaban las manufacturas de lana y la producción de papel, mientras que en la zona de Crevillent y Elx, se trabajaba con el esparto, el cáñamo y el lino. Alcoi sería la única localidad que evolucionaría tempranamente hacia un sistema centralizado de producción fabril, inicialmente con la industria papelera

\footnotetext{
308 Recordar la desamortización de Mendizábal, que fue un largo proceso histórico, económico y social iniciado a finales del siglo XVIII con la denominada «Desamortización de Godoy» (1798), y cerrado bien entrado el siglo XX (1924). Consistió en poner en el mercado, previa expropiación forzosa y mediante una subasta pública, las tierras y bienes que hasta entonces no se podían enajenar (vender, hipotecar o ceder), y que se encontraban en poder de las llamadas "manos muertas», es decir, la Iglesia Católica y las órdenes religiosas, y los llamados baldíos y las tierras comunales de los municipios, que servían de complemento para la precaria economía de los campesinos.
} 
(Olcina, 1986). Todavía a mediados del siglo XIX las únicas fábricas se encuentran ubicadas en Valencia, Alcoi, Morella, Segorbe, Enguera y Ontinyent.

Sin embargo la situación agraria irá cambiando a lo largo de la segunda mitad del siglo XIX: la transformación de tierras de secano en regadío, el uso de la máquina de vapor para la extracción de aguas subterráneas, la importación de guano para fertilizar la tierra y la exportación de vino y cítricos, harán que la vida de la población rural mejore en general, dándole por fin una capacidad de compra de bienes industriales.

En cuanto a la sedería, a finales del siglo XVIII, poseía un brillante futuro, con un potente gremio de artesanos ${ }^{309}$. Esta tradición, arraigada realmente desde hacía varios siglos, fue el impulso en el paso de la tradición artesanal a la industria, con todas sus implicaciones (la nueva organización del trabajo, el proceso de mecanización y acumulación de maquinaria ${ }^{310}$, y la capitalización) (Giménez, 2011).

Y así sucesivamente: la mecanización de los telares irá tomando parte en cada uno de los pequeños fabricantes del sector del tejido de seda. Todo ello hasta que en 1854 aparece la epidemia del gusano de seda, la pebrina, que provoca que la producción entre en un proceso de decadencia, y que casi hizo desaparecer el

309 El ilustrado valenciano Cabanilles en sus Observaciones sobre historia natural, geografía, agricultura, población y frutos del Reyno de Valencia (1795 - 1797), citaba que las moreras "forman estas comúnmente filas en las orillas de los campos, y es tanta su multitud, que suministran alimento a los innumerables gusanos que fabrican anualmente millón y medio de libras de seda".

${ }^{310}$ La fábrica de Lapayese, instalada en Vinalesa en 1770, será una de las primeras en instalar nuevas tecnologías (Lapayese, 1996). Su éxito se corresponderá con la puesta en marcha de las máquinas Vaucanson, impulsadas por las aguas de la acequia Real de Moncada a su paso por la población (Franch, 2000).

Por establecer un paralelismo, Richard Arkwright patentó su máquina de hilar en 1769, y construyó su fábrica en Cromford (Derbyshire) accionada hidráulicamente un año después.

En Patraix, como se verá posteriormente, se instala la fábrica de hilados y torcidos La Batifora, en 1837. Su propietario Santiago Luis Dupuy de Lome instalará la primera máquina de vapor para uso industrial en Valencia [Confrontar apartado 2.4]. 
potente gremio de tejedores artesanos, los velluters, y dejando a Lyon y Barcelona más libres sin la competencia valenciana (Sebastià, 2007).

Las hilaturas subsistieron, aunque con un número mucho menor de fábricas, donde se concentraron la mayoría de los telares supervivientes. Por ello, la producción de morera descendió dejando paso a otros cultivos, los citrícolas, que empezaron entonces su expansión por el regadío valenciano. La agricultura generó nuevos recursos para competir fuera del ámbito propiamente del sector agrícola e incluso fuera del ámbito geográfico valenciano y español.

A finales del siglo XIX, pese a la crisis de la sedería, lo que pudo haber sido pero que no fue el motor de la industria valenciana, no se creó un vacío total industrial. Las estadísticas tributarias del momento demuestran que la economía del territorio, basada en la especialización industrial, podía ser asimilable a Cataluña y al País Vasco (Sánchez, 2009). Eso sí, el tipo de industria, en contraposición a estas dos regiones, era de un tipo de actividad generalmente de pequeño tamaño y muy diversificada, no solo sectorialmente sino geográficamente hablando. 


\subsubsection{Localizaciones.}

Es el momento ahora de hacer un somero estudio sobre cada una de las polarizaciones que tuvo el sector industrial valenciano durante estos dos siglos, XVIII y XIX. Seguidamente, en el siguiente capítulo, se estudiarán algunos casos de interés con un amplio detalle.

Se empezará por Alcoi, la ciudad industrial valenciana por antonomasia. La pañería de lana era la principal actividad económica (Vidal, 1981) ${ }^{311}$, aunque incluso anteriormente ya se producía allí papel, lo que de alguna manera acercó a la industria del tabaco, y a la de la fabricación de maquinaria, por la incipiente mecanización, junto a la ciudad de Valencia ${ }^{312}$ (Reig, 2007) $)^{313}$.

En lo que respecta a l'Horta Sud y a la ciudad de Valencia, también en la segunda mitad del siglo $\mathrm{XIX}^{314}$, proliferaron las fábricas de muebles: mecedoras, sillas de asiento y de rejilla, muebles curvados, tapizados, etc. Su origen industrial se asocia a la privatización de los montes tras los procesos desamortizadores ${ }^{315}$. Estaban provistos de los aserraderos próximos, que igual proporcionaban la

\footnotetext{
${ }^{311}$ La Real Fábrica de Paños de Alcoy fue una organización del siglo XVIII de fabricantes textiles de Alcoi que fabricaba tejido para los ejércitos reales del Rey Carlos IV de España.

El mercado llegaba donde no había sido cubierto previamente por los centros de producción de mayor calidad (como Cataluña). Se orientaba principalmente al sur de España y para el ejército, los cuales, pese a su condición económica, dinamizaron este sector. A mitad del siglo XIX ya se había pasado del huso manual al mecánico para la fase de hilatura. La mecanización del tejido llegó después, a final de ese siglo (Reig, 2007).

312 Por su parte, en el sur de Alicante, la difícil situación de la agricultura no podía absorber la expansión demográfica del siglo XVIII, lo que provocó la estimulación de la artesanía local: alpargatas de esparto o de cáñamo, zapatos hechos con cuero procedente de las montañas de Alcoi, y el sector cordelero. Todo ello evolucionó hacia las fábricas de calzado, las cuales con el tiempo fueron también mecanizándose.

${ }^{313}$ En 1880 hay 10 talleres mecánicos movidos a vapor en Alcoi, frente a los 7 de Madrid y 6 de Sevilla (Sánchez, 2009).

${ }^{314}$ En términos muy generales, entre alrededor de 1850 y 1900, Valencia abandona generalmente su carácter de artesanía tradicional.

${ }^{315}$ El monte valenciano sufrió por entonces un gran proceso de desamortización.
} 
madera para las cajas de pasas y naranjas ${ }^{316}$, y para toneles de vino, que para los fabricantes de instrumentos musicales y los productores de muebles. Estos talleres requerían poco capital, lo que hacía que algunos artesanos emprendedores fueran independizándose una vez dominado el oficio, creando sus propios pequeños establecimientos (Martínez, 1995) ${ }^{317}$.

Poco antes de 1850 arrancan las fundiciones industriales de hierro, que encuentran un negocio incipiente en la fabricación de norias para el riego y pozos artesanos, sobre todo para la agricultura: norias, bombas de agua, trilladoras, prensas hidráulicas de aceite y vino, destiladoras, básculas, máquinas de clasificar y pulverizar, etc. Como ejemplo destaca La Primitiva Valenciana, de 1843, la única empresa de maquinaria española que fue condecorada en la Exposición Universal de Filadelfia de 1876. Esta empresa evolucionó muy rápidamente, al intercambiar la producción de maquinaria agrícola por la ferroviaria, tanto, que a partir de 1884, ya de la mano de su hijo, aparece la primera locomotora fabricada en España, para cubrir el trayecto de Barcelona - Sant Joan d'Horta. De ella surgió la empresa La Maquinista Valenciana [Figura 219, Figura 220, Figura 221 y Figura 222], de reconocido prestigio en su campo, que fabricaba estructuras metálicas, ruedas hidráulicas y máquinas de vapor ${ }^{318}$.

La importancia de esta última fábrica, específicamente dentro de esta tesis, reside en que se toma como referencia en la fabricación pionera de piezas metálicas, como vigas y pilares, favoreciendo por proximidad su utilización.

\footnotetext{
${ }^{316}$ A finales del diecinueve se exportan más de 4 millones de cajas de cítricos (Martínez, 1995).

${ }^{317}$ Martínez Gallego (Martínez, 1995) indica que en 1916, las fábricas de la madera suman más del $25 \%$ de las del resto de sectores afincados en la ciudad de Valencia, exportando muebles por un valor total de 809 millones de pesetas.

${ }^{318}$ Concretamente, en 1891, se crean los famosos talleres especializados en metalurgia y calderería gruesa Talleres Devis, toda una institución en la historia industrial valenciana. En las primeras décadas del siglo XX, se instalan en el Camino Real de Madrid dando trabajo a más de 2.000 obreros y que más tarde, en 1947, se une a otra empresa catalana para formar Macosa.
} 


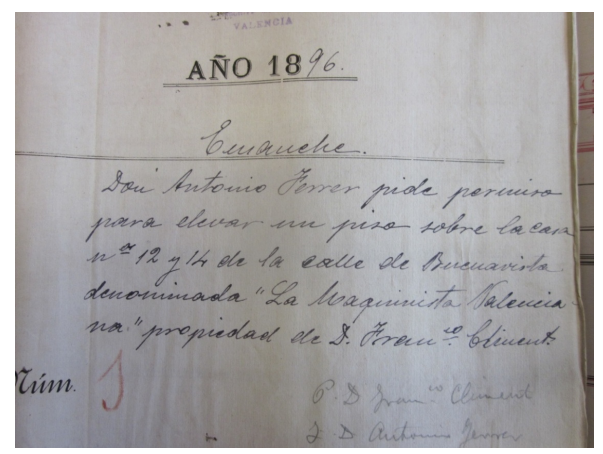

Figura 219. Localización: Solicitud de licencia para la ampliación de una altura sobre la fábrica de Francisco Climent "La Maquinista Valenciana", en la C/ Buenavista, 12 y 14, en el año 1896 (Archivo Histórico Municipal. Fotografía propia. Julio 2012).

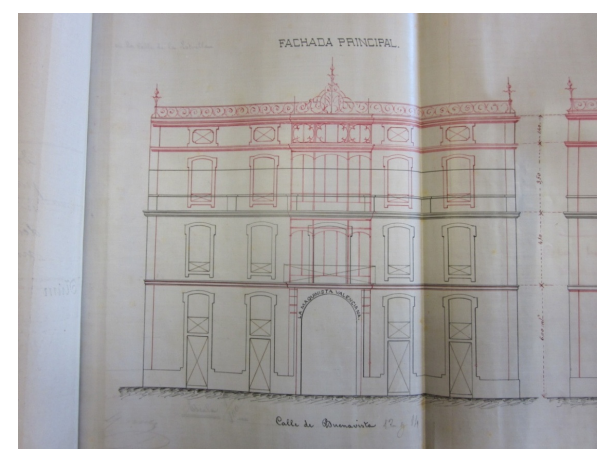

Figura 220. Fachada principal de La Maquinista Valenciana, en la antigua C/ Buenavista, 12 y 14, en el año 1896. Se comprueba en este plano de proyecto de ampliación de una altura (Archivo Histórico Municipal. Fotografía propia. Julio 2012).

Como se aprecia en Figura 219 y Figura 220, el estado "actual" en ese año según el proyecto de ampliación del edificio, indicaba que tenía una planta baja y un entresuelo (altura: $6 \mathrm{~m}$ ); y una planta primera destinada a fábrica (altura: 4,10 $\mathrm{m})^{319}$. Al tratarse de un uso para actividad pesada, la viabilidad de construir varias plantas no resultaba conveniente.

${ }^{319}$ La licencia de obra del citado proyecto solicitaba un piso superior destinado a vivienda (altura: $3,50 \mathrm{~m}+$ altillo de 1,40 m). 


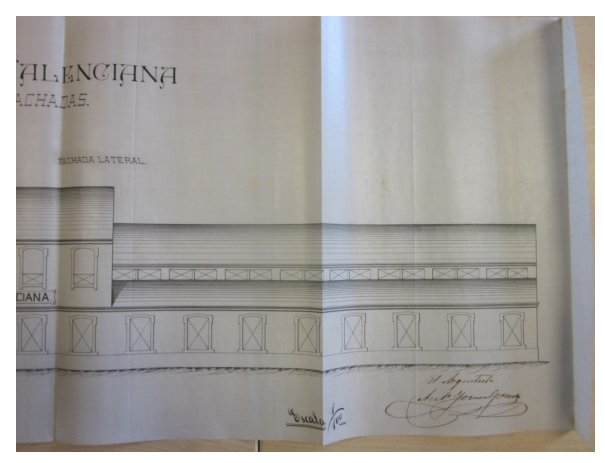

Figura 221. Fachada de La Maquinista Valenciana, en la antigua C/ Estrella, en el año 1896. Estado previo en el proyecto de solicitud de ampliación de altura y reforma de fachadas (Archivo Histórico Municipal. Fotografía propia. Julio 2012).

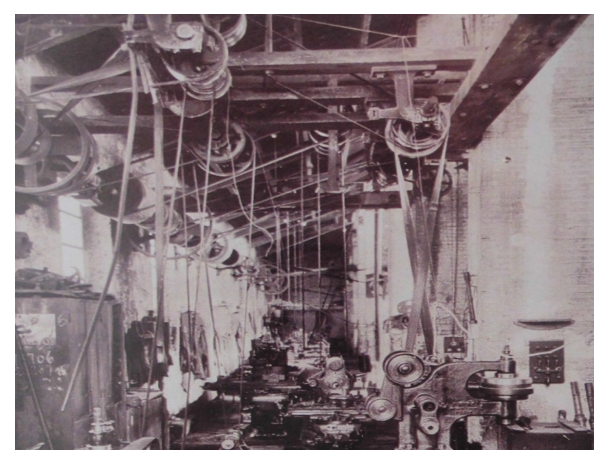

Figura 222. Fotografía del interior de la fábrica, concretamente en la sala de tornos (Álvarez, 2001).

El edificio tenía una cubierta a base de cerchas de madera que apoyaban sobre las pilastras de la fachada, permitiendo la apertura de grandes huecos entre los vanos, y de los que colgaban los ejes de transmisión mecánica y las poleas, cuyo accionamiento proveía de la máquina de vapor a modo de punto único. El cerramiento de cubierta se realizaba mediante teja cerámica sobre tablones de madera.

Al hacer un inciso también acerca de este complejo fabril valenciano, conviene relacionarlo con las fundiciones que se habían construido en Inglaterra, cuna de los espacios fabriles con el hierro como material base de sus estructuras fen apartado 3.2.4 más atrás\}. 
Tal y como puede apreciarse en las fotografías [Figura 222] los muros de obra de fábrica de ladrillo son de gran espesor, siendo en algunos sitios de sillería y en otros de mampostería, actuando como elementos portantes sobre los que apoyan las vigas, todavía de madera ${ }^{320}$. Los pilares están realizados también en fábrica de ladrillo, de dimensiones considerables. Por su parte, las fundiciones de Boulton y Watt, si bien un siglo anteriores, también respondían a esta estructura ladrillomadera $^{321}$ (sin embargo, en esta época de la Maquinista Valencia de cambio al siglo XX, en Inglaterra el uso del hierro ya estaba completamente extendido, por lo que aquellas fundiciones que se estuvieran construyendo allí, probablemente no siguieran la misma estructura que en Valencia).

Su apariencia externa, como se ha dicho anteriormente, con una planta a nivel de calle y una primera planta, se asemeja a la fundición que Boulton y Watt construyeron en la Foundry de Birmingham, a principios del siglo XIX, unos 100 años antes [Figura 223 y Figura 224].

\footnotetext{
${ }^{320}$ No aparece todavía en la fotografía ningún elemento metálico (a modo de referencia, en Inglaterra se estaban construyendo los primeros edificios, como el East Mill, donde la estructura metálica había llegado a la fachada, constituyendo así un edificio iluminado verdaderamente de forma natural.

${ }^{321}$ Sin embargo, se podría añadir, que al tratarse de paredes y pilares de ladrillo, la estructura estaba protegida frente a los riesgos de incendio, muy frecuentes en las fundiciones, sobre todo en las españolas, que carecían de los medios de protección que ya disponían en América (rociadores), o en Inglaterra (servicio de bomberos).

El primer Cuerpo de Bomberos de la Ciudad de Valencia, data de 1857 (Ajuntament de València, 2007).

Asimismo, se preveían vanos grandes para permitir la extracción e introducción de grandes piezas.
} 


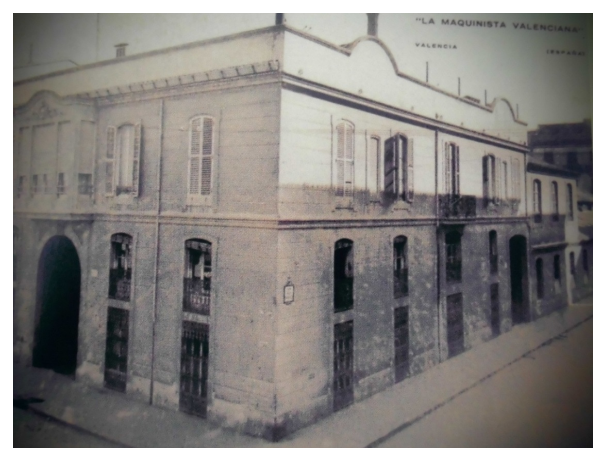

Figura 223. Fotografía de las fachadas de la fábrica, recayentes a la C/ Buenavista y C/ Estrella (Álvarez, 2001).

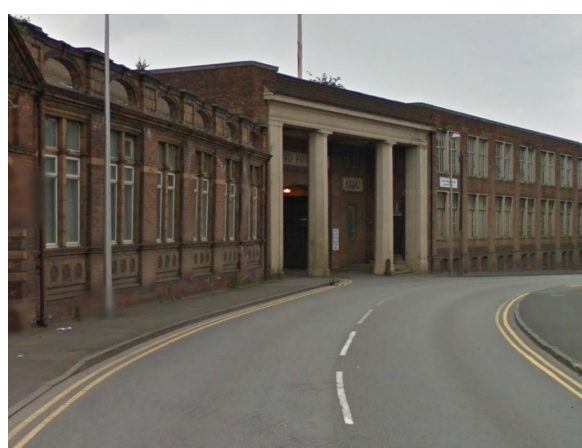

Figura 224. Soho Foundry, 1796, Birmingham, Inglaterra. (www.google.es/maps).

Más al norte, en l'Alcora ${ }^{322}$, Onda y Manises (Besó, 2010), y en la zona de Castellón y alrededores, se crearon numerosas fábricas de azulejos ${ }^{323}$. La industria cerámica y de la construcción se verá afectada por el proceso general industrializador pero, sobre todo, por la demanda de materiales de construcción impulsada por el desarrollo urbano experimentado a partir de la segunda mitad del XIX (Martínez, 1995). El crecimiento económico conllevará la concentración de mano de obra y nuevos alojamientos, así como la renovación de la ciudad: es la época en la que se plantean los ensanches por su crecimiento.

Por su parte, aquellos municipios con recursos naturales propios, como por ejemplo materias primas básicas como tierras arcillosas, caolín, etc, despegaron industrialmente en este sector, instalando las primeras fábricas de ladrillos (Estall,

\footnotetext{
${ }^{322}$ Real Fábrica de Alcora o Real Fábrica de Loza y Porcelana, manufactura real construida en 1727, por parte de Buenaventura Ximénez de Urrea y Abarca de Bolea, IX conde de Aranda, según los preceptos de Carlos III y Carlos IV de España.

Este es un ejemplo de una Real Fábrica como impulso industrializador valenciano.

${ }^{323}$ Partieron del conocimiento de la escuela de formación de la fábrica de porcelana fina del Conde de Aranda de l'Alcora, del siglo XVIII, siguiendo los modelos de fábricas reales dieciochescas, y de la proximidad y abundancia de materias primas (Franch, 2002).
} 
1997) ${ }^{324}$ : Aldaia, Alaquàs, Quart de Poblet, Catarroja, Oliva y Alzira. Pero en particular, es la industria azulejera la que se muestra relevante ${ }^{325}$.

Tal y como se acaba de ver, en 1900 la industria ha cuajado claramente en la región, por lo que no se debería decir que Valencia no fue un territorio industrial ${ }^{326}$, del que resulta tan necesario como atrayente el estudio detallado de sus espacios fabriles ${ }^{327}$.

\footnotetext{
${ }^{324}$ En 1862 existían 5 fábricas de azulejos en Onda, y en 1905, 32 en la provincia de Castellón, y 13 en Valencia.

${ }^{325}$ La primera fábrica que sustituye los métodos artesanales por la mecanización de los procesos de producción se instala en las afueras de la ciudad de Valencia aproximadamente en 1840. Se trata de la de Juan Bautista White y Bonelli, en la fábrica de azulejos de San Carlos. En 1863, en el barrio de Marxalenes, extramuros de la ciudad se introduce el "privilegio para la introducción de una máquina importada de Bélgica para conformar ladrillos", movida por medio de una máquina de vapor (Franch, 2000).

${ }^{326}$ Diversas investigaciones han puesto de relieve que en la segunda mitad del siglo XIX y principios del XX, tiene lugar en España un proceso importante de concentración de la actividad industrial en unas pocas regiones. Por ejemplo, según Ernest Reig (Reig, 2007), la producción valenciana no sale mal parada en esas observaciones, según las estadísticas del momento, en las que este autor se basa (Barciela, 2005).

El 8\% sobre el total de la industria española que representa este territorio en el cambio de siglo, relativamente muy poco frente al $38 \%$ de Cataluña, da una gran relevancia a la infraestructura industrial valenciana que la aleja de la trivialidad de su reputación exclusivamente agraria.

BARCIELA, C. y CARRERAS, A. Estadísticas históricas de España: siglos XIX-XX. Fundación Banco Exterior eds., Madrid: Madrid: Fundación Banco Exterior, 1989 (Barciela, 1989).

Y, Estadísticas de la contribución industrial española. Primer volumen de las Estadísticas históricas de España. Siglos XIX-XX, coordinado por Albert Carreras y Xavier Tafunell, y publicado por la Fundación BBVA. Issue 31, 2006, no. 31. "La comparación excluye I País Vasco y Navarra del total de España, por razones de falta de disponibilidad de información en la fuente de base" (Carreras, 2006). Dos siglos de industrialización en la Comunitat Valenciana = Dos segles d'industrialització a la Comunitat Valenciana. [Exposición: 19/09/2007 - 2/12/2007. Valencia]: Valencia: Colegio Oficial de Ingenieros Superiores Industriales de Valencia, 2007. Pp. 37.

${ }^{327}$ Según Reig (Reig, 2007), las empresas industriales valencianas prosiguen su expansión a lo largo de las dos primeras décadas del $\mathrm{XX}$, con una estructura productiva basada principalmente en pequeños negocios a los que comienzan a sumarse algunos de grandes dimensiones.
} 


\subsubsection{Edificios valencianos.}

En esta última parte del estudio, una vez analizados los factores influyentes en la fisonomía de los edificios fabriles, se utilizarán estos para tratar de encontrar las analogías que pudieran existir entre aquellos primeros "mill buildings" origen de la revolución industrial inglesa y las que se construyeron posteriormente en el territorio valenciano.

Con ello se cumplirá el objetivo principal expuesto al principio, y que no surge más allá que de la motivación por descubrir, de forma general, por qué las fábricas valencianas han adquirido una determinada disposición, y si estas tipologías se corresponden con un proceso evolutivo similar al que sufrieron anteriormente otros países.

El movimiento económico que supuso la tecnificación agraria y la industrialización paralela se produce en esta región de España principalmente a finales del XIX, un siglo después de aquella extraordinaria transformación social que apareció en Gran Bretaña, conocida como la revolución industrial.

De hecho, al basarse en un análisis económico comparativo entre ambas zonas, se puede concluir que, aunque obviamente a diferente escala, también hubo revolución industrial, y también hubieron unos cuantos "mill buildings" en el sentido anglosajón de la palabra. Como ejemplos de ello, se han escogido unos cuantos edificios de Alcoi, de la ciudad de Valencia y de la comarca de La Safor, al sur de la provincia [Figura 225], que lejos de representar un hito arquitectónico como la fábrica de los hermanos Lombe, el Ditherington Mill o el North Mill, representan la modesta casuística valenciana. 


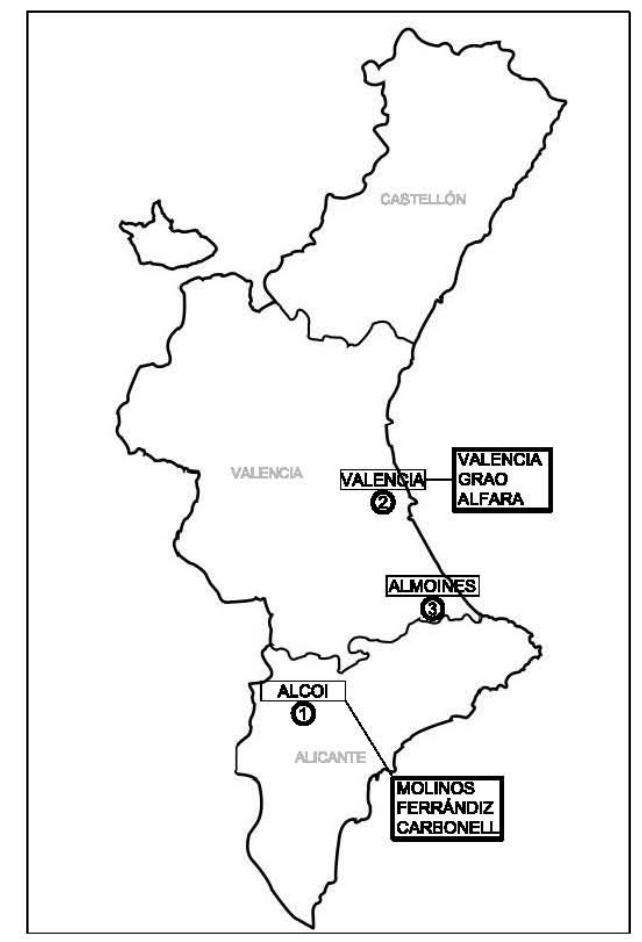

Figura 225. Mapa de la Comunidad Valenciana con la localización de los edificios estudiados en el Capítulo 4.2.

En primer lugar se hace un estudio sobre la molinería alcoyana y sendos complejos fabriles con tipología "mill building" que la sucedió. Resulta interesante examinar su estrecha relación con aquellos edificios representados en el capítulo anterior \{en apartado 3.2 más atrás\}, construidos años antes en Inglaterra.

Posteriormente, se estudian sendos almacenes también ubicados en Valencia, en los Camins al Grau, zona de expansión de la ciudad: una dedicada a la conserva y la otra a la producción de harina. El sector agroalimentario adquiere su relevancia económica gracias a la consolidación de la producción agrícola, especialmente la citrícola y la de la huerta. La vía ferroviaria que enlazaba el centro de la ciudad con 
el puerto sirvió de base para el establecimiento de nuevas fábricas, generalmente de poco tamaño y no muchas plantas de altura, con cubiertas a dos aguas, y con estructura a base de cerchas de madera apoyadas sobre muros de carga de sillería.

Seguidamente, se presenta el imponente molino de harina de Alfara del Patriarca, de principios de siglo pasado, del que tan solo se conserva su fachada, el cual es un ejemplo de edificio de hierro con múltiples alturas cuyas vigas apoyan en muros de carga de mampostería, y con bóvedas tabicadas de ladrillo revoltón, que lo hacen sobre viguetas también de hierro. Este complejo es también un ejemplo de ingeniería hidráulica valenciana perfectamente ideada, por donde la Real Acequia de Moncada esquiva el paso del Barranc del Carraixet ${ }^{328}$.

En términos generales, los factores iluminación y el estructural serán los que más condicionarán la forma, sencilla y relativamente sobria, de la pequeña industria valenciana (hay otros muchos ejemplos a lo largo de toda su geografía, como en Bocairent, Banyeres de Mariola, Albaida, Ontinyent y la zona de Morella).

Y por último, se procede al análisis de otro "mill building" en la comarca de La Safor, poco habitual en el territorio valenciano en cuanto a su tamaño se refiere: la imponencia y la sobriedad no desmerecen su magnitud. La mera contemplación de la sedera de Lombard en Almoines, también de principios del siglo pasado, invita al análisis de su edificio, cuyo detalle conlleva un amplio estudio por la diversidad de las soluciones constructivas utilizadas, todas ellas basadas en pilares de hierro fundido macizo y en perfiles en doble $U$, así como en forjados de vigas de madera y cerchas mixtas de madera y hierro.

\footnotetext{
${ }^{328}$ Tanto por su desconocimiento por la bibliografía valenciana como por la soledad que refleja su abandono, se suscita su revalorización y puesta en conocimiento, reflejo de la actividad de tantas y tantas personas que dejaron parte de su vida dentro de sus imponentes fachadas.
} 


\subsection{ALCOI.}

Originariamente, el término que se utilizaba en Inglaterra para nombrar al molino "mill" se complementó más tarde con el adjetivo correspondiente al sector productivo. Por ejemplo, a las fábricas textiles se les llamaba "cotton mill", a las fábricas de papel "paper mill", y a las metalurgias "steel mill". Sin su especificación significaba simplemente fábrica o establecimiento industrial, "industrial mill building". En Alcoi, en un principio se denominó en la lengua autóctona al batán "molí draper" (alrededor del XVIII), y a la fábrica de papel “molí paperer"

\subsubsection{Los molinos de Alcoi.}

A mediados del siglo XIX la cuenca industrial del Barxell había alcanzado su pleno desarrollo económico. Los recursos hidráulicos de este río se habían aprovechado casi al máximo y se dificultaba la instalación de nuevos artefactos por la escasez de suelo. La única alternativa era ampliar los molinos ya existentes o construir en su lugar unos nuevos más grandes ${ }^{330}$.

Pero durante las dos últimas décadas del siglo, y debido sobre todo a la competencia del papel fabricado en continuo en otras partes de España ${ }^{331}$, el sector papelero alcoyano en general se vio obligado a realizar una renovación tecnológica de tal trascendencia que únicamente las manufacturas o particulares que pudieron hacer frente a las grandes inversiones necesarias que suponía el cambio del proceso de fabricación pudieron continuar funcionando. De hecho, en la zona del Barxell fueron muchos los molinos papeleros que paralizaron su producción y se transformaron en molinos harineros, probablemente porque la

\footnotetext{
329 Olcina (Olcina, 1986), simplemente los llama "edificios hidráulicos".

${ }^{330}$ Los sectores de fabricación más representativos de la cuenca eran el papelero (con 17 molinos), los tintes (con 14 establecimientos), el harinero (13 molinos) y el sector textil (11 máquinas y batanes) (Olcina, 1986).

${ }^{331}$ La primera máquina continua de fabricar papel que se instaló en Alcoi fue en el año 1884.
} 
inversión que ello conllevaba era mucho menor que la exigida para instalar máquinas continuas de fabricar papel.

Los nuevos procesos, sin embargo, exigían ahora mucha mayor cantidad de agua de la que habitualmente se podía disponer en esta cuenca y esas industrias papeleras reformadas se tuvieron que trasladar a otras zonas con mayores disponibilidades, por lo que este sector dejó de tener el significado que había tenido desde sus orígenes en la ciudad.

\section{LOS BATANES:}

El batán o "molí draper" en Alcoi es el artefacto antecedente de las manufacturas textiles de $\mathrm{Alcoi}^{332}$, antes de la maquinización de esta industria ${ }^{333}$.

Los primitivos batanes, instalados ya en la comarca en la alta Edad Media, eran unos ingenios rudimentarios con unas mazas grandes de madera que golpeaban el tejido hasta conseguir el grado de acabado deseado ${ }^{334}$. El movimiento alternativo de esos mazos se lograba con el acoplamiento de una rueda hidráulica al ingenio, que convertía el movimiento de rotación en alternativo, por medio de un árbol de espolones, o un mecanismo de biela-manivela ${ }^{335}$.

\footnotetext{
${ }^{332}$ El proceso de batanado, una de las últimas fases de la elaboración de los tejidos de lana, tenía por misión fieltrear el tejido, manufacturado en el telar, para dotarlo de un tacto agradable, y un grueso adecuado para la aplicación a que se destinaba.

${ }^{333}$ En el río Molinar había una partida llamada de Los Batanes, cercana a la Ermita de la Virgen del Pilar, nombre ya hoy en desuso, debido a la gran cantidad de batanes que había.

${ }^{334}$ RAE.

${ }^{335} \mathrm{El}$ primer batán construido en el término de Alcoi del que se tienen referencias, estaba emplazado en el río Alcoi en el año 1310 (Olcina, 2006).

Con el paso del tiempo, y conforme la producción de paños se fue asentando en la zona, otros artefactos se fueron instalando en las diversas cuencas del término, como el Molinar y el Serpis.
} 
Como se ha dicho 3 párrafos antes, a mediados del siglo XVIII algunos de estos batanes empezaron ya a ser transformados en molinos papeleros ${ }^{336}$.

\section{DEL MOLINO A LA FÁBRICA:}

Los molinos hidráulicos para moler grano pueden considerarse como los prototipos de la fábrica alcoyana del siglo XVIII, antes de la utilización del vapor como fuente de energía (Olcina, 1996). Según este autor, ello es así porque es el ejemplo más antiguo que se tiene en la Comunidad Valenciana en la asociación de una máquina con un edificio. En el molino de grano, la máquina, originariamente de madera, consistía en una rueda de paletas inmersa en un curso de agua que a través de un sistema mecánico de transmisión de la energía hacía girar la muela para triturar el grano. Todo ello formando un único conjunto edificatorio [Figura 121 y Figura 135], que respondía básicamente a una arquitectura popular, en el más estricto sentido de la palabra. Como se estudia algunos párrafos después, se trataba de estructuras rudimentarias a base de gruesos muros de carga con forjados realizados con vigas de madera de escasa luz. Es por ello, que en esta Figura 226 no se les ha asignado ninguna evolución constructiva más allá que la utilización de sistemas constructivos básicos, ni en cuanto a un desarrollo tecnológico destacado por la utilización de maquinaria específica para la concentración del trabajo.

En cuanto a su forma de accionamiento, el molino de rueda vertical se solía instalar en ríos caudalosos, colocando esta dentro del cauce, y que a través de su eje horizontal transmitía el movimiento a otro eje vertical, el cual estaba unido a la muela (generalmente, la transmisión de la energía se realiza de forma básica mediante la unión de ejes con ruedas dentadas de madera).

\footnotetext{
${ }^{336}$ Lo que produjo cierta desavenencia con la Real Fábrica de Paños, que consideraba este cambio del sector productivo como perjudicial para sus intereses, basados exclusivamente en la producción de telas de gran calidad por parte de artesanos muy cualificados, y muy bien retribuidos.

Un ejemplo: el primer molino-fábrica de papel fue edificado por Mosén Vicente Albors en 1755, conocido como Molí d'Albors, en la partida de los Batanes, en el curso alto del río Molinar.
} 
Figura 226 (pág. sig.). Esquema conceptual donde se refleja la evolución constructiva que sufrieron los primeros batanes al convertirse en molinos para la fabricación de tejidos, o bien después, en su reconversión a molinos papeleros o de harina, tomando como referencia la base del progreso de los "mill buildings" textiles de la llamada Revolución Industrial inglesa durante los siglos XVIII y XIX \{confrontar edificios en apartado 3.2 más atrás\}. Se aprecia cómo el camino seguido no llega hasta la definición de "mill building", puesto que son todavía el prototipo o antecedente de la próxima industria valenciana de edificios en altura mecanizados. 


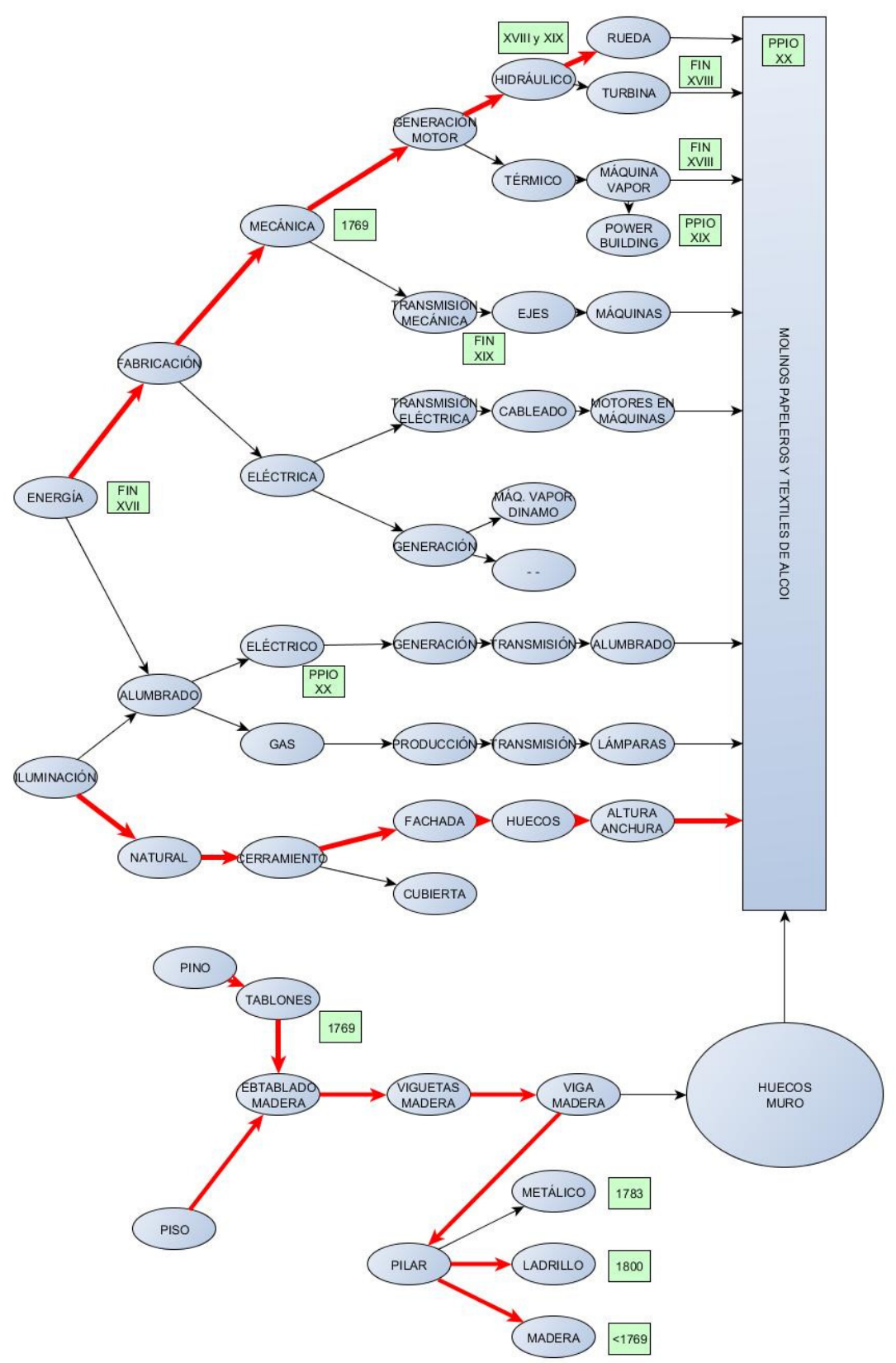

$404 / 525$ 
Por el contrario, el molino de rueda horizontal es el que se adaptaba mejor donde había un menor caudal o este era irregular. Sin embargo, la rueda no se podía situar en medio de ningún río o canal, sino debajo del propio molino. Es allí donde recibía el agua de forma artificial, conducida hasta ella gracias a la red de acequias, canales y presas que se construían para tal fin, como es precisamente el caso de las cuencas de los ríos alcoyanos [Figura 227].

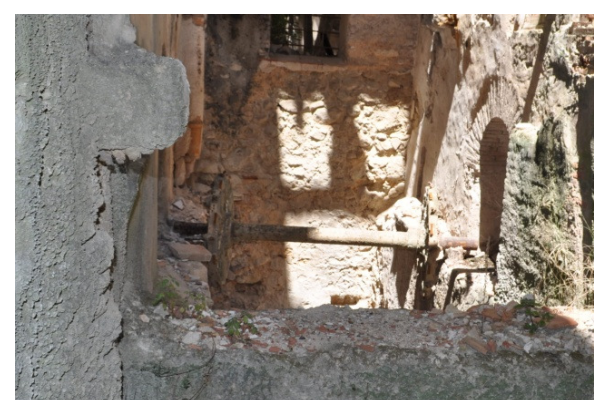

Figura 227. Restos de rueda hidráulica de eje horizontal en un molino del cauce del río Barxell (Alcoi) (Fotografía propia. Julio 2012). Esta era la forma habitual de accionamiento de los molinos de la zona, debido a la irregularidad del caudal de los ríos.

Como se ve, los molinos de agua no solo se tenían que adaptar a las condiciones del suelo, del agua y del clima, sino que también su edificio debía amoldarse a la rueda hidráulica que movía sus muelas. De este modo, en el molino que tenía la rueda vertical instalada dentro del río, su casal debía estar metido en el mismo lecho o próximo a él. Y por el contrario, el edificio del molino que albergara en su cárcavo una rueda horizontal podía estar retirado del cauce, ya que los canales artificiales llevarían el agua hasta donde estuviera su rodezno ${ }^{337}$ [Figura 228].

\footnotetext{
${ }^{337}$ Conforme los molinos de grano fueron evolucionando, la rueda hidráulica se emplazó en el nivel más bajo de los edificios de varias plantas, efectuándose en la última planta la carga del grano. Este había sido previamente transportado hasta allí por una serie de tolvas, cayendo por gravedad a través de una serie de cedazos giratorios hasta la máquina.

En cuanto al coste económico de los molinos hidráulicos, es importante destacar que era muy elevado, ya que cuando se trataba de molinos de rueda horizontal, se tenía que desviar la corriente hasta sus ruedas por medio de canales, acequias y presas, aunque todo dependía de las facilidades
} 
Esta forma de accionamiento no coincidía con la que se realizaban en Inglaterra, puesto que allí los ríos eran mucho más caudalosos, con energía hidráulica muy superior a la de las montañas del interior de Alicante. Esta es una primera gran diferencia que conduciría a diferentes evoluciones tipológicas, especialmente relacionadas con el tamaño de los edificios.

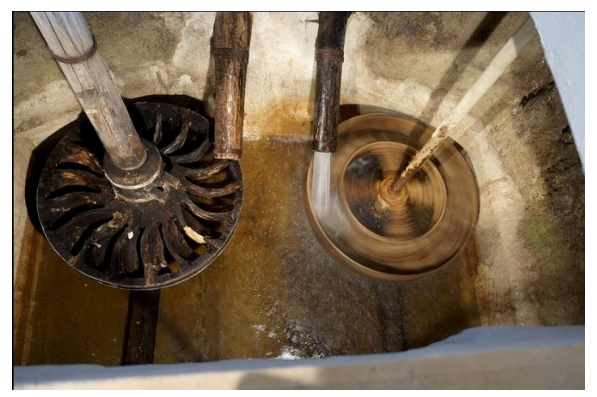

Figura 228. Rueda hidráulica de eje vertical de San Miguel de Oñati (Guipúzcoa), molino del siglo XV. Esta rueda no era la habitualmente empleada en la cuenca de los ríos mediterráneos, que no eran excesivamente caudalosos por lo general (https://www.flickr.com/photos/apari/ 8704438545/).

Esta misma forma de accionamiento y de funcionamiento fue adaptándose a los diversos sectores productivos para poner en movimiento sus máquinas: textil, papelero y harinero.

Más tarde, en la segunda mitad del XIX, tal y como ocurrió en otros núcleos industriales españoles las máquinas de vapor y las turbinas hidráulicas se incorporaron a estos establecimientos industriales como nuevas fuentes de energía. Ello provocó que las proporciones y el aspecto de las fábricas alcoyanas se transformaran considerablemente, puesto que las posibilidades productivas eran mucho mayores.

de los recursos hidráulicos y de la orografía. Cuando se trataba de molinos de rueda vertical, la maquinaria era mucho más costosa que la de los molinos de rodezno, ya que estaba formaba de una rueda principal instalada en el cauce del río, la cual poseía una altura y un diámetro mayor que la anterior, y de otras más pequeñas, las cuales formaban el engranaje para cambiar el movimiento vertical en horizontal. Esta forma de transmisión mecánica definía el volumen del edificio, recordando lo estudiado en el apartado referente al estudio de la transmisión energética en los "mill buildings". 


\section{ORGANIZACIÓN DE LA PRODUCCIÓN Y LA CARACTERIZACIÓN DE LOS MOLINOS PAPELEROS. COMPARACIÓN CON LOS EDIFICIOS EN ALTURA INGLESES}

El molino papelero de Alcoi de finales del siglo XVIII tenía normalmente tres alturas $^{338}$, generalmente de planta rectangular (como se verá a continuación), con un accionamiento que se realizaba mediante el sistema de motor único, y siendo la transmisión de la energía por tramos horizontales y verticales mediante ejes giratorios que hacían que la maquinaria, todavía rústica, se moviese. Es por esta similitud con los "mill buildings" en base a los parámetros que los definen, y aparte de que se pueden considerar, siguiendo las tesis reflejadas al principio de este capítulo sobre las bases socio-económicas valencianas, como los antecedentes o los orígenes de la industria moderna de la región de finales del XIX y del siglo $X X$, que se ha motivado su inclusión en el primer apartado de este capítulo de esta tesis doctoral.

\footnotetext{
338 En cuanto a la organización general de la producción en este edificio, en la planta baja se realizaba normalmente la fabricación propiamente dicha del papel, además de la sección de clasificación, limpieza y maceración de los trapos, y donde se encontraba la zona de morteros, la de tinas y la de satinado e igualado de las hojas. Toda la organización de la planta giraba en torno a las baterías de morteros que ocupaban gran parte de la superficie.

En el martinete, o mazo de satinar, se batían a golpes las hojas hasta darles el brillo adecuado. Esta operación era realizada habitualmente por niños, dado el estrecho espacio que quedaba disponible para el operario al lado del ingenio.

Tanto los morteros como los martinetes se ubicaban en la planta baja, con el objeto de que el propio terreno absorbiera los golpes y vibraciones durante su funcionamiento sin producir daños a la estructura del edificio.
} 


\section{TIPOLOGÍA CONSTRUCTIVA:}

Como regla general en el río Barxell, la estructura de la planta baja debía soportar las cargas y sobrecargas verticales de las restantes plantas del edificio, más el empuje horizontal del terreno al estar semienterrada en la ladera del valle en pendiente hacia el río. Se ejecutaba mediante un sistema de bóvedas de gravedad por $\operatorname{arista}^{339}$ y pilares de gran rigidez ${ }^{340}$. Se trataba de una tipología correspondiente a edificios con pilares de ladrillo, con forjados de bóveda de rosca ladrillo, tal y como las llamaba Guastavino (García-Gutiérrez, 2001) [Figura 229]. En esto se asemeja al edificio de Belper, el North Mill, de 1804, que tenía también el forjado de la primera planta abovedado, apoyando sobre pilares de piedra [Figura 230], si bien el sistema constructivo utilizado para la formación del forjado que soportaba el peso de la maquinaria del primer piso, la más pesada, estaba formado por bóvedas de arista frente a los sistemas en bóvedas de cañón empleadas en la misma época (o incluso anteriormente) en Inglaterra.

\footnotetext{
339 "La bóveda por arista se produce por la intersección de dos bóvedas de cañón que tienen un mismo plano de arranque e igual montea, tomando la agrupación de cuatro lunetos, por lo que presenta cuatro arcos frontales y se apoya en cuatro puntos.

Cuando la planta es cuadrada las directrices son iguales y por lo tanto los cuatro arcos frontales también. Si la planta es rectangular las directrices son una en círculo y la otra en elipse, con lo cual las líneas de clave o espinazo de cada uno de los cañones se encontrarán al mismo nivel. Reciben este nombre porque la intersección de los dos cañones da aristas por su intradós o superficie inferior. Por el contrario, en su extradós o superficie exterior, el encuentro adopta la forma entrante formando una acanaladura o media caña.

Las bóvedas por arista también reciben el nombre de vs estrelladas, por la figura que toman en planta, al ir subdividiendo progresivamente las superficie entre los nervios con otros intermedios que se entrecruzan, dando lugar a innumerables combinaciones." (Blat, 2007).

${ }^{340} \mathrm{El}$ uso de este tipo de estructuras se generalizó con el paso del tiempo en los molinos de la comarca por su buen comportamiento frente a empujes horizontales y verticales.
} 


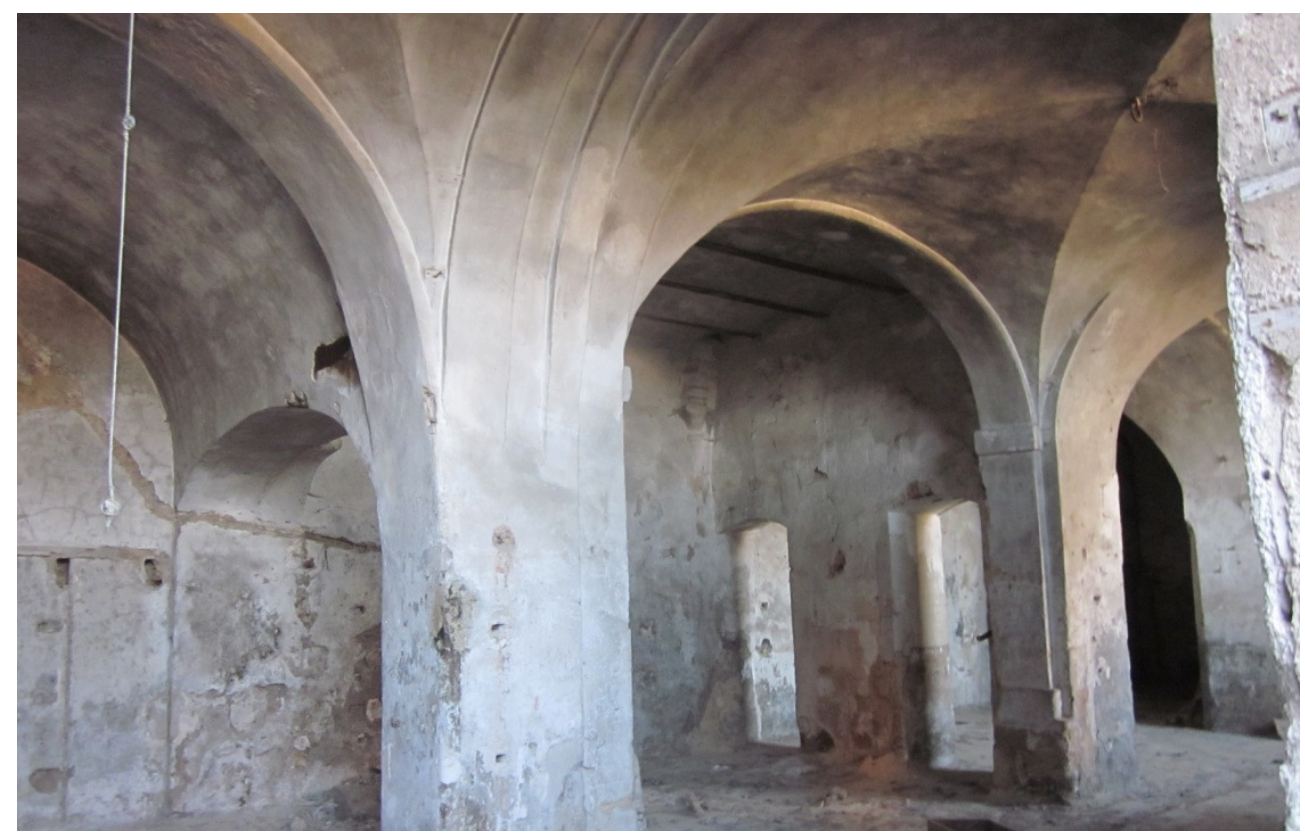

Figura 229. El batán de Brutinel o Molino viejo (construido entre 1760 y 1774), en el cauce del río Barxell. Como se ve, el sistema constructivo de formación del forjado de planta baja no coincide con el de los "mill buildings" ingleses. Aquí se trata de bóvedas de rasilla, que en este caso concreto se han enlucido con mortero de cal (Fotografía propia. Julio 2012).
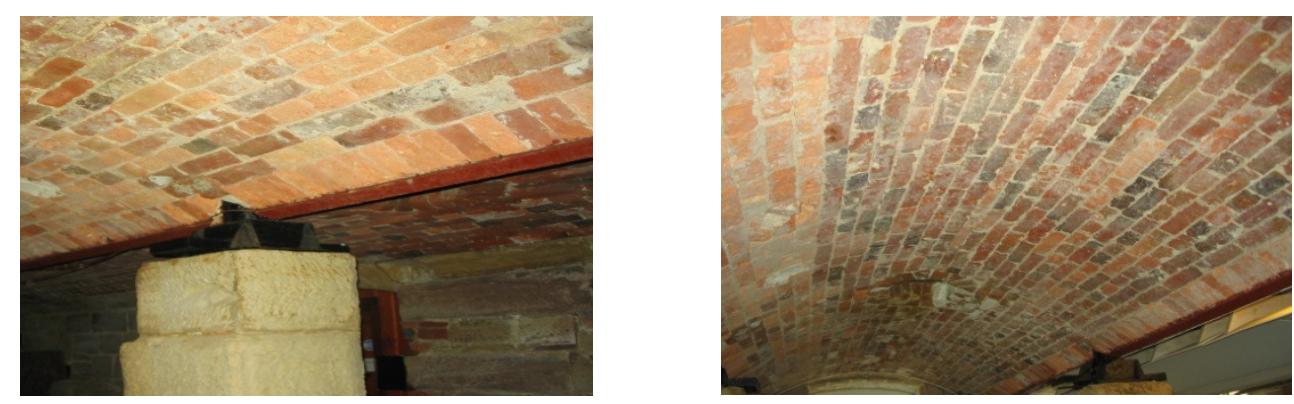

Figura 230. Forjado de la planta baja del North Mill, Belper (Inglaterra), 1804, con bóveda de cañón en ladrillo y pilares de piedra (propia). 
En general, los cerramientos de las plantas bajas estaban constituidos por fábrica de sillería de piedra tosca o toba en fachadas en contacto con el terreno a modo de muro de contención para contener el terreno de la ladera, y tapial ${ }^{341}$ en el resto de fachadas (como por el ejemplo el molino de Brutinel, en la Figura 231 y Figura 232, construido entre 1760 y 1774).

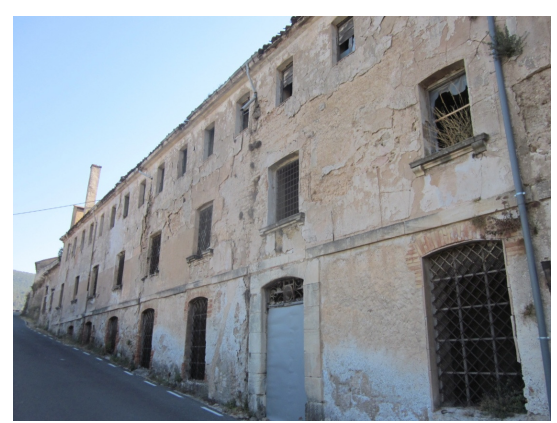

Figura 231. Molino Nuevo de Brutinel, en las inmediaciones del Molino Viejo. El aumento del número de ventanas en la planta superior, y debido a su proceso productivo, no tiene su origen en la necesidad de mayor iluminación, sino de ventilación, para el secado de las de papel. De ahí su nombre en valenciano hablado "ventanes" (Fotografía propia. Julio 2012).

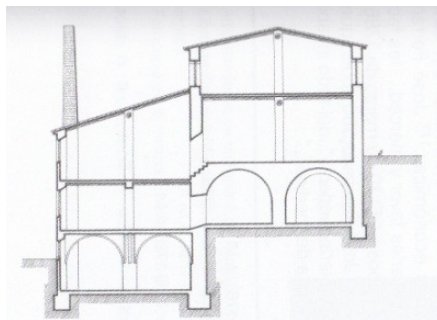

SECCIÓN A-B

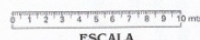

SCALA

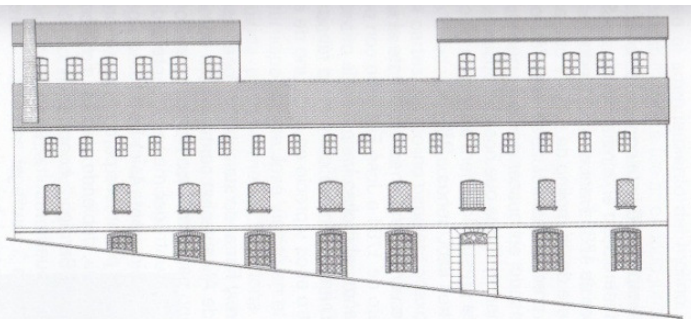

PACHADA A LEVANTE

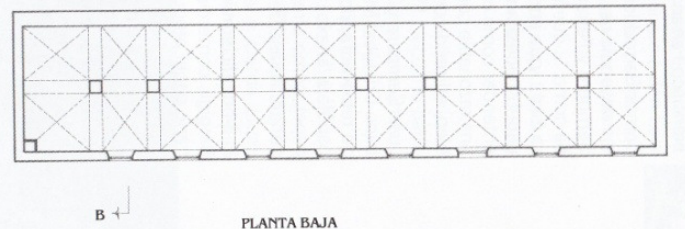

Figura 232. Molino Nuevo de Brutinel (Olcina, 2012).

${ }^{341}$ Antigua técnica consistente en construir muros con tierra arcillosa húmeda, compactada a golpes, empleando un encofrado de madera. 
Este tipo constructivo aseguraba la estabilidad de la construcción, formando un forjado de la 1a planta con gran capacidad portante que absorbía al mismo tiempo esos esfuerzos horizontales debidos al empuje de tierras [Figura 229, Figura 231 y Figura 232].

En las primeras y segundas plantas los cerramientos se construían con tapial y cantoneras de fábrica de sillar de piedra, que daba estabilidad a los paramentos verticales, y con muros de menor espesor conforme se iba ganando altura. La estructura de la primera planta estaba formada por pilares de ladrillo, vigas de madera y forjado realizado con viguetas de madera [Figura 232].

La cubierta del molino, que era el cerramiento de la segunda planta, estaba soportada por un entramado de vigas de madera sobre los pilares de ladrillo y jácenas también de madera ${ }^{342}$. Se construía siempre con teja árabe asentada con barro sobre tablero de ladrillo macizo, soportado por rastreles o listones de madera clavados sobre las vigas. Eso sí, como los "mill buildings" ingleses que se estaba construyendo, se trataba también de una planta totalmente libre.

Este modelo constructivo se aleja bastante del de los edificios que se estaban construyendo en el cambio de siglo del XVIII al XIX en la Inglaterra de la Revolución Industrial. Allí, generalmente, se estaban empezando a extender los edificios en altura, cuya solución constructiva se estrenaba con el hierro como material fundamental. En lo que sí que coincidían era en la utilización de cerchas de madera en la planta de cubierta, como es el caso de los contemporáneos North Mill o los de Arkwright, o incluso en otros ejemplos de la segunda mitad del XIX $X^{343}$. Asimismo, la última planta era totalmente diáfana con posibilidades de apertura de huecos en las dos fachadas paralelas principales.

\footnotetext{
${ }^{342}$ Estructura del tipo "king post", o cercha tradicional, dos barras diagonales que se encuentran en el vértice de la cercha y una barra horizontal que se sirve de cierre en la parte inferior.

${ }^{343}$ Estructuras del tipo "queen post", como las de la Figura 150 y la Figura 154, más diáfanas en su parte central.
} 
La escalera, generalmente estaba en un lateral del edificio, arrancando en la planta baja hasta la segunda. Se convertía en un elemento funcional indispensable del edificio, ya que durante el proceso de fabricación las hojas de papel eran transportadas varias veces de piso a piso, arriba y abajo. Pero a pesar de su importancia, estas escaleras eran habitualmente de dimensiones muy reducidas. Como todos los procesos productivos eran casi todos iguales, los edificios que se construían eran muy parecidos, con distribuciones muy similares ${ }^{344}$.

Este tipo de molino característico descrito, estuvo vigente durante más de un siglo, hasta la aparición de los procesos continuos de fabricación más modernos, incluso sirviendo para albergar con ligeras modificaciones, a industrias papeleras, y posteriormente, a otras industrias.

${ }^{344}$ El tipo constructivo se estandarizó en la cuenca, pudiéndose encontrar edificios casi idénticos. Sus formas constructivas no son autóctonas y pueden encontrarse edificios similares en cuencas papeleras de la misma época en Cataluña y otras partes de España. 


\section{LAS VENTANAS DE LOS MOLINOS PAPELEROS DEL BARXELL:}

En los molinos papeleros tradicionales de tres plantas de la cuenca del río Barxell, las fachadas recayentes al río seguían los siguientes estándares:

- En la planta baja y en la primera había huecos que coincidían con los ejes verticales de cada bóveda de la estructura.

- En la segunda planta, además, se duplicaban de forma que había un nuevo hueco entre cada dos de los de las plantas inferiores.

Esta disposición de huecos para iluminación y ventilación, que era la única que le permitía la estructura, tenía una clara doble función: la iluminación y la ventilación que el proceso de fabricación del papel requería ${ }^{345}$. Como se ve, en los espacios industriales siempre se persiguen los mismos objetivos, salvando las dimensiones de cada coyuntura económica.

La seriación en la ubicación de las ventanas de la planta baja era la única posible estructuralmente hablando, dado que los pilares de sillar que soportaban las bóvedas impedían su emplazamiento en otro lugar diferente de la fachada. Además, así se proporcionaba gran uniformidad de iluminación en todo el fondo del edificio.

Por su parte, todos los huecos se abocinaban interiormente con objeto de recoger la mayor cantidad de luz posible del exterior. Esta misma solución en las jambas de las ventanas se realizará más de 100 años después en otros edificios fabriles de principios del siglo XX (Ej. La fábrica de seda de Lombard de Almoines) [Figura 325].

\footnotetext{
${ }^{345}$ La ubicación de los huecos en la planta baja era la misma que en la planta primera, con ventanas de tamaño similar. Esta estaba toda ella sobre el nivel del terreno, por lo que los huecos se repetían en las fachadas opuestas, con lo que podía así lograrse mayor cantidad de luz.
} 
Las ventanas de la última planta adoptaron en el argot papelero local la denominación de "ventanes", cuando en realidad en la lengua autóctona se denominan "finestres", precisamente por permitir la ventilación necesaria para el secado de las láminas de papel [Figura 233 y Figura 234]

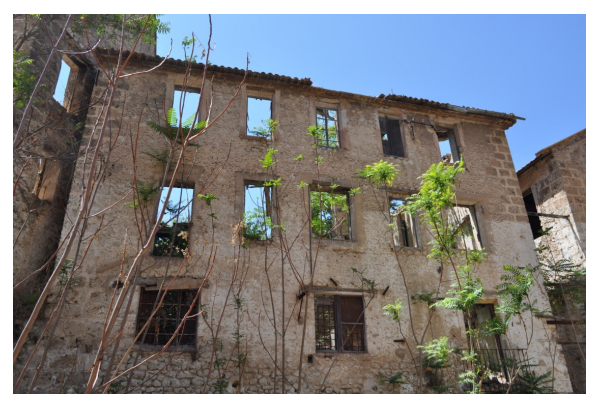

Figura 233. Molino en el Río Molinar. En este caso la duplicación de ventanas se hace ya en la planta primera, no solo en la segunda como en el caso anterior (siglo XVIII) (Fotografía propia. Julio 2012).

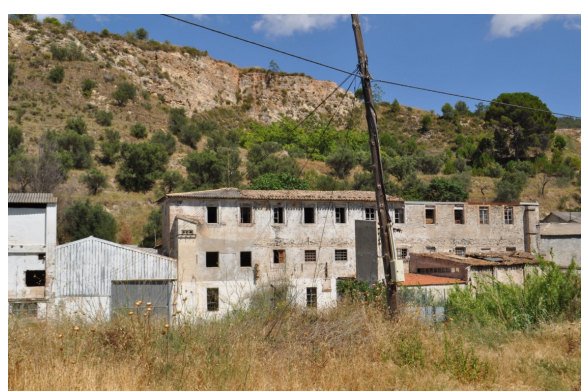

Figura 234. Molino en el Río Molinar (segunda mitad siglo XVIII) (Fotografía propia. Julio 2012).

Posteriormente, los molinos que se construyeron en el río Serpis, a principios del siglo XX, tenían varias plantas, precisamente para conseguir mayor espacio de producción, si bien sus fachadas todavía seguían siendo portantes, y la relación hueco/fachada no alcanza los valores que lo habían hecho en la misma época en Gran Bretaña [Figura 235]. 


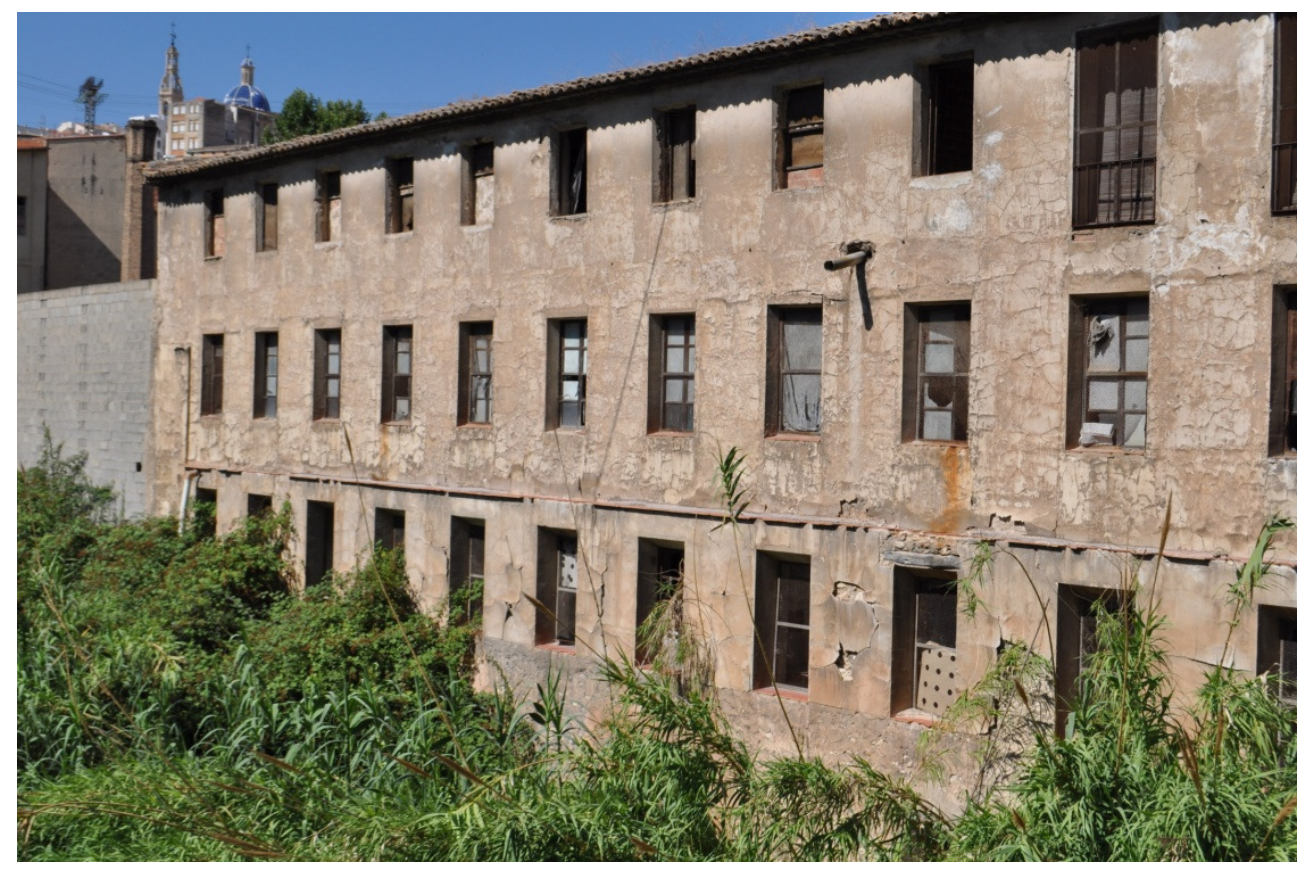

Figura 235. Molino en el Río Serpis. Principios del siglo XIX (Fotografía propia. Julio 2012).

En la Figura 235, los machones de la fachada no permiten la diafanidad suficiente. A pesar de ser un escalón siguiente en la tipología de molinos alcoyanos, todavía no recoge los avances tecnológicos que se estaban viviendo en Inglaterra y otros países europeos, predominando la construcción tradicional, autóctona. Y eso a pesar de que en cuanto a maquinaria, sí se iba introduciendo las novedades aportadas por la máquina de vapor. 


\section{ESTRUCTURA. LAS BÓVEDAS:}

El uso de las bóvedas de rasilla para soportar los forjados de la primera planta se generalizó en los molinos de la cuenca del Barxell (Olcina, 1986), porque resolvía bien los esfuerzos verticales propios del peso del edificio y de su uso ${ }^{346}$ :

"Estas bóvedas de arista, se construían levantando unos arcos de sillarejo de medio punto, sobre los que se componía una membrana de ladrillo. El encuentro de las membranas de cada par opuesto de arcos, definía las aristas que daban nombre a este modelo estructural. La ortogonalidad de las trazas de las aristas se conseguía regularizando el módulo de la trama, con pilastras de sillería, generalmente de sección cuadrada. Los arcos de sillarejo, de pilar a pilar, se intercambian sirviendo de guía y cimbra perdida en la construcción de estas bóvedas, que se construyen con una rosca de rasilla maciza hecha a mano, doblada con un tablero, también de rasilla cerámica maciza. [...].

El que la dimensión tipo de estas bóvedas se estabilizara alrededor de la medida citada (20 palmos $\cong 4,5 \mathrm{~m}$ ) se explica observando que las luces entre las pilastras que soportaban estas bóvedas y que se prolongan hasta la cubierta, eran cubiertas en la primera planta por jácenas y vigas de madera, para formar el forjado del suelo de la última planta. Esta medida de 4,5 $\mathrm{m}$ es una de las luces máximas que pueden soportar este tipo de vigas de madera del país para las condiciones de carga y flecha que se les exigía."

Así pues, según este autor, las bóvedas se construían mediante arcos de sillarejo de medio punto sobre pilastras de sillería. Sobre los arcos se componía una doble o triple membrana de ladrillo macizo de 1 pulgada de espesor $(2,54 \mathrm{~cm})$, "macizadas con un relleno humedecido y compactado de tierra arcillosa, arena, grava y piedra de río, transmitiendo todos los esfuerzos a las pilastras ${ }^{\prime 347}$ [Figura 236].

\footnotetext{
${ }^{346}$ Aunque la bóveda de 20 palmos constituye un tipo-patrón utilizado en un gran número de edificios de la cuenca, también suelen encontrarse bóvedas de otras medidas ligeramente superiores e inferiores a esta.

${ }^{347}$ Sobre este relleno "se solaba con baldosas cuadradas de barro cocido", que era el mismo pavimento que el utilizado en la segunda planta.
} 


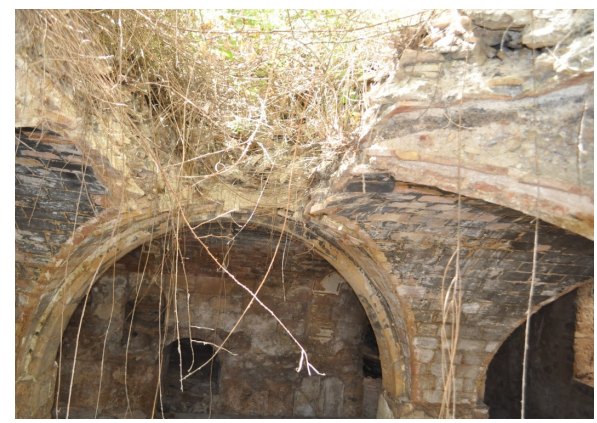

Figura 236. Molino en el Río Molinar. Bóvedas con rasilla (no de canto) y pilares cruciformes de ladrillo macizo (Fotografía propia. Julio 2012).

Si se compara esta información gráfica con los edificios del capítulo 3 anterior, se deduce que esta tipología de forjado no se encuentra en ninguno de los mills estudiados en Inglaterra ubicados en los cauces de los ríos, en lo que respecta al forjado de la planta primera. Se trata pues de una arquitectura vernácula, de la que no se pueden obtener analogías ni consecuencias de la evolución constructiva de los molinos ingleses, al menos, de aquellos construidos durante el siglo XIX [Figura 237].

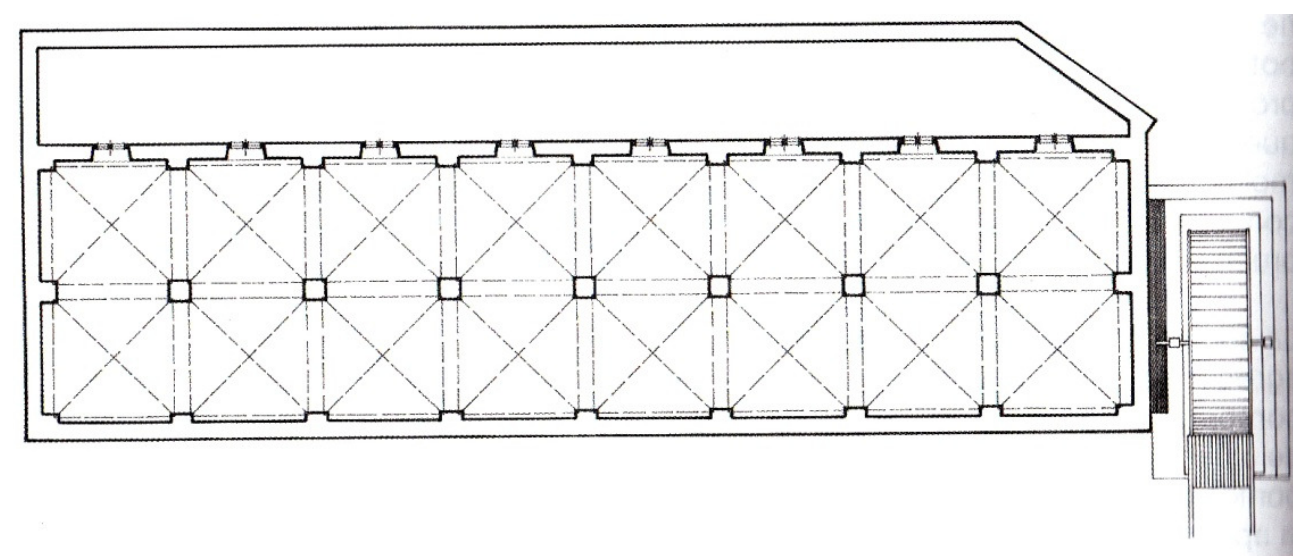

Figura 237. Molino de Quicalo (Río Barxell). Planta lineal de dos crujías, estrecho y alargado, con ventanas solo en la fachada que no sujeta las tierras de la ladera. A la izquierda de la fotografía, la rueda hidráulica que era accionada por las aguas del río Barxell (Olcina, 2006). 


\section{ESTRUCTURA BAJO CUBIERTA:}

La cubierta, como regla general, es ligera, sin peso excesivo, y a base de teja árabe. Se trataba de cerchas de madera, que apoyaban sobre los muros laterales del edificio a los que transmitían las cargas. En muchas ocasiones era planta libre que permitió instalar la primera maquinaria que venía importada de los países que estaban tecnológicamente más avanzados, generalmente de mayor tamaño.

La evolución que sufrieron consistía en la utilización de hierro, especialmente de fundición en las últimas décadas del siglo XIX, aunque la Ditherington Mill ya lo había hecho a principios de siglo, lo que como allí además del aligeramiento posibilitó aumentar la luz.

Así se comprende que los materiales metálicos acabarían imponiéndose en las primeras décadas del siglo pasado en la construcción de estructuras para edificios industriales, no solo en Alcoi sino en el resto de España, como había ocurrido previamente en los edificios industriales europeos durante el siglo XIX.

Por tanto, empezaron a emplearse esos nuevos materiales de construcción porque como allí, también habían demostrado un mejor comportamiento mecánico e ignífugo en Inglaterra.

Según Vidal (Vidal, 1981), una de las soluciones que se adoptó para las cubiertas de finales del siglo XIX, fue la de cerchas mixtas de madera, fundición ${ }^{348}$ y tirantes de acero de sección circular, sobre las que descansaban los tabloncillos para la cubierta [Figura 238]. Esto revela ya un cierto conocimiento teórico y mecánico de los materiales. Los esfuerzos de flexo-compresión eran soportados por la madera, los de compresión por la fundición, y los de tracción por las barras de acero, lo que indica la introducción temprana de este último material, puesto que

\footnotetext{
${ }^{348}$ Realizada en las fundiciones de la ciudad que realizaban piezas de maquinaria.
} 


\section{alrededor de esta misma época se empezó a extender su utilización en Inglaterra ${ }^{349}$.}

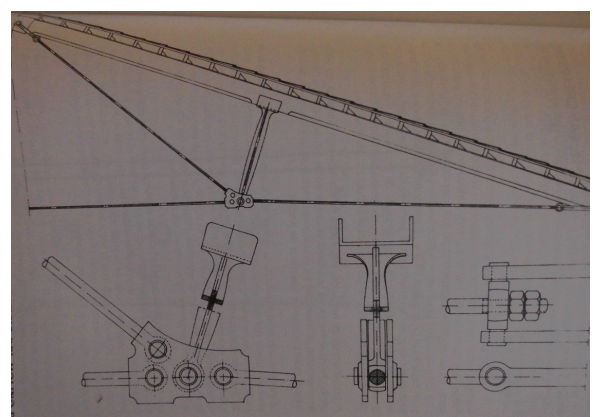

Figura 238. Molino de Gracia (Río Barxell), a finales del siglo XIX. En él se utilizaron cerchas mixtas de madera de pino, con fundición en los elementos sometidos a esfuerzos de compresión y tirantes de acero trabajando a tracción, lo que se traduce en una gran innovación tecnológica (Olcina, 2006).

\footnotetext{
${ }^{349}$ El primer edificio británico realizado íntegramente en acero fue el National Liberal Club, en Londres, de 1879, si bien en la década de 1860 ya se había utilizado para los raíles de los trenes, ejes y calderas a presión. Alrededor de 1900, el acero ya era habitual en las construcciones de ese país, aunque todavía eran muy comunes los tradicionales pilares de hierro fundido apoyados en muros de carga (University of the West of England, Bristol, en http://fet.uwe.ac.uk/conweb/commercial/ ironandsteel/section6.htm).
} 


\section{LAS COLUMNAS DE FUNDICIÓN:}

Los pilares de sillería y de fábrica de ladrillo, que tradicionalmente eran utilizados para soportar los forjados de bóveda de arista de la planta baja y los de la planta primera y segunda, fueron sustituyéndose en los nuevos edificios a partir de la segunda mitad del siglo XIX por columnas de fundición, siendo en primer lugar, en la planta bajo cubierta (Vidal, 1981).

Según este autor, la aparición de estos elementos estructurales coincide aproximadamente con la llegada de la "planta libre, evitando todo obstáculo interior que limitara la instalación y el funcionamiento de las nuevas máquinas", cada vez más grandes y que gradualmente iban automatizando los procesos de producción. Además, este material también podía aligerar la estructura del edificio, como ocurriera del mismo modo ya en el edificio del Ditherington Mill, a finales del XVIII en Inglaterra. Comparando estos dos datos, existe pues una diferencia de unos 50 años en el empleo de este material.

Estas columnas de fundición se componían habitualmente de una basa, un fuste y un capitel. Normalmente la unión de la columna al resto de la estructura del edificio se realizaba mediante una placa de anclaje ${ }^{350}$, siguiendo un modelo completamente consolidado en Inglaterra, en donde no se tardaría ya en usar el hormigón y el acero como principales materiales de construcción [Figura 239 y Figura 240]. Tómese como referencia, como ya se comentó en el apartado 3.2.2, que las primeras columnas de fundición en edificios fabriles aparecieron en el

\footnotetext{
${ }^{350}$ Las columnas del edificio del Molino de Gracia, estaban formadas por una basa que se apoyaba sobre una placa cuadrada de dos palmos de lado. Su sección cilíndrica, de $17 \mathrm{~cm}$ de diámetro exterior, estaba rematada a $90 \mathrm{~cm}$ de altura por una moldura que separaba a la basa del fuste. Este último interrumpía a tres palmos del capitel y mediante otra moldura se unía con este mediante un prisma rectangular de sección cuadrada. Estas superficies planas de las caras del prisma posibilitaban el montaje sobre la columna de las silletas de los árboles de transmisión. El nudo estaba formado por la cajera del capitel con dos guías laterales para el asiento de las jácenas, unidas estas mediante bulones que aseguraban la continuidad de los tramos, formando un verdadero nudo de gran rozamiento, resistente por tanto a los esfuerzos horizontales (Olcina, 1986).
} 
Masson Mill, de Arkwright, en 1783, y las primeras que fueron huecas, se utilizaron en la Fábrica de hilos de Salford, de Phillips, Wood \& Lee, en 1799, de la mano de la fundición de Boulton \& Watt. Como se ve, el retardo existente entre las dos zonas comparadas es evidente, puesto que fue en aquel país donde la construcción evolucionaba de forma pionera, tratando de adaptarse a los requerimientos industriales.

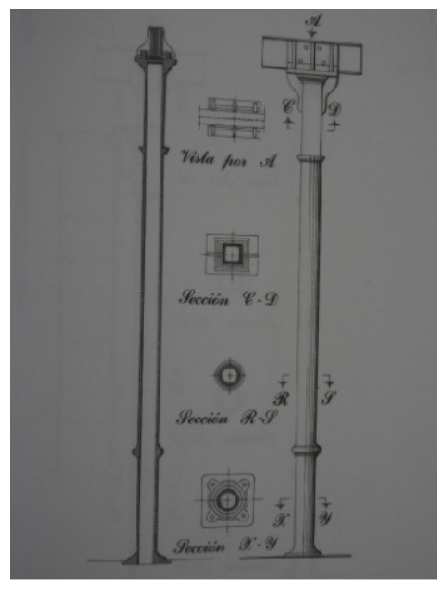

Figura 239. Columna de fundición del edificio del Molino de Gracia, segunda mitad del siglo XIX (Olcina, 1986).

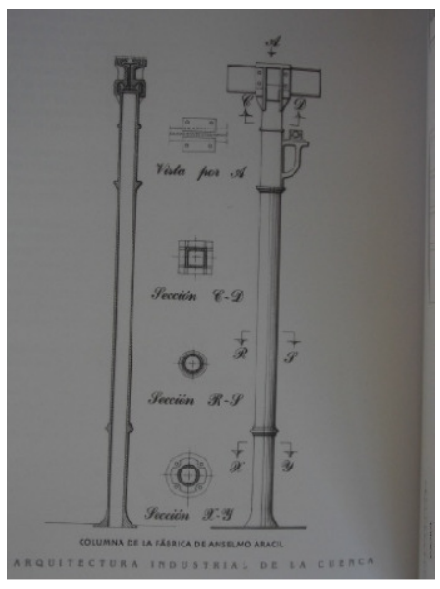

Figura 240. Columna de fundición de la fábrica de Anselmo Aracil, segunda mitad del siglo XIX (Olcina, 1986). 


\section{EL EDIFICIO DE LA ALGODONERA O "LA COTONERA":}

Uno de los edificios más singulares en la cuenca del río Barxell fue el construido por la familia Barceló en las inmediaciones del puente de Algezares a mediados del siglo XIX, conocido desde entonces como La Algodonera o La Cotonera (García, 2001).

Este edificio es de planta rectangular de $16 \times 39 \mathrm{~m}$, con una planta baja y dos alturas, distribución idónea para la transmisión de energía mediante ejes giratorios accionados desde la rueda hidráulica [Figura 242], tal y como se estudió en el capítulo correspondiente, acerca de los factores influyentes en la morfología de los edificios fabriles "mill buildings" \{confrontar el apartado 3.3 más atrás\}, a los que este edificio, junto con la conformación en varias plantas, se podría correlacionar.

Sin embargo, una característica del edificio la constituye su estructura, construida enteramente de madera de pino vista, solución constructiva completamente diferente a los molinos que se habían construido en la ladera del Barxell, que eran de ladrillo ${ }^{351}$. Tampoco se encuentra similitud alguna con los pilares empleados en su época en las fábricas inglesas, que ya eran de fundición de manera generalizada.

\footnotetext{
${ }^{351}$ La estructura del edificio está formada por soportes prismáticos de sección cuadrada, biselados en sus cantos, dispuestos cada 3,33 m en el centro de la planta del edifico en dirección longitudinal. La luz, de 7,7 m entre estos soportes y los muros de cerramiento laterales del edificio, se resuelve mediante jácenas de madera. Sobre estas unos rastreles clavados a ellas cada $70 \mathrm{~cm}$, que soportan los entarimados de madera que forman el suelo de la primera y la segunda planta (Cucó, 1978).

Algunos de estos soportes de la planta inferior fueron sustituidos en algún momento por pilares de fundición, posiblemente como consecuencia del deterioro de los originales. Estos se prolongan desde la planta baja hasta la cumbrera, sirviendo de apoyo central a los pares que soportan la cubierta. Estos pares están arriostrados con sendos tornapuntas que los unen a los soportes centrales en cada vano. La cubierta, de teja árabe, está montada sobre un entarimado de madera de características muy similares a los que forman el suelo de cada planta (Olcina, 1986).
} 
Según este autor citado 3 párrafos antes (García, 2001), los muros de cerramiento del edificio son de piedra arenisca en la fachada principal, y tosca en la restantes, y se interrumpen de forma ordenada en el centro de cada vano de la estructura por los huecos de los ventanales del edificio. Estas aberturas, que mantienen la misma ubicación en las tres plantas, son abocinadas interiormente para permitir el paso de la mayor cantidad de luz posible al interior ${ }^{352}$ [Figura 241 y Figura 242].

Por su parte, esta misma regularidad había quedado consolidada desde los primeros edificios del Valle del Derbyshire desde el inicio de la Revolución Industrial, en las últimas décadas del siglo anterior.

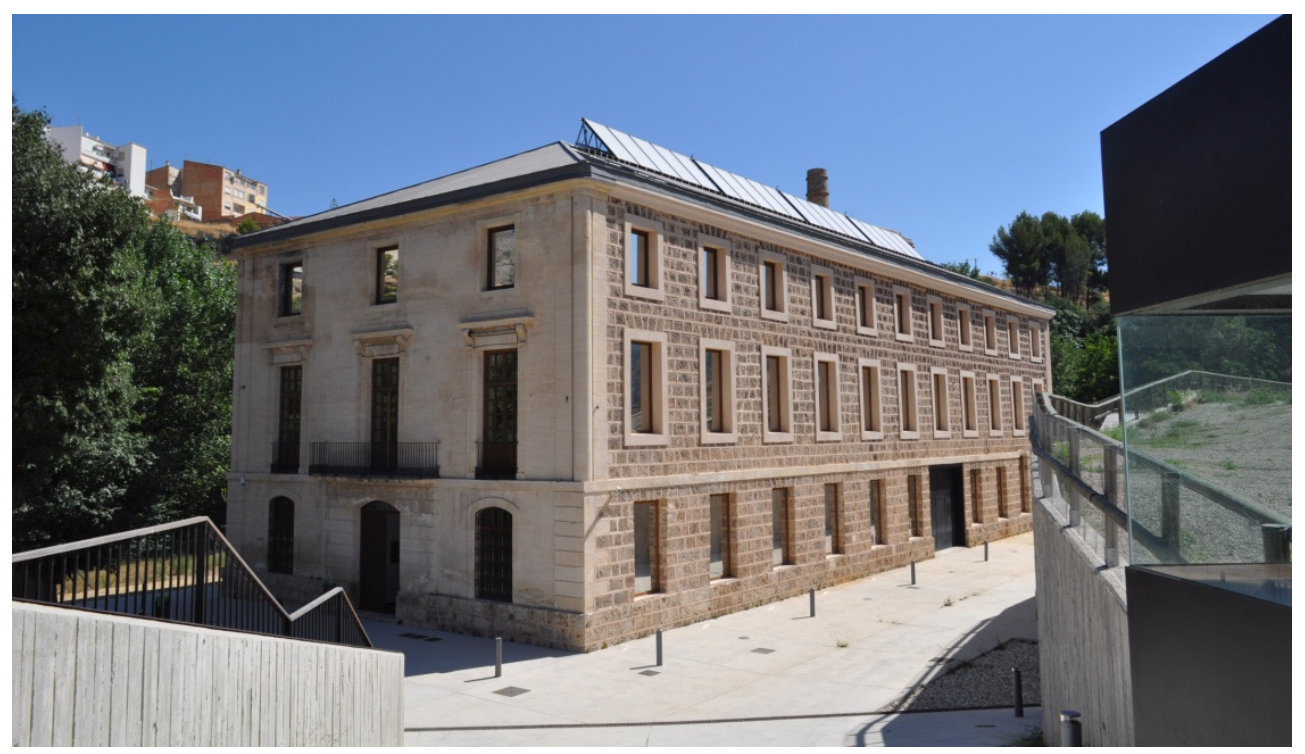

Figura 241. La Cotonera (Río Serpis). Se trata de un edificio para la fabricación textil de la $2^{a}$ mitad del XIX. Aunque solo tenga 2 plantas, y los materiales empleados sean completamente diferentes a los que se estaban utilizando en Inglaterra en la misma época, recuerda a aquellos edificios al tener una base rectangular, alargada, con distribución de ventanales uniforme (Fotografía propia. Julio 2012).

352 Pocas décadas después se construyó una chimenea de fuste troncocónico, construida en ladrillo, y que se integró en el edificio como elemento característico. 


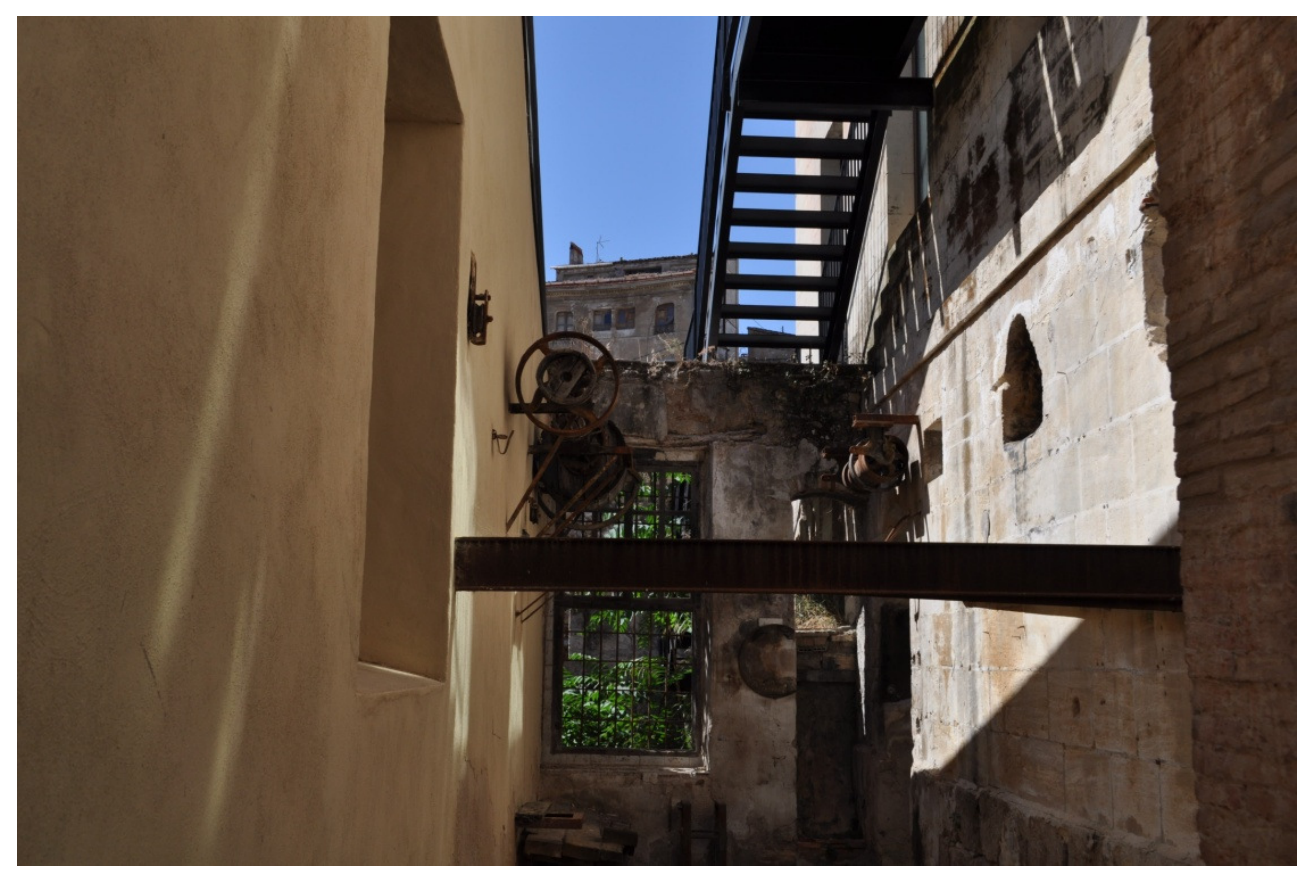

Figura 242. La Cotonera (Río Serpis). En esta fotografía se muestra el lugar donde quedaba instalada la rueda hidráulica de eje horizontal que accionaba toda la maquinaria de producción, a modo de punto único, tal y como también lo hacían las fábricas anteriores en Inglaterra (Fotografía propia. Julio 2012). 


\subsubsection{La fábrica de Ferrándiz, Alcoi, 1909.}

A comienzos del siglo $\mathrm{XX}$, el modernismo y el eclecticismo son las dos corrientes artísticas que de forma generalizada conviven en todo el estado español. Especialmente la primera de ellas se establece con fuerza en la ciudad de Alcoi (Doménech, 2010), beneficiada económicamente por la industria textil ya asentada de forma extendida, tal y como se ha visto en el párrafo anterior.

El modernismo se extiende unos años después de un relativamente intenso proceso de industrialización. Esa pujanza económica producía grandes beneficios en la burguesía empresarial, parte de los cuales se invirtieron en diferentes edificios de estética modernista ${ }^{353}$.

La "arquitectura vernácula popular racionalista tenía que compatibilizarse con los nuevos tiempos modernos que se avecinaban", y con las influencias de otros países tecnológicamente más avanzados. $Y$ es en Alcoi, mayor punto industrial de la región valenciana, donde se proyectarán importantes edificios modernistas como espacios fabriles significativos (Colomer, 2002) ${ }^{354}$.

La escasa burguesía adinerada invierte en diseño ${ }^{355}$, y es precisamente en el conjunto modernista de las fábricas de Ferrándiz y Carbonell, donde se puede encontrar un buen ejemplo de espacios fabriles merecedores de referencia en

\footnotetext{
353 Pero la otra cara de la moneda de comienzos de este siglo fue la de los graves problemas de hacinamiento e insalubridad de las viviendas obreras, así como también el movimiento reivindicativo de las clases trabajadoras.

Por otro lado la Gran Guerra, de la que como se sabe España no tomó parte de forma directa, produjo un efecto negativo en el país, que ya de por sí sufría comparativamente un retraso económico e industrial respecto de otros países europeos, según las estadísticas económicas (Torró, 2002), aunque se preveían nuevos cambios políticos (Alonso de Armiño, 2002).

${ }^{354}$ Los lugares elegidos por la burguesía industrial fueron la calle San Nicolau, la Plaza de España, el entorno de la Glorieta y la calle Juan Cantó.

${ }^{355}$ Es durante el siglo XIX cuando en Alcoi se desarrolla la industria, con ella una clase obrera concienciada y organizada, y una burguesía industrial que no solo produce hilo y tela, sino también funda sociedades recreativas, organizaciones empresariales y lugares para el desarrollo de sus actividades asociativas.
} 
este estudio. Así, como buen ejemplo de arquitectura alcoyana vanguardista, se tienen estas dos fábricas del arquitecto local Vicente Pascual| ${ }^{356}$, así como su conocida Casa del Pavo ${ }^{357}$.

La construcción de estas dos fábricas se encuadra dentro del impulso industrial local, basado por entonces en la actividad textil, y cuyo origen provenía sobre todo de la segunda mitad del siglo XIX ${ }^{358}$. De hecho, las consecuencias de ello en la ciudad no solo fueron económicas, sino también culturales, sociales y estéticas, situándola en el mapa español como referente industrial.

En cuanto a su encaje dentro de la acepción de "mill building" se puede confirmar en tanto en cuanto son edificios en altura; con diferentes cuerpos rectangulares en los que predomina una de las dos dimensiones; cuya producción está accionada por motor único, en este caso una máquina de vapor (aunque posteriormente la electricidad); en un espacio industrial donde todo el proceso se encuentra concentrado y cuyas máquinas dependen de ese punto motriz. La forma de conseguir la iluminación en su interior es claramente intencional, mediante la disposición regular de grandes ventanales. Además, en su diseño se aleja totalmente de la Fábrica Real de Paños que ya existía un siglo antes en la localidad, en los que no se cumple ninguna de las características mencionadas. Insistir pues en la conveniencia de su inclusión en esta tesis doctoral por sus bases similares a los "mill buildings" ingleses de finales del siglo XVIII.

En este caso es remarcable su ligera aproximación, salvando las distancias y la magnitud económica y dimensional, al "mill" tipo de Fairbairn (Fairbairn, 1863) [Figura 79], unos 70 años anterior, en tanto en cuanto se trata de grandes

\footnotetext{
${ }^{356}$ Vicente Pascual Pastor (1865 - 1941).

357 "El arquitecto Vicente Pascual Pastor había seguido en su proyecto las configuraciones curvilíneas y los cánones del Art Nouveau que estaban de moda en Europa. En la misma calle, dos casas más arriba, se encontraba el Círculo Industrial de Alcoy, lugar frecuentado por la burguesía empresarial alcoyana, también muy concurrido por profesionales liberales, artistas, músicos y poetas." (Doménech, 2013).

${ }^{358}$ Con la molinería que se estableció en los ríos Barxell, Molinar y Serpis a su paso por la ciudad.
} 
fachadas con espacios huecos para iluminación y ventilación dispuestos de forma regular en cada una de las diversas plantas. Al mismo tiempo, y como se procede a valorar, en su interior se aproxima al edificio inglés coetáneo East Mill [Figura 80], a pesar de que en este último sus fachadas ya son prácticamente diáfanas, todas ellas conformadas por huecos de ventana tan solo interrumpidos por una liviana estructura de hierro.

Por su parte, sendas fábricas que conforman el conjunto, la de Ferrándiz y la de Carbonell, se localizan en un entorno urbano singular: una plaza cuadrada que se atraviesa diagonalmente entre los dos enormes edificios con plantas en forma de L, que conforman los dos ángulos opuestos cerrados [Figura 244]. 


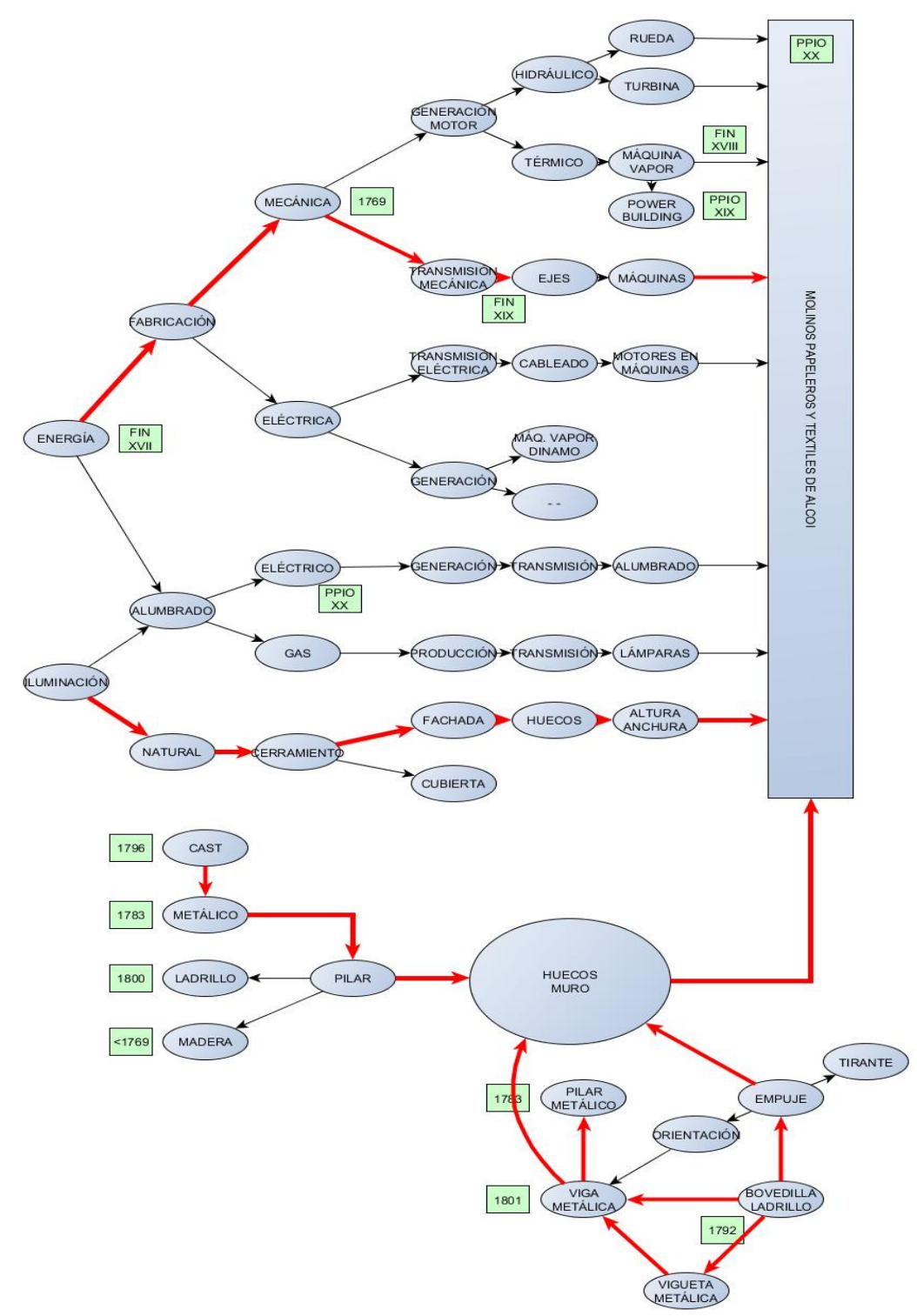

Figura 243. Esquema conceptual donde se reflejan los orígenes tecnológicos en los que se basa la fábrica de Ferrándiz, tomando como referencia los progresos de los sistemas constructivos de los "mill buildings". 
En este mapa conceptual [Figura 243] se sigue la consecución tecnológica que sigue, dentro de todas las posibilidades vistas en el capítulo anterior \{confrontar los factores vistos en apartado 3.3 más atrás\}: en primer lugar, como nota característica, la iluminación natural se obtiene a través de los huecos de fachada del muro perimetral portante, cuyo porcentaje alcanza a casi el $40 \%$ respecto de la totalidad de la fachada ${ }^{359}$, como se verá más adelante [Figura 244].

En lo que respecta a su estructura, sí se observa un claro y generalizado uso temprano del acero en vigas, así como en las viguetas para la formación de los forjados [Figura 245], en comparación con otros espacios de producción de la zona que se habían estado realizando a base de madera durante el siglo pasado (s.

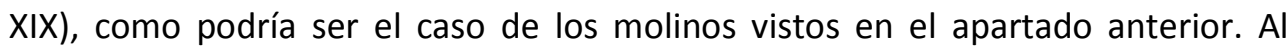
mismo tiempo, estas vigas descansan sobre pilastras que conforman la fachada [Figura 246], en cierta diferencia con aquellos muros portantes que no permitían grandes aperturas para la iluminación natural. Asimismo, y de forma general, hay un uso extensivo del acero en vigas también de celosía que permiten grandes luces y ligereza estructural, que junto con la casuística comentada de las pilastras de fachada, proporcionan abundante iluminación natural [Figura 246].

Además de su comparación anterior con el East Mill, la innovación en el uso del hierro en la estructura interior es un sistema comparable al utilizado por la Marshall's Temple Mill, de 1842 \{confrontar el edificio en apartado 3.2.8 más atrás\}, y que también disponía de ventanales de considerable tamaño aún siendo sus fachadas portantes.

En cuanto al suministro energético se utiliza inicialmente el vapor ${ }^{360}$, y posteriormente la electricidad, que se implantó tempranamente poco después de sus puesta en marcha, en las primeras décadas del siglo XX.

\footnotetext{
${ }^{359}$ El East Mill de Belper, construido alrededor de la misma época, rondaba en casi el $90 \%$.

${ }^{360} \mathrm{Si}$ bien sus chimeneas ya han desparecido.
} 


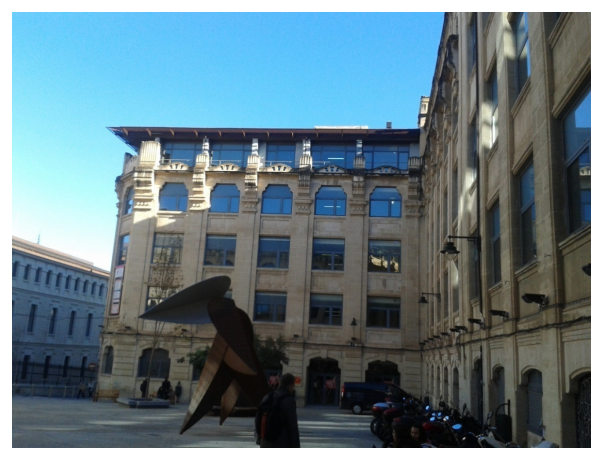

Figura 244. Fábrica de Ferrándiz, construida entre 1909 y 1917. Estado actual, en Plaza Ferrándiz y Carbonell, Campus de la UPV en Alcoi. Fachada suroeste (Fotografía propia. Diciembre 2013).

En cuanto a su estructura interior esta está compuesta de soportes metálicos de acero (sistema constructivo que ya se había empleado más de un siglo antes, como por ejemplo en la fábrica de Arkwright de Cromford), muros portantes en fachada (a modo de pilastras) y forjados de bóvedas de ladrillo apoyando en viguetas metálicas. Sus vigas metálicas en celosía están roblonadas, consiguiendo grandes luces entre pilares [Figura 239 y Figura 240].

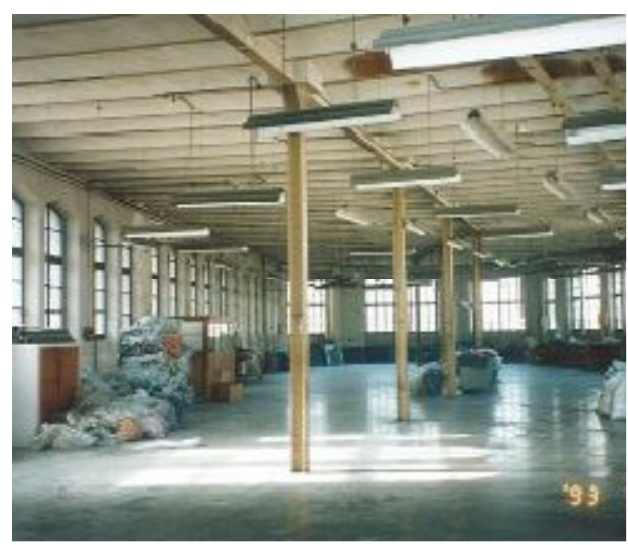

Figura 245. Interior de la fábrica de Ferrándiz, antes de su reforma.

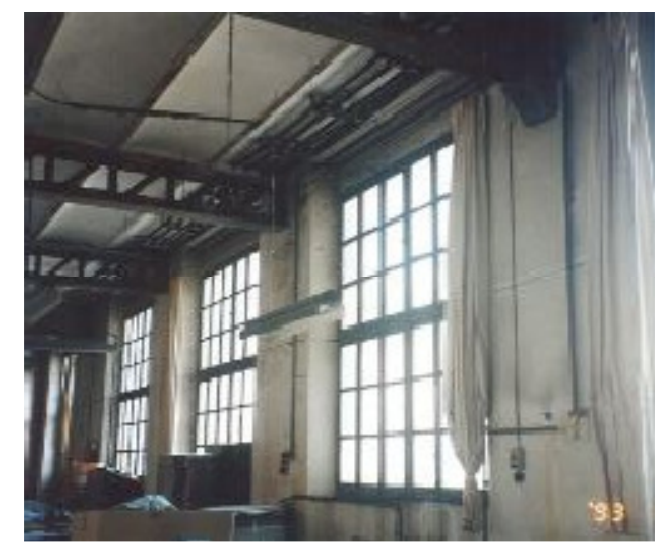

Figura 246. Fábrica de Ferrándiz, interior antes de su reforma. 


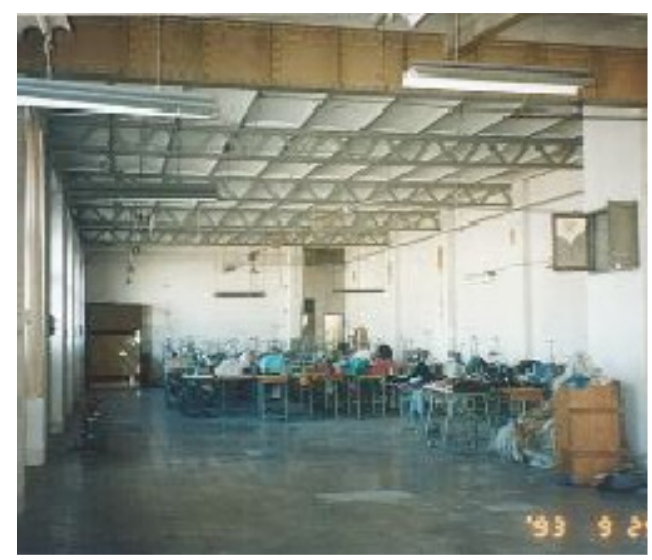

Figura 247. Fábrica de Ferrándiz, interior antes de su reforma.

Asimismo, dispone de vigas metálicas en celosía tipo Warren, propias de las grandes fábricas de la primera mitad del siglo XX, y vigas de alma llena roblonada, que soportan los forjados a base de viguetas en doble $T$ de donde arrancan las bovedillas de rasilla (con interdistancia en general $<1 \mathrm{~m}$ ) [Figura 247].

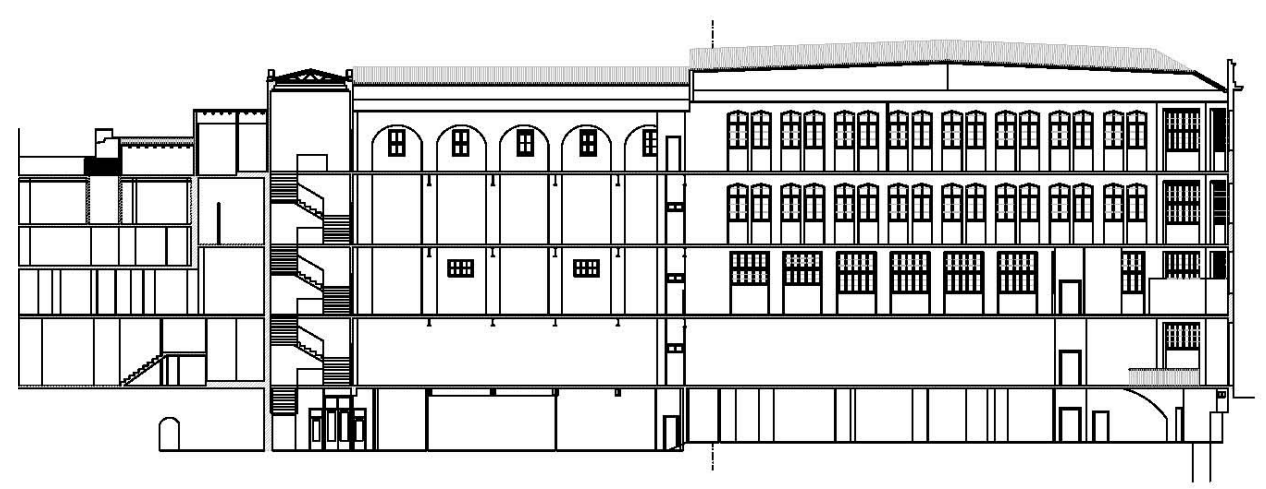

Figura 248. Sección de la fábrica de Ferrándiz, estado actual (S/E). La Figura 245 se corresponde con la $2^{a}$ planta a la derecha del plano, y la Figura 246 con la $1 \stackrel{a}{a}$ planta. 
Además de lo comentado sobre su apariencia al "mill" de Fairbairn y al East Mill de Belper, estas cuatro fotografías anteriores [Figura 245, Figura 246, Figura 247 y Figura 248] recuerdan asimismo a las fachadas e interiores de los espacios de producción ingleses con tipología mill building construidos durante la segunda mitad del siglo XIX, como el de Saltaire's Mill, de 1853 [Figura 139], en cuanto a sus gruesos machones exteriores, grandes ventanales con distribución regular y número de alturas, siempre salvando la distancia temporal y la evolución tecnológica en la construcción. Ahora bien, para establecer una verdadera comparación tipológica y constructiva, se ha de establecer una semejanza con todo lo acontecido en Inglaterra y América a principios del siglo XX, puesto que allí ya se empezaba a emplear el hormigón con regularidad, mientras que en Alcoi, como se ve en estos edificios, todavía no, siendo el acero un material novedoso.

Por todo lo dicho y con ayuda de estas dos fotografías de interior [Figura 245 y Figura 246], junto con las 2 anteriores de fachada, se puede afirmar que la fábrica de Ferrándiz sigue la misma tipología que un mill building, estudiado en el apartado anterior \{confrontar en apartado 3.2.\}, en cuanto que:

1. La producción es mecánica, ya que utiliza la energía para el accionamiento de la maquinaria.

2. Disponía de sistema energético propio, mediante máquina de vapor.

3. Se trata de un edificio de producción centralizada: todo el proceso de producción se realiza dentro de un mismo espacio.

4. Tiene varias plantas, por lo que se viene a llamar un "edificio en altura", siendo la distancia entre forjados considerable, de 4,62 m, sobradamente grande para los operarios pero muy adecuada para la entrada de iluminación [Figura 206]. 
5. Se caracteriza por su intensa iluminación interior gracias a sus grandes ventanales. En la calle Sant Doménech [Figura 249] se alcanza en la primera planta hasta un $60 \%$ de superficie de huecos, y en la $2 \stackrel{a}{a}, 3$ a y 4 a alrededor del $40 \%$; en la fachada recayente a la plaza Ferrándiz y Carbonell [Figura 250], sobre el 50\%; y en la calle Bartolomé J. Gallardo, también cerca del $50 \%$, encontrándose cerca del orden de los últimos mill buildings estudiados en Inglaterra, sobre todo los de la segunda mitad del siglo XIX (40 ó 50 años antes).

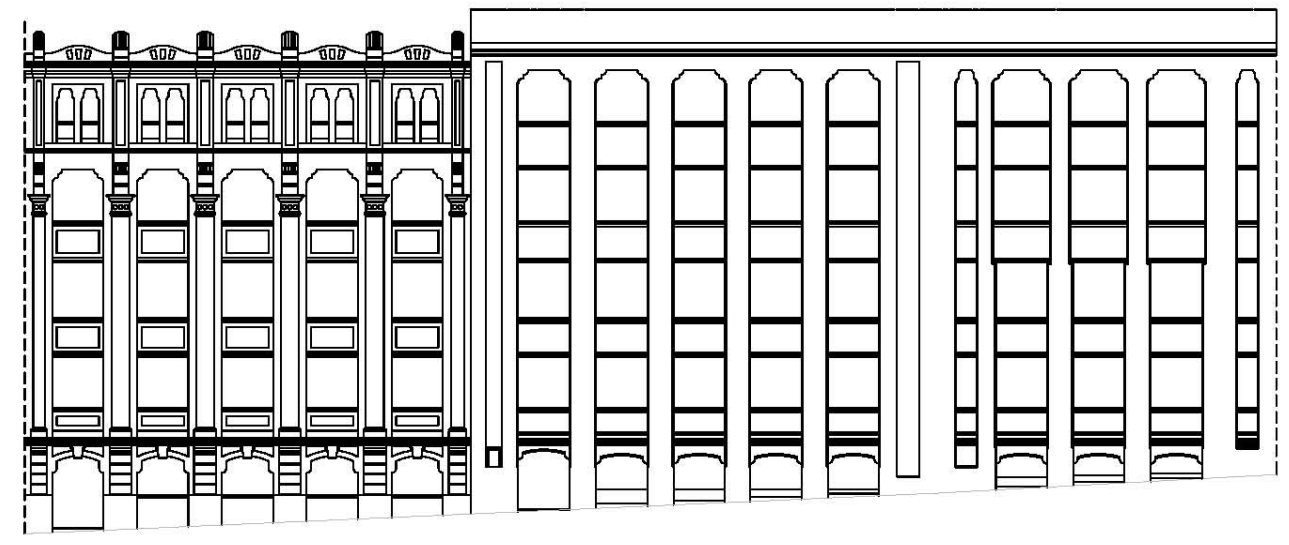

Figura 249. Fábrica de Ferrándiz, fachada a la C/Sant Doménech.

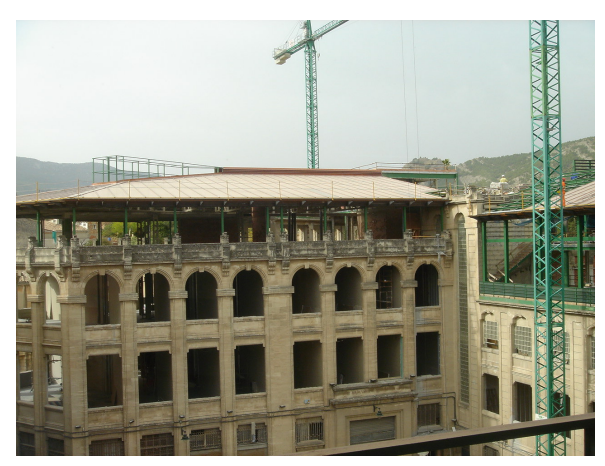

Figura 250. Fábrica de Ferrándiz, fachada con grandes ventanales gracias la altura entre forjados y los machones que soportan las vigas de los forjados. 
6. Su fachada sigue siendo portante, aunque a base de pilastras.

7. Su geometría, especialmente alargada, responde a los requerimientos de la producción textil, con sendos telares a ambos lados de un operario para su fácil maniobrabilidad. Como regla general utilizan un pilar metálico intermedio entre fachadas [Figura 251], a modo del que Arkwright [Figura 172] construyó a finales del XVIII, si bien, también existen gruesos pilares de ladrillo macizo [Figura 252].

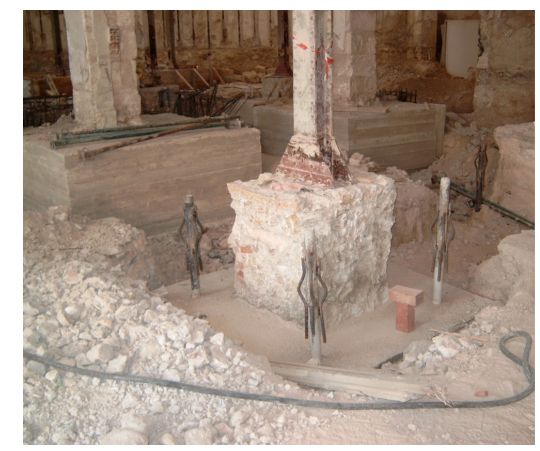

Figura 251. Fábrica de Ferrándiz, detalle del apoyo del pilar sobre la zapata en planta baja, donde se aprecia su esbeltez al tratarse de un pilar metálico.

Muchos de estos pilares tenían una sección en cruz, mediante la unión de dos perfiles en $L$ unidos por pletinas roblonadas.

8. Construido con vigas metálicas, en ocasiones, a base de celosías roblonadas [Figura 246, de tipo Warren], que permiten conseguir grandes separaciones entre soportes. También hay vigas de alma llena.

9. Los forjados están hechos a base de bóvedas de rasilla apoyando sobre viguetas metálicas en doble $\mathrm{T}$, que en cierto modo eran más resistentes al fuego que las estructuras de madera ${ }^{361}$. Esta metodología constructiva, junto a la utilización del hierro como material fundamental, caracterizó la construcción de las fábricas de la revolución industrial inglesa y europea

\footnotetext{
${ }^{361}$ Aunque la forma de realizarlas en Inglaterra y en Alcoi era diferente, puesto que las bóvedas eran tabicadas con los ladrillos dispuestos radialmente.
} 
del siglo XIX, si bien, las de la fábrica de Ferrándiz no son tan grandes ${ }^{362}$ como las de edificios como el Ditherington Mill, donde alcanzaban hasta los $3 \mathrm{~m}$ de arco, permitiendo así cantos de forjado menores, y consecuentemente mucho más ligeros [Figura 252].

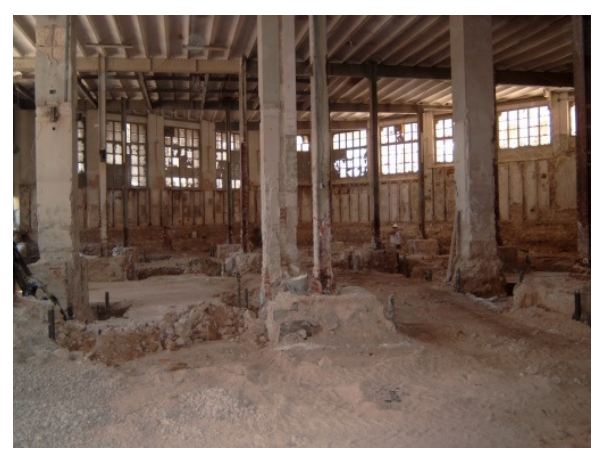

Figura 252. Fábrica de Ferrándiz, vista del forjado con bovedillas apoyando en viguetas metálicas, que a su vez descansan sobre vigas de acero de alma llena roblonada. También se ven los pilares de acero mediante perfiles roblonados, cuya distancia es de $5 \mathrm{~m}$.

10. Por lo dicho anteriormente, se permite una gran diafanidad, con lo que se logra mayor libertad para la instalación de maquinaria y movimiento de operarios. Esta característica permite también libertad de planta.

Se trataría pues de un espacio fabril característico de la revolución industrial valenciana de principios del $\mathrm{XX}$, de los que no existen en gran cantidad, $\mathrm{Y}$ desarrollado:

1) Con los avances y técnicas en los sistemas constructivos que empezaron a ser disponibles 100 años antes con los primeros edificios ingleses, como la utilización del hierro fundido y los arcos de ladrillo, que ya se había estado realizando en ese país en 1796 con el edificio de Bage o el de Salford, de 1799.

\footnotetext{
${ }^{362}$ La distancia entre los pilares metálicos que aparecen en la Figura 252 es de $5 \mathrm{~m}$, habiendo 8 viguetas, por lo que la interdistancia es de $0,63 \mathrm{~m}<3 \mathrm{~m}$.
} 
2) Misma relación de huecos en fachada que el Marshall's Temple Mill, de $1842, \approx 50 \%$, aunque por debajo de los primeros edificios de hormigón [Figura 253].

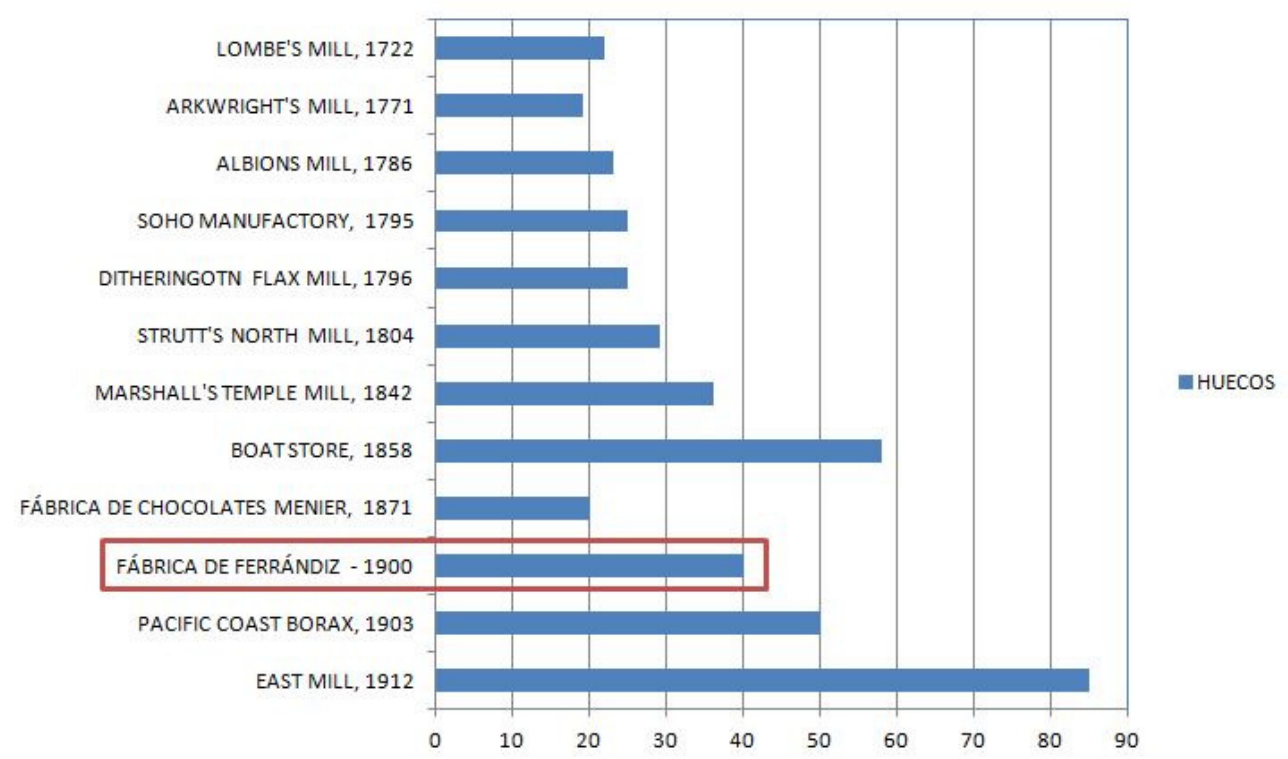

Figura 253. Fachada de la fábrica de Ferrándiz de Alcoi, de la que se extrae la relación fachada/hueco (\%), y su relación con otros edificios característicos de la arquitectura industrial.

3) Como avance tecnológico, el accionamiento que ya no es hidráulico, sino con los sistemas de transmisión energética propios de las fábricas inglesas de la misma época: máquina de vapor y cables mecánicos. 


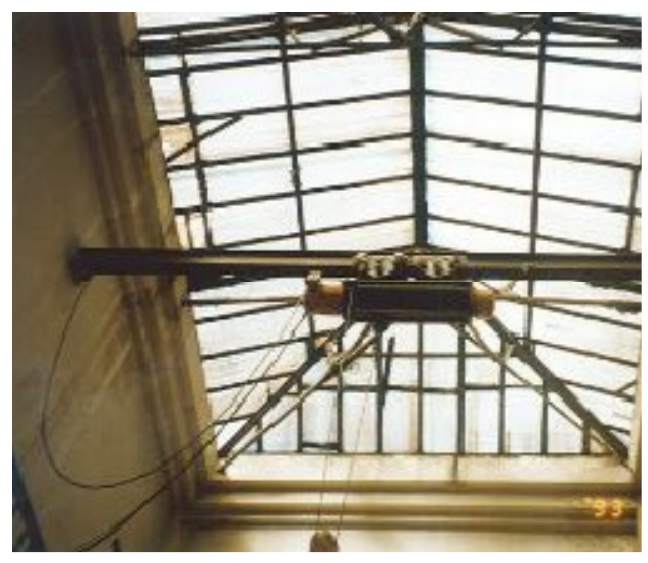

Figura 254. Fábrica de Ferrándiz, interior.

También existe un detalle interesante en su escalera principal [Figura 254]. Se trata de iluminación cenital desde la cubierta de la caja de escalera, y cuya solución ya se utilizó en la Albion's Mill, de 1786, reflejadas en la Figura 43.

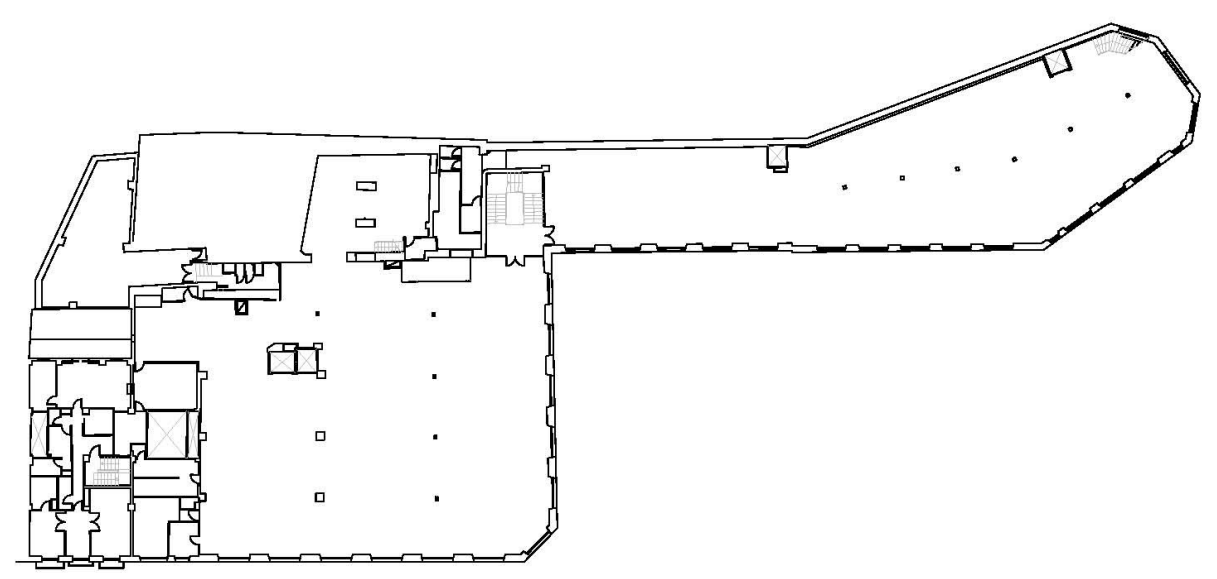

Figura 255. Fábrica de Ferrándiz, planta baja. Estado actual. Pese a no estar este plano a escala, sirve como referencia de magnitud del edificio, y como confirmación de su diafanidad. En la parte central del plano aparecen los pilares metálicos de la Figura 252, con distancia de separación de $5 \mathrm{~m}$. 


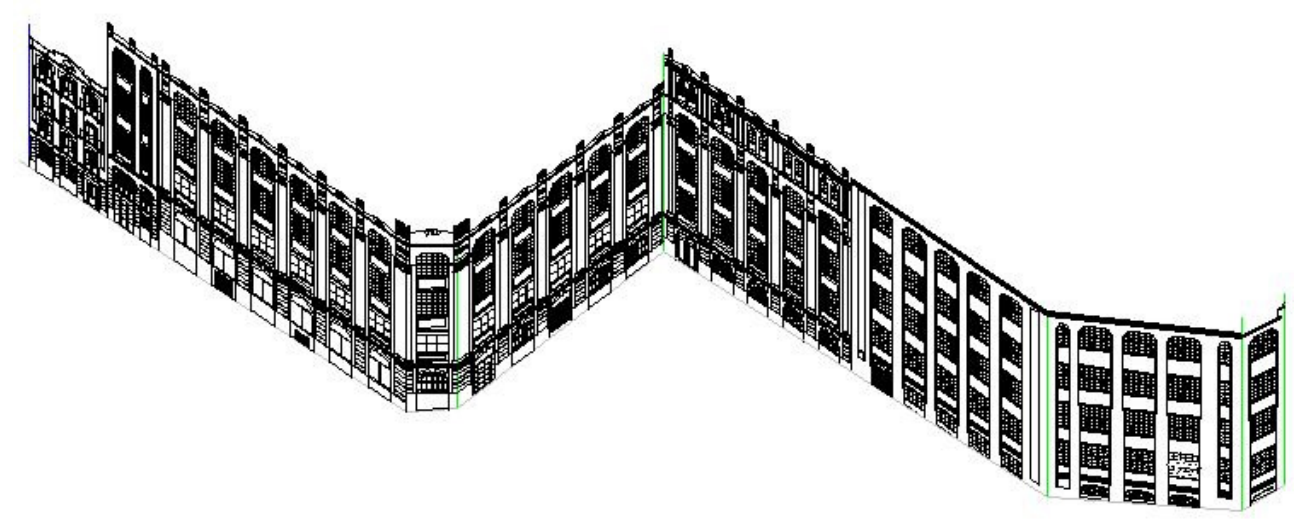

Figura 256. Fábrica de Ferrándiz, perspectiva de la fachada recayente a la fachada principal (S/E).

En cuanto a la descripción general del edificio, como se aprecia en las figuras anteriores [Figura 255 y Figura 256], estaba compuesto por 4 alturas y una planta semisótano, con un área por planta de poco más de $1.800 \mathrm{~m}^{2}$. 


\subsubsection{La fábrica de Carbonell, Alcoi, década de 1920.}

Otro ejemplo de la arquitectura fabril de Alcoi, de la 2a década del siglo XX es la fábrica textil de Carbonell, de aspecto y características similares a la anterior, y que utiliza un sistema constructivo equivalente. Ambas estuvieron diseñadas por el mismo arquitecto, en la misma plaza, la cual toma nombre de los propietarios de sendas fábricas y conformando así un mismo conjunto fabril [Figura 257 y Figura 258].

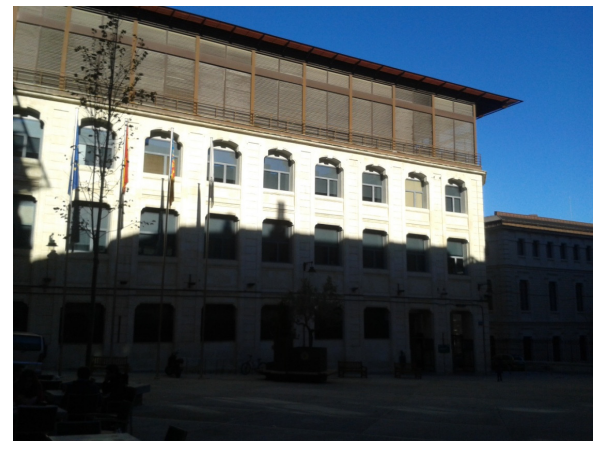

Figura 257. Fábrica de Carbonell, de la segunda década del siglo XX. Estado actual, en plaza Ferrándiz y Carbonell, Campus de la UPV en Alcoi. Fachada noreste.

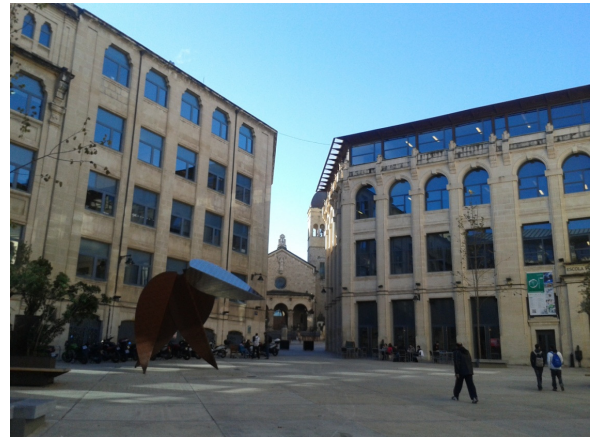

Figura 258. Plaza peatonal Ferrándiz y Carbonell, Alcoi. A la izquierda de la fotografía, la fábrica Ferrándiz, y a la derecha, la Carbonell.

Esta fábrica tiene el mismo argumento expuesto en el apartado anterior \{confrontar apartado 4.3.2.\} para su clasificación como tipología "mill building". 


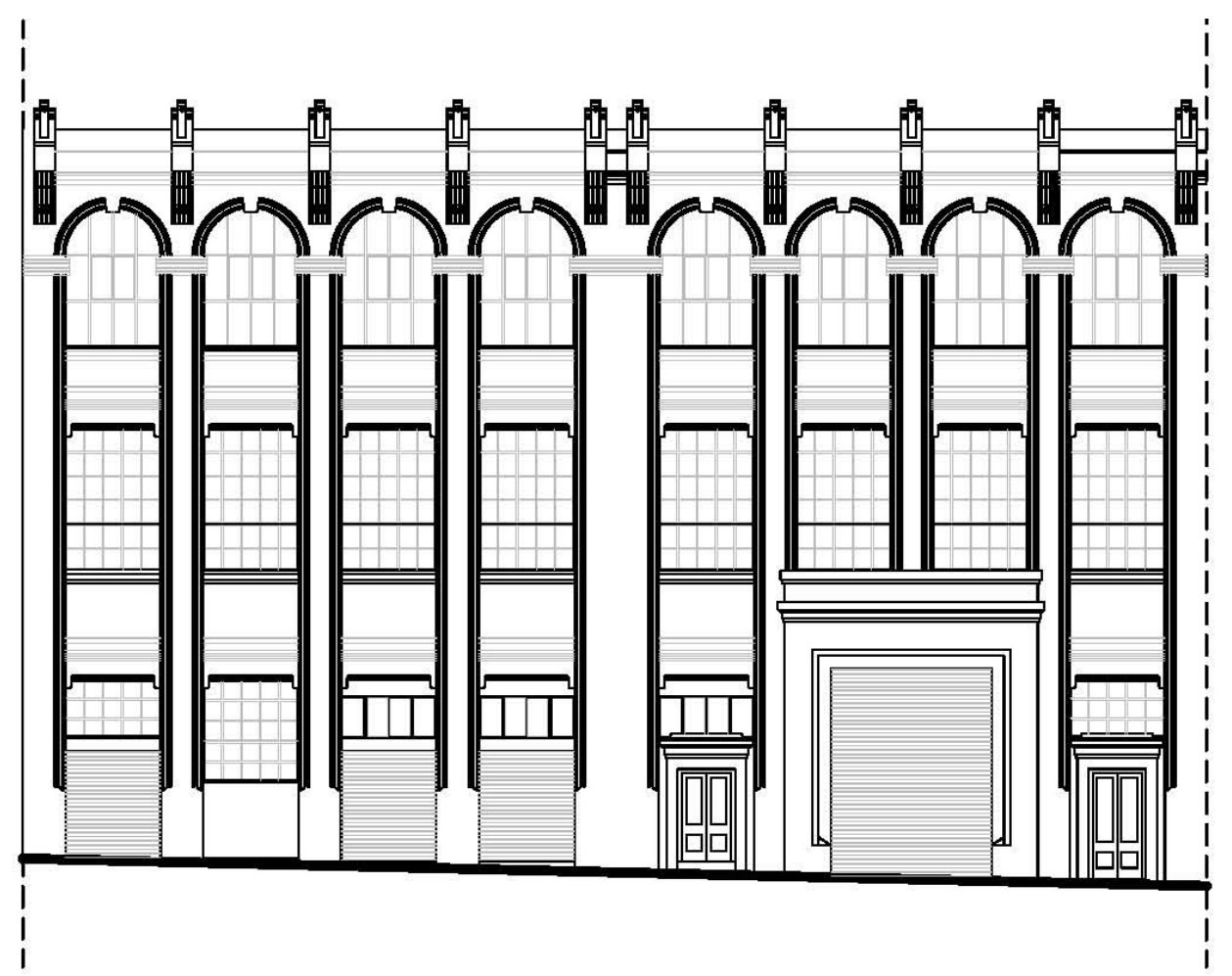

Figura 259. Fábrica de Carbonell. Estado actual. Fachada noreste, correspondiente a la de la derecha de la Figura 258.

Como se aprecia en la Figura 259, se deduce que la relación hueco/fachada alcanza valores como los obtenidos en su antecesora fábrica de Ferrándiz, puesto que ambas tienen una composición similar, consiguiendo los mismos efectos de diafanidad e iluminación interior.

Al mismo tiempo, se confirma que según el plano de la Figura 261, la diafanidad alcanzada es relevante. 
Por su parte, la forma longitudinal propia de los "mills" se adquiere tan solo en el cuerpo de la izquierda del citado plano, quedando el resto adaptado a la parcela disponible.

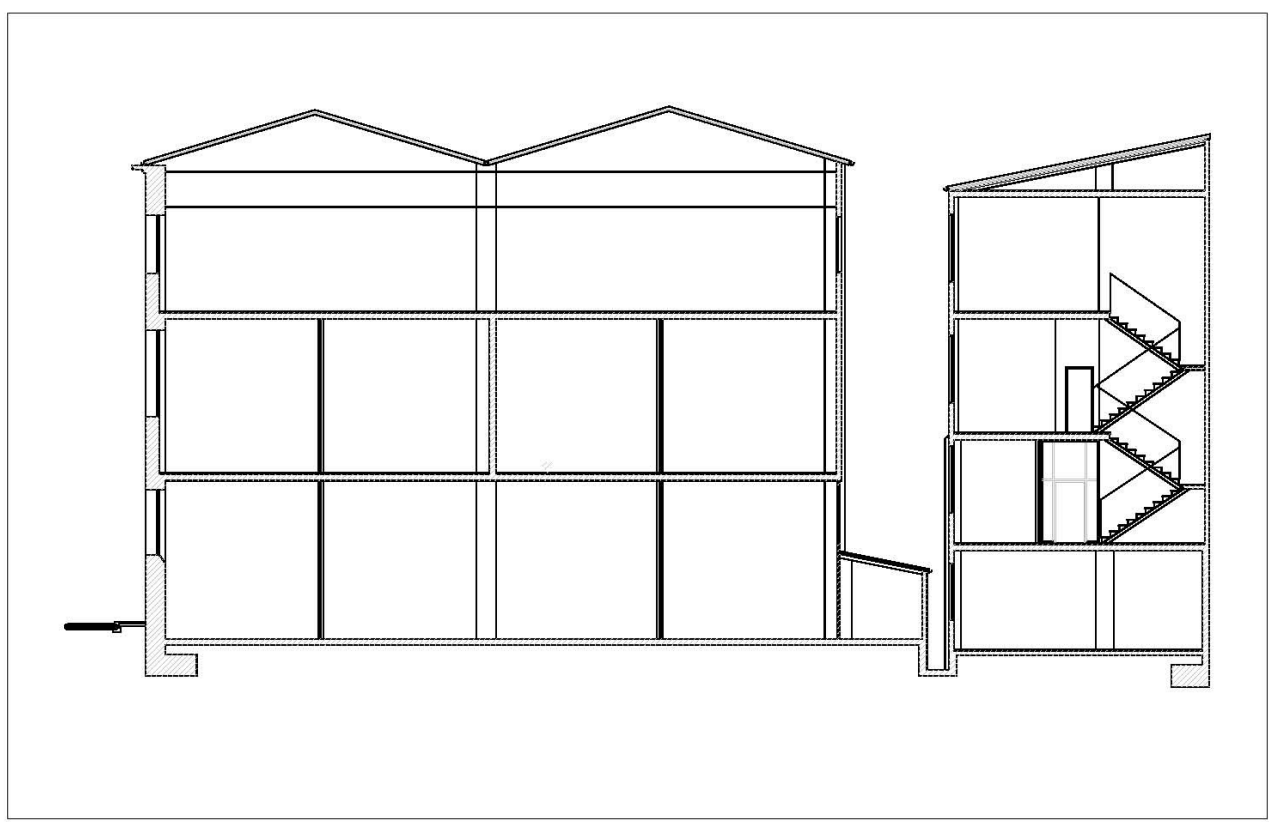

Figura 260. Fábrica de Carbonell. Sección. Altura libre entre forjados $>5 \mathrm{~m}$.

La estructura interior es mixta: acero y pilares de ladrillo. El primero de ellos se refleja en la parte central de la Figura 260, a modo de lo ya expuesto para la fábrica de Ferrándiz ${ }^{363}$ [Figura 261 y Figura 262].

${ }^{363}$ El pilar intermedio metálico, que ayuda a aumentar la distancia entre los laterales del edificio, recuerda al que Arkwright dispuso ya en el Masson Mill, a finales del XVIII [Figura 172]. 


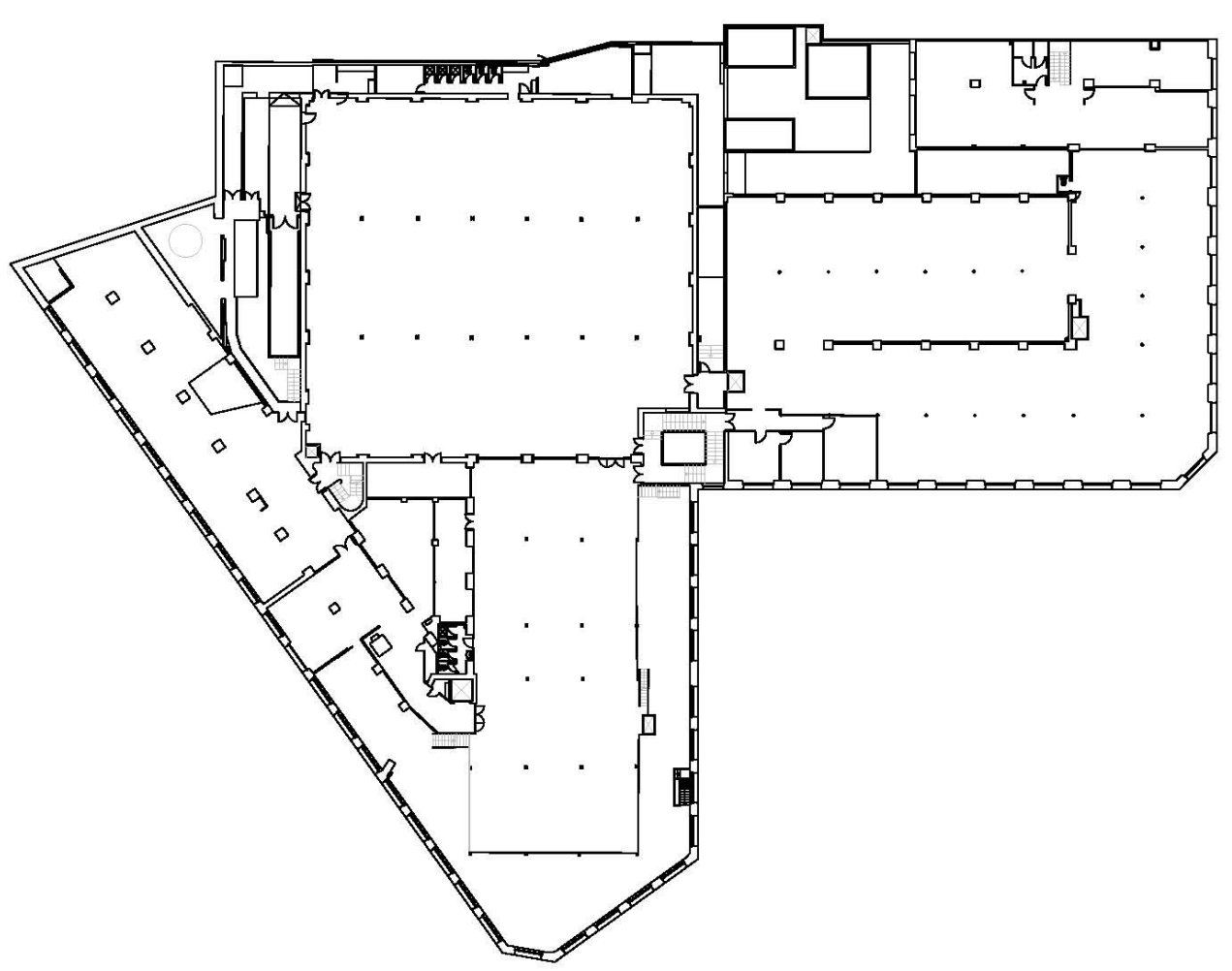

Figura 261. Fábrica de Carbonell. Estado actual. Planta baja. Combinación de pilares metálicos (mayoritariamente en la zona interior del mismo), así como de ladrillo macizo y pilastras de apoyo en envolvente (S/E).

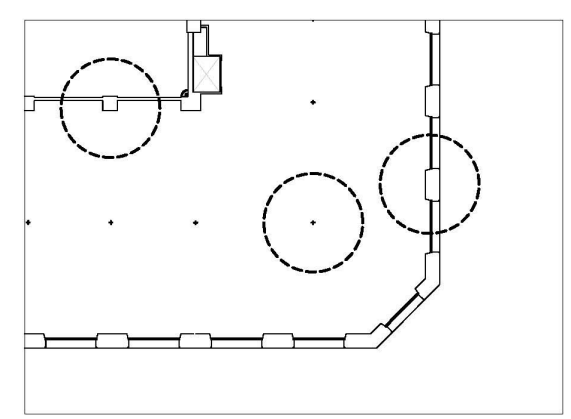

Figura 262. Fábrica de Carbonell. En el plano de la figura se aprecian los pilares metálicos y de ladrillos interiores, y las pilastras de las fachadas, lo que indica que la envolvente continúa teniendo una función portante pese al tamaño de las ventanas (S/E). 


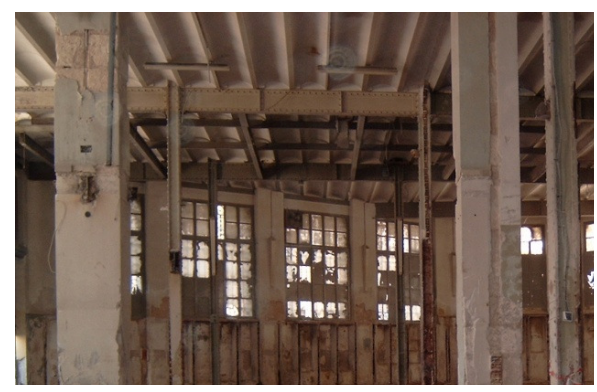

Figura 263. Fábrica de Carbonell. Se distinguen en el interior los forjados de bóvedas apoyando en las viguetas metálicas, así como las vigas de acero.

Según la Figura 263, el sistema constructivo empleado para la formación de los forjados es el de bóvedas de rasilla apoyando sobre viguetas metálicas, del mismo modo que la fábrica de Ferrándiz, y como ya comenzaron a hacerlos los predecesores "mills" ingleses durante todo el siglo anterior.

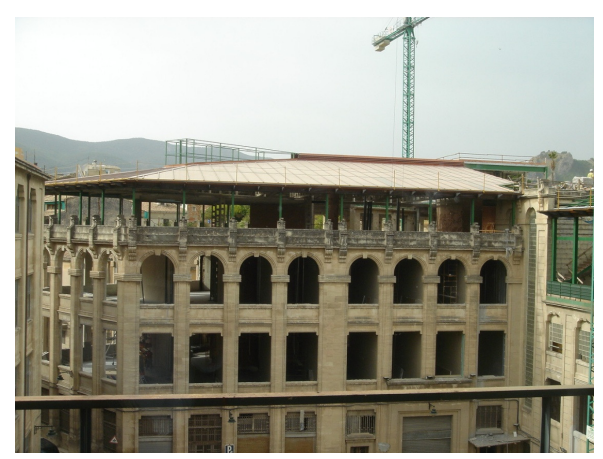

Figura 264. Fábrica de Carbonell: grandes espacios huecos en fachada revestida de piedra artificial, con el remate en las ventanas de la última planta.

Solo cuando los perfiles de acero de la estructura interior alcanzan la fachada, y sustituyen las pilastras de la Figura 264, la envolvente se convierte en ligera, siendo así capaz de conseguir la máxima diafanidad posible, tal y como sí había ya ocurrido en el East Mill de Belper [Figura 80] (las fábricas de Ferrándiz y Carbonell y este edificio fueron edificados alrededor de la misma época, a principios del siglo XX). 


\subsection{VALENCIA}

\subsubsection{Fábricas en la ciudad de Valencia. Principios del siglo XX.}

Tal y como se comentó en el Capítulo 2, en Valencia se instala la primera máquina de vapor en 1837 [confrontar con el Apartado 2.4], en la fábrica de sedas de Santiago Dupuy, conocida como La Batifora, en Patraix (Ardit, 1977). En esta fábrica, se refleja como el sector textil valenciano se alojará también en fábricas de pisos, de planta alargada, si bien, no de la misma envergadura y complejidad que los espacios fabriles ingleses de la primera mitad del XIX en Inglaterra [Figura 265].

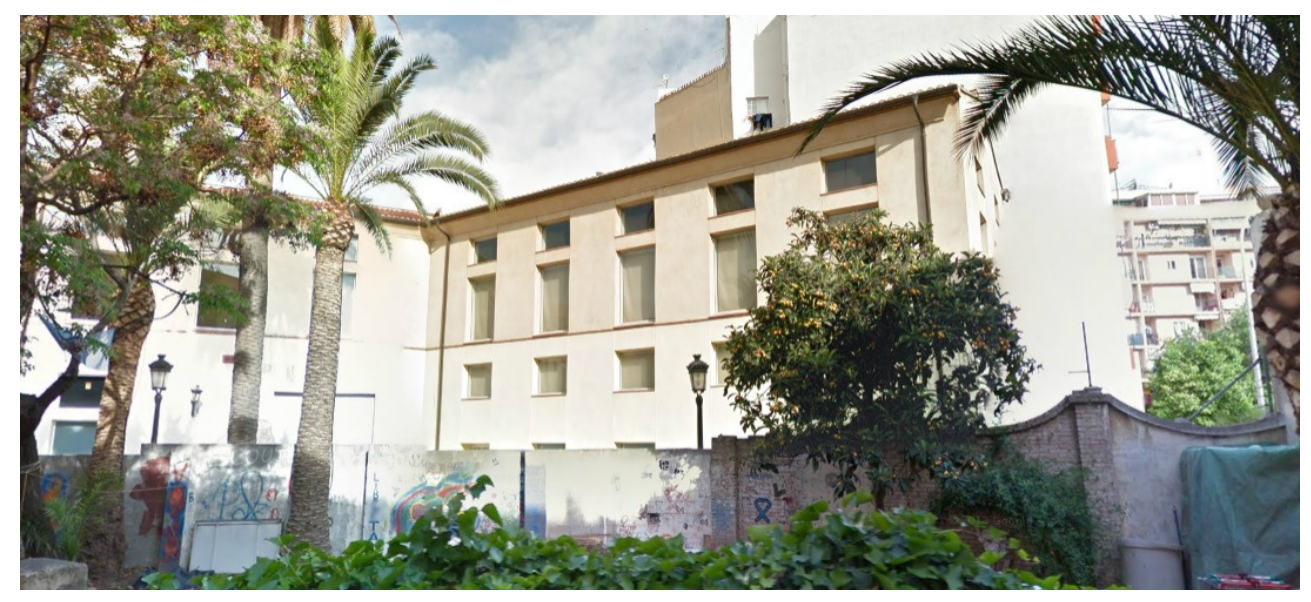

Figura 265. La Batifora, 1837, Valencia (https://www.google.es/maps).

Por otro lado, y tal y como se refleja al principio de este apartado de ámbito regional \{confrontar al principio de este apartado 4\}, los datos históricos apuntan que en el cambio al siglo XX Valencia se situaba como la tercera región más industrializada del país. Las razones ya se han explicado, pero conviene recordar que principalmente su estructura industrial había evolucionado desde la base artesanal, que era el sistema predominante en el siglo XIX. Además, su agricultura tenía unas nuevas exigencias tecnológicas que requerían de una tecnificación 
específica que solo podía ser proporcionada por las industrias locales (Solaz, 2002), puesto que solo ellas por proximidad conocían perfectamente el sector y sus necesidades ${ }^{364}$.

En primer lugar, para poder construir los nuevos edificios fabriles, se necesitaba suelo. La oferta de terreno industrial ya se había consolidado antes con el Plan de Ensanche de $1884^{365}$, con ciertas infraestructuras. Entre ellas, el ferrocarril ${ }^{366}$ y el puerto, así como diversas instalaciones y actividades industriales ${ }^{367}$ (Cano, 2002) [Figura 266].

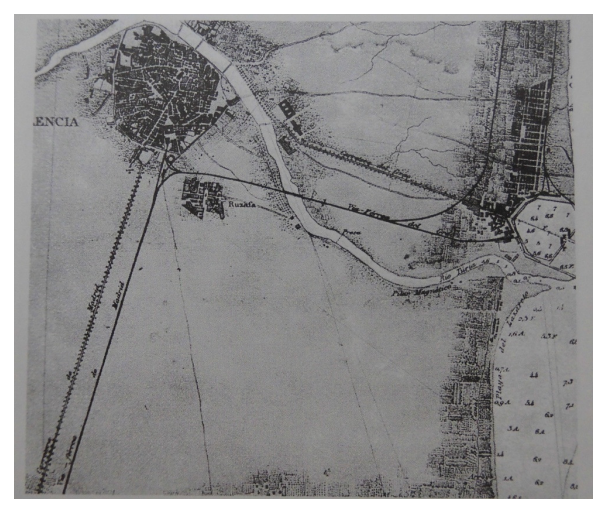

Figura 266. Valencia a finales de siglo XIX, con la vía férrea y el eje por el que discurrirá el Paseo Valencia al Grau (hoy Avda. del Puerto) (Cano, 2002).

Con todo "este conjunto de nuevas oportunidades de capital en el sector de la agricultura se produce un incremento de la demanda de bienes destinados al

\footnotetext{
${ }^{364}$ En el caso concreto de la ciudad de Valencia, que en la citada época ya contaba con un elevado número de habitantes, la especialización de la industria se convierte en su característica principal, coincidiendo con una expansión económica y un aumento de la demanda de bienes y servicios.

365 J. Calvo, L. Ferreres y J. M. Arnau, 1884.

${ }^{366}$ El ferrocarril de Valencia al Grao se inauguró en 1852.

367 Por otro lado, "aparecerán también medidas coyunturales dirigidas a facilitar o permitir un desarrollo más flexible de la economía: desaparecen las regulaciones relativas al control de la producción, [...] y a la disponibilidad de nuevos inmuebles adaptados para la industria, y se acuerda la eliminación de las aduanas interiores, posibilitando la liberación definitiva del tráfico de mercancías" (Cano, 2002).
} 
consumo doméstico", y así, la industria agroalimentaria adquiere una gran relevancia de mercado ${ }^{368}$ (Martínez, 1995).

A lo largo de los Camins al Grau, cerca del puerto, y donde se había facilitado el establecimiento de actividades industriales, se instalan algunas industrias conserveras $^{369}$.

Es por ello que se estima muy conveniente el estudio de dos casos, construidos en esta coyuntura: una fábrica destinada a las conservas y otra a la fabricación de harina. Además, con respecto a sus edificios, salvando las distancias socioeconómicas, muestran ciertos aspectos comunes a los "mill buildings" británicos, como se verá a continuación.

Para su análisis, hay que tener en cuenta que durante la primera década del siglo XX, la cantidad de licencias de obra solicitadas al Ayuntamiento de Valencia se dispara ${ }^{370}$. Pero la documentación existente en los expedientes es escasa, sobre todo debido a que los proyectos de ejecución no estaban realizados tal y como ahora se entienden. En un proceso de investigación, tan solo se pudieron encontrar planos de situación, de fachadas, y en algunos casos, de las secciones

\footnotetext{
${ }^{368}$ Conforme la ciudad se agranda, se generan más necesidades de alimentos. Su conservación se convierte pues en un potencial negocio que es captado por varios empresarios, puesto que aunque el mercado se encuentra abastecido, con el calor del verano surgían grandes problemas para su preservación (tifus, cólera, bacilos, etc eran desgraciadamente muy comunes incluso a finales del $X I X)$. La llegada del hielo proveniente de las neveras de la nieve caída en invierno en los pueblos de interior, cada vez es más costosa (Ibi es un caso de pueblo de interior que abastecía la ciudad de Alicante y alrededores, y que ha conservado su tradición), y las ciudades demandaban cantidades que esas neveras de montaña no podían satisfacer (entre los años 1850 y 1860 aparecen ya las primeras fábricas de hielo en Valencia y pueblos grandes) (Martínez, 1995).

Según este autor, a partir del 1900 la industria conservera alimentaria entra en contacto con los productos locales (la expansión de las conserveras es cada vez más rápida: se pasa de 16 centros de producción censados en 1916 a 41 en 1922). Comienzan a enlatarse frutas y verduras de la huerta de Valencia. En esta época, se inicia la producción de zumos de naranja.

${ }^{369}$ Los dos edificios fabriles referenciados en el apartado siguiente se encuentran en los Camins al Grau o en calles cercanas, siendo ambos construidos más o menos en la misma época.

${ }^{370}$ Fuente: Archivo Histórico Municipal. Ajuntament de València.
} 
longitudinales y transversales. Es difícil obtener detalles de la estructura con despieces, así como una memoria explicativa del sistema constructivo, ni siquiera de los materiales empleados, así como un presupuesto de ejecución.

Pese a esto, la documentación gráfica que a continuación se muestra, proporciona una información valiosísima en este estudio, centrándose en las fachadas, los materiales, la estructura, las cubiertas y la distribución interior. 


\subsubsection{Fábrica de conservas. Camino al Grao (Valencia), 1901.}

Al camí del Grau de la ciudad de Valencia se le dotó de una anchura considerable, porque a finales del siglo XIX se había convertido en la principal vía de comunicación del centro de la ciudad con el puerto. Allí se construyeron diversas fábricas del sector de la alimentación, como las que se detalla a continuación [Figura 268 y Figura 267].

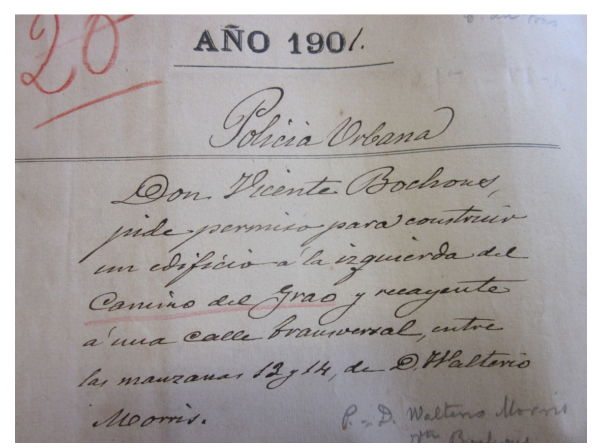

Figura 268. Solicitud de licencia de obras para construir un edificio destinado a fábrica de conservas en el Camí del Grau, Valencia, 1901, cuyo maestro de obras fue Vicente Brochons $^{371}$ (Archivo Histórico Municipal. Fotografía propia. Julio 2012).

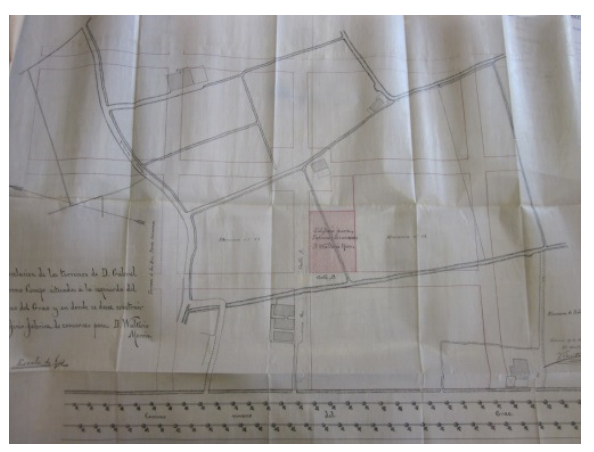

Figura 267. Plano de parcelación del Cami del Grau. Valencia, 1901 (Archivo Histórico Municipal. Fotografía propia. Julio 2012).

${ }^{371}$ Vicente Brochons (1845 - 1918): Maestro de obras valenciano, que entre otras obras llevó la del Mercado del Cabañal (1869) o el chalet de Blasco Ibáñez, en la Malvarrosa (1902) (García, 2001). 


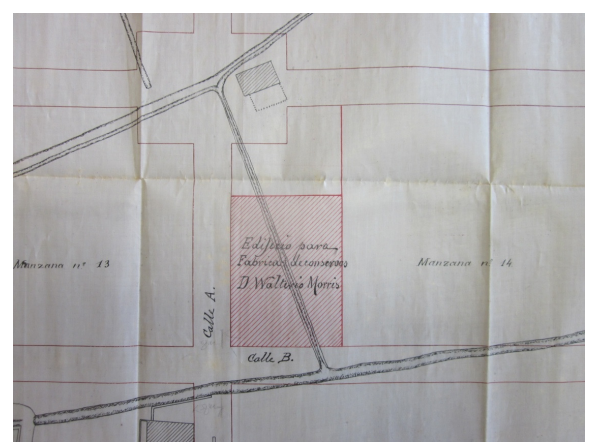

Figura 269. Ubicación de esta fábrica de conservas de Walterio Morris en el Camí al Grau. Valencia, 1901 (Archivo Histórico Municipal. Fotografía propia. Julio 2012).

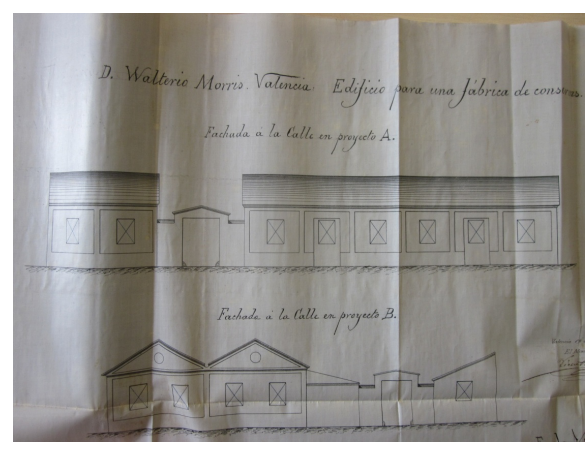

Figura 270. Plano de fachadas (Archivo Histórico Municipal. Fotografía propia. Julio 2012).

Como se puede apreciar en las fotografías anteriores [Figura 269 y Figura 270], el complejo consistía en un conjunto de edificios adosados, todos ellos de una única planta, con cubiertas inclinadas.

Las fachadas no están ornamentadas en absoluto, tal y como se correspondería con los edificios residenciales modernistas valencianos del cambio de siglo. La iluminación y la ventilación se realizaban mediante aperturas al exterior, situadas una en cada vano de la estructura. El tamaño de estas ventanas no es excesivo, representando poco más del $25 \%$ de la superficie de fachada. Comparativamente con los edificios vistos en el Capítulo 3.2 \{confrontar\}, ello queda en el orden de las fachadas del North Mill de los Strutt, en Belper, de 1804, y el del Ditherington Mill, en Shrewsbury, de 1796, un siglo anteriores [Figura 271 y Figura 272]. 


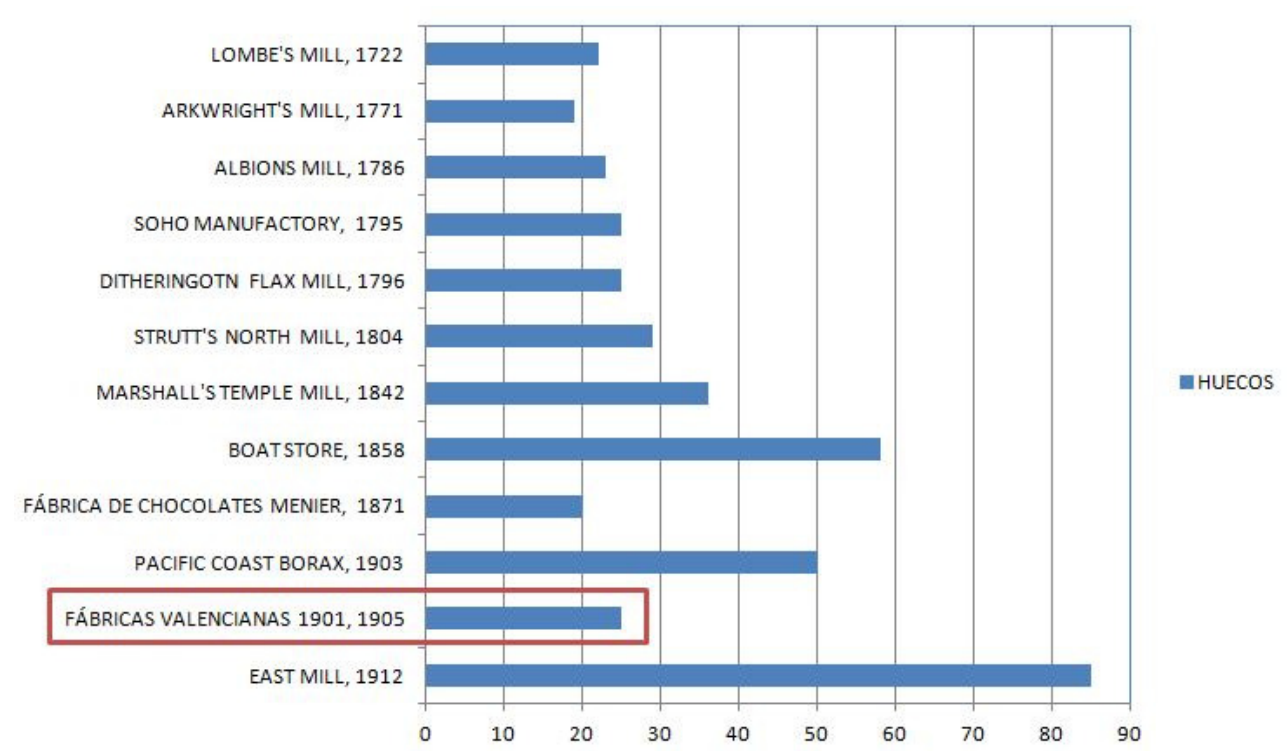

Figura 271. Comparativa con los porcentajes de huecos de fachada entre los edificios vistos en el Capítulo $3^{372}$ y los valencianos de principios del siglo XX.

Su característica principal es la austeridad en sus muros de carga de mampostería, en los que solo caben huecos para una mínima iluminación y ventilación [Figura 272].

${ }^{372}$ La producción en serie era una tendencia que progresivamente se iba importando desde los países europeos industrialmente más avanzados, pese a lo tradicional de la industria conservera valenciana (Sánchez, 2009). 

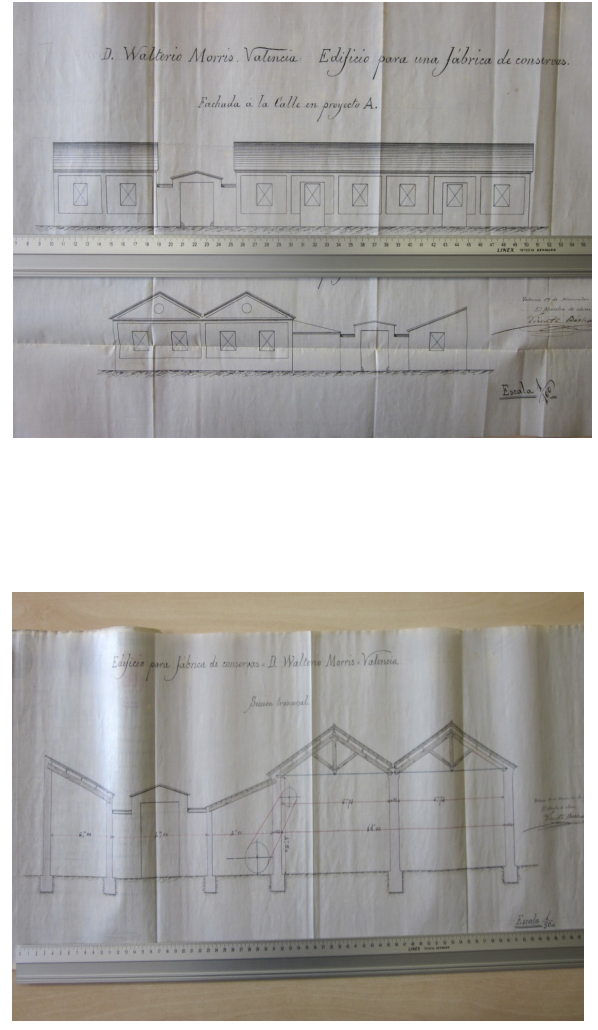

Figura 273. Plano de sección transversal. Las cerchas son de madera, por lo que el hierro no se ha incorporado todavía como material principal de construcción. Plano original a escala 1/100 (Archivo Histórico Municipal. Fotografía propia. Julio 2012)
Figura 272. Plano original de fachadas a escala 1/100 (en la fotografía se pierde la escala) (Archivo Histórico Municipal. Fotografía propia. Julio 2012).

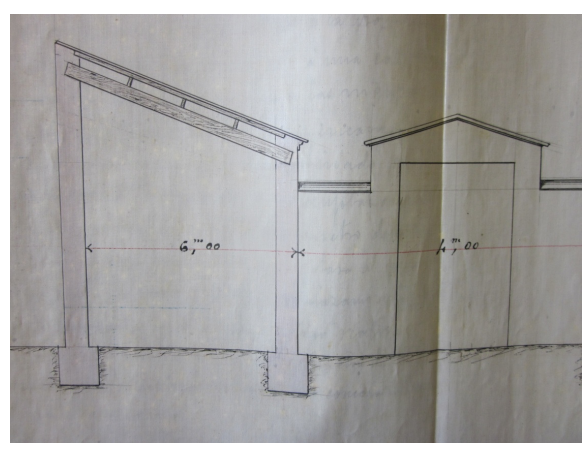

Figura 274. Plano de sección transversal (Archivo Histórico Municipal. Fotografía propia. Julio 2012). 


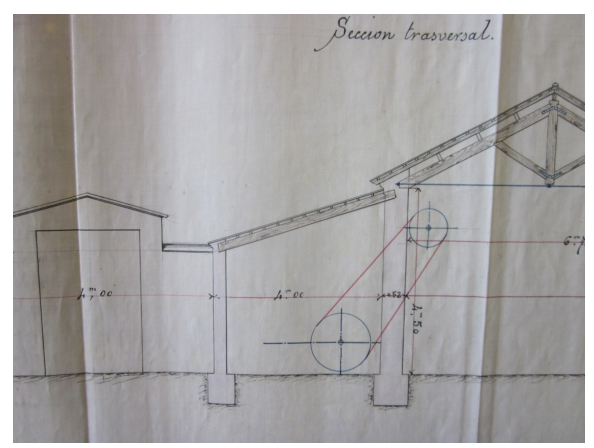

Figura 275. Plano de sección transversal, con los mecanismos de transmisión del movimiento entre edificios (Archivo Histórico Municipal. Fotografía propia. Julio 2012).

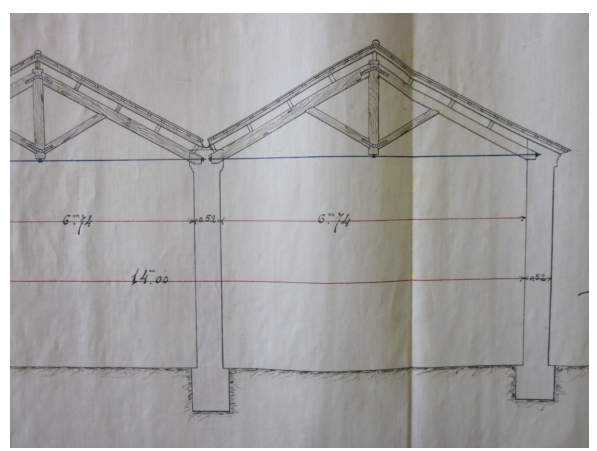

Figura 276. Plano de sección transversal. El hierro solo aparece en las uniones de las vigas. Los pilares son de ladrillo (Archivo Histórico Municipal. Fotografía propia. Julio 2012).

En estos planos de secciones transversales [Figura 273, Figura 274, Figura 275 y Figura 276] se puede observar que la estructura está realizada a base de vigas y cerchas de madera, que alcanzan los 6,74 m de luz ${ }^{373}$, estando apoyadas sobre muros de carga de sillería, de medio metro de espesor. Podría resultar intuitivo comparar esta estructura con las primeras que utilizaron el hierro fundido de principios del periodo en estudio, como la Ditherington Mill (1796), la fábrica de hilos de Salford $(1799 \div 1801)$ o la North Mill (1804), puesto que las cubiertas en todas ellas se realizaron también en madera a dos aguas, 100 años antes. Aunque lo que se puede afirmar es que en esta modesta fábrica, de principios del siglo XX, el único hierro que dispone es el de los elementos auxiliares de unión, pero no en soportes ni en elementos horizontales. Los pilares de ladrillo, soportan, como era habitual en los edificios de su alrededor, no más de dos o tres alturas, diferenciándose en este sentido de los edificios vistos en el Capítulo 3.

\footnotetext{
${ }^{373}$ Frente a los 4,2 m que se consiguieron el Ditherington Mill, Inglaterra, pero 100 años antes, en
} 1796. 
Este tipo estructural fue muy repetido en la construcción industrial valenciana, por tratarse de un modelo históricamente tradicional, económico y que había funcionado con total seguridad. Los bajos precios de la madera y los conocimientos sobre su utilización estructural influyeron de una manera decisiva a la hora de elegir este material. Eso sí, su utilización se restringe a naves con poca luz entre crujías.

El tipo de cuchillo o armadura de madera más utilizada era la llamada "tradicional" o "a la española", consistente en "dos pares con tirante y un pendolón con dos tornapuntas que dividen el vano de los pares" (Blat, 2007). Eso sí, en aquellas ocasiones en las que se pretendía salvar grandes luces, se recurría a soluciones mixtas de cerchas con pares de madera y tirantes de metal, como el caso visto en la Figura 238.

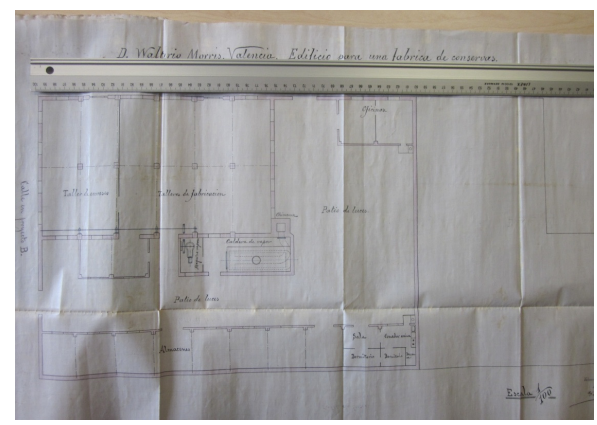

Figura 277. Plano de planta, en el que se aprecia la distribución para la producción, así como la caldera de vapor instalada. Plano original a escala 1/100 (Archivo Histórico Municipal. Fotografía propia. Julio 2012).

Como se aprecia también en la Figura 277, los muros eran de obra de fábrica de ladrillo (en muchas ocasiones también de mampostería), de grandes espesores. En algunos puntos aparecen reforzados mediante pilastras, preferentemente para realizar aperturas de ventanas para iluminación y ventilación. 


\subsubsection{Fábrica de harinas. C/ de la Industria (Valencia), 1905.}

Pese a la buena calidad que tenían el arroz y el aceite valenciano, el sector agroalimentario más pujante seguía siendo la molinería de harina de trigo. De hecho, en la Exposición Regional de 1909, la presencia de los harineros fue notable, demostrando sus grandes avances tecnológicos y la magnitud de la cantidad que alcanzaban a producir ${ }^{374}$ (Sánchez, 2009). En concreto, en Valencia y alrededores se encontraban importantes molinos harineros ${ }^{375}$ (Martínez, 1995).

Dada esta significativa cantidad de producción, se crea por entonces la Asociación de Fabricantes de Harinas del Reino de Valencia, con molinos de la capital y de toda la comarca de l'Horta. Todos ellos aprovechaban las acequias del Turia, si bien muy pronto incorporarán la energía eléctrica para mover sus motores ${ }^{376}$.

Así pues, en los años de expansión de la agricultura comercial, durante las últimas décadas del XIX, junto con el crecimiento demográfico y la mejora general de la

\footnotetext{
${ }^{374}$ En 1909, la fábrica de Ramón Colomer de Canals, producía 25.000 kg diarios; el molino de La Marquesa, de Valencia, $22.000 \mathrm{~kg}$ (esta fue la primera fábrica que empleó la electricidad para mover sus máquinas, si bien, todavía disponía de tres turbinas hidráulicas, accionadas por las aguas de la acequia de Mestalla); la fábrica de Manuel Galindo, en la calle San Vicente, $70.000 \mathrm{~kg}$; la fábrica de harinas de D. Antonio Andrés Piquer, surgida de la transformación de una antiguo batán pañero y papelero que aprovechaba las aguas de la acequia de Moncada, 20.000 kg, etc (Sánchez, 2009).

${ }^{375}$ A finales del XIX ya se contaba con grandes fábricas que disponían de un importante número de trabajadores (alguna de ellas entre 30 y 50), las cuales producían tanto para el mercado interno como para el exterior, como por el ejemplo, para el cubano. En ese año de la exposición, las fábricas valencianas de harina producían en torno a los $350.000 \mathrm{~kg}$ diarios, y entre ellas, una de las más importantes era la de Alpera y Cía., en la calle de la Industria, que se describe en este apartado (Martínez, 1995).

${ }^{376}$ Su buen rendimiento económico se debió a los grandes beneficios que consiguieron con la Gran Guerra (28 de julio de 1914 - 11 de noviembre de 1918), al liberarse la entrada de grano en España. Ello pudo ocurrir hasta que llegó el prohibicionismo en materia de importación de granos, en 1919, que hizo que la industria harinera se estancara durante las siguientes décadas. Es por esto, que durante las primeras décadas del siglo, se construyeran numerosas fábricas harineras, y muchas de ellas, de tamaño apreciable.

El dinamismo del sector de la harina también provocó que otras industrias tuvieran importantes ganancias. Valga como ejemplo las pastas alimenticias y el almidón, que ya comenzaron a tener relevancia en los años 70 del XIX, bastante antes incluso del cambio de siglo (Martínez, 1995).
} 
economía, permitió la creación de fábricas dedicadas a la manipulación de productos alimentarios $^{377}$.

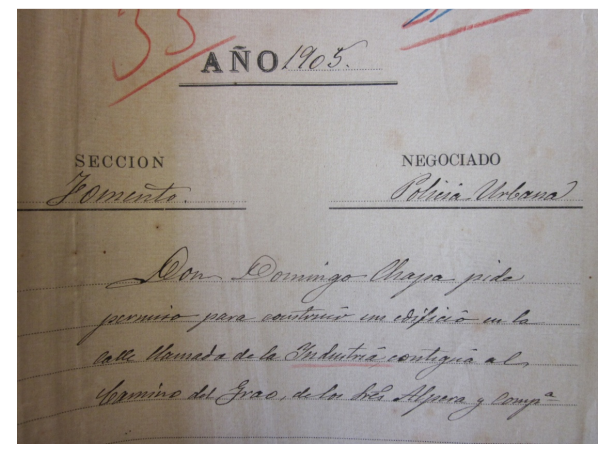

Figura 279. Solicitud de licencia de obras para construir un edificio destinado a fábrica de harinas en la calle de la Industria. Valencia, 1905 (Archivo Histórico Municipal. Fotografía propia. Julio 2012).

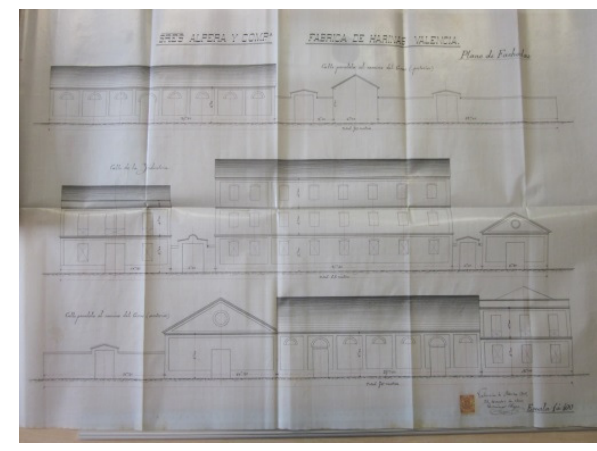

Figura 278. Plano de alzados y fachadas (Archivo Histórico Municipal. Fotografía propia. Julio 2012)

Como se ve en la Figura 278, aunque la mayor superficie de esta fábrica de harinas Alpera y Compañía [Figura 279] la ocupa un edificio de única planta, existen además de este uno de planta baja y primera, el de menor tamaño, y otro de planta baja y dos alturas más, en el centro de la fotografía. Esto, junto con la disposición repetida de las ventanas en fachada en cada piso y su planta rectangular alargada, su accionamiento mecánico centralizado en un único punto y transmitido a toda la producción mediante ejes giratorios, recuerda en parte a los edificios iniciales en altura de principios de la revolución industrial británica, tipología repetida durante todo el siglo XVIII, especialmente la primera mitad (los "mill buildings" estudiados en el Capítulo 3). Por su parte, todas las cubiertas son, como aquellas, a dos aguas.

\footnotetext{
${ }^{377}$ Por ejemplo, en 1907, existen dos fábricas de almidones y dos de pastas en la ciudad, como La Barcelonesa, que tenía 40 trabajadores y sus máquinas estaban ya accionadas por motores eléctricos y de vapor (Martínez, 1995).
} 


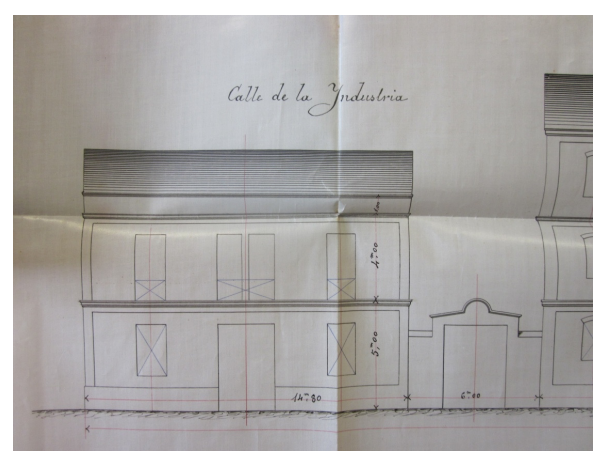

Figura 280. Plano de alzados y fachadas (Archivo Histórico Municipal. Fotografía propia. Julio 2012).

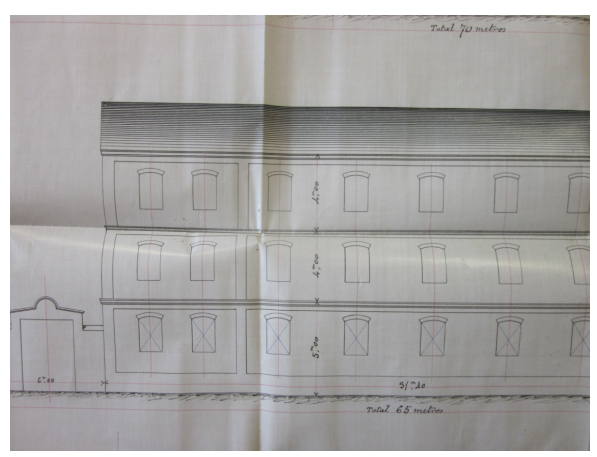

Figura 281. Plano de alzados y fachadas del edificio de mayor altura (Archivo Histórico Municipal. Fotografía propia. Julio 2012).

En la Figura 280 y Figura 281, y según la acotación, las alturas de 5 y $4 \mathrm{~m}$ de las plantas, demostrarían la importancia de la diafanidad y la iluminación natural en los espacios de producción, al conseguir la mayor dimensión en vertical que permite la estructura sin contar el antepecho de protección. El edificio de la Figura 281 , el de mayor altura del complejo industrial, es el que más se asimila a un "mill building", o molino en altura (aunque solo disponiendo de 2 plantas $(5 \mathrm{~m}$ en la primera y $4 \mathrm{~m}$ en las dos superiores), y evidentemente de menores dimensiones que los ingleses).

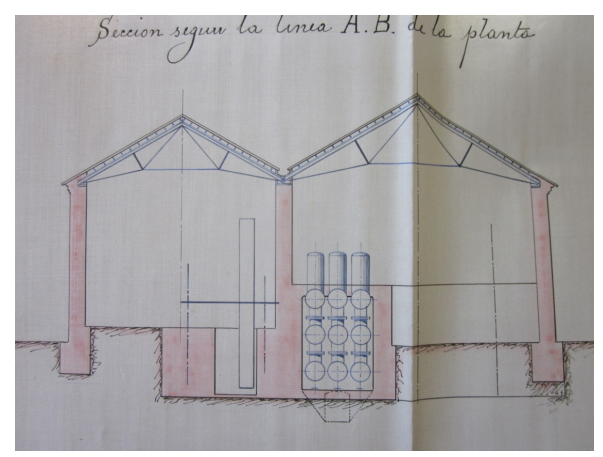

$456 / 525$
Figura 282. Plano de sección (Archivo Histórico Municipal. Fotografía propia. Julio 2012). 
En la Figura 282 se aprecia como la cercha metálica apoya sobre los muros de carga, sistema constructivo muy habitual en los edificios fabriles de principios del siglo XX en España. Surge como consecuencia lógica de la incorporación del hierro a la construcción industrial, como ya había ocurrido previamente en otros países europeos (por ejemplo, en Inglaterra y Francia, como se ha visto con anterioridad), para conseguir mayores luces. En el caso que nos ocupa, no existe documentación en el expediente de solicitud de obra del Ayuntamiento que indique las dimensiones de los perfiles ni sus características. Asimismo, tampoco se habla del diseño de las cimentaciones, circunstancia habitual en los proyectos de principios del siglo XX.

Los tipos de cercha metálica empleados en esta época son muy variados [Figura 282]: tipo Polonceaux, norteamericana, inglesa, belga, alemana, o cualquier otra triangulación que surgiera, importadas de "otros países tecnológicamente más avanzados". Las barras de estas cerchas están constituidas por perfiles metálicos que suelen ser en " $\mathrm{L}$ " $\mathrm{y}$ en " $\mathrm{T}$ ", $\mathrm{y}$ en muchas ocasiones, las uniones suelen ser remachadas (Álvarez, 2001)

En los muros de obra de fábrica de ladrillo y de mampostería se empieza a notar una tendencia: grandes vanos en las fachadas, utilizados para la colocación de amplios ventanales (relacionando con los molinos alcoyanos que se habían construido en la segunda mitad del siglo anterior, el XIX). Asimismo, al muro se le añaden machones a cierta distancia, como elementos sustentantes, haciéndolos coincidir con el apoyo de las cerchas. Esto mismo ocurre en los primeros edificios en altura que se erigieron en el cambio de siglo XVIII al XIX en Inglaterra, como el Ditherington Mill o el de la fábrica de hilos de Salford, o Phillips, Wood \& Lee, de 1799 , en los que se aprecian ligeros aumentos del tamaño de las ventanas respecto sus antecesoras fábricas de Arkwright, dos décadas anterior a estos. De este hecho se deduce un cierto retardo en el concepto de espacio fabril. A ello se añadiría lo que se estaba edificando a principios del siglo XX en el país anglosajón, como el East Mill \{confrontar el edificio en Apartado 3.2.7\}. 
Con todo esto y lo expuesto en la introducción de este capítulo ${ }^{378}$, y en comparación con otras partes del país o de Europa, en el territorio valenciano no se puede hablar de grandes fábricas o grandes industrias. $Y$ ello, entre otros motivos, por la "sectorización industrial" (Sánchez, 2009), con empresas cuyos orígenes eran tradicionalmente artesanos, lo que explica en parte, que el tamaño de los edificios no se corresponde con grandes volúmenes fabriles, sino con tamaños medios.

Del mismo modo, en estos años en los que Ford en los EEUU estaba implantando su sistema de producción en cadena, la industria valenciana todavía no se ha mecanizado. Según Sánchez Romero (Sánchez, 2009), se va introduciendo muy poco a poco un conjunto de máquinas que funcionan independientemente unas de otras, pero eso sí, "sin llegar a alcanzar una articulación propia de un sistema donde los diversos procesos parciales se articulen mutuamente, con máquinas diferentes escasamente vinculadas entre sí. Las máquinas en general no estaban armónicamente integradas hasta el nivel requerido para el desarrollo de una gran industria". Así, la revolución tecnológica de la industria valenciana fue bastante débil, con bases muy limitadas, y careciendo del peso suficiente para convertirse, al igual que la construcción, en un elemento primordial.

\footnotetext{
${ }^{378}$ Con todo, y pese a la inmigración a la ciudad de operarios mayoritariamente provenientes del campo de la provincia para trabajar en la industria incipiente, la tradición artesana continuó presente. La artesanía alcanzó un nivel alto de desarrollo y especialización que permitió el nacimiento del Modernismo, tanto en la arquitectura como en la manufactura. Lo mismo ocurrió en otras poblaciones medianas, como es el ejemplo de Sueca, donde todavía se pueden observar residencias modernistas que los agricultores adinerados poseían (C/ Sequial, la Punta o Avda. de Valencia), así como en Alcoi \{confrontar apartado 4.3\}.
} 


\subsubsection{Molino fábrica "Harinas Hijos de Jerónimo Alcañiz". Principios del siglo XX.}

A continuación se estudia un edificio en alturas, diáfano y con iluminación natural en cantidad suficiente, cuya actividad inicial, para la que fue construido a principios del siglo XX, fue la de molino de harinas [Figura 283 y Figura 284].

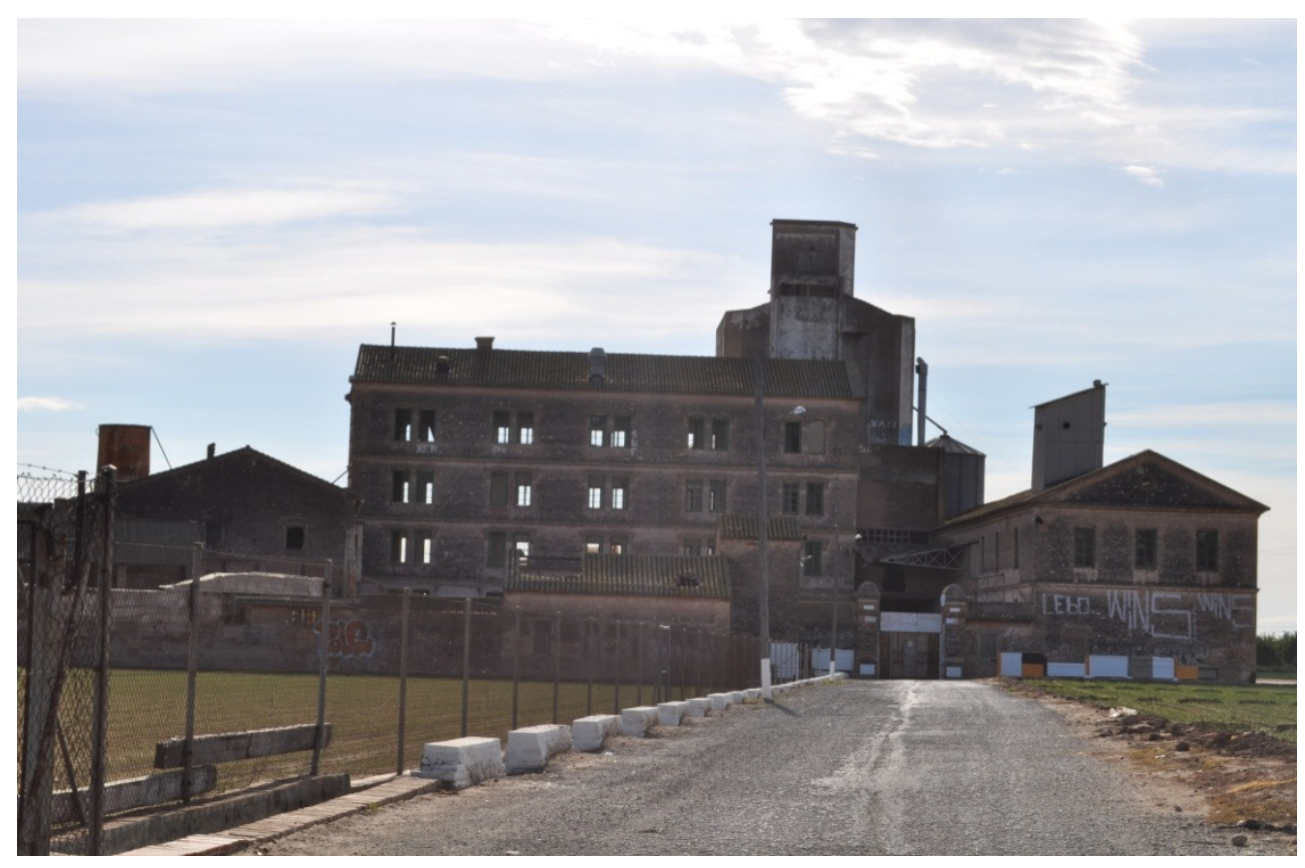

Figura 283. Fachada principal norte. Acceso al edificio desde la carretera de Alfara del Patriarca a Vinalesa. Actualmente la fábrica no está en funcionamiento (Fotografía propia. Diciembre 2012). 


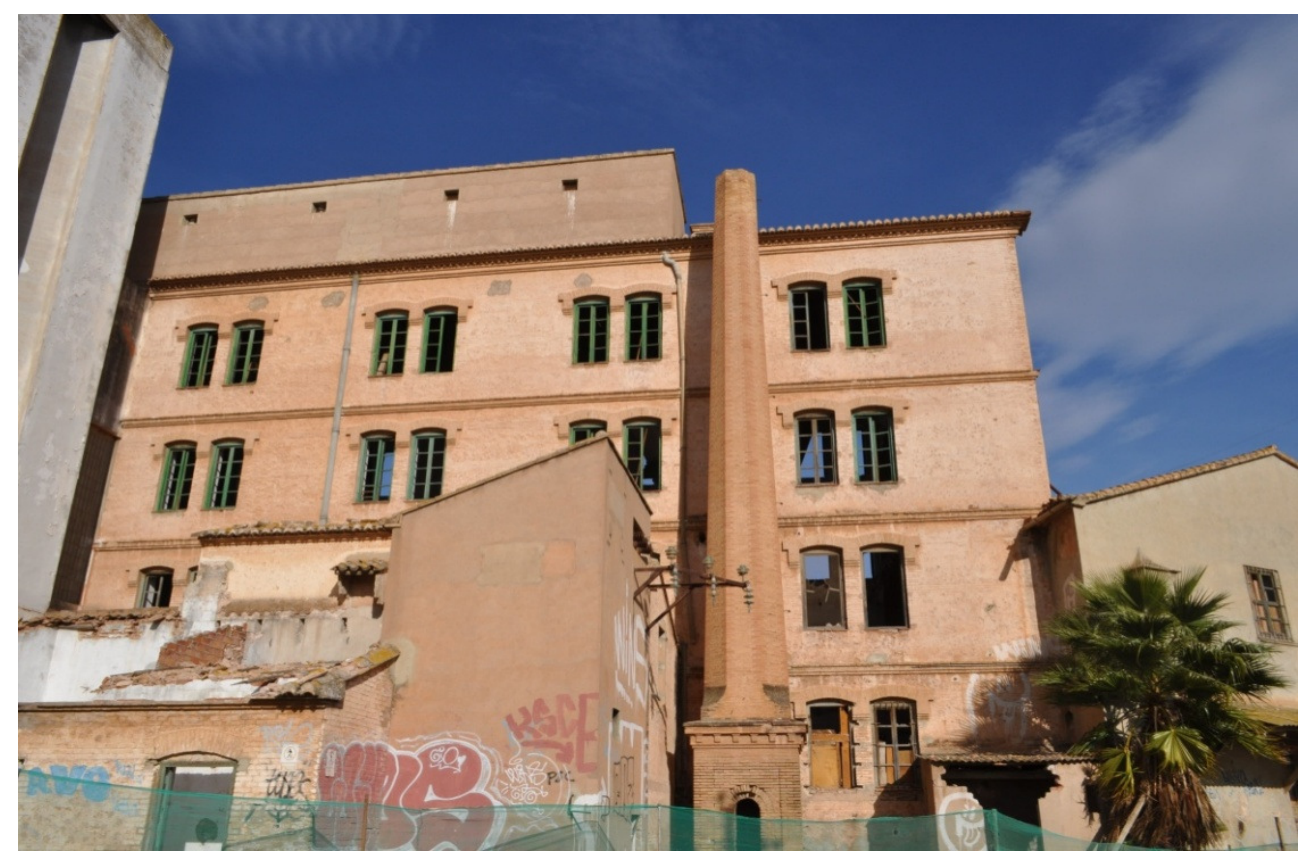

Figura 284. Fachada lateral. Orientación sureste. Se constata en la imagen que su accionamiento fue mecánico por medio de máquina de vapor y su posterior acometida eléctrica trifásica. Aparentemente, su exterior demuestra un buen estado de conservación (Fotografía propia. Diciembre 2012).

Este molino de la primera década del siglo pasado está ubicado a las afueras de Alfara del Patriarca, al Norte de la ciudad de Valencia. Su situación no es aleatoria, puesto que se encuentra justo al lado de la Real Acequia de Moncada, unos metros antes de que esta cruce el barranco del Carraixet [Figura 285]. 


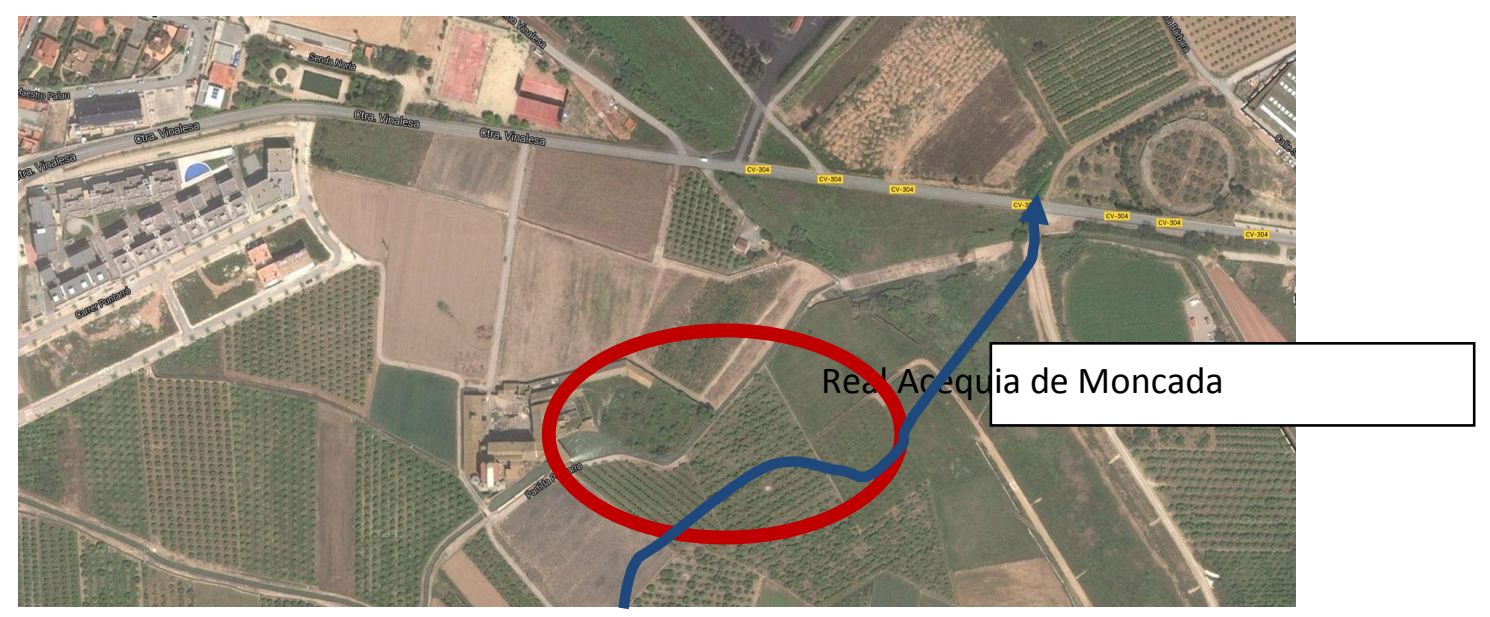

Figura 285. Entorno de la fábrica (https://www.google.es/maps).

Para poder entender su posición estratégica, es imprescindible comprender el entramado hidráulico en el que se encuentra este edificio, en el que también se hallan otros molinos harineros cercanos, como el Molino de la Real Acequia de Moncada, en Moncada, del siglo XVIII. El cano del Carraixet $^{379}$ es una gran conducción subterránea que permite a esta acequia de Moncada cruzar el lecho del barranco del Carraixet, entre los términos de Alfara y Vinalesa.

\footnotetext{
${ }^{379}$ Un cano es una gran conducción subterránea que le permite a una acequia cruzar los anchos cauces de los barrancos o ríos evitando los destrozos de las avenidas, además de seguir manteniendo la misma cota a uno y otro lado de su recorrido. La conducción a cielo abierto de la acequia se interrumpe bruscamente sobre la vertiente del barranco, para descender por debajo de su lecho y volver a emerger en el otro lado. El conjunto construido utiliza la técnica de los vasos comunicantes para la circulación del agua, aunque las galerías de bajada y subida suelen ser planos inclinados o ligeramente curvos, sin tramos verticales. El cano está formado, desde el punto de vista arquitectónico, por diversos elementos: unos visibles en la superficie, como son los puntos de entrada y salida del agua, situados a un lado y al otro del barranco y con obra reforzada, y por otro lado, el tramo de galería subterránea en forma de túnel en bóveda que conecta estos dos extremos. En algunos casos también dispone de pozos de aireación, para que no se produzcan bolsas de aire que dificulten la circulación del agua.
} 


\section{DESCRIPCIÓN}

En el recorrido cronológico de esta fábrica de harinas se puede observar que ha sido accionada por las tres fuentes de energía vistas en esta tesis, pese a haberse puesto en funcionamiento a principios del siglo XX: la hidráulica, la del vapor y finalmente la eléctrica, si bien, la última de estas es la que como en otros casos, menos influencia ha tenido en la configuración de la forma del edificio, no solo por su implantación posterior, sino por su mayor flexibilidad en la alimentación de cada una de las máquinas de la producción ${ }^{380}$.

Se trata de un edificio formado por varios cuerpos, todos ellos de planta rectangular, con planta baja y tres alturas. Como se aprecia en las fotografías, dispone de un gran número de huecos de ventana, todos ellos distribuidos uniformemente y con escasa ornamentación. Las cubiertas son a dos aguas, de teja árabe.

\section{ESTRUCTURA}

De hecho, como se puede observar en la documentación gráfica adjunta, el estado actual es de un gran deterioro (pese a lo señalado en la Figura 284), puesto que a la falta de conservación a partir del momento en que dejó de funcionar, se añade el gran número de expolios que ha sufrido [Figura 286 y Figura 287]: entre otros, gran parte de su estructura interior, a excepción de la cubierta [Figura 289]. Su protección actual como edificio se motiva, entre otros aspectos, por su inclusión en el listado de bienes inmuebles de etnología de la Dirección General de Patrimonio Valenciano, al que pertenece desde el año 1997.

\footnotetext{
${ }^{380}$ La mecanización, factor principal de diseño en todo proceso de industrialización, caracterizó tanto el pensamiento del momento que a la hora de diseñar el edificio que se quería, la máquina debía estar perfectamente ubicada, con sus necesidades reales de espacio, y que pudiera estar perfectamente conectada a la fuente de accionamiento.
} 


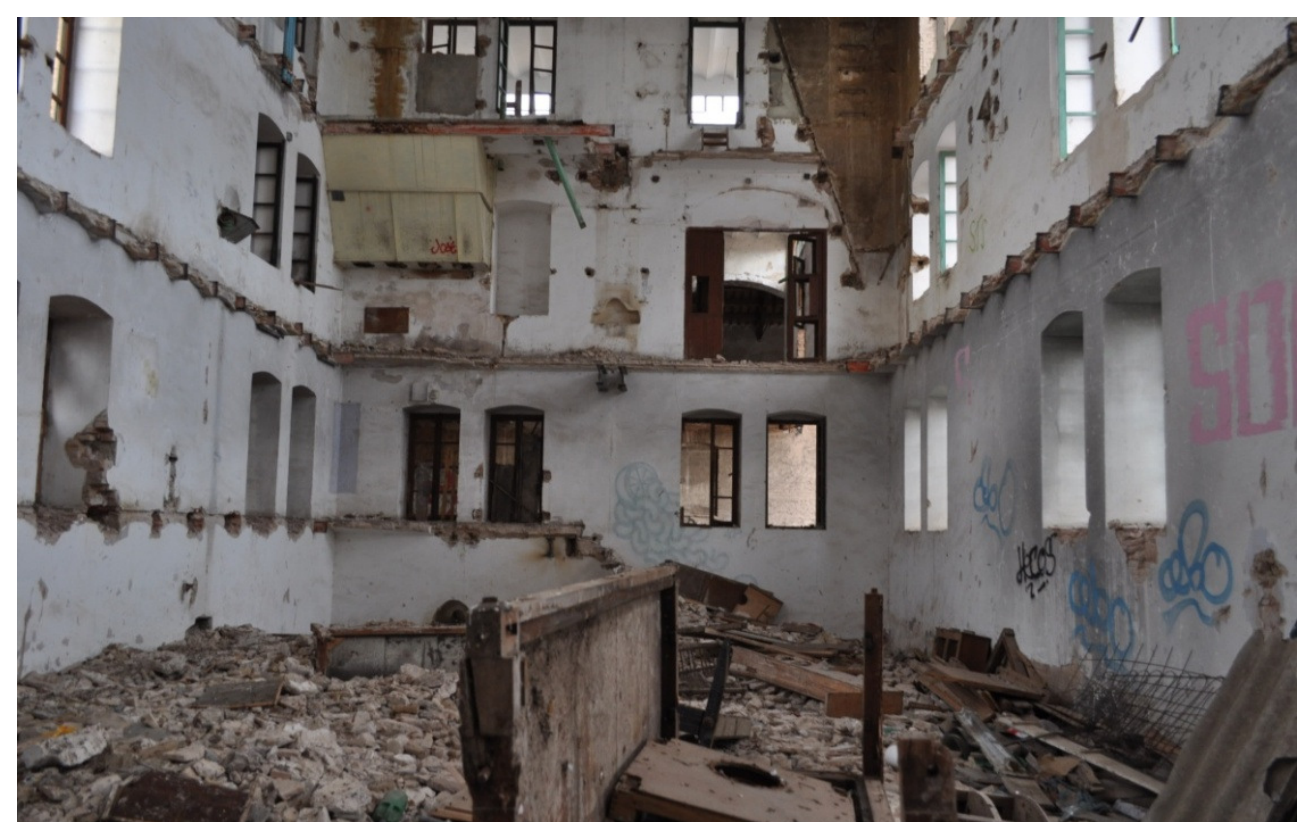

Figura 286. Vista de la estructura interior.

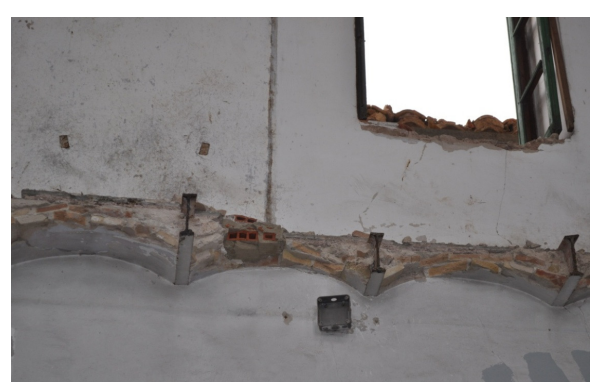

Figura 287. Detalle de la estructura del forjado, con viguetas de hierro con perfil en doble $T$ y bóvedas de ladrillo demolidas.

Sin embargo, sus muros portantes siguen en perfecto estado y, de momento, no han sido demolidos por ninguno de los diferentes propietarios que ha ido teniendo a lo largo del siglo anterior. Se trata de mampuestos de cierto espesor 
solamente interrumpidos por las aberturas, las cuales presentan mayor dimensión en altura que en anchura, estando dispuestas regularmente en todas las plantas. Ello, junto con la distribución en planta alargada en varias alturas, provoca desde el exterior una semejanza a los mills ingleses (como por ejemplo podría ser el Ditherington Mill, construido un siglo antes para la fabricación textil, ya que también estaba accionado hidráulicamente y tenía huecos distribuidos uniformemente por las fachadas de mampuestos).

En cuanto a su estructura interior, los forjados estaban formados por bóvedas de ladrillo macizo que apoyan sobre viguetas de acero en doble $\mathrm{T}$, las cuales se encastraron en los muros que configuran los cerramientos longitudinales del edificio. Esta solución constructiva se asemeja también a la empleada por el mill building North Mill, en Belper, de 1804, justo 100 años antes de la construcción de este edificio, o la Salford Mill. Se trata de un modelo similar a esos "brick arch" (o de bóvedas de ladrillo), típico de los primeros edificios industriales que utilizaron el hierro en su construcción y que precisamente por ello, se dieron a conocer por su resistencia al fuego o "fire proof" [Figura 288]. 


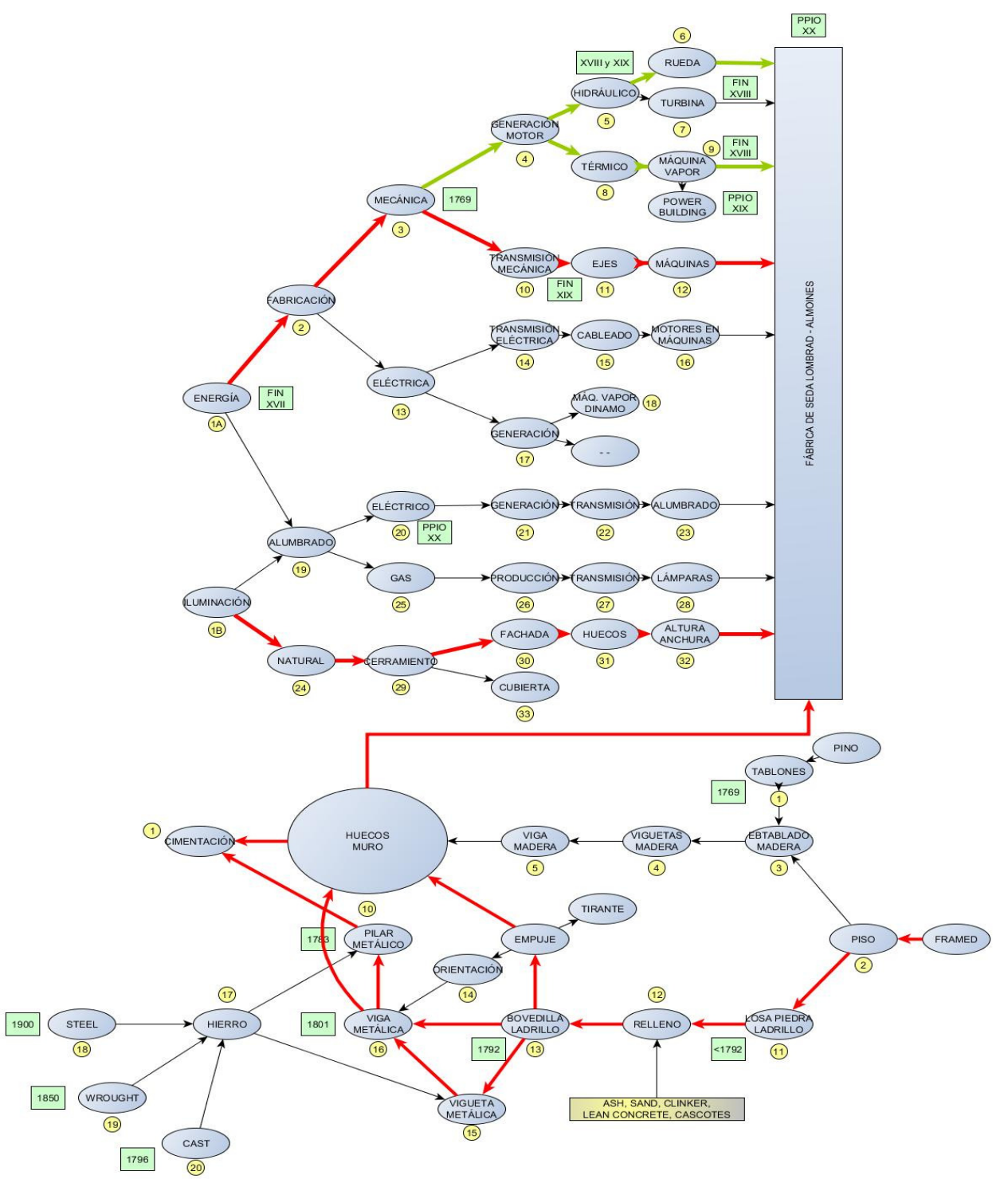

Figura 288. Esquema conceptual donde se reflejan los orígenes en los que se basa el edificio en estudio, tomando como referencia los progresos de los "mill buildings" textiles de la llamada Revolución Industrial en Inglaterra durante los siglos XVIII y XIX \{confrontar edificios vistos en apartado 3.2\}. 
En este mapa conceptual se sigue la consecución constructiva siguiente: la iluminación natural se obtiene a través de los huecos de fachada del muro perimetral portante, porcentaje que en este caso concreto no alcanza el $18 \%$ respecto a la totalidad de la fachada [Figura 293]. En lo que respecta a su estructura, sí se observa un uso temprano del hierro en vigas, así como en las viguetas para la formación de los forjados, en comparación con otros espacios de producción que se realizaban en madera en la región, como los vistos en los párrafos anteriores \{confrontar las fábricas vistas en apartado 4.4.1 más atrás, y los molinos de Alcoi\}. Por otro lado, las vigas descansan sobre el propio muro (en los escombros del interior del edificio no existen ya pilares intermedios de apoyo), de lo que se deduce que la estructura metálica no ha llegado a la propia envolvente (lo que sí ocurría en edificios coetáneos de Inglaterra, como el East Mill o incluso 40 años antes, en el Boat Store).

En cuanto a la transmisión energética para el accionamiento de su maquinaria, el molino originariamente fue alimentado por la fuerza hidráulica de la acequia que trascurría cercana, si bien, la presencia de la chimenea de ladrillo indica la transición al vapor [Figura 294]. Ello no resulta especialmente llamativo, puesto que este sistema había mostrado sus ventajas desde su implantación general a finales del siglo XVIII, sin ser sustituida por la electricidad, a principios del XX. 


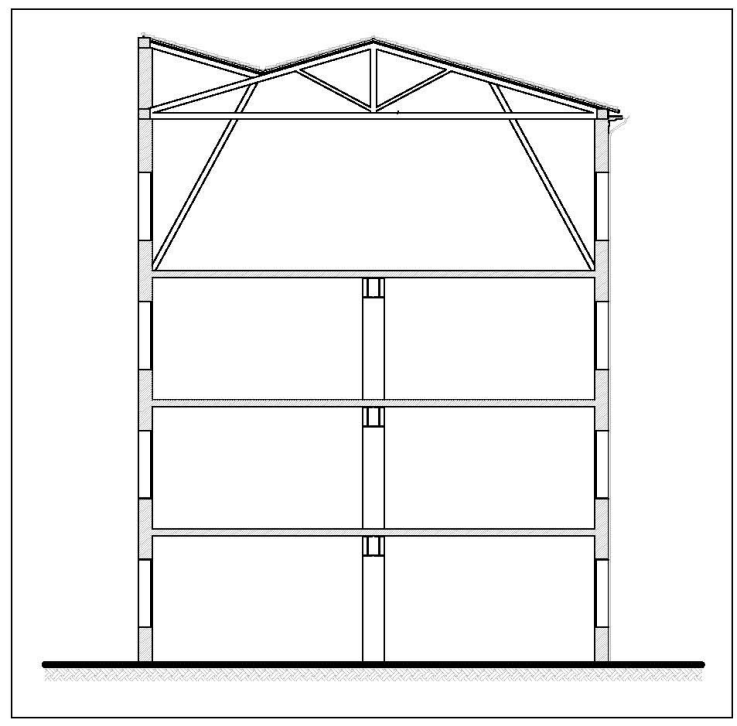

Figura 289. Sección del edificio (S/E).

En cuanto a la cubierta [Figura 289 y Figura 290], sigue el mismo esquema que el visto en los edificios de principios del siglo anterior: cerchas de madera para la formación de espacios diáfanos en última planta.

En este caso concreto, existen en sendos laterales apoyos de la cercha acodalados en la planta inferior, reforzando el sistema. Sin embargo, esta solución de cubierta no ha podido ser identificada con ninguna de las estudiadas en los "mill buildings" ingleses.

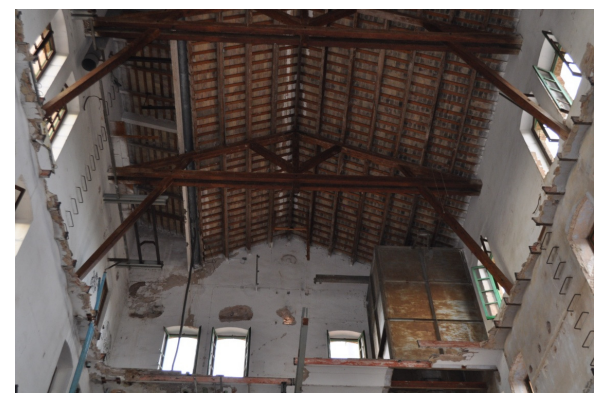

Figura 290. Cubierta desde el interior del edificio. 


\section{CERRAMIENTOS}

Como se acaba de comentar, los cerramientos hacen las veces de muros portantes estructurales, solamente interrumpidos por los huecos de ventana que se distribuyen de forma uniforme a lo largo de las fachadas laterales. Estos son de poco tamaño, justo lo que el muro de carga permitiría estructuralmente.

Evidentemente, para conseguir la mayor cantidad de iluminación posible, las ventanas tenían una gran proporción altura-anchura, puesto que ello no perjudicaba a los esfuerzos verticales a soportar. Como es conocido, este efecto lograba un mayor rendimiento si la altura entre los forjados de las diferentes plantas era suficientemente grande. En este tipo de estructuras portantes esta era la única opción posible \{confrontar el factor iluminación en apartado 3.6 más atrás\} [Figura 291 y Figura 292].

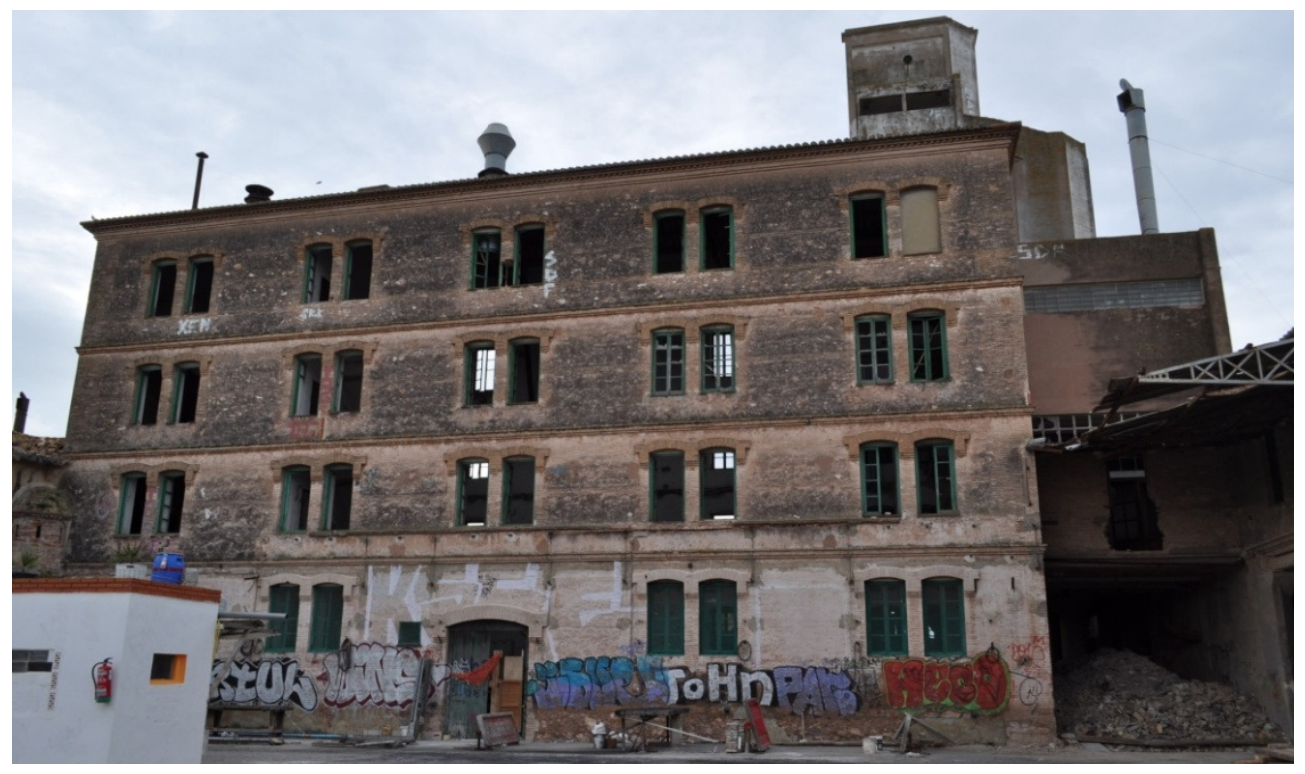

Figura 291. Fachada desde el patio interior. Se aprecia la consistencia de los muros portantes, y la disposición repetida de las ventanas, sistema constructivo típico encontrado en los "mills" ingleses del siglo anterior. 


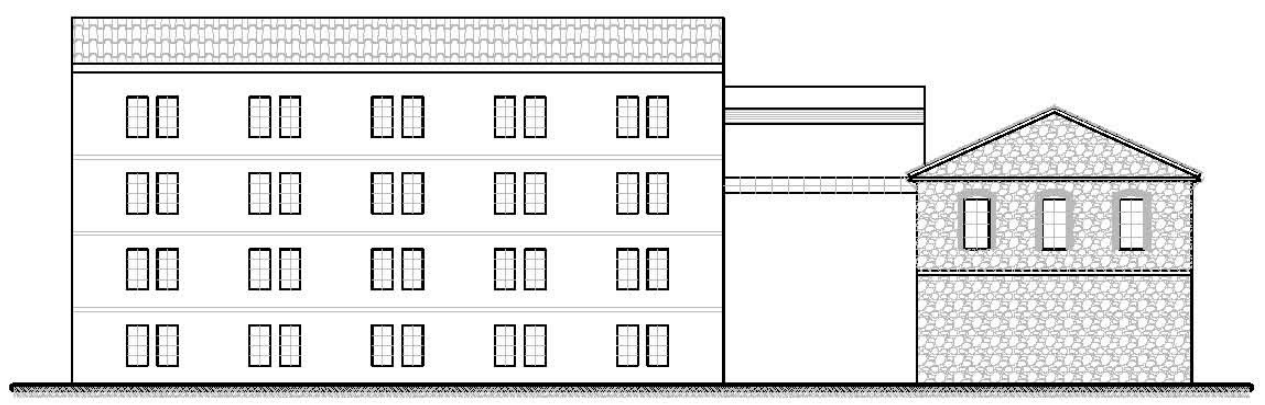

Figura 292. Fábrica de harinas de Alfara del Patriarca: relación fachada/hueco (\%) (S/E).

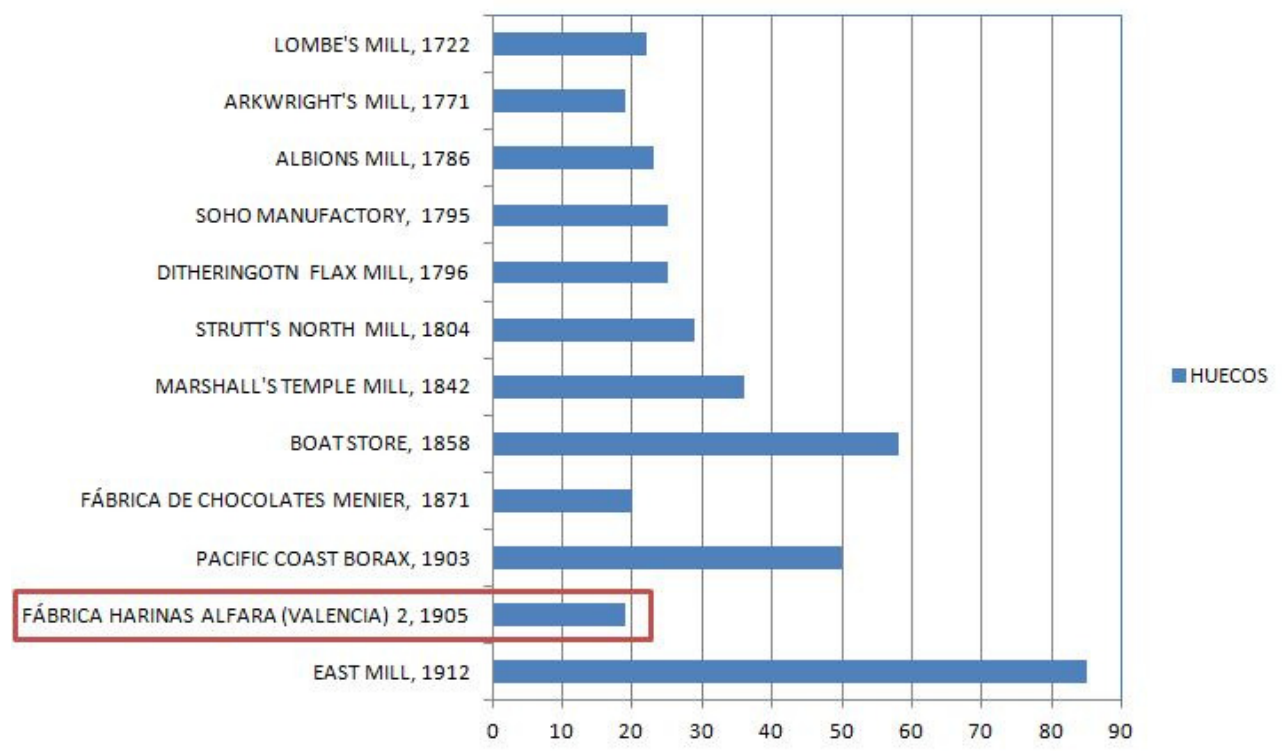

Figura 293. Relación fachada/hueco (\%).

En sendas fachadas no se alcanza el $20 \%$ de huecos libre para iluminación, lo que según la Figura 293, da cuenta de su inferioridad en general respecto de otros edificios estudiados en esta tesis. 


\section{FUENTES DE ENERGÍA}

En este molino valenciano se aprecia un dato muy revelador de lo que ha sido la evolución del accionamiento mecánico de las fábricas harineras tradicionales. Originalmente sus piedras de moler eran accionadas por las aguas de la Real Acequia de Moncada, la cual discurría por sus laterales, pese a su año de construcción, a principios del siglo pasado, cuando la máquina de vapor ya se había extendido en otras zonas industriales, como Cataluña o Alcoi, y la electricidad comenzaba a ser conocida por sus mayores prestaciones.

Con la siguiente instalación de la máquina de vapor para el accionamiento de la maquinaria, se construyó una chimenea de gran altura para la evacuación de los humos de combustión. Aunque su parte superior ha sido demolida, todavía se aprecian sus dimensiones considerables. Su planta es hexagonal [Figura 294].

Posteriormente, con la llegada de la electricidad y sus innumerables ventajas técnicas supuestamente, motivó a la propiedad a conectarse al suministro eléctrico, lo que le daría a esta fábrica, hasta no hace mucho tiempo en funcionamiento, una mayor flexibilidad en la transmisión mecánica y la posibilidad de la instalación de máquinas de mayor tamaño y más eficientes, que realizarían la función de molienda de una forma más económica. Pero esto último, no condicionó en ningún momento la forma exterior del edificio.

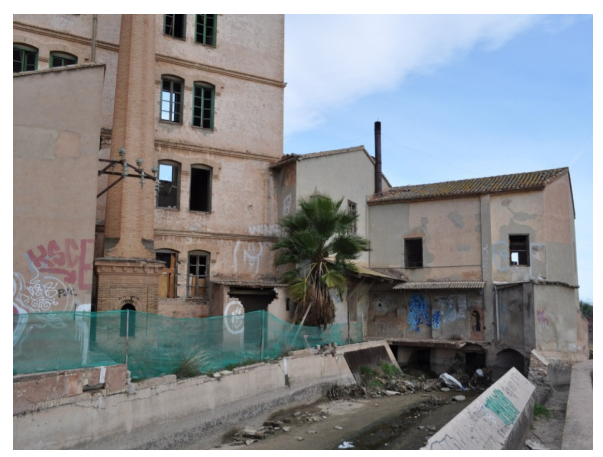

Figura 294. Molino de accionamiento (Fotografía propia. Diciembre 2012). 
En estas fotografías se percibe claramente el recorrido que hace la Real Acequia de Moncada, desde el molino hasta su intersección con el barranco del Carraixet, resolviendo dicho encuentro mediante el cano, obra hidráulica de grandes dimensiones.

La ingeniería hidráulica, que en la mayoría de los casos estudiados está estrechamente interrelacionada con el propio proceso fabril, tiene una correspondencia directa con la que Arkwright ya diseñó en su complejo de Cromford, en 1771, para accionar su nueva maquinaria de hilar [Figura 35]. 


\subsection{LA SAFOR (VALENCIA).}

\subsubsection{Introducción.}

Almoines es un pequeño pueblo del sur de la provincia de Valencia, en la comarca de La Safor ${ }^{381}$. Desde siempre se ha considerado como una zona eminentemente agrícola, ya que incluso remontándose a la época romana, se puede encontrar el tríade: el cultivo del cereal, el olivo y la viña. Asimismo, en el siglo XV el cultivo del azúcar estuvo presente en toda la zona así como el extensivo de morera ${ }^{382}$. La sedería incluso persistió hasta la primera mitad del XVIII, junto al cultivo del trigo y el maíz.

Según el Diccionario geográfico-estadístico-histórico de Alicante, Castellón y Valencia (Madoz, 1987), en términos generales, el trabajo con la seda para la producción de tejidos se remonta al menos al siglo XIV en Valencia ${ }^{383}$. En este mismo diccionario, según Soler (Soler, 2009), en Almoines, a finales del siglo XVIII la torcedura y el hilado era una actividad con relativa trascendencia económica. De hecho, en el cambio de siglo, en la calle Mayor, un "emprendedor" del pueblo, Francesc Lozano, decidió montar una fábrica "de torcer la seda", justo al lado de la Acequia Madre que pasaba por la localidad. Pero cuando este murió, la actividad acabó $^{384}$. Unos años después, como señala este mismo autor, concretamente en 1848, un comerciante francés que conocía perfectamente la comarca, y coincidiendo con una de las tantas visitas para la compra de seda de "baja calidad", decidió montar allí una fábrica "de torcer la seda"385. Se trataba del

\footnotetext{
${ }^{381}$ Su ubicación se refleja en las figuras [Figura 298].

382 Pero con la expulsión de los moriscos, a partir de la primera década de 1600, la producción de azúcar sufrió una gran disminución.

${ }^{383}$ La Lonja de Valencia fue construida entre 1484 y 1486.

${ }^{384}$.Y así quedaron sus trabajadores sin empleo, ya que a diferencia de Alcoi, con más tradición manufacturera, aquí no había antecedentes industriales ni protoindustriales, sino más bien tareas eminentemente agrícolas (En 1838, según el Ayuntamiento de Gandía, no había ningún taller de industria textil (Sanchis, 1987)).

${ }^{385}$ La actividad empezaría en este año en el viejo obrador de Lozano (Soler, 2009).
} 
industrial $\mathrm{H}$. Lombard, que ya tenía una fábrica en Nimes, empleando aquellos trabajadores locales ${ }^{386}$ que tenían una gran experiencia productiva ${ }^{387}$.

Lombard no se trataba de un caso aislado. Los comerciantes franceses conocían bien la producción sedera de la comarca por su relación calidad/precio, y aprovechaban el puerto de Gandía para transportarlo hasta su país. Pero a diferencia de estos, el personaje en cuestión tenía una "intención más industrial e inversora" (Soler, 2009). Pero entre 1850 y 1865, coincidiendo con los comienzos de "La Fábrica", la plaga de la Pebrina se extendió por toda la provincia, aunque en esta zona no afectó con tanta crudeza. Ello contribuyó a que el negocio floreciera en mayor medida. Tanto, que en 1857 se decidió ampliar la fábrica, y 10 años después, ya existía un edificio anexo a la acequia que pasaba por el pueblo ${ }^{388}$. Esta fábrica tenía "grandes ventanales y grandes rejas, al estilo de la arquitectura fabril inglesa, francesa y alcoyana de la época. Aquel era un edificio nunca visto en La Safor, de $2.920 \mathrm{~m}^{2 \prime \prime}$. Así, este edificio se había convertido en "referente para la industria valenciana". En 1899, la fábrica fue ampliada considerablemente (Soler, 2009), "con instalaciones mecanizadas" y con suministro eléctrico, mediante una turbina accionada en un molino cercano ${ }^{389}$. Le sucedieron 3 ampliaciones más en 1925, 1960 y 1973, que es la parte más nueva, que evidentemente queda fuera del periodo de estudio de esta tesis, aunque confirma la situación actual del complejo.

En otro orden de cosas, en la década de 1890 llegó el "tren de los ingleses" ${ }^{390}$, que unía Gandía con Alcoi gracias a una inversión británica, lo que mejoró en gran medida las perspectivas económicas de la fábrica ${ }^{391}$.

\footnotetext{
${ }^{386}$ Sabía perfectamente cómo obtener la seda con los mínimos recursos.

${ }^{387}$ Según este autor (Soler, 2009), de la información que se dispone de este empresario, "el francés evaluó como positivas las posibilidades de desarrollo fabril que presentaba la comarca".

${ }^{388} \mathrm{C} /$ Major, actualmente C/ La Fàbrica.

${ }^{389}$ Según este mismo autor, en octubre de 1904 se instaló también la primera línea telefónica en la fábrica, considerada como una gran novedad tecnológica.

${ }^{390}$ Alcoy \& Gandía Railway \& Harbour Company.

391 En 1898, 3 de los hijos de Lombard refundaron la empresa como Lombard Frères, y crearon asimismo una banca privada en Valencia, la Banca Lombard, que junto con los Trénor.
} 


\subsubsection{La fábrica de seda Lombard de Almoines.}

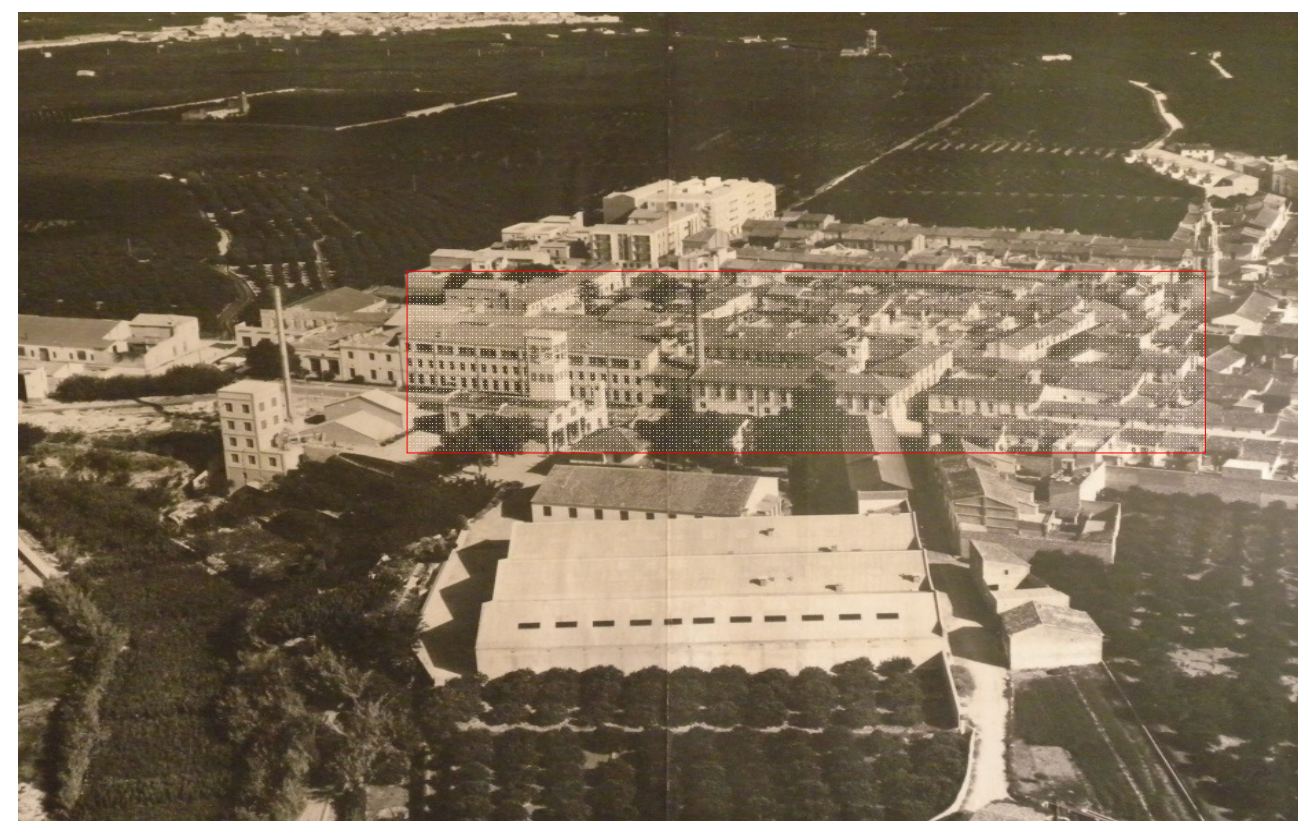

Figura 295. Almoines, vista aérea. Se trata de un pueblo de 2.000 habitantes al sur de la provincia de Valencia, en la comarca de La Safor, entre Gandía y Oliva. En la fotografía aparece resaltada la fábrica de seda de Lombard, cuyo tamaño es relativamente grande respecto a todo el núcleo urbano.

Valorando las posibles correspondencias de la definición de "mill building" \{confrontar apartado 3.1\} con esta fábrica en cuestión [Figura 295], se puede concluir que efectivamente existe una clara similitud con los edificios ingleses estudiados en el capítulo anterior, correspondientes al siglo XIX, pudiendo así incluirse en este estudio al acercarse en cierta manera a alguna de estas características: se trata de un edificio de 2 o 3 alturas, conformado por varios bloques todos ellos estrechos y alargados. Asimismo, la mayoría de su maquinaria original en el momento de su puesta en funcionamiento ( 2 a mitad del siglo XIX) era 


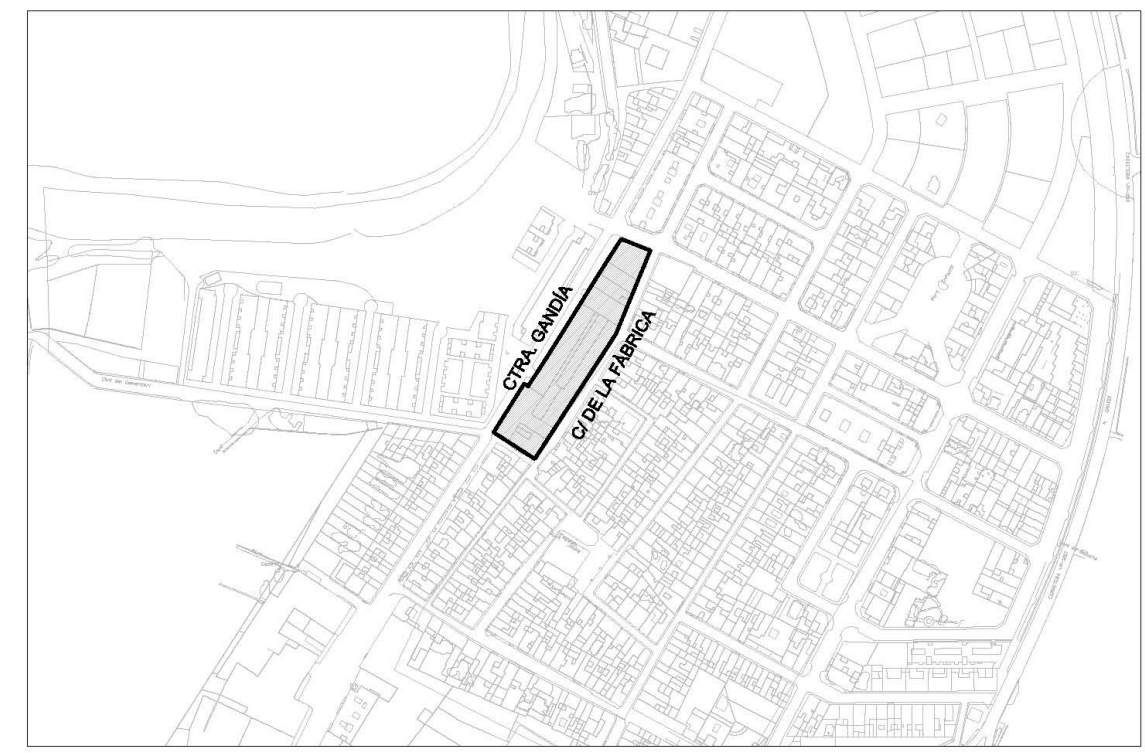

Figura 296. Almoines. Situación de la fábrica actual en el entramado urbano (S/E).

accionada por la acequia Comuna de Gandía [Figura 305], cuyas aguas provenían del río Serpis, la cual transcurría paralelamente a la calle donde recae la fachada principal o de acceso (Ctra. Gandía - Villalonga) [Figura 296], y que fue reemplazada por máquina de vapor en el cambio de siglo siguiente (Sanchis, 1987)) ${ }^{392}$.

En cuanto a los antecedentes constructivos de los que proviene esta edificación, realizada con diferentes sistemas constructivos, se especifica según el siguiente mapa conceptual [Figura 297]:

\footnotetext{
392 Según Soler (Soler, 2009), en la "matrícula industrial del 1927", la fábrica de los Hermanos Lombard, disponía de "una máquina de hilar seda, con motor de agua y vapor, una máquina de electricidad de $5 \mathrm{~kW}$ de potencia, y 2.480 husos de torcer seda".
} 

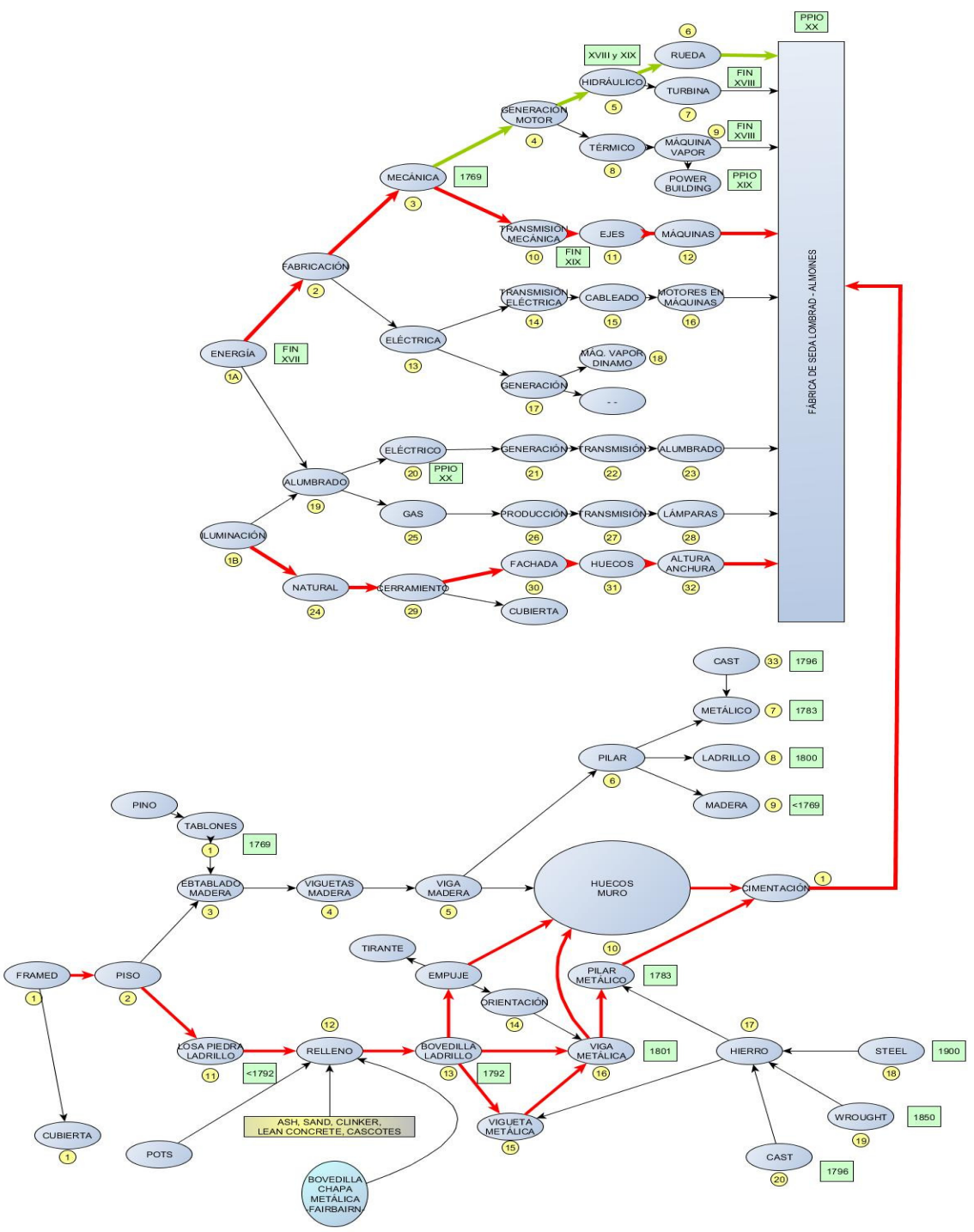

Figura 297. Esquema conceptual donde se reflejan los orígenes en los que se basa el edificio en estudio, tomando como referencia los progresos en los métodos constructivos y las características de los "mill buildings" textiles de la Ilamada Revolución Industrial en Inglaterra durante los siglos XVIII y XIX \{confrontar los edificios vistos en apartado 3.2 más atrás\}. 
Tal y como se representa en la Figura 297, este complejo edificatorio para la fabricación de tejidos de seda está caracterizado por un sistema energético que originariamente parte de un punto único de accionamiento y cuya transmisión mecánica se realiza a base de ejes metálicos distribuidos longitudinalmente en cada planta hasta cada una de las máquinas. Asimismo, la iluminación natural se realiza por los huecos en fachada que alcanzan hasta un $60 \%$ del total en algunos casos (lo que se analiza posteriormente), definidos todos ellos por una mayor altura que anchura, conforme la estructura envolvente les permite. En cuanto a los materiales utilizados, al tratarse de sucesivas ampliaciones, estos son de diversa índole: desde los ladrillos macizos para la conformación de los pilares; la madera tanto para soportes como para las vigas; hasta la fundición posterior para pilares siguiendo la caracterización de resistente al fuego "fire proof". Todo ello por sí mismo, junto a su distribución en planta longitudinal en diversas alturas, conduce, como se ha comentado, a la tipificación de "mill building".

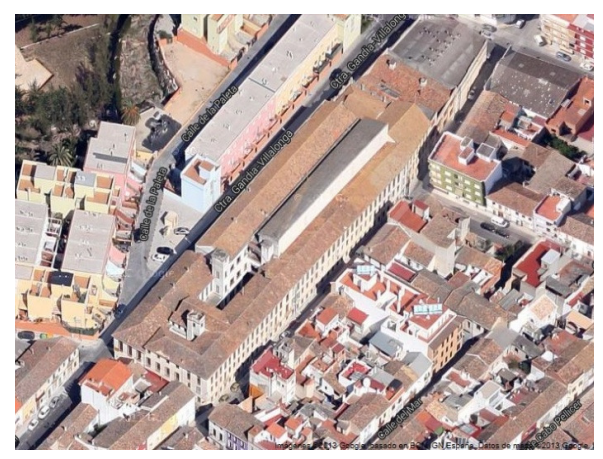

Figura 298. Almoines. En esta fotografía se aprecia la proporción entre el núcleo urbano consolidado con las dimensiones de la fábrica. (www.google.es/maps).

En la Figura 299 se reflejan cada una de las ampliaciones que fueron realizándose en el complejo, de modo que se facilite su compresión a la hora de especificar los sistemas constructivos y los restantes factores que intervinieron en su configuración. 
FACTORES DETERMINANTES DE LA ARQUITECTURA DE LOS "MILL BUILDINGS" Y SU INFLUENCIA EN LA ARQUITECTURA INDUSTRIAL VALENCIANA

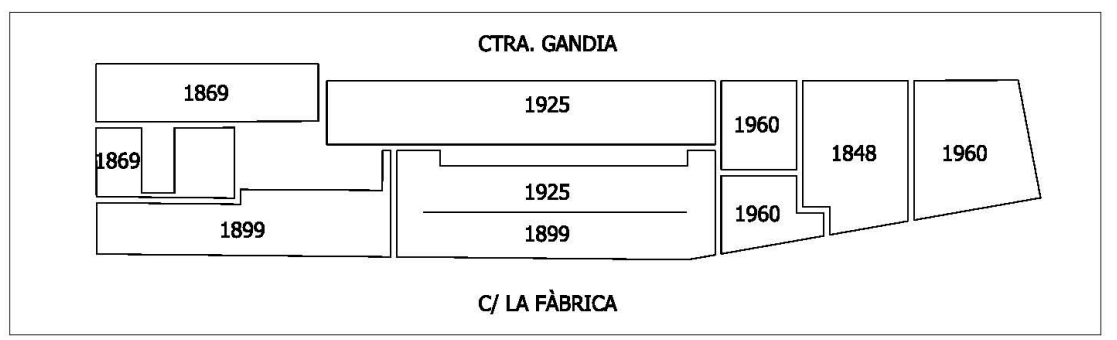

Figura 299. Planta del complejo industrial donde se reflejan cada una de las fases y ampliaciones que constituyeron la actual fábrica. 


\section{FÁBRICA INICIAL (1848):}

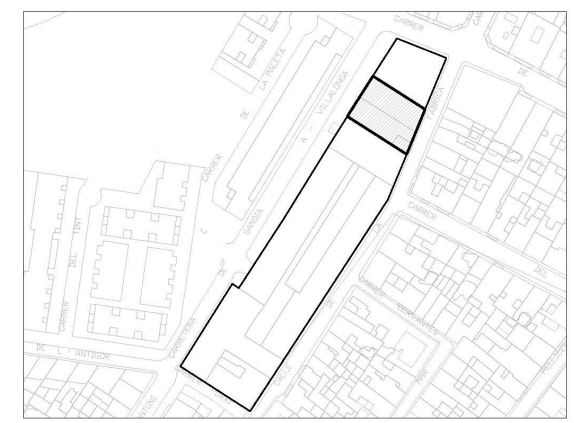

Figura 300. Almoines: vista de la fábrica. Remarcada a la parte noreste del complejo, correspondiente a la Figura 301 (actualmente almacenes municipales) (www.google.es).

\subsection{PLANTA BAJA Y ÚNICA}
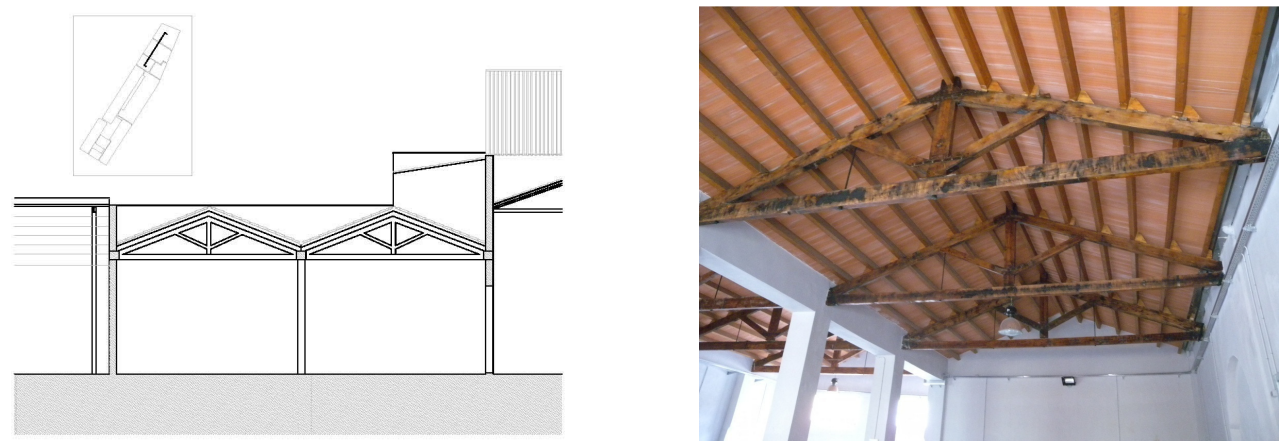

Figura 301. Interior del edificio señalado (única parte que en estos momentos tiene titularidad municipal). Este inmueble ha sido restaurado recientemente, conservando su estructura original.

Esta parte de la fábrica está considerada como el obrador más antiguo de todos, y donde en sus orígenes, se realizaba la manufactura de la seda. Como se refleja en la Figura 300, este almacén se encuentra ubicado al noreste del complejo, siendo de consideración pasante entre la C/ Gandia y la Fàbrica. Recientemente ha sido rehabilitando resultando lo que se observa en la Figura 301. 
Se trata de un edificio en única planta, prácticamente rectangular, de una superficie de $402 \mathrm{~m}^{2}(\approx 17 \times 24 \mathrm{~m})$. En principio se corresponde con una tipología habitual en almacenes y talleres artesanales de la época, aunque en la fotografía de la Figura 302, de alrededor de 1900, ya incluye maquinaria de producción de telas de seda. Es por ello que originariamente no disponía de rueda hidráulica para el accionamiento de telares, ni por ello de ninguna fuente de energía.

Su estructura es básica, basándose en muros de carga perimetrales a base de mampuestos, pilares de ladrillo y cerchas de madera para la cubierta [Figura 302].

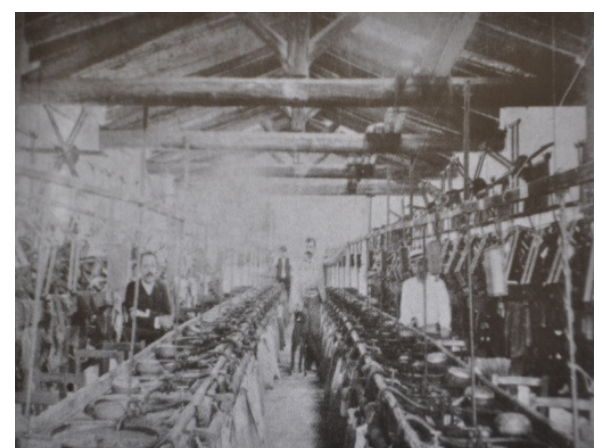

Figura 302. Interior del edificio señalado. Fotografía tomada alrededor de 1900 (Soler, 2009).

Las cerchas de madera responden al esquema tipo "King" ${ }^{393}$. Esta solución constructiva coincide con la empleada en la última planta de los edificios ingleses a dos aguas durante el siglo XVIII ${ }^{394}$, usadas en muchas ocasiones como aula de

\footnotetext{
${ }^{393}$ La madera como material en la construcción fue ampliamente utilizada incluso desde antes de la Edad Media. Según Blat (Blat, 2007) "La madera y la piedra, son, posiblemente, los materiales más antiguos utilizados por el hombre en su actividad constructiva. [...]. La madera no ha dejado de utilizarse en ninguna época, como material de construcción".

La cercha tipo "King Post", es una tipología estructural basada en el esquema de la cercha tradicional, que se compone de dos barras diagonales que se encuentran en el vértice de la cercha, una barra horizontal que se sirve de cierre en la parte inferior y el King Post, es decir poste central que conectan el vértice superior con la barra inferior.

${ }^{394}$ En el caso inglés, el tipo de cercha utilizado es el "Queen”, la cual alcanzaba mayor luz a costa de añadir el número de montantes (no lo había en el centro, de manera que la zona transitable quedaba entre las dos barras verticales). La altura de estas plantas inglesas era menor que la alcanzada en este edificio de Almoines.
} 
estudio para los niños que allí trabajaban, o grandes salas diáfanas para la gran maquinaria de tejer. Como ejemplos de cubiertas con cerchas de madera se tiene, entre otros: el Derby Cotton Mill de William Strutt, de 1792 [Figura 154]; el mill de la [Figura 150], de 1830; o el Spotland Bridge Mill, en Rochdale, de $1820 \div 1830$ [Figura 177], todos ellos anteriores al que nos ocupa, por lo que no se aprecia innovación constructiva alguna en estas naves, sino una continuidad en la utilización del material. No se trata más que una asimilación a los "cottage" ingleses originales, donde se hilaba de forma individual, según el método de la concentración del trabajo.

En cuanto a la iluminación, la única de la que se tiene es la proporcionada por los dos muros hastiales recayendo sobre sendas calles de acceso. 


\section{AMPLIACIÓN DE 1869}

La primera ampliación que se realizó no fue justo al lado del primer edificio originario de 1848 [Figura 303]. Ello fue debido a que se realizó una compra de unas casas ubicadas calle más abajo. No obstante lo anterior, en el transcurso del tiempo, el complejo sí conformó una única unidad.

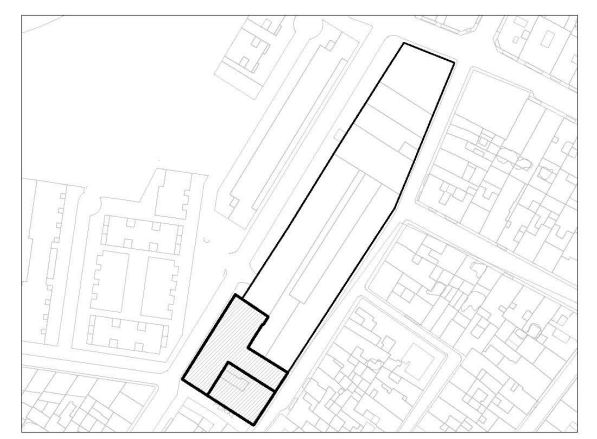

Figura 303. Almoines: vista de la fábrica. Remarcados los edificios correspondientes a la Figura 304, Figura 308, Figura 310 y Figura 311, en la Ctra. Gandía a Villalonga, donde se ubicó originariamente la rueda hidráulica de accionamiento de la maquinaria. (www.google.es/maps).

Se trata como la anterior, de construcción con muros de carga a base de mampuestos y estructura de forjados en madera [Figura 304]. 


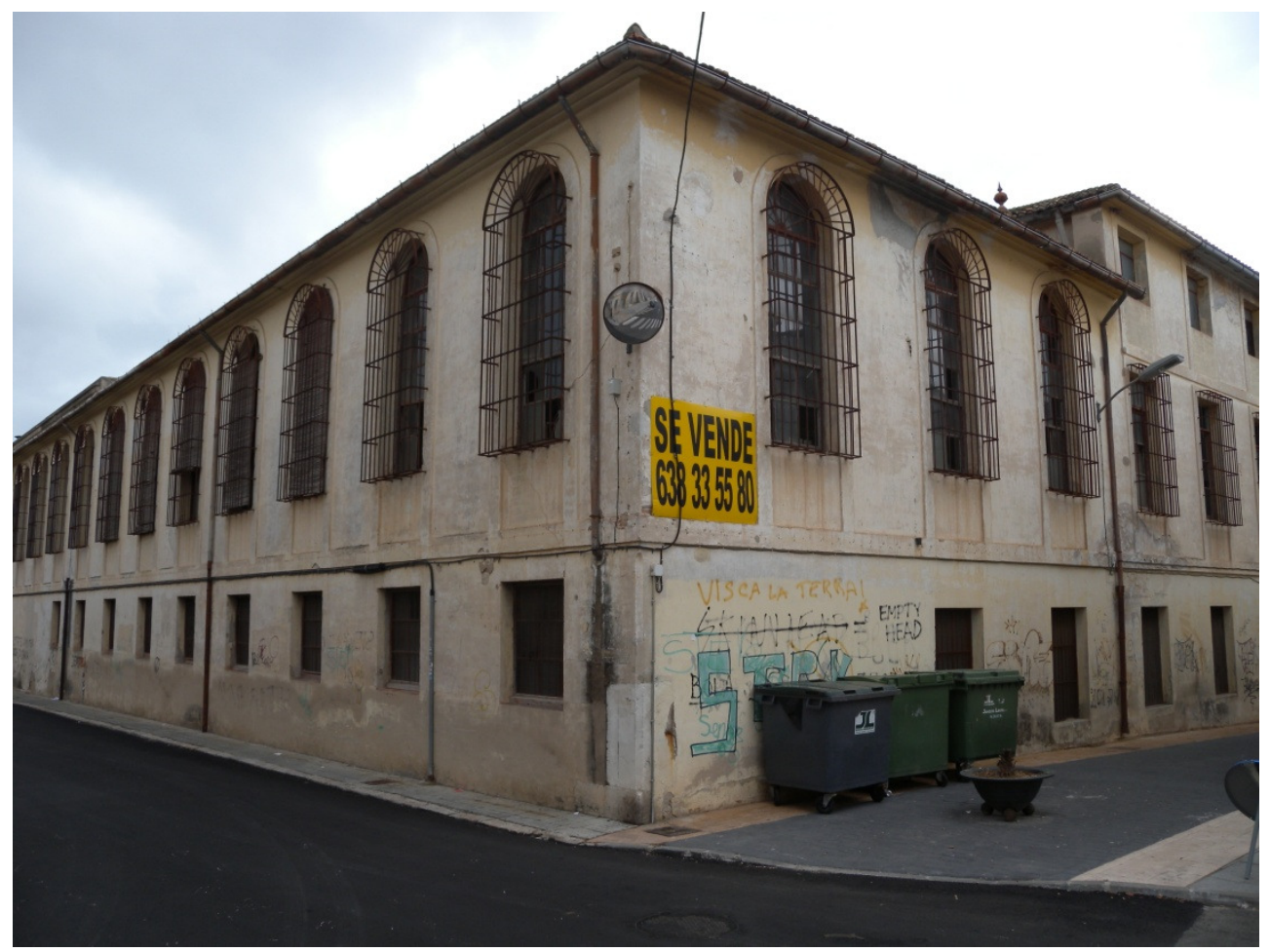

Figura 304. Fachada suroeste de la fábrica, C/ Gandia esquina C/ Porxí. En esta parte del edificio era donde en un principio se situaron las ruedas hidráulicas motrices [Figura 305], desaparecidas una vez se instaló la electricidad. Cerca de este edificio transcurría la "séquia mare", como afluente del río Serpis, que transcurría a escasos $100 \mathrm{~m}$ al oeste del edificio. 


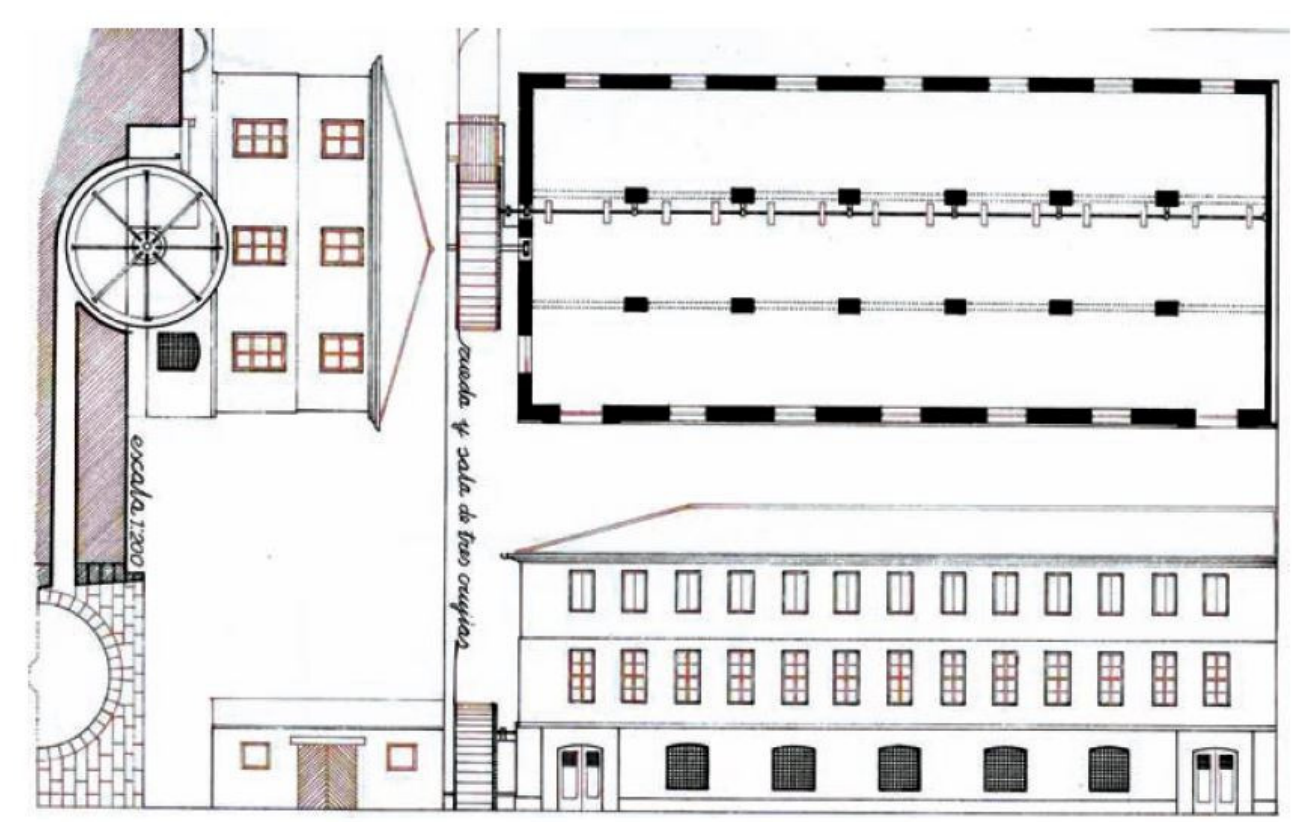

Figura 305. Esquema del recorrido del agua de la acequia por el interior de la fábrica. Este tipo de accionamiento hidráulico caracterizaba los "mill buildings" ingleses a finales del XVIII y durante gran parte del XIX (Navarro, 2007).

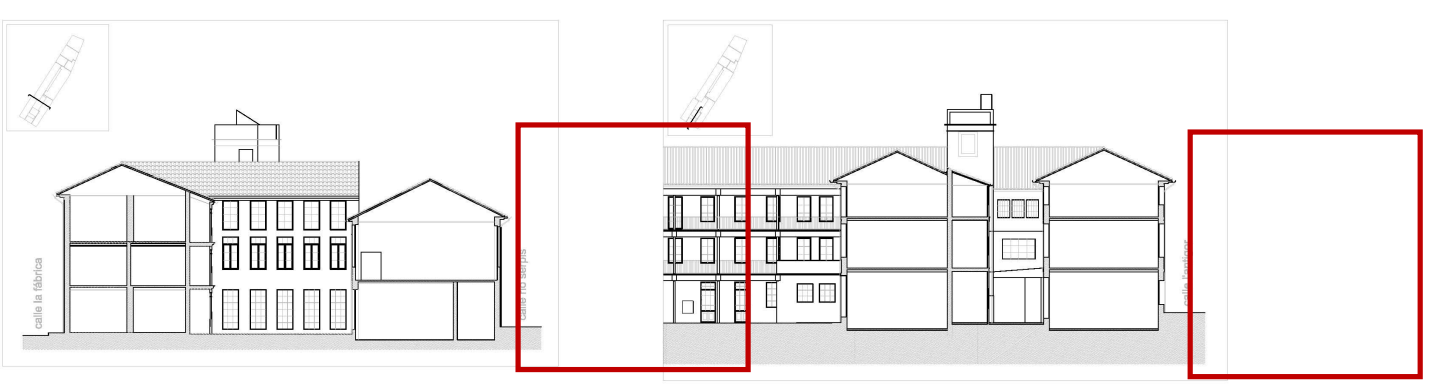




\subsection{PLANTA BAJA}
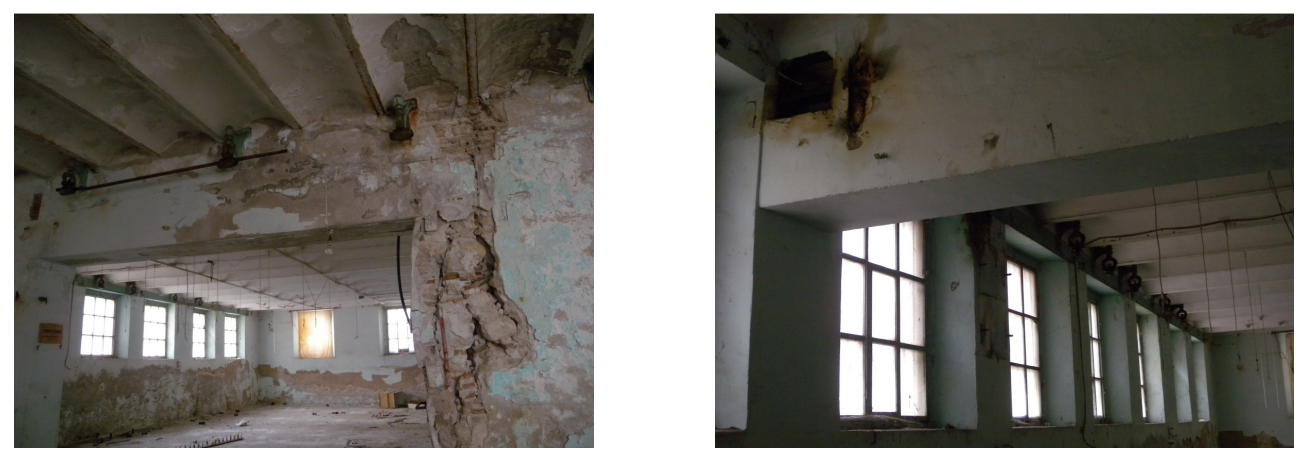

Figura 306. Interior del edificio señalado, planta baja, donde se aprecian perfectamente los soportes de los ejes giratorios que accionaban las máquinas.

En general, el tamaño de las vigas de madera, algunas de ellas recubiertas en yeso, era considerable. En cuanto a los forjados, estos eran a base de bovedillas, y los pilares seguían también siendo de ladrillo, como lo hacía en general la arquitectura autóctona [Figura 306]. Comparativamente, esta construcción fue realizada a principios de la $2 \underline{a}$ mitad del siglo XIX, correspondiendo aproximadamente con la misma fecha de construcción del Boat Store (Inglaterra) [Figura 95], si bien este 'último ya había sido realizado íntegramente en hierro fundido, por lo que sendos sistemas constructivos no guardan relación temporal alguna. 
2.2. PLANTA PRIMERA

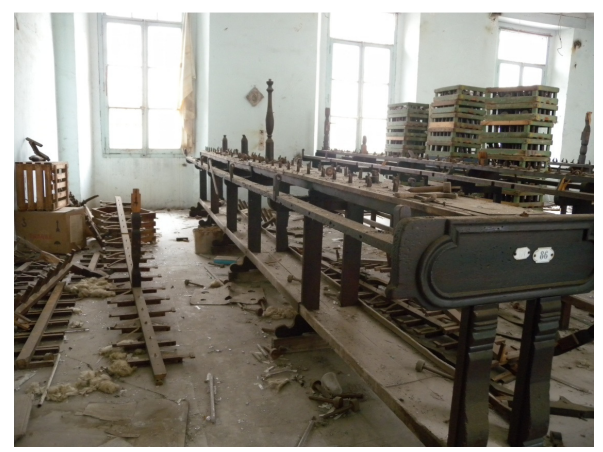

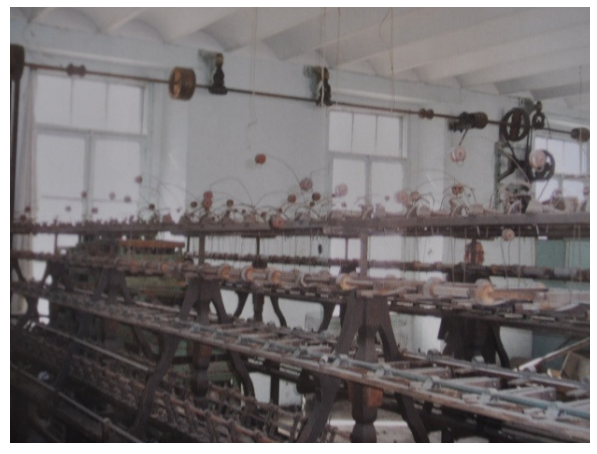

Figura 307. Taller de hilados, con abundante iluminación natural desde la C/ Porxí. Todavía queda la maquinaria de madera.

A pesar de los gruesos muros de carga, la iluminación conseguida con los huecos de ventana se aprecia suficiente, puesto que como se verá en párrafos consecuentes, la relación muro/hueco es elevada [Figura 307].

Con lo que respecta a las fachadas, como se ha comentado, estaban realizadas con mampuestos [Figura 308, Figura 310 y Figura 309].

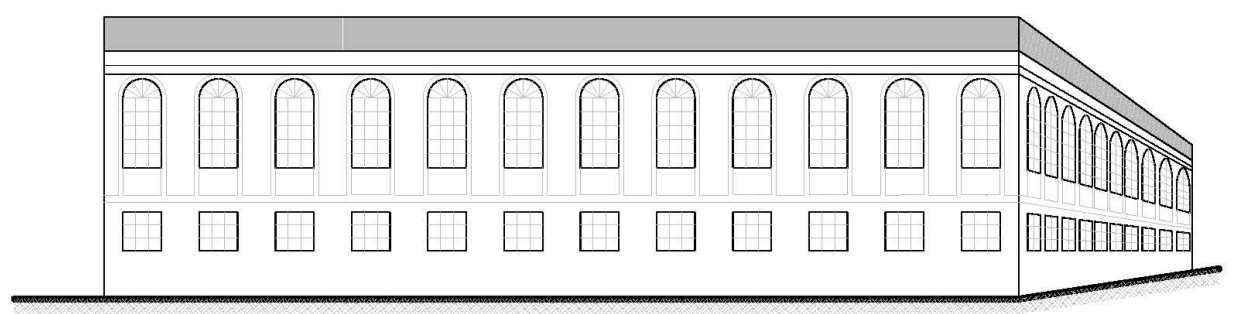

Figura 308. Fachada de la fábrica de seda Lombard de Almoines por la C/ Gandía. 


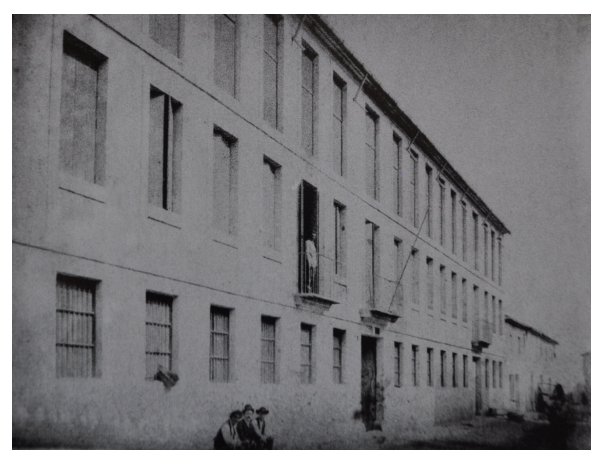

Figura 309. Exterior del edificio señalado en la C/ La Fàbrica (Soler, 2009).

Esta fachada, recayente a la C/ Gandía [Figura 304 y Figura 308], tiene una relación fachada/hueco de $\approx 75 / 25(\%)$, lo que demuestra que queda próxima a la tendencia con la que ya se construía en Inglaterra [Figura 310]:

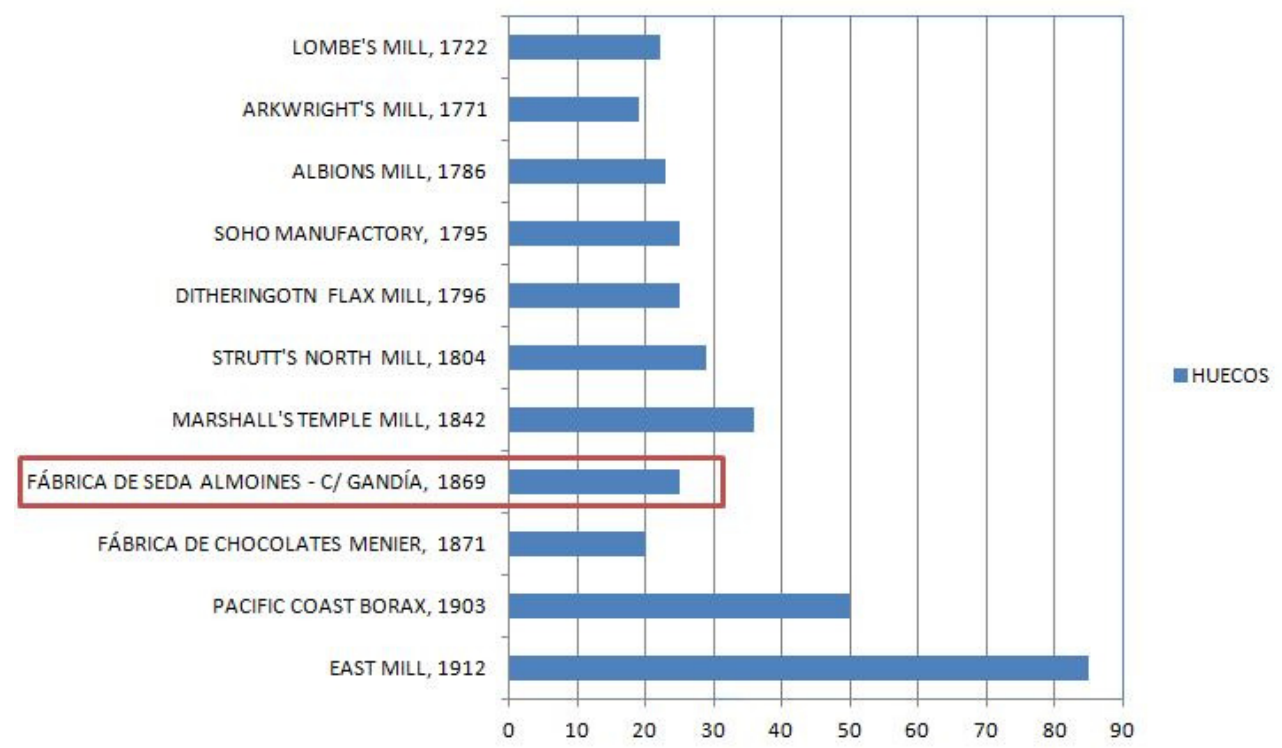

Figura 310. Relación fachada/hueco (\%) de la fábrica de seda Lombard de Almoines. 
En lo que respecta a la cubierta, esta estaba realizada con cerchas metálicas a dos aguas $^{395}$ [Figura 311], típica de los mill buildings de finales del siglo XVIII y principios del XIX, como el Ditherington Mill [50 años antes, Figura 54 $]^{396}$. Ya no se trata de cerchas de madera como las empleadas en el edificio original de 1848, sino que resultan mucho más ligeras y alcanzan mayores luces. Esta tipología de cerramiento de cubierta se corresponderá también con la usual de los cobertizos y naves que se construirán en las últimas décadas del siglo XIX en la región, como es el caso de los almacenes vistos en el aparatado anterior, en la ciudad de Valencia del cambio al siglo XX \{apartado 4.4.1\}.

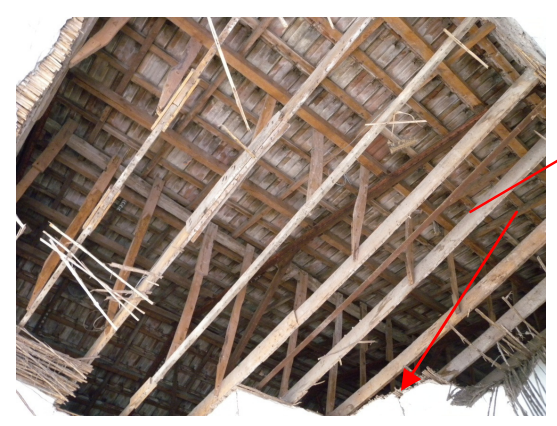

Figura 311. Cubierta a dos aguas correspondiente al edificio señalado. Las cerchas son metálicas. El entramado de madera es la estructura de sujeción del forlso techo.

Por último, en cuanto al accionamiento energético de esta primera ampliación del edificio de 1848, como se ha mencionado al principio de este apartado, fue hidráulico [Figura 305] $]^{397}$. Por su parte, la transmisión mecánica interior se realizaba mediante ejes giratorios, propios de este tipo de accionamientos. Posteriormente se reemplazó por la energía térmica [Figura 306].

\footnotetext{
395 En la bibliografía consultada, no aparece información sobre alguna reforma estructural de entidad de la cubierta de esta parte del edificio, por lo que se presupone originalmente de estructura metálica, atendiendo a la época de construcción.

${ }^{396}$ Aunque ya se ha mencionado, que la altura alcanzada en estas plantas es inferior por utilizarse las cerchas de tipo "Queen Post".

${ }^{397}$ En las fotografías del mismo edificio del año 1900, aparece una gran chimenea que correspondía a una máquina de vapor, año en el que se realizó una gran ampliación y en la que se aprovechó para la instalación de la electricidad para el accionamiento de una máquina de torcer seda con "2.480 husos y 233 cabezas", de "5 kW de potencia" (Soler, 2009).
} 


\section{AMPLIACIÓN DE 1899}

La segunda ampliación se realizó en 1899, esta vez con edificios anexos al primero, de 1869 [Figura 312]:

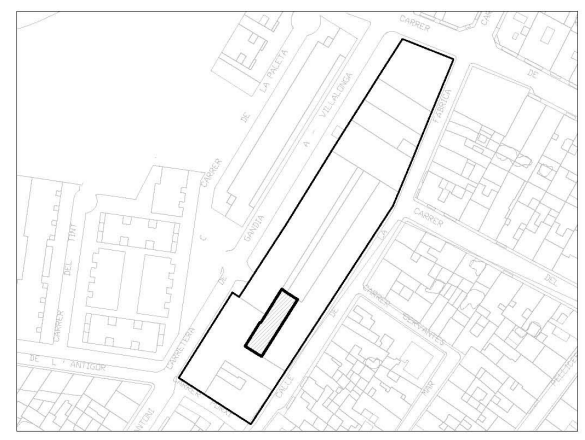

Figura 312. Almoines: vista de la fábrica. Patio central correspondiente a la Figura 313, Figura 314 (www.google.es/maps).
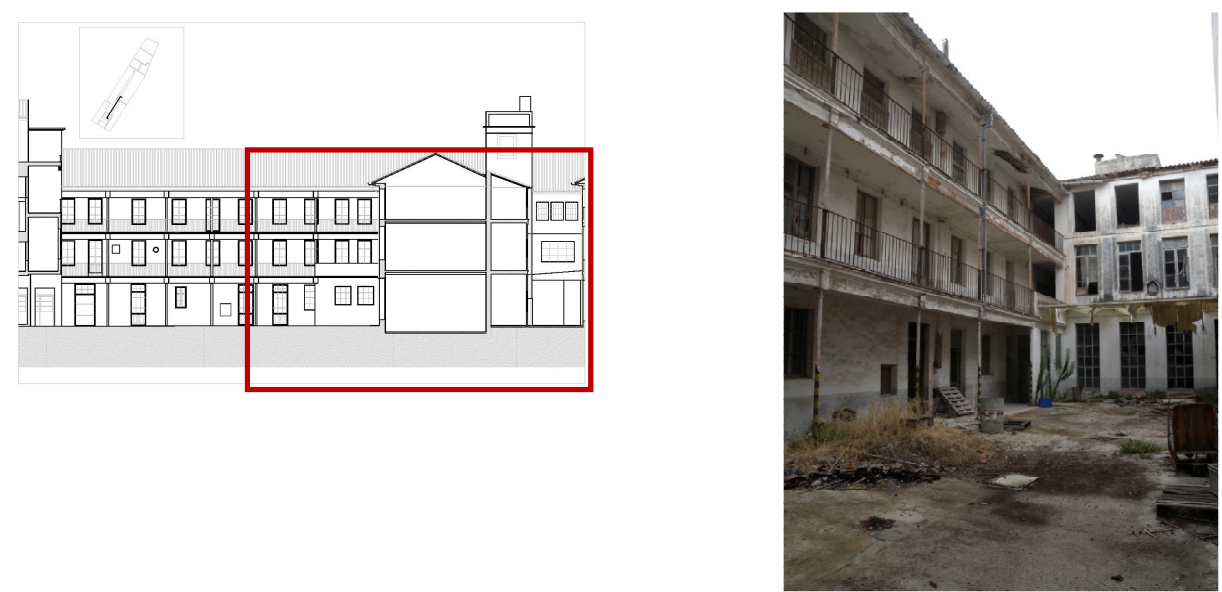

Figura 313. Patio interior donde recaían las oficinas, ubicadas a la izquierda de la fotografía. 
El sistema constructivo es novedoso en este complejo: este edificio se realizó mediante pilares macizos de hierro fundido sobre los que apoyaban vigas de madera [Figura 313 y Figura 314$]^{398}$.

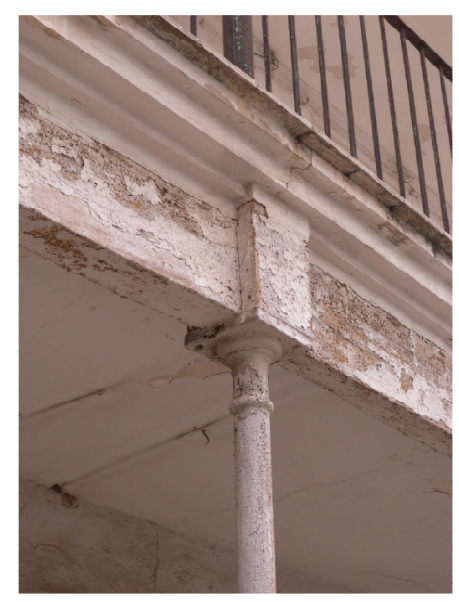

Figura 314. Patio interior. Detalle del apoyo de la viga de madera sobre un pilar de fundición macizo con capitel.

Ello recuerda al apoyo que Arkwright realizó en su fábrica Masson Mill en el río Derwent \{confrontar los edificios de Arkwright ingleses en el apartado 3.2.2 más atrás\}, en 1783. Aquella fue, la primera vez que se utilizó el hierro fundido como elemento estructural, sujetando vigas de madera, y que incluso más de un siglo después se ha venido utilizando aquí como solución constructiva.

${ }^{398}$ Al fondo de dicha figura, el edificio con planta baja y dos alturas para la fabricación de hilo, cuya fachada se construyó a base de pilares de ladrillo anteriormente en 1869 [Figura 307]. 

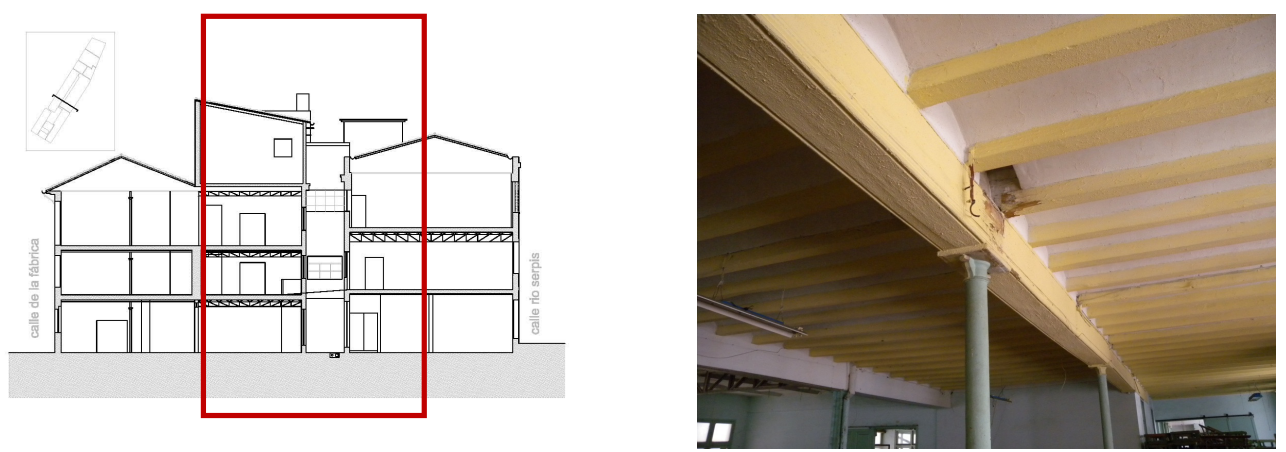

Figura 315. Interior del edificio señalado, planta primera. 


\subsection{PLANTA BAJA}

En esta ampliación del edificio, se utilizan los soportes el hierro fundido, si bien la mayoría de las vigas son de madera [Figura 315], lo que constata la existencia de diferentes materiales y sistemas constructivos en el complejo [Figura 316 y Figura 317].

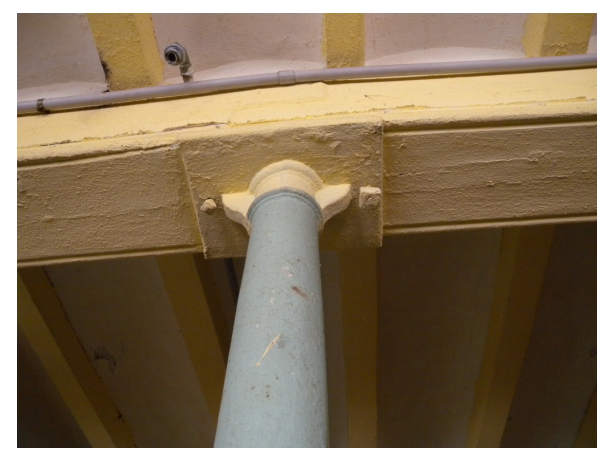

Figura 316. Columnas de fundición

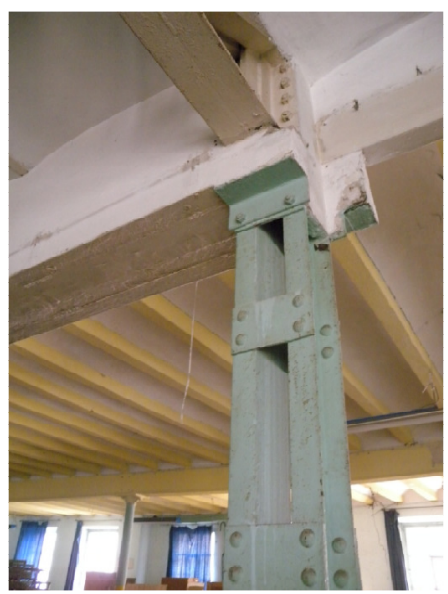

Figura 317. Pilares de acero.

Las columnas de fundición eran macizas, continuando en la planta superior, y sobre las que apoyan las vigas de madera (continuas en el apoyo), tal y como ya se ha indicado sucedía también en la fábrica de hilo que Arkwright construyó en 1783. Los forjados están construidos también con viguetas de madera y bovedillas de ladrillo [Figura 316].

Sin embargo, se encuentran algunos pilares a base de sendos perfiles en $U$ empresillados mediante roblones (si bien, su colocación debería haber sido justo a la inversa, de forma que trabajaran mejor frente a las solicitaciones, pero de mayor dificultad de ejecución). También se aprecian las distintas soluciones para formar el forjado, con vigas en celosía, y bóvedas de ladrillo que arrancan del ala inferior de la vigueta metálica [Figura 318]. 


\subsection{PLANTA PRIMERA}

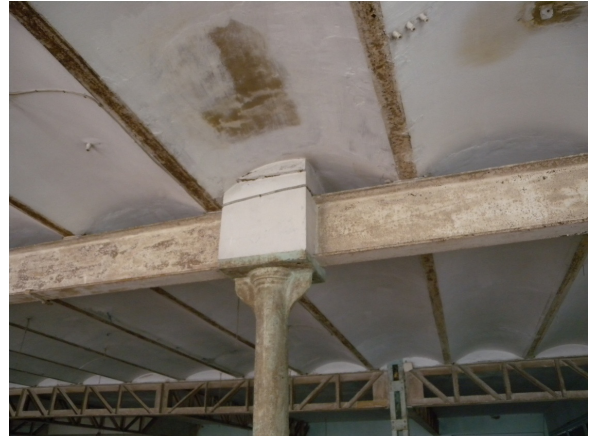

Figura 318. Planta primera del edificio de ampliación de 1899, con diferentes tipos de vigas en la misma sala.

En esta primera planta del edificio, se observan diferentes tipos de vigas en la misma sala, lo que es una casuística en general en totalidad del complejo, probablemente entre otros motivos, por sus diferentes fases de construcción [Figura 318].

Se podría aseverar que con sus pilares y viguetas de hierro fundido, se asemejan a los primeros "fire proof" que los arquitectos ingleses idearon al principio de la revolución industrial, como el Ditherington Flax Mill que el arquitecto Charles Bage mandó construir en 1796. 


\subsection{PLANTA SEGUNDA}

Esta segunda planta se caracteriza por las vigas en celosía roblonadas, encastradas por su parte superior en el propio forjado, solución poco usual. También aparecen multitud de pilares empresillados, así como macizos de fundición. Los forjados son realizados mediante bóvedas en arco apoyando sobre las viguetas de acero.

A pesar de la estructura interior metálica en soportes y vigas, los muros exteriores todavía son de carga, aunque la diafanidad conseguida es apreciable. En cuanto al suelo, en muchas salas solía ser de madera [Figura 319].
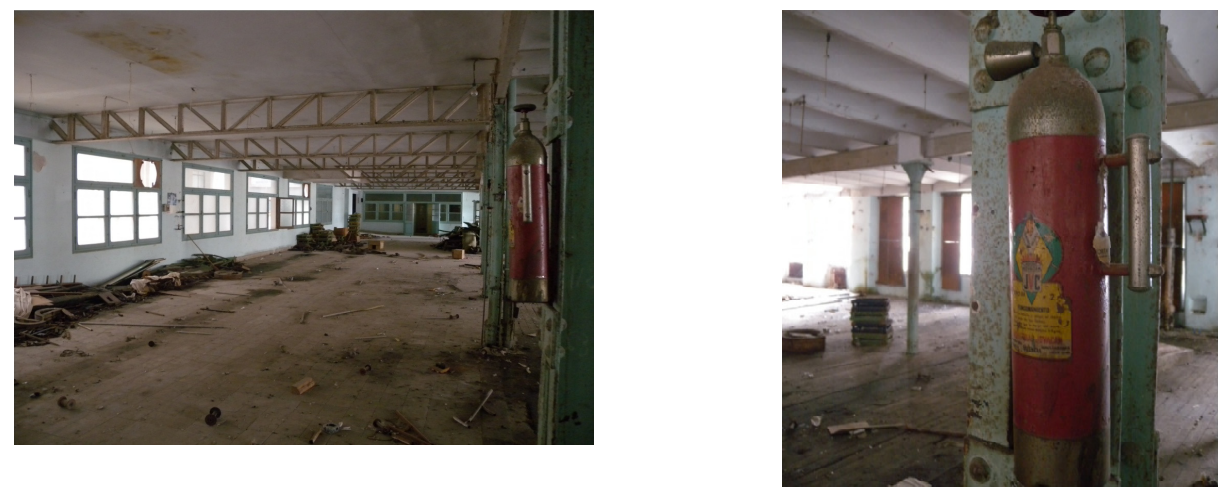

Figura 319. Pilares empresillados y macizos de fundición. Apreciar el suelo de madera.

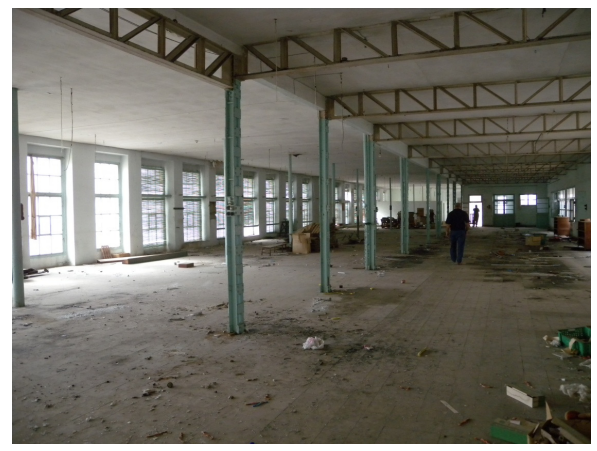

Figura 320. Diafanidad e iluminación, con todavía muros de carga. Columnas empresilladas con roblones. 


\section{AMPLIACIÓN DE 1925}

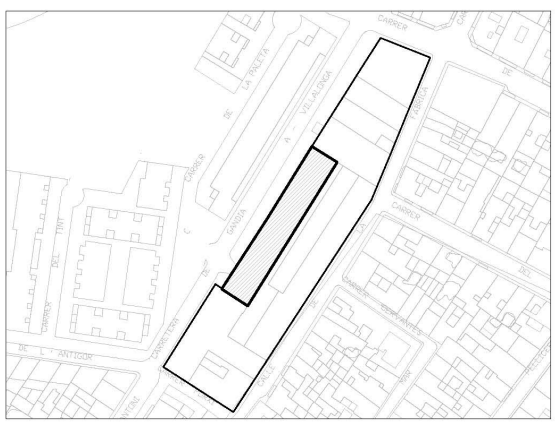

Figura 321. Almoines: vista de la fábrica (www.google.es/maps).

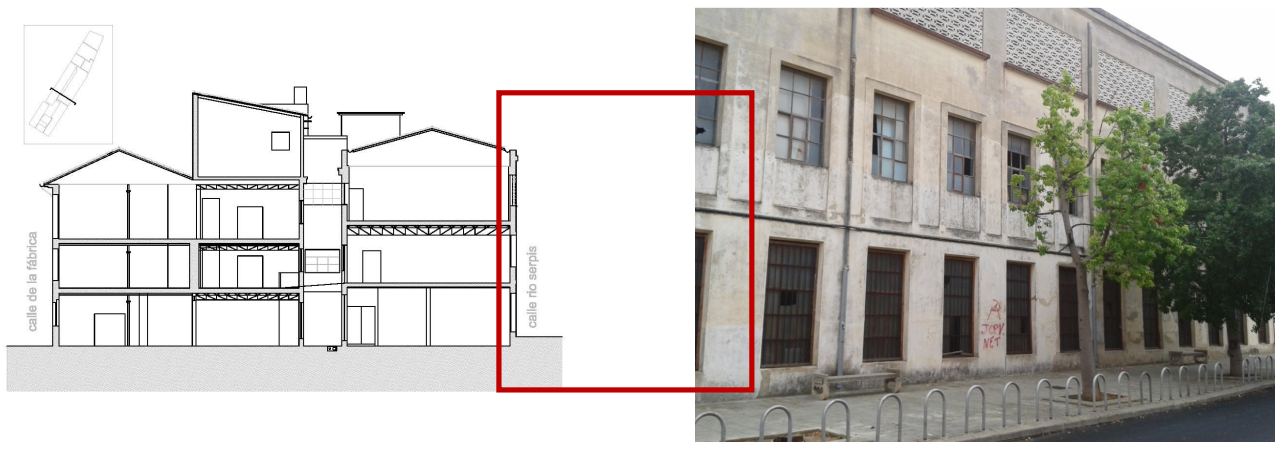

Figura 322. Fachada actual de la fábrica de seda Lombard de Almoines, en la Carretera de Gandía a Villalonga, construida a principios del siglo pasado. La flecha roja indica por dónde pasaba en el siglo XIX la "Séquia Mare" que provenía del río Alcoy desde Gandía.

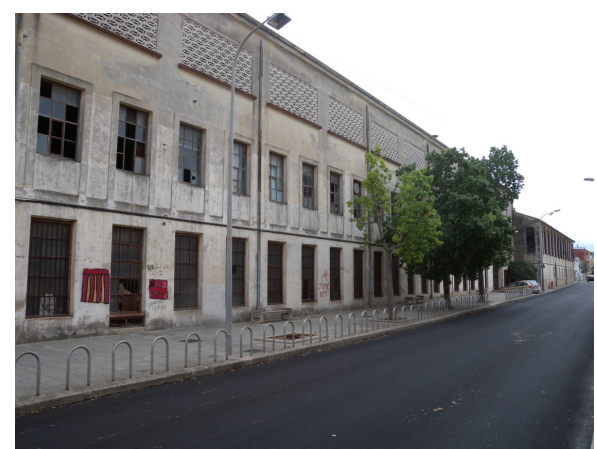

Figura 323. Fachada de la fábrica de seda Lombard de Almoines, recayente a la Ctra. Gandía a Villalonga. Al fondo el acceso actual al edificio. Estado actual de semiabandono. 


\subsection{PLANTA BAJA}

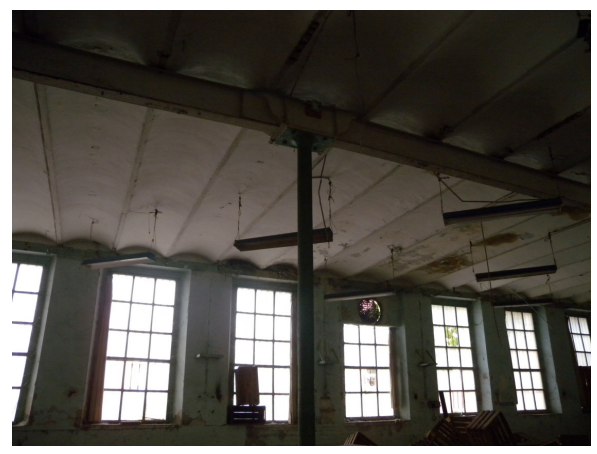

Figura 324. Interior del edificio señalado, planta baja.

En esta ampliación, el forjado está formado por vigas de acero y viguetas de hierro forjado, con bóvedas de ladrillo apoyando también sobre pilastras que conforman la fachada [Figura 324]. Esto último, junto con la apreciable altura entre forjados, permite conseguir grandes ventanales para iluminación, que junto con la diafanidad conseguida con la estructura metálica, convertía el espacio en óptimo para la producción.

El sistema constructivo ya fue empleado en 1799, en la Fábrica de hilos de Salford (Manchester), cuyas vigas fueron elaboradas por la fundición de Boulton \& Watt. La similitud reside en el empleo del hierro fundido en los soportes, y las bóvedas tabicadas de ladrillo revoltón empleadas para la formación de los forjados (no es el caso de las vigas, puesto que Almoines ya utiliza el acero, material ya ampliamente extendido: por la fecha de construcción no resulta extraño su uso, lo que por supuesto, no había podido hacerse en las anteriores ampliaciones comentadas).

En este caso, las pilastras abocinadas de la fachada sostienen el peso de los forjados [Figura 325]. 

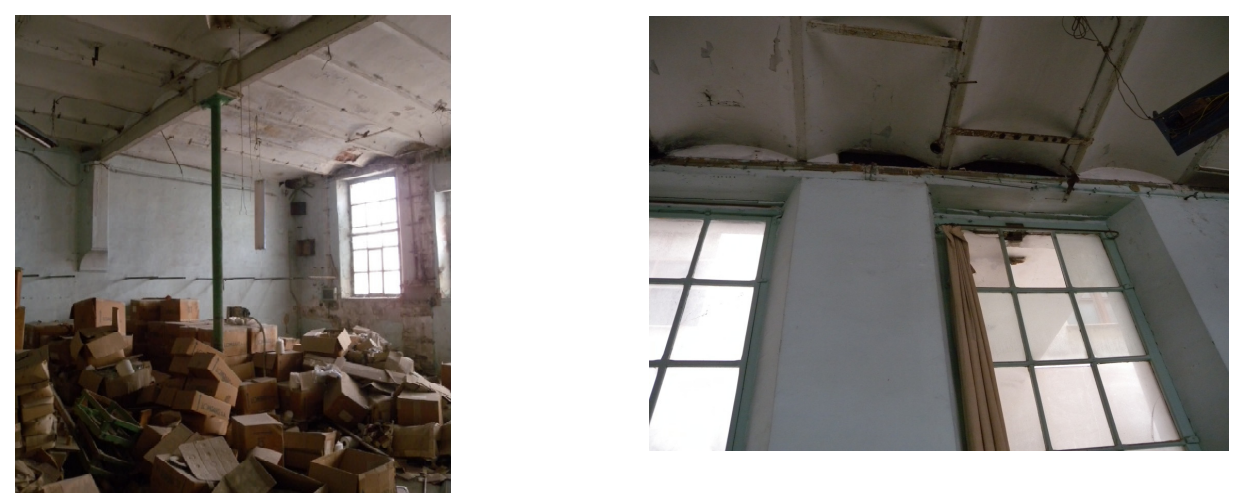

Figura 325. Ventanas.

También hay pilares de fundición macizos, muy esbeltos, sobre los que apoyan vigas, ahora sí, de acero en doble T. Por su parte, el entrevigado es de ladrillo revoltón en forma de bóvedas con viguetas también de acero. Las ventanas son de gran superficie, permitiendo la entrada de luz, lo que le proporciona a la sala una gran iluminación a lo largo de todo el día [Figura 324 y Figura 325] (en la Figura 325 se ven los machones de ladrillo que hacen las veces de estructura portante). Este es un claro ejemplo de que en el cambio de siglo todavía no había llegado la estructura a la fachada, como ya había ocurrido en Inglaterra, en el East Mill [Figura 81], de la misma época que el que se está analizando en este apartado.

Asimismo, las viguetas del forjado apoyan en el muro exterior sobre una viga de madera que hace de dintel de las ventanas, y que a su vez apoyan sobre el muro de carga. Aparecen las jambas en cuña, para permitir al máximo el paso de la iluminación natural. Por su parte, toda la carpintería es de madera [Figura 326]. 

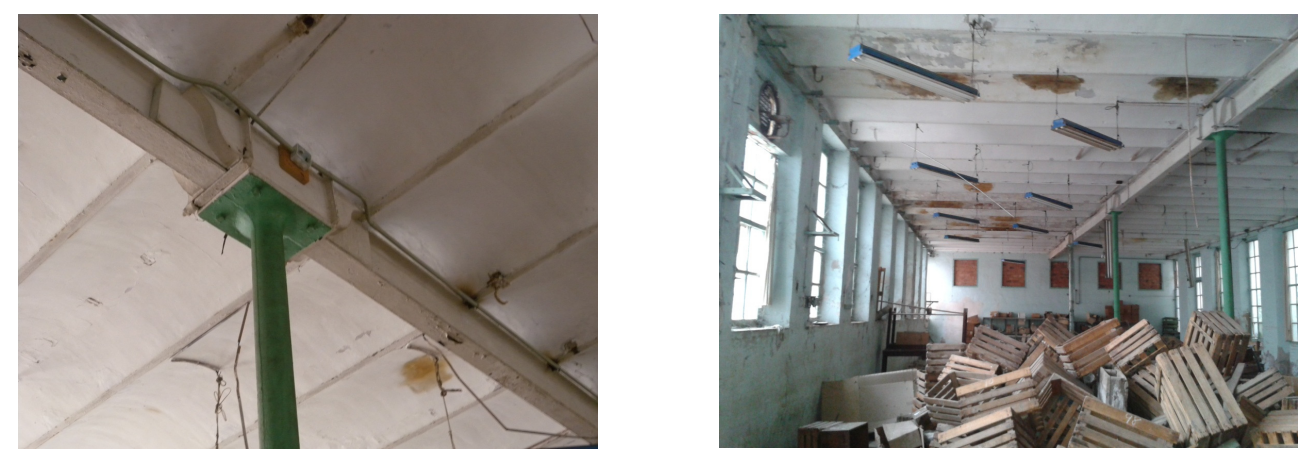

Figura 326. Detalle del apoyo de la viga de acero sobre el pilar. Se aprecian los roblones de unión entre pilar y viga. Como se ve en la sección de la Figura 292, este pilar no tiene continuidad en la planta superior.

Resaltar dos características principales que se pretendían conseguir en este tipo de instalaciones: la diafanidad y la iluminación natural. Además, el pórtico es longitudinal, de forma que la fachada no soporta el empuje, quedando más libre. Este sistema es el mismo que el visto en la Figura 245, correspondiente a la fábrica de Ferrándiz, de la misma época. 
4.2. PLANTA PRIMERA

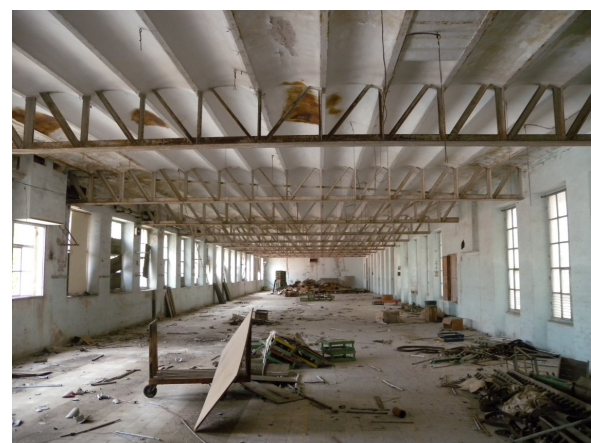

Figura 327. Diafanidad e iluminación. Suelos de madera.

Esta parte del edificio continúa con la viga Pratt [Figura 327], donde en los extremos de la viga, los perfiles tienen una sección mayor que en la parte central, lo que conduce a deducir la precisión con la que se realizaron los cálculos estructurales. 


\subsection{PLANTA SEGUNDA}

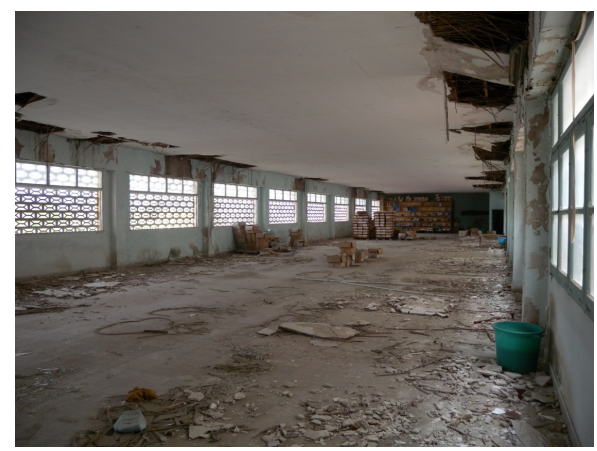

Figura 328. Interior del edificio señalado, planta segunda. Ala izquierda la C/ Gandía, según la Figura 296.

En cuanto a las fachadas [Figura 329]:
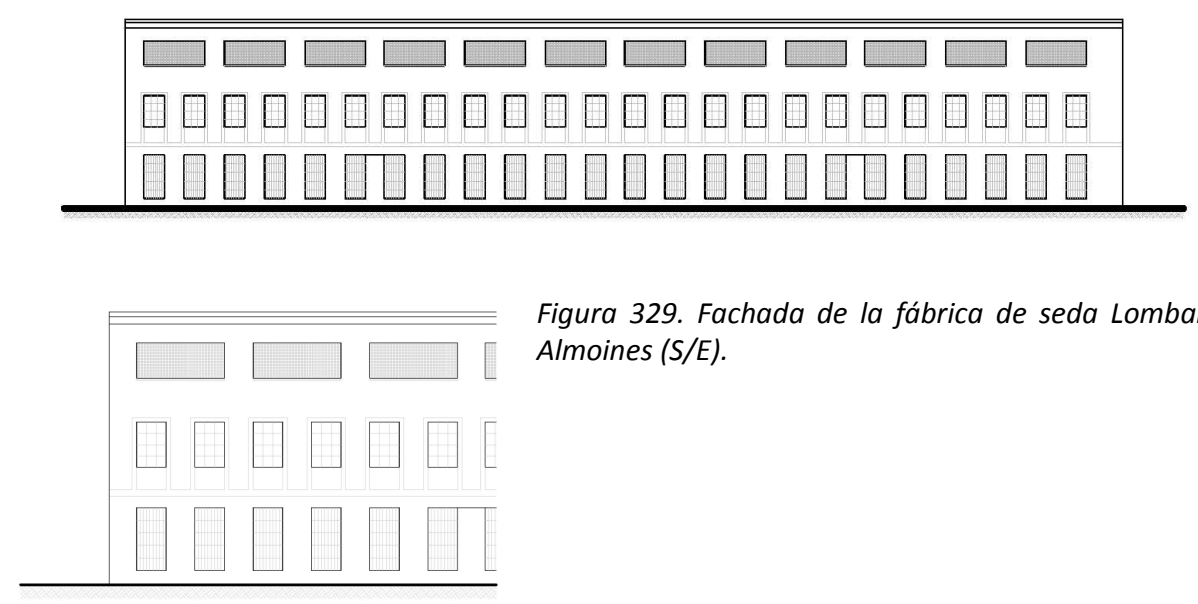

Figura 329. Fachada de la fábrica de seda Lombard de Almoines (S/E).

La recayente a la C/ Gandía, tiene una relación fachada/hueco de 70/30 (\%), inferior a lo construido en la misma época en otros países, como Inglaterra o Estados Unidos, como Pacífic Coast Borax [Figura 198], que utilizó el hormigón armado como material de construcción. También muy inferior al East Mill de 
Belper [Figura 80], también de principios del siglo XX, cuya fachada estaba totalmente realizada con hierro [Figura 329 y Figura 330]:

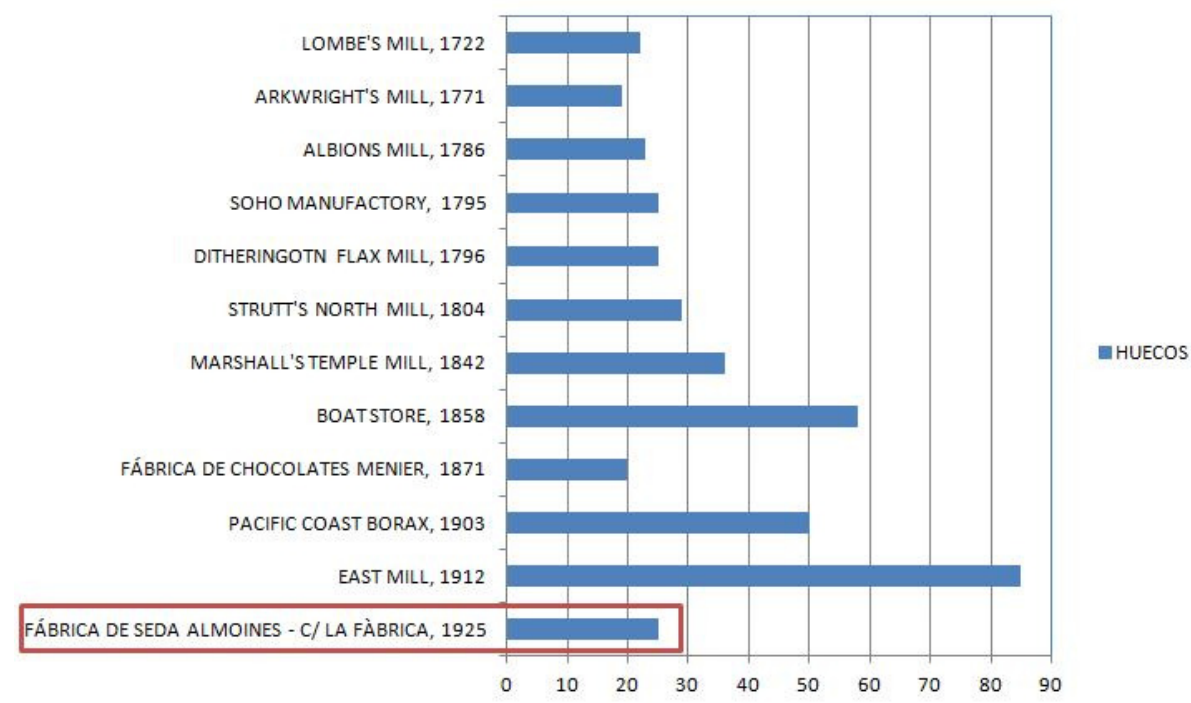

Figura 330. Relación fachada/hueco (\%) de la fábrica de seda Lombard de Almoines. 


\section{CONCLUSIONES}

La presente tesis, basada en un análisis comparativo entre Inglaterra, como cuna de la industrialización a nivel mundial, y la Comunidad Valenciana, demuestra que, aunque obviamente a diferente escala, también hubo en esta última una revolución industrial, y donde también se construyeron "mill buildings" en el sentido anglosajón de la palabra, que aunque lejos de representar un hito arquitectónico como el Ditherington Flax Mill o el North Mill, representan la modesta casuística valenciana ${ }^{399}$. De hecho, su industria en la segunda mitad del

\footnotetext{
${ }^{399}$ Ejemplos como los de Alcoi, centro industrial valenciano por excelencia, ayudan a comprender mejor la implantación del sistema edificio-motor-máquina a finales del siglo XVIII y principios del XIX. Pero otros edificios, como la fábrica de harinas de Alfara del Patriarca o la de sedas de Almoines de inicios del XX, ratifican la existencia de los "mill buildings". Eso sí, no se construyeron edificios tan altos como aquellos ingleses, ni tampoco se aplicaron al mismo tiempo las mismas técnicas
} 
siglo XIX y principios del XX, estuvo influida, en cierto modo, por los mismos condicionantes que lo fueron aquellos primeros edificios fabriles ingleses desde la mitad del siglo XVIII.

Para ello, se han estudiado un conjunto de edificios fabriles ingleses relevantes como el originario Lombe's Mill, de 1722, y otros comprendidos en el periodo entre el nacimiento de la llamada revolución industrial, alrededor de 1770, hasta principios del siglo XX. La elección de estos se fundamenta en que cada uno de ellos introduce o mejora alguna novedad tecnológica que condiciona su diseño y funcionamiento.

En base a ellos, entre las conclusiones más importantes que se obtienen destacan:

1. Del estudio del conjunto de edificios, se han identificado una serie de factores que han influido de manera significativa en la evolución y configuración de los edificios industriales, independientemente de los derivados propiamente del proceso fabril.

2. Estos factores pueden condensarse en tres: el factor de la energía (accionamiento y transmisión), el factor del uso de materiales de construcción, y por último, el factor de la iluminación. Su análisis y valoración permite entender y leer la evolución constructiva y arquitectónica de los edificios fabriles.

3. El factor energético, del que en general se constata una clara repercusión sobre la forma de los espacios fabriles. Su punto de accionamiento cambió de hidráulico originalmente (siglo XVIII) moviendo las primeras máquinas de hilar de Arkwright, pasando por la implantación de la máquina de vapor, hasta la llegada de la electricidad. La transmisión energética inicial por el interior mediante embarrados, suponía entre otros, unas pérdidas de carga por rozamiento considerable (así como

constructivas, puesto que los promotores ingleses priorizaron ante todo la resistencia al fuego de sus fábricas con la introducción de nuevos materiales para sus estructuras. 
recalentamientos e incesantes peligros de incendio), conllevando a una concentración de los espacios de producción, y a la aparición del edificio de varias plantas. Seguidamente, se generalizó la reconversión hacia la impulsión por cuerdas y poleas, que facilitó la distribución interna de las fábricas. El último paso ocurre a principios del siglo XX con la explotación de las posibilidades de la electricidad, extendiéndose de forma global en los países más desarrollados, como España, por las ventajas inherentes que traía consigo, y desligando la forma del edificio de la fuente de energía.

4. El factor de los materiales, que aparte de permitir el aumento de tamaño de los edificios, estuvo fuertemente condicionado por los incendios, especialmente a raíz del del Albion Mill, en 1791, en pleno centro de Londres. Ello propició la aparición de los edificios fabriles considerados como "fire proof mill building" o resistentes al fuego, que incorporaban unos materiales, como el hierro fundido, las bóvedas de ladrillo y los morteros de protección. Más tarde se suman nuevos materiales como el hierro forjado, y finalmente el acero y el hormigón, ya al final del periodo en estudio.

5. El factor iluminación es el resultado de la confluencia de dos avances simultáneos: el crecimiento del tamaño de las huecos de fachada y el avance de la estructura hacia la fachada, liberándola de la función portante, de lo que surgirá lo que en terminología inglesa se denomina "daylight factory", que constituyó un nuevo paradigma de la arquitectura industrial de la primera mitad del siglo XX.

Según la segunda parte de la tesis (Capítulo 4), en el periodo estudiado es cuando se produce el impulso industrial valenciano, y cuando se construyen el mayor número de fábricas. En general, la entidad del tejido industrial es incomparable con el inglés, por lo que resulta difícil establecer similitudes directas en el tiempo. Lo que sí es cierto es que algunas características sí han coincidido, a saber: 
1. La transmisión mecánica se realiza originariamente por punto único, siguiendo la misma evolución tecnológica que los países europeos más industrializados: hidráulicamente, térmicamente y eléctricamente.

2. La prevalencia en planta de una dimensión frente a la otra (normalmente los edificios también son alargados y estrechos, como por ejemplo los de Alcoi o Almoines, la fábrica de harinas de Alfara, etc). Ello también debido a los condicionantes energéticos, de materiales y de iluminación.

3. En fachada, el porcentaje de hueco originariamente es mínimo, mientras este conserva su función portante, aumentando conforme el hierro se emplea como elemento estructural.

4. El hierro se utiliza primero en el interior, a modo de soportes primero, y vigas y viguetas en los forjados después, tal y como ya había ocurrido en Inglaterra. 


\section{FUTURAS LÍNEAS DE INVESTIGACIÓN}

En el Capítulo 4 de este estudio tan solo se ha realizado el análisis detallado de unos cuantos edificios, por lo que resultaría muy interesante, la realización de estudios monográficos de otros espacios fabriles valencianos que también siguiesen el patrón establecido por un "mill building". Identificar cómo se ha producido la transformación energética, o la de su forma, es un trabajo que queda abierto a aquel investigador motivado por este campo de la arquitectura. Asimismo, se puedo ampliar el campo geográfico a otros espacios industriales españoles y europeos, puesto que la tipología "mill" fue extendida por todos los países que sufrieron una transformación industrial durante los últimos 250 años.

En segundo lugar, la naturaleza de este trabajo deja la posibilidad de poder profundizar en la arquitectura de la industria valenciana diversificando según 
sectores. En la bibliografía que se ha podido encontrar referida al estudio de la forma de los edificios fabriles, se observa que en la mayoría de los casos se realiza una caracterización por sectores, o por el uso del edificio. En cierto modo, esta visión es lógica, por cuanto en la mayoría de las regiones industriales, sufrieron su particular revolución industrial especialmente en un solo campo: textil, fundición, agroalimentario, papelero, etc.

Pero, ¿se hubiera podido hacer una caracterización de cada sector industrial valenciano? Como se ha visto, el territorio valenciano siempre ha tenido una revolución industrial más bien sectorial. Pero encontrar un elevado número de fábricas con un mismo tipo de producción resulta difícil, con insuficientes datos como para poder obtener tipologías concretas de edificios fabriles. No obstante, es una labor abierta al estudio que podría resultar de gran interés.

Por otro lado, existen ya algunas tesis que tratan de los molinos textiles alcoyanos, dado que esta ciudad y su zona geográfica, si tenía una especialización pañera y textil de gran relevancia.

Un ejemplo de lo anterior podría ser el focalizar en el sector textil morellano, agroalimentario o de almacenes y tratamiento de cítricos de la Ribera o la Safor. La labor resultará efectiva si se es capaz de obtener una tipología específica para todo un mismo sector y para todo el territorio valenciano, cuáles han sido sus antecedentes, y si las ha habido, sus influencias arquitectónicas externas.

En tercer lugar, el estudio del origen o arranque de la moderna industrialización valenciana está íntimamente relacionado con los procesos de transformación económica y social. Es por ello que el análisis de las interrelaciones entre las ramas técnicas, sociales y económicas, es sumamente necesario e indispensable para poder profundizar aún más si cabe en la casuística del pueblo valenciano, aunque sea en su historia más moderna. 
En cuarto lugar, se considera fundamental profundizar en el análisis comparativo de diferentes elementos constructivos, obteniendo catálogos de soluciones constructivas autóctonas y aquellas importadas.

Las futuras líneas de investigación se podrían dividir en 4 grandes áreas temáticas:

1. El área de la historia industrial local.

2. El área de la historia de la economía // El desarrollo de la electricidad en las 2 primeras décadas del siglo XX y su influencia en la fisiología de los edificios // El aumento de la capacidad tecnológica como consecuencia de su desarrollo.

3. El área de la historia de la arquitectura industrial // Aclarar aspectos de la industrialización valenciana de finales del siglo XIX y principios del XX, que ayuden a comprender mejor los procesos de modernización valencianos // En términos generales, conseguir entender el presente a través del pasado, y evitar situaciones erróneas para el futuro.

4. El desarrollo del hormigón y su aplicación a la construcción de naves industriales diáfanas y bien iluminadas // El siglo XX industrial. 


\section{BIBLIOGRAFÍA}

ABERCROMBIE, S. Peter Behrens and a New Architecture for the Twentieth Century. Interior Design, 133, Vol. 71, no. 10, pp. 133. ISSN 0020-5508, 2000.

AGREDA PINO, A. M. Las rutas de la seda en España. Los intercambios productivos y artísticos entre Valencia y Zaragoza en la edad moderna. Artigrama: Revista del Departamento de Historia del Arte de la Universidad de Zaragoza, ISSN 02131498, № 17, págs. 293-312, 2002.

AGUILAR CIVERA, I. Arquitectura Industrial: Concepto, Método y Fuentes. Museu d'Etnología Valencia ed., Valencia: Valencia: Museu d'Etnología de la Diputació de València, 1998.

AGUILAR CIVERA, I. Mapa Arquitectura Industrial. Levante-EMV. Valencia, 2012. 
ÁLVAREZ RUBIO, A. Valencia industrial: las fundiciones. Ajuntament de València, ed., Valencia: Valencia: 2001.

ALONSO DE ARMIÑO, L. Registro de Arquitectura del S. XX: Comunidad Valenciana. Fondo Documental. Colegio Oficial de Arquitectos de la Comunidad Valenciana e Instituto Valenciano de la Edificación ed., Valencia: Valencia, 2002.

ÁlVARO i FÉLIX, F. y BARBERÀ i MIRALleS, B. Molins Fariners d'Aigua. Centre d'Estudis del Maestrat ed., Benicarló: Benicarló, 2001.

ARDIT LUCAS, M. Revolución liberal y revuelta campesina: un ensayo sobre la desintegración del régimen feudal en el País Valenciano (1793-1840). Madrid: Ed. Ariel Historia, 1977.

ARNOLD, H. L. y FAUROTE, Fay L. Ford Methods and the Ford Shops. The Engineering magazine company, 7947, ed., New York, 1919.

AYUGA TÉLLEZ, F. Las primeras fábricas de harina, un ejemplo de arqueología agroindustrial. Informes de la Construcción, vol. 49, no. 450, p.31, ISSN 00200883, 1997.

AZAGRA ROS, J.; MARTÍNEZ CARRIÓN, J.; MATEU, E. y VIDAL, J. De la sociedad tradicional a la economía moderna. Estudios de historia valenciana contemporánea. Revista de Historia Industrial, Issue 12, no. 12, 1997.

BANHAM, R. La Atlántida de Hormigón: Edificios Industriales de los Estados Unidos y Arquitectura Moderna Europea, 1900-1925. Nerea, Madrid: Madrid, 1989.

BARCIELA LÓPEZ, C. y CARRERAS DE ODRIOZOLA, A. Estadísticas Históricas de España: Siglos XIX-XX. Fundación Banco Exterior eds., Madrid: Madrid, 1989.

BARCIELA LÓPEZ, C.; CARRERAS i DE ODRIOZOLA, A y TAFUNELL i SAMBOLA, $X$. Estadísticas Históricas de España: Siglos XIX-XX. Fundación BBVA eds., Bilbao: Bilbao: 2005. 
BASALLA, G. La Evolución de la Tecnología. Crítica, Barcelona: Barcelona, 1990.

BENÉVOLO, L. Historia de la Arquitectura Moderna. Gustavo Gili, Barcelona: Barcelona, 2010.

BESÓ ROS, Adrià. La factoría de la Empresa Nacional Elcano en Manises. Una Valoración Patrimonial. Archivo de Arte Valenciano, no. 91, pp. 269-288. ISSN 0211-5808. Valencia: Valencia, 2010.

BIGGS, L. The Rational Factory: Architecture, Technology and Work in America's Age of Mass Production. Baltimore: Baltimore: Johns Hopkins University Press, 1996.

BLASCO SÁNCHEZ, M. C.; JUAN MARTíNEZ, F. y CANO HURTADO, J. J. El Espacio Industrial en la Comunidad Valenciana. Universidad Politécnica de Valencia eds. Valencia: Valencia, 2002.

BLASCO SÁNCHEZ, M. C.; JUAN MARTÍNEZ, F. y CANO HURTADO, J. J. Urbanismo e Industria: La Caracterización Urbanística del Espacio Industrial en la Comunidad Valenciana. Universidad Politécnica de Valencia, Departamento de Ingeniería de la Construcción y de Proyectos de Ingeniería Civil eds., Valencia: Valencia, 2003.

BLAT LLORENS, J. V. Construcción. Valencia: Valencia: Librería Politécnica de Valencia, 2007.

BRADLEY, B. The Works: The Industrial Architecture of the United States. Oxford University Press, 1999.

BRYANT NEWBOLD, H. Modern Practical Building. Caxton, 1950.

BURGOS NÚÑEZ, A. Los Orígenes del Hormigón Armado en España. Madrid: Madrid: Ministerio de Fomento: CEDEX-CEHOPU, 2009. 
CALATAYUd GINER, S. L'Expansió Citrícola Valenciana. Producció i Propietat de la Terra a la Ribera del Xúquer (1850-1930). Recerques: Història, Economia i Cultura, 115, no. 22, pp. 95-115. ISSN 0210-380X. Valencia: Valencia, 1989.

CAÑIZARES RUIZ, Ma C y PILLET CAPDEPÓN, F. Territorio y Patrimonio MineroIndustrial en Castilla-La Mancha. Biblio 3w: Revista Bibliográfica de Geografía y Ciencias Sociales, Vol.10, 2007.

CARRERAS i DE ODRIOZOLA, A.; PAREJO BARRANCO, J. A. y TAFUNELL i SAMBOLA, X. Estadísticas Históricas de España. Siglos XIX-XX. Revista de Historia Industrial, no. 31, Issue 31, 2006.

CERDÀ PÉREZ, M. Arqueología industrial. Valencia: Valencia: Publicacions Universitat de València, 2008.

CHALONER, W. H. People and industries. Londres: Londres: Frank Cass and Co, LTD, 1963.

COLOMER SENDRA, V. Registro de Arquitectura del S. XX: Comunidad Valenciana. Tomo 1. Colegio Oficial de Arquitectos de la Comunidad Valenciana e Instituto Valenciano de la Edificación ed., Valencia: Valencia, 2002.

COLOMER SENDRA, V. Registro de Arquitectura Del S. XX: Comunidad Valenciana. Tomo 2. Colegio Oficial de Arquitectos de la Comunidad Valenciana e Instituto Valenciano de la Edificación ed., Valencia: Valencia, 2002.

CRUZ, P. y CRUZ, P. S. Structures and Architecture: New concepts, applications and challenges. CRC Pr I LIc, 2013.

CRUMP, T. How the industrial revolution changed the world. London: Constable \& Robinson Ltd, 2010.

CUCÓ GINER, M. J. y FABRA SÁNCHEZ, M. A. La Qüestió Agrària al Pais Valencià. Aedos eds., Barcelona: Barcelona: 1978. 
CUEVAS CASAÑA, J. Innovación Técnica y Estructura Empresarial en la Industria Textil de Alcoi, 1820-1913. Revista de Historia Industrial, pp.13-44, pp. 13-44. ISSN 1132-7200. Universitat de Barcelona Publicacions. Barcelona: Barcelona, 1999.

CUEVAS CASAÑA, J. y TORRÓ GIL, L. Pels Camins de la " Via Valenciana": La Indústria en el Segle de la Revolució. Recerques: Història, Economia i Cultura, Issue 44, nº. 44, pp.21-60, ISSN 0210-380X, 2002.

DARLEY, G. Built in Britain. A view of traditional architecture based on TV series. Londres: Londres: Weidenfeld and Nicolson, 1983.

DARLEY, G. La Fábrica como Arquitectura: Facetas de la Construcción Industrial. Barcelona: Barcelona: Reverté, 2010.

DE FUSCO, R. D. Historia de la Arquitectura Contemporánea. Madrid: Madrid: Celeste, 1992.

DERRY, T.K. y WILLIAMS, T. I. Historia de la Tecnología. Volumen 2, Desde 1750 hasta 1900 (I). Madrid: Madrid: Siglo XXI, ed., 1980.

DERRY, T.K. y WILLIAMS, T. I. Historia de la Tecnología. Volumen 3, Desde 1750 hasta 1900 (I). Madrid: Madrid: Siglo XXI, ed., 1980.

DEVINE, W. D. From shafts to wires: historical perspective on electrification. The Journal of Economic History. Junio, 1983.

DÍEZ RODRÍGUEZ, F. L'Estructura Ocupacional d'una Ciutat Pre-Industrial: València, Segle XVIII. Recerques: Història, Economia i Cultura, Issue 24, pp.75-90, no. 24. ISSN 0210-380X. Valencia: Valencia: 1991

DISRAELI, B. Sybil, or the Two Nations. Earl of Beaconsfield, 2003.

DOMÉNECH ROMÁ, J. El Modernismo en Alcoy: su Contexto Histórico y los Oficios Artesanales. Aguaclara, 2010.

514/525 
ELLIS, H. A General Introduction to Domesday Book: Accompanied by Indexes of the Tenants in Chief and Under Tenants, at the Time of the Survey. London, 1833.

ESCOFET ROIG, Anna; RUBIO HURTADO, M. J. y TOLCHINSKY, L. Tesis, Tesinas y Otras Tesituras: de la pregunta de investigación a la defensa de la tesis. Barcelona: Barcelona: Edicions Universitat de Barcelona, 2002.

ESTALL i POLES, V. J. La Industria Cerámica En Onda: Las Fábricas, 1778-1997. Onda: Onda: Ajuntament d'Onda, 1997.

FABRA SÀNCHEZ, M. A. El País Valencià (1939 - 1959): autarquía i industrialització. Universitat de València, 2000.

FAIRBAIRN, W. The application of cast and wrought iron for building purposes. London: Bradbury and Evans Printers Whitefriars, 1857.

FAIRBAIRN, W. Treatise on mills and millwork. London: Longman, 1863.

FALCONER, K. A. Fireproof Mills. The Widening Perspectives. Extract from Industry Archaeology Review. Vol. XVI (1), 1993.

FALCONER, K. A. The Industrial Heritage in Britain - the First Fifty Years. La Revue pour l'histoire du CNRS, no. 14. ISSN 1298-9800, 2006.

FRAMPTON, K. Modern Architecture: 1920-1945. Global Architecture ed., Tokyo: Tokyo: A.D.A. Edita, 1989.

FRANCH BENAVENT, R. La real sociedad económica de amigos del país y el fomento de la industria valenciana de la seda en el siglo XVIII. Valencia: Universitat de València, 2000.

FRENCH, G. J. The life anf times of Samuel Crompton. Charles Simms \& Co ed., Manchester, 1862. 
FUENTES PARDO, J. M. et al. The Development of the Flour-Milling Industry in Spain: Analysis of its Historical Evolution and Architectural Legacy. Journal of Historical Geography, 241, vol. 37, no. 2, pp. 232-241. ISSN 0305-7488, 2011.

GALE, W.K.V. Ironworking. Oxford: Shire Publications, Ltd, 1981.

GARCÍA MARTÍNEZ, S. y HERNÁNDEZ SEMPERE, T. Ferrocarriles y capitalismo en el País Valenciano 1843-1879. Valencia Ayuntamiento eds., Valencia: Valencia, 1983.

GARCÍA PÉREZ, J. Arquitectura Industrial en Alcoy: Siglo XIX. Instituto de Cultura Juan Gil Albert ed., Alicante: Alicante, 2001.

GARCÍA-GUTIÉRREZ MOSTEIRO, J. et al. Las Bóvedas de Guastavino en América: Libro Publicado con Ocasión de la Exposición: Guastavino Co. (1885-1962). La Reinvención de la Bóveda. Ministerio de Fomento: Instituto Juan de Herrera eds. Madrid: Madrid, 2001.

GARRABAU, R. Un Fals Dilema: Modernitat o Enderrariment de l'Agricultura Valenciana. (1850-1900). Valencia: Valencia: Institució Alfons el Magnànim, 1985.

GEIJO BARRIENTOS, J. M. y ZULUETA PÉREZ, P. De artefacto a fábrica: recuperación gráfica de la arquitectura industrial del siglo XVIII en el Canal de Castilla. Universidad de Valladolid, Escuela Técnica Superior de Ingenieros Industriales. Departamento CMIM, EGI, ICGF, IM, IPF. Área de Expresión Gráfica en la Ingeniería, en Congreso Internacional Conjunto XVII Ingeniería Gráfica de INGEGRAF y XV Associazione Nazionale Disegno di Macchine. Sevilla, 2005.

GIEDION, S. La Mecanización Toma el Mando. Barcelona: Barcelona: Gustavo Gili, 1978.

GIEDION, S. Espacio, Tiempo y Arquitectura: Origen y Desarrollo de una Nueva Tradición. Barcelona: Barcelona: Reverté, 2009. 
GIMÉNEZ GUARINOS, J. M. Un passeig per Vinalesa. Elèctrica de Vinalesa, Cooperativa Valenciana. Vinalesa, 2011.

GLICK, T. F. Els Molins Hidràulics Valencians. Tecnologia, Història i Context Social. Institución Alfonso el Magnánimo, eds., Valencia: Valencia, 2000.

GUMÀ i ESTEVE, R. y DÍAZ GÓMEZ, C. Origen i Evolució de les Tipologies Edificatòries i Característiques Constructives dels Edificis de la Indústria Tèxtil a Catalunya (Període 1818-1925). Universitat Politècnica De Catalunya. Departament de Construccions Arquitectòniques I eds. Barcelona, 1997.

GUTIÉRREZ HIDALGO, F. y ROMERO F. La gestión del Tiempo en el Entorno Productivo: El Caso de la Real Fábrica de Tabacos de Sevilla (1744-1790). Revista Española De Financiación y Contabilidad, 662, no. 109, pp. 641-662. ISSN 02102412, 2001.

HEREDIA SCASSO, R. Desarrollo Histórico de la Arquitectura Industrial. Universidad Politécnica de Madrid Escuela Técnica Superior de Ingenieros Industriales ed., Madrid: Madrid: Universidad Politécnica de Madrid, Escuela Técnica Superior de Ingenieros Industriales, 1995.

HILL, H. Annual Conference of the Textile Institute, at Bolton. $7^{\text {th }}, 8^{\text {th }}$, and $9^{\text {th }}$, June, 1927. (Held on the 7th, 8th and 9th June 1927, on the occasion of the centenary of the death of Samuel Crompton. The opening of conference at Derby Hall, Bowkers' Row). Bolton: The Textile Institute, 1927.

HILLS, R. L. Richard Arkwright and cotton spinning. Londres: Londres: Priority Press, Ltd, 1973.

HILLS, R. L. Power from wind: a history of windmill technology. Cambridge: Cambridge University Press, 1994.

HOSPITALER, A. Memoria de Cátedra. Universidad Politécnica de Valencia, 1999. 
FRAILE MORA, J. Máquinas Eléctricas. Aravaca: Aravaca: McGrawHill/Interamericana de España, 2004.

JOHNSON, H. R. y SKEMPTON, A. W. William Strut's Cotton Mills. Transactions of the Newcomen Society, 1955.

JOHNSON, H. R. y SKEMPTON, A. W. William Struts Cotton Mills, 1793-1812. Extract from The Newcomen Society Transactions, pp 179-205, 1955-57.

JONES, P. B. Peter Behrens and a New Architecture for the Twentieth Century. Vol.209 (1252), pp.97-97, ISBN 0003-861X, 2001.

KETCHUM, M. S. Steel mill buildings and the calculation of stresses in framed structures. New York: Mcgraw-Hill Book Company, 1912.

KNOWLES, P. Design of Structural Steelwork. $2^{\text {nd }}$ Edition. Surrey University Press, 2003.

LAPAYESE, J. Tratado del arte de hilar, devanar, doblar y torcer. Las sedas según el método de Mr. Vaucanson con algunas adiciones y correcciones a él: Principio y progresos de la fábrica de Vinalesa, en el Reyno de Valencia, establecida baxo la protección de S.M. Valencia: Valencia: Roig Impresores, 1996.

LETKEMANN, P. G. The Works: The Industrial Architecture of the United States. (Review). Vol.102(1), p.210(2), 2000. ISBN 0002-7294.

LLUCH MARTíN, E. La Vía Valenciana. Valencia: Valencia: Eliseu Climent/3i4, 1976.

MADOZ, I. Diccionario Geográfico-Estadístico-Histórico de Alicante, Castellón y Valencia. Vol. 1. Valencia: Valencia: Institució Alfons el Magnànim, 1987.

MARKUS, T. A. Buildings and Power: Freedom and Control in the Origin of Modern Building Types. London: London: Routledge, 1993. 
MARTÍNEZ GALLEGO, F. A. Desarrollo y crecimiento: La Industrialización Valenciana 1834-1914. Conselleria d'Indústria,Comerç i Turisme, ed., Valencia: Valencia, 1995.

MARTÍNEZ GONZÁLEZ, J. Congreso Internacional. La Arquitectura Norteamericana, Motor y Espejo de la Arquitectura Española en el Arranque de la Modernidad (1940-1965): Actas Preliminares (Pamplona, 16-17 Marzo 2006). Escuela Técnica Superior de Arquitectura, Universidad de Navarra: Pamplona. T6 Ediciones, 2006.

MASTERS, E. L. Domesday Book, 1920.

MATTHEIB, J. Hormigón armado, armado aligerado, pretensado. Ed. Reverté. Badalona, 1980.

MORITZ, K. Manual de Cubiertas Planas en la Construcción. Madrid: Madrid. Blume, 1969.

MUMFORD, L. El Mito de la Maquina. Buenos Aires: Buenos Aires: Emecé, 1969.

MUMFORD, L. Técnica y Civilización. Madrid: Madrid: Alianza, 1971.

MUMFORD, L. El Mito de La Máquina. Técnica y Evolución Humana. Logroño: Logroño. Pepitas de Calabaza, 2010.

MUMFORD, L. El Mito de La Máquina. El Pentágono del Poder (2). Logroño: Logroño. Pepitas de Calabaza, 2011.

NADAL OLLER, J. El Desenvolupament de I'Economia Valenciana a la Segona Meitat del Segle XIX: Una Via exclusivament Agrària?. Recerques: Història, Economia, Cultura, Issue 19, no. 19, 1987.

NAVARRO, J. Daylighting Provided by Horizontal Openings using the Illumination Vector. Renewable Energy, vol. 31, no. 15, pp. 2513-2523. ISSN 0960-1481, 2006. 
NAVARRO ESTEVE, P. Revista del Instituto del Patrimonio Histórico Español. Bienes Culturales. Ministerio de Educación, Cultura y Deporte. IPHE. Número 7. Plan de Patrimonio Industrial (2007).

NEWBOLD, H. B. Modern Practical Building. Artigrama: Londres: Ed. Caxton, 1934.

OLCINA LLORENS, G. y DALMAU PORTA, J. I. Origen y desarrollo de la cuenca industrial del Río Barchell. Universidad Politécnica de Valencia Departamento de Organización de Empresas, Economía Financiera y Contabilidad eds., Valencia: 1986.

OLCINA LLORENS, G. y OLCINA CARBONELL, E. Una Industria Legendaria. Alcoy: Alcoy. El autor, ed. 2006.

OLCINA LLORENS, Gilberto. El Primer Molino Papelero de la comarca de Alcoy. Recerques Del Museu d'Alcoi, , Issue 21, no. 21, 2012.

OMAR, M. A. E. Translation of Islamic Culture into Arabian Architecture. Curtin University of Technology, School of Architecture, Construction and Planning, 2000.

OSUNA, R. y VALCARCE LABRADOR, M. T. Peter Behrens: Guía de Arquitectura. Madrid: Madrid: Nerea, ed., 1997.

PELHAM, C. A commonplace book. Michigan University. Michigan, 1957.

PEVSNER, N. A History of Building Types. Princeton, N.J.: Princeton, N.J.: Princeton University Press, 1976.

PEVSNER, N. Historia de las Tipologías Arquitectónicas. Barcelona: Barcelona: Gustavo Gili, 1979. 
PONS i PONS, A. y SERNA, J. La Ciudad Extensa: La Burguesía Comercial-Financiera en la Valencia de Mediados del XIX. Diputació de València eds. València: València, 1992.

POSENER, J. From Schinkel to the Bauhaus. London: Lund Humphries Publishers Limited, 1972.

PRICE, G. M., The modern factory safety, sanitation and welfare. John Wiley \& Sons, Inc. Nueva York: Nueva York, 1914.

RANSOME, E. L. y SAURBREY, A. Reinforced Concrete Buildings: A Treatise on the History, Patents, Design and Erection of the Principal Parts Entering into a Modern Reinforced Concrete Building. ed., New York etc.: McGraw-Hill Book Company, 1912.

REgalado TESORO, F. Los Forjados de los Edificios: Pasado, Presente y Futuro. Alicante: Alicante: CYPE Ingenieros, 1999.

REIG MARTíNEZ, E. Dos siglos de industrialización en la Comunitat Valenciana: = Dos Segles d'Industrialització a la Comunitat Valenciana: Exposición] 19/09/2007 2/12/2007. Valencia: Valencia: Colegio Oficial de Ingenieros Superiores Industriales de Valencia, 2007.

RICHARDSON, C. An iron will. The Building Conservation Directory, 2005.

RÓDENAS VILLENA, C. La Banca i la Industrialització Valenciana a Mitjan Segle XIX. Recerques: Història, Economia i Cultura, Issue 8, pp.73-83, ISSN 0210-380X, 1978.

SAMBRICIO, C. Engineering in Spanish Architectural Journals: 1920-1936. Informes de la Construcción, Vol.60 (510), vol. 60, no. 510. ISSN 0020-0883, 2008.

SÁNCHEZ BELTRÁN, M. J. La Porcelana de la Real Fábrica del Buen Retiro. Madrid: Madrid: Electa, 1998. 
SÁNCHEZ ROMERO, M. A. La Industria Valenciana en Torno a la Exposición Regional de 1909. Universidad Politécnica de Valencia, Departamento de Proyectos de Ingeniería eds., Valencia: Valencia, 2009.

SÁNCHEZ RON, J. M. Ciencia y sociedad en España: de la llustración a la Guerra Civil. Madrid: Ed. El Arquero/CSIC, 1988.

SANCHIS COSTA, J y GIL PERICÁS, F. Rasgos Históricos de Almoines. Ajuntament d'Almoines, 1987.

SEBASTIÀ TALAVERA, J. La Belleza Industrial: Historia de la Fábrica y Su Estética. Fundación Bancaja ed., Valencia: Valencia, 2007.

SKEMPTON, A. W. The Boat Store, Sheerness (1858-60) and its Place in Structural History. Read at the Science Museum, London, 3 February 1960.Londres, 1960.

SMILES, S. Lives of the engineers - Boulton and Watt-. The steam engine and transport. London: John Murray, 1904.

SOBRINO SIMAL, V. J. Arquitectura Industrial en España, 1830-1990. Madrid: Madrid: Cátedra, 1996.

SOBRINO SIMAL, V. J. La Arquitectura de la Industria en Andalucía. Sevilla: Sevilla: Instituto de Fomento de Andalucía, 1998.

SOBRINO SIMAL, V. J. El Espacio del Trabajo: Producir, Protestar, Soñar. Fabrikart: Arte, Tecnología, Industria, Sociedad, Issue 4, no. 4, pp.86-99. ISSN 1578-5998, 2004.

SOBRINO SIMAL, V. J. Patrimonio Industrial en Andalucía: Portfolio Fotográfico. Andalucía Consejería de Obras Públicas y Transportes ed., Sevilla: Sevilla: Junta de Andalucía, Consejería de Obras Públicas y Transportes, 2006. 
SOLAZ ALBERT, R. Guía de las guías de Valencia: 1700-1975. Valencia: Valencia: Ayuntamiento de Valencia, 2002.

SOLER, A. Almoines: Geografia, Història, Patrimoni. Almoines: Almoines: Ajuntament d'Almoines, 2009.

STRIKE, J. De la Construcción a los Proyectos: la influencia de las nuevas técnicas en el diseño arquitectónico, 1700-2000. Barcelona: Barcelona: Reverté, 2004.

SWAILES, T. Y MARSH, J. Structural appraisal of iron-frames textile mills. Institution of Civil Engineers, ICE; Design and practice guide, 1998.

THOMPSON, E. La Formación Histórica de la Clase Obrera: Inglaterra: 1780-1832. Barcelona: Barcelona: Laia, 1977.

TORRÓ GIL, L. Los inicios de la mecanización en la industria lanera de Alcoi. Revista De Historia Industrial, 142, pp. 133-142. ISSN 1132-7200, 1994.

VIDAL VIDAL, V. M. Arquitectura e Industria: Un ensayo tipológico de los edificios fabriles de I'Alcoia. Universidad Politécnica de Valencia, Departamento de Sistemas Informáticos y Computación ed., Valencia, 1981.

WATTS, M. Water mills. Botley: Oxford: Shire Publications, Ltd, 2006.

WATTS, M. Water and wind power. Princes Risborough: Buckinghamshire: Shire Publications, Ltd, 2008.

WESTON, R. Plantas, Secciones y Alzados: Edificios Clave del Siglo XX. Barcelona: Barcelona: Gustavo Gili, 2005.

WINDSOR, A. Peter Behrens: Architect and Designer. London: London: Architectural Press, 1981. 
ZEVI, B. Espacios de la Arquitectura Moderna. Barcelona: Barcelona: Poseidón, 1980.

Ajuntament de València. 150 años del Cuerpo de Bomberos de Valencia. Ajuntament de València, Servicio de Publicaciones, 2007.

French Worker: Autobiographies from the Early Industrial Era. Issue 33, p.371-3, 1994. ISBN 0700-3862.

La Arquitectura de la Industria, 1925-1965: Registro Docomomo Ibérico. Fundación Docomomo Ibérico ed., Barcelona: Barcelona: Fundación Docomomo Ibérico, 2005.

De l'ofici a la fàbrica: "La Maquinista Valenciana": Una família industrial valenciana en el canvi de segle: [Exposición] Maig-Juny 2000, Sala de la Muralla, Col.legi Major Rector Peset. Universitat de València, Vicerectorat de Cultura ed., Valencia: Valencia, 2000.

Historia de la Cartuja de Sevilla: de Ribera del Guadalquivir a Recinto de la Exposición Universal. Sociedad Estatal para la Exposición Universal Sevilla 92, ed. Madrid: Madrid: 1989. 
